\title{
Advanced Technologies for Decontamination and Conversion of Scrap Metal
}

\author{
Phase III Topical Report \\ Contract Number DE-AC21-93MC30170
}

Valerie MacNair (VMACNAIR@MNSCI.COM; 423-481-0455)

Steve Sarten (SSARTEN@MNSCI.COM; 423-481-0455)

Thomas Muth (TMUTH@MNSCI.COM; 423-481-0455)

Manufacturing Sciences Corporation

804 Kerr Hollow Rd

Oak Ridge, TN 37803

Brajendra Mishra (303-273-3893)

Colorado School of Mines

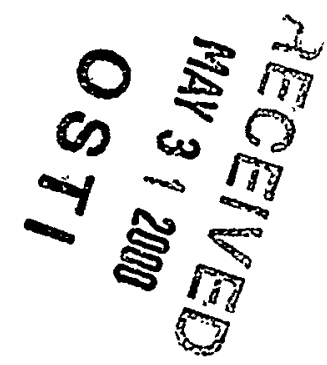

Department of Metallurgical Engineering

Golden, CO 80401

Writing assistance from Elizabeth Terry and Gail Lee

May 27, 1999 


\section{DISCLAIMER}

This report was prepared as an account of work sponsored by an agency of the United States Government. Neither the United States Government nor any agency thereof, nor any of their employees, make any warranty, express or implied, or assumes any legal liability or responsibility for the accuracy, completeness, or usefulness of any information, apparatus, product, or process disclosed, or represents that its use would not infringe privately owned rights. Reference herein to any specific commercial product, process, or service by trade name, trademark, manufacturer, or otherwise does not necessarily constitute or imply its endorsement, recommendation, or favoring by the United States Government or any agency thereof. The views and opinions of authors expressed herein do not necessarily state or reflect those of the United States Government or any agency thereof. 


\section{DISCLAIMER}

Portions of this document may be illegible in electronic image products. Images are produced from the best available original document. 


\begin{abstract}
The Department of Energy (DOE) faces the task of decommissioning much of the vast U.S. weapons complex. One challenge of this effort includes the disposition of large amounts of radioactively contaminated scrap metal (RSM) including but not limited to steel, nickel, copper, and aluminum. The decontamination and recycling of RSM has become a key element in the DOE's strategy for cleanup of contaminated sites and facilities. Recycling helps to offset the cost of decommissioning and saves valuable space in the waste disposal facilities. It also reduces the amount of environmental effects associated with mining new metals.
\end{abstract}

Work on this project is geared toward finding decontamination and / or recycling alternatives for the RSM contained in the decommissioned gaseous diffusion plants including approximately 40,000 tons of nickel. The nickel is contaminated with Technetium-99, and is difficult to remove using traditional decontamination technologies.

The project, titled "Advanced Technologies for Decontamination and Conversion of Scrap Metal was proposed as a four phase project. Phase I and II are complete and Phase III will complete May 31, 1999.

Stainless steel made from contaminated nickel barrier was successfully produced in Phase I. An economic evaluation was performed and a market study of potential products from the recycled metal was completed. Inducto-slag refining, after extensive testing, was eliminated as an alternative to remove technetium contamination from nickel.

Phase II included successful lab scale and pilot scale demonstrations of electrorefining to separate technetium from nickel. This effort included a survey of available technologies to detect technetium in volumetrically contaminated metals. A new process to make sanitary drums from RSM was developed and implemented.

Phase III included a full scale demonstration of electrorefining, an evaluation of electro-refining alternatives including direct dissolution, melting of nickel into anodes, a laser cutting demonstration, an investigation of commercial markets for RSM, and refinement of methods to quantify isotopic elements, 


\section{Acknowledgements}

The authors gratefully acknowledge the support of the U.S. Department of Energy's Federal Energy Technology Center, partcularly the encouragement and cooperation of Jagdish L. (Jeet) Malhotra, FETC Project Manager and COR, and Mary Spatafore

Gabrielle, Contract Administrator. The contract was awarded September, 1993 under a Programmatic Research and Development Agreement (PRDA). Phase III of the contract was initiated in Jan, 1997. 


\section{TABLE OF CONTENTS}

\section{Page}

Table of Acronyms

Executive Summary

Introduction

Purpose

Background

Methodology

3.0 Pilot Scale Electrorefining Cell for Nickel Decontamination

3.0.1 Background and Results of Preliminary Research

3.0.2 Removing Contaminates from the RSM

3.1 Full Scale Electrorefining 20

3.1.1 Developing Design Criteria for the Full Scale Cell 20

$\begin{array}{ll}\text { 3.1.2 Pre-design research } & 20\end{array}$

3.1.3 Full scale Electrorefining Cell Design 20

3.1.4 Major components of the Full Scale Cell 23

3.1.5 Electrolyte Solution $\quad 26$

3.1.6 Potential Hazards and Safeguards 26

3.1.7 Testing and Commissioning the ER System 27

3.1.8 Electrical Design Inspection $\quad 27$

3.1.9 Testing of Integrated System . 27

3.1.10 Nickel Source for Full Scale Electrorefining 28

3.1.11 Operations $\quad 28$

3.1.12 Lessons Learned $\quad 28$

$\begin{array}{ll}3.1 .13 \text { Results } & 30\end{array}$

3.1.14 Phase III Nickel Recovery Research Costs 35

3.1.15 Projections Based on One Full Scale Cell 36

3.1.16 Path Forward 37

3.1.15 Nickel Melting $\quad 38$

Designing molds $\quad 38$

Effects of Fluorine on Refractories $\quad 39$

3.1.16 Nickel Direct Dissolution $\quad 42$

Research by the Colorado School of Mines (CSM) 42 
Research by the Colorado School of Mines (CSM) 42

Direct Dissolution Experiments on Nickel Barrier 43

3.2 Full Scale Laser Cutting 44

3.2.1 Background and Overview 44

3.2.2 Research Approach $\quad 45$

3.2.3 Pretesting $\quad 45$

3.2.4 ETEC Demonstration 46

3.2.5 System Components for MSC's Demonstration 47

3.2.6 System Configuration $\quad 50$

3.2.7 Safety Features $\quad \cdot \quad 51$

3.2.8 Personnel Training 51

3.2.9 Equipment and Operations Training 51

3.2.10 Laser Safety Training 52

3.2.11 Set Up for MSC's Demonstration $\quad 52$

3.2.12 MSC Laser Cutting Demonstration 53

3.2.13 Part Handling $\quad 53$

3.2.14 Laser Cutting Using Robotic Manipulator 53

3.2.15 Scrap Removal $\quad 55$

3.2.16 Results of MSC's Experiments and Demonstration 56

3.2.17 Additional Bench Scale Testing 56

3.2.18 Conclusions $\quad 56$

$\begin{array}{ll}\text { 3.2.19 Path Forward } & 57\end{array}$

3.3 Develop and Fabricate a New Product from RSM 58

$\begin{array}{ll}3.3 .1 \text { Background } & 58\end{array}$

3.3.2 History of RSM Products $\quad 58$

3.3.3 Detailed Analysis of DWPF Specification 58

3.3.4 Products Made from RSM $\quad 59$

3.4 Refinement of Methods to Quantify Isotopic Elements 61

3.4.1 Executive Summary 61

3.4.2 Electrorefining Sampling $\quad 61$

3.4.3 Statistical Methods 61

3.4.4 EMPORE Radiation Filter Disks $\quad 62$

3.4.5 Liquid Scintillation Counting 63

Measurements by Thermo NUtech 63

Measurements by Analytical Services Organization $\quad 65$

Liquid Scintillation at MSC $\quad 67$

3.4.6 Bulk Activity Approximation $\quad 69$

$\begin{array}{ll}\text { Purpose } & 69\end{array}$

$\begin{array}{ll}\text { Correlation } & 69\end{array}$

Approximate Bulk Activity 69

Theoretical Basis 69

Average Energy of Beta Particles $\quad 70$ 
Range of Beta Particles in Nickel $\quad 70$

Linear Distance Traveled by the Beta Particles 71

Instrumentation, Surface Activity Measurements, $\quad 73$

and Statistical Analysis

Higher Activity Level $\quad 74$

Alternate System $\quad 75$

Results 76

3.4.7 Sampling During ER Operations 6/98-10/98 77

Conclusions

79

Appendix 3.1

Appendix 3.2

Appendix 3.3

Appendix 3.4 


\section{List of Acronyms}

\begin{tabular}{|c|l|}
\hline & \\
\hline A & amps \\
\hline AFCH & Auto focus cutting head \\
\hline ALARA & As Low As Reasonably Achievable \\
\hline ANSI & American National Standards Institute \\
\hline ASME & American Society of Mechanical Engineers \\
\hline BNFL & British Nuclear Fuels \\
\hline Bq & Bequerel \\
\hline CSM & Colorado School of Mines \\
\hline D\&D & Decontamination and Decommissioning \\
\hline DOE & Department of Energy \\
\hline DWPF & Defense Waste Processing Facility \\
\hline ETEC & Energy Technology Engineering Center \\
\hline ETTP & East Tennessee Technology Park \\
\hline EWI & Edison Welding Institute \\
\hline FETC & Federal Energy Technology Center \\
\hline g & gram \\
\hline HEPA & High efficiency particulate air \\
\hline INEL & Idaho National Engineering Labs \\
\hline LGT & Lockwood Green Technologies \\
\hline MRU & Metals recovery unit \\
\hline MSC & Manufacturing Sciences Corporation \\
\hline NDA & Non destructive analysis \\
\hline NdYAG & Neodymium \\
\hline ORNL & Oak Ridge National Laboratory \\
\hline PLC & Programmable logic controller \\
\hline PRDA & Programmatic Research and Development Agreement \\
\hline QA & Quality Assurance \\
\hline RSM & Radioactively contaminated scrap metal \\
\hline VDP & Vacuum Induction Degas and Pour \\
\hline VIM & Vacuum Induction Melter \\
\hline & \\
\hline & \\
\hline & \\
\hline
\end{tabular}




\section{Executive Summary}

\section{Introduction}

The DOE has begun to decommission the vast United States nuclear weapons complex. This effort includes the disposition of large amounts of radioactively contaminated scrap metal including but not limited to steel, nickel, copper, and aluminum. Diffusion plant nickel barrier from the Oak Ridge, Paducah, and Portsmouth diffusion plants accounts for nearly 40,000 tons of contaminated nickel.

Work on this project is geared toward finding decontamination and recycling alternatives for the nickel barrier. Technetium-99, present in the nickel barrier, is known to be particularly troublesome to remove using conventional decontamination technologies. Traditional chemical and mechanical means have been ineffective at removing this contaminate from the nickel barrier.

Recycle options available for the disposition of the nickel include decontamination and release, and recycled product manufacture.

Work during Phase I of this project:

- Successfully demonstrated the ability to make stainless steel from nickel barrier feed.

- After repeated trials and studies, the inducto-slag decontamination process was eliminated as a suitable alternative.

Phase II efforts included:

- Successful lab scale and pilot scale demonstrations of electrorefining to separate technetium from nickel.

- A survey of available technologies to detect technetium in volumetrically contaminated metals.

- A new process to make sanitary drums from RSM was developed and implemented.

Work in phase III of the project, as proposed, contained the following five elements:

- Nickel barrier decontamination using electrorefining

- Full scale laser cutting demonstration

- Develop and fabricate a new product made from RSM

- Refinement of methods to quantify isotopic elements

- Project Management 


\section{Purpose}

The expected results for phase III, as proposed were:

- To remove technetium from nickel using a full scale electrorefining cell

- To determine if technetium could be removed from nickel in the classified form (without declassification by melting)

- To section a diffusion plant converter shell into pieces small enough to be processed through MSC's recycling facility .

- To fabricate a new product using RSM 


\section{Background}

On August 25, 1997, BNFL Inc. and the Department of Energy (DOE) signed a $\$ 238$ million fixed price contract for the Decontamination and Decommissioning (D\&D) of Three Buildings at the former K-25 site (now called the East Tennessee Technology Park - ETTP). BNFL Inc. is to dismantle, remove, decontaminate, and recycle the process equipment within the three Gaseous Diffusion Plant buildings K-33, K-31, and K29, which represent approximately five million square feet of floor space. The ETTP Three Building D\&D project supports DOE's Vision 2010 to clean up these facilities and locate new commercial industries at the former $\mathrm{K}-25$ site.

BNFL Inc. contracted with Manufacturing Sciences Corporation (MSC) to decontaminate and recycle more than 126,000 tons of metals, including the 6,000 tons of nickel. MSC will decontaminate the metals and recycle them where economically feasible. The contract recognized the value of recovering the metals, including nickel, and the DOE has received a credit for this material. The following is a quote from the DOE/ORO office web page:

"The $\$ 238 \mathrm{M}$ contract cost included a credit back to DOE of $\$ 55,569,748$ for the recyclable material. This amounts to quarterly cost savings of $\$ 2,646,178$ over 21 quarters for the materials recycled or reused. The recycling activities began in the 4th calendar year quarter of 1998 and will continue throughout the duration of the contract."

As part of the ETTP Three Building Decomissioning and Decontamination (D\&D) Project, approximately 6,000 tons of radioactively contaminated nickel will be removed. This nickel will be decontaminated and eventually released for reuse. The process that will be used for decontamination of the nickel, electrorefining, was developed under the FETC contract during phases II and III.

\section{Methodology}

The detailed descriptions of experimentation that took place during phase $\mathrm{II}$ appear in this report. Also, activities that took place near the end of phase II, and due to timing of the report, were not reported in the phase II report, are described in section 3.0. This report is categorized into five main headings as follows:

- 3.0 Pilot Scale Electrorefining Cell (from Phase II)

- 3.1 Full Scale Electrorefining

- 3.2 Full Scale Laser Cutting Demonstration

- 3.3 Develop and Fabricate a New Product from RSM

- 3.4 Refinement of Methods to Quantify Isotopic Elements 


\subsection{Pilot Scale Electrorefining}

\subsubsection{Background and Results of Preliminary Research}

DOE facilities have an estimated 1.5-million-ton inventory of radioactive scrap metal (RSM) that must be dispositioned. The safe recycle of the metals is environmentally preferable to disposal in waste facilities as it saves space, and reduces the overall environmental effects and cost associated with producing new metals.

Because much of the RSM is high-value nickel, the potential for cost recovery is significant. DOE's gaseous diffusion plants have an estimated 40,000 tons $(80,000,000$ pounds) of nickel barrier.

Manufacturing Sciences Corporation worked under a contract with the Federal Energy Technology Center (FETC) in Morgantown, West Virginia to research and develop processes to decontaminate the nickel barrier. This work was completed under a Programmatic Research and Development Agreement (PRDA) with FETC. The original objective of the research and development was to reduce the contaminants in the nickel to levels suitable for recycle.

\subsubsection{Removing Contaminants from the RSM}

The nickel in the gaseous diffusion process is contaminated with technetium $\left({ }^{99} \mathrm{Tc}\right)$ and uranium, along with possible trace amounts of transuranic elements $(\mathrm{Np}, \mathrm{Pu}$, and other actinides). The melting process removes most of the uranium \& transuranic elements. However, ${ }^{99} \mathrm{Tc}$ becomes stubbornly bound to the nickel, making it particularly difficult to separate the two elements.

Two processes had been considered as good options for decontaminating the nickel; namely, melt refining and electrorefining. Melt refining is done in a vacuum induction melting (VIM) furnace in the presence of an oxidizing flux. The melt refining process eliminates the uranium and transuranic elements, but is ineffective in removing technetium. Electrorefining dissolves the nickel electrolytically (as an anode) in an acidic aqueous electrolyte; and the purified nickel is deposited in its metallic state on a cathode. Like melt refining, electrorefining is also capable of eliminating the uranium and transuranic elements. However, the process, as practiced by others prior to this PRDA agreement, is unable to reduce the amount of technetium in the nickel to levels near $1 \mathrm{~Bq} / \mathrm{g}$.

Several secondary processes were investigated in an effort to separate the technetium from the nickel, including ion exchange, liquid-liquid extraction, chemical precipitation, evaporation, and carbon adsorption. These did not show promise. One option that did appear promising, however, was an electrorefining process that incorporated both a cationic membrane between the anode and cathode and a secondary cementation (or displacement reaction) treatment. The membrane filter and the displacement treatment removed technetium from the electrolyte before the nickel deposited on the cathode and 
proved to be exceptional in preventing the technetium from co-depositing with the nickel. Further, this process eliminated the need for the ion exchange treatments previously proposed for removing technetium.

An effective electrorefining and metal displacement approach to removing contaminants was proposed by Covofinish, Inc., Providence, Rhode Island.

\subsubsection{Electrorefining Research}

MSC subcontracted with Covofinish to apply their electrorefining and displacement reaction process toward removing technetium from contaminated nickel barrier. The initial objectives of these experiments were:

- to determine whether or not decontamination could be effectively and economically achieved through electrorefining; and if so,

- to optimize the parameters needed for successful pilot-scale operations.

Covofinish researchers, under the subcontract, designed and developed a lab-scale electrorefining system to conduct experiments on clean nickel. In addition, Covofinish contracted Brown University to establish an operational equilibrium expression that would accurately predict the effects of $\mathrm{pH}$, temperature, and nickel concentration on nickel plating and technetium displacement. Brown researchers also documented other kinetic data. A brief summary of the lab-scale research, the overall results, and the parameters established for a pilot-scale electrorefining cell are provided in the following paragraphs. (Details of the Covofinish and Brown University research are available in a topical report issued to FETC at the end of Phase II titled "Advanced Technologies for Decontamination and Conversion)

Brown University researchers determined that both temperature and $\mathrm{pH}$ significantly effected the displacement reaction of ${ }^{99} \mathrm{Tc}$ from the nickel sulfate solution. Researchers found that the optimal displacement environment (rate of displacement and quality of nickel plating) occurred at a temperature of about 40 degrees $\mathrm{C}$, with $\mathrm{pH}$ levels of 4.0 to 4.5. By fitting experimental results with first-order reaction rate expressions, Brown researchers also developed an equation for the rate of displacement reaction as a function of temperature and nickel surface area.

Optimized parameters provided by the Brown research were incorporated into the $500 \mathrm{ml}$ lab-scale electrorefining system set up at Covofinish. Using the equation and other data provided by Brown University, Covofinish researchers developed a numerical model to calculate other parameters, such as the amount of nickel powder necessary to maintain the desired ${ }^{99} \mathrm{Tc}$ concentrations during cementation processes and the rate of acid addition to maintain the $\mathrm{pH}$ and increase the effectiveness of the liquid/solid contactor.

Finally, Covofinish performed a 42-hour experiment using pieces of previously melted contaminated nickel barrier (supplied by MSC). A lab-scale tank was filled with technetium-free Watt's nickel electrolyte, and the anolyte was separated from the catholyte by a Nafion ${ }^{\mathrm{TM}}$ cationic membrane. During the concluding lab-scale experiments, the nickel anode was electro-dissolved; and the technetium was successfully separated from the nickel ions. Technetium ions, which were confined to the anolyte by 
the Nafion ${ }^{\mathrm{TM}}$ membrane, were subsequently displaced onto a fresh nickel surface in the cementation unit. The nickel ions were free to pass through the membrane and plate out on the cathode without a co-deposit of technetium.

The nickel plating on the cathode was sampled at two time intervals at current densities of $100 \mathrm{~A} / \mathrm{ft}^{2}$. and $34 \mathrm{~A} / \mathrm{ft}^{2}$. Also, the technetium concentrations in both the anolyte and the catholyte were periodically monitored. The $460 \mathrm{~Bq} / \mathrm{g}$ of contamination initially found in MSC's nickel ingot was reduced by the electrorefining processes to values around $1 \mathrm{~Bq} / \mathrm{g}$.

\subsubsection{Initial Development of a Pilot-Scale Electrorefining Cell}

After successfully completing the lab-scale experiments, Covofinish researchers began developing a pilot-scale electrorefining cell for further optimizing the process. The pilot-scale research efforts were divided into four major tasks; design, fabrication, proof of concept, and electrorefining of the ${ }^{99} \mathrm{Tc}$ contaminated nickel. As in the lab-scale experiments, the nickel in the pilot-scale cell would be electrodissolved into the electrolyte, passed through the cationic membrane, and plated out onto the cathode. The technetium contamination would be trapped by the membrane and would remain in the anolyte (the solution surrounding the anode). Finally, the anolyte would be passed through a regenerative process (that is, a displacement reaction in the cementation unit) which would remove the technetium and other contaminates.

\subsubsection{Design and Fabrication of Pilot Scale Cell}

The objectives for designing and building a pilot-scale electrorefining cell at MSC were:

1. To demonstrate that the parameters for the lab-scale electrorefining experiments could be equally as successful in a production environment.

2. To provide important production data for establishing design criteria and operating parameters needed to develop a full-scale cell.

Generally, the pilot-scale cell was a modification of the lab-scale design, both in configuration and in materials. The anolyte in the pilot-scale cell was designed to be continuously circulated through a cementation chamber that could capture the technetium ions and prevent them from co-depositing with the nickel on the cathode. Major components of the pilot-scale electrorefining cell as set up at Covofinish included:

Cell Tank: The cell was scaled up from the $500 \mathrm{ml}$ lab-scale cell to a 200 gallon pilot cell. The cell was fabricated from 1/2-inch, stress-free polypropylene.

Anodes and Cathodes: For initial trial "clean" testing, anodes were made from clean nickel, and a stainless steel sheet with a nonconducting edge frame was used as the initial cathode. The system was operated at $20 \mathrm{~A} / \mathrm{ft}^{2}$, to allow nickel plating on the cathode starter sheet. The cathode was withdrawn and the edge frame removed. Deposited nickel foil sheets peeled from the stainless steel cathode were straightened, equipped with nickel foil hanging straps, and used as the cathode starter sheets in subsequent experiments. 
Electrolyte Solution: Watts nickel electrolyte was prepared and added to the cell tank. Watts nickel electrolyte contains nickel sulfate, nickel chloride, and boric acid. Makeup Water: Filtered makeup water was automatically introduced into the electrolyte as needed to replenish water lost through evaporation. This was accomplished through the use of a solenoid valve signaled by a level probe.

Heaters: The electrolyte was pumped to a heated sump to maintain temperature.

Filters: Electrolyte (both anolyte and catholyte) was also pumped through 5 micron polyester filters for particulate removal.

Pipes and Fittings: Pipes and fittings for the pilot-scale cell were either manufactured at Covofinish or designed by Covofinish researchers and manufactured by qualified vendors.

Cementation Unit: Anolyte was circulated through a cementation chamber. Removal of technetium from the anolyte was accomplished using the attraction of technetium to fresh nickel surface.

Data Logging: Various sensors measuring voltage, temperature, $\mathrm{pH}$, and other variables were monitored periodically and documented. Anolyte and catholyte activity were also monitored daily by sampling.

A sketch of the pilot scale nickel electrorefining cell is provided in Figure 3.0.1. 


\section{Pilot Scale Nickel Electro-Refining Cell}
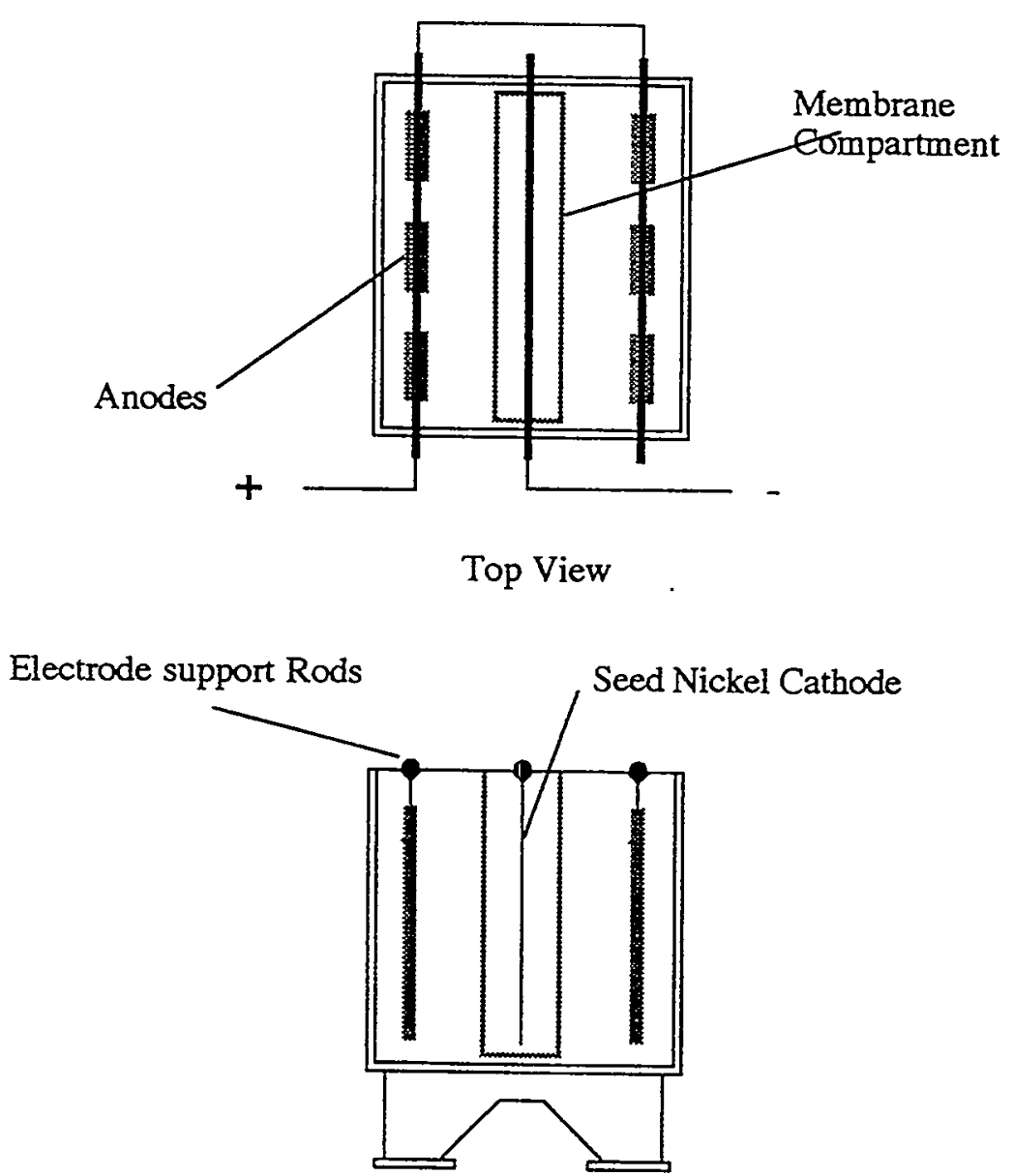

Side Section View

Figure 3.0.1. Sketch of pilot-scale cell. 


\subsubsection{Pilot Cell Pre-Testing}

Covofinish researchers filled the pilot-scale cell with water and performed a trial run of the integrated electrorefining system. The purpose of the trial run was to verify proper operation of valves, heaters, probes, and pumps before initiating electrorefining pretests on the pilot-scale cell. These pretests not only confirmed proof-of-concept but also determined where modifications were needed to further optimize the cell's efficiency prior to shipping the cell to MSC.

Covofinish researchers further optimized current density, cell voltage, and the rate of acid addition to improve cathode quality. During the pretests, Covofinish also optimized parameters on the displacement reaction in the cementation unit which resulted in further improvements. After pre-testing experiments were completed, Covofinish dismantled and shipped the pilot-scale electro-refining cell to MSC for experiments using ${ }^{99} \mathrm{Tc}$ contaminated nickel.

\subsubsection{Pilot-Scale Electro-refining at MSC}

MSC personnel installed the cell components received from Covofinish, and set up the required piping, power supplies, filters, and pumps needed to run the experiments. The major components of the cell and the cell setup was similar to that at Covofinish, with the following exceptions:

Anodes and Cathodes: At MSC, ten anodes ( 0.75 in. $\times 4$ in. $\times 28$ in.) were located on either side of one nickel cathode starter sheet $(\sim 0.0625$ in $\times 24$ in. $x 24$ in.). The anodes at MSC consisted of two arrays of five nickel slabs. The anodes had been produced by MSC from melt-refined nickel barrier material provided by the K-25 plant. The anodes were cut from a melted (declassified) nickel ingot. These anodes, which contained approximately $250 \mathrm{~Bq} / \mathrm{g}$ of ${ }^{99} \mathrm{Tc}$, were located on either side of the cathode .

The electrolyte used in the pilot-scale experiment was a Watt's type electrolyte containing nickel sulfate, nickel chloride, and boric acid. The electrolyte solution was heated to an operating temperature of 140 degrees $\mathrm{F}$. The initial $\mathrm{pH}$ of the electrolyte was approximately 4.0. Current supplied to the anodes was adjusted to $160 \mathrm{amps}$.

The anolyte was circulated continuously through the cationic membrane and then through a cementation unit and a five-micron filter. The catholyte was circulated through a heating chamber and a five-micron filter.

A photo of the pilot-scale cell is shown in Figure 3.0.2. 


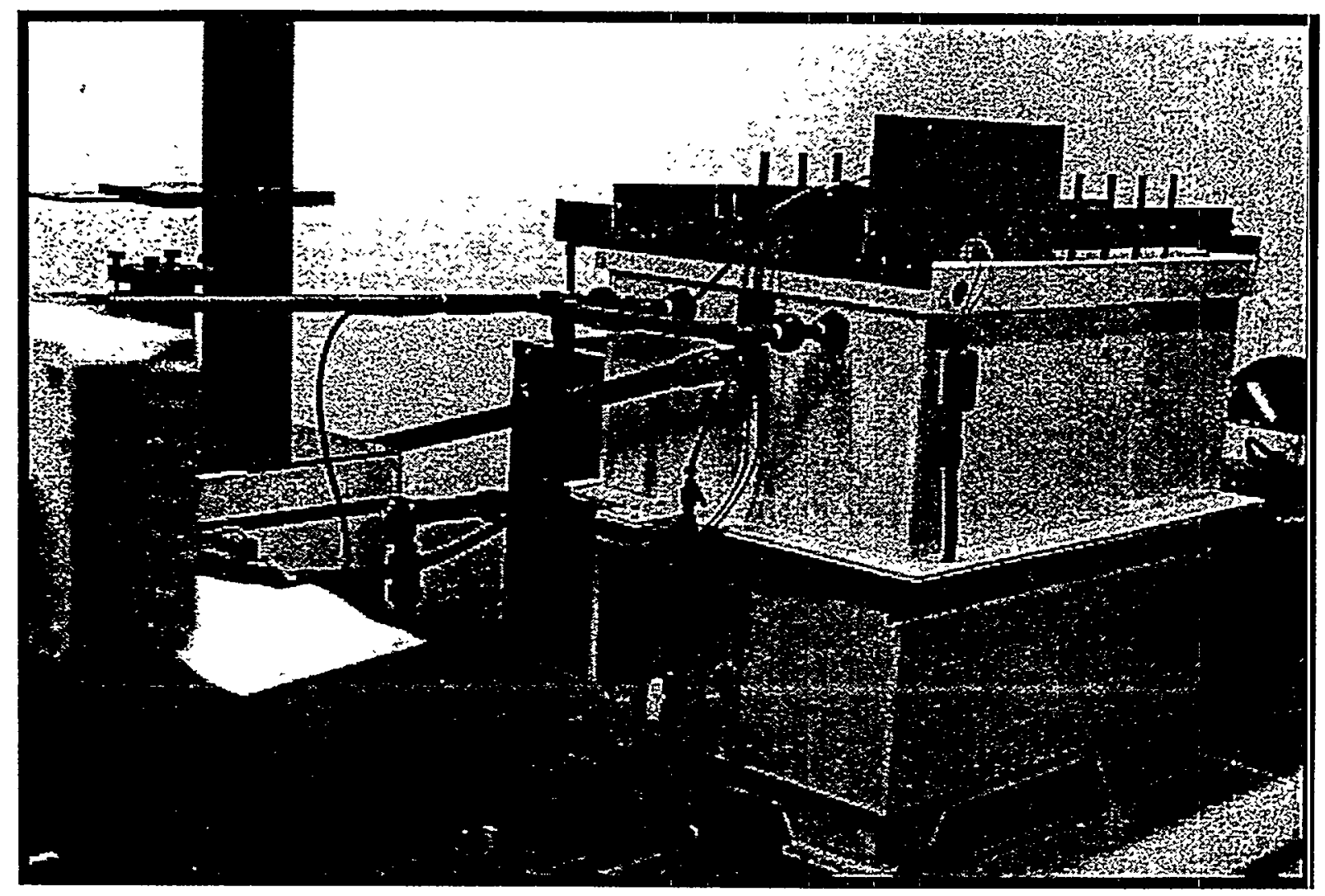

Figure 3.0.2. Photo of pilot-scale electrorefining cell.

Once the pilot-scale cell was operational, Covofinish researchers traveled to the Oak Ridge site to assist MSC personnel in the cell's startup. Like the experiments at Covofinish, the pilot-scale cell was run continuously. Voltage, temperature, and $\mathrm{pH}$ were also monitored periodically and recorded. Anolyte and catholyte were sampled daily. Nickel content in the solutions was monitored using Inductively Coupled Plasma (ICP). Nickel cathodes were also monitored daily for quality. Samples of nickel cathode were plated onto small, stainless steel cathode coupons that had been attached to the cell bar and placed in the catholyte. A checklist was developed for daily operations. This included checks of the catholyte drain flow, the $\mathrm{pH}$ indicators, filter changeout, data logging, and cell parameter adjustments as needed. 


\subsubsection{Research Results and Conclusions}

The initial test duration was thirteen days from $8 / 15 / 96$ to $8 / 27 / 96$. The weight of the starter cathode before operation was $10 \mathrm{lbs}$.

During the test, the $\mathrm{pH}$ of the catholyte was maintained between from 3.6 to 4.8 . The anolyte $\mathrm{pH}$ ranged from 2.6 and 3.8. Cell current was maintained at 160 amps. At the end of this test, the cathode weight was approximately 125 pounds. The cell was drained and cleaned. Drillings of the cathode were taken and tested using a Packard scintillation counter. In summary, lab analysis indicated a technetium content of less than $1.1 \mathrm{~Bq} / \mathrm{g}$.

The second test of the pilot scale electro-refining cell took place from 9/13/96 to $9 / 30 / 96$ with one cathode change-out on $9 / 24 / 96$. Since the cell was brought up slowly, full current was not applied until $9 / 18 / 96$. A metals recovery unit was added to the operation to pull out impurities in the nickel. Again the cell current was maintained at 160 amps. The catholyte $\mathrm{pH}$ ranged from 1.8 to 4.8 . Anolyte $\mathrm{pH}$ ranged from 2.3 to 3.8 . Nickel Carbonate was added to the anolyte in an attempt to control the $\mathrm{pH}$ on $9 / 27$ with little effect. On the last day of operation, the catholyte $\mathrm{pH}$ dropped from 2.7 to 1.8. The decision was made to shut down the cell and inspect the components.

Particulate on the membrane indicated that the membrane needs to be washed off before reuse. This could have caused some interference with nickel ions passing through the membrane. The first cathode from the second test weighed $65 \mathrm{lbs}$ and the second cathode weighed $60 \mathrm{lbs}$ yielding a total of $125 \mathrm{lbs}$ for 12 days or $10.4 \mathrm{lbs} /$ day. Results from cathode samples revealed similar results to the first run with technetium contents around $1 \mathrm{~Bq} / \mathrm{g}$.

For more details on methods for determination of isotopic content, see the section titled "Refinement of methods to quantify isotopic elements" in this report and the topical report issued to FETC at the end of Phase II (Advanced Technologies for Decontamination and Conversion of Scrap Metal (9/30/96).

At the end of the testing, a mass balances was documented in order to estimate the material handling and flows required for the full scale cell. A summary of the mass balance is shown in table 3.0.3 below for run 2 . 


\begin{tabular}{|l|r|l|r|}
\hline \multicolumn{1}{|c|}{ IN } & Weight (lbs) & \multicolumn{1}{|c|}{ OUT } & Weight (lbs) \\
\hline 10 anodes & & \multicolumn{1}{|c|}{157} \\
\hline Cathode 1 starter & 270 & 10 spent anodes & 65 \\
\hline Cathode 2 starter & 10 & Cathode 1 & 60 \\
\hline & 10 & Cathode 2 & 4.3 \\
\hline & & Main cell deposits & 0.4 \\
\hline & & Metals recovery & 0.3 \\
\hline & & Cementation & \\
\hline & & & 287 \\
\hline Total & 290 & Total & \\
\hline
\end{tabular}

Table 3.0.3 (Run 2)

Discrepancies in the totals at the bottom of the mass balance are attributed to measurement error and material on the filters, which was not measured. The deposits generated are relatively higher than those anticipated for a full scale unit because iron was introduced into this nickel during the melt as a slag addition. This created deposits that are not anticipated to be a part of a full scale operation.

Challenges during operation of the pilot scale cell included maintaining the optimal $\mathrm{pH}$ of the solutions, keeping the 5 micron filters changed to prevent plugging, and keeping the cationic membrane clean to prevent any restriction for the flow of nickel ions from the anode to the cathode. As operation of the cell progressed, these issues were raised and solved resulting in a higher quality product from each test run.

The objectives and goals set for the pilot-scale cell experiments were met and, in some cases, exceeded. Specifically, the pilot-scale research:

- demonstrated that the parameters for the lab-scale electro-refining experiments could be equally as successful in a production environment and

- provided important production data for establishing design criteria and operating parameters needed to develop a full-scale cell.

Knowledge gained and parameters established in the pilot-scale experiments will be applied toward establishing a full-scale electro-refining cell set up at MSC. Experiments with the full-scale cell will further optimize the efficiency, cost-effectiveness, and safety of this system in a production mode at MSC's facilities. 


\subsection{Full-Scale Electrorefining}

In Phase II of this effort, experiments on a lab-scale cell confirmed that technetium could be removed from nickel through electrorefining and cementation processes. A pilot-scale electrorefining system was used to optimize parameters for improved efficiency and to prove applicability on a larger scale. In Phase III, a full-scale electrorefining system was set up to optimize parameters, and specific to electrorefining nickel barrier and to improve system efficiency and cost effectiveness in a production mode. The design, installation and setup, and resulting data from investigations on the full-scale electrorefining cell are discussed in this section.

\subsubsection{Developing Design Criteria for the Full-Scale Cell}

The criteria for designing a full-scale electrorefining system came from assimilating information from hands-on experience with the 200-gallon, pilot-scale electrorefining cell, and data gathered from industries using electrorefining in a production mode.

\subsubsection{Pre-Design Research}

MSC researchers gathered data from various industries that use electrorefining processes in a production mode. MSC personnel traveled to a Phelps Dodge copper refining facility in El Paso, Texas. The purpose of the trip was to gain first-hand production knowledge from an industry with a long history in electrorefining processes.

MSC researchers gained important information relevant to electrorefining such as electrolyte content, electrical distribution, safety issues, material handling, equipment design, and maintenance issues. Although many modifications to basic electro-refining were required to decontaminate the nickel barrier, the trip produced a significant number of usable applications and important considerations, that were incorporated into the design of the full-scale cell at MSC.

One MSC engineer attended a course in Extractive Metallurgy to gain insight into electro-refining as practiced by industry. As part of the course, the class toured several electro-refining facilities including electro-winning and electro-refining operations. This helped to optimize the full scale cell design.

\subsubsection{Full-Scale Electrorefining Cell Design}

The conceptual design work for the proposed full-scale electrorefining cell began in the fall of 1996 and continued through mid-1997. The full-scale cell was designed to be able to decontaminate up to 160 pounds of nickel per day. Tank size, anode and cathode size and number, current density, and electrochemicals were all considered in the conceptual design. A cementation unit and a metal impurities recovery unit were also incorporated in the design. The process flow is shown in Figure 3.1.1. MSC engineers projected that the full-scale unit would consist of ten anodes and eleven cathodes, each 
approximately 38 -inches by 38 -inches by 2 inches. Equipment parameters, process parameters, and process flow considerations were updated regularly to reflect new information gained from the scale up, from advice of nationally recognized metallurgical experts, and from MSC's own pilot-scale experiments. 


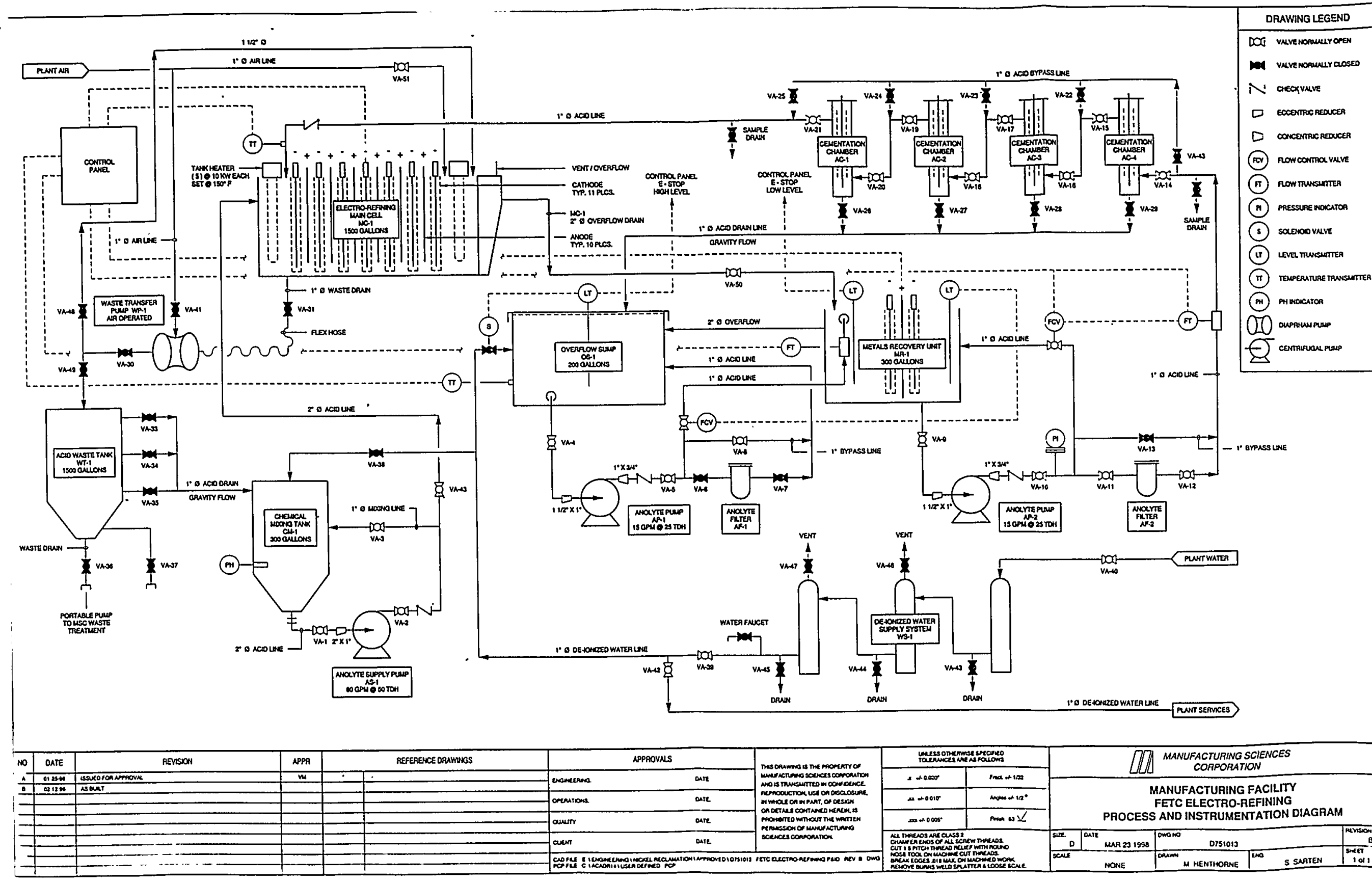


In phase III, MSC engineering staff began designing MSC's full-scale electrorefining cell. Lessons learned by the visit to electrorefining production plants and various experiments (including test melts) by MSC scientists, engineers, and production personnel were included in a functional design specification.

\subsubsection{Major Components of Full-Scale Cell}

The full-scale cell design included the following major components:

Main Tank: The full-scale cell was a 2,000 gallon tank made of polymer concrete. The eleven cathodes and ten anodes were installed in the tank, alternating anode and cathode. A membrane frame was used to support a cationic membrane surrounding each cathode. The cationic membrane separated the anolyte (contaminated solution around the anode) from the catholyte (clean solution around the cathode). The cell was equipped with a push/ pull ventilation system. Ventilation volume consisted of a 6,000 CFM inline scrubber connected to the existing building HEPA filtration system. Power distribution at the cell included a copper bus running down each side along the top of the tank (lengthwise). One buss connected to anodes to provide a positive electrical charge. The buss on the opposite side connected the cathodes to provide a negative electrical charge. The buss on both sides connected to the.power supply via water cooled leads.

Metal Impurities Recovery Unit (MRU): Solution exiting the main cell entered the MRU for impurities removal. The MRU included one anode and two internal cathodes. The cathode in the MRU was surrounded by a frame that supported a cationic membrane on both sides. The MRU cell was equipped (on the top of the tank) with a vent that connected it to the same scrubber that ventilated the main cell. After filtration, anolyte entered the top corner of the MRU cell tank and exited at the bottom middle.

Electrolyte Solution: The solution used in the full-scale cell was a Watts-type electrolyte containing nickel sulfate, nickel chloride, and boric acid at a $\mathrm{pH}$ level of around 3.0. The solution was mixed in a 300-gallon tank and transferred to the main cell.

Temperature Controls: The electrolyte was heated using five immersion heaters located inside the main cell. The temperature of the electrolyte (both in the main cell and in the heated sump) was monitored by a sensor and displayed on the operators' control panel. The temperature control was set between 145 and 155 degrees $F$. The electronic controls provided an automatic shut down of the process if the temperature of the electrolyte exceeded 170 degrees $F$. The temperature of the electrolyte at the metals recovery unit (MRU) was monitored and read from the MRU display.

Power Supplies: Current from the power supply to the main cell, the cementation unit, the metal recovery unit, and the polarity reversing unit, was monitored and controlled from the central operator control panel. Electricity was provided to the ten anodes at a current density of $15-20 \mathrm{amps} / \mathrm{ft}^{2}$. The cell was run at 1800 to $3600 \mathrm{amps}$ at about 6 volts. 
Cementation Chambers: Cementation chambers, for removal of technetium from solution, were made of polypropylene. Four chambers were arranged in series. The bottom of the chamber was flanged to allow cleanout of sludge as needed, and the top was flanged for accessibility. Each chamber was approximately 8 inches in diameter and 54 inches high. Electrolyte passed from the bottom port, filled the chamber, and exited through the top port.

Overflow Sump: The overflow anolyte from the main cell was originally gravity fed into the 200-gallon, chemical-resistant sump tank. The overflow sump was located under the main electrorefining cell. A level indicator in the sump controlled the outlet pump, turning it off if levels got too low and turning off both anolyte pumps and the makeup water if levels got too high. The overflow from the main cell was redesigned. The overflow sump is now fed by an overflow from the MRU.

Catholyte Recirculation Pump: A portable catholyte recirculation pump was located between the main cell and the catholyte filter. The pump could be turned on manually as needed when the catholyte began to appear cloudy or when particulate was visible. The portable pump would circulate the catholyte from inside any one of the eleven cathode frames (cell chamber), through the catholyte filter, and then return the catholyte to the same chamber. The pump could be used in any of the catholyte chambers.

Anolyte Filters: An anolyte recirculation pump located behind the sump, delivered anolyte from the sump through the first anolyte filter and into the MRU. A second anolyte pump pulled anolyte from the MRU, through the second filter, then through the cementation process and back into the main cell to complete the loop. Both pumps circulated anolyte at $5 \mathrm{gpm}$ and ran continuously, except when shut down by the operators.

Deionized Water Supply System: Deionized water was used during startup for chemical additions and mixing and was also used to make up for the evaporative losses during cell operation. A sensor in the sump signaled low fluid levels. The signal was sent to a solenoid on the deionized water supply system, allowing flow. The makeup water was supplied from the MSC plant water supply and passed through ion-exchange columns to provide deionized water to the system.

Anode/Cathode Rack: The portable anode/cathode racks were made available to allow for rinsing chemicals off the anodes or cathodes as they were removed from the main cell. A pressure washer was used to clean the anodes or cathodes after removal.

Hoist: A one-ton hoist and a steel frame was used for material handling above the electrorefining cell. A spreader beam was specifically designed to enable operators lift one anode or cathode at a time.

Compressed Air Supply: Compressed air was used to aerate the anolyte in the main cell. A pipe was permanently installed in the main cell that extended to the bottom of the 
anolyte and ran the length of the tank. Compressed air was filtered and "de-oiled" (made oil free) before use in the cell. A manual valve was available to vary the flow.

$\mathrm{pH}$ Monitor: The $\mathrm{pH}$ (in both the anolyte and the catholyte) was monitored in the MRU using a continuous monitor. $\mathrm{PH}$ in the main cell was monitored as needed using a portable $\mathrm{pH}$ probe. Samples of anolyte and catholyte were taken daily during operation and sent to the lab for compositional analysis and $\mathrm{pH}$.

Ventilation System: Fumes from the main cell and from the MRU were scrubbed by an intermediate scrubber system. The intermediate system scrubbed the acid in the air stream before the air stream reached the building's HEPA ventilation system, protecting the HEPA system from chemical attack inherent in the electrorefining processes.

Piping, Pumps, and Tanks: Piping, pumps, tanks, etc. were constructed of materials suitable for safe containment of the chemicals used in the system.

Phone Dialer: A phone dialer was purchased to automatically contact the operators in case of problems with the system. This allowed continuous 24 hour, 7-days-per-week operation of the cell.

Figure 3.1.2 Photo of Electrorefining cell:

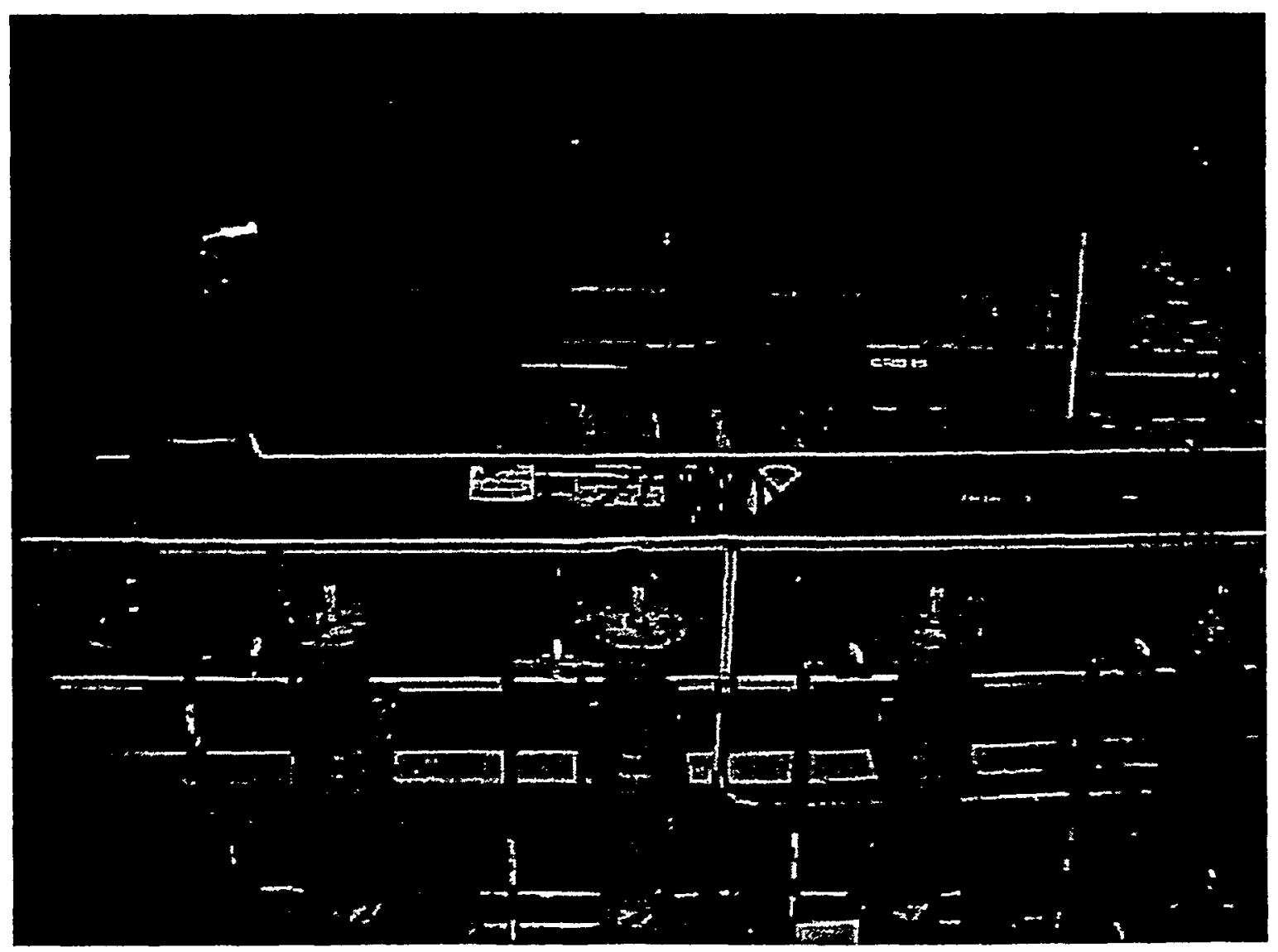




\subsubsection{Electrolyte Solution}

A Watts-nickel electrolyte solution was used in the nickel electrorefining process. Specifications (concentrations and purities) for the chemical components needed for MSC's specific processes were obtained from specialists in the field. Vendor product specifications were evaluated and costs and solubility data were compared.

Initial optimization efforts included minimizing the presence of any elements that could interfere with the electrorefining process. This was achieved by purchasing chemicals of the highest purity. Reports on the research and analysis of the optimized Watts solution are provided in Appendix 3.1.

Initial plans were to mix acid in a separate mixing tank. The acid temperature could not be maintained in the mixing tank. As a result, acid was mixed in the main electrorefining cell. For this, nickel sulfate, nickel chloride, and boric acid were purchased in solid form and added to the heated cell. As procedures for acid mixing were optimized, it was discovered that procuring nickel sulfate and nickel chloride in liquid form, mixing in small batches, and then transferring to the main cell proved the most efficient method. The MSC mixing plan for Watts nickel electrolyte is shown in appendix 3.1.

\subsubsection{Potential Hazards and Safeguards}

Safeguards were implemented to address potential hazards inherent in the electrorefining processes. Potential hazards were identified in the following major areas; electrical, power lifting equipment, thermal, and chemical (solids and fumes). Work instructions were prepared for all job duties associated in these (and other) process areas. Employees were given extensive training on the safe operation of all components and machinery associated with their job descriptions as it related to work in the electrorefining production area. Examples of the hazards are shown below are for the one full scale electrorefining cell.

\begin{tabular}{|l|l|}
\hline Electrical & Maximum 15 volts D.C., 3600 amps \\
\hline Chemical/ burns & $\begin{array}{l}\text { Heated nickel sulfate, nickel chloride, boric } \\
\text { acid. PPE required as well as restricted } \\
\text { access to the top of the cell }\end{array}$ \\
\hline Fumes & $\begin{array}{l}\text { Mainly water vapor, potential for chemical } \\
\text { fume, however, results from samples taken } \\
\text { by independent source revealed no fumes } \\
\text { from cell that are potentially harmful to } \\
\text { people. Ventilation system implemented as } \\
\text { a precaution }\end{array}$ \\
\hline Material handling & $\begin{array}{l}\text { Potential for cuts, drops, etc. PPE required. } \\
\text { Special handling devices were designed } \\
\text { and implemented. }\end{array}$ \\
\hline
\end{tabular}




\subsubsection{Testing and Commissioning the Electrorefining System}

Once the components of the electrorefining system were installed, the integrated system was made ready for testing and commissioning. A functional test and commissioning plan was written for final testing of the entire system before startup. The plan (which incorporated industrial and ALARA safety requirements) proposed to functionally test individual components, subsystems, and the integrated electrorefining process. Production and maintenance employee work instructions were developed for all phases of the electrorefining processes.

Mechanical and electrical controls for individual components of the full-scale electrorefining system (including peripheral units) were tested. Tested components also included individual flow valves, controllers and instrumentation, piping and ductwork, and power supplies. Subsystems, including the chemical mixing system, the ventilation system and scrubbers, the de-ionized water system, the overflow sump, the cementation system, and the monorail system were also tested. Test activities included comparing the drawings and sketches from the functional design to the actual installed system components.

\subsubsection{Electrical Design Inspection}

Lockwood Green Technologies (LGT) performed a walkdown of the full-scale electrorefining system to observe and inspect the installation for conformance to LGT drawing E001. Finding no major problems with the installation of the electrical devices, LGT inspectors verified that the workmanship was professional and was (with minor discrepancies) in compliance with all licensing codes. Discrepancies noted by LGT personnel were corrected by MSC. LGT also provided engineering support in accordance with the previously approved QA program.

\subsubsection{Testing of Integrated System}

The integrated electrorefining system was tested under conditions that would be similar to those expected in the electrorefining production processes. The full system test used salt water as a substitute for electrolyte to verify fluid flow and sensor indicators.

A function check was made of the integrated system's monitoring of flow systems, temperature, current, and voltage, $\mathrm{pH}$, and level alarms. Testing with the initial optimized - parameters were used as the standards for verifying overall operation of the system as specified in the functional design. Discrepancies found during the system test were redlined or noted. A punch list was made to ensure that corrections were incorporated in the operations plan.

A safety review was also performed to ensure that the system was safe to operate, based on information obtained during commissioning and functional testing. 


\subsubsection{Nickel Source for Full-Scale Electrorefining}

MSC requested 4,500 pounds of contaminated nickel barrier from the ETTP site to use for testing MSC's full-scale electrorefining cell. Researchers were unable to complete the transfer of this material due to costs to transfer the nickel into fiber (sacrificial) drum and transport the nickel to MSC.

MSC was able to obtain nine contaminated nickel ingots from Paducah, however, with a total weight of approximately nine tons (18,000 pounds). This nickel already had been previously melted during the Cascade Improvement Program/Cascade Upgrade Program (CIP/CUP) from the late 1970's and early 1980's. Full scale testing of electro-refining was conducted on this nickel. For the full-scale cell tests, these nickel ingots were sliced into anode sheets, mounted to hangers, and placed directly into the electrorefining cell. In addition, the cut ingots were used for test melts.

\subsubsection{Operations}

The full scale cell was started for the first time in June 1998. After one day of operation, the cell was shut down due to cationic membranes sticking to the cathodes, mandating a re-design of the cathode frames. During the month of July, as the cathode frames were under design changes, several tests were carried out on the cell to improve plating quality. Trials were carried out in the cell on a single strip plate. Plating was improved from a "flaking" appearance to a smooth plated product. Parameters such as current, current reversal, and temperature were modified to achieve the desired result. Optimizing parameters to reduce "dendrite growths" on the surface of the cathode was also a subject of testing during this time. The making of a nickel starter sheet by plating on a titanium surface was accomplished during this time. During July, a new prototype membrane frame was placed in the full scale cell. Trials on this new frame and membrane indicated good performance of the assembly. Once proven, additional frames were ordered. In September, the new cathode boxes were installed and tested. The nickel cell ran successfully from Oct. 6 to Oct. 15 when the cell was shut down for cathode change-out. A demonstration for FETC was held on October 13 at MSC.

\subsubsection{Lessons Learned}

Several challenges were experienced and resolved during the testing and the process demonstration.

Safety: In October 1998, during a shutdown for cathode changeout, a chemical scald injured an electro-refining cell operator. The cell was shut down immediately and the accident investigated. A corrective actions list was developed and implemented. This included adding an additional platform for improved access to the top of the cell. A new instruction was developed and extensive training took place. The Radiation and Industrial Safety Work Permit was reviewed and rewritten. The cell was restarted on 2/18/99. 
Membrane Frames: After the June 1998 startup of the full-scale cell, MSC experienced difficulties with membrane materials sticking to the cathodes. The cell ran for only one day. MSC researchers tried various techniques to solve the problem, including adding inflated tubes on the side to stretch (tighten) the membrane and adding stiffeners to the membrane frames. After several unsuccessful attempts to modify the frames, MSC researchers concluded that new, wider membrane frames would be required. A new membrane frame was designed by MSC. One new membrane frame was purchased as a prototype and tested before a purchase order was released for enough membrane frames to fill the cell.

When the new frames, Nafion ${ }^{\mathrm{TM}}$ membranes, gaskets, and bolts arrived for the fullscale cell, the cathode boxes were assembled. A few of the PVC bolts broke during assembly and were replaced with coated stainless steel bolts. The new membrane and frame assembly was placed in the full-scale cell. Trials were run at various settings to further optimize plating. The new frame and membrane appeared to function well.

Nickel Plating Quality: While waiting for the new frames, trials continued in the electrorefining cell on a single strip plate. The goal was to optimize the electrodeposition appearance and to set electrorefining parameters. These trials produced continuouslyimproved results, moving from a plated metal coupon with a "corn-flake" appearance to a plated thin foil on a titanium surface. The thin foil was then peeled off and used as a nickel starter sheet. More nickel was plated onto the starter sheet, producing a strip with uniform deposition on the surface of better quality than was accomplished on the pilot scale.

Difficulties With Flow Controllers: MSC also experienced difficulties with the flow controllers. The controllers lacked the flexibility needed to control the flow in the system. In addition, electrical interference caused the transmitters to send incorrect signals to the controllers. The transmitters were relocated to avoid interference.

Pump failures: Two centrifugal pumps (with mechanical seals) in the acid recirculating loop failed. It was determined that cycling the cell through heating and cooling have caused crystals to form in the pumps causing failure. The start/ stop is inherent in a development process. In a continuous process, this effect would be minimized. Magnetic drive centrifugal pumps were specified, procured, installed and tested. Also, any time there is an interruption to the system that causes cooling of the anolyte, pumps are flushed before shut down to prevent buildup of crystals inside the pump. As of this writing, the new pumps are continuing to operate successfully.

Decontamination of the Nickel: The first tests did not decontaminate the nickel to levels to reach our goal $(\sim \mathrm{Bq} / \mathrm{g})$. Researchers concluded this was probably caused by 1$)$ some of the anolyte splashing over the membrane frame, causing contamination of the catholyte (the new frames remedied this situation); and 2) the cationic membrane that was purchased appeared to be of inferior quality to that used on the pilot-scale cell. MSC 
purchased Nafion 450 membrane materials to place in the new frames. This also improved decontamination. Over time, decontamination levels improved dramatically.

\subsubsection{Results}

Chart 3.1.5 shows the contamination levels in the Paducah Ingots before electrorefining. Technetium contamination ranged from $226 \mathrm{~Bq} / \mathrm{g}$ to $627 \mathrm{~Bq} / \mathrm{g}$.

Paducah Ingot Contamination Before Electrorefining

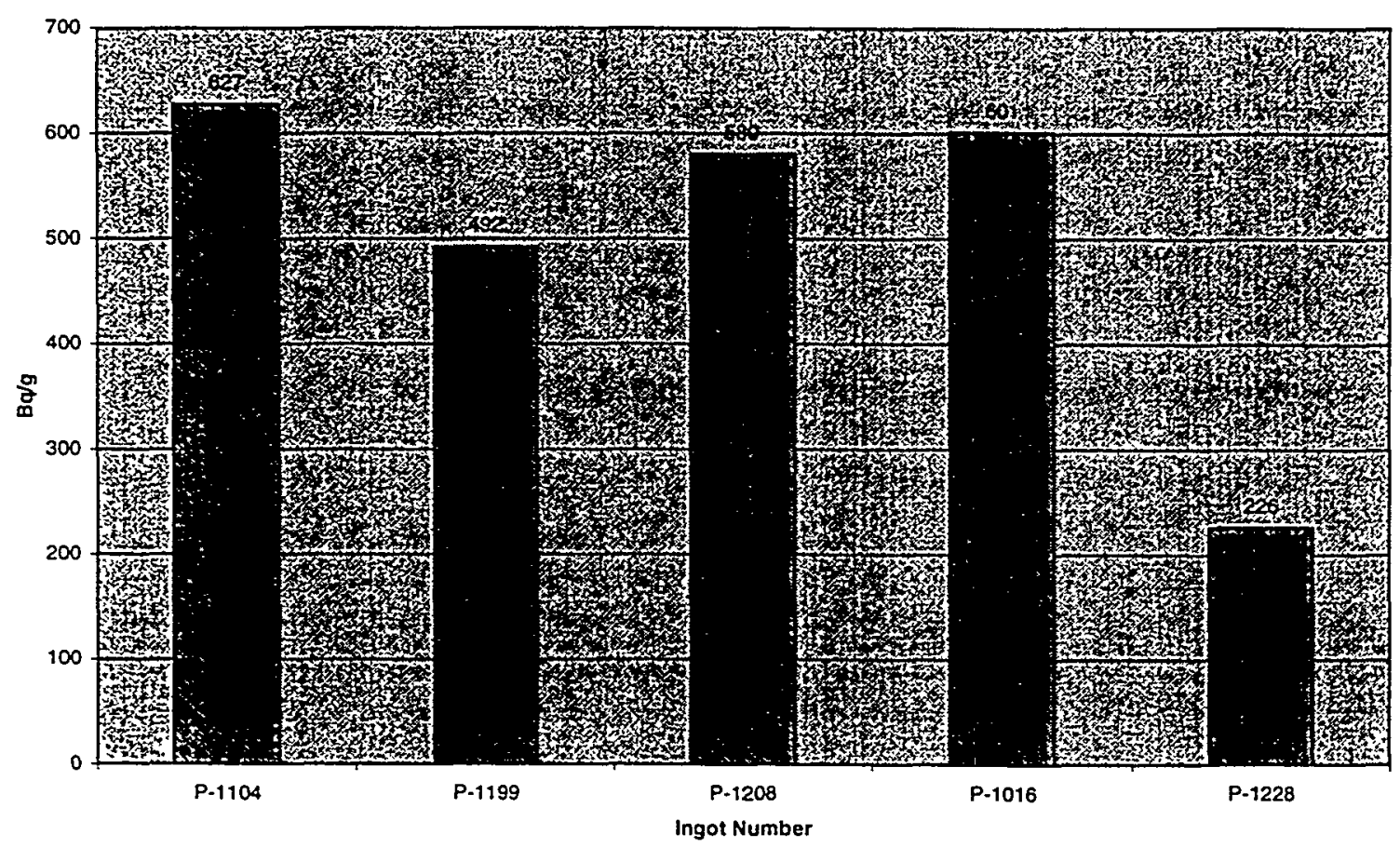

Figure 3.1.5 Paducah Ingot Contamination Levels

After implementation of corrective actions and optimization, the cell was re-started on $2 / 18 / 99$. First, starter sheets were made by plating out nickel onto a Titanium sheet. After approximately 24 hours, the titanium sheets are pulled from the cell and the nickel starter sheet is "stripped" or separated from the titanium sheet. See photo 3.1.6. 


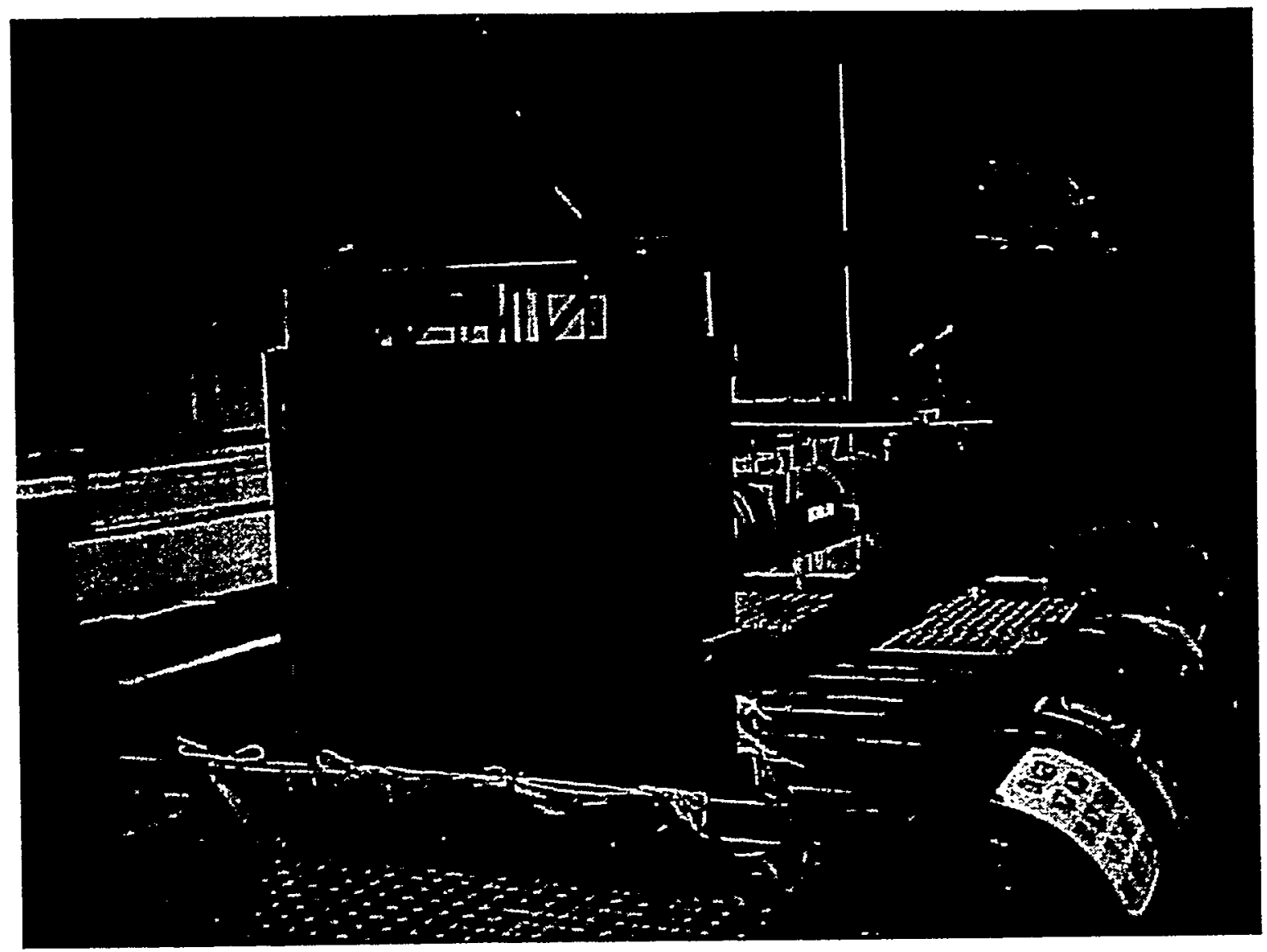

Figure 3.1 .6

After the nickel starter sheet is stripped from the titanium sheet, it is placed back into the electrorefining cell to make a nickel cathode. Approximately 14 lbs per day of nickel is plated onto each cathode. 
Samples of anolyte and catholyte were taken daily to track levels of technetium in the solutions. These levels are indicators of potential contamination reaching the final product cathode. Figure 3.1.7 shows technetium levels in the anolyte and catholyte over time. Anodes that were left in the cell, which dissolved and contributed contamination to the solution, explains the upward trend of contamination in the anolyte. Also, adjustments were necessary to the anolyte purification circuit before contamination levels were dropped to acceptable levels. This graph demonstrates the learning curve necessary to optimize operating parameters. The catholyte trends were added to review the effect of the cationic membrane. This graph shows that the cationic membrane is an effective barrier between the anolyte and catholyte.

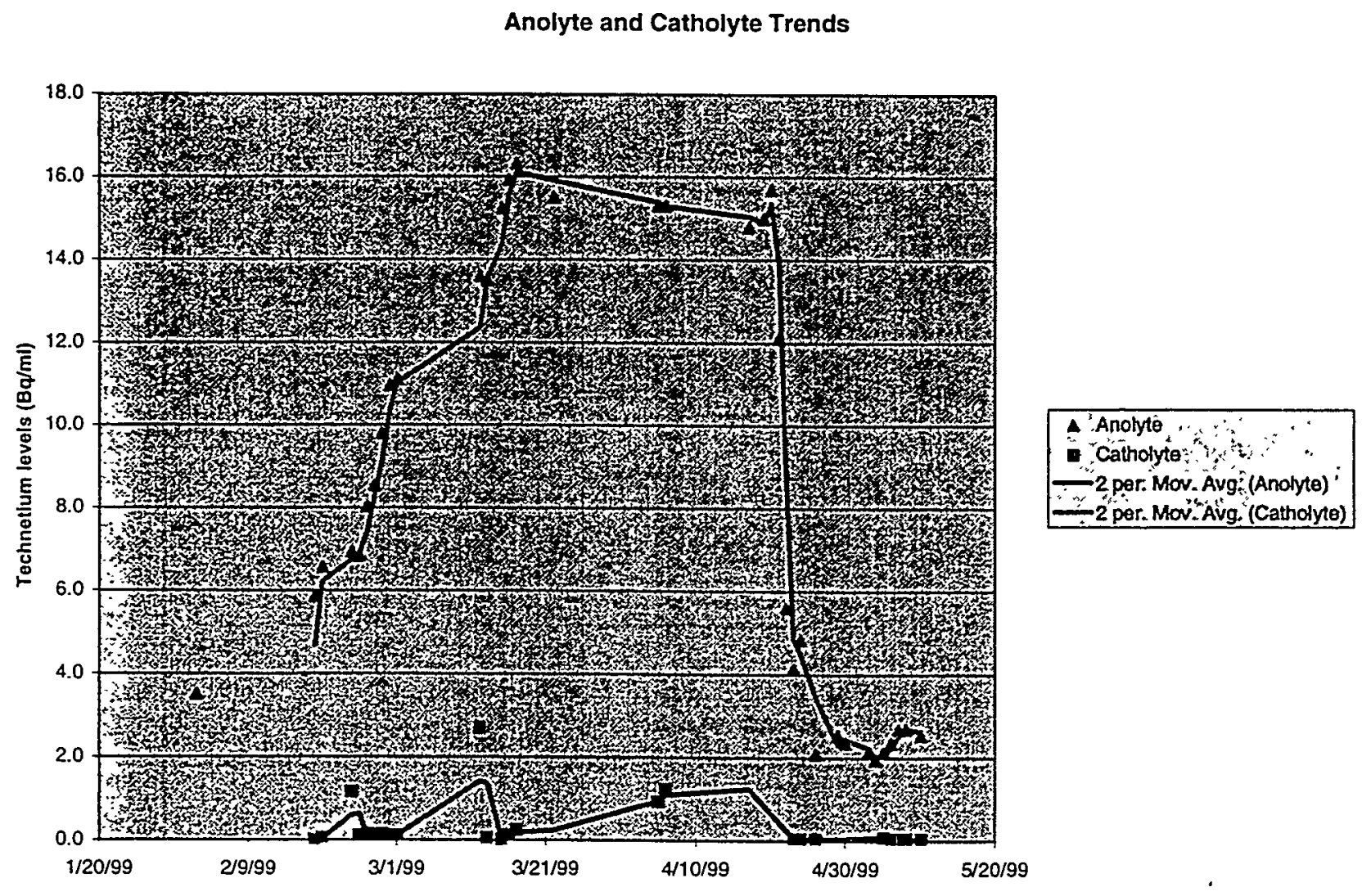

Figure 3.1.7 
The technetium levels in the cathode product were also tracked over time as shown in Figure 3.1.8. Again, as parameters were optimized, cathode results were above goal. Once the system was brought under control, results in the range of $1-2 \mathrm{~Bq} / \mathrm{g}$ were achieved.

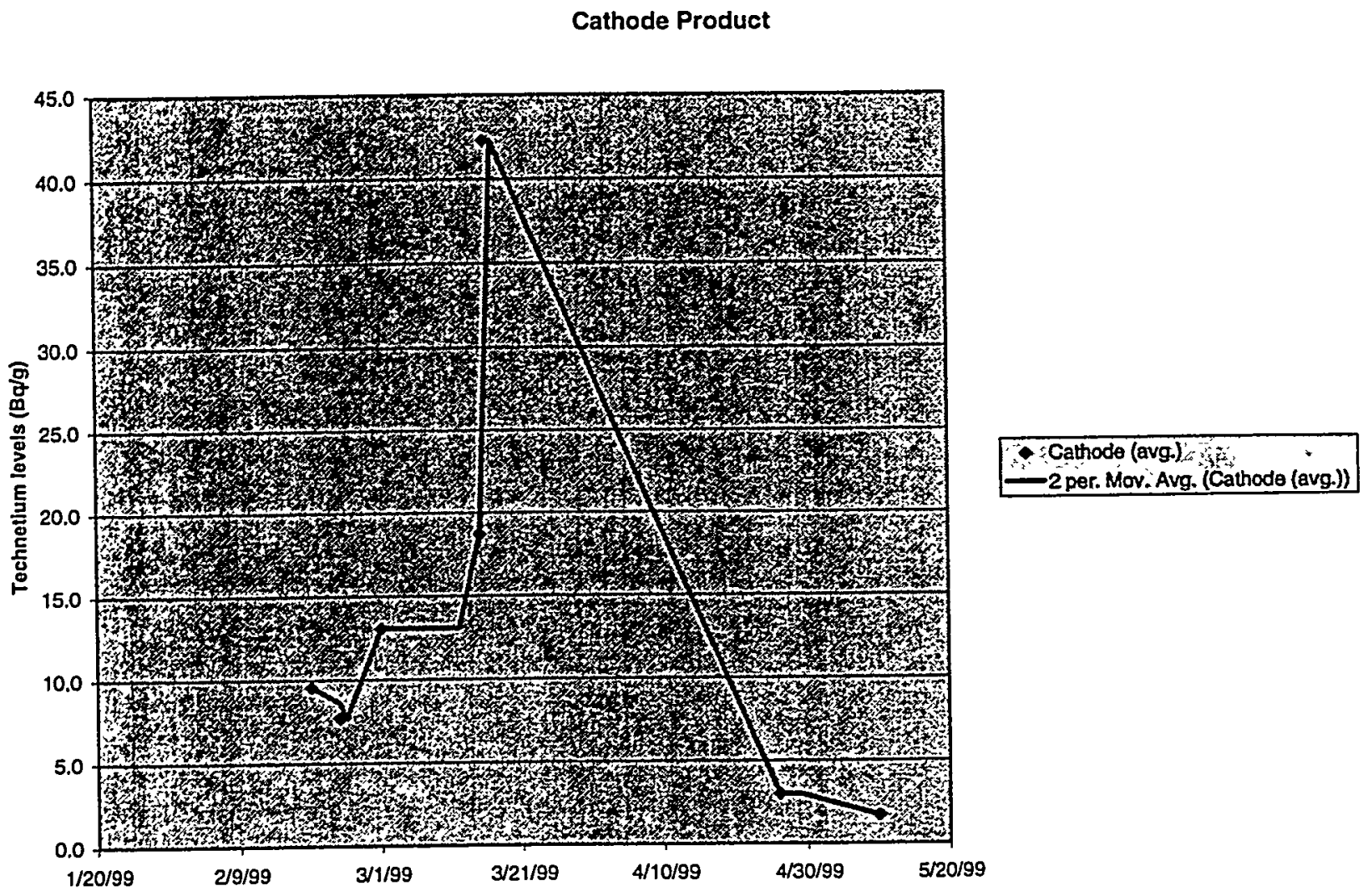

Figure 3.1 .8 
It was found that tracking anolyte technetium contamination levels is a good indicator of final nickel cathode values. As shown in figure 3.1.9, even though the anolyte levels are tracked in $\mathrm{Bq} / \mathrm{ml}$, and values for the cathode are in $\mathrm{Bq} / \mathrm{g}$, a correlation between the two are evident. Tracking and controlling anolyte contamination is imperative for acceptable product nickel.

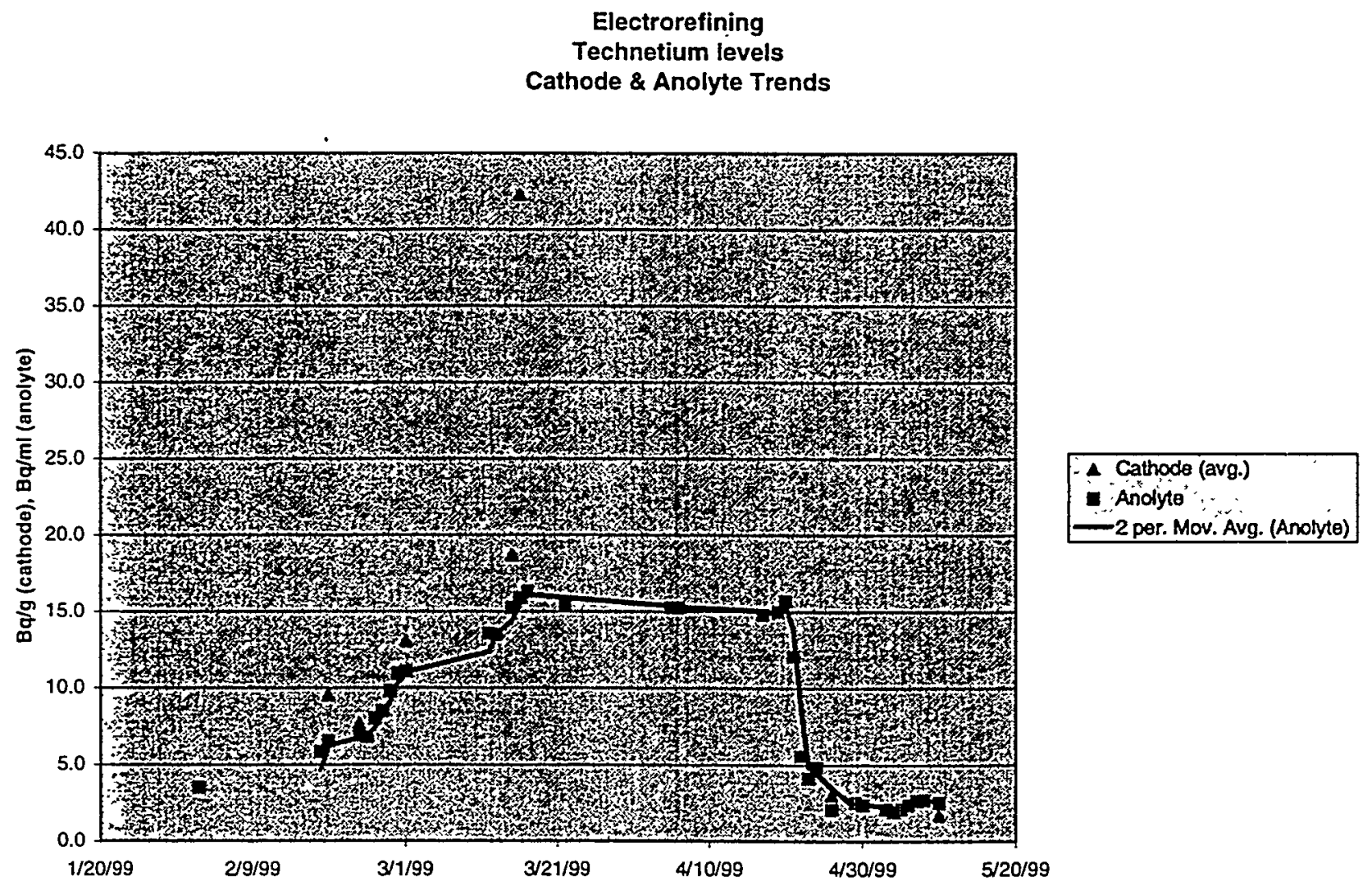

Figure 3.1.9

Latest results as of May 1999:

\begin{tabular}{|l|l|}
\hline Contaminated anode & $592 \mathrm{~Bq} / \mathrm{g}$ \\
\hline Product cathode & $1-2 \mathrm{~Bq} / \mathrm{g}$ \\
\hline Cementation chamber (where ${ }^{99} \mathrm{Tc}$ is removed) & $2315 \mathrm{Bg} / \mathrm{g}$ \\
\hline
\end{tabular}

Figure 3.1.10

Once process parameters were stabilized and optimized, the full-scale electrorefining system worked as anticipated. The cementation units revealed high levels of technetium 
as expected. Nickel was decontaminated by the full scale cell between 1 and $2 \mathrm{~Bq} / \mathrm{g}$ which meets our stated goal of decontamination around $1 \mathrm{~Bq} / \mathrm{g}$.

As of May 20,1999, over one ton of barrier nickel was processed through the electrorefining cell. Over one month of actual plating time was logged.

\subsubsection{Phase III nickel recovery research costs}

Task 311, One full scale electrorefining Cell

Task 312, Anode baskets (direct dissolution)

Task 313, Chemical dissolution

\section{TASKS $311,312,313$ COST SUMMARY}

\begin{tabular}{|c|c|c|c|c|c|c|}
\hline DATE & $\begin{array}{c}\text { TASK } \\
\#\end{array}$ & $\begin{array}{l}\text { ENGINEERING } \\
\text { LABOR+OH }\end{array}$ & $\begin{array}{l}\text { PRODUCTION } \\
\text { LABOR+OH }\end{array}$ & $\begin{array}{c}\text { OTHER } \\
\text { SUBCONTRACTOR } \\
\text { COST }\end{array}$ & $\begin{array}{l}\text { OTHER } \\
\text { DIRECT } \\
\text { COST }\end{array}$ & $\begin{array}{l}\text { TOTAL } \\
\text { COSTS }\end{array}$ \\
\hline \multicolumn{7}{|c|}{1997} \\
\hline & 311 & $\$ 46,546.79$ & \$ $189,559.79$ & $\$ 4,281.71$ & $\$ 151,219.66$ & $\$ 415,679.56$ \\
\hline & 312 & $\$ 8,596.24$ & - & $\$ 23,165.91$ & $\$ 248.74$ & $\$ 35,635.47$ \\
\hline & 313 & $\$ 228.05$ & $\$ 190.44$ & - & - & $\$ 418.49$ \\
\hline TOTAL & & $\$ 55,371.07$ & $\$ 189,750.23$ & $\$ 27,447.62$ & $\$ 151,468.40$ & $\$ 451,733.52$ \\
\hline \multicolumn{7}{|c|}{1998} \\
\hline & 311 & $\$ 46,609.10$ & $\$ 73,648.54$ & $\$ 8,843.12$ & $\$ 124,643.55$ & \$ 274,408.05 \\
\hline & 312 & $\$ 3,787.69$ & - & - & $\$ 94.00$ & $\$ 3,896.25$ \\
\hline & 313 & - & - & $\$ 39,459.26$ & \$17,686.24 & $\$ 65,991.62$ \\
\hline TOTAL & & $\$ 50,396.80$ & $\$ 73,648.54$ & $\$ 48,302.38$ & $\$ 142,423.79$ & \$ 344,295.92 \\
\hline \multicolumn{7}{|c|}{1999} \\
\hline & 311 & - & $\$ 9,702.28$ & - & $\$ 22,033.48$ & $\$ 35,146.55$ \\
\hline & 312 & - & - & - & $\$$ & - \\
\hline & 313 & - & - & - & $\mathbf{s}$ & - \\
\hline TOTAL & & - & $\$ 9,702.28$ & - & $\$ 22,033.48$ & $\$ 35,146.55$ \\
\hline $\begin{array}{l}\text { GRAND } \\
\text { TOTAL }\end{array}$ & & $\$ 105,767.87$ & S 273,101.05 & $\$ 75,750.00$ & $\$ 315,925.67$ & $\$ 831,175.99$ \\
\hline
\end{tabular}

Additional cost detail for the full scale cell is shown in appendix 3.1. 


\subsubsection{Projections based on one full scale cell:}

The following data provides an economic estimate for a scaled up version of the electrorefining cell that was built under a FETC contract and is currently operating at MSC. Economies of scale can be expected from a large plant. However, the estimates for this evaluation are based on equipment, material, and personnel costs associated with the fullscale cell. The assumed economy of scale for this evaluation is a range of 10 to 40 percent. The estimates are given as ranges, based on uncertainty. In determining economic viability of deploying this or any new technology, requires risk-based decision making. The technology has proven to work and in order to determine if it is economical, assumptions have to be made about how a large-scale plant will be built and operated and how the price of nickel will fluctuate over the life of the project. MSC and its Parent Corporation BNFL, INC. performed this risk analysis early before the full-scale project was completed or the technology proven and based on the results entered into a fixed price contract with the DOE to D\&D three buildings at the ETTP site. The contract recognized the value of recovering the nickel and the DOE has received a credit for this material. The following is a quote from the DOE/ORO office web page:

“The $\$ 238 \mathrm{M}$ contract cost included a credit back to DOE of $\$ 55,569,748$ for the recyclable material. This amounts to quarterly cost savings of $\$ 2,646,178$ over 21 quarters for the materials recycled or reused. The recycling activities began in the 4 th calendar year quarter of 1998 and will continue throughout the duration of the contract." 


\section{Assumptions:}

Cost projections are based solely on the performance of the one full scale research cell

These numbers are not based on any operational experience of a production scale electrorefining plant

Costs from the one full scale cell are for electrorefining only and do not include costs for pre-processing nickel

Preprocessing could include pretreatment and melting to delassify nickel and cast into anodes

\section{Electrorefining}

\section{Costs}

\section{One cell cell totals:}

Equipment for one full scale cell ( $\sim 15^{\prime}$ long) cost $\sim \$ 316,000$

Production rate $160 \mathrm{lbs} /$ day

\section{A possible plant}

size:

20 cells $\sim 30^{\prime}$ long, or 40 cells $\sim 15^{\prime}$ long

Production rate $\sim 9,000 \mathrm{lbs} /$ day

\section{Projections:}

Scaling equipment costs from one cell to a plant size, expected savings as a result of:

Bulk discount

Production facility instead of research

Shared acid regenerative loop between cells

Shared waste treatment facilities between cells

Could result in equipment costs savings of $10-40 \%$ for a potential plant equipment costs of:

$40 \times \$ 316,000 \times(1-(10 \%$ to $40 \%))=\sim 7,600,000$ to $\sim 11,400,000$

Operation of the pilot scale cell (technician only) for one year $=\sim \$ 120,000$

Same discounts as assumed above

Estimate savings 10 to $40 \%$

$\$ 120,000(1-(10 \%$ to $40 \%) \times 40$ cells $=\sim 2,800,000 / \mathrm{yr}$ to $-\$ 4,300,000 / \mathrm{yr}$

Pre-processing of nickel could cost in the range of $\$ 0.75$ to $\$ 1.50 / 1 \mathrm{~b}$

This assumes existing vacuum induction equipment at MSC can be used for melting and casting

\subsubsection{Path Forward}

The path forward includes the design and installation of a production scale electrorefining facility in support of the ETTP Three Building D\&D Project. This facility, as currently planned, will be located at MSC in Oak Ridge and will have an initial capacity of about 1200 tons/yr. As of this writing, the plant is in final design. 


\subsubsection{Nickel Melting}

For ETTP nickel, melting of nickel would be required to declassify the nickel and prepare anodes for electrorefining. Developing an anode casting process required researching a mold design suitable to produce a shape that would fit directly into the electrorefining cell. Selecting mold materials that could sustain the superheat during casting was part of the design process as well. Developing casting methods included optimizing melting parameters, such as temperature, residual gasses refractory containment, and metal flow.

\section{Designing Molds}

Anode molds were sized to create anodes that fit directly into the tank on the fullscale cell. The anode molds were made of ductile iron. Graphite dams were installed at the ends of each mold to provide a fill cavity of 36-in. by 36-in. by 2 -in. thick.

Various means of casting molds in a production mode were investigated. One promising option under consideration is to fit the molds into a mold chamber by stacking them in a spiral-staircase configuration in MSC's six metric ton vacuum induction degassing and pouring furnace. Casting and cascading would occur by pouring the molten metal into the top mold and allowing the superheated liquid to cascade down to the bottom molds, as indicated in Figure 3.1.6. Other casting methods, such as casting molds one at a time in MSC's one ton vacuum induction furnace, were also investigated.

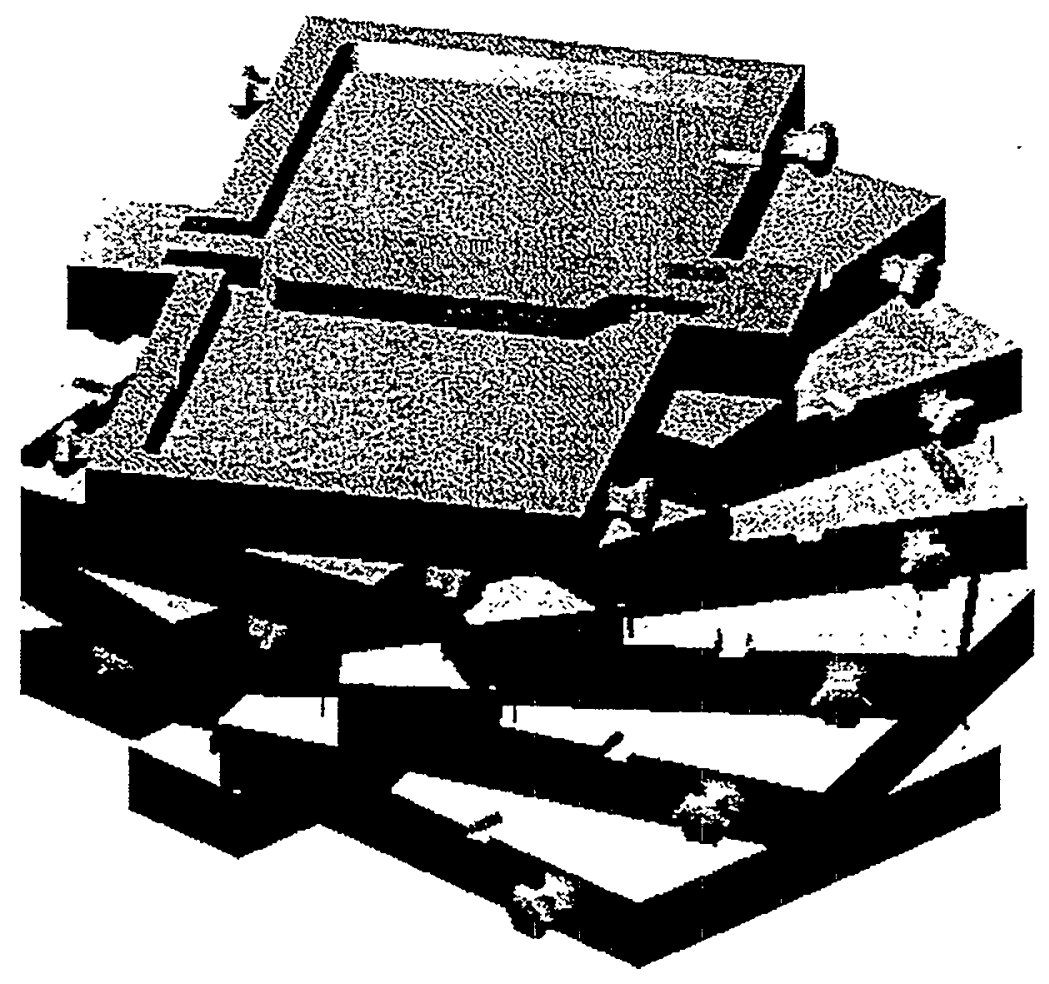

Figure 3.1.6. Spiral stacking of molds for production mode, cascade casting. 


\section{Effects of Fluorine on Refractories}

In order to produce anodes for electrorefining that mimic commercial electrorefining practices, melting and casting of diffusion plant nickel is required. The life of the oxide refractory used to normally contain molten nickel in a melting process is in question. The presence of fluorine compounds (e.g. $\left(\mathrm{UO}_{2} \mathrm{~F}_{2}\right.$ and $\left.\mathrm{NiF}_{2}\right)$ causes corrosive attack to oxide refractories.

Frequent relining would be a major expense in materials and labor. Moreover, the used refractories would constitute a significant volume of radioactive waste that would incur burial costs.

To avoid corrosive attack by fluorine, MSC researchers recommended a replacement of the oxide refractory system with graphite. Melting nickel in graphite would require that the melts take place in vacuum or inert atmosphere. In addition, the molten nickel would become saturated in carbon to about 0.6 weight percent. The effects of high carbon nickel on the casting process and on the anode quality was uncertain. MSC researchers had to devise a practical method to melt nickel in a graphite system. The basic question was, could carbon saturated nickel be cast into acceptable anodes.

To answer that issue, researchers performed 500 pound test melts of nickel in a graphite crucible in the vacuum furnace available in MSC's plant (see figure 3.1.7). After the first casting run several findings occurred. Molten nickel dissolved the graphite crucible sufficient to saturate the metal with carbon. After casting the nickel showed evidence of high gas loading during solidification, as seen by the appearance of a "boiled" surface.

The crucible dissolution was deemed unacceptable. The conclusion was carbon must be present in a free form, and available for dissolution when nickel becomes molten, otherwise the crucible will be attacked.

Small amounts of aluminum were added to stop the evolution of gasses, suspected to be $\mathrm{CO}$, during solidification.

Several more 500 pound test melts were performed attempting to solve the aforementioned issues. To provide free carbon when nickel became molten remained a difficulty. Efforts to apply a sacrificial graphite mortar to the hot face of the graphite crucible were unsuccessful. The crucible was dissolved below the mortar depth even though excess was provided. The aluminum addition coupled with a time/ temperature hold to allow for degassing was successful in stopping gas evolution during solidification.

To date, the high carbon nickel anode has not been used in the cell to determine if there are detrimental effects to the operation. Parameters in the electrorefining cell have been kept as consistent as possible to assure repeatable results. It was deemed prudent not to introduce a high carbon anode into the cell as of this writing 


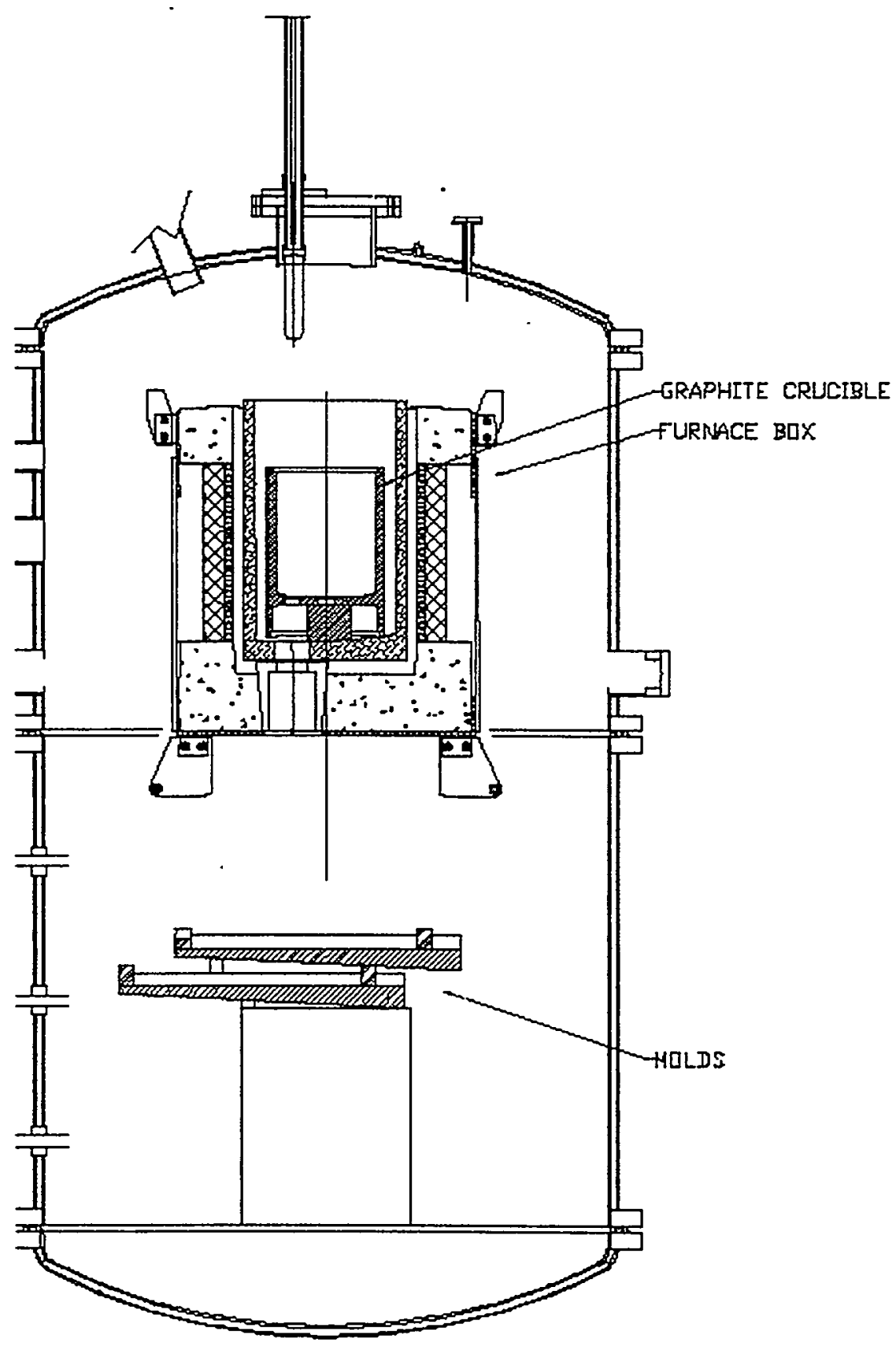

Figure 3.1.7 VIM furnace and crucible setup

Results of literature had indicated carbon to be inimical to nickel casting. Therefore, MSC scientists consulted with several experts in the metallurgical field to determine the specific effects of carbon and its compounds on nickel castings. The overall conclusion from the experts consulted indicated that carbon should be tolerable in the electrorefining cell. 
The tolerance of carbon in the cast nickel anodes was further tested in subsequent preliminary melts under multiple variables. Lab analyses showed promising results, but further testing on high-carbon castings is on hold as MSC researchers are currently considering options to remove the fluorine before melting. 


\subsubsection{Nickel Direct Dissolution}

\section{Research by the Colorado School of Mines (CSM)}

During Phase III of this research effort, CSM researchers (1) investigated direct dissolution and chemical dissolution as alternatives to melt refining and (2) characterized emissions inherent in the nickel electrorefining processes.

Experiments were performed on nickel electrowinning and nickel electroplating under various conditions and test setups.

One major expense in electrorefining nickel barrier was tied to the melt process. Fluorine compounds, (e.g. $\left(\mathrm{UO}_{2} \mathrm{~F}_{2}\right.$ and $\left.\mathrm{NiF}_{2}\right)$, present in the nickel diffusion barrier are now known to attack the oxides in refractory materials and significantly shorten the expected refractory life. In an effort to reduce or eliminate the cost associated with melting nickel, CSM and MSC researchers looked for alternatives to melting. Two options CSM researchers examined were electrowinning (chemical dissolution) and electroplating (direct dissolution). Chemical dissolution involved placing the barrier material into an acid tank, allowing it to dissolve, and then electrorefining the solution to recover the nickel. Direct dissolution involved placing the nickel directly in an electrochemical solution, electro-dissolving the nickel into solution and then electrowinning the nickel.

CSM researchers set up experiments for both options using clean nickel of various sizes and geometries. Both options proved to be successful with dissolving the nickel anode, by direct dissolution being the most promising. Details of CSM's experiments and their research results are provided in Appendix 3.1.

CSM researchers also captured and tested fumes emanating from the surface of the electrorefining cell to determine the types of off-gas and the volume of fumes that could be expected from operating a full-scale cell. The data was used to establish the size and capacity of the ventilation systems that would be needed for a full-scale cell. 


\section{Direct Dissolution Experiments on Nickel Barrier}

After the successful results of CSMs electrowinning and electroplating experiments, MSC personnel repeated the electroplating (direct dissolution) experiments using actual contaminated nickel barrier in a $100 \mathrm{ml}$ lab-scale cell. MSC researchers had received security clearances and were able to perform these experiments at the ETTP site using classified, contaminated nickel barrier. The purpose of the test was to perform direct dissolution to show nickel can be electro-dissolved and plated. The membrane, used for decontamination purposes was not included in these tests.

The direct dissolution method was chosen because it was faster and more effective than chemical dissolution for dissolving the nickel and plating it out on a cathode.

These lab scale tests found direct dissolution to be a promising method for nickel decontamination. Further, scaled up versions of the experiments would be required to provide a detailed economic assessment of the process and to determine its ability to decontaminate nickel. While initially, direct dissolution promised to be economically attractive, such issues as possible increased process waste, effects on the cationic membrane, and security concerns would have to be addressed. Further design would be required to determine modifications required to the existing cell design to accommodate direct dissolution. 


\subsection{Full-Scale Laser Cutting Demonstration}

\subsubsection{Background and Overview}

Radioactive scrap metals (RSMs) are received at Manufacturing Sciences Corporation (MSC) for decontamination and recycle where economically feasible. Incoming materials are sorted, and a conveyor moves most of the steel scrap to a tumble grit-blasting unit for mechanical decontamination. A chemical decontamination facility is available for cleaning soft metals such as copper, aluminum, and nickel.

One of the challenges of decontaminating scrap metal is reducing the large pieces to a size that can be accommodated by MSC's automated processing equipment. If, for example, a piece of metal exceeds $2 \mathrm{ft}$. or is more than $3 / 4$ in. thick, then it must be reduced to a manageable size using either cold-cutting tools, such as band saws or pipe cutters, or (more typically) thermal processes, such as plasma or other oxy-fueled torches. There are several disadvantages to each of these size reduction methods:

1. Manual cold cutting tools and thermal technologies are both very time consuming for setting up as well as executing the cutting operations.

2. Thermal technologies produce fumes and excessive heat. Also, the kerf (the cut width) of conventional thermal technologies is wide, increasing the amount of waste.

3. Workers must wear personal protective equipment, including respirators, to manually perform thermal cutting operations. This is especially unpleasant in environments where the thermal cutting technologies have produced high ambient temperatures.

Automating the cutting processes could increase productivity and reduce worker exposure. Until recently, however, automation has been limited because of the wide diversity in the size, shape, and composition of incoming RSM materials and because the technological advances of cutting tools were too limited to efficiently handle an automated process.

Both of the above limitations were dispelled in a project opportunity made available to MSC. This opportunity is part of the three-building decontamination and decomissioning efforts at the Oak Ridge Gaseous Diffusion Plant (ETTP). There is a large quantity of radioactively contaminated process components, which are of similar geometry and material composition. This large volume of metal makes automating the size-reduction processes both practical and prudent.

To investigate the potential for automation using laser technologies, MSC planned and executed a full-scale laser cutting demonstration using an off-the-shelf, Nd:YAG 2000-Watt laser with fiber-optic beam delivery and a remotely controlled robotic manipulator. The laser-cutting demonstration was designed to meet specific research objectives: 
1. To compare, in a full-scale operation, the cutting performance of the laser to the cutting performance of existing technologies,

2. To evaluate the potential for using lasers to automate size-reducing activities when materials are both geometrically and compositionally similar, and

3. To optimize parameters for automated cutting operations in a production mode.

\subsubsection{Research Approach}

In preparation for the laser-cutting demonstration, MSC researchers began gathering information on cutting operations for oxy-propane and plasma torches. Values were compared on a number of variables, including ventilation (filter clogging issues), cut speeds, secondary waste, ease of operation, and quality of cut. Researchers also gathered information on remote operations, fixturing, material handling, laser safety and containment, personnel training requirements, and special needs for radiological environments. The information gained established the criteria used to identify needed components for an automated laser cutting system and divide the research activities into achievable and manageable steps.

The laser cutting demonstration was divided into four steps. First, the cutting capabilities of a commercially available Nd:YAG laser system were established by initial lab testing performed by the Edison Welding Institute (EWD). Test results determined the parameters to be used in subsequent demonstrations. Second, the Energy Technology Engineering Center (ETEC) in California used the Nd:YAG laser to demonstrate its size reducing capabilities on reactor fuel storage tubes. The laser was then shipped to MSC, along with data and lessons learned from the EWI testing and the ETEC demonstrations.

Third, MSC performed a follow-on, full-scale laser cutting demonstration where the remote laser cutting operations were more fully automated. Finally, a subsequent series of laboratory bench-scale tests were performed to enhance the laser cutting data base in areas identified by the demonstrations.

\subsubsection{Pretesting}

Initial lab testing of the Nd:YAG laser was performed by the Edison Welding Institute (EWI) under contract to ETEC. The purpose of the pretesting was to ensure that the Nd:YAG could adequately cut the materials projected to be used in the demonstration at MSC.

EWI researchers used a continuous-wave (nonpulsed) 3-kW Nd:YAG laser with a 15 -m-long fiberoptic beam delivery system. The laser was able to successfully cut a 1$\mathrm{cm}$-thick steel pipe over a laser power range of 1000 to 2700 watts. In an investigation involving 41 cuts, EWI researchers experimented with a number of variables to determine their effect on kerf (cut width). These variables included beam power, laser end-effector focal length, assist gas type and pressure, and cutting speeds.

EWI Researchers found that a smaller kerf minimized secondary waste but a wider kerf helped keep molten dross from bridging the cut and rewelding it. Researchers also found that the primary parameters controlling the quality of the cuts were the type and 
pressure of the assist gas. (Assist gas is the gas that flows across the work area, blowing away from the cutting zone the debris caused by the cutting process.) Researchers also determined that oxygen was the optimum assist gas because it increased the burn and the cutting efficiency of the laser.

The full report of the EWI research is provided as Appendix 3.2.

\subsubsection{ETEC Demonstration}

ETEC investigated the capabilities of the fiberoptic beam delivery system using remote control technologies. ETEC researchers identified two laser systems as promising candidates for remote cutting applications-the currently available Nd:YAG (neodymium-doped yttrium aluminum garnet) laser (as used in the MSC demonstration) and the COL (chemical oxygen iodine laser), which offers higher-power laser output.

Using information from the initial EWI lab tests, ETEC performed several benchscale tests, followed by two deployment demonstrations to evaluate the effectiveness of the available Nd:YAG lasers for size reducing RSM.

The laser resonator, power supply, water chiller, gas assist supply, and operational controls were located in a nonhazardous environment for protection and maintenance accessibility. The laser focusing head and a tube holding fixture were located in a radiologically controlled containment tent that had been fitted with an HEPA-filtered ventilation system. The laser beam was delivered to the focusing head through a $15-\mathrm{m}-$ long fiber-optic cable. ETEC was able to successfully use the $2 \mathrm{~kW} \mathrm{Nd:YAG} \mathrm{laser} \mathrm{to} \mathrm{size}$ reduce (for disposal) approximately 300 , contaminated fuel storage tubes that were 5-in diam by 118 -in long.

Each storage tube was positioned horizontally on a fixture. Two longitudinal cuts were made by moving the laser head lengthwise along the tube. One circumferential cut was made by rotating the tube. Each tube was thus sectioned into four approximately equal sections.

A continuous wave laser with a power level of $0.8 \mathrm{~kW}$ was used for cutting these thin-walled (1/16"-thick) tubes. Oxygen was used as the assist gas. At a linear cutting speed of about $400 \mathrm{~cm} / \mathrm{min}$, the laser was able to size reduce each tube in about 2.5 minutes. This included the time it took to manually load each tube and unload the tube sections. (Only the laser cutting was automated for this demonstration).

ETEC researchers performed a number of additional test cuts using a plasma-arc torch to develop comparative data on laser cutting versus cutting with current technologies. The plasma-arc tests used the identical geometry and cutting procedure that had been used with the laser. Both the laser and the plasma-arc systems had comparable cutting speeds, but the plasma-arc system required greater maintenance. Researchers noted, however, that there were costs savings with the laser cutting system over the plasma arc system because of reduced secondary waste and lower maintenance requirements. Nevertheless, the maintenance requirements for the laser system were significant. One example was multiple filter changeouts caused by higher levels of airborne debris generated by the laser cutting operation.

Additional cost estimates for size reducing much larger quantities of contaminated tubes were also provided by ETEC researchers. Those estimates included the capital 
equipment costs of the cutting hardware (which was markedly higher for the laser system) and also assumed replacement of the current filter system with self-cleaning filters. Because of capital equipment costs, plasma arc cutting was less expensive for smaller quantities of tubing while laser cutting was less expensive for larger quantities. The break-even point in ETEC's comparisons was about 230,000 tubes. These estimates, however, included manual handling of the tubes rather than robotically controlled automation in a full-scale cutting process.

ETEC researchers concluded that the use of the laser system resulted in significant reductions in secondary waste generation and personnel exposure. While not demonstrated in the task because of the manual tube handling, exposure to personnel was reduced as a by product of the laser's lower maintenance requirements and the system's capability for remote cutting operations.

ETEC researchers further test operated the $\mathrm{Nd}$ :YAG laser at their facility before shipping it to MSC; and they preset the laser at the optimum parameters for ensuring a successful demonstration. ETEC also transferred all data and lessons learned to MSC for use in their automated, full-scale laser cutting demonstration. The full ETEC report is provided in Appendix 3.2.

\subsubsection{System Components for MSC's Demonstration}

Prior to receiving the laser equipment from ETEC, MSC had prepared a functional design specification that covered component acquisition, setup and installation of equipment, and remote control requirements for an integrated and automated system. The major components for the laser demonstration, as identified in the functional design, include the following:

K-25 Converter Shell: A No. 2 converter shell made of 1/2-inch thick nickel plated carbon steel was selected from the $\mathrm{K}-25$ site as the object to be cut during the full-scale laser cutting demonstration. The No. 2 converter shell (Figure 3.1) is representative of the hundreds of similarly shaped and sized converter shells that await removal from the K-25 site. Also, the shell's size ( $6 \mathrm{ft}$. in diameter $\mathrm{x} 12 \mathrm{ft}$. long) was small enough to be shipped to MSC in one piece. Since the shell had been used only for cooling, it's design was unclassified; therefore, no special handling was required for security purposes. A nondestructive analysis (NDA) was performed on the shell to verify that it could be shipped on MSC's license. 


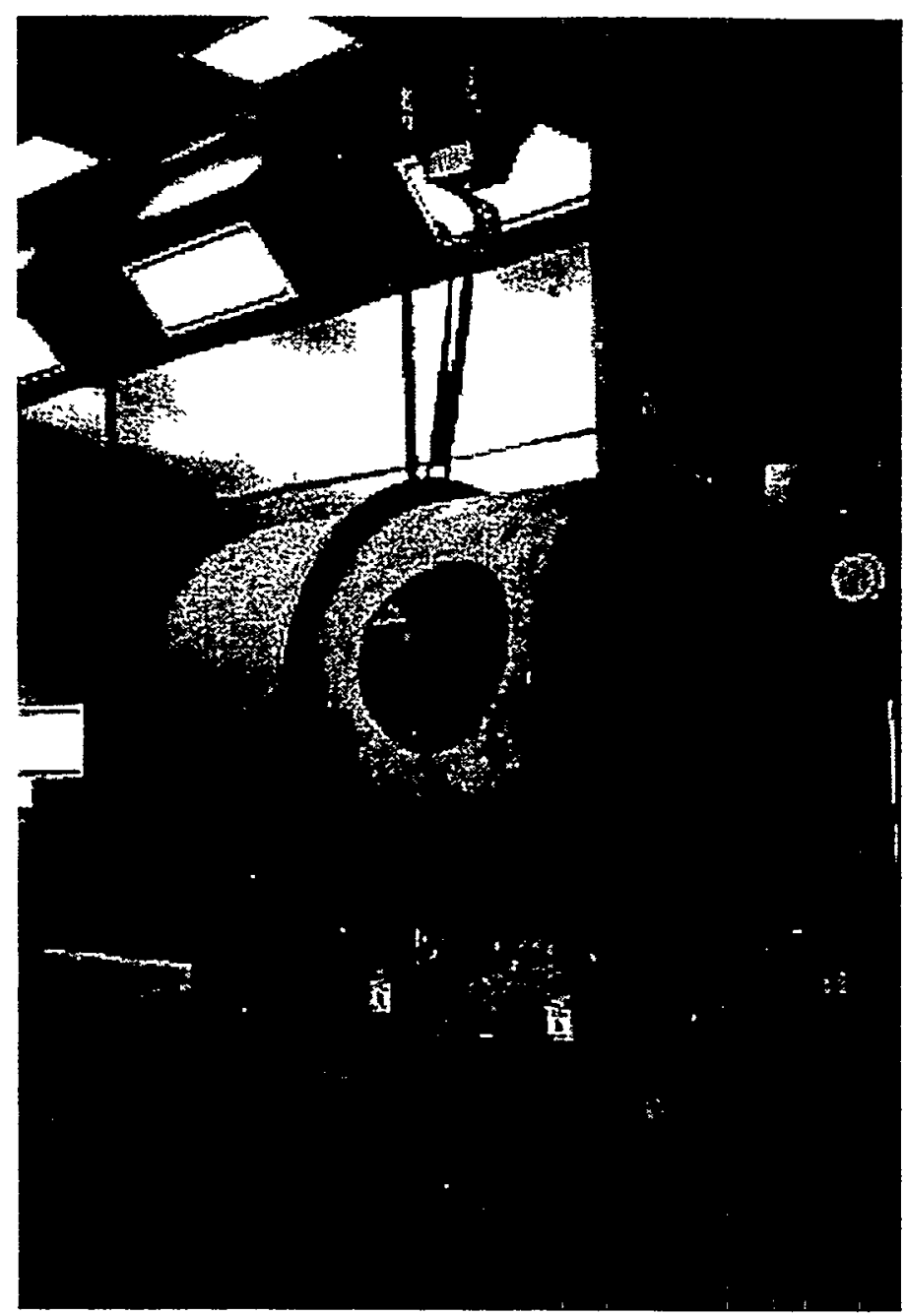

FIgure 3.2.I No. 2 Converter Shell from ETTP on turning cart.

NdYAG Laser: DOE located a Lumonics Nd:YAG laser and arranged for it to be made available for the laser-cutting demonstrations. The 2000 Watt multiwave laser, which was capable of cutting up to $1 / 2$-inch carbon steel, included a power supply, a chiller, and a fiber optic cable. The fiber-optic cable transported the beam from the power supply to the laser focusing head.

Auto-Focus Cutting Head (AFCH): The Lumonics AFCH is a non-contact, capacitive clearance measuring end-effector designed for use in robotic cutting applications. In the demonstration, the AFCH was driven by a high-speed DC servo motor. Its copper nozzle tip served as a sensing electrode. Because it could compensate for part and program deviations, the AFCH was used to maintain a distance of $2 \mathrm{~mm}$ from the demonstration shell for cutting. 
Robotic Manipulator: Both new and used robots, as well as welding manipulators, were evaluated for use in the laser-cutting demonstration. The manipulator selected was a pre-owned Cincinnati Milacron robot, as illustrated in Figure 3.2.2. (A similar robot had been used to size-reduce RSM at the Capenhurst site in the United Kingdom.) The robotic manipulator controlled the cutting head of the laser. The Cincinnati Milacron robot was capable of holding the AFCH to within 1 inch of the surface to be cut and was able to perform a smooth cutting operation. The manipulator also had adequate horizontal and vertical reach to accommodate the $5 \mathrm{ft}$. in diameter $\mathrm{x} 12 \mathrm{ft}$. long shell.

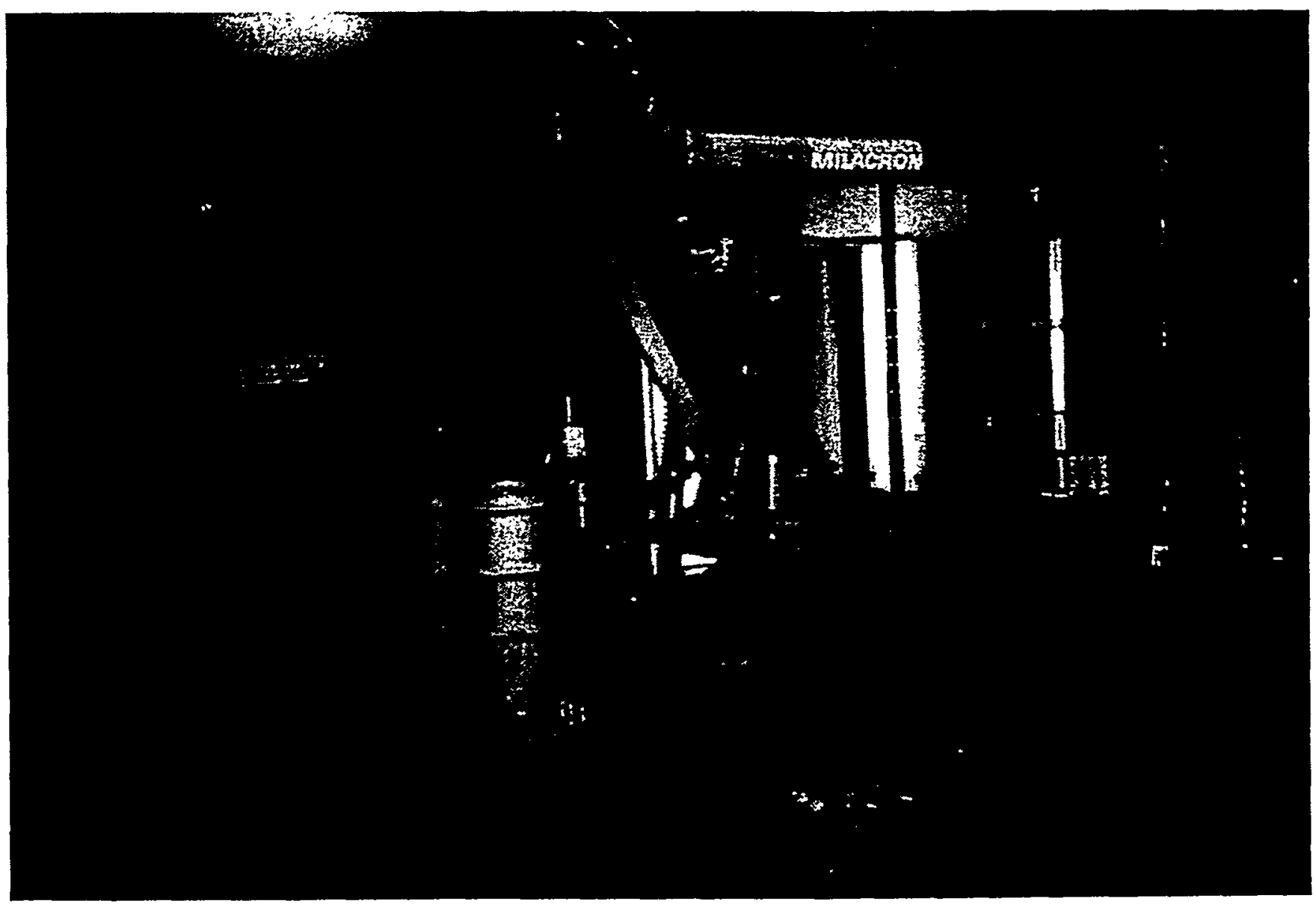

Figure 3.2.2 Cincinnati Milacron robotic manipulator.

Indexing Cart and Turning Rollers: An indexing cart with turning rollers was used to rotate the converter shell in the horizontal plane during cutting operations. (The cart and rollers can be seen in place in Figure 3.2.1)

Light-Proof Room: A prefabricated lightproof room was purchased to house the laser, shell, manipulator, and other equipment needed for the full-scale laser cutting demonstration. The room was equipped with protective windows to allow operators and visitors to safely view the cutting operation without being exposed to hazards from the laser or the robotic manipulator. 
Ventilation System: A high efficiency, facility ventilation system was installed in the lightproof room to control airborne contaminants generated by the laser-cutting process.

Programmable Logic Controller (PLC): Each component of the automated cutting system was equipped with independent controls. An Allen Bradley SLL500 system was put in place to interface between the major components and to take control when all components were placed in a "ready" state. Designed with a touch screen and keypad, the PLC provided the operator with overall system control via selected analog variables and digital logic. For the demonstration, independent control of each system was referred to as "manual mode" while the PLC system control was referred to as "automatic mode." Position feedback was accomplished using a regenerative DC drive with tach speed feedback and an encoder mounted on the turning rolls. The equipment allowed the operators to control the speed for a specified distance as indicated by feedback from the encoder. The PLC control system provided the following functions:

- An alarm monitoring function alerted operating personnel of abnormal conditions and, if necessary, halted operations in a controlled manner.

- A control step sequencing function performed startup, operation, and shutdown routines.

- An analog and digital control function provided the necessary interface between the six components to coordinate the equipment operation as one system.

- An operator interface, a backlit LCD screen with touch screen capabilities and keypad, allowed the operator to view the control system operation.

Operator's Control Booth: Operations were controllable from a booth that was separated from the laser and other components in the lightproof room. A video camera was mounted in the cutting room such that an operator in the booth could view the cutting operations from a monitor.

\subsubsection{System Configuration}

A decision matrix was used to compare several layout options for the laser cutting demonstration. Various methods of rotating the converter shell were evaluated to optimize the productivity of the robotic manipulator and the laser.

The converter shell, laser, robotic manipulator, turntable with indexing rollers, waste box, and monorail (along with all associated hardware and power supplies) were housed in the lightproof room. Electrical hardware was purchased to connect the major components and integrate them through the PLC. Minor peripheral equipment needed to perform a successful demonstration were also installed. Water pipes, for example, were installed between the laser and the chiller to provide a continuous cooling supply to the laser.

A cooling block was used on the AFCH to help dissipate heat generated by the laser process and the drive unit on the $\mathrm{AFCH}$. The $\mathrm{AFCH}$ was also equipped with oxygen as an assist gas to promote the cutting effect. Nitrogen was used to prevent dirt or oil from 
forming on the focus lens. Finally, the AFCH was equipped with three crash-detection switches, plus one temperature switch.

Final component configuration was established by MSC engineering, with representatives from the Industrial Systems Design Corporation. Industrial System Design experts provided programming assistance. Representatives from Lockwood Greene Technologies ensured component integration. Final wiring and PLC programming and debugging were completed, hardware was cold tested, and preliminary demonstrations were performed on other materials by MSC's technical staff.

\subsubsection{Safety Features}

Laser safety was incorporated into every step of the planning process, and a number of safety features were installed in preparation for the laser-cutting demonstration. The lightproof room, which provided total enclosure of the laser cutting operation, had over its viewports UV protection as approved by the Laser Institute of America (LIA) and in accordance with ANSI Z136.1 1993. Installed in the lightproof room (at the room doorway) were interlocks that automatically turned off the laser in case the door to the room were opened. Warning signs and placards were installed to indicate when the laser was in use. A blue warning light was installed to alert personnel in the area that a laser is in use.

The operator's station was completely removed from the work area in the lightproof room to protect workers from exposure to the radioactivity in the RSM, to the laser beam, and to keep them from being injured by the automatically operated robotic manipulator.

\subsubsection{Personnel Training}

All MSC personnel who were to be involved in either operation, maintenance, or management of the laser-cutting activities received comprehensive training in the operation of remote equipment and in laser safety.

\subsubsection{Equipment and Operations Training}

Production personnel were fully trained to operate both the laser and the robotic manipulator. After instructional training, the operators began practicing on individual components in the automated system. Initial cutting with the laser was performed manually (for training purposes) without the benefit of the programming that would later automate the system. Practice cuts were made on stainless steel and carbon steel materials-both of which were thinner than the $1 / 2$-inch carbon steel used for the converter shells.

Operators also received a week of in-house training provided by the vender of the Cincinnati Milacron Robotic Manipulator. As part of this training, operators practiced controlling the robot for cutting at various movements and at differing speeds. In addition, they spent time testing and evaluating methods of rotating the shell during the cutting operations. 


\subsubsection{Laser Safety Training}

MSC identified and trained a Laser Safety Officer (LSO) and a deputy LSO to oversee the safe operation of the laser-cutting demonstration. These officers were given the responsibility and authority to monitor for potential laser hazards and to enforce appropriate controls to assure safe laser operations. The LSO trained operating personnel on laser safety using guidelines from the American National Standard for Safe Use of Lasers, American National Standards Institute (ANSI Z136.1-1993) and the Laser Safety Guide, 9th edition, prepared by the Laser Safety Committee of the LIA.

The American National Standards material included visual presentations that incorporated key components of the ANSI ZI36 laser safety standards. Student workbook (included with the training materials) provided practice questions and exercises to test the trainee's understanding of the materials being presented in each series. The workbook also served as a desk reference.

A number of topics were covered in the laser training which encompassed the safe operation of low, medium, and high-powered lasers and the use of high-powered lasers in manufacturing and laboratory environments. Additional equipment-specific training on the safe use of the Nd:YAG laser was provided by Lumonics representatives.

\subsubsection{Set Up For MSC's Demonstration}

The Nd:YAG laser and Cincinnati Milacron robotic manipulator were set up in the lightproof room inside MSC's manufacturing facility. The Lumonics Auto-Focus Cutting Head was mounted on the working arm of the robotic manipulator. This special laser head, which delivered the laser beam via the fiber optic cable, provided a means of effectively cutting the converter shell and tracking the surface to compensate for deviations, either in the part itself or in the program. The AFCH enabled the cutting beam to maintain a $1 \mathrm{~mm}$ distance from the cutting surface at all times.

The robotic manipulator was positioned with the laser end effector always pointed downward so that the laser beam would not be directed toward the observation ports of the lightproof room.

The converter shell was placed on a cart with automatic indexing rollers that rotated the shell 360 degrees on the horizontal axis.

A PLC was used to control the path of the laser and the size of the piece to be cut. The PLC was also interlocked to the doors and the robot to stop the laser if any set perimeters were out of the desired range.

The 25-ton chiller (shipped with the laser) was located outside the containment facility (the lightproof room). The chiller was housed in a portable out building to protect it from the weather. Pipes connecting the chiller water to the laser were located along the wall and were insulated for maximum cooling efficiency.

A laser expert had been employed as a consultant to assist in the installation and operation of this project. The expert had also instructed MSC personnel on the operation and safeguards of laser operations. 


\subsubsection{MSC Laser-Cutting Demonstration}

The full-scale laser cutting demonstration consisted of three different operations: (1) part handling, (2) laser cutting using a robotic manipulator, and (3) scrap removal.

\section{Part Handling}

A track mounted cart supporting the converter shell could be independently moved in and out of the work area using remote control. For the demonstration, the converter shell was placed on the cart mounted indexing rollers and moved into the lightproof room.

\section{Laser Cutting Using Robotic Manipulator}

Laser power, assist gas, and cutting speeds were optimized during previous cutting trials on stainless steel, carbon steel of varying thicknesses, and aluminum.

Laser cutting head motions were directed by the PLC, which allowed the operator to move the robotic arm over the full converter shell surface. Using the robotic arm to move the cutting head, operators made axial cuts along the converter shell. Circumferential cuts were made by rotating the converter shell on the remotely controlled turntable.

The automated laser-cutting system removed $30-\mathrm{cm}$ by $30-\mathrm{cm}$ sections of the converter shell. Cutting parameters included a laser power level of $1.8 \mathrm{~kW}$, oxygen assist gas, and a cutting speed of $76 \mathrm{~cm} / \mathrm{min}$. The auto-focus enhancement of the laser cutting head improved cutting performance by controlling the cutting head standoff distance.

A photo of the cutting operation is shown in figure 3.2.3. 


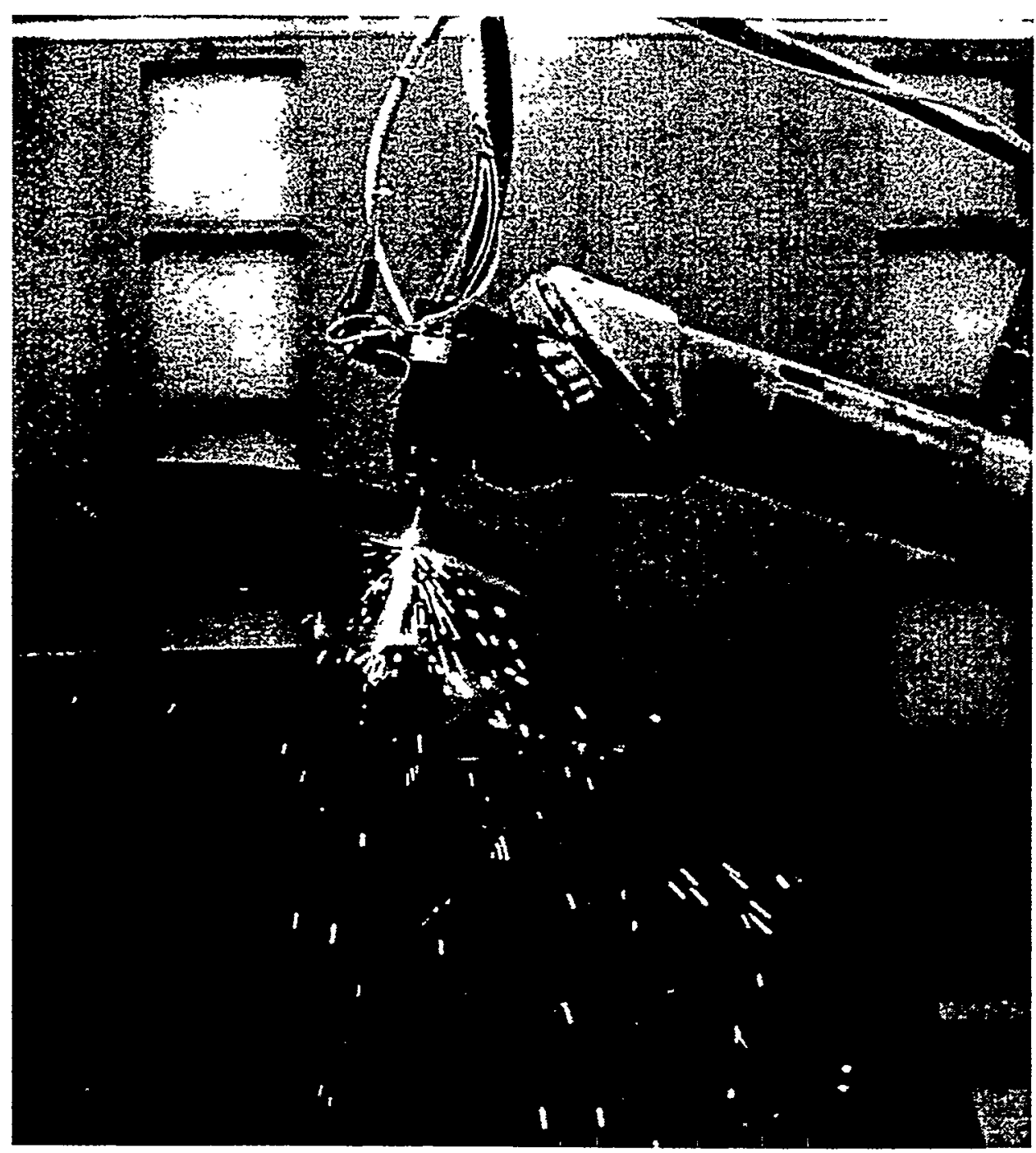

Figure 3.2.3 Laser cutting

Most of the laser cutting was performed using a continuous-wave (CW) laser beam. An exception was aluminum. To cut aluminum, the laser beam had to be delivered in a square wave, pulsed mode. Since aluminum cutting required higher laser power than steel, more instantaneous power was delivered to the cutting site using a pulsed beam. Drawbacks were that the pulsed-beam cutting was uneven. Also, the cutting speed was slower. This was expected due to the reflective properties of aluminum. 
Additional laser cutting tests were performed at MSC to investigate the ability of the remote laser system to cut other materials. Results are summarized in Table 3.2.4

Table 3.2.4 Comparative results of laser-cutting experiments and demonstration.

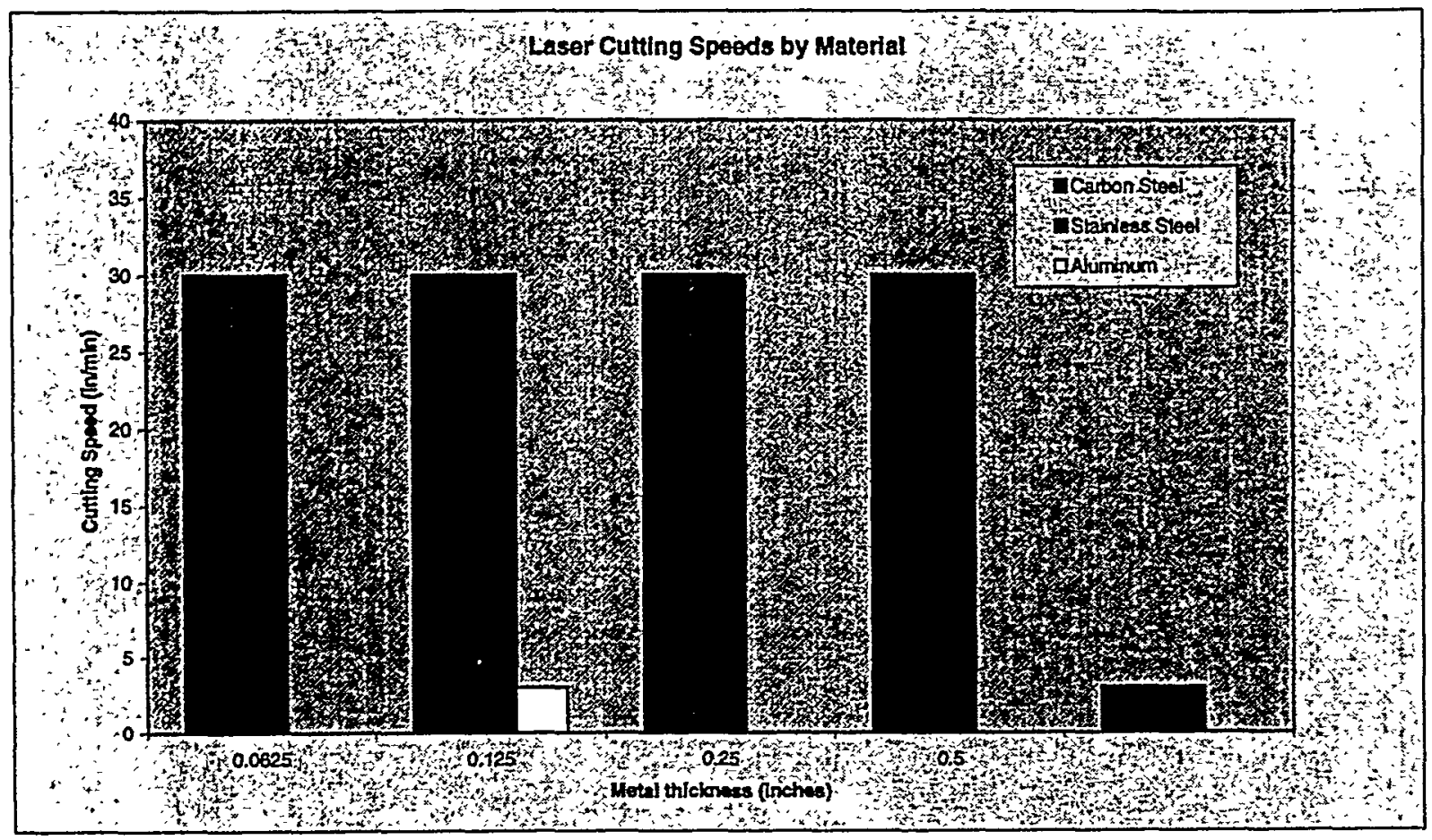

Carbon steel and stainless steel followed the same performance curve. Steels at $1 / 2$ inch or less were cut at speeds around 30-inches per minute, which rivals the speed of plasma cutting. The speed is drastically reduced, however, when cutting aluminum or 1inch thick carbon steels. Aluminum $1 / 8$ inch thick was cut at 1 inch per minute at 1500 watts square wave and 1 -in thick carbon steel was cut at 3 inches per min at 1900 watts. The 1-inch per minute and 3-inches per minute cutting speeds for these materials are too slow to be feasible for size reducing these types of scrap metals in a production mode.

\section{Scrap Removal}

The adapted procedures of keeping the laser head pointing downward and restricting the cutting head motion limited the laser beam to linear travel. Therefore, this method allowed the sectioned pieces of the converter shell to drop directly into a waste box when a cut was complete. To eliminate manual handling, a conveyor stand was indexed into the opposite end of the shell and a monorail box was positioned so that the RSM could be removed using remote controls. 


\subsubsection{Results of MSC's Experiments and Demonstration}

There were two notable differences between the cutting performance in the ETEC demonstration and the performance in the demonstration at MSC. First, the amount of airborne contaminate generated at ETEC was much greater than the amount generated at MSC; therefore, the airborne contaminate was more easily managed at MSC. This appears to be a function of the thickness of the material being cut. This relationship was observed in subsequent bench-scale tests as well.

Second, the maintenance requirements for the focusing head were greater at MSC. Frequent cleaning was necessary to remove the deposited airborne debris. Focus head cleaning was not required for any of the other cutting tests. The difference was attributed to the location of the cutting head (directly above the cutting site) in conjunction with the increased amount of cutting performed. This problem was minimized by installing a protective glass plate in front of the focusing lens and directing a dry-nitrogen purge gas through the auto-focus head to blow airborne debris away from the lens assembly. Those two changes reduced maintenance requirements significantly.

Preliminary cuts with the laser were successful. Continued optimization of cutting parameters, such as cutting speed, assist gas pressures, and laser power levels allowed MSC's full-scale laser cutting demonstration to be successful. The 5 foot diameter carbon steel converter shell was size reduced at 1800 watts, at 10 psi oxygen, and at a speed of 10 to 30 inches per minute. The resulting pieces (measuring about $1 \mathrm{ft}^{2}$ ) were captured in the monorail box. As anticipated, the use of the monorail box (the standard scrap metal handling box in MSC's recycling facility) prevented double handling of the size-reduced pieces.

Kerf for plasma-arc cutting was compared to the kerf for laser cutting. The average plasma kerf measured 0.125 -inches while the laser kerf measured 0.035 inches for the $1 / 2$-inch thick material. The laser's smaller kerf will result in savings due to the reduction of slag and the change out of HEPA filters

\subsubsection{Additional Bench-Scale Testing}

The ETEC and MSC laser-cutting demonstrations identified a number of areas where additional laser cutting information would be beneficial for future applications. A supplemental series of laboratory bench-scale tests was performed at EWI (under contract to ETEC) to investigate:

- the quantity of airborne particulate generated during laser cutting,

- the maximum cutting speeds for cutting various thickness of steel pipe, and

- the maximum thickness of steel plate that could be cut with a 3-kW, off-the-shelf $\mathrm{Nd}$ :YAG laser using fiberoptic beam delivery.

The results are shown in appendix 3.2.

\subsubsection{Conclusions}

All test results from the laser-cutting research are being examined to determine the cost-effectiveness of using lasers to reduce the size of the hundreds of converter shells 
and other RSM from the ETTP three-building D\&D project. The demonstration provided the MSC team with a better understanding of the risks involved in laser cutting operations and pointed out the safety measures that must be adhered to when using laser technologies. Other specific challenges drawn from the demonstration include the following:

- The fiber optic cable is delicate and it incurs high maintenance costs

- Using automated equipment with lasers requires extensive programming

- Using an auto-focus head requires regular cleaning

- A considerable amount of time is needed when troubleshooting the entire system

In spite of these drawbacks, MSC's demonstration confirmed that a laser and robotic manipulator could be used to effectively and safely cut converter shells into pieces manageable for automated processing while minimizing radioactive and chemical exposure to personnel. The series of tests described here demonstrate that the Nd:YAG laser can cut both thin and thick components, can be operated under various degrees of remote operation and automation, and can cut up to $1 / 2$ inch-thick steel at high linear cutting rates.

The ETEC demonstration showed the potential for cost savings using remote laser cutting. The MSC demonstration extended the application to thick materials using automated robotics. Subsequent bench scales tests provided further data on cutting capabilities using off-the-shelf laser systems. These various tests and demonstrations provided data useful for establishing operating parameters for production cutting. Test and demonstration data also provided important knowledge that could be directly applied to a production environment.

The relatively expensive laser hardware makes other technologies initially more cost effective for small-scale applications. However, reductions in personnel exposures and minimal maintenance requirements may override cost considerations in hazardous environment applications.

In summary, the successful series of lab and field-deployment tests and demonstrations confirms that current, off the shelf, laser technologies with remote fiberoptic beam delivery systems can be used effectively for automating material or component size reduction in D\&D applications.

\subsubsection{Path Forward}

The project scope for the three-building D\&D activities at the ETTP site includes size reduction, decontamination (where required), and disposition of over 126,000 tons of metals and over 1500 converter shells. Lasers should be further evaluated for possible use in this D\&D work. High initial capital costs have inhibited their use to date. Also, newly installed equipment in MSC's recycling facility will handle larger components. This increases the size of components that can be accepted into automated cleaning facilities and reduces the need for size reduction activities. 


\subsection{Develop and Fabricate a New Product from RSM}

\subsubsection{Background}

Recycling contaminated scrap metal saves space from disposal of scrap metals and minimizes the need for non contaminated metals to be used in the nuclear industry where they could become contaminated.

\subsubsection{History of RSM Products}

MSC has supported DOE in the recycle of contaminated scrap metals. Examples of past products are shown below:

Savannah River - Converted stainless steel piping, ductwork, slug buckets, and heat exchanger parts to over 1,000 stainless steel drums, $55 \& 85$ gallon size. This contract also included the fabrication of stainless steel boxes and closed head sanitary drums.

Oak Ridge - Converted over 1,000,000 pounds of metal into useful products including over 1,000 carbon steel B-25 boxes, carbon steel drums, stainless steel drums and specialty containers. Also, utilized lead from ORNL and INEL to make stainless steel clad, lead shielded overpack containers for storage and transportation of high level RH-TRU waste from INEL.

Idaho National Engineering Labs - Fabricated 12 shielded boxes for storage of U233 contained in drums. Each box recycled over 8,000 pounds of contaminated lead.

\subsubsection{Detailed analysis of DWPF specification}

MSC examined the prospect of producing a finished DWPF canister at it's current facilities. The conclusion was to compete for the long term supply of DWPF canisters a facility and infrastructure would have to be built that would look substantially like that which is available in commercial industry (an integrated steel mill coupled with an ASME code fabrication shop). The driving force and funding for such a facility is not available.

Economies of scale and high demand for stainless steel products drove the cost of austenitic stainless steel plate to a little over a doller per pound. This cost is primarily in the raw materials, not labor. Scrap conditioning, melting furnaces, continuous casters, reheating furnaces, rolling mills, material handling assets, and pickling lines are all designed to reduce the man hours and increase the throughput. Typical throughput is between $1,200,000$ to $1,600,000$ tons per year. Steel plate in industry requires less than one man hour per ton in a fully tooled, highly integrated steel mill, and a yield from liquid metal to finished plate is in excess of $90 \%$. 
ASME certified fabrication shops typical of industry today, are equipped with the appropriate tools and retain the quality infrastructure to meet the requirements of a DWPF canister. Tools such as material handling assets, three roll benders, weld fixturing, and inspection tooling needed to make pressure vessels of all sizes are in place within commercial industry. A quality assurance program commensurate with the needs of the DWPF canisters, which include a certified weld inspector and appropriate NDE equipment as well as ASME code protocol, are in place in commercial shops.

MSC is a low volume specialty melting shop, geared to environmental compliance within a radioactive contol area. The melting machine at MSC, a 6 metric ton Vacuum Induction Degassing and Pouring (VIDP) furnace is capable, with slight modifications, of producing the liquid, high quality steel, but the rest of the facility is not geared for the needs of DWPF. Static cast ingots from the VIDP require manual surface conditioning and have a $60 \%$ by weight yield (from cast shape to rollable ingot). The rolling mill at MSC is limited in capacity to about 3 foot widths, and is designed as a nonferrous rolling mill with comparatively low torque output. This limitation causes a need for alternative DWPF designs, that utilize small plate sizes. After hot-rolling, the plate must be pickled to remove rolling scale. The descaling line at MSC is labor intensive and has limited throughput. Steel plate requires about 24 manhours per ton to produce. Coupled with low material yields, waste liabilities, and rolling mill constraints, plate production cannot be cost competitive with clean metal production.

The fabrication process at MSC is not commensurate with ASME code shop. The material handling assets, three roll bender, weld fixturing, and inspection cannot make the commercial industry design DWPF. The infrastructure to accomplish such a highly specialized container is not in place. That infrastructure includes the QA program and trained and qualified people to become an ASME code shop.

MSC alone, cannot make the investment to tool its existing plant to accomplish the task of producing cost effective DWPF canisters. A duplication of an existing commercial industrial base inside a radiation control area would be required. A feasibility study was performed by MSC in 1994 to determine the cost of a production steel facility inside a radiation control boundary. The cost was $\$ 140 \mathrm{M}$.

MSC does not see DWPF as a viable candidate for an RSM product line. Investment by MSC in this concept would not be financially responsible at this time. It is our estimation that the cost to produce the DWPF canister and be competitive within $25 \%$ of current canister costs is not feasible.

\subsubsection{Products made from RSM}

Fundamentally, a product made from RSM should include some or all of the following traits:

- Contain a large volume of RSM 
- Not designed for efficient use of material (no need to design for minimization of metals used)

- Minimize processing steps

- Compete as a substitute for, not as a replica of, non-contaminated products

Candidate products requiring sophisticated machining and testing, with low material utilization, have much less chance of ever being successfully deployed. MSC has, and will continue to work with the Metals Recycling group within DOE to determine good candidates for products made from RSM. See the concept paper titled "MSC Recycled Contaminated Metals" in appendix 3.3.

In a letter to FETC in February, 1998, MSC requested to modify the scope and redistribute costs to support electro-refining and anode preparation activities. The results of these efforts are shown in the full scale electro-refining and melting sections of this report. 


\subsection{Refinement of Methods to Quantify Isotopic Elements}

\subsubsection{Executive Summary}

Phase II efforts narrowed the field of characterization procedures to four that showed the most promise for determining the amount of technetium present in a bulk contaminated metal. The technologies were Inductively Coupled Plasma Mass Spectrometer (ICP Mass Spec), Tennelec LB5100 (Low level alpha/ beta counting), liquid scintillation, and EMPORE ${ }^{\mathrm{TM}} \mathrm{rad}$ disks. During Phase III, the investigation of these technologies used to quantify ${ }^{99} \mathrm{Tc}$ contained in a bulk contaminated nickel matrix continued.

MSC's technical staff and laboratory technicians determined that liquid scintillation with random verification using ICP mass spec would be the preferred method for radiological detection. It was also decided that the ICP mass spec was the preferred method to provide information of metals concentration. Listed below are the results of the various techniques performed.

\subsubsection{Electrorefining Sampling}

All samples analyzed for ${ }^{99} \mathrm{Tc}$ by the various techniques were nickel shavings obtained by drilling through a nickel cathode. Immediately after being drilled from the cathode, each set of nickel shavings was allowed to cool, sealed in a plastic bag, and labeled with a number representing the cathode location from which it was drilled. The nickel shavings were stored in the sealed plastic bags until needed for analysis. For each analysis, the appropriate amount of nickel shavings was weighed out, the weight recorded, and the shavings sealed and transported in a plastic bag to the designated equipment or facility where the quantitative analysis of the nickel for ${ }^{99} \mathrm{Tc}$ was performed.

Samples of each cathode produced, anolyte and catholyte samples were taken during operations. This method of sampling allowed MSC to closely monitor the process and monitor the process for $\mathrm{pH}$ adjustments or indications of a breach in the cationic membranes.

\subsubsection{Statistical Methods}

After each analytical technique was employed, results were collected and analyzed using standard statistical methods. Data obtained with each analytical technique were evaluated for normality using the Kolmogorov-Smirnov test and verified by an independent analytical lab. 


\subsubsection{EMPORE ${ }^{\mathrm{TM}}$ Radiation Filter Disks}

A technetium-specific ligand contained in the filter traps the technetium on the surface of the disk as a liquid sample is passed through the filter. Three liquid samples were prepared by dissolving the nickel shavings in nitric acid.

After dissolution of the nickel, hydrochloric acid was added to prevent precipitation of iron compounds. Each solution was diluted to a $500 \mathrm{ml}$ final volume and filtered two times through a purchased EMPORE ${ }^{\mathrm{TM}}$ radiation filter disk. The filters were dried in a laboratory oven for 15 minutes at $50^{\circ} \mathrm{C}$. The radioactivity trapped on the filters was counted using an LB-5100 alpha beta counter. The LB-5100 is a gas flow proportional charged particle detector that uses an argon-methane atmosphere to detect both alpha and beta particles. The results are presented below.

$\underline{\text { Results }}$

\begin{tabular}{|c|c|c|c|}
\hline \multicolumn{4}{|c|}{$\begin{array}{c}\text { T9 measurements obtained by Manufacturing Sciences Corporation } \\
\text { using EMPORE radiation filter disks and an LB-5100 gross } \\
\text { alpha beta counter }\end{array}$} \\
\hline $\begin{array}{c}\text { Sample } \\
\text { designation }\end{array}$ & $\begin{array}{c}\text { Results } \\
\text { (decays/min) }\end{array}$ & $\begin{array}{c}\text { Results } \\
\text { (pCi/g) }\end{array}$ & $\begin{array}{c}\text { Results } \\
(\mathrm{Bq} / \mathrm{g})\end{array}$ \\
\hline 1 & 77.90 & 11.7 & 0.43 \\
\hline 4 & 40.84 & 6.1 & 0.23 \\
\hline 5 & 59.37 & 8.9 & 0.33 \\
\hline
\end{tabular}

${ }^{a}$ Each sample contained $3.0 \mathrm{~g}$ of nickel shavings.

\begin{tabular}{|l|c|}
\hline \multicolumn{2}{|c|}{$\begin{array}{c}\text { Results from application of statistical tests } \\
\text { to the measurements reported by } \\
\text { Manufacturing Sciences Corporation }\end{array}$} \\
\hline Mean & $\begin{array}{c}8.9 \mathrm{pCi} / \mathrm{g} \\
(0.33 \mathrm{Bg} / \mathrm{g})\end{array}$ \\
\hline Standard deviation & $\begin{array}{c}2.8 \mathrm{pCi} / \mathrm{g} \\
(0.10 \mathrm{~Bq} / \mathrm{g})\end{array}$ \\
\hline Standard error of the mean & $\begin{array}{c}1.6 \mathrm{pCi} / \mathrm{g} \\
(0.06 \mathrm{Bg} / \mathrm{g})\end{array}$ \\
\hline Probability that data is & 0.654 \\
normally distributed & \\
\hline
\end{tabular}

The Kolmogorov-Smirnov test for normality is passed by this data. The probability of 0.654 is well above the 0.200 cutoff value.

Even though the results pass the test for normality, the results appear lower than those presented by other methods, investigation into other techniques for verification was pursued. 


\subsubsection{Liquid Scintillation Counting}

Phase III continued the investigation of liquid scintillation counting that was initiated in Phase II. During Phase II, some results for the amounts of ${ }^{99} \mathrm{Tc}$ detected in the metal samples were variable using scintillation counting. This variability was attributed to the loss of some ${ }^{99} \mathrm{Tc}$ during the hydroxide precipitation of the metal prior to an Eichrom column separation performed before the actual scintillation counting. These inconsistencies in the amounts of ${ }^{99} \mathrm{Tc}$ detected using scintillation counting prompted examination of the entire procedure entailed in employing this technique to quantify ${ }^{99} \mathrm{Tc}$ in a metal matrix. One of the procedures used in the Phase II investigation of liquid scintillation counting is actually a two-part process, a combination of counting and separation techniques.

Typically for the counting process of the liquid scintillation technique, a sample is prepared by dissolving in an acid. One to two milliliters of this solution is added to 15 or $20 \mathrm{ml}$ of a scintillation cocktail in a plastic vial. The vial is then placed between two photomultiplier tubes (PMTs). The radioactive decay of ${ }^{99} \mathrm{Tc}$ produces a beta particle which deposits energy in a molecule of the scintillation cocktail. When the excited molecule returns to a lower energy state, it emits a flash of light. The PMT detects the light flash and turns the signal into an electric pulse. If a flash is seen by both PMTs, located on either side of the sample, it is recorded as a count. However, if a pulse is read from only one of the PMTs, the signal is considered as electronic noise and is not counted. Reducing the noise signal allows this technology to successfully count radioactivity levels to near background levels.

The separation of the nickel from the ${ }^{99} \mathrm{Tc}$ is necessary to ensure that the ${ }^{99} \mathrm{Tc}$ is present in the sample at concentrations sufficient to produce an activity level significantly above the background. However, as demonstrated in Phase III, the separation of the nickel from the ${ }^{99} \mathrm{Tc}$ must be accomplished without loss of ${ }^{99} \mathrm{Tc}$ in order for the count to yield an accurate measure of the quantity of ${ }^{99} \mathrm{Tc}$.

In Phase III, two independent investigations of liquid scintillation counting were conducted, both utilizing solid phase extraction to separate the nickel matrix from the ${ }^{99} \mathrm{Tc}$. The organizations contracted to perform the analyses were Thermo NUtech and Analytical Services Organization of Lockheed Martin Energy Systems of Oak Ridge. Both of these evaluations proved that the results from the MSC analytical lab were accurate methods of detection.

\section{Measurements by Thermo NUtech}

Batch 1. Four samples of ${ }^{99} \mathrm{Tc}$-contaminated nickel shavings were given to Thermo NUtech for analysis. There were two samples from each of two locations on cathode \#3. Each sample contained about $10 \mathrm{~g}$ of nickel shavings. The shavings were digested in nitric acid at a low temperature (not specified). The ${ }^{99} \mathrm{Tc}$ was extracted using Eichrom TCS01 modified resin and the activity was determined using liquid scintillation counting. The results are presented below. 


\begin{tabular}{|c|c|c|c|}
\hline \multicolumn{4}{|c|}{$\begin{array}{c}\text { Measurements reported by Thermo NUtech } \\
\text { on Batch 1 }\end{array}$} \\
\hline \hline $\begin{array}{c}\text { Sample } \\
\text { Location }\end{array}$ & $\begin{array}{c}\text { Results } \\
(\mathrm{pCi} / \mathrm{g})\end{array}$ & $\begin{array}{c}\text { Error } \\
(\mathrm{pCi} / \mathrm{g})\end{array}$ & $\begin{array}{c}\text { Minimum } \\
\text { detectable activity } \\
\text { (pCi/g) }\end{array}$ \\
\hline 3 & 3.20 & 1.22 & 1.92 \\
& $(0.118 \mathrm{~Bq} / \mathrm{g})$ & $(0.045 \mathrm{Bg} / \mathrm{g})$ & $(0.071 \mathrm{~Bq} / \mathrm{g})$ \\
\hline 3 & 2.14 & 1.20 & 1.95 \\
& $(0.079 \mathrm{Bg} / \mathrm{g})$ & $(0.044 \mathrm{Bg} / \mathrm{g})$ & $(0.072 \mathrm{Bg} / \mathrm{g})$ \\
\hline 5 & 26.50 & 1.67 & 1.69 \\
& $(0.981 \mathrm{~Bq} / \mathrm{g})$ & $(0.062 \mathrm{~Bq} / \mathrm{g})$ & $(0.062 \mathrm{Bg} / \mathrm{g})$ \\
\hline 3 & 4.90 & 1.10 & 1.62 \\
& $(0.181 \mathrm{Bg} / \mathrm{g})$ & $(0.041 \mathrm{Bg} / \mathrm{g})$ & $(0.060 \mathrm{Bg} / \mathrm{g})$ \\
\hline 5 & 2.23 & 1.05 & 1.69 \\
& $(0.083 \mathrm{~Bq} / \mathrm{g})$ & $(0.039 \mathrm{Bg} / \mathrm{g})$ & $(0.062 \mathrm{Bg} / \mathrm{g})$ \\
\hline
\end{tabular}

\begin{tabular}{|c|c|}
\hline \multicolumn{2}{|c|}{$\begin{array}{l}\text { Results from application of statistical tests to the } \\
\text { measurements reported by Thermo NUtech for Batch } 1\end{array}$} \\
\hline Mean & $\begin{array}{l}7.794 \mathrm{pCi} / \mathrm{g} \\
(0.288 \mathrm{~Bq} / \mathrm{g})\end{array}$ \\
\hline Standard deviation & $\begin{array}{l}10.516 \mathrm{pCi} / \mathrm{g} \\
(0.389 \mathrm{Bg} / \mathrm{g})\end{array}$ \\
\hline Standard error of the mean & $\begin{array}{l}4.703 \mathrm{pCi} / \mathrm{g} \\
(0.174 \mathrm{Bg} / \mathrm{g})\end{array}$ \\
\hline $\begin{array}{l}\text { Probability that data is } \\
\text { normally distributed }\end{array}$ & 0.006 \\
\hline
\end{tabular}

With a probability of 0.006 , the data fails the Kolmogorov-Smirnov test for normality. The very small probability suggests that there may be a systematic, rather than random, error in the measurements. Visual inspection of the Batch 1 data in Figure 1 reveals one measurement near $27 \mathrm{pCi} / \mathrm{g}(1 \mathrm{~Bq} / \mathrm{g})$ and four much smaller values [the mean of the smaller values is $3.2 \mathrm{pCi} / \mathrm{g}$ $(0.12 \mathrm{~Bq} / \mathrm{g})]$. The most likely systematic error that would produce the observed measurements would be the loss of ${ }^{99} \mathrm{Tc}$ during sample preparation.

Batch 2. Three 10-g samples of ${ }^{99} \mathrm{Tc}$-contaminated nickel shavings were digested in nitric acid by the laboratory at Manufacturing Sciences Corporation and were sent to Thermo NUtech for analysis. All three samples were taken from the same location on cathode \#3. The shavings were digested in heated nitric acid as specified by Thermo NUtech. The ${ }^{99} \mathrm{Tc}$ was extracted by Thermo NUtech using Eichrom TCSO1 modified resin and the activity was determined using liquid scintillation counting. The results are summarized below. 


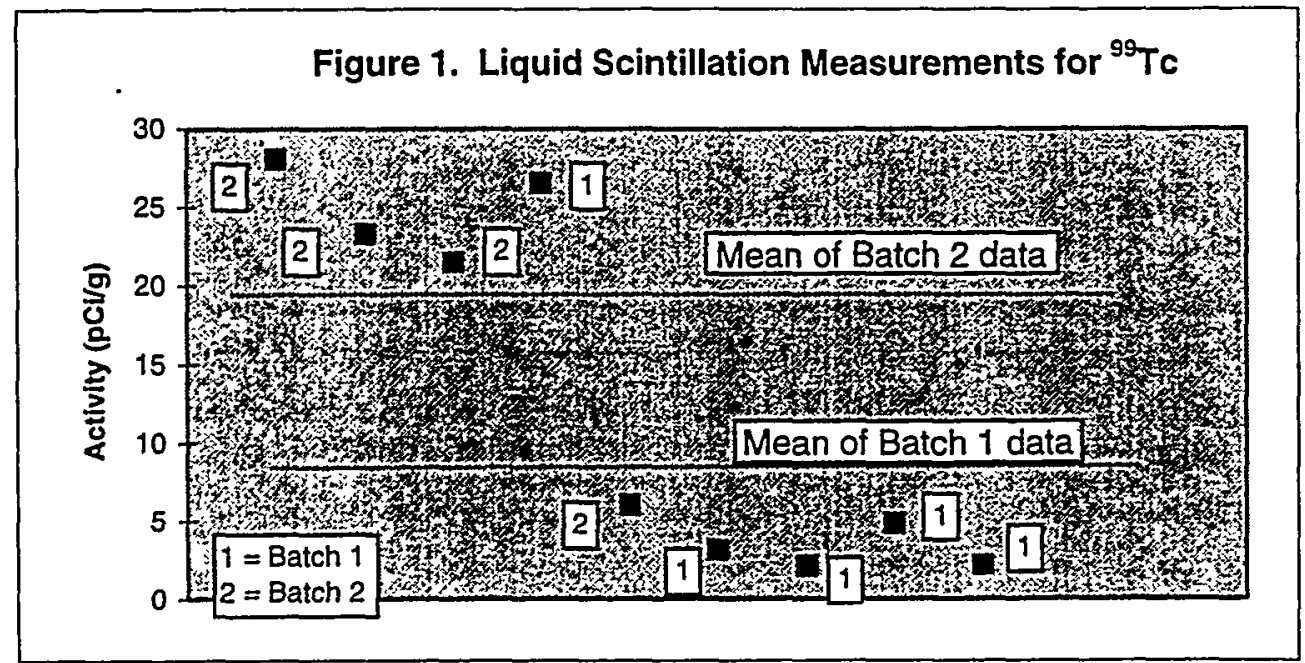

Again, the data fails the Kolmogorov-Smimov test for normality. The results suggest that there may be a systematic, rather than random, error in the measurements. Visual inspection of the Batch 2 data in Figure 1 reveals three measurement around $27 \mathrm{pCi}(1 \mathrm{~Bq} / \mathrm{g})$ the mean of the three measurements is $24.3 \mathrm{pCi} / \mathrm{g}(0.898 \mathrm{~Bq} / \mathrm{g})]$ and one much smaller value. The most likely systematic error that would produce the observed measurements would be the loss of ${ }^{99} \mathrm{Tc}$ during sample preparation.

. Concerned about the validity of the data, MSC chose to continue research on liquid scintillation and sample preparation through other resources. Data provided by Thermo NUtech is provided in Appendix 3.4 .

\section{Measurements by Analytical Services Organization}

A $10.8 \mathrm{~g}$ sample from near the center of nickel cathode \#3 was obtained by drilling through the cathode. The shavings were bagged, labeled, and delivered to the analytical laboratory contracted to perform the liquid scintillation counting measurements. The Analytical Services Organization of Lockheed Martin Energy Systems in Oak Ridge, Tennessee was contracted to make the measurements.

The sample received from Manufacturing Sciences Corporation was reduced in size with metal cutters to facilitate digestion. For a preliminary investigation, roughly $0.1 \mathrm{~g}$ of samples were digested in Teflon ${ }^{\mathrm{TM}}$ beakers that were heated to a low temperature on a hot plate. For the primary investigation, between 0.25 and $0.5 \mathrm{~g}$ of sample was placed in a Teflon ${ }^{\mathrm{TM}}$ reaction vessel and digested in an open vessel microwave system using both nitric acid and hydrogen peroxide to dissolve the sample. The digestion temperature was controlled to $80 \pm 0.1^{\circ} \mathrm{C}$. In both the preliminary and primary investigations, the digested samples were diluted to $1 \mathrm{M}$ nitric acid and placed in an automated solid phase extraction column. The radioactivity of the extracted samples were counted by liquid scintillation techniques.

Recovery of the digested ${ }^{99} \mathrm{Tc}$ with a Tevaspec extraction resin in a solid phase extraction unit was almost quantitative, ranging from approximately 98 to $102 \%$. 


\begin{tabular}{|c|c|c|c|}
\hline \multicolumn{4}{|c|}{ Measurements Reported by Analytical Services Organization } \\
\hline \hline $\begin{array}{l}\text { - Sample } \\
\text { Location }\end{array}$ & $\begin{array}{c}\text { Results } \\
(\mathrm{Bq} / \mathrm{g})\end{array}$ & $\begin{array}{c}\text { Error } \\
(\mathrm{Bq} / \mathrm{g})\end{array}$ & $\begin{array}{c}\text { Minimum } \\
\text { detectable activity } \\
(\mathrm{Bq} / \mathrm{g})\end{array}$ \\
\hline \multicolumn{4}{|c|}{ Preliminary Investigation } \\
\hline 2 & $1.15^{*}$ & 0.47 & 0.53 \\
\hline \multicolumn{4}{|c|}{ Primary Investigation } \\
\hline 2 & 1.01 & 0.21 & 0.34 \\
\hline 2 & 0.928 & 0.21 & 0.34 \\
\hline 2 & 0.884 & 0.22 & 0.35 \\
\hline 2 & 0.847 & 0.22 & 0.35 \\
\hline 2 & 0.751 & 0.21 & 0.35 \\
\hline
\end{tabular}

*Represents the average of 2 sample runs.

\begin{tabular}{|l|l|}
\hline \multicolumn{2}{|c|}{$\begin{array}{c}\text { Results from application of statistical tests to the } \\
\text { measurements reported by Analytical Services } \\
\text { Organization }\end{array}$} \\
\hline \hline Mean & $0.884 \mathrm{~Bq} / \mathrm{g}$ \\
\hline Standard deviation & $0.096 \mathrm{~Bq} / \mathrm{g}$ \\
\hline Standard error of the mean & $0.043 \mathrm{Bg} / \mathrm{g}$ \\
\hline Reported mean ${ }^{a}$ & $0.88 \mathrm{~Bq} / \mathrm{g}$ \\
\hline Reported error & \\
\hline $\begin{array}{l}\text { Probability that data is } \\
\text { normally distributed }\end{array}$ & $0.49 \mathrm{Bg} / \mathrm{g}$ \\
\hline \multicolumn{2}{|c|}{${ }^{a}$ Computed result reported by Analytical Services Organization } \\
\hline
\end{tabular}

With a probability of 0.742 , the measurements pass the Kolmogorov-Smirnov test for normality. A probability this large indicates that any errors are likely to be random and there is a large degree of similarity between the distribution of these measurements and a theoretical normal distribution.

The Analytical Services Organization was requested to develop a liquid scintillation counting technique for ${ }^{99} \mathrm{Tc}$ that was accurate to $1-2 \mathrm{pCi} / \mathrm{g}(0.037-0.074 \mathrm{~Bq} / \mathrm{g})$. As seen from the results, this level of detection was not achieved using liquid scintillation counting. The minimum detectable activity was found to be approximately a factor of nine higher than requested, 0.34 $\mathrm{Bq} / \mathrm{g} \approx 9 \times 0.037 \mathrm{~Bq} / \mathrm{g}(9.2 \mathrm{pCi} / \mathrm{g} \approx 9 \times 1.0 \mathrm{pCi} / \mathrm{g})$.

Increasing the amount of contaminated nickel metal placed into solution could lower the minimum detectable activity. Decreasing the minimum detectable activity by a factor of nine, would involve the temperature-controlled digestion of large masses of nickel metal with large volumes of nitric acid. Passing even larger diluted volumes through the extraction columns would involve prohibitively long periods of time. It appears that it is not practical to achieve the desired 1-2 pCi/g detection limit with liquid scintillation counting.

Although the minimum detectable value was not met, the samples had a relatively constant value within their analytical uncertainty. There is some fluctuation in the values, especially if the release limit is around $1 \mathrm{~Bq} / \mathrm{g}$. However, at these low levels, this is probably 
attributable to preparation variables including pipetting errors, transferring errors, and weighing errors. Using an automated system maximized the precision of the extraction process.

To validate the liquid scintillation counting results, the activity of the sample was measured by Lockheed Martin Analytical Services Organization using inductively coupled plasma mass spectroscopy. The result from mass spectroscopy was $1.36 \mathrm{~Bq} / \mathrm{g}$ with an uncertainty of $0.04 \mathrm{~Bq} / \mathrm{g}(1.36 \pm 0.04 \mathrm{~Bq} / \mathrm{g})$ and a minimum detectable activity of $0.02 \mathrm{~Bq} / \mathrm{g}$. The mass spectroscopy measurement is in agreement with the liquid scintillation result $(0.88 \pm 0.49 \mathrm{~Bq} / \mathrm{g})$ within the stated errors. The report provided by the Analytical Services Organization is included in appendix 3.4 .

\section{Liquid Scintillation at MSC}

When counting a sample in a scintillation cocktail, radiation emissions are converted to light which are seen by a photomultiplier tube of the detector. If a sample contains quenching agents, either color or chemical, the counting efficiency of the system is affected.

If disintegrations per minute (DPM) are being calculated, the sample must be checked and corrected for quench or erroneous results may be determined. By comparing the spectra and number of counts in a quenced and unquenched version of the same sample, a quence curve can be constructed to correct for the loss of activity.

The quench curve correlates the known DPM of a standard to some measured amount of quenching agent. The curve is generated by counting a series of standard samples, each containing the same amount of nuclide, in our case ${ }^{99} \mathrm{Tc}$ and varying amounts of quenching agent, $\mathrm{NiNO}_{3}$. The sample containing no quenching agent generates the highest counts, while the sample with the most quench generates the lowest counts. The efficiency for each sample is calculated and the quench curve is plotted as \% efficiency vs amount of quenching material added.

Figure 3.4.1 show the quench correction curve generated using ${ }^{99} \mathrm{Tc}$ and varying amounts of $\mathrm{NiNO}_{3}$ (indicated as tSIE - transformed Spectral Index of the External standard - on the $\mathrm{x}$ axis) and the corrected DPM values obtained when using the curve to obtain the number of counts present.

The corrected values indicate that as much as $2.5 \mathrm{ml}$ of a $\mathrm{NiNO}_{3}$ solution at the concentrations to be used for analyzing the Tc-99 can be added to the cocktail with little or no loss in DPM. .

Liquid scintillation at MSC, with random verification by external laboratories has proven to be a successful method for characterization of low levels of technetium in nickel. 
Tine: 1.00

Data Hode: DPM

Background Subtract: None
Nuclide: TC-99/NI Quench set: TC-99 oC

LL UL LCR 25\% 8KG

$\begin{array}{llll}0.0-293 & 0 & 0.0 & 0.00\end{array}$

$\begin{array}{llll}2.0-293 & 0 & 0.0 & 0.00\end{array}$

$\begin{array}{llll}0.0-0.0 & 0 & 0.0 & 0.00\end{array}$

Region

Region C:

Quench Indicator: tSIE/AEC

Ext Std Terainator: Count

$\mathrm{Ni}$ in Nitric Acid:Noninal 19/25aL

Coincidence Time(ns): 18

Delay Before Burst(ns): Norgal

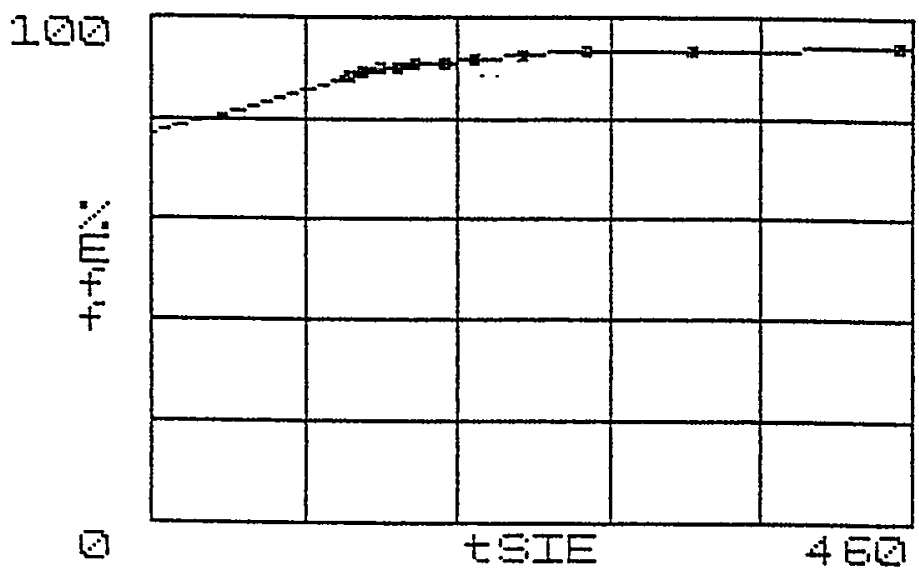
TSIE \%Eff
452.8594 .17
$326.05 \quad 93.21$
$262.00 \quad 93.69$
$222.04 \quad 92.34$
193.7991 .83
$175.40 \quad 90.98$
$157.38 \quad 91.14$
145.1990 .27
$135.44 \quad 89.72$
$125.28 \quad 89.08$
$116.84 \quad 88.24$

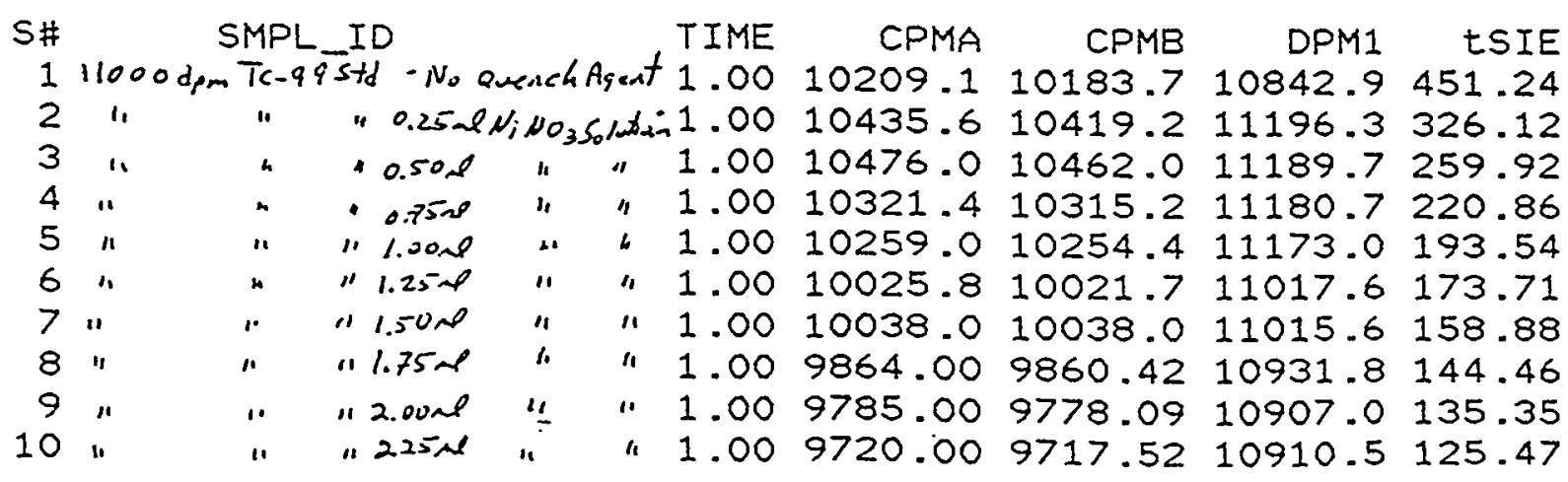




\subsubsection{Bulk Activity Approximation}

\section{$\underline{\text { Purpose }}$}

A bulk activity method was also researched to determine the concentration of ${ }^{99} \mathrm{Tc}$ in nickel that has been decontaminated. This method would allow a surface survey of nickel to estimate the activity in the bulk. The activity of ${ }^{99} \mathrm{Tc}$ in the decontaminated nickel cathode was $0.88 \pm 0.49 \mathrm{~Bq} / \mathrm{g}$ as measured by liquid scintillation counting. It is desirable, however, to identify a more rapid, less costly measuring technique for estimating the ${ }^{99} \mathrm{Tc}$ activity in the cathodes. These estimates, if correlated to the accurate, more rigorous measurements of activity obtained by liquid scintillation counting, would be a means to approximate the ${ }^{99} \mathrm{Tc}$ activity in each cathode. Currently, the purpose of this technique would be to establish quick methods to estimate levels of contamination for internal purposes only. More rigorous approaches, such as liquid scintillation or ICP Mass Spec, would be required to quantify for potential metals release.

\section{Correlation}

A correlation will provide the relationship between the rigorously determined bulk activity and the approximate bulk activity. Determination of the correlation function requires at least three repeatable liquid scintillation measurements from nickel with significantly different levels of bulk activity. A measurement of the approximate bulk activity must be obtained for each of the liquid scintillation measurements. After the data have been collected, the correlation function may be constructed by curve fitting using either graphical or statistical techniques.

\section{Approximate Bulk Activity}

The approximate bulk activity of the bulk-contaminated nickel was calculated from the surface activity using the relationship

$$
\mathrm{A}_{\text {bulk }}=\mathrm{A}_{\text {surface }} / \mathrm{m}
$$

where $m$ is the mass of the nickel producing the surface activity. This relationship was developed from the definition of specific activity. The surface activity is a measurement easily obtained with readily available surveying instruments. The mass was determined after making the following assumptions.

(1) The ${ }^{99} \mathrm{Tc}$ in the cathode is distributed homogeneously.

(2) The beta particles reaching the surface can be characterized by their average energy.

(3) There is no loss of energy by the beta particles as they pass through the air interface and probe window that are between the surface of the nickel and the detector.

(4) The beta particles are emitted from a volume of nickel with an assumed surface area and a thickness that is the linear distance traveled by a beta particle of average energy. 


\section{Theoretical Basis}

The mass of nickel from which the beta particles detected at the surface are emitted is given by

$$
\mathrm{m}_{\mathrm{Ni}}=\mathrm{V}_{\mathrm{Ni}} \cdot \rho_{\mathrm{Ni}}
$$

where $\rho_{\mathrm{Ni}}$ is the density of nickel $\left(8.8 \mathrm{~g} / \mathrm{cm}^{3}\right)$ and $\mathrm{V}_{\mathrm{Ni}}$ is the volume of the nickel emitting the beta particles detected at the surface. The volume is given by

$$
\mathrm{V}_{\mathrm{Ni}}=\mathrm{x}_{\mathrm{Ni}} \cdot \mathrm{A}
$$

where $A$ is the assumed surface area $\left(100 \mathrm{~cm}^{2}\right)$ and $x_{\mathrm{Ni}}$ is the linear distance traveled by the negative beta particle emitted by the ${ }^{99} \mathrm{Tc}$ in nickel.

The linear distance $\mathrm{x}_{\mathrm{N}}$ is defined as

$$
\mathrm{x}_{\mathrm{Ni}}=\mathrm{R} / \rho_{\mathrm{Ni}}
$$

(Choppin and Rydberg)

where $\mathrm{R}$ is the range or density thickness $\left(\mathrm{g} / \mathrm{cm}^{2}\right)$ of the beta particle in nickel. The value of $\mathrm{R}$ for $\mathrm{a}^{99} \mathrm{Tc}$ beta particle of average energy $(100 \mathrm{keV})$ is $2.225 \times 10^{-2} \mathrm{~g} / \mathrm{cm}^{2}$, as given in Table 2. Using this value for $\mathrm{R}$, the maximum thickness of nickel that a $100-\mathrm{keV}$ beta will penetrate is

$\mathrm{x}_{\mathrm{Ni}}=\left(2.225 \times 10^{-2} \mathrm{~g} / \mathrm{cm}^{2}\right) /\left(8.8 \mathrm{~g} / \mathrm{cm}^{3}\right)=2.528 \times 10^{-3} \mathrm{~cm} \cong 2.53 \times 10^{-3} \mathrm{~cm}$.

The volume, $V_{\mathrm{Ni}}$, was computed to be

$$
\mathrm{V}_{\mathrm{Ni}}=\mathrm{x}_{\mathrm{Ni}} \bullet \mathrm{A}=\left(2.53 \times 10^{-3} \mathrm{~cm}\right) \bullet\left(100 \mathrm{~cm}^{2}\right)=2.53 \times 10^{-1} \mathrm{~cm}^{3} \text {. }
$$

Using the computed volume and the given density, the mass of nickel from which the detected beta particles are emitted is

$$
\mathrm{m}_{\mathrm{Ni}}=\mathrm{V}_{\mathrm{Ni}} \cdot \rho_{\mathrm{Ni}} \cong\left(2.53 \times 10^{-1} \mathrm{~cm}^{3}\right) \cdot\left(8.8 \mathrm{~g} / \mathrm{cm}^{3}\right)=2.23 \mathrm{~g} .
$$

\section{Average Energy of Beta Particles}

Beta decay events do not produce beta particles with a unique energy. Rather, because the available decay energy is shared with the nucleus, the beta particles emerging from beta decay events have a continuous range of energies from the maximum down to zero. The negative beta particles (electrons) emitted in the decay of ${ }^{99} \mathrm{Tc}$ have a maximum energy of $292 \mathrm{keV}$, approximately $300 \mathrm{keV}$, cited in Nuclides and Isotopes, $14^{\text {th }}$ edition.

Choppin and Rydberg gives the following approximation for a typical beta decay: the average energy of a beta particle is equal to $1 / 3$ the maximum energy. For ${ }^{99} \mathrm{Tc}$, the average beta particle energy is assumed to be $1 / 3$ of $300 \mathrm{keV}$, or $100 \mathrm{keV}$. This average energy was used as the basis for determining the penetration distance of the beta particles and the mass of nickel from which the beta particles are emitted.

\section{$\underline{\text { Range of Beta Particles in Nickel }}$}

There are no readily available tabulated values for $R$ in nickel. There are, however, tabulated values of $R$ for other elements, including copper which has a density approximately equal to that of nickel $\left(\rho_{\mathrm{Cu}}=8.96 \mathrm{~g} / \mathrm{cm}^{3}, \rho_{\mathrm{Ni}}=8.8 \mathrm{~g} / \mathrm{cm}^{3}\right)$. For this approximation, it is assumed that $R_{\mathrm{Cu}} \cong \mathrm{R}_{\mathrm{Ni}}$.

The variation of $R$ with the energy of the beta particles in copper is given in Table 1. These tabulated values of $R$ were computed using the continuous slowing down approximation (CSDA). Because the CSDA models the slowing down of the beta in terms of the number of 
interactions with atomic electron clouds, materials of approximately equal densities would be expected to have roughly equivalent values for $R$, justifying the assumption that $R_{\mathrm{Cu}} \cong R_{\mathrm{Ni}}$.

Table 1. Range and computed penetration distance of beta particles in copper

\begin{tabular}{|c|c|c|c|c|}
\hline Material & $\begin{array}{c}\text { Energy } \\
(\mathrm{keV})\end{array}$ & $\begin{array}{c}\text { Density } \\
\rho \\
\left(\mathrm{g} / \mathrm{cm}^{3}\right)\end{array}$ & $\begin{array}{c}\text { Range } \\
\mathrm{R} \\
\left(\mathrm{g} / \mathrm{cm}^{2}\right)\end{array}$ & $\begin{array}{c}\text { Penetration } \\
\text { Distance } \\
\mathrm{x}=\mathrm{R} / \mathrm{\rho} \\
(\mathrm{cm})\end{array}$ \\
\hline \hline Copper & 300 & 8.96 & $1.26 \mathrm{E}-01$ & 0.014096 \\
\hline Copper & 100 & 8.96 & $2.23 \mathrm{E}-02$ & 0.002483 \\
\hline Copper & 90 & 8.96 & $1.87 \mathrm{E}-02$ & 0.002085 \\
\hline Copper $\cdot$ & 80 & 8.96 & $1.54 \mathrm{E}-02$ & 0.001713 \\
\hline
\end{tabular}

Source: ICRU Report 37, Range of Beta Particles

and Positrons, International Commission on Radioactive

Units and Measurements, Volume 37

\section{Linear Distance Traveled by the Beta Particles}

The linear distance traveled by the beta particles through the nickel is given by $\mathrm{x}_{\mathrm{Ni}} \cong \mathrm{R}_{\mathrm{Cu}} / \rho_{\mathrm{Ni}}$, also referred to as the penetration distance. Table 2 shows the values for the penetration, $\mathrm{x}_{\mathrm{Ni}}$, that would result if the range of beta particles in copper were used to determine the penetration of beta particles in nickel. Figure 1 shows the linear penetration as a function of energy from 0.1-4 $\mathrm{MeV}$ for materials ranging in density from air to lead.

Table 2. Computed penetration of beta particles in nickel using range values for copper

\begin{tabular}{|l|c|c|c|c|}
\hline Material & $\begin{array}{c}\text { Energy } \\
(\mathrm{keV})\end{array}$ & $\begin{array}{c}\text { Density } \\
\rho \\
\left(\mathrm{g} / \mathrm{cm}^{3}\right)\end{array}$ & $\begin{array}{c}\text { Range } \\
\mathrm{R} \\
\left(\mathrm{g} / \mathrm{cm}^{2}\right)\end{array}$ & $\begin{array}{c}\text { Penetration } \\
\text { Distance } \\
x=\mathrm{R} / \rho \\
(\mathrm{cm})\end{array}$ \\
\hline \hline \multicolumn{5}{|c|}{ Use copper range values for nickel } \\
\hline Nickel & 300 & 8.8 & $1.263 \mathrm{E}-01$ & 0.014352 \\
\hline Nickel & $\mathbf{1 0 0}$ & $\mathbf{8 . 8}$ & $\mathbf{2 . 2 2 5 \mathrm { E } - 0 2}$ & $\mathbf{0 . 0 0 2 5 2 8}$ \\
\hline Nickel & 90 & 8.8 & $1.868 \mathrm{E}-02$ & 0.002123 \\
\hline Nickel & 80 & 8.8 & $1.535 \mathrm{E}-02$ & 0.001744 \\
\hline
\end{tabular}

Source: ICRU Report 37, Range of Beta Particles and Positrons, International Commission on Radioactive Units and Measurements, Volume 37 


\section{Instrumentation, Surface Activity Measurements, and Statistical Analyses}

A Ludlum Model 4389 alpha/beta plastic scintillation probe with a Ludlum Model 2224 scalar was chosen to test the ${ }^{99} \mathrm{Tc}$ in the cathode to calculate the approximate bulk activity. The area of the probe is $100 \mathrm{~cm}^{2}$; the density thickness of the probe window is $1.2 \mathrm{mg} / \mathrm{cm}^{2}$. The probe efficiency is $9.4 \%$ for beta particles and $17.0 \%$ for alpha particles. The area of each measured location on the cathode is greater than $100 \mathrm{~cm}^{2}$. When the alpha/beta scintillation probe is placed in contact with the cathode, the entire active area of the probe is filled. Data collected during these tests and the corresponding statistical analysis are provided in Appendix 3.4.

The average surface activity of cathode \#3 may be calculated from the Set 1 measurements by subtracting the mean background count rate from the mean combined count rate and converting to Becquerels.

$$
\begin{aligned}
& \mathrm{A}=\left((438.3 \pm 24.3)-(427.2 \pm 41.0) \frac{\text { counts }}{\mathrm{minute}}\right)\left(\frac{\text { disintegrations }}{0.094 \text { counts }}\right)\left(\frac{\mathrm{min}}{60 \mathrm{sec}}\right)\left(\frac{\mathrm{Bq}}{\frac{\text { disintegrations }}{\mathrm{sec}}}\right) \\
& \mathrm{A}=1.97 \pm 0.30 \mathrm{~Bq} \cong 2.0 \pm 0.3 \mathrm{~Bq}
\end{aligned}
$$

The average bulk activity of cathode \#3 is found by dividing the measured surface activity by the mass of the emitting layer, $2.23 \mathrm{~g}$.

$$
A_{\text {bulk,cathode } \# 3}=\frac{(1.97 \pm 0.30 \mathrm{~Bq})}{2.23 \mathrm{~g}}=0.883 \pm 0.13 \frac{\mathrm{Bq}}{\mathrm{g}} \cong 0.88 \pm 0.13 \frac{\mathrm{Bq}}{\mathrm{g}}
$$

Using measurements from set 2 , the average surface activity of cathode $\# 3$ may be calculated.

$$
\begin{aligned}
& A=\left((183.25 \pm 15.61)-(170.0 \pm 17.4) \frac{\text { counts }}{\text { minute }}\right)\left(\frac{\text { disintegrations }}{0.094 \text { counts }}\right)\left(\frac{\mathrm{min}}{60 \mathrm{sec}}\right)\left(\frac{\mathrm{Bq}}{\frac{\text { disintegrations }}{\mathrm{sec}}}\right) \\
& \mathrm{A}=2.35 \pm 0.44 \mathrm{~Bq} \cong 2.4 \pm 0.4 \mathrm{~Bq}
\end{aligned}
$$

The average bulk activity of cathode \#3 resulting from Set 2 measurements is computed by dividing the average surface activity by the mass of the emitting layer, $2.23 \mathrm{~g}$.

$$
A_{\text {bulk.cuthode } * 3}=\frac{(2.35 \pm 0.44 \mathrm{~B} \mathrm{q})}{2.23 \mathrm{~g}}=1.054 \pm 0.197 \frac{\mathrm{Bq}}{\mathrm{g}} \cong 1.05 \pm 0.20 \frac{\mathrm{B} \mathrm{q}}{\mathrm{g}}
$$


Additional measurements were taken (sets 3-5) but were unusable due to inconsistencies that indicated an equipment malfunction. This data is shown in appendix 3.4 .

\section{Higher Activity Level}

A correlation between the approximate bulk activity of ${ }^{99} \mathrm{Tc}$-contaminated nickel and liquid scintillation bulk activity requires activity measurements at several levels. The surface activity of cathode \#3 is near the background activity. To produce the desired correlation between the approximate bulk activity and the rigorously determined bulk activity, it is necessary to measure the activity of samples with higher levels of ${ }^{99} \mathrm{Tc}$ than those measured in cathode \#3. A piece of ${ }^{99} \mathrm{Tc}$-contaminated nickel barrier was measured that had higher surface activity than the decontaminated nickel. Additionally, the surface activity of a piece of decontaminated nickel, which had been removed from cathode \#3, was measured with the alpha-beta scintillation detector.

The probe used for these measurements was $7.5 \mathrm{~cm}$ by $16.5 \mathrm{~cm}, 123.75 \mathrm{~cm}^{2}$. The contaminated barrier nickel was roughly $8.5 \mathrm{~cm}$ by $9.8 \mathrm{~cm}, 83.3 \mathrm{~cm}^{2}$, and the piece from cathode \#3 was approximately a $10.2 \mathrm{~cm}$ square, $104.0 \mathrm{~cm}^{2}$. The change in probes requires a change in the mass from which the beta particles are assumed to emerge. These corrections are $83.3 \%$ for the barrier nickel and $104.0 \%$ for cathode \#3. The detailed measurements are shown in appendix 3.4. A summary is shown below.

\begin{tabular}{|c|c|c|c|}
\hline \multicolumn{4}{|c|}{$\begin{array}{c}\text { Statistical analysis of measurements of beta particle } \\
\text { emissions from barrier nickel and cathode \#3 } \\
\text { with an alpha/beta scintillation probe }\end{array}$} \\
\hline \hline $\begin{array}{c}\text { Sample } \\
\text { location }\end{array}$ & $\begin{array}{c}\text { Mean } \\
\text { (counts/min) }\end{array}$ & $\begin{array}{c}\text { Standard } \\
\text { deviation } \\
\text { (counts/min) }\end{array}$ & $\begin{array}{c}\text { Standard error } \\
\text { of the mean } \\
\text { (counts/min) }\end{array}$ \\
\hline Barrier nickel & 1970.3 & 39.64 & 12.54 \\
\hline $\begin{array}{c}\text { Cathode \#3 } \\
\text { (removed piece) }\end{array}$ & 322.9 & 17.19 & 5.44 \\
\hline Background & 298.7 & 22.54 & 7.13 \\
\hline
\end{tabular}

The average surface activity of nickel barrier may be calculated from the measurements and converted to Becquerels. The average bulk activity of the barrier nickel is then calculated by dividing the average surface activity by the mass of the emitting layer, $2.23 \mathrm{~g}$ with the appropriate geometry correction.

$$
A_{\text {bulk.burrer nickel }}=\frac{(296.38 \pm 18.35 \mathrm{~Bq})}{(0.833 \times 2.23 \mathrm{~g})}=159.55 \pm 9.88 \frac{\mathrm{Bq}}{\mathrm{g}} \cong 159.6 \pm 9.9 \frac{\mathrm{Bq}}{\mathrm{g}}
$$

Similarly, the bulk activity of cathode \#3 is found to be

$$
A_{\text {bulk. . whtwode } \# 3}=\frac{(4.29 \pm 0.55 \mathrm{~Bq})}{(1.040 \times 2.23 \mathrm{~g})}=1.85 \pm 0.24 \frac{\mathrm{Bq}}{\mathrm{g}} \equiv 1.9 \pm 0.2 \frac{\mathrm{Bq}}{\mathrm{g}}
$$




\section{Alternate System}

The continued difficulties encountered during sets 3-5 measurements prompted a change in the instrumentation. The Ludlum Model 2200 scaler was retained, but the alpha/beta scintillation probe was replaced with a shielded Geiger-Müller tube. The area of the probe is 15 $\mathrm{cm}^{2}$. This is much smaller than the area of the previously used probe, $100 \mathrm{~cm}^{2}$.

The efficiency of this new system was determined using a ${ }^{99} \mathrm{Tc}$ source of known activity. The source activity is 13,200 decays/min into $4 \pi$ steradians. Based on two 10 -min counts of the ${ }^{99} \mathrm{Tc}$ source, the average count rate of the source is $1809.5 \pm 11.0$ counts $/ \mathrm{min}$.

The average background was determined from two 900 -min counts to be $30,934.5$ counts/900 min with a standard deviation of 195.9 counts/900 min and a standard error of the mean equal to 138.5 counts $/ 900 \mathrm{~min}$. This produces a background count rate equal to $34.37 \pm 0.22$ counts $/ \mathrm{min}$.

Correcting the ${ }^{99} \mathrm{Tc}$ source average count rate, 1809.5 counts/min, for the background count rate, 34.37 counts $/ \mathrm{min}$, gives 1775.1 net counts $/ \mathrm{min}$. Dividing the corrected count rate by the known activity of the source gives the efficiency of the detection system

$$
E=\left(\frac{1775.1 \frac{\text { counts }}{\mathrm{min}}}{13,200 \frac{\text { counts }}{\mathrm{min}}}\right) \times 100=13.45 \%
$$

Detailed measurements taken with the shielded Geiger-Muller tube are shown in Appendix 3.4. A summary of the data is shown below.

\begin{tabular}{|c|c|c|c|}
\hline \multicolumn{4}{|c|}{$\begin{array}{c}\text { Statistical analysis of measurements of beta particle } \\
\text { emissions from barrier nickel and cathode \#3 } \\
\text { with a shielded Geiger-Müller tube }\end{array}$} \\
\hline \hline $\begin{array}{c}\text { Sample } \\
\text { location }\end{array}$ & $\begin{array}{c}\text { Mean } \\
\text { Total counts }\end{array}$ & $\begin{array}{c}\text { Standard } \\
\text { deviation } \\
\text { (counts) }\end{array}$ & $\begin{array}{c}\text { Standard error } \\
\text { of the mean } \\
\text { (counts) }\end{array}$ \\
\hline Nickel barrier & $34,521.5$ & 276.59 & 138.30 \\
\hline $\begin{array}{c}\text { Cathode \#3 } \\
\text { (removed piece) }\end{array}$ & 2148.5 & 55.51 & 27.76 \\
\hline $\begin{array}{c}\text { Cathode \#3 } \\
\text { (locatiön 1B) }\end{array}$ & 2082.3 & 60.18 & 34.74 \\
\hline
\end{tabular}

The average surface activity of the nickel barrier may be calculated and converted to Becquerels. 


$$
\begin{aligned}
& A=\left(\left(\frac{34,521.5 \pm 276.59}{60}\right)-(34.37 \pm 0.22) \frac{\text { counts }}{\text { minute }}\right)\left(\frac{\text { disintegrations }}{0.1345 \text { counts }}\right)\left(\frac{\mathrm{min}}{60 \mathrm{sec}}\right)\left(\frac{\mathrm{Bq}}{\frac{\text { disintegrations }}{\mathrm{sec}}}\right) \\
& \mathrm{A}=67.04 \pm 0.54 \mathrm{~Bq} \equiv 67.0 \pm 0.5 \mathrm{~Bq}
\end{aligned}
$$

The average bulk activity of the barrier nickel is then calculated by dividing the average surface activity by the mass of the emitting layer, $2.23 \mathrm{~g}$ with the appropriate geometry correction.

$$
A_{\text {bulk.burrier nickel }}=\frac{(67.04 \pm 0.54 \mathrm{~Bq})}{(0.15 \times 2.23 \mathrm{~g})}=200.30 \pm 1.61 \frac{\mathrm{Bq}}{\mathrm{g}} \cong 200.3 \pm 1.6 \frac{\mathrm{Bq}}{\mathrm{g}}
$$

The average bulk activity of cathode \#3 at location $1 \mathrm{~B}$ and the excised piece of cathode \#3 can be determined in a similar manner.

$$
\begin{aligned}
& A_{\text {bulk.cuthode \#3(location 1B) }}=\frac{(0.042 \pm 0.0015 \mathrm{~B} \mathrm{q})}{(0.15 \times 2.23 \mathrm{~g})}=0.124 \pm 0.004 \frac{\mathrm{Bq}}{\mathrm{g}} \cong 0.12 \pm 0.01 \frac{\mathrm{Bq}}{\mathrm{g}} \\
& A_{\text {bulk.cuthode\#3(removed piece) }}=\frac{(0.178 \pm 0.015 \mathrm{~Bq})}{(0.15 \times 2.23 \mathrm{~g})}=0.533 \pm 0.045 \frac{\mathrm{Bq}}{\mathrm{g}} \cong 0.53 \pm 0.05 \frac{\mathrm{Bq}}{\mathrm{g}}
\end{aligned}
$$

The bulk activity of cathode \#3 at location $1 \mathrm{~B}$ is rather low. Computationally, this was caused by the one low count that substantially lowered the average count rate. Additional sampling could produce results for location $1 \mathrm{~B}$ that are closer to the bulk activity computed for the removed piece of cathode \#3.

\section{$\underline{\text { Results }}$}

To determine if surface measurements of ${ }^{99} \mathrm{Tc}$ activity could be related to bulk contamination, measurements were obtained using two surface activity measuring probes: an alpha/beta plastic scintillator and a shielded Geiger-Müller tube. In total 10 sets of measurements were collected. Eight sets of data were collected from samples of decontaminated nickel (cathode \#3), and two sets of data were collected from nickel barrier that had not been decontaminated. Three of the sets of measurements of the surface activity of the decontaminated nickel were unusable. The data are presented in the following section.

Measurements of the surface activity of the barrier nickel were performed with an alpha/beta plastic scintillator and a shielded Geiger-Müller tube. One data set was collected with each detector. The bulk activities of the barrier nickel were calculated from the surface activities using the method described in the Approximate Bulk Activity section. The computed bulk activities are as follows:

$$
\begin{array}{ll}
\text { alpha/beta plastic scintillator } & 159.6 \pm 9.9 \mathrm{~Bq} / \mathrm{g} \text { and } \\
\text { shielded Geiger-Müller tube } & 200.3 \pm 1.6 \mathrm{~Bq} / \mathrm{g} \text {. }
\end{array}
$$

For five sets of measurements of the surface activity of decontaminated nickel, the bulk activity of ${ }^{99} \mathrm{Tc}$ was computed. Three sets of measurements were obtained using an alpha/beta 
scintillation probe and two sets of measurements were obtained using a shielded Geiger-Müller tube. The bulk activities are given in Table 3 .

\begin{tabular}{|l|c|}
\hline \multicolumn{1}{|c|}{ Table 3. Computed bulk activity of decontaminated nickel } \\
\hline \hline Probe type & $\begin{array}{c}\text { Bulk activity } \\
(\mathrm{Bq} / \mathrm{g})\end{array}$ \\
\hline alpha/beta plastic scintillator & $0.88 \pm 0.13$ \\
\hline alpha/beta plastic scintillator & $1.05 \pm 0.20$ \\
\hline alpha/beta plastic scintillator & $1.85 \pm 0.24$ \\
\hline shielded Geiger-Müller tube & $0.12 \pm 0.01$ \\
\hline shielded Geiger-Müller tube & $0.53 \pm 0.05$ \\
\hline
\end{tabular}

The average of the computed bulk activities for the decontaminated nickel is $0.89 \mathrm{~Bq} / \mathrm{g}$. This compares well with the average of independently obtained liquid scintillation measurements of the decontaminated nickel, $0.88 \pm 0.49 \mathrm{~Bq} / \mathrm{g}$.

A further study was conducted in the MSC lab in July 1998. A nickel cathode from early trials of the full scale electrorefining cell were sectioned in nine equal portions. Sections were counted using a Ludlum 2224 with a alpha/beta scintillation detector. The counted section was marked and a $100 \mathrm{~cm}^{2}$ area cut from the quadrant and cut into small pieces. Twenty $\mathrm{ml}$ of HNO3 was added to the samples and heated until dissolved. Water was added and the solution evaporated down to $15 \mathrm{ml}$ at 60 degrees $C$ to reduce the nitric acid concentration. The sample was quantitatively rinsed into a $100 \mathrm{ml}$ volumetric flask and diluted to $100 \mathrm{ml}$ with distilled water. One $\mathrm{ml}$ of the solution was removed and added to $12 \mathrm{ml}$ of liquid scintillation cocktail and counted for 100 minutes in the Packard 2700 TR counter. Sample A was taken from the front starter sheet from the mother blank and Sample B was taken from the back side. Sample A averaged $5.69 \mathrm{~Bq} / \mathrm{g}$ using liquid scintillation and Sample B averaged $4.46 \mathrm{~Bq} / \mathrm{g}$. Using the 2224 alpha/ beta scintillator, Sample A averaged $0.37 \mathrm{~Bq} / \mathrm{g}$ and sample B averaged $4.66 \mathrm{~Bq} / \mathrm{g}$ indicating that the results are not close enough to rely on a surface measurement solely for determination of bulk isotopic content of nickel volumetrically contaminated with technetium. Details of this study are shown in Appendix 3.4.

The results of these studies, obtained with an alpha-beta plastic scintillation detection system, demonstrate the feasibility of using this surface technique only for screening for bulk activity. More rigorous detection methods, such as liquid scintillation are required for reliable isotopic measurements.

\subsubsection{Sampling During Electrorefining Operations}

Details of results obtained during operation of the one full scale electrorefining cell are shown in section 3.1 (Full-scale electrorefining). Examples of laboratory results are shown in appendix 3.4 . 


\section{REFERENCES}

Choppin and Rydberg, Nuclear Chemistry: Theory and Applications, 278-280, Pergamon Press, Oxford, U.K., 1980.

ICRU Report 37, Stopping Powers for Electrons and Positrons, International Commission on Radioactive Units and Measurements, Volume 37, Bethesda, Maryland.

Meyer, Data Analysis for Scientists and Engineers, 17-18, John Wiley \& Sons, New York, 1975.

Meir and Zünd, Statistical Methods in Analytical Chemistry, 49-54, John Wiley \& Sons, New York, 1993.

NCRP Report No. 58, A Haindbook of Radioactivity Measurements Procedures, 307-311, National Council on Radiation Protection and Measurements, Bethesda, Maryland, 1985.

Nuclides and Isotopes, $14^{\text {th }}$ edition, General Electric Company, Nuclear Energy Operations, San Jose, California, 1989.

Tsoulfanidis, Measurement and Detection of Radiation, 57-68, McGraw-Hill Book Company, New York, 1983. 


\section{Conclusions}

- Electro-refining technology developed in this project has demonstrated the capability, on a full scale, to remove technetium from diffusion plant nickel barrier to $1-2 \mathrm{~Bq} / \mathrm{g}$.

- Direct dissolution has proven promising on a lab scale but requires additional research for scale up activities.

- An automated NdYAG laser cutting system is capable of size reducing a $1 / 2$ inch thick converter shell from the gaseous diffusion plant. High initial capital costs have prevented its further use in decommissioning activities at MSC.

- Liquid Scintillation is the method of choice for quantifying low levels of technetium in nickel verified on a random basis by Inductively Coupled Plasma Mass Spectrometer.

- Detailed evaluation of the DWPF product specification revealed that the cost to produce the DWPF canister from RSM at MSC's facility and be competitive within $25 \%$ of current canister costs is not feasible at this time. 
Appendix 3.1 


\title{
Watts Solution for Electro-refining of Nickel Specification and Costs
}

\author{
March 6, 1998
}

Elizabeth H. Terry 


\section{Watts Solution for Electro-refining of Nickel Specifications and Costs}

Information was collected to determine specifications and costs of the chemical components for a Watts solution to be used in the electro-refining process to recover nickel from barrier nickel contaminated with ${ }^{99} \mathrm{Tc}$. The findings support the following recommendations.

(1) The proposed concentrations of chemical components for the initial make-up of the Watts solution are $40 \mathrm{oz} / \mathrm{gal} \mathrm{NiSO} \cdot 6 \mathrm{H}_{2} \mathrm{O}$ (nickel sulfate hexahydrate), $8 \mathrm{oz} / \mathrm{gal}$

- $\mathrm{NiCl}_{2} \cdot 6 \mathrm{H}_{2} \mathrm{O}$ (nickel chloride hexahydrate), and $6 \mathrm{oz} / \mathrm{gal} \mathrm{H}_{3} \mathrm{BO}_{3}$ (boric acid).

(2) The rickel salts used in the preparation of the Watts solution should be purchased in the form of concentrated liquids rather than crystalline solids.

(3) Nickel salts of the highest purity available in liquid form should be used to prepare the Watts solution.

(4) Southeastern Chemical, Inc. of Chattanooga, Tennessee is the preferred vendor to supply concentrated liquid nickel salts of high purity.

Concentrations. The recommended concentrations of nickel salts and boric acid are the Dremco ideal concentrations shown (boldfaced) in Table 1. These concentrations are within the range of other reference values given in the table. The concentrations suggested by Lockwood Greene are not recommended due to the low level of chlorides. A higher concentration of chloride ions generally resuits in more rapid corrosion of the anode. Increasing the rate of anode corrosion results in more nickel ions moving into the solution per unit time. This will allow the overall movement of nickel ions from anode to cathode to occur at a faster rate, assuming that all other system parameters are optimal.

Note that these concentrations are recommended as starting points in the optimization process. It will be necessary to fine tune the recommended concentrations to achieve optimal concentrations of the chemical components for the Watts solution as other operating parameters are optimized.

Having established the concentrations of rickel sulfate, nickel chloride, and boric acid for the initial make up of the Watts solution, calculations (Attachment A) were performed to determine the amounts of components required to achieve the established concentrations. Specification sheets (Attachment B) provided information necessary for the calculations. The preparation of a 1,500-gallon batch of Watts solution having the recommended concentrations requires these components:

\begin{tabular}{lll}
\hline \multicolumn{1}{c}{$:$} & $\begin{array}{l}\text { Using Crystalline Solids of } \\
\text { Nickel Salts }\end{array}$ & $\begin{array}{l}\text { Using Concentrated Liquids } \\
\text { of Nickel Salts }\end{array}$ \\
\hline nickel sulfate & 3,750 pounds & 746 gallons \\
nickel chloride & 750 pounds & 125 gallons \\
boric acid & 563 pounds & 563 pounds \\
DI water & 1,190 gallons & 580 gallons \\
sulfuric acid (pH adjustment) & to be determined & to be determined \\
sodium hydroxide & to be determined & to be determined \\
(pH adjustment) & & \\
\hline
\end{tabular}


The concentrated liquid nickel salts contain nickel sulfate at $133 \mathrm{~g} / \mathrm{L}$ (17.8 oz/gal) and nickel chloride at $178 \mathrm{~g} / \mathrm{L}(23.5 \mathrm{oz} / \mathrm{gal})$ both as nickel metal.

Physical states. The nickel salts as hexahydrates may be purchased as crystalline solids or as concentrated liquids with the nickel salts in solution. Comparing costs of nickel salts for the crystalline solids and concentrated liquids (presented in Tables 2 and 3), the solids cost slightly less than the liquids. The maximum savings in choosing solids over liquids is about $\$ 340$ for nickel sulfate and $\$ 240$ for nickel chloride. These saving are insignificant compared with the costs associated with handling and mixing solids. Additionally, there is the cost of producing 1,190 gallons of DI water needed to put the crystalline solids into solution in comparison with only 580 gallons of DI required with the concentrated liquids. All factors considered, liquid form is the better choice.

Purity. Optimization of the electro-refining process requires that interfering elements be minimized. Potential sources of interfering elements are the chemical components of the Watts solution. By purchasing chemicals of the highest purity available, the minimization of interfering elements is achieved.

Examination of Tables 4-7 shows that generally the rickel salts in concentrated liquid form contain fewer impurities than the crystalline solids. Therefore, nickel salts in concentrated liquid form are a better choice for minimizing interfering elements.

Of the vendors surveyed, Tables 4 and 5 reveal that Southeastern Chemical supplies the highest purity liquid nickel salts. The concentrations of impurities range from a factor of 5 to an orcler or magnitude lower for Southeastern's products as compared to products of Gumm and VanWaters \& Rogers.

After MSC has established criteria for the purity of the nickel product, Southeastern Chemical . working with Titan International, the manufacturer of the rickel salts, will attempt to supply nickel salts that meet MSC's criteria with no increase in cost. A certificate of analysis indicating concentrations of contaminants will be provided with each batch.

Suppliers and Costs. Direct comparison of the prices shown in Table 3 for a 1,500-gallon batch is valid becaúse the nickel metal concentrations are equivalent (see Attachment $C$ ) in each type of liquid nickel salt sold by all the vendors. Following the recommendations given in items (I)'(4) using prices from Table 3 , the total cost of the concentrated liquid rickel salts is $\$ 7,372$ (including shipment to MSC) if purchased from Southeastern Chemical.

If purchased from Frederick Gumm Chemical, the lowest total price for the nickel salts is $\$ 6,057$ (FOB Gastonia, NC), \$1,300 less than the price quoted by Southeastern Chemical. Despite the $\$ 1,300$ cost difference, Southeastern Chemical is the preferred vendor for these reasons: (1) the purity of Southeastern's nickel salts is substantially higher and (2) Gumm was slow to respond to inquiries and appeared disinterested in meeting specific needs.

Of all the vendors contacted, Southeastern Chemical responded the most promptly to requests for specifications. Additionally, Southeastern's sales staff demonstrated a thorough knowledge of chemicals used for electroplating, experience in mixing Watts solutions, and a willingness to provide technical support to MSC. 


\section{Concentrations of Watts Solution}

Table 1. Range of reference Watts solution concentrations

\begin{tabular}{|c|c|c|c|}
\hline \multirow{2}{*}{ Reference } & \multicolumn{3}{|c|}{$\begin{array}{c}\text { Concentrations } \\
\text { [oz (av)/gall] }\end{array}$} \\
\hline & $\mathrm{NiSO}_{4} \cdot 6 \mathrm{H}_{2} \mathrm{O}$ & $\mathrm{NiCl}_{2} \cdot 6 \mathrm{H}_{2} \mathrm{O}$ & $\mathrm{H}_{3} \mathrm{BO}_{3}$ \\
\hline $\begin{array}{l}\text { Dremco } \\
\text { (ideal) }\end{array}$ & $\begin{array}{l}40 \\
(300 \mathrm{~g} / 1)\end{array}$ & $\begin{array}{l}8 \\
(60 \mathrm{~g} / 1) \\
\end{array}$ & $\begin{array}{l}6 \\
(45 \mathrm{~g} / \mathrm{l})\end{array}$ \\
\hline $\begin{array}{l}\text { Dremco } \\
\text { (range) }\end{array}$ & $\begin{array}{l}32-42 \\
(240-315 \mathrm{~g} / \mathrm{l})\end{array}$ & $\begin{array}{l}6-12 \\
(45-90 \mathrm{~g} / \mathrm{l})\end{array}$ & $\begin{array}{l}6-7 \\
(45-52 g / 1)\end{array}$ \\
\hline Lockwood Greenea & $\begin{array}{l}37 \\
(280 \mathrm{~g} / \mathrm{I})\end{array}$ & $6(44 \mathrm{~g} / 1)$ & $\begin{array}{l}5 \\
(40 \mathrm{~g} / \mathrm{l})\end{array}$ \\
\hline Dennis and Suche & $\begin{array}{l}20-53 \\
(150-400 \mathrm{~g} / \mathrm{l})\end{array}$ & $\begin{array}{l}3-11 \\
(20-80 \mathrm{~g} / \mathrm{l})\end{array}$ & $\begin{array}{l}2-7 \\
(15-50 \mathrm{~g} / \mathrm{l})\end{array}$ \\
\hline Draperd $^{d}$ & $\begin{array}{l}41 \\
(310 \mathrm{~g} / 1)\end{array}$ & $\begin{array}{l}7 \\
(50 \mathrm{~g} / \mathrm{I}) \\
\end{array}$ & $\begin{array}{l}5 \\
(40 \mathrm{~g} / 1)\end{array}$ \\
\hline Grahame & $\begin{array}{l}40 \\
(300 \mathrm{~g} / 1)\end{array}$ & $\begin{array}{l}6 \\
(45 \mathrm{~g} / 1)\end{array}$ & $\begin{array}{l}45 \\
(30-37 \mathrm{~g} / \mathrm{l})\end{array}$ \\
\hline
\end{tabular}

aCrotzer, H., Lockwood Greene Technologies, Oak Ridge, Tennessee, letter report to V. MacNair, Manufacturing Sciences Corporation, November 25, 1997.

BRobinson, D. J., Dremco, Inc., Phoenix, Arizona, facsimile transmission to S. Sarten, Manufacturing Sciences Corporation, January 6, 1998.

CDennis, J. K. and T. E. Such, Nickel and Chromium Plating, 2nd Edition, Butterworths, London, 1986.

DBrugger, R., Nickel Plating, Robert Draper Ltd., Teddington, England, 1970.

York, 1971.

EGraham, A. K., Electroplating Engineering Handbook, 3rd Edition, Van Nostrand Reinhold Company, New

The ideal concentrations proposed by Dremco, as shown in Table 1, were used to calculate the quantities of chemicals required to make up a 1,500-gallon batch of Watts solution. These quantities and the resulting costs are presented in Tables 2 and 3.

To determine the total cost for preparing the Watts solution, costs must be added to those presented in Tables 2 and 3. These additional costs include the preparation of deionized water and the purchase of sulfuric acid and sodium hydroxide required for $\mathrm{pH}$ adjustment.

Preparation of the Watts solution from crystalline nickel compounds would require approximately 1,190 gallons of deionized water. Preparation of the Watts solution from liquid nickel solutions would require approximately 580 gallons of deionized water. The quantities of sulfuric acid and sodium hydroxide for $\mathrm{pH}$ adjustment must be determined based upon . performance of the electro-refining cell. . 
Watts Solution

Prices and Suppliers of Chemicals

Table 2. Crystalline Solids + Approximately 1,190 Gallons of DI Water

\begin{tabular}{|c|c|c|c|}
\hline Vendor & $\begin{array}{l}\mathrm{NiSO}_{4} \cdot 6 \mathrm{H}_{2} \mathrm{O} \\
(\$ / \mathrm{lb})\end{array}$ & $\begin{array}{l}\text { Quantity per batch } \\
\text { (lbs. } / 1,500 \text { gal.) }\end{array}$ & Costb \\
\hline Frederick Gumm Chemical & 1.33 & 3,750 & $\begin{array}{l}\$ 4,987.50+\text { shipping } \\
\text { (FOB Gastonia, NC) }\end{array}$ \\
\hline Southeastern Chemical & 1.60 & 3,750 & $\begin{array}{c}\$ 6,000.00+\text { shipping } \\
\text { (FOB Chattanooga, TN) }\end{array}$ \\
\hline Van Waters \& Rogers & 1.60 & 3,750 & $\begin{array}{l}\$ 6,000.00+\text { shipping } \\
\text { (FOB Rock Hill, SC) }\end{array}$ \\
\hline Dremco & no quote & no quote & no quote \\
\hline S & 3ris & 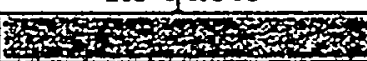 & W \\
\hline Vendor & $\begin{array}{l}\mathrm{NiCl}_{2} \cdot 6 \mathrm{H}_{2} \mathrm{O} \\
(\$ / \mathrm{lb})\end{array}$ & $\begin{array}{l}\text { Quantity per batch } \\
\text { (lbs./1,500 gal.) }\end{array}$ & $\operatorname{Cost}^{b}$ \\
\hline Southeastern Chemical & 1.65 & 750 & $\begin{array}{c}\$ 1,237.50+\text { shipping } \\
\text { (FOB Chattanooga, TN) }\end{array}$ \\
\hline Van Waters \& Rogers & 1.68 & 750 & $\begin{array}{l}\$ 1,260.00+\text { shipping } \\
\text { (FOB Rock Hill, SC) }\end{array}$ \\
\hline Frederick Gumm Chemical & 1.71 & 750 & $\begin{array}{l}\$ 1,282.50+\text { shipping } \\
\text { (FOB Gastonia, NC) }\end{array}$ \\
\hline Dremco & no quote & no quote & no quote \\
\hline $\mathrm{SP}^{2}$ & Sos & S & y \\
\hline . Vendor ${ }^{a}$ & $\begin{array}{l}\mathrm{H}_{3} \mathrm{BO}_{3} \\
(\$ / \mathrm{lb})\end{array}$ & $\begin{array}{l}\text { Quantity per batch } \\
\text { (lbs. } 1,500 \text { gal.) }\end{array}$ & Cost \\
\hline Southeastern Chemical & 0.61 & 563 & $\begin{array}{c}\$ 343.43+\text { shipping } \\
\text { (FOB Chattanooga, TN) }\end{array}$ \\
\hline Van Waters \& Rogers & 0.81 & 563 & $\begin{array}{c}\$ 456.03 \\
\text { (includes delivery) }\end{array}$ \\
\hline Dremco & 1.00 & 563 & $\begin{array}{l}\text { \$563.00+ shipping } \\
\text { (FOB Nashville, TN) }\end{array}$ \\
\hline Frederick Gumm Chemical & no quote & no quote & no quote \\
\hline
\end{tabular}

${ }^{a}$ Additional vendor information is found in Attachment $D$.

b Price will increase or decrease with the price of nickel which changes daily.

For $\mathrm{pH}$ adjustment

$\mathrm{H}_{2} \mathrm{SO}_{4} \quad \$ 0.0865 / \mathrm{lb}$ with a $\$ 35$ drum deposit (source: Roy Flynn on 1/14/98)

$\mathrm{NaOH} \quad \$ 0.1850 / \mathrm{lb}$ with a $\$ 35$ drum deposit (source: Roy Flynn on 1/14/98) 
Watts Solution

Prices and Suppliers of Chemicals (continued)

Table 3. Liquids + Approximately 580 Gallons of DI Water

\begin{tabular}{|c|c|c|c|}
\hline Vendor ${ }^{a}$ & $\begin{array}{c}\mathrm{NiSO}_{4} \text { solution } \\
(\$ / \text { gallon })\end{array}$ & $\begin{array}{l}\text { Quantity per batch } \\
\text { (gal./1,500 gal.) }\end{array}$ & Costb \\
\hline Frederick Gumm Chemical & 6.72 & 746 & $\begin{array}{l}\$ 5,013.12+\text { shipping } \\
\text { (FOB Gastonia, NC) }\end{array}$ \\
\hline Southeastern Chemical & 8.18 & 746 & $\begin{array}{c}\$ 6,102.28 \\
\text { (includes delivery) }\end{array}$ \\
\hline Van Waters \& Rogers & 8.50 & 746 & $\begin{array}{l}\$ 6,341.00+\text { shipping } \\
\text { (FOB Rock Hill, SC) }\end{array}$ \\
\hline Dremco & 9.00 & 746 & $\begin{array}{l}\$ 6,714.00+\text { shipping } \\
\text { (FOB Nashville, TN) }\end{array}$ \\
\hline W & 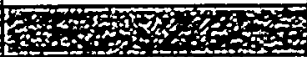 & 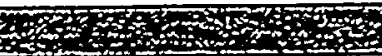 & Pyon \\
\hline Vendor & $\begin{array}{c}\mathrm{NiCl}_{2} \text { solution } \\
(\$ / \text { gallon })\end{array}$ & $\begin{array}{l}\text { Quantity per batch } \\
\text { (gal./1,500 gal.) }\end{array}$ & Costb \\
\hline Frederick Gumm Chemical & 8.35 & 125 & $\begin{array}{l}\text { \$1,043.75 + shipping } \\
\text { (FOB Gastonia, NC) }\end{array}$ \\
\hline Dremco & 10.00 & 125 & $\begin{array}{l}\$ 1,250.00+\text { shipping } \\
\text { (FOB Nashville, TN) }\end{array}$ \\
\hline Southeastern Chemical & 10.16 & 125 & $\begin{array}{c}\$ 1,270.00 \\
\text { (includes delivery) }\end{array}$ \\
\hline Van Waters \& Rogers & 10.50 & 125 & $\begin{array}{l}\text { \$1,312.50 + shipping } \\
\text { (FOB Rock Hill, SC) }\end{array}$ \\
\hline
\end{tabular}

Additional vendor information is found in Attachment $D$.

$b$ Price will increase or decrease with the price of nickel which changes daily.

For $\mathrm{pH}$ adjustment

$\mathrm{H}_{2} \mathrm{SO}_{4} \quad \$ 0.0865 / \mathrm{lb}$ with a $\$ 35$ drum deposit (source: Roy Flynn on 1/14/98)

$\mathrm{NaOH} \quad \$ 0.1850 / \mathrm{lb}$ with a $\$ 35$ drum deposit (source: Roy Flynn on 1/14/98) 


\section{Watts Solution}

Table 4. Impurities in Concentrated Liquid Nickel Sulfate

\begin{tabular}{|c|c|c|c|}
\hline \multirow{2}{*}{$\begin{array}{l}\text { Values taken from } \\
\text { specification sheets } \\
\text { in Attachment B }\end{array}$} & \multicolumn{2}{|r|}{ Suppliers } & Southeastern \\
\hline & \multicolumn{3}{|c|}{ Manufacturers } \\
\hline cobalt & not detected & not specified & < I ppm typicalc \\
\hline iron & 3 ppm max & $\begin{array}{l}10 \text { ppm max } \\
<5 \text { ppm typical }\end{array}$ & $0.9 \mathrm{ppm}$ measured \\
\hline copper & 2 ppm max & $\begin{array}{l}2 \text { ppm max } \\
<1 \text { ppm typical }\end{array}$ & 0.4 ppm measured \\
\hline zinc & 1 ppm max & $\begin{array}{l}1 \text { ppm max } \\
<1 \text { ppm typical }\end{array}$ & not detected \\
\hline chromium & 5 ppm max & $\begin{array}{l}5 \text { ppm max } \\
<1 \text { ppm }\end{array}$ & 1.4 ppm measured \\
\hline manganese & 1 ppm max & $\begin{array}{l}5 \text { ppm max } \\
<5 \text { ppm typical }\end{array}$ & not analyzed \\
\hline cadmium & $<1$ ppm max & $\begin{array}{l}1 \text { ppm max } \\
<1 \text { ppm typical }\end{array}$ & $0.2 \mathrm{ppm}$ measured \\
\hline lead & $<1$ ppm max & $\begin{array}{l}3 \text { ppm max } \\
<1 \text { ppm typical }\end{array}$ & not detected \\
\hline \multicolumn{4}{|c|}{ 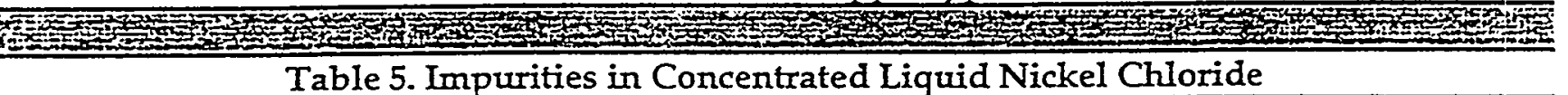 } \\
\hline \multirow{2}{*}{$\begin{array}{l}\text { Values taken from } \\
\text { specification sheets } \\
\text { in Attachment B }\end{array}$} & \multicolumn{3}{|c|}{$\begin{array}{c}\text { Suppliers } \\
\text { Van Waters \& Rogers }\end{array}$} \\
\hline & \multicolumn{3}{|c|}{ Manufacturers } \\
\hline cobalt & $120 \mathrm{ppm} \max$ & not specified & $<1$ ppm typical $c$ \\
\hline iron & 10 ppm max & 20 ppm typical & 0.1 ppm measured \\
\hline copper & 1 ppm max & $\begin{array}{l}10 \text { ppm max } \\
<10 \text { ppm typical }\end{array}$ & not detected \\
\hline zinc & 1 ppm max & $\begin{array}{l}10 \text { ppm max } \\
<10 \text { ppm typical }\end{array}$ & $0.1 \mathrm{ppm}$ measured \\
\hline chromium & 10 ppm max & $\begin{array}{l}10 \text { ppm max } \\
<10 \text { ppm typical }\end{array}$ & 0.6 ppm measured \\
\hline mangarese & not specified & not specified & not specified \\
\hline cadmium & 1 ppm max & not specified & not specified \\
\hline lead & 1 ppm max & $\begin{array}{l}10 \text { ppm max } \\
<5 \text { ppm typical }\end{array}$ & 0.3 ppm measured \\
\hline
\end{tabular}

The specifications for the concentrated liquids offered by Dremco are the same as those obtained from Palm,Frederick Gumm's manufacturer. However, Dremco sells them for a higher price than Frederick Gumm (see Table 3).

${ }^{B}$ After MSC has established criteria for the purity of the nickel product, Southeastern working with Titan have agreed to supply rickel salts that meet MSC's criteria with no increase in cost.

This value does not appear on the Titan specification sheets. It was obtained during a telephone conversation on Tuesday, February 24, 1998, with the Titan representative, Ellen Jansen. 


\section{Watts Solution}

Table 6. Impurities in Crystalline Solid Nickel Sulfate

\begin{tabular}{|c|c|c|c|}
\hline \multirow{2}{*}{$\begin{array}{l}\text { Values taken from } \\
\text { specification sheets } \\
\text { in Attachment B }\end{array}$} & \multicolumn{3}{|c|}{ Suppliers } \\
\hline & Palm & Manufacturers & $\mathrm{OMG}$ \\
\hline cobalt & 150 ppm max & not specified & $\begin{array}{l}150 \text { ppm max } \\
<10 \text { ppm measured }\end{array}$ \\
\hline iron & 10 ppm max & $\begin{array}{l}15 \text { ppm max } \\
10 \text { ppm typical }\end{array}$ & $\begin{array}{l}10 \text { ppm max } \\
<1 \text { ppm measured }\end{array}$ \\
\hline copper & 5 ppm max & $\begin{array}{l}5 \text { ppm max } \\
<5 \text { ppm typical }\end{array}$ & $\begin{array}{l}5 \text { ppm max } \\
<1 \text { ppm measured }\end{array}$ \\
\hline zinc & 5 ppm max & 2 ppm max & $\begin{array}{l}5 \text { ppm max } \\
<1 \text { ppm measured }\end{array}$ \\
\hline chromium & 10 ppm max & $\begin{array}{l}1 \text { ppm max } \\
<1 \text { ppm typical }\end{array}$ & $\begin{array}{l}10 \text { ppm max } \\
<5 \text { ppm measured }\end{array}$ \\
\hline manganese & 5 ppm max & 2 ppm max & not analyzed \\
\hline cadmium & 1 ppm max & $\begin{array}{l}1 \text { ppm max } \\
<1 \text { ppm typical }\end{array}$ & $\begin{array}{l}1 \text { ppm max } \\
<1 \text { ppm measured }\end{array}$ \\
\hline lead & 5 ppm max & $\begin{array}{l}2 \text { ppm max } \\
1 \text { ppm typical }\end{array}$ & $\begin{array}{l}1 \text { ppm max } \\
<1 \text { ppm measured }\end{array}$ \\
\hline \multicolumn{4}{|c|}{ 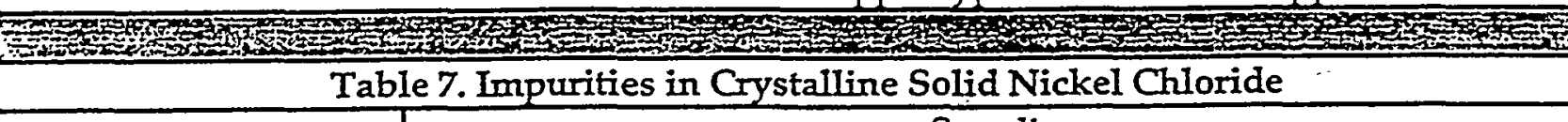 } \\
\hline \multirow{2}{*}{$\begin{array}{l}\text {." } \\
\text { Values taken from } \\
\text { specification sheets } \\
\text { in Attachment B }\end{array}$} & \multicolumn{3}{|c|}{$\begin{array}{c}\text { Suppliers } \\
\text { Van Waters \& Rogers }\end{array}$} \\
\hline & \multicolumn{3}{|c|}{ Manufacturers } \\
\hline $\begin{array}{l}\text { cobalt } \\
\text { iron } \\
\text { copper } \\
\text { zinc } \\
\text { chromium } \\
\text { manganese } \\
\text { cadmium } \\
\text { lead }\end{array}$ & $\begin{array}{l}200 \text { ppm max } \\
100 \text { ppm max } \\
20 \text { ppm max } \\
20 \text { ppm max } \\
\text { not specified } \\
\text { not specified } \\
50 \text { ppm max } \\
20 \text { ppm max }\end{array}$ & $\begin{array}{l}200 \text { ppm max } \\
100 \text { ppm max } \\
20 \text { ppm max } \\
20 \text { ppm max } \\
\text { not specified } \\
\text { not specified } \\
50 \text { ppm max } \\
20 \text { ppm max }\end{array}$ & $\begin{array}{l}200 \text { ppm typical } \\
100 \text { ppm typical } \\
20 \text { ppm typical } \\
20 \text { ppm typical } \\
\text { not specified } \\
\text { not specified } \\
\text { not specified } \\
20 \text { ppm typical. }\end{array}$ \\
\hline
\end{tabular}




\section{ATTACHMENT A}

\section{Calculation of Weights/Volumes of Watts Solution Components}


Recommended concentrations. for Watts solution taken from Table I (boldfaced) and... given below.

(1) $\frac{\mathrm{roz}(\mathrm{av})}{\mathrm{gal}} \mathrm{NiSO}_{4} \cdot 6 \mathrm{H}_{2} \mathrm{O}$

(2) $80 z(a v) ~ N i \mathrm{Cl}_{2} \cdot 6 \mathrm{H}_{2} \mathrm{O}$

gal

(3) $\frac{6 \text { ez far) }}{\text { gal }} \mathrm{H}_{3} \mathrm{BO}_{3}$

Basis $=1500$ gals. total makeup Watts. solution

Calculations to obtain weights (l obs) of each chemical component needed to achieve the recommended concentrations:

(1) MiSO $6 \mathrm{H}_{2} \mathrm{O}: \frac{40 \mathrm{oz}}{\mathrm{gl}}=$ recommended conc.

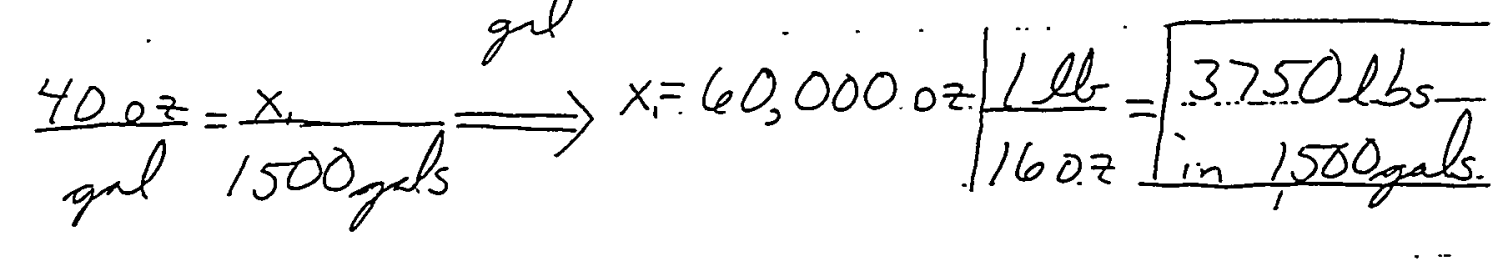

(2) $\mathrm{NiCl}_{2} \cdot \mathrm{CH}_{2} \mathrm{O}: \frac{8 \mathrm{oz}}{\mathrm{gal}}=$ recommended conc.

$$
\frac{8 \text { oz }}{\text { gal }}=\frac{x_{2}}{1500 \mathrm{gab}} \Rightarrow x_{2}=12,000.0 z \mid \frac{1 \mathrm{lb}}{160 z}=\left[\begin{array}{c}
750 \mathrm{lbs} \\
\text { in } 1500 \\
\mathrm{gals}
\end{array}\right]
$$

Page 9 
(3) $\mathrm{H}_{3} \mathrm{BO}_{3}: \frac{6 \mathrm{Oz}}{\mathrm{gal}}=$ recommended conc. 
Calculations to obtain the volumes Coal concentrated liquid nickel salt solution. to be purchased:

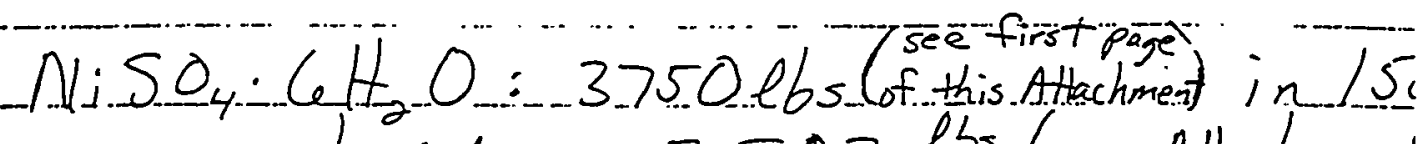
purchased conc $=5.03 \mathrm{lb}$ ) (see Attachment

i

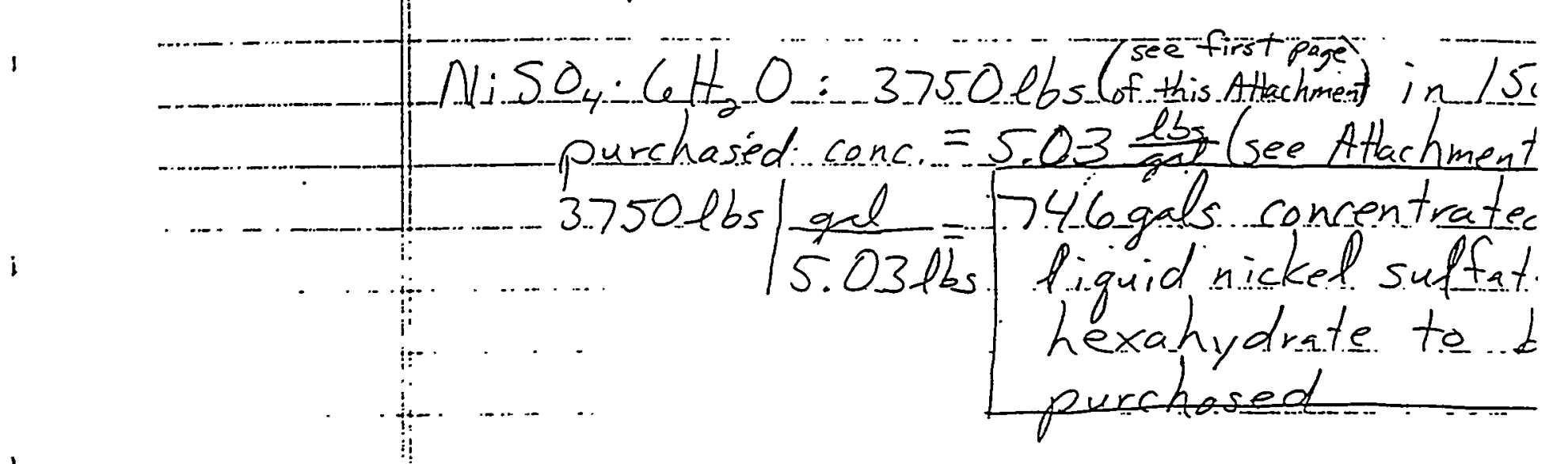

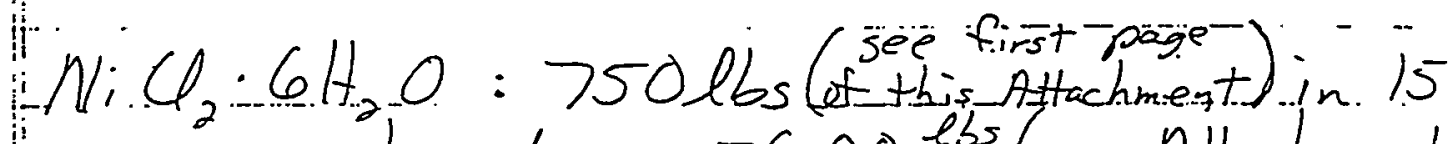
purchased conc. $=6.00 \frac{\mathrm{ebs}}{\mathrm{gl}}$. see Attachment 750 lbs $\mid \frac{\text { gal }}{6.00 \mathrm{lbs}}=125 \mathrm{gals}$ concentrates hexad rate to ib 


\section{Dremco, Inc}

Specialized Products for Electrowinaing

1550 E Missouri Ave, Ste 302, Pboenix AZ 85014

Tet. 602-234-8908, Fax 602-234-8909

\section{Fax Transmission}

Date: $\quad 1 / 6 / 98 \quad 1: 30 \mathrm{PM}$

To: $\quad$ Mr Steve Sarten

Manufacturing.Science

Phone: 423-481-0455

Fax: $\quad 423-481-3142$

Pages:___

Dear Steve

Subject: Supply of Watts Nickel Bath Chemicals

The Watts Nickel bath is comprised of three principal components,

\begin{tabular}{lll} 
component & conc. range & $\frac{\text { ideal conc }}{40 \mathrm{oz} / \mathrm{gal}=300 \mathrm{~g} / \mathrm{l}}$ \\
\cline { 2 - 2 } & $32-42 \mathrm{oz} / \mathrm{gal}$ & $8 \mathrm{oz} / \mathrm{gal}=60 \mathrm{~g} / \mathrm{l}$ \\
NiCL2 & $6-12 \mathrm{oz} / \mathrm{gal}$ & $6 \mathrm{oz} / \mathrm{gal}=45 \mathrm{~g} / \mathrm{l}$
\end{tabular}

For your 1500 gal batch, you could purchase these components in liquid form, as follows:

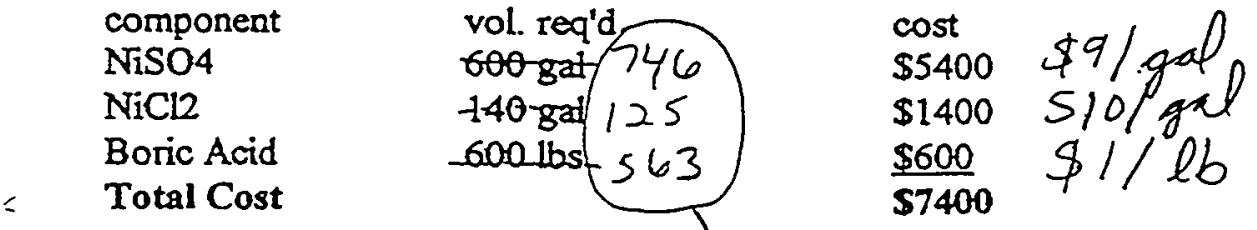

The solutions are available in drums, fob Nashville.

Sincerely,

Dr. Douglas J. Robinson

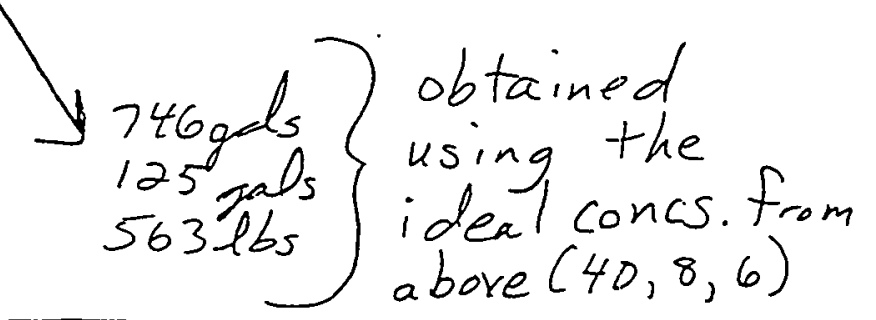

I0.d $\angle 00^{\circ}$ ON $80: \varepsilon T \quad 86,90 \mathrm{NHL}$

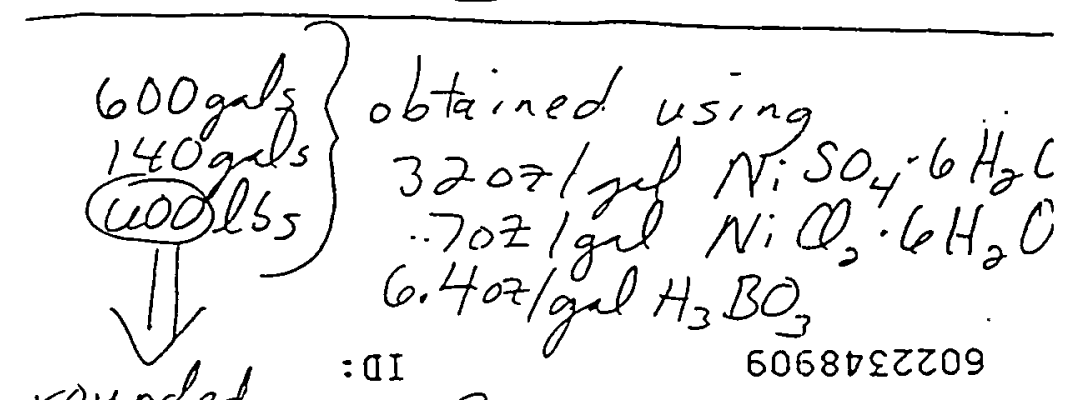

page 12 up from 563 ? 


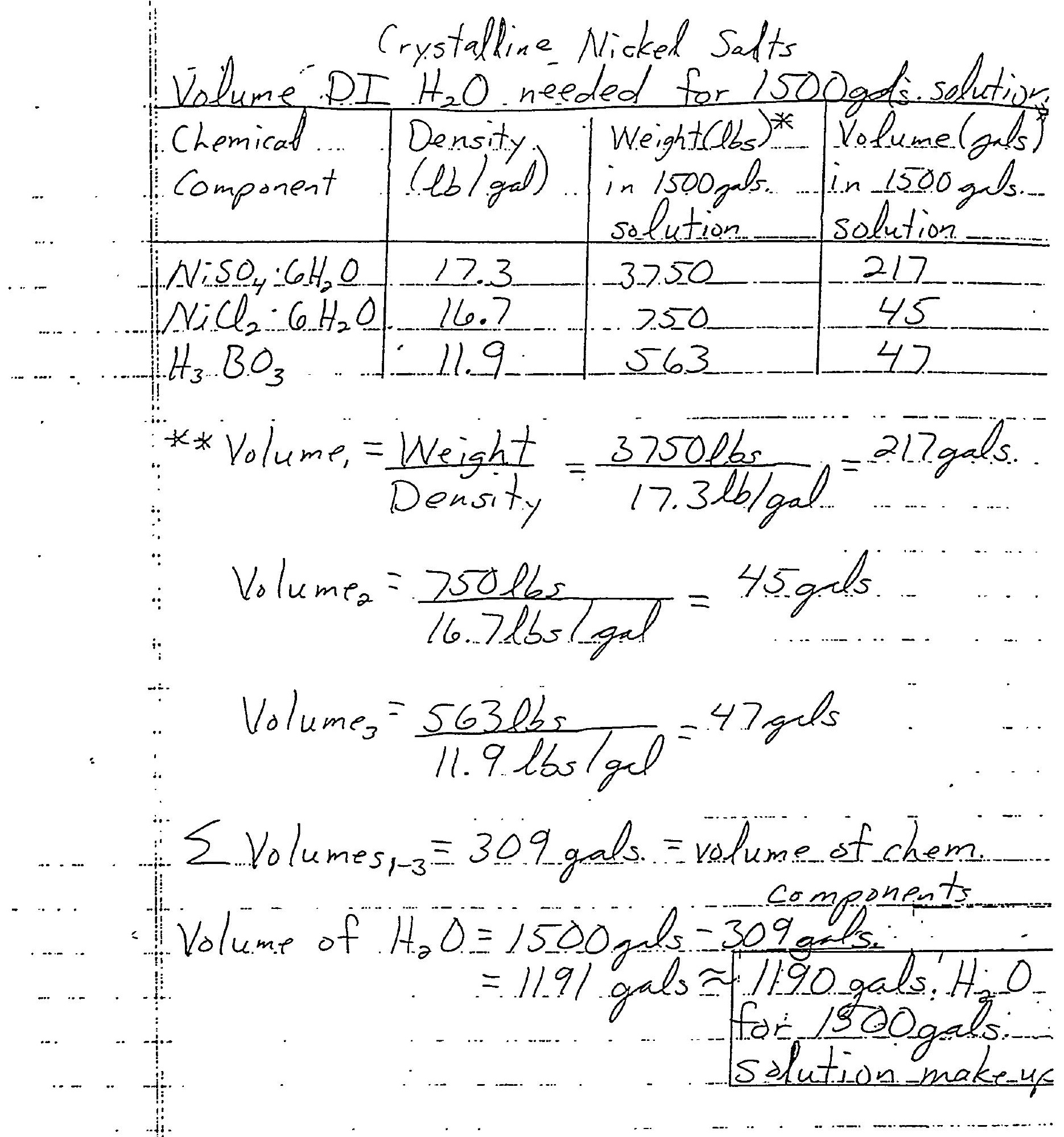

* See lost 2 pages of this attachment. page 13 
Concentrated Liquid Nickel salts Volume. DI Ha needed for 1500 gals. Solution

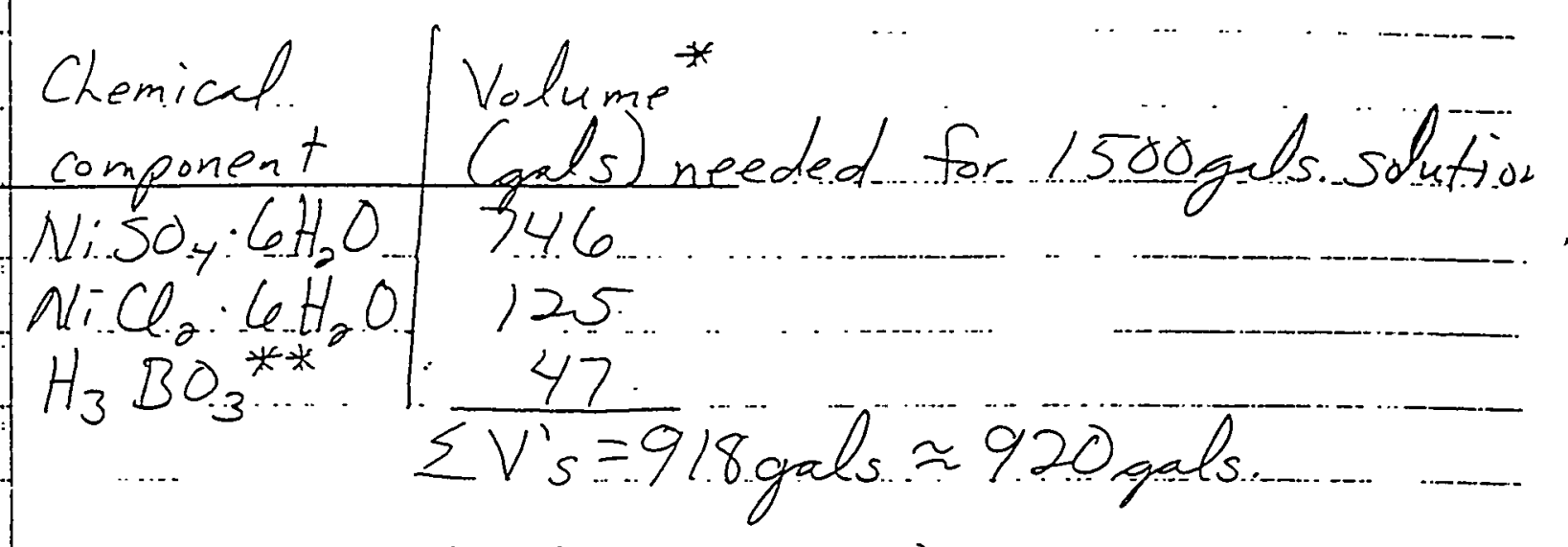

$$
\begin{aligned}
& \mathrm{H}_{2} \mathrm{O} \text { needed }=(1500-920)_{\mathrm{guls}} \text {. } \\
& =580 \text { gals. DI Ha O } \\
& \text { needed for } 150 \text { opals. } \\
& \text { solution makeup }
\end{aligned}
$$

* See Brad page of this attachment * Occupied volume of $\mathrm{H}_{3} \mathrm{BO}_{3}$. See 5 th page of this attachment.

page 14 


\section{ATTACHMENT B \\ Price Quotes and Specification Sheets}




\section{Dremco, Inc \\ Spocialized Products for Eloctropinining 1550 E Missouri Ave, Ste 302, Pboenix AZ 85014 \\ Td. 602-234-8908, Fax 602-234-8909 \\ Fax Transmission}

$\begin{array}{lll}\text { Date: } & 1 / 6 / 98 & 1: 30 \mathrm{PM}\end{array}$

To: $\quad$ Mr Steve Sarsen

Manufacturing Science

Fax: $-423-481-3142$

Pages: 1

Dear Steve

Subject: Supply of Watts Nickel Bath Chemicals

The Watts Nickel bath is comprised of three principal components,

$\begin{array}{lll}\text { component } & \text { conc range } & \text { ideal conc } \\ \text { NiSO4 } & 32-42 \mathrm{oz} / \mathrm{gal} & 40 \mathrm{oz} / \mathrm{gal} \\ \mathrm{NiCl} & 6-12 \mathrm{oz} / \mathrm{gal} & 8 \mathrm{oz} / \mathrm{gal} \\ \text { Boric Acid } & 6-7 \mathrm{oz} / \mathrm{gal} & 6 \mathrm{oz} / \mathrm{gal}\end{array}$

For your 1500 gal batch, you could purchase these components in liquid form, as follows:

$\begin{array}{lll}\text { component } & \text { vol. req'd } & \text { cost } \\ \text { NiSO4 } & 600 \mathrm{gal} & \$ 5400 \\ \mathrm{NiCl} & 140 \mathrm{gal} & \$ 1400 \\ \text { Boric Acid } & 600 \mathrm{Ibs} & \$ 600 \\ \text { Total Cost } & & \$ 7400\end{array}$

The solutions are available in drums, fob Nashville.

Sincerely,

Dr. Douglas J. Robinson 


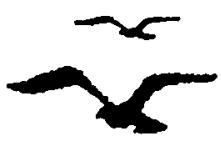

$$
\begin{array}{r}
\text { Dremco Inc. } \\
\text { Specialized Products for Electrowinning and Electrorefining } \\
17020 \mathrm{~N} .32 \text { nd Street, Phoenix Az, } 85032 \\
\text { Tel } 602-787-8105, \text { Fax 602-787-8106 } \\
\text { Email: dremco@syspac.com } \\
\text { Dr. Douglas J Robinson, President }
\end{array}
$$

Fax Transmission From: *602-234-8909* No. of pagcs on this fax $=$ January 22, $1998 \quad 4: 58 p$

Libbie Terry

FAX: $423-481-3142$

Dear Libbic,

\section{* Re: Spec Sheets*}

Plcusc find attatched the spoc sheets that you requested on Boric Acid, Nickel Sulfate and Nickcl Chloridc.

Sincercly,

$$
\text { Dr. Douglas J Robinson }
$$




\section{Manufacturing Specificatlon for \\ LIQUID NICKEL SULFATE}

v

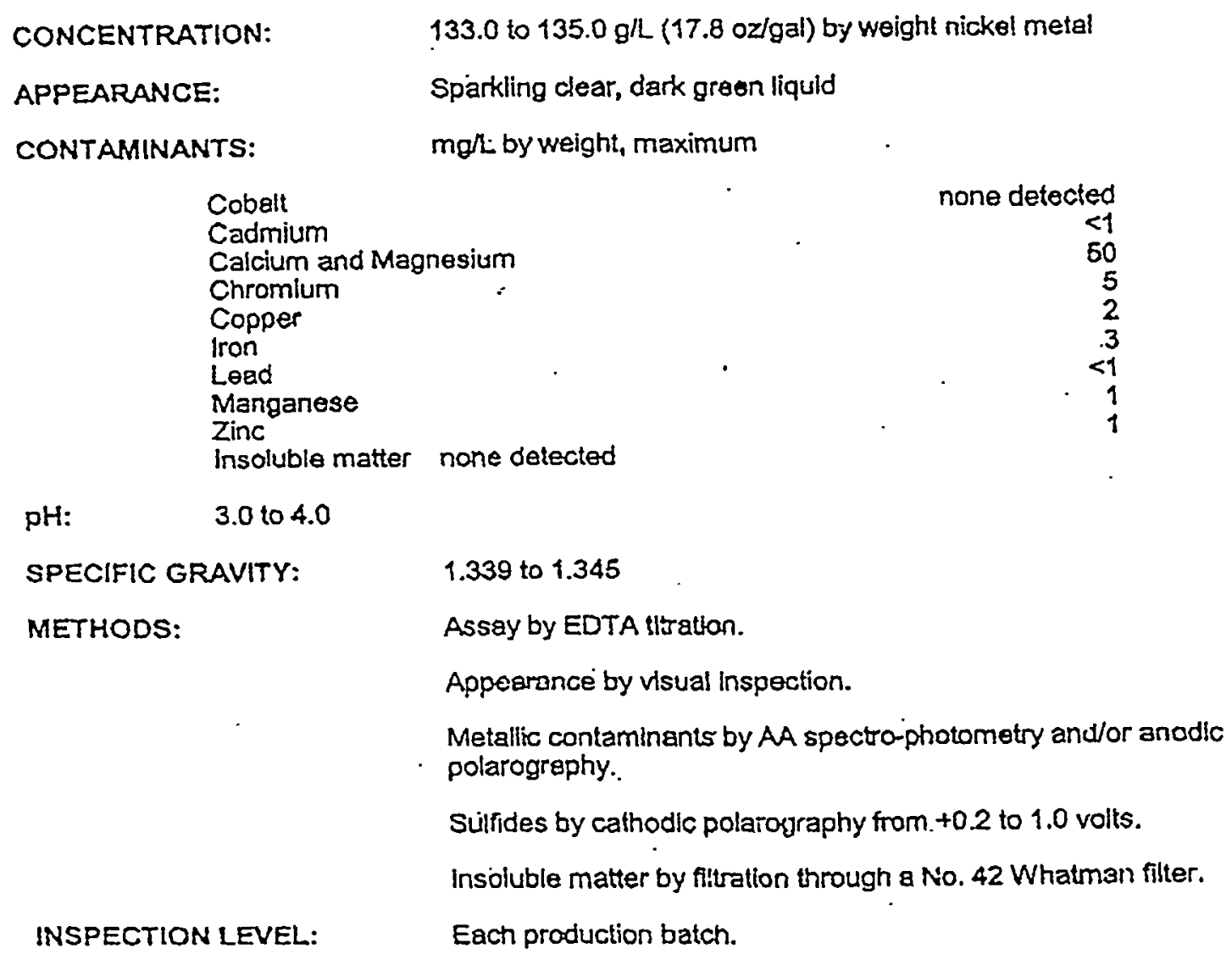




\section{Manufacturing Spectication for \\ LIQUID NICKEL CHLORIDE}

CONCENTRATION:

APPEARANCE:

CONTAMINANTS:

$\begin{array}{ll}\text { Arsenic } & 5 \\ \text { Calcium } & 60 \\ \text { Cobalt } & 120 \\ \text { Iron } & 10 \\ \text { Magnesium } & 20 \\ \text { Tin } & 5 \\ \text { Zinc } & 1\end{array}$

$178 \div 18.1 \mathrm{~g} / \mathrm{L}$ (23.5ozjoal min) by weight nickel meial.

$13.3 \%$ minimum as Nickel+Cobalt $(\mathrm{NH}+\mathrm{CO})$

$6 \mathrm{lbs} / \mathrm{gal}$ as $\mathrm{NiCl}_{2} \cdot 6 \mathrm{H}_{2} \mathrm{O}$

Sparkling cloar, dark green liquid.

mg/ by welght, maximum

$\begin{array}{lll}5 & \text { Cadnium } & 1 \\ 60 & \text { Chromium } & 10 \\ 120 & \text { Cooper } & 1 \\ 10 & \text { Lead } & 1 \\ 20 & \text { Nitrates } & <10 \\ 5 & \text { Vanadlum } & 5 \\ 1 & \text { Insolubles } & \text { non detected }\end{array}$

$2.0-3.0$

pH:

\% FREE ACID: $\quad<1.0$.

SPECIFIC GRAVITY: $\quad 1: 330-1.350$.

METHODS: Assay by EDTA titration

Appearance by visual inspection

Metallic contaminants by Fiame AAS and/or anodic polarography Insoisbles by nitration through a No. 42 Whatman filter.

INSPECTION LEVEL: Each production batch 


\section{Purchasing Specification for $56 \%$ Boric Acid}

Item/Property

$\mathrm{B}_{2} \mathrm{O}_{3} \%$

Equivalent $\mathrm{H}_{3} \mathrm{BO}_{3}, \%$

$\mathrm{SO}_{4}$

Cl, ppm

Iron, ppm
Product Specification

$56.3-56.8$

99.9-100.9

$<=450$

$\Leftrightarrow 18$

$<=6$

A CERTIFICATE OF ANALYSIS MUST ACCOMPANY EACH SHIPMENT. 
- Japm14-98 02:24P Gum Chemical Co NC

$17048669006 \quad P .01$

FREDERICK FUM CHEMICAL CO., INC 2098 CHESPARK DRIVE

GASTONIA, NORTH CAROLINA 28052

(704) 865-2800 OUTSIDE N.C. 1-800-541-7878

FAX \#: (704) 866-9006

FACSIMILE TRANSMISSION COYER SHEET

DATE: $\quad 1-14-68$

ATTENTION:

berry

COMPANY:

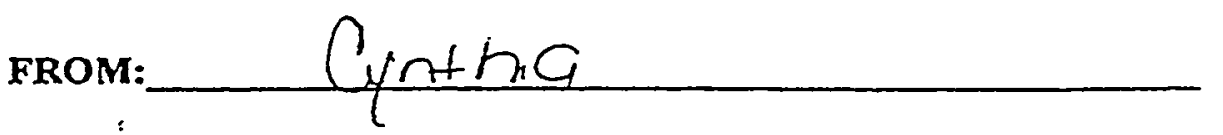

TOTAL\# OF PAGES: $\quad 6 \quad$ (including cover sheet)

REMARKS:

page 21 


\section{columm}

January 14, 1998

MANUFACTURING SCIENTIST

Attn: Libby Terry

RE: Pricing for nickel sulfate and chloride

Dear Libby,

Per our comersation the pricing we discuss is as follows:

NICKEI SULFATE IIQUID.............55gal $\mathrm{dr} \ldots \ldots \ldots \ldots \ldots \ldots \ldots .76 .72 / \mathrm{gal}$

NICKEL SULFATE CRYSTAL............55Ib bag............\$1.33/Ib

NICKEL CHLORIDE LIQUID.............55gal dr............\$8.35/gal

NICKEI CHLORIDE CRYSTAL...........441b bag............. \$1.71/Ib

*Also accompanying this quotation are the specification sheets for each item quoted.

If you should have any further questions, please give me a call at 1-800-541-7878.

Regards,

FREDERICK GUMM CHEMICAL $\infty$.

Cunthia: Cootner

Cyfithia costner

Computer Operator

$\propto / s$

$\therefore$ NOTE THE PRICE OF NICKEI CHANGES DAILY- PRICE OUID INCREASE OR DECREASE :

FREDERICK GUMM CHEMICAL COMPANY. INC.

538 Forest Street. Kearny. New Jersey $07032 \cdot 1.201 .991 .4171$

Fax: 201-991-5855

$$
\text { page } 22
$$




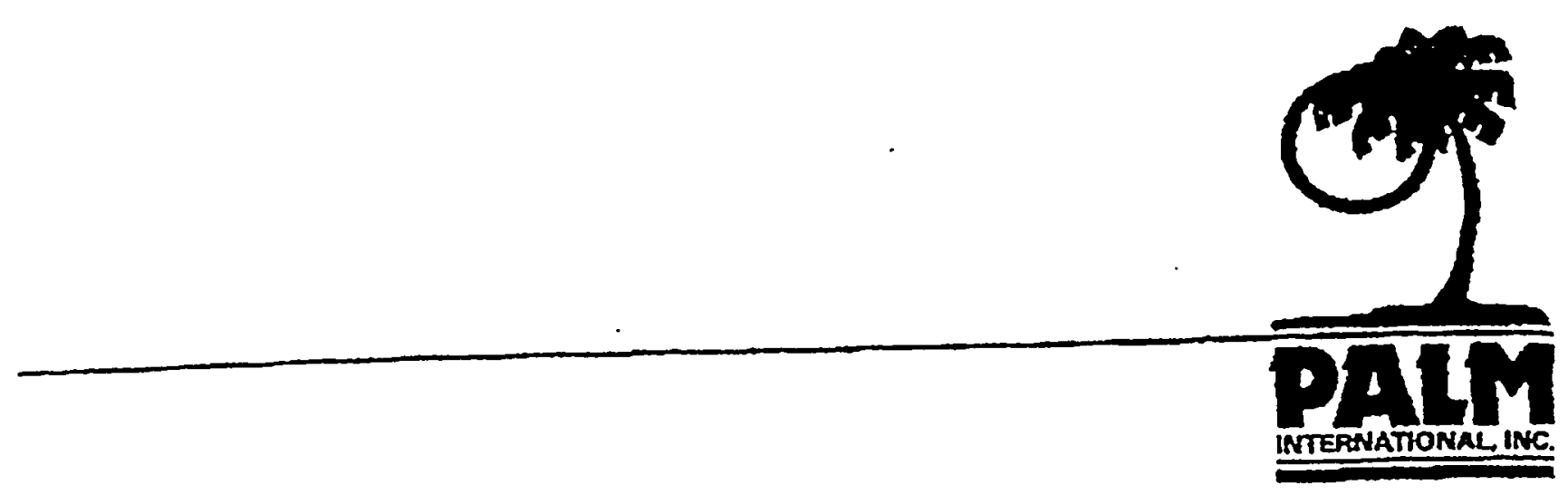

\begin{tabular}{|l|l|}
\hline PALM INTERNATIONAL. IAC. & MANUFACTURING \\
\hline SPECIFICATION\#.PMS-1 & ISSUE DATE: 12-1.9 \\
\hline APPROVED BY: & REVISION DATE:07 \\
\hline TITLE: & REVSON\#.5 \\
Manufacturing Specification for & LIQUID NICKEL SULFATE
\end{tabular}

CONCENTRATION:

APPEARANCE:

CONTAMINANTS:

\section{Cobah}

Cadmium

Calcium and Mapresium

Chrorium

Copper

Iron

Lead

Manganese

Zinc

insoluble matter none detected.

pH: $\quad 3.0$ to 4.0

SPECIFIC GRAVTY:

METHODS:

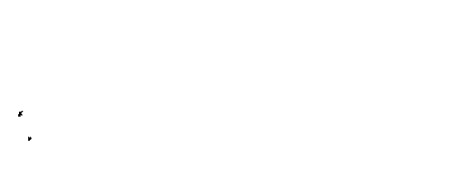

INSPECTION LEVEL: Each production batch.

1.339201 .345 poleragraptry. none detected

$<1$
50
5
2
3
$<1$
1
1

Assay by EDTA titration.

Appearance by visual inspoction.

Matilic contaminants by AA spectro-phodometry andior anodlc

Sutfides by cathodic polarography from t0.2 to 1.0 volts.

insoluble mattor by filtration through a No. 42 Whatman fiter.

Each production betch.

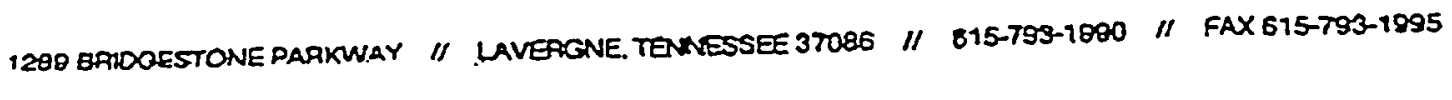

$$
\text { page } 23
$$




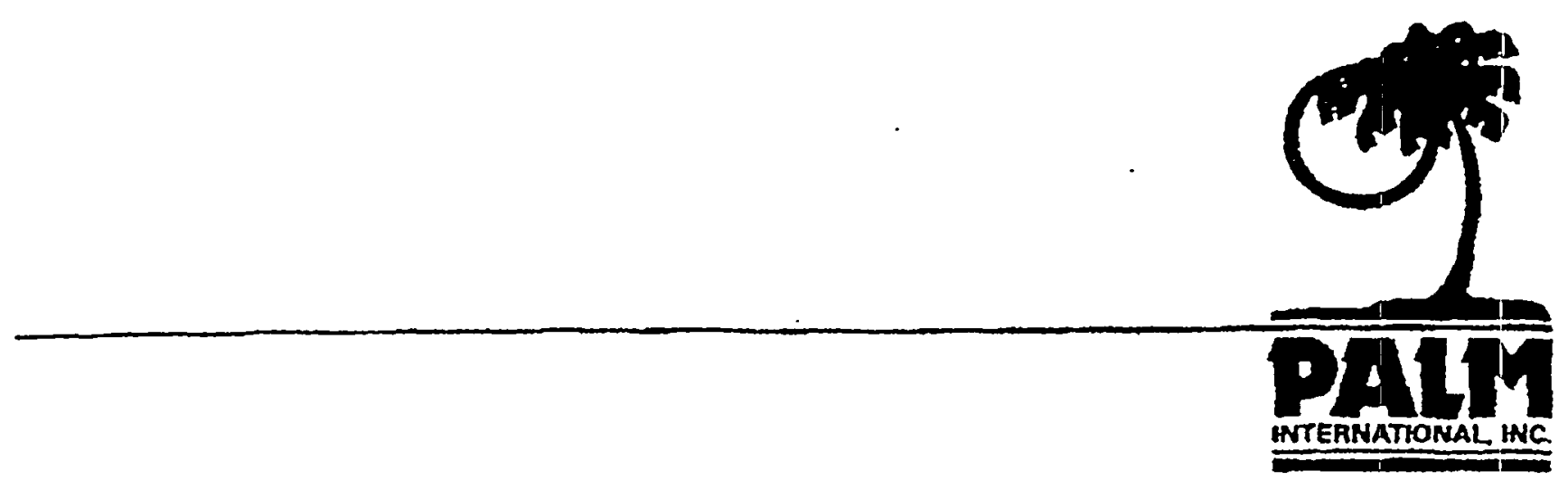

\begin{tabular}{|l|l|}
\hline PALM INTERNATIONAL, InC. & MANUFACTURING SPECIFICATION \\
\hline SPECIFICTATION \#: PMS-4 & ISSUE DATE: 07-19-94 \\
\hline APPROVED BY: & REVISION DATE: 07-21-97 \\
\hline TTLE: & REVISION \#: 3 \\
\hline
\end{tabular}

Manufacturing Spocification for

\section{LIQUID NICKEL CHLORIDE}

CONCENTRATION:

APPEARANCE:

CONTAMHANANTS:

$\begin{array}{ll}\text { Arsenic } & 5 \\ \text { Calcium } & 60 \\ \text { Cobalt } & 120 \\ \text { Iron } & 10 \\ \text { Magnesium } & 20 \\ \text { Tin } & 5 \\ \text { Zinc } & 1\end{array}$

pH:

\% FREE ACID:

SPECIFC GRAVTY:
$178-181 \mathrm{ght}$ (23.5aztod min) by waight nicket matal

$13.3 \%$ minimum as $\mathrm{Nickol}+\mathrm{Cobalt}(\mathrm{Ni}+\mathrm{CO})$

$6 \mathrm{Ha} / \mathrm{gai}=\mathrm{NiCl}_{2}-6 \mathrm{H}_{2} \mathrm{O}$

Sparkling ctoar, dark green liquid.

mgl by welght maximum

$2.0-3.0$
1

10

1

1

$<10$

5

non delectod

METHOOS: Assay by EDTA titration

Appearanco by viruas inspection

Metalfic contaminants by Flame AAS and/or anodle polarograptry insolubles by fitration through a No. 42 Whatmen nitar.

INSPECTION LEVEL: Each production bateh

$$
\text { page } 24
$$




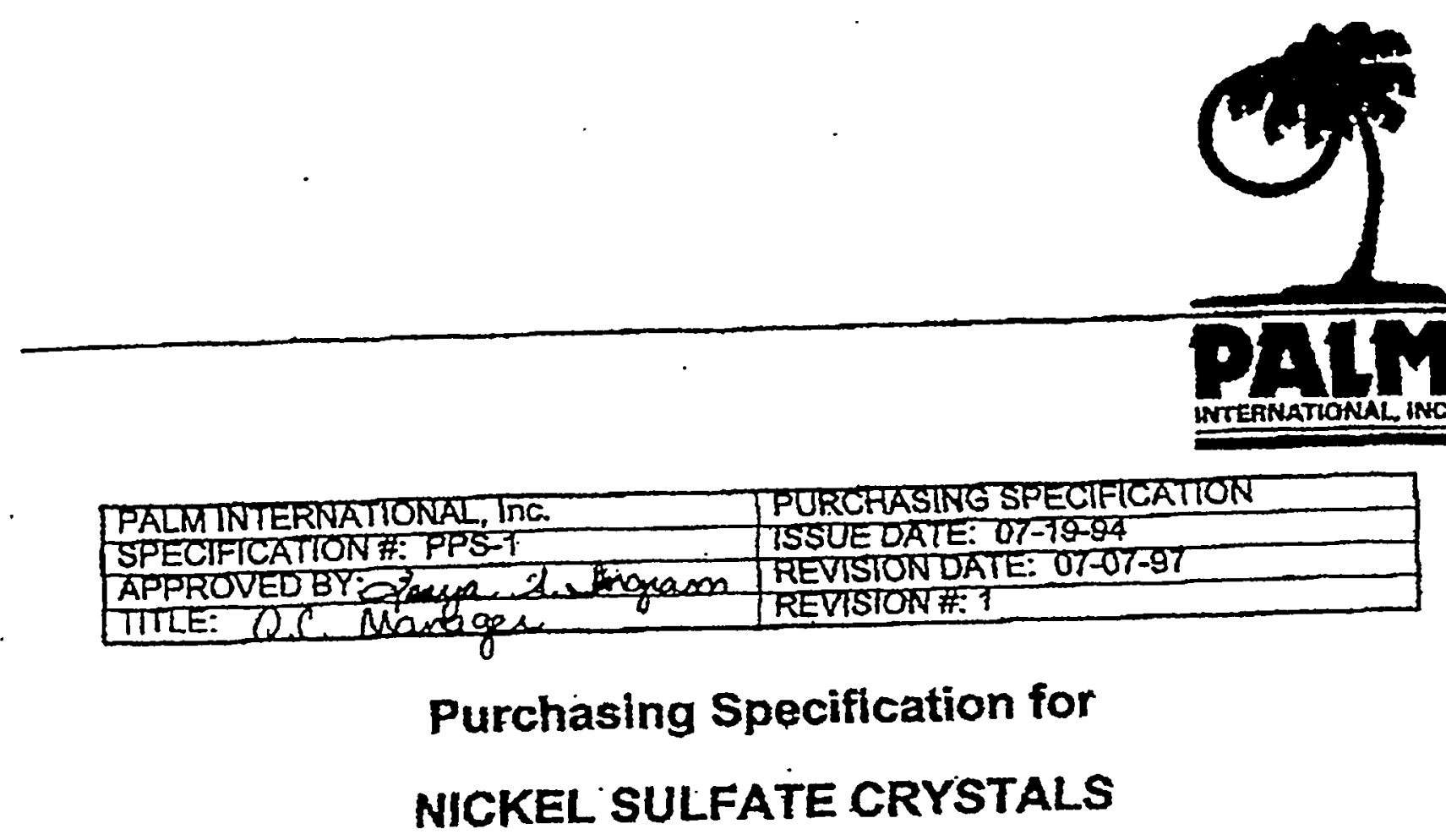

Item/Property

$\% \mathrm{Ni}$

$\%$ Insoluble

ppm Co

ppm Fe

ppm $\mathrm{Cu}$

ppm Zn

ppm Ca

ppm Mg

ppm Mn

ppm Na

ppm Cl

ppm $\mathrm{Cr}$

ppm Al,

ppm Cd

$\mathrm{ppm} \mathrm{Pb}$

\section{Product Specification}
$22.0 \mathrm{~min}$
$0.015 \max$
150 max
10 max
$5 \max$
5 max
10 max
50 max
5 max
$20 \max$
5 max
10 max
25 max
1 max
5 max

CERTIFICATE OF ANALYSIS MUST ACCOMPANY EACH SHIPMENT.

IVERIFY ALL MATERIALS SUPPLIED BY

WILL MEET PALM'S PURCHASING SPECIFICATTON.

NAME:

TITLE:

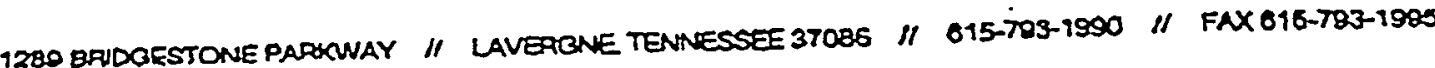

$$
\text { page } 25
$$


17048669006 PALM INTERNATIONAL
P. .94

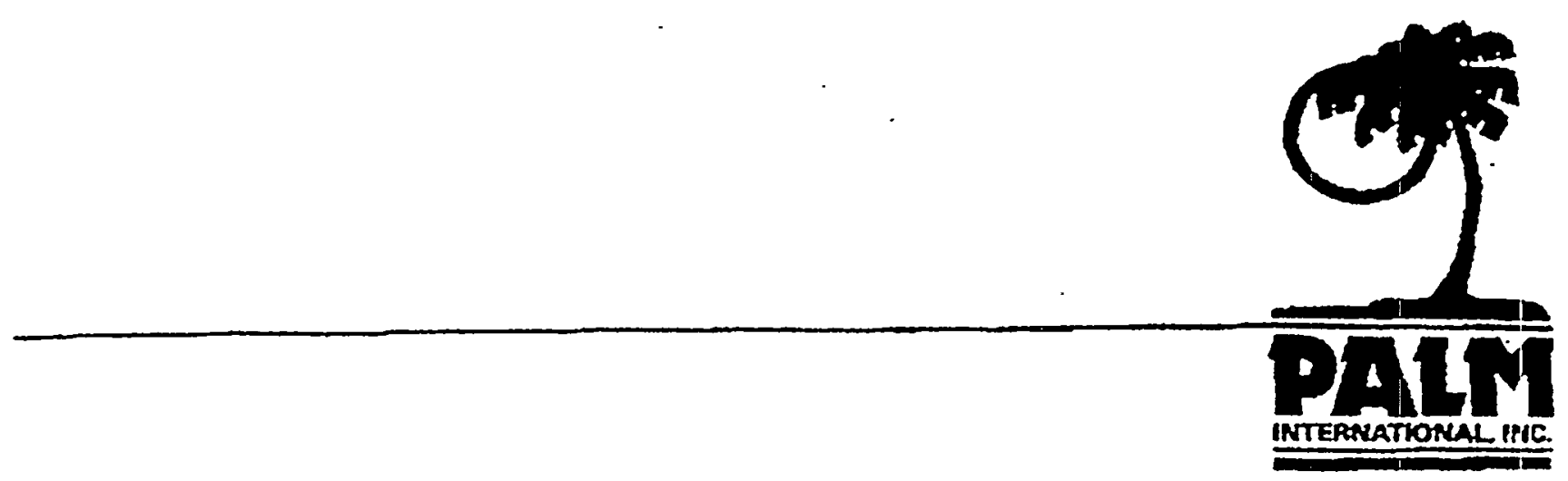

\begin{tabular}{|c|c|}
\hline PALMINTERTARTIONAL, InC. & PURCHASING SPECIFICATTON \\
\hline SPECIFTCATION F. PPS-2 & TSSUE DATE: 07-30-92 \\
\hline APPROVED BY: QRQSWLL & REVISTONDATE: /T-T7-9T \\
\hline TITIE: $Q C$ Manabes & REVISTON\#. 4 \\
\hline
\end{tabular}

\section{Purchasing Specification for}

\section{NICKEL CHLORIDE CRYSTAL}

FORMULA: $\quad \mathrm{NiCl}_{2} \cdot 6 \mathrm{H}_{2} \mathrm{O}$

ASSAY: $\quad 24.0$ to 25.5 percent by weight as nickel

\section{maximum allowable contaminaNTS:}

Cadmium
Calchum
Cobalt
Copper
Iron
Lead
Zine
Insoluble matter

$0.0050 \%$

$0.0050 \%$

$0.0200 \%$

$0.0020 \%$

$0.0100 \%$

$0.0020 \%$

$0.0020 \%$

less than $0.05 \%$

CERTIFICATE OF ANALYSIS MUST ACCOMPANY EACH SHIPMENT.

I VERIFY ALL MATERIALS SUPPLIED BY MEET PALM'S PURCHASING SPECIFICA TION.

WILL

NAME:

TTLE:

1280 BRDGESTONE PARMWAY /" LAVERGNE TENNESSEE 37085 / 6 615-793-1990 || FAX 615-703-1995

$$
\text { page } 26
$$




\section{FAST FAX}

l'acsinile Trunsmitlal Cover Shect

\section{JiROM: \\ SOUTHEASTERN CHEMICAL, INC. 1512-A Sholar Avenue \\ $\therefore \quad$ Chattanooga, TN 37406}

liax: $423-698-5152$

1'12: $\quad 123-622-5154$

To Manufacturing sciences Dale $1 / 14 / 98$

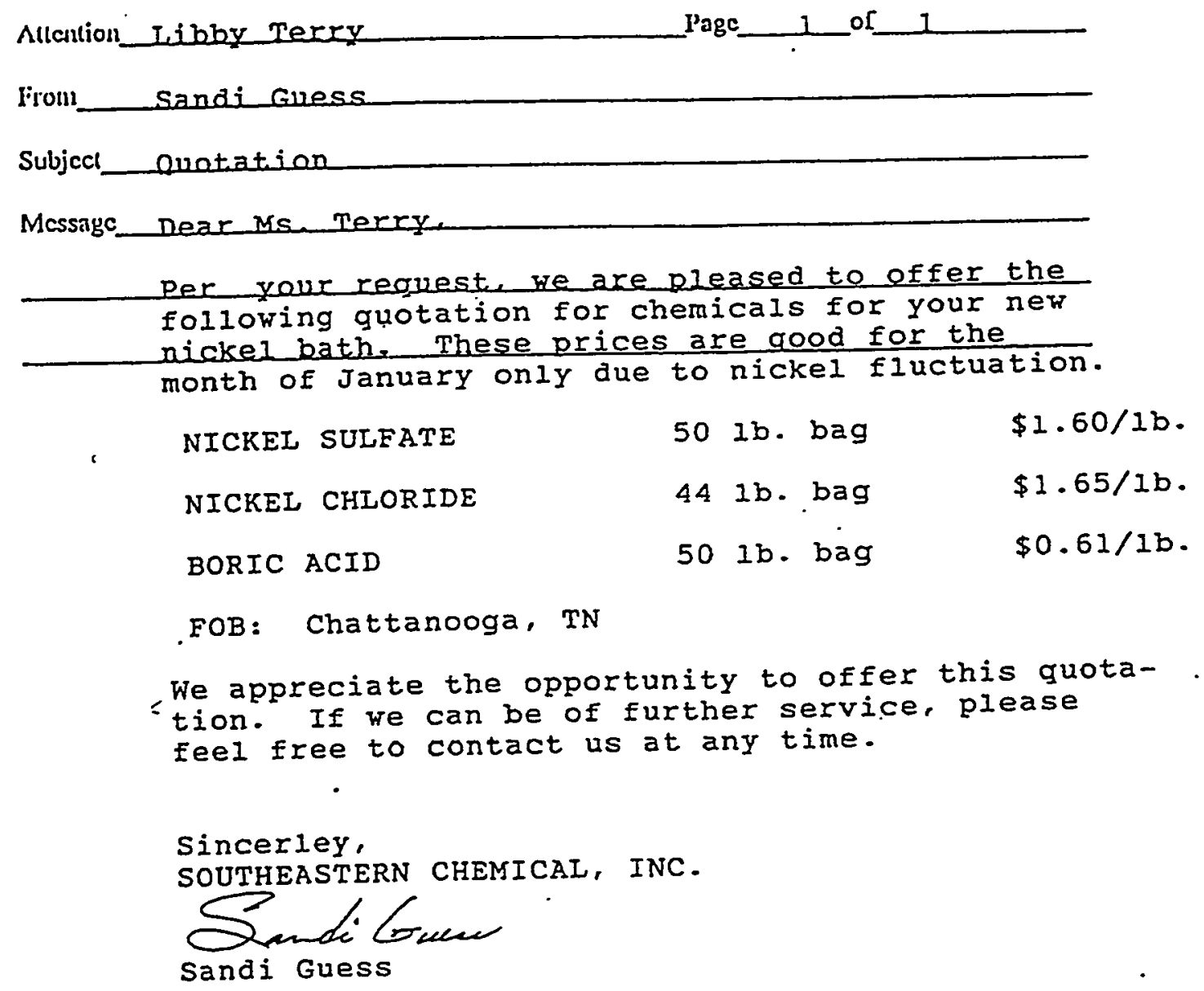




\section{FAST FAX}

l'acsinile Trumsmittal Cover Shed

liROM:

SOUTHEASTERN CHEMICAL, INC.

1512-A Sholar Avenue

Chattanooga, TN 37406

lax: 423-698-5152

1'll: $\{23-622-5154$

To Manmfacturing Sciences

Dalc $2 / 26 / 98$

Allention

Libby Terry

l'agc 1 of 1

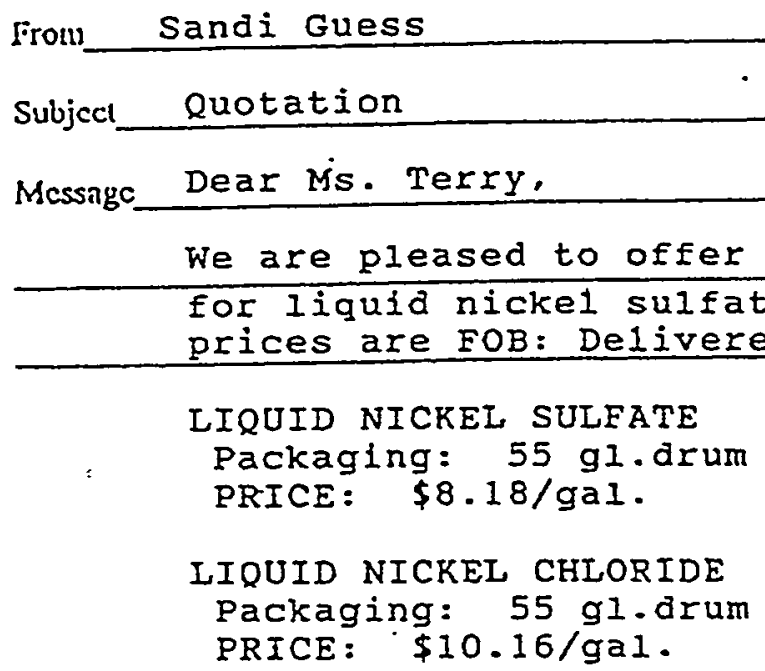

We hope you rill find the above of interest. If we can be of further service, please feel free to contact us at any time.

Sincerely, SOUTHEASTERN CHEMICAL, INC.

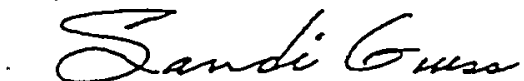

Sandi Guess

$$
\text { page } 28
$$


FAST FAX

Facsimile Transmittal Cover Sheet

FROM:

Southeastern Chemical, Inc.

1512 - A Solar Avenue

Chattanooga, TN 37406

To

1. Attention LIBBY TERAY

From

Subject Sand Guess

Fax: 423-698-5152

Ph: 423-622-5154

Date $2 / 20 / 98$

Page

1 of 5

Typical Analysis Ni Sulfate i Ni Chloride

Message

$\varepsilon$

page 29 


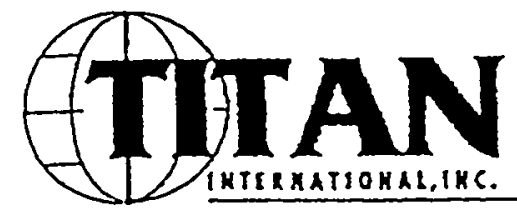

\title{
Liquid Nickel Sulfate
}

\author{
Electroless Grade
}

-

Certificate of Analysis

Lot No: $\quad$ 8000IS

Nickel, $\quad$ g/L

$\mathrm{pH}$,

Specific Gravity,

Cadmium, $\mathrm{mg} / \mathrm{L}$

Calcium,

$\mathrm{mg} / \mathrm{L}$

Chromium,

Cobalt,

Copper,

Iron,

Lead,

Magnesium,

$\dot{Z}$ inc.

In $g / L$

$\mathrm{m} g / \mathrm{L}$

$\mathrm{mg} / \mathrm{L}$

$\mathrm{mg} / \mathrm{L}$

$\mathrm{mg} / \mathrm{L}$

$\mathrm{mg} / \mathrm{L}$

$\mathrm{mg} / \mathrm{L}$

Insoluble matter,
133.31

3.03

1.345

0.2

12.9

1.4

ND

0.4

0.9

ND

2.7

$\mathrm{ND}$

ND

January 20, 1998

205 Chester Avenue. Suite 100 Moorestown. New Jersey 08057 609-786-1147 Fax: 009.786-3978

page 30 
$\because$ PER-20-98 FRI 8:42 AM SOUTEEASTERN CBEMICAL IN FAX NO. 4236985152

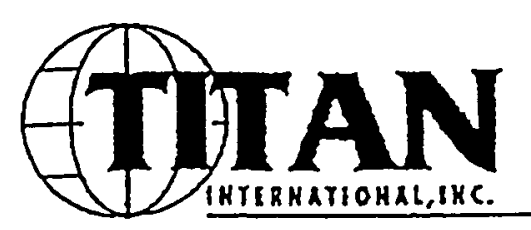

\section{Liquid Nickel Chloride \\ Certificate of Analysis}

Lot No: 8011LC .

Nickel, $\quad \mathrm{g} / \mathrm{L} \quad$ :

179.38

Nickel, $\%$ by wt.

13.4729

Specific Gravity

1.345

$\mathrm{pH}$

Iron,

ppm

0.1

Copper,

ppm

ND

Zinc,

ppm

0.1

Chromium, ppm

0.6

Lead,

ppra

0.3

Februaty 18, 1998

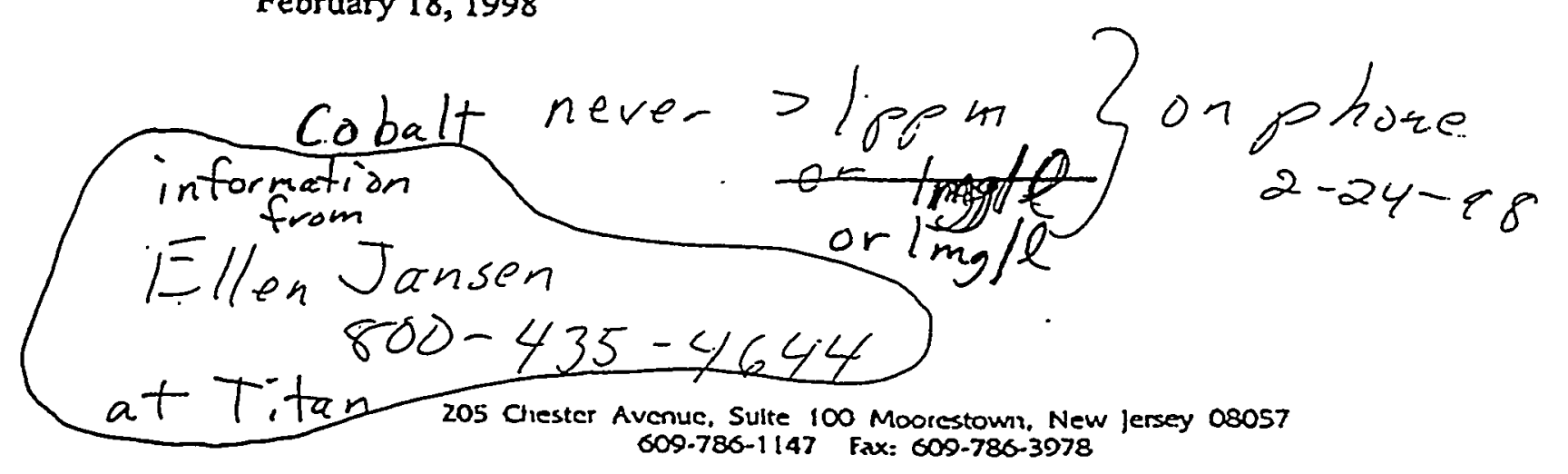

page 31 


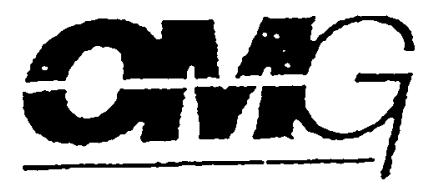

OM GROUP. INC.

Kokkola Chernicals Oy

Mooney Chemicals. Inc.

Vassel fồ iember 11, 1997

PALM COMMODITIES INTERNATIONAT

1289 BRIDGESTONE PARKWAY

IR VERGNE

Attention: RECEIVING - QUALITY CONTROL.

Date shipped : : : : $11-12-97$

Customer P.O. Number.: 133.17

Customer Number. : : 043406

Quantity shipped . : 630 BAGS

Customer Product Code: 2040048

OMG product code.: : 00571 K2

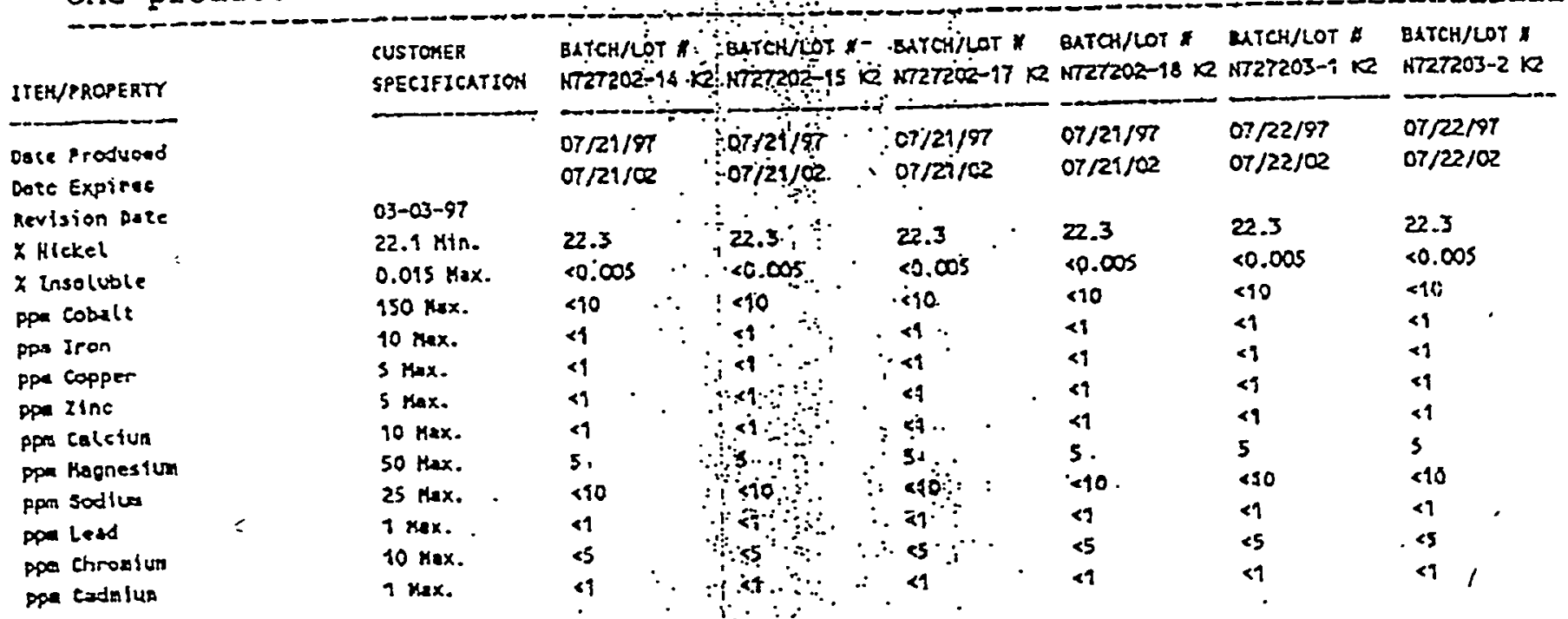

The material designated in this: certificate has beed manufactured in accordance with standard manulacturing procedures and meets all specifications contained. In the "above purchase order.

Manufactured t: omg Koxkola chanjeis: Oy; Kokkola, FlnIand

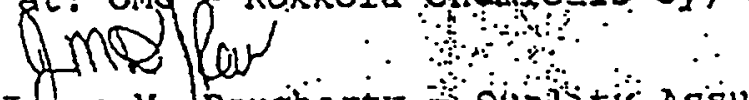

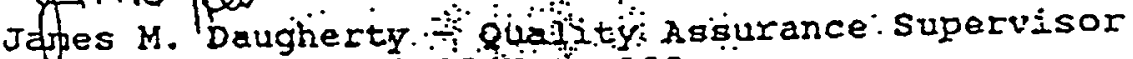

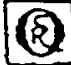

araimatin them oremosing Phone: (814) 432-2125 Ext. .102.

Order Number: 42629<smiles>[As]=[Te]</smiles> \\ , P. P. $30^{3}$}


- FEB-20-98 FRI 8:43 AM SOUTHEASTERN CBEMICAL IN

FAX NO. $\quad 4236985152$

P. 5

Fab-19-98 $16: 42$

sates \& Marketing

$609786 \quad 3978$

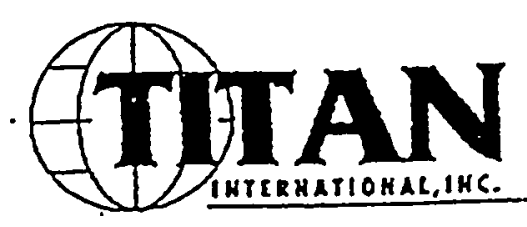

Product: N1ckel Chloride Hexahydrate

$\therefore$ TYRICAL ANAIYSIS

ELEMENT

Nickel

Lead

Zinc

Copper

Iron

cobalt

Insolubies

\section{PERCENTAGES}

24.0
.002
.002
.002
.01
.02
.05

$24.0 \%$

$.002 \%$

$.002 \%$

$.002 ;$

$.01 \div$

$05 \%$

$=$
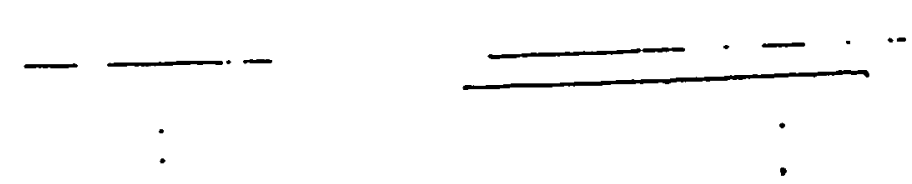

page 33 
Libby Tery

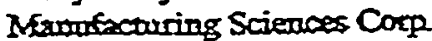

804 Kon Ffollow Rowd

Oak Ridge, IN 37830

Dear Litbs:

Thank you for the opportanity of quote on the following chemicils I hope you will find oar prices to be comptitive and we will be given the chance to provide Manufzcturing Sciences with the same quality service and expatise that our costomess have cane to depend on. If you have any further gaestions or would libe to place an order please contact me.

\begin{tabular}{|c|c|c|}
\hline Product & Packay & Price \\
\hline Nicted Sulfate Spec. 101Granalar & 50 tags & 1.60/1 FOB: Rode IIII) SC \\
\hline Nickel Sulfate Liquid & 55 gro & 8.50/gl FOB: Rock Hail, SC \\
\hline Nicted Chicride Cryorit & $20 \mathrm{knl}$ bg & 3.FOhi FOB: Rock Ejill, SC \\
\hline Nided Chloxide Liquid & 55 gl di & 10.5O/gl FOB: Rock Hill, SC \\
\hline Boric Acid Tech Gren & 50\#年战 & $.81 / \mathrm{mb}$ Delivered \\
\hline
\end{tabular}

Sincerety,

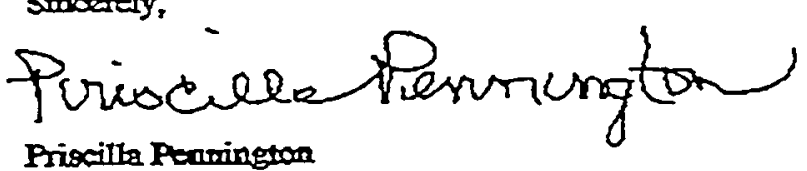

Priscills Ptarington

Szles Representative 
Van Waters E Rogers hic:

subsidiary of Univar
3 FMERTIE LANE CHATTANDOSA TN SO406

PTHONE [615] 698-De31

(800) $233-0531$

$F 4 \times(515) 524-4190$

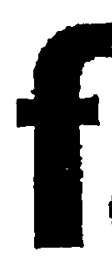

tro:

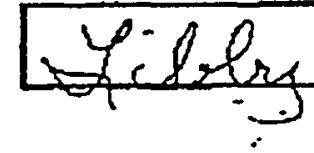

$\operatorname{tax}$

$x$

from: Priscilla Pennington

date: $\quad$ 2/8 198

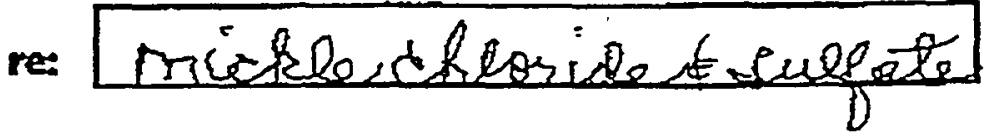

pages: $\quad$ (induding cover shet) 9

\section{HOTES:}

are inst choice

We amicipede end proside the best in cretomarsabed distrbution services. 


\section{Technical Information}

NICKEL SULFATE LIQUID

Aactech Nickel Suttato, LIquild, EN/EG was specifically devaloped to meet the neads of the elactrolass sideol and elecurblytic nickel industry where very fow impurity levals are required. It is produced from high purty origin nickel porndar which guarante日s a high punty and consistent product.

\section{Specifications:}

Specification

\section{$5.0 \mathrm{lb} / \mathrm{ggt}$}

$70.05 \% \mathrm{~min}$

10 ppm max.

2 ppin max.

3 ppm max.

5 ppm max

5 ppm max

$1 \mathrm{ppm}$ max.

1 ppm max

$1 \mathrm{ppm}$ max

1 ppom max

1 ppm max

10 ppm mrax.

$50 \mathrm{ppm}$ max.
Typical

$\begin{aligned} & 5.0 \mathrm{pb} / \mathrm{gal} \\ & 10.25 \% \\ < & 5 \mathrm{ppm} \\ < & 1 \mathrm{ppm} \\ < & 1 \mathrm{ppm} \\ < & 5 \mathrm{ppm} \\ < & 1 \mathrm{ppm} \\ < & 1 \mathrm{ppm} \\ < & 1 \mathrm{ppm} \\ < & 1 \mathrm{ppm} \\ < & 1 \mathrm{ppm} \\ < & 1 \mathrm{ppm} \\ < & 7 \mathrm{ppm} \\ < & 50 \mathrm{ppm}\end{aligned}$

\section{Propentias \& Product Characteriatics}

Clear green liquid
Densiny:
pH:
Approx
11 itrsfgal
Liquiá
$4.0-5.0$

Particudate matter in Electropure oniy: 2 mierons

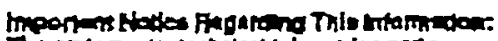

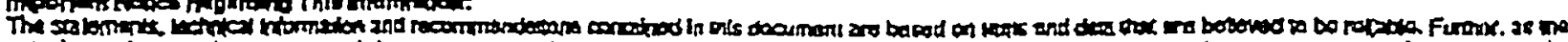

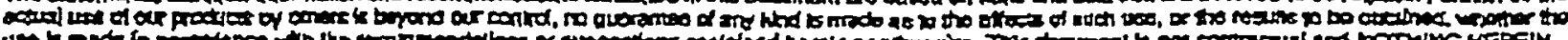

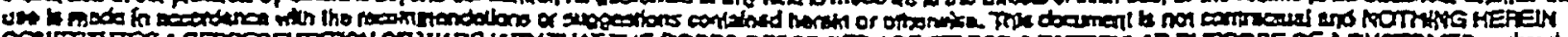

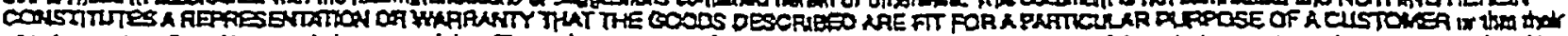

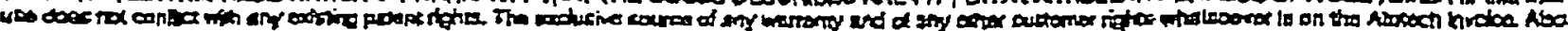

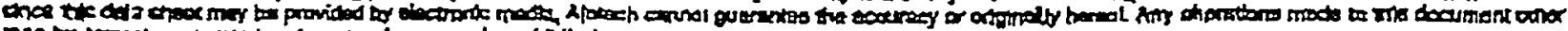

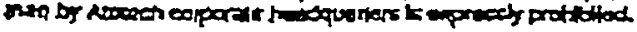

\section{atotech}

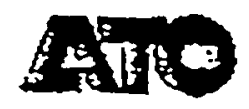

Atotech USA Inc. 1750 Ovaniow Drive, F.0. Bax 12000. Flack Hill, SC 29737-2000 Telephone: 803-817-3500 - Fax: 803-817-3665

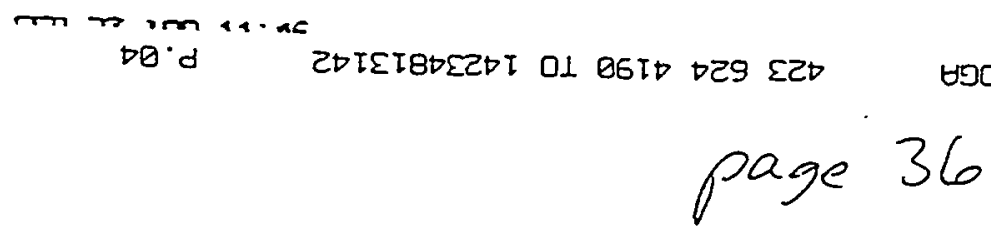


Packaging:

55 Gallon Fiber Drum

5 Galion Palyethylene inner cubes in an auter liner

4 DTums per pallet: 36 cubes per pallet.

NoTE: Drums to be stipped and stared at bemperatures above Ea ${ }^{\circ} \mathrm{F}$ to avaid possibility of crustalization taking place.

\section{WASTE DISPOSAL}

This material must be disposed of in accordance with all applicable faderal, state, and local regulations. Consuth the MSDS for additional regulatory information.

\section{GENERAL SAFETY PRECAUTIONS}

Avaid diract contect with this material. Do not inhale associated mist, vapors, andior dust. As applicable, teep exposere bolow the limite racommended by OSHA, ACGIH, the manufacturet, and others Wash contaminatad clathing hafore reuss. Always comply with the Hazand Communication Standard, 29CFR 1910.1200; emergency showers and Eyewashes must be available.

It. is recommanded that the plating chamistry productisl meferred to in this Technical information shieet bo used: (1) in aceordance with the provided in produet specific MSDS; and (2) in complianee with all appropriace requiremants and guidelines establistred by OSHA, NIOSH, ACGIH, NFPA, and athers.

\section{FIRST-AID AECOMMENOATIONS}

\section{Iypes af Exposure}

\section{Becornmendations}

Eys

Skin

Intralation

Ingertion
Flubh with water for at least 75 minutes.

Wash thoraughly with soap and water.

Ramove to fresh air immediately.

Give water or milk fif conscious and not having convutsionsl.

REYIEW MSDS BEFORE USING THIS PLATING CHEMISTRY AND FOR PRODUCT SPECIFIC INFOBMATION. A precautionary approach should be usad when there is potential for chamical exposure - this includes minimizing exposure potential, rapid decontamination, and modical followsup.

NOTE: A Material Safory Data Sher (MSDS) for this product is available an request from Atotech USA Inc., Customer Senvioersales Suppor Grour 1750 Overview Driva, P.O. Bax 12010, Rock Hill, SC $29731-2000$.

\section{TELEPHORE NLMBERS}

Cuspomer Senvice/Sales Support Group: (803) g17-3538 (MSDS raquests?

Product Safety Department. (8003) B13-3649 (regulatary inquiries and emergencies)

\section{TO PLACE AN ORDER: 1-800-PLATING 1350}

FEB $23 \cdot 9811=47$

so.d

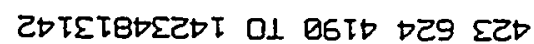

80319173627

PREE 69

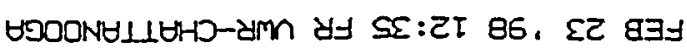


.$\cdot$

FEP. -23 ' 98 (KON) $11: 23$ ATOTECH

\section{Technical Information}

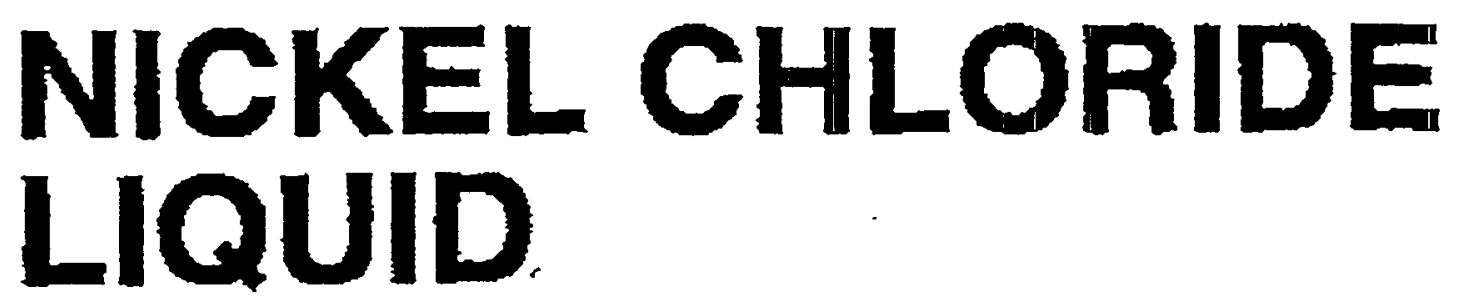

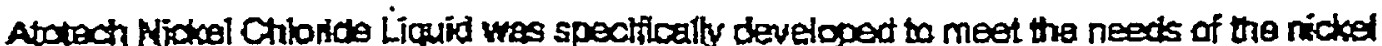
platting industry where very bow Impurtites are required. It is produced from a high purty virgin nickel powder which gusrantes a high quality and consistent product.

Specificutions

NiClalbHoO

$\mathrm{Ni}+\mathrm{CO}$ (as $\mathrm{NB} / 2$

Fo"

Gu:

Zั5

cro

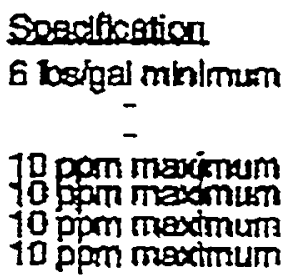

Inojeat"

6.05 ibgal

$133 \%$ by

$20 \mathrm{pm}$

ㄱopom

<to ppm

$<10 \mathrm{ppm}$

$<5$ pprt

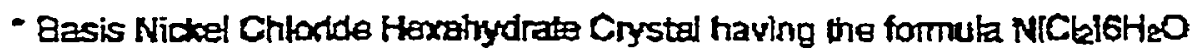

Properties \& Product Characteristics

Clear green fouid

Specific Gravity

Denslty

$$
\begin{aligned}
& 20-25 \\
& 195 \text { lbofga }
\end{aligned}
$$

-HAPOATANT MOTICE REGAFDING THL INFORLATION:

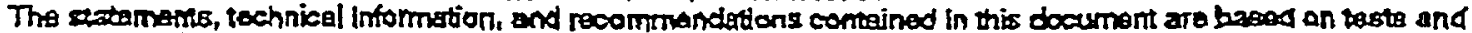

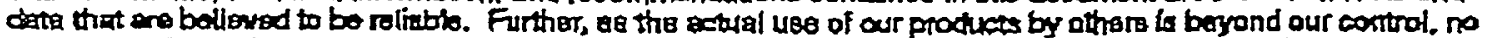

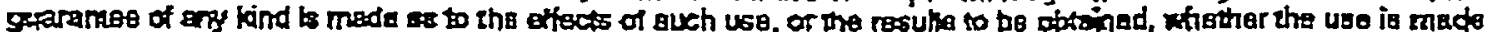

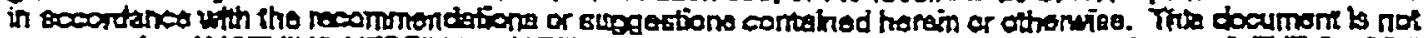
CONTOCHAI and NOTHING HEREIN CONSTITUTES A REPAESENTATION OR WARRARTY THAT THE GOOOS

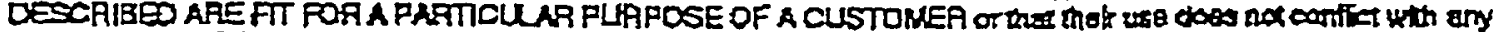

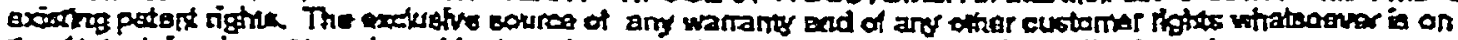

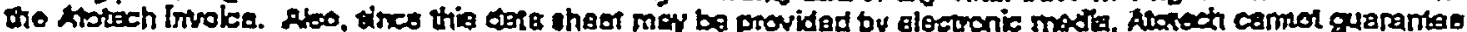

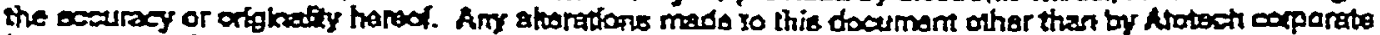
hesdquartere is exprasehy prohibitad-

\section{atotech}

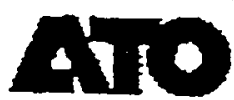

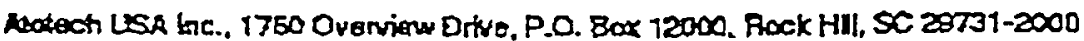

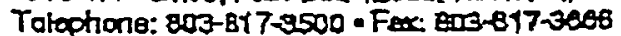

mom and

$90^{\circ} \mathrm{d}$

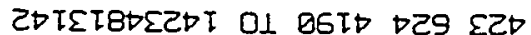

8038173627

PACE. B4

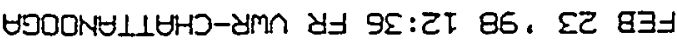

$$
\text { page } 38
$$




\section{NiCKEL CHLORIDE LIOUID Page 2.}

\section{Packeging}

5 geflon atatiatar

56 gation dim

\section{WASTE DISPOSAL}

This material must be dleposed of in gocordance with all appilcadila facteral state, and bocal regulations. Consult the hsos for additanal regulatory information.

\section{GENERAL SAFETY PRECAUTIONS}

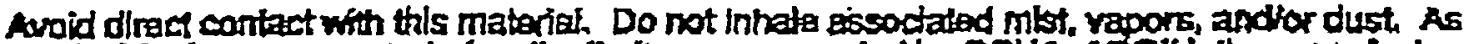

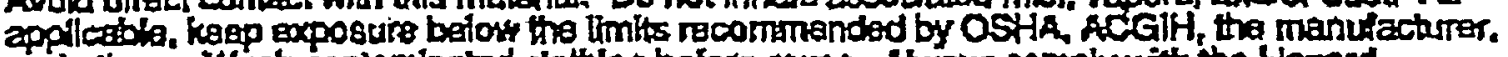
and athero. Wash contaminated dothing betote relse. Ahways comply with the Hazard Communication Standard, 29CFA1910.7200; emergency showers and eyewiashes must be avallablo.

It is recornmended that the plating hemistry produeot(s) rafaned to th thls Technical Information sheset be used: (1) in eccorctancs whth the information provided in product spercific MSps; and (2) in complance with all aporopriale requirements and guidelines estabilished by OSHA, NOSH, ACGHH, NFPA, and others.

\section{FIRST-AID RECOMMENDATIONS}

Iypes of Expesurg

Eya
sidn
intatalon
ingestion
c.

Becommandations

Flush with water for at least 15 mänetas. Wash thoroughty with soap and water. Remore to frash ar mmectialaty. Give water or milk fff conscious and not having convulsions\}. Aemova to fresh eir immodlately.

- REVIEW MSDS BEFORE USING THIS PLATING CHEMISTHY AND FOR PRODUCT SPECIFIC NFOAMATION. A precautionary apptoach shoutd be usod unen there ts potentlal for chemical exposurb - titis inchudes minimizing exposure potantial, rapid docontamination, and medical folfow ip.

AOTE: A Matariat Safety Data Sheet (MSDS) for this product is Evalable on request from Alotach USA Inc, Customer Service Sales Support Group, i75D Ovenviene Dive, P.O. Box 12000, Rock Hill, SC2973I-2000.

\section{TELEPHONE NUKBEAS}

Customer SenvicorSales Suppon Graup: (809) 817-3538 (MSDS mauests)

Procket Sateby Department: (BC3) B17-3549 (regulalory inquifies art emengenctess)

\section{TO PLACE AN ORDER: 1-BDO-PLATING}


Shet NO NIGKEL SULFATE CRYSTAL

Reviston: 4 MT/96

\section{Technical Information}

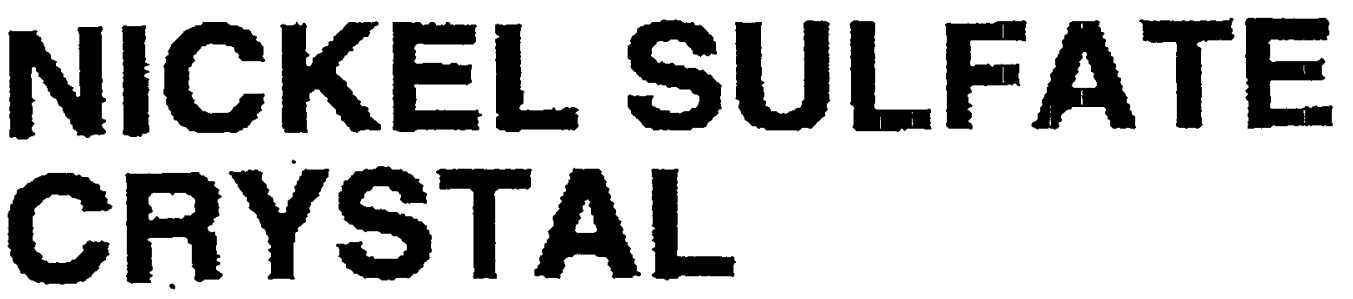

Atotech Nickel Sulfafe, Crytal. Electropuree Spec 103 was spectilealy developed to meet the nasds ch

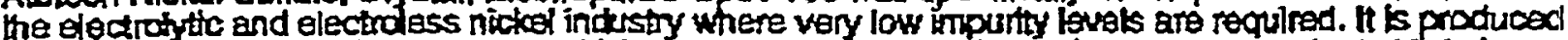
from higli purity virgin nlckel powwder which guarantees a high purity and consistent product. Nhokel Suffete Coystal Spec 101 is of Belgium arigin and mests most nickel plating applicetions.

Specifications:

Spacificalinn
ELECTROPURETM (Spec 103):

$\mathrm{Ni}+\cos \cos$

Co

$\mathrm{Fa}$

$\mathrm{Pb}$

Hin

in

Zn

Cd

Se

As

Bi

Ca

$\mathrm{Mg}$

Na

Cothtgaca

A-AE as $5 \mathrm{O}_{4}$

Acidry as $\mathrm{H}_{2} \mathrm{SO}$.

He Insal.

$22.0 \%$ min
-
15 ppm mex.
5 ppm max.
2 ppm max
3 ppm max.
1 pam max
5 ppm max.
1 ppm max
1 pam max
1 pom max.
1 ppm
50 pam
50 ppm
-
$0.20 \%$ mex
$0.08 \%$ mex.
$0.01 \%$ max.
$0.01 \%$ max.

$225 \%$

10 ppm

< 5 ppm

1 ppom

2 pam

$<7$ pprn

2 pan

$<1$ pom

< 7 ppm

< 1 pom

$<1$ parm

20 ppm

35 ppm

6 pom

abses

$0.05 \%$

aor $\%$

$<0.07 \%$

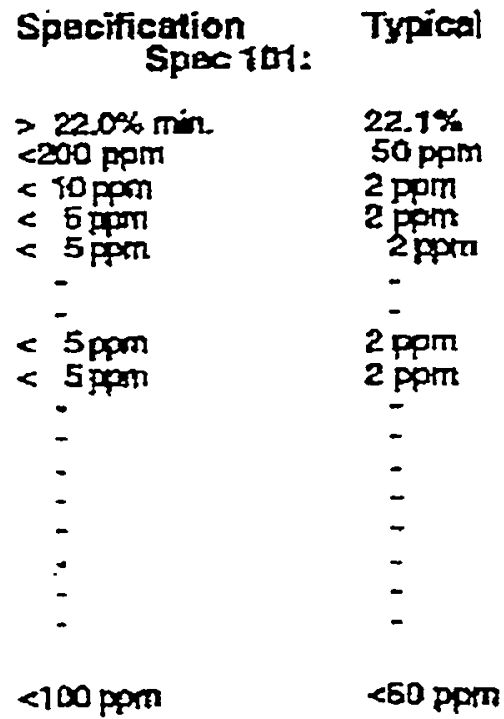

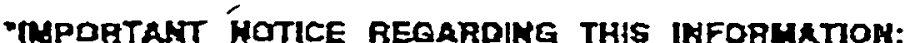

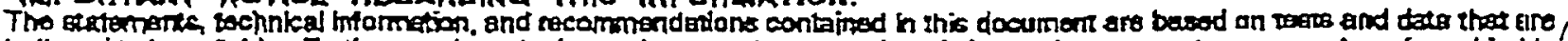

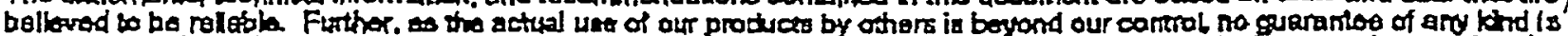

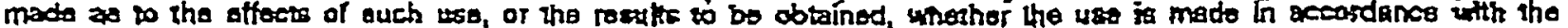

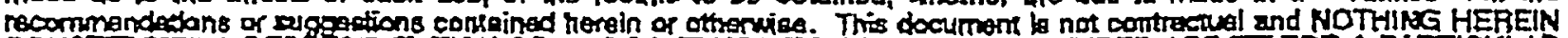
CONSTIUTES A FEPAESENTATKON OA WARAANTY THAT THE GOODS DESCRIBED ARE FII FOA A PAFTICLILA

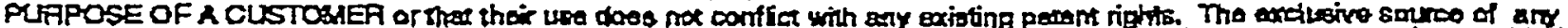

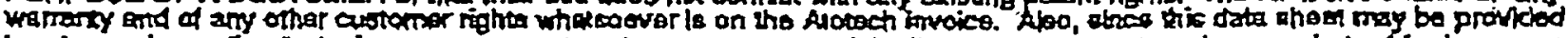

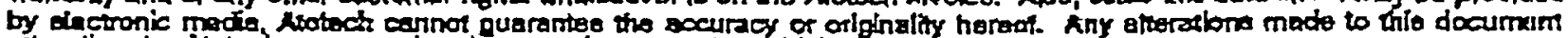
other than by Atotech corporate hesdquarters bs expresely prohibicod."

\section{atotech}

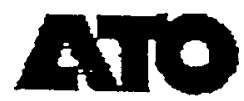

Atorech USA inc. 1750 Overviaw Drwe, F.O. Box 12000 Fock HIl, SC 28731-2000

Tolephone: B03-8173500 - FBX 803-B173856

FEB $23 \cdot 98$ 11:45

$2 \theta^{\circ} d$

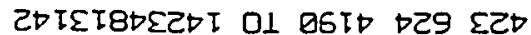

8838173527

PALE-EQ

$$
\text { page } 40
$$




\title{
NICKEL SULFATE CAYSTAL.
}

\author{
Propertias \& Product Characteristles \\ Sheaf graen oystals, trea towing \\ Denaltyr

$$
100 \% \text { through } 4 \text { Mash }
$$$$
95 \% \text { on } 35 \text { Mesh }
$$

\section{PACKAGING:}

Mulfirall Bag - 50 ibs. Nat

40 to bags per pallet

\section{WASTE DISPOSAL.}

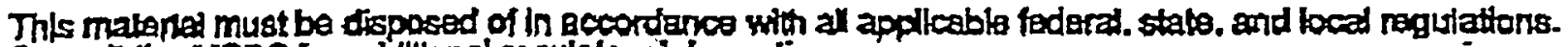
Consult the Misps for addittonal regulatory hiformation.

\section{GENERAL SAFETY PAECAUTIONS}

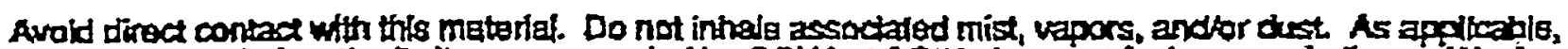
beep exposura below the Anits recommended by OSHA, ACGIH, the manutacturer, end ofhers. Wash contaminated clothing before reuse. Ahways comply with the Hazard Commenteaton Stardard, 29CFP1910.1200; emergency showers and ayewashas mustbe auallable.

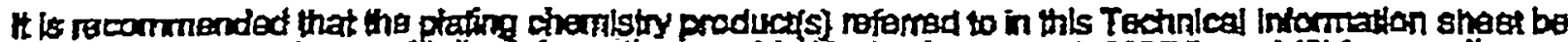
used: (1) in eccordance with the informatlon providod in product spertic NSDS; and (2) in complance with all approprlate requirements and guidelines ostablished by USHA, NIOSH. ACGtH, NFPA, and others.

\section{FIRST-AID RECOKNENDATIONS \\ Irpes ól Expossura. \\ Eye Fush wilth water for at least 15 misuries. \\ Sffin Wash thoroughly with soap and water. \\ Intratation Fiemove to fresti air immediatety. \\ Ingastion Give water of milk if consolious and not having

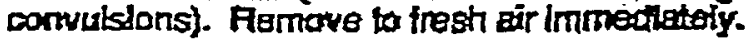

REYIEY MSDS REFOAE USING THIS PLRTING CHEMISTAY AND FOR PAODUCT SPECIFIC INFOAMATION. A precalsionary approsech stould be used when thars is potantial far chamical

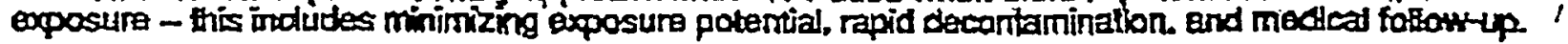

NOTE- A Material Safety DEta Sheal (MSDS) for this product is Evailabla on request from Atotach USA Inc. Oustamer Servicersalas Support Group. 1750 Overvlaw Diva, P.O. Bax 12000, Fock Hal, SC 2973 1-2000.

\section{TELEPHONE NUHBERS}

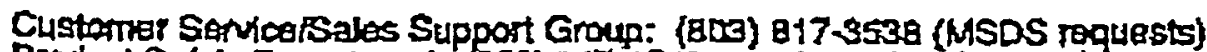

Produrot Sabety Department: (803) B17 3549 pregutatory Inquirios and amengencles)

\section{TO PLACE AH ORDER: 1-BOO-PLATING}

FEB 23 '98 11:45
EO'd

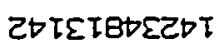

8038173627

PACE.GS

$$
\text { page } 41
$$




\section{Technical Information}
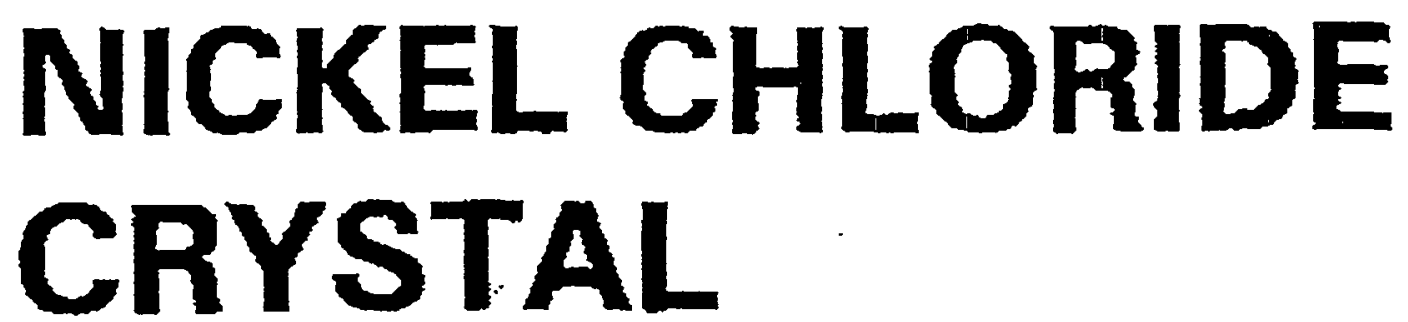

A Chech Nicket Chloride Crystal is of French origin, produced by Eramet - SLN. th is a high quality and consistemt product suibable for use in nickel plating applications, manufacture of Symthetic ink, colorant for glass and oil well treating.

Specifiotions:

\section{Nickol Chloride \\ Hexahydrata \\ Gyarantered}

$\begin{array}{ll}\mathrm{Ni} & >24.0 \% \\ \mathrm{Co} & <0.02 \% \\ \mathrm{Fe} & <0.01 \% \\ \mathrm{Cu} & <0.002 \% \\ \mathrm{Pt} & <0.002 \% \\ \mathrm{Zn} & <0.002 \% \\ \mathrm{Cd} & <0.005 \% \\ \text { Insols } & <0.05 \%\end{array}$

Proparties \& Product Characteristics

Light green caarse pauder

Densizy Approx. $6.5 \mathrm{lbs} / \mathrm{gal}$
Green Hydrated Crystal

Density Approx. 10 lbs/ga:

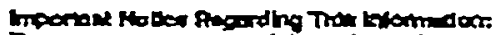

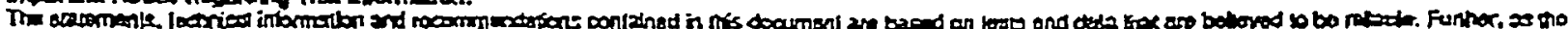

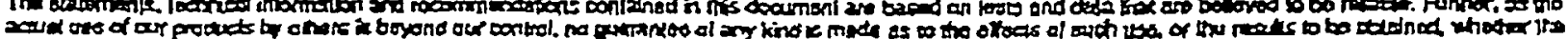

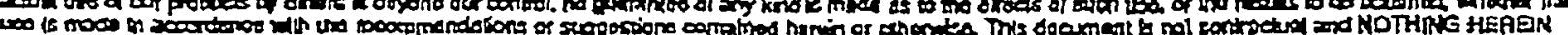

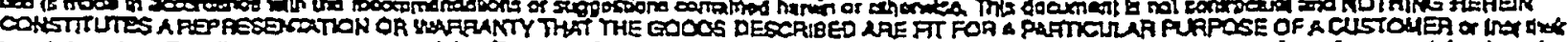

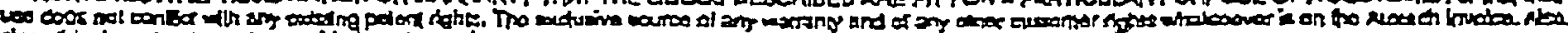

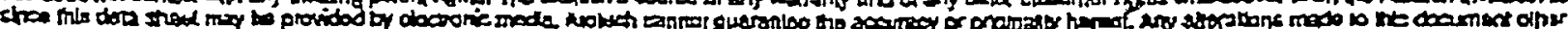

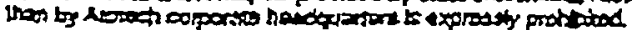

\section{atotech}

LP $22 \cdot 19: \Delta 5$

$80^{\circ} 0^{\circ}$

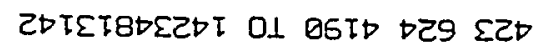

8038173627

PATE. 06

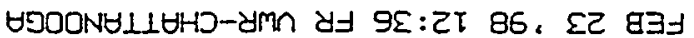

$$
\text { page } 42
$$




\section{WASTE DISPOSAL}

This material must be disposod of in accordance with all applicable federal, state, and local regulations. Consult the MSDS for additional ragulatary information.

\section{GENERAL SAFETY PRECAUTIONS}

Avoid direct cantact with this material. Do not inhale assaciated mist, vapors, andlor dust. As applicable, kBep exposure below the limirs recommended by OSHA ACGIH, the manufacturer, and others. Wash contaminated clothing botore reuse. Ahwrys comply with the Hazard Communication standard. 29CFR 19Ta 1200; emergency showers and eyawashes must be available.

It is racommended that the plating chemistry product(s) refarred to in this Technical Information sheet be used: (1) in accordance with the provided in product specific MSDS; and (2) in compliance with all appropriate requirements and guidelines established by OSHA, NIOSH, ACGIH. NFPA, and others.

\section{FRST-AID RECOMMENDATIONS}

\section{Iypes af Exogsura}

\section{Eve $\quad \therefore$ \\ Skin \\ - Inhalation \\ Ingestian}

\section{Becemmendations}

Flush with water for at least 15 minutes.

Wash tharoughly with saap end water.

Remove to fresh air immediately.

Give water or milk (if canscious and not having convulsionsl.

REVIEW MSDS GEFORE USING THIS PLATING CHEMISTRY AND FOR PRODUCT SPECIFIC INFORAATION. A precautionary approseh should be used when there is porential for chamiesl exposure - this jincludes mintimizing expossre patential, rapid decontamination, and medical followsup.

NOTE: A Mtaterial Safoty Data Shest (MSDS) for this product is avejlable on request from Atorech USA Ine. Clestomer Service/Sales Support Group, 1750 Overviow Drives P.O. Bax 12000, Rock Hill. SC $29731-2010$.

\section{TELEPHORE NUMBERS}

Customer Servicersales Support Group: (B03) 817-3538 (MSDS requestst Product Safety Departmem: (803) 817-3549 [regulatory inquiries and emergencies]

TO PLACEAN OFDER: 1-BOO-PLATING

7342

$$
\begin{aligned}
& \text { mon } 97 \text { im } 19 \cdot n e
\end{aligned}
$$

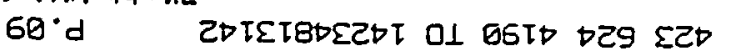




\section{ATTACHMENT C}

Equivalence of Nickel Metal Concentrations in Liquid Nickel Salts 
Concentrations. of liquid $\mathrm{NiSO}_{4} \cdot 6 \mathrm{H}_{2} \mathrm{O}$ as obtained from spec. sheets (Attachment B) and shown below as (A, (B), and .(C).

$(A)=17.8 \frac{\mathrm{oz}}{\mathrm{gl}}=\mathrm{Ni}$ metal. conc. (Dremco, Gum) $(B)=133 \frac{g}{2}=N_{i}$ metal conc. (Dremco)...Gumm, Southeastern).

$(C)=5.0 \frac{\mathrm{lbg}}{\mathrm{gl}}=\mathrm{NiSO}_{4} \cdot 6 \mathrm{H}_{2} \mathrm{O}$ conc. (Van Waters) Calculations to show equivalence of $(A),(B)$, and (C). (A) $=\frac{17.80 z}{\text { gal }}\left|\frac{1 l b}{160 z}\right| \frac{454 \mathrm{~g}}{12 b} \mid \frac{\mathrm{Lgal}}{3.79 l}=\frac{133 \mathrm{~g}}{l}=(B$

(C)

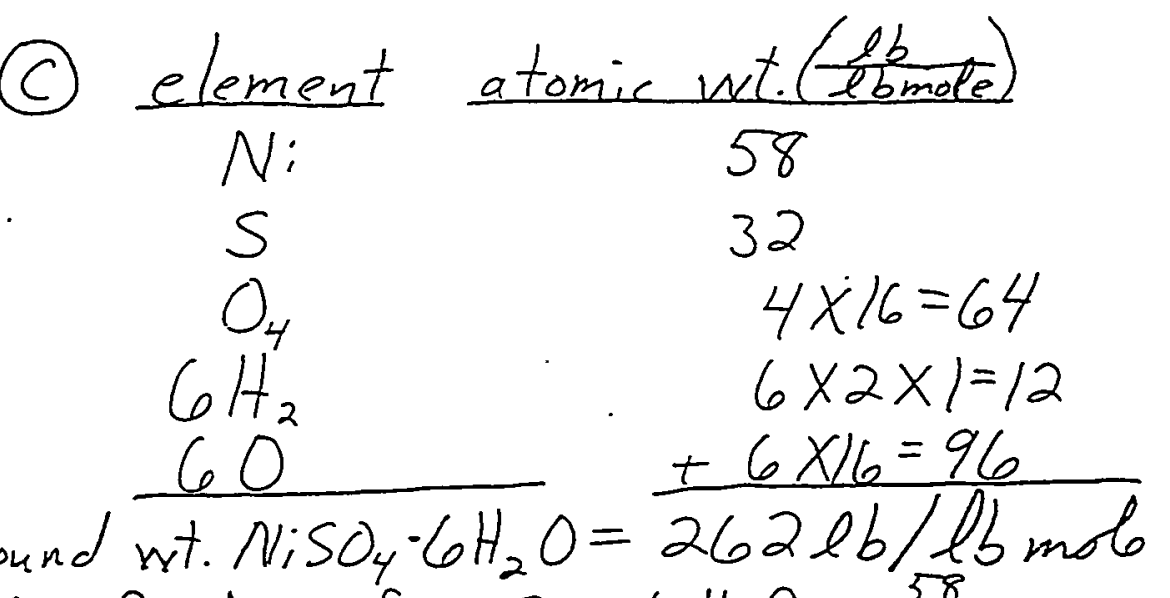

: $\mathrm{Ni}$ fraction of $\mathrm{Ni}_{2} \mathrm{SO}_{4} \cdot 6 \mathrm{H}_{2} \mathrm{O}=\frac{38}{262}$. purchased $x=$ concentration of $\mathrm{NiSO}_{4} \cdot 6 \mathrm{H}_{2} \mathrm{O}$ inn solution

$$
\frac{58}{262}=\frac{12.8 \frac{\mathrm{oz}}{x}}{x} \Rightarrow x=80.4 \mathrm{oz} N \mathrm{NiSO} \cdot 6 . \mathrm{H}_{2} 0 \mid \frac{\mathrm{Leb}}{160 z}
$$

$$
x=5.0 \frac{3 l b s}{g a l}=(C)
$$

$\therefore(A,(B)$, and (C) have equivalent cons. of $N$ imo 
.$!$

Concentrations: of liquid $\mathrm{Ni} \mathrm{Cl}_{2}: 6 \mathrm{H}_{2} \mathrm{O}$ as. 1 obtained from spec sheets (Attachment B) and shown below as. (A), (B), and (C).

$(A)=2.3 .5 .0 z=N i$ metal conc. (Dremso, Cum)

(B) $=178 \frac{g}{d}=$ Ni_metal conc. (Demo, Gum, Southeoter

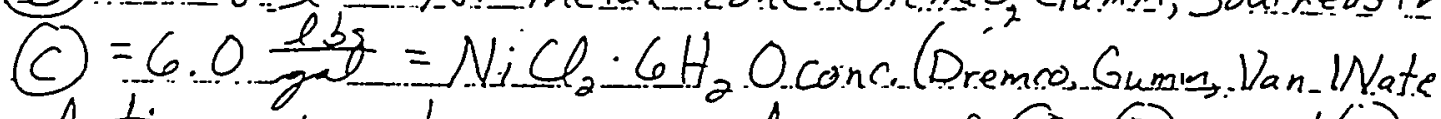
Calculations, to show equivalence of $(A),(B)$, and (C):

(A) $=\frac{23.50 z}{\mathrm{gal}}\left|\frac{1 \mathrm{lb}}{160 \mathrm{z}}\right| \frac{454 \mathrm{~g}}{1 \mathrm{lb}} \mid \frac{\mathrm{Lgal}}{3.79 \mathrm{l}}=176 \mathrm{~g} \approx(B)$

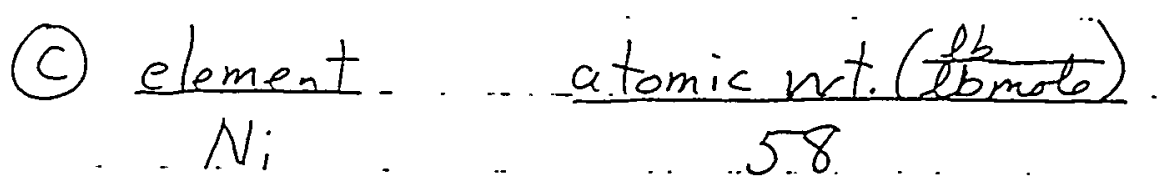

$\begin{array}{lll}\therefore & \mathrm{Cl}_{2} & 2 \times 35.5=71 \\ \therefore & 6 \mathrm{H}_{2} & 6 \times 2 \times 1=12 \\ \therefore & \frac{6 \mathrm{O}}{\mathrm{NiCl} \cdot 6 \mathrm{H}_{2} \mathrm{O}}= & \frac{6 \times 16=96}{23.7 \mathrm{lb} / \mathrm{lb} \text { mol }}\end{array}$

compound wt. $\mathrm{NiCl}_{2} \cdot 6 \mathrm{H}_{2} \mathrm{O}=23.7 \mathrm{lb} / \mathrm{lb}$ mol
$\quad \mathrm{Ni}$ fraction of $\mathrm{Ni}_{i} \mathrm{Cl}_{2}: 6 \mathrm{H}_{2} \mathrm{O}=\frac{58}{237}$

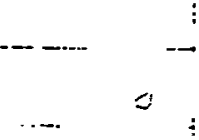
$x=$ concentration of $\mathrm{NiCl} \cdot 6 \mathrm{H}_{2} \mathrm{O}$ in purchased.

$\Rightarrow \frac{58}{237}=\frac{23.5 \frac{\mathrm{oz}}{\mathrm{zal}} \Rightarrow x=960 \mathrm{zz}}{x} \overrightarrow{\mathrm{N}}_{i} \mathrm{Cl}_{2} \cdot 6 \mathrm{H}_{2} \mathrm{O} \mid \frac{\mathrm{llb}}{160 z}$

$$
x=6.0 .2 b_{s}=\text { C. C. }
$$

$\therefore(A)$, B), and (C) have equivalent concentrations of $N$ i metal. page 46 
,$f z^{i}$

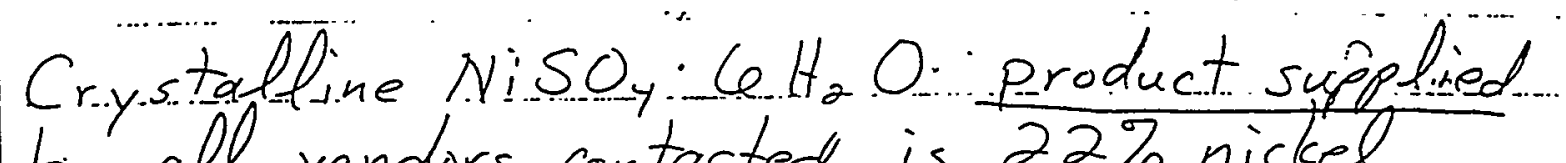

by all vendors contacted is $22 \%$ nickel ... by weight (see Attachment B).

Crystalline viCo $6 . H_{0} O$ product supplied $6 y$ all vendors contacted is $24 \%$ o.nicled ..... by -weight (see. Attachment. B).

For pure $\mathrm{NiSO}_{4} \cdot 6 \mathrm{H}_{2} \mathrm{O}_{\text {compound }}$ (see lost par this attachment) $N$ : fraction of compound $\frac{58}{262}=0.22=22 \%$

For pure $\mathrm{NiCl}_{2} \cdot 6 \mathrm{H}_{2} \mathrm{O}$ compound See aid page oof Ni fraction of compound $=\frac{58}{237}=0.24=24 \%$

page 47 


\section{Attachment D \\ Watts Solution \\ Suppliers of Chemicals}

Dremco, Inc

1550 E Missouri Ave, Ste 302

Phoenix, Arizona 85014

Tel. 602-234-8908, Fax 602-234-8909

Contact. Doug Robinson

Frederick Gumm Chemical Company, Inc.

Gastonia, North Carolina

1-800-541-7878

Contact. Cynthia Costner

Southeastern Chemical, Inc.

1512-A Sholar Avenue

Chattanooga, Tennessee 37406

Tel. 423-622-5154, Fax 423-698-5152

Contacts: Sandi Guess and Ben Johnson (800-376-7113)

Titan International (manufacturer for Southeastern)

Tel. 800-435-4644

Contact: Ellen Jansen

Van Waters \& Rogers, Inc.

Three Riverside Lane

Chattanooga, Tennessee 37406

Tel. 800-233-0633, Fax 423-624-4190

Contact. Priscilla Pennington

Vendors which were contacted, but did not provide information as of 3/05/98.

King Supply Company

Ilinois

847-698-4564

Contact: Dave Tony

P B \& S Chemical Co. Inc.

Knoxville

423-523-7171

Contact: Sheila

Southern Industrial Chemicals, Inc.

1450 Marietta Boulevard, Northwest

Atlanta, Georgia 30318

Tel. 800-394-9770

Contact: Robert Allen 
Instructional Guide

Preparation of Watts Solution for Electrorefining

Equipment and Chemicals Required

300-gallon chemical mixing tank made of stainless steel with a kynar lining .

Marker for the tark that indicates these levels: 97 gallons and 250 gallons

Ventilation for tark

Immersion-type heater with the capacity to heat and maintain the temperature of the 300-gallon tank at $55-60^{\circ} \mathrm{C}\left(131-140^{\circ} \mathrm{F}\right)$, constructed of materials that will not react with the Watts solution.

Temperature indicator, immersion type

$\mathrm{pH}$ indicator for continuous monitoring of $\mathrm{pH}$

Deionized (DI) water

Concentrated liquid hydrated nickel sulfate $\left[\left(\mathrm{NiSO}_{4} \cdot 6 \mathrm{H}_{2} \mathrm{O}\right)\right.$ see Table I]

Concentrated liquid hydrated nickel chloride $\left[\left(\mathrm{NiCl}_{2} \cdot 6 \mathrm{H}_{2} \mathrm{O}\right)\right.$ see Table 1]

Nickel sulfate and rickel chloride are EPA-listed hazardous wastes due to their nickel content.

See MSDSs for environmental information: spill response and recommended disposal. Do

not store rickel sulfate and rickel chloride near acids. They can react with acids to generate

hydrogen gas.

Crystalline solid boric acid $\left(\mathrm{H}_{3} \mathrm{BO}_{3}\right)$ to buffer the solution (see Table 1 )

There are no special storage requirements for boric acid. See MSDS for environmental information: spill response and recommended disposal.

Hydrometer to monitor solution density

Chemical composition aralyzer (i.e:, ion-selective electrodes)

Personal protective clothing and equipment (see item 1. following and MSDSs for details)

Table 1. Characteristics, quantities, and concentrations of the Watts solution components

\begin{tabular}{|c|c|c|c|}
\hline Component & Appearance and odor & $\begin{array}{c}\text { Quantity in a } \\
250 \text {-gallon batch }\end{array}$ & $\begin{array}{l}\text { Concentration in } \\
\text { Watts solution }\end{array}$ \\
\hline $\begin{array}{l}\text { Nickel sulfate } \\
\left(\mathrm{NiSO}_{4} \cdot 6 \mathrm{H}_{2} \mathrm{O}\right)\end{array}$ & $\begin{array}{l}\text { green liquid with } \\
\text { characteristic odor }\end{array}$ & 124 gallons & $40 \mathrm{oz}(\mathrm{av}) / \mathrm{gal}$ \\
\hline Nickel chloride & cleaŕ green liquid & 21 gallons & $8 \mathrm{oz}(\mathrm{av}) / \dot{\mathrm{g} a l}$ \\
\hline$\left(\mathrm{NiCl}_{2} \cdot 6 \mathrm{H}_{2} \mathrm{O}\right)$ & $\begin{array}{l}\text { with characteristic } \\
\text { odor }\end{array}$ & & \\
\hline $\begin{array}{l}\text { Boric acid } \\
\left(\mathrm{H}_{3} \mathrm{BO}_{3}\right)\end{array}$ & $\begin{array}{l}\text { white powder with } \\
\text { no odor }\end{array}$ & 94 pounds & - $6 \mathrm{oz}(\mathrm{av}) / \mathrm{gal}$ \\
\hline $\begin{array}{l}\text { Deionized water } \\
\left(\mathrm{H}_{2} \mathrm{O}\right)\end{array}$ & & 97 gallons & \\
\hline
\end{tabular}


Method of Preparation

1. While handling and mixing the liquid nickel salts and boric acid, take safety precautions. Wear appropriate protective clothing and equipment to prevent skin and eye contact and inhalation. Do not wear contact lenses. Local exhaust is recommended. Do not breath dust, mist, or fumes generated by handling or using these products. Use with adequate ventilation. Use NIOSH-approved dust respirator if ventilation is inadequate. Keep containers closed when not in use. Avoid prolonged or repeated skin contact. Wash skin thoroughly after handling nickel compounds. A dermatitis known as "rickel itch" may result from skin sensitization. See MSDSs for pertinent information conceming the properties, safe handling, health effects and specific first aid procedures for rickel sulfate, rickel chloride, and boric acid.

2. Add 97 gallons of DI water to the chemical mixing tank.

3. Turn on the heater and heat the water to $60^{\circ} \mathrm{C}\left(140^{\circ} \mathrm{F}\right)$. Adjust the settings of the heater throughout the mixing process to maintain the temperature in the range of $55-60^{\circ} \mathrm{C}$ $\left(131-140^{\circ} \mathrm{F}\right)$. The temperature must be maintained at approximately $60^{\circ} \mathrm{C}$-not lower than $55^{\circ} \mathrm{C}$. This temperature is crucial. The boric acid will come out of solution at lower temperatures.

4. Turn on the agitator.

5. While agitating the solution and monitoring the temperature, slowly add 94 pounds of boric acid. If the temperature increases above $60^{\circ} \mathrm{C}\left(140^{\circ} \mathrm{F}\right)$, stop adding the boric acid. Resume the addition when the temperature decreases to $60^{\circ} \mathrm{C}$.

6. While agitating the solution and moritoring the temperature, slowly add 124 gallons of rickel sulfate.

7. While agitating the solution and monitoring the temperature, slowly add 21 gallons of rickel chloride.

8. Turn off the agitator.

9. If needed, add additional DI water into the tank to make the total volume 250 gallons.

10. Turn on the agitator.

11. Check the temperatureand adjust the heater to attain and maintain a temperature in the range of $55-60^{\circ} \mathrm{C}\left(131-140^{\circ} \mathrm{F}\right)$.

12. Mix the solution for 20 minutes while monitoring and maintaining the temperature in the specified range.

13. Tum off the agitator and immediately take a sample of the solution. Restart the agitator. Visually inspect the solution sample. The color of the solution should be green. All solids in the sample should be dissolved. If the solids are not dissolved, repeat steps 12 and 13 until the solids are dissolved. If the solids are dissolved, proceed to step 14.

14. When the solids are dissolved, check the specific gravity of the solution with the hydrometer. The specific gravity should be between 1.2 and 1.35. Record the specific gravity. If the specific gravity of the sample is within this range, proceed to step 15. If the specific gravity is not within the stated range, the chemistry of the solution must be adjusted with the addition of chemicals.

15. Check the $\mathrm{pH}$ of the solution as shown on the $\mathrm{pH}$ indicator. The $\mathrm{pH}$ should be approximately 3 . If the $\mathrm{pH}$ is outside the range 3 to 3.5 , the $\mathrm{pH}$ will be adjusted after the solution is pumped to the electrorefining cell.

16. Send the sample of solution to be aralyzed for chemical composition. When this analysis is completed, ensure that the results are recorded. 
17. Turn off the agitator and the heater.

18. Transfer the solution to the holding tank of the electrorefining cell where the $\mathrm{pH}$ will be adjusted if necessary with sulfuric acid and sodium hydroxide.

19. For each batch of solution that is mixed, record the $\mathrm{pH}$, specific gravity, and the chemical composition. 
100 gallon Mix Plan

Watts Nickel

Using 38 gallons of Hot D/I Water mix 33 lbs. of Boric acid until the Boric dissolves.

Mix into the boric solution 46 gallons of Nickel Sulfate.

Mix into the same container 10 gallons of Nickel Chloride.

This should be approximately 100 gallons use additional $D / 1$ water to obtain 100 gallons if necessary.

50 gallon Mix Plan

Watts nickel

Using 19 gallons of Hot D/I Water mix 17 lbs. of Boric acid until the Boric dissolves.

Mix into the boric solution 25 gallons of Nickel Sulfate.

Mix into the same container 5 gallons of Nickel Chloride.

This should be 50 gallons of Watts Nickel Electrolyte or just a little over in a 55-gallon drum.

\section{0 gallon Mix Plan \\ Watts Nickel}

Transfer 100 gallons of Hot D/I water into the Main Cell.

Add 94 lbs. of Boric acid slowly until it dissolves.

Add 120 gallons of Nickel Sulfate.

Add 20 gallons of Nickel Chloride.

Using Air agitation mix thoroughly while introducing the acids.

Repeat (4) times or until proper level is maintained. Top off the cell with additional acid from MRU and Sump or with D/I water. 


\section{Comments and Notes \\ Preparation of Watts Solution from Crystalline SOLIDS}

1. The specifications given in the Instruction and Instructional Guide are based on 250 gallons of Watts solution mixed in a 300-gallon tank. Six batches will have to be mixed to prepare enough Watts solution for the 1500-gallon electrorefining cell. The quantities of chemical components specified are based on a Watts solution with these concentrations: $40 \mathrm{oz}$ (av)/gal nickel sulfate, 8 oz (av)/gal nickel chloride, and $6 \mathrm{oz}$ (av)/gal boric acid.

2. It is assumed that the temperature of the mixing tank is maintained between 55 and $60^{\circ} \mathrm{C}$ $\left(131\right.$ to $140^{\circ} \mathrm{F}$ ). If this temperature is not maintained in the mixing tank or in the electrorefining cell, the boric acid will not remain dissolved.

3. Note carefully that the instructions state 94 pounds as the quantity of boric acid to be mixed with 100 gallons of water. The solubility of boric acid at $50^{\circ} \mathrm{C}\left(131^{\circ} \mathrm{F}\right)$ is about 1.07 pounds per gallon of water - meaning that 100 gallons of water will only hold 107 pounds of boric acid at $50^{\circ} \mathrm{C}\left(131^{\circ} \mathrm{F}\right)$ under optimal conditions. At $60^{\circ} \mathrm{C}\left(140^{\circ} \mathrm{F}\right), 100$ gallons of water will hold 123 pounds of boric acidb. Therefore, it is imperative that no more than 100 pounds of boric acid be added to each 250 -gallon batch with a temperature exceeding $50^{\circ} \mathrm{C}\left(131^{\circ} \mathrm{F}\right)$ while agitating.

4. Note: the holding tank of the electrorefining cell (or any other place the solution is kept) should be heated to approximately $60^{\circ} \mathrm{C}\left(140^{\circ} \mathrm{F}\right)$. If this tank is not heated, the solids will come out of solution.

5. Adjustment of the solution chemistry while it is in the mixing tank, referred to in steps 14 and 15 of the instructional guide, should be addressed in more detail after some experience is gained with the solution chemistry.

6. After all the equipment is installed for the mixing process, the instructional guide should be checked for consistency and modified as required.

aInterpolation from graph based upon data presented in CRC Handbook of Chemistry and Physics, 54th edition and MSDS for boric acid (attached).

bLange's Handbook of Chemistry, 14th edition. 
Solubility calculations

From attached graph, solubility of boric acid at $50^{\circ} \mathrm{C}=\frac{12.8 \mathrm{~g} \mathrm{H}_{3} \mathrm{BO}_{3}}{100 \mathrm{~mL} \mathrm{H}_{2} \mathrm{O}}=\frac{1.0671 \mathrm{~b} \mathrm{H} \mathrm{BO}_{3}}{\text { gal } \mathrm{H}_{2} \mathrm{O}}$.

Using the data given above, the maximum mass of boric acid that can be dissolved in 100 gallons of water at $50^{\circ} \mathrm{C}$ is given by $\frac{1.067 \mathrm{lb} \mathrm{H}_{3} \mathrm{BO}_{3}}{\text { gal } \mathrm{H}_{2} \mathrm{O}} \times\left(100 \mathrm{gal} \mathrm{H}_{2} \mathrm{O}\right)=107 \mathrm{lb} \mathrm{H}_{3} \mathrm{BO}_{3}$.

Therefore, the $94 \mathrm{lb}$ of boric acid needed can be dissolved in the specified 100 gal of water at $50^{\circ} \mathrm{C}$.

From $14^{\text {th }}$ edition of Lange's Handbook of Chemistry, the solubility of boric acid at $60^{\circ} \mathrm{C}=\frac{14.8 \mathrm{~g} \mathrm{H}_{3} \mathrm{BO}_{3}^{\circ}}{100 \mathrm{~mL} \mathrm{H}_{2} \mathrm{O}}=\frac{1.234 \mathrm{lb} \mathrm{H}_{3} \mathrm{BO}_{3}}{\text { gal H} \mathrm{H}_{2} \mathrm{O}}$.

Using the boric acid solubility data for $60^{\circ} \mathrm{C}$, the maximum mass of boric acid that can be dissolved in 97 gallons of water at $60^{\circ} \mathrm{C}$ is $\frac{1.234 \mathrm{lb} \mathrm{H}_{3} \mathrm{BO}_{3}}{\mathrm{gal} \mathrm{H}_{2} \mathrm{O}} \times\left(100 \mathrm{gal} \mathrm{H}_{2} \mathrm{O}\right)=123 \mathrm{lb} \mathrm{H}_{3} \mathrm{BO}_{3}$. Clearly, the required $94 \mathrm{lb}$ of boric acid will remain in solution at $60^{\circ} \mathrm{C}$.

Conversion factor to go from $\frac{\mathrm{g}}{100 \mathrm{~mL}}$ to $\frac{\mathrm{lb}}{\mathrm{gal}}$ is

$\frac{1 \mathrm{~g}}{100 \mathrm{~mL}}\left[\frac{1 \mathrm{lb}}{454 \mathrm{~g}}\right]\left[\frac{1000 \mathrm{~mL}}{1 \mathrm{~L}}\right]\left[\frac{3.785 \mathrm{~L}}{1 \mathrm{gal}}\right]=\frac{0.0834 \mathrm{lb}}{1 \mathrm{gal}}$

The solubility value from the graph was $15.8 \mathrm{~g} / 100 \mathrm{~mL}$. The lower, more conservative', value of 14.8 from Lange's Handbook was used in an attempt to assure that the mixing would be accomplished successfully. 


\section{Solubilitz $\mathrm{H}_{3} \mathrm{BO}_{3}$ in $\mathrm{H}_{2} \mathrm{O}$}




\section{ELECTROWINNING}

OF 
X-Ray diffraction of the cathode deposit (Experiment dated: Jan. 9, 1998)

Experimental conditions

Anode material - Platinum coated tungsten wire

Cathode material - Stainless Steel

Anode to cathode distance -2.5 inches.

Current Density applied $-1.31 \mathrm{~A} / \mathrm{dm}^{2} \equiv 20 \mathrm{~A} / \mathrm{ft}^{2}$

Appearance of the cathode deposit

- Nickel deposited is brownish metallic gray in color.

- The nickel deposit is cracked at places and lifted up from the cathode surface

Objective: To identify the species that co-deposited with Nickel.

Results The summary of the resutts of XRD of the deposit is given below:

\begin{tabular}{|c|c|c|c|c|}
\hline \hline No. of Peak & 2 theta & d-space & Intensity & Species \\
\hline \hline 1 & 44.599 & 2.0301 & $100^{\circ}$ & $\mathrm{Ni}:$ (Fe) \\
\hline 2 & 51.917 & 1.7598 & 29 & $\mathrm{Ni}$ \\
\hline 3 & 76.481 & 1.2445 & 17 & $\mathrm{Ni}$ \\
\hline 4 & 92.982 & 1.0621 & $17^{-}$ & $\mathrm{Ni}$ \\
\hline .5 & 98.510 & 1.0167 & $8 \cdot$ & $\mathrm{Fe}$ \\
\hline 6 & 116.103 & 0.9078 & 1 & $\mathrm{Fe}$ \\
\hline
\end{tabular}

Standard tables for Nickel and Iron for comparison are given below:

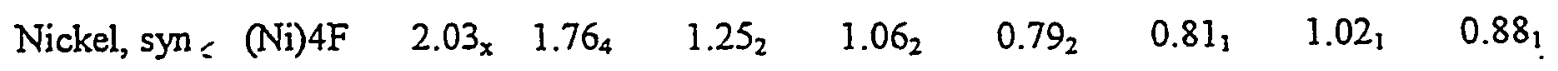

Fe, syn $\quad \propto-(\mathrm{Fe}) 2 \mathrm{~B} \quad 2.03_{x} \quad 1.17_{3} \quad 0.91_{1} \quad 1.01_{1} \quad 0.83_{1}$

It scems that may be some iron co-deposited with nickel and imparted a brownish tinge to the deposited product. However, some other method of analyses is also required to confirm the findings. Copper, chromium and tungsten werf apsent. 


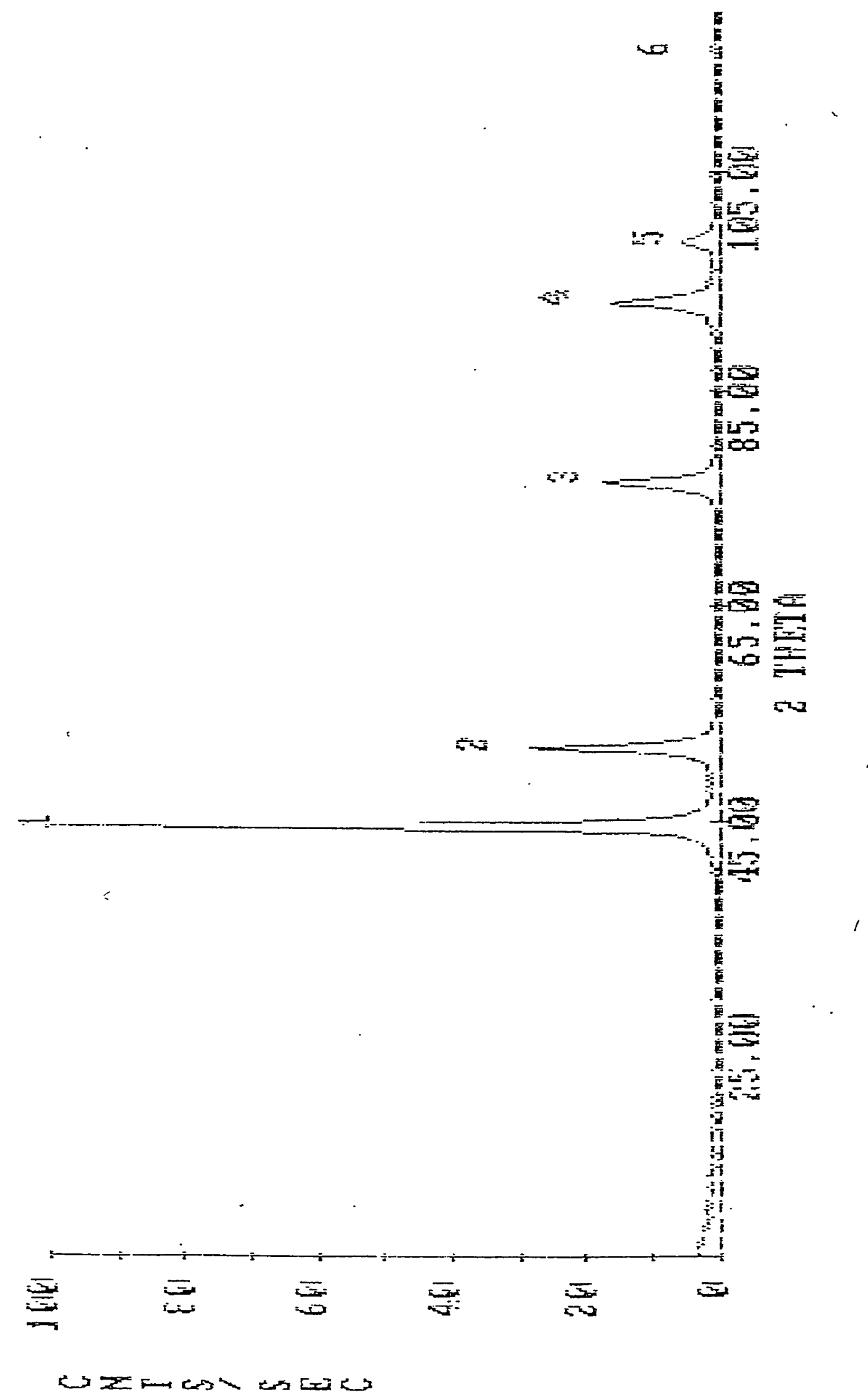


- $0 \quad 6-11-57 \quad N i-T i-H$

1. START ANGIEE $=5.0 O 0$ TIEI,TA ZTHETA $=.200$ TIME $=1.0$ TURE=CU LAMDA $=1.541$

$S H=0 \quad H K G R=0(0) \quad K A 2=0$ TUBE $=C U$ SCH=15 SENS=3.00 CENTROID=15 NTP= 5

$\begin{array}{rrrrrrrrr}\text { N } & \text { 2THETA } & \text { DSFACF } & (1 / D * 22) & \text { HEIGHT } & \text { AREA } & \mathrm{P} & \text { W2 } & \text { W4 } \\ & & & & & & & \\ 1 & 44.599 & 2.0301 & .2427 & 3921 . & 3022 . & 2361 . & 2.114 & .771 \\ 2 & 51.917 & 1.7548 & .3229 & 1128 . & 1116 . & 702 . & 1.879 & .989 \\ 3 & 76.481 & 1.2445 & .5457 & 691 . & 798 . & 485 . & 1.879 & 1.154 \\ 4 & 92.982 & 1.0621 & .8865 & 632 . & 885 . & 512 . & 2.114 & 1.400 \\ 5 & 98.510 & 1.0167 & .9674 & 2007 . & 280 . & 131 . & 1.879 & 1.355 \\ 6 & 116.103 & .9678 & 1.2134 & 55 . & 55 . & 20 . & 2.114 & .999\end{array}$




\section{NICKEL ELECTRO WINNING}

One Anode and one Cathode System

Anode material - Platinum coated tungsten wire

Cathode material - Stainless - Steel

Anode to cathode distance -2.5 inches

Current Density applied - $1: 31 \mathrm{~A} / \mathrm{dm}^{2} \equiv-20 \mathrm{~A} / \mathrm{ft}^{2}$.

Voltage changes: At start - TV

At end $-7 \mathrm{~V}$

Total Time-allowed for Electro winning - 4 hours

Nickel-jon concentration as the function of time.

Time interval for metal ion concentration determination - 1 hour

At the start of experiment -9.1 ozdgallom

a) Affer lhour - not measured.

b) After 2 hours - 8.9 oz/gallon

c) After 3 hours - 9.1 oz/galton

d) After 4 kours - 9.1 oz/gallon

Temperature Recording The thermometer was dipped in cormer at a depth of -2.5 inches.

Time interval for monitoring the temperature changes - 1 hour

At the start of experiment $-29.8^{\circ} \mathrm{C}$

a) After 1 hour $-29.8^{\circ} \mathrm{C}$.

b) After 2 hours $-29.9^{\circ} \mathrm{C}$

c) After 3 hours $-30.8^{\circ} \mathrm{C}$

d) After 4 hours $-31.2^{\circ} \mathrm{C}$

Experiment switched off.

\section{Current Efficiency $\quad 65.1 \%$}

\section{Observations}

- Vigorous gas bubbles evolved from the cathode and the amode surfaces

- The pungent smell of the anode gas identified it tó be $\mathrm{Cl}_{2}$ gas

- Nickel deposited is browish-metallic gray in color.

- The nickel deposit is cracked at places and lified up from the cathode surface

Remarks This anode material is not suitable for the electro winning of nickel. The anode should be carefully selected and reptaced by an inert material which will reduce or avoid $\mathrm{Cl}_{2}$ gas evolution and the contamination of the solution through the anode dissolution, and consequently will require a lower cell driving voltage: 


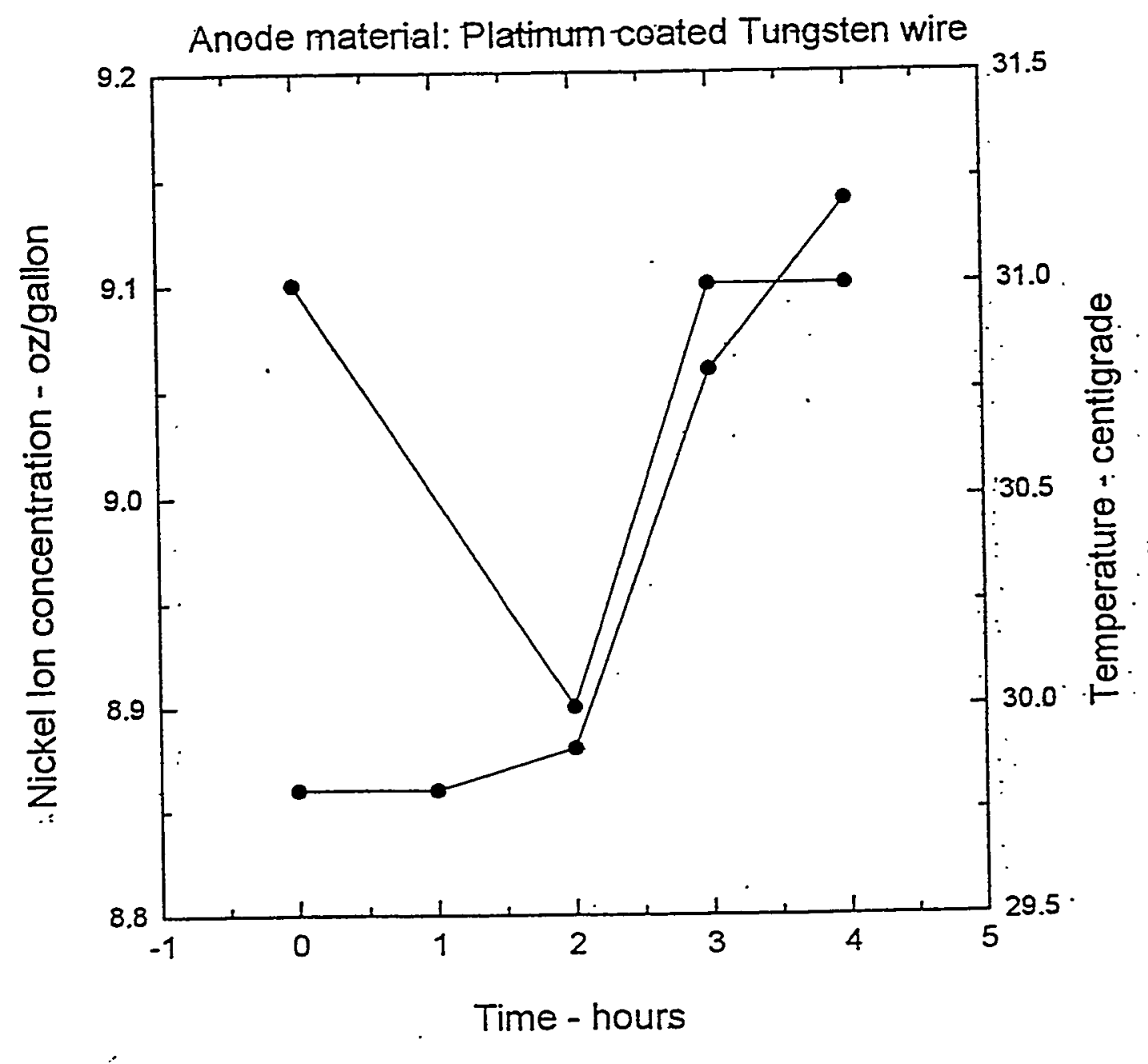

Change in the nickel ion concentration and temperature with time. Current density. $-20 \mathrm{Amps} / \mathrm{ft}^{2}$ Anode-cathode distance -2.5 inches 


\section{NICKEL ELECTRO WINNING}

One Anode and one Cathode System

Anode material - Titanium-vanadium Alloy

Cathode material - Stainless Steel

Anode to cathode distance -2.5 inches

Current Density applied $-1.31 \mathrm{~A} / \mathrm{dm}^{2} \equiv 20 \mathrm{~A} / \mathrm{ft}^{2}$

Results: The voltage could be increased to $25 \mathrm{~V}$ but.the current could not increase more than $1 \mathrm{~A}$ and it decreased continuously.

The experiment was switched off.

The same experiment was repeated with a SS Anode of the same composition as that of the cathode

Voltage changes: At start $-5 \mathrm{~V}$

At end $-3 \mathrm{~V}$

Total Time allowed for Electro winning - 4 hours

Nickel ion concentration as the function of time

Time interval for metal ion concentration determination - 1 hour

At the start of experiment -9.5 oz/gallon

a) After lhour - $9.5 \mathrm{oz}$ gallon

b) After 2 hours - 9.4 oz/gallon

c) After 3 hours - 9.3 oz/gallon

d) After 4 hours - 9.3 oz/gation

Temperature Recording The thermometer was dipped in corner at a depth of $\sim 2.5$ inches.

Time interval for monitoring the temperature changes -1 hour

At the start of experiment $-22^{\circ} \mathrm{C}$

a) After lhour $-24^{\circ} \mathrm{C}$

b) After 2 hours $-25.8^{\circ} \mathrm{C}$

c) After 3 hours $-26.8^{\circ} \mathrm{C}$

d) After 4 hours - $27^{\circ} \mathrm{C}$

Experiment switched off.

\section{Current Efficiency $\quad 70.5 \%$}

\section{Observations}

- Gas bubbles evolved from the cathode and anode surfaces

- Metallic nickel particles were observed floating in the solution

- Brown rust particles were observed at the anode/solution interface

- The anode pitted as elongated oval, cavities

- Nickel deposited in the form of thin, ductile, dark flakes

Remarks The anode material should be carefully selected to avoid gas evolution and the contamination of the solution through the anode dissolution. 


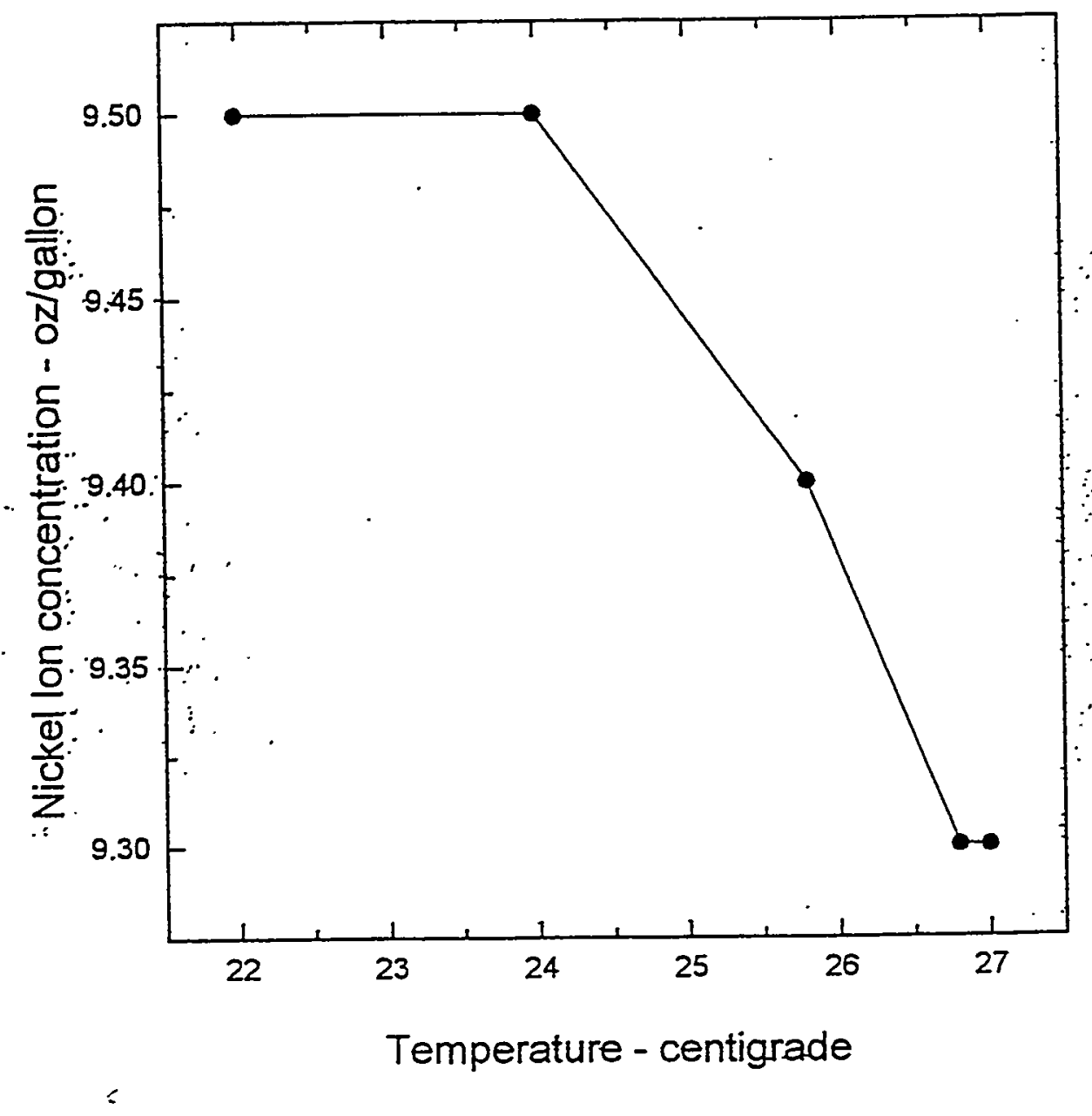

Change in the nickel ion:concentration with temperature.

Current density.- 20 Amps/ft ${ }^{2}$

Anode-cathode-distance - 2:5-inches 


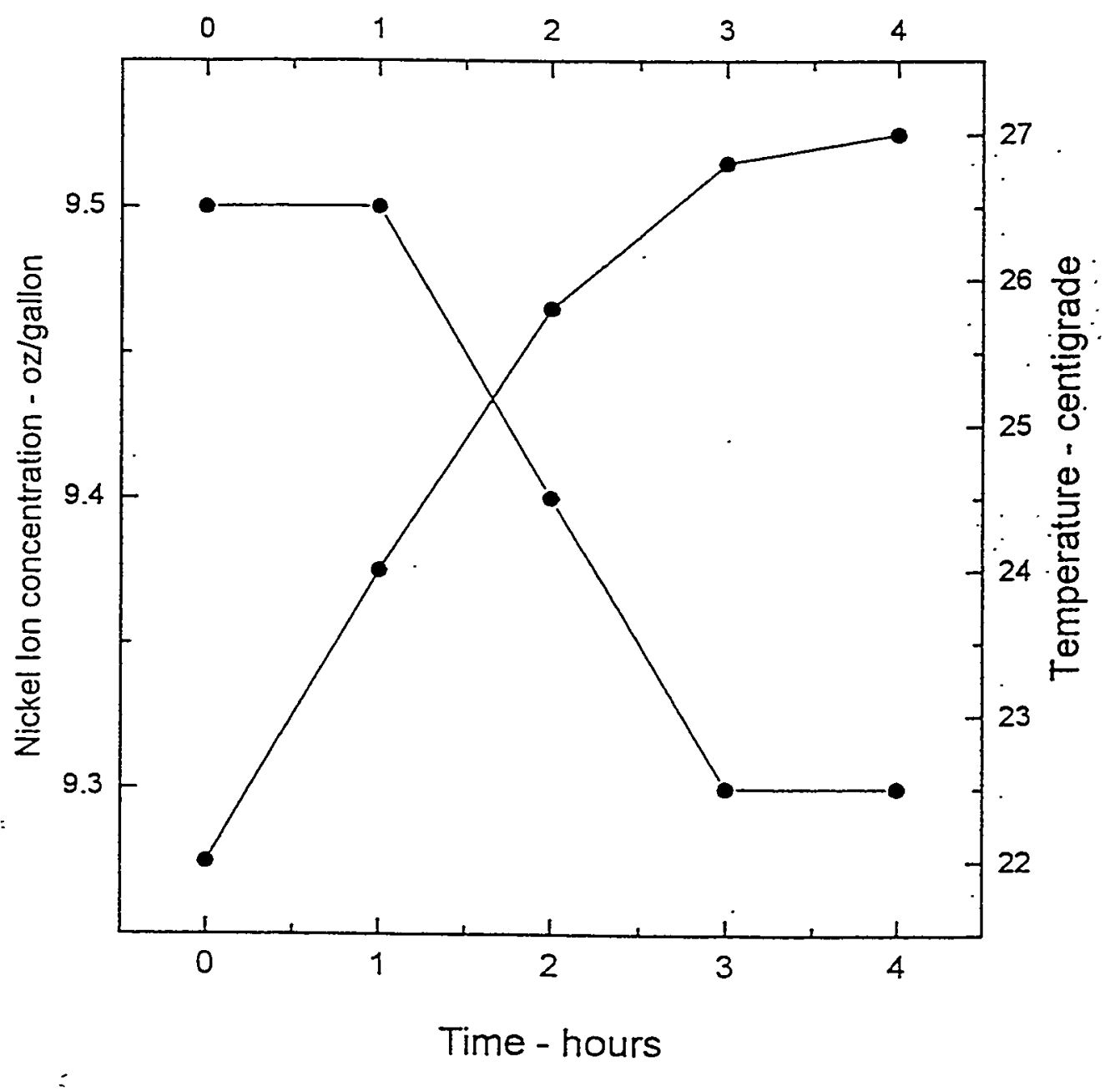

Change in the nickel ion concentration and temperature with time.

Current density - 20 Amps/ft ${ }^{2}$

Anode-cathode distance -2.5 inches 


\section{ELECTROPLATING}

OF

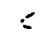

NICKEL 


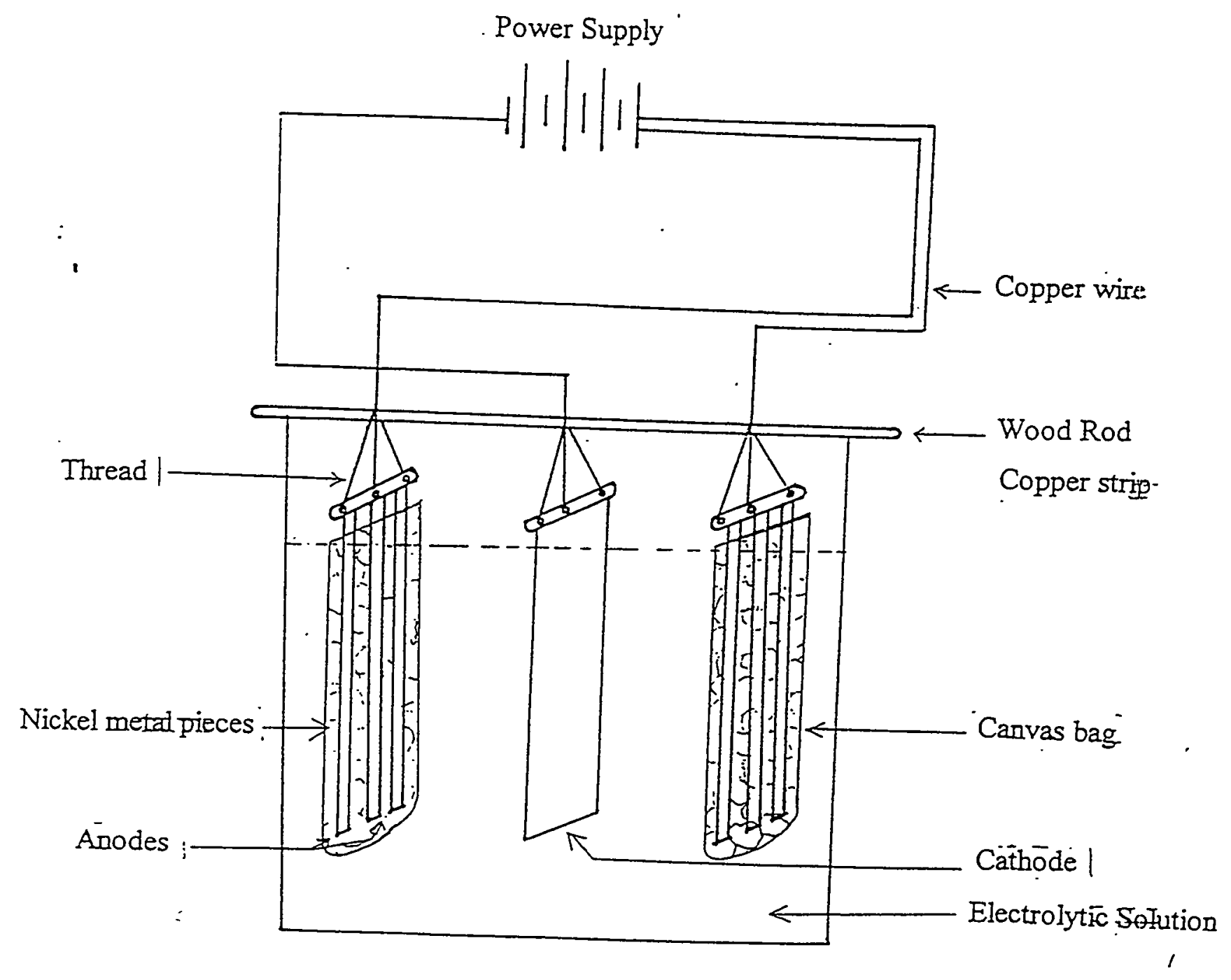

ELECTROLYTIC CELL FOR NICKEL.ELECIROPLATING.

Two Anodes and one-Cathode-System- 
NICKEL ELECTROPLATING

\section{Two Anodes and one Cathode System}

Current Density applied - $5.0 \mathrm{~A} / \mathrm{dm}^{2} \quad 46.4 \mathrm{~A} / \mathrm{ft}^{2}$

Voltage applied - $5 \mathrm{~V}$

Anode to cathode distance -2.5 inches

Total Time allowed for Electroplating - 4 hours

Nickel ion concentration as the function of time

Time interval for metal ion concentration determination - 1 hour
a) At the start of experiment - $9.99 \mathrm{oz}$ gallon
b) After lhour - $9.99 \mathrm{oz}$ gallon
c) After 2 hours $-9.97 \mathrm{oz}$ gallon
d) After 3 hours - 9.99 oz/gallon
e) After 4 hours -9.90 oz/gallon

Experiment switched off.

Current Efficiency $95 \%$

Observations Flakes of ductile whitish bright Nickel were deposited.

Remarks. A distance of 2.5 inches between the anodes and the central cathode should be increased for these experimental conditions for it may cause short circuiting. 
NICKEL ELECTROPLATING

Two Anodes and one Cathode System

Current Density applied $-2.15 \mathrm{~A} / \mathrm{dm}^{2} \equiv 20 \mathrm{~A} / \mathrm{ft}^{2}$

Voltage applied - $1.5-2.0 \mathrm{~V}$

Anode to cathode distance -2.5 inches

Total Time allowed for Electroplating -4 hours

Nickel ion concentration as the function of time

Time interval for metal ion concentration determination - 1 hour

At the start of experiment - $10.19 \mathrm{oz} / \mathrm{gallon}$

a) After thour - $9.86 \mathrm{oz} /$ gallon

b) After 2 hours -10.08 oz/gallon

c) After 3 hours - 9.95 oz/gallon

d) After 4 hours -10.06 oz/gallon

Experiment switched off.

Current Efficiency $\quad 88 \%$

Observations Flakes of ductile whitish bright Nickel as thin sheets were deposited.

Remarks. The Nickel deposited is in the form of thin sheets and hence the stirrer speed should be adjusted to avoid the breaking of the nickel sheet from the cathode surface. 


\section{NICKEL ELECTROPLATING}

\section{Two Anodes and one Cathode System}

Current Density applied - $1.62 \mathrm{~A} / \mathrm{dm}^{2} \equiv 15 \mathrm{~A} / \mathrm{ft}^{2}$

Voltage applied $-2.5_{\text {sart }}-2.0 \mathrm{~V}$

Anode to cathode distance -2.5 inches

Total Time allowed for Electroplating - 4 hours

Nickel ion concentration as the function of time

Time interval for metal ion concentration determination - 1 hour

At the start of experiment $-9.72 \mathrm{oz} /$ gallon

a) After lhour - 9.72 oz/gallon

b) After 2 hours - 9.80 oz/gallon

c) After 3 hours - 9.95 oz/gallon

d) After 4 hours - 9.83 oz/gallon

Temperature Recording The thermometer was dipped in corner at a depth of -2.5 inches. Time interval for monitoring the temperature changes - 1 hour

At the start of experiment $-30^{\circ} \mathrm{C}$

a) After thour $-29.8^{\circ} \mathrm{C}$

b) After 2 hours $-29.8^{\circ} \mathrm{C}$

c) After 3 hours $-30^{\circ} \mathrm{C}$

d) After 4 hours $-30^{\circ} \mathrm{C}$

Experiment switched off.

\section{Current Efficiency $\quad 68 \%$}

Observations Flakes of ductile whitish bright Nickel as thin sheets were deposited.

Remarks. The nickel flakes grew outward in the middle towards the anodes. Short circuiting is highly expected under these conditions. 
NICKEL ELECTROPLATING

Two Anodes and one Cathode System

Current Density applied - $1.24 \mathrm{~A} / \mathrm{dm}^{2} \equiv 11.5 \mathrm{~A} / \mathrm{ft}^{2}$

Voltage applied - 1.0V

Anode to cathode distance - 2.5 inches

Total Time allowed for Electroplating - 4 hours

Nickel ion concentration as the function of time

:Time interval for metal ion concentration determination - 1 hour

At the start of experiment $-6.98 \mathrm{oz}$ gallon

a) After 1hour - $7.01 \mathrm{oz} /$ gallon

b) After 2 hours - $6.98 \mathrm{oz}$ gallon

c) After 3 hours - 7.01 oz/gallon

d) After 4 hours - 6.98 oz/gallon

Chloride ion concentration as nickel chloride

Time interval for metal ion concentration determination - 1 hour

At the start of experiment $-9.54 \mathrm{oz}$ /gallon

a) After 1hour - $9.54 \mathrm{oz}$ gallon

b) After 2 hours -9.45 oz/gallon

c) After 3 hours - $9.50 \mathrm{oz}$ gallon

d) After 4 hours -9.50 oz/gallon

Temperature Recording The thermometer was dipped in corner at a depth of $\sim 2.5$ inches. Time interval for monitoring the temperature changes - 1 hour

At the start of experiment $-25.5^{\circ} \mathrm{C}$

a) After thour $-25.5^{\circ} \mathrm{C}$

b) After 2 hours $-25.5^{\circ} \mathrm{C}$

c) After 3 hours $-25.5^{\circ} \mathrm{C}$

d) After 4 hours $-25^{\circ} \mathrm{C}$

Experiment switched off.

Current Efficiency $70.5 \%$

Observations Flakes of ductile whitish bright Nickel as thin sheets were deposited.

Remarks. The Nickel deposited is in the form of thin sheets and hence the stirrer speed should be adjusted to avoid the breaking of the nickel sheet from the cathode surface. There is a danger of short circuiting under this set of experimental conditions. 


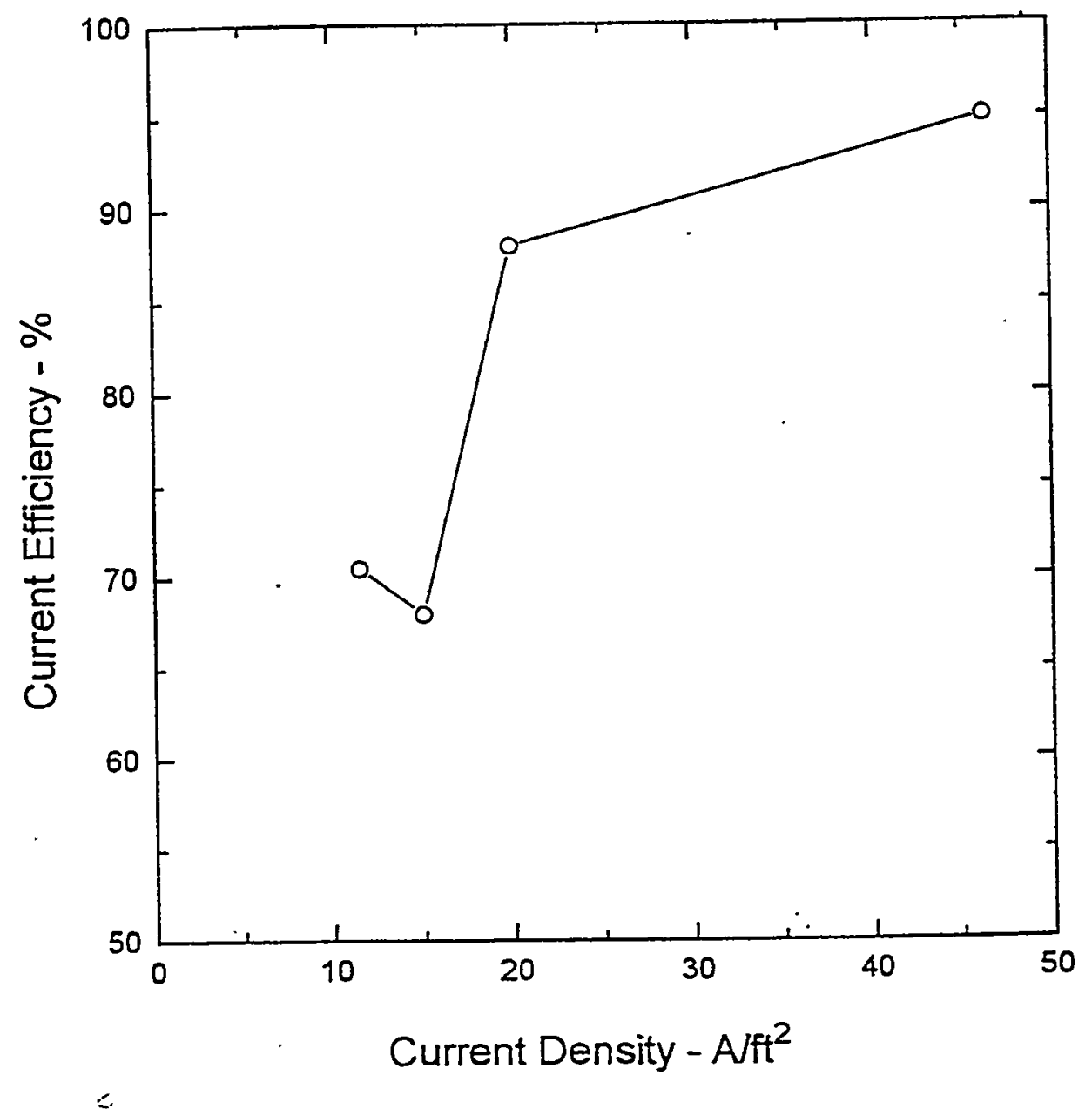

Figure showing the effect of the applied current density on the current efficiency at an anode to cathode distance of 2.5 inches 


\section{NICKEL ELECTROPLATING}

Two Anodes and one Cathode System

Current Density applied $-2.15 \mathrm{~A} / \mathrm{dm}^{2} \equiv 20 \mathrm{~A} / \mathrm{ft}^{2}$

Voltage applied - $1.5-2.0 \mathrm{~V}$

Anode to cathode distance - 3.0 inches

Total Time allowed for Electroplating - 4 hours

Nickel ion concentration as the function of time

Time interval for metal ion concentration determination - 1 hour

At the start of experiment $-7.29 \mathrm{oz}$ gallon

a) After 1hour - $7.26 \mathrm{oz}$ gallon

b) After 2 hours - 7.26oz/gallon

c) After 3 hours - 7.20 oz/gallon

d) After 4 hours - $7.230 z /$ gallon

Chloride ion concentration as nickel chloride

Time interval for metal ion concentration determination - 1 hour

At the start of experiment $-9.54 \mathrm{oz} /$ gallon

a) After 1hour - $9.41 \mathrm{oz} /$ gallon

b) After 2 hours - $9.360 z$ gallon

c) After 3 hours - 9.36 oz/gallon

d) After 4 hours -9.36 oz/gallon

Temperature Recording The thermometer was dipped in corner at a depth of $\sim 2.5$ inches. Time interval for monitoring the temperature changes - 1 hour

At the start of experiment $-23^{\circ} \mathrm{C}$

a) After 15 minutes $-23^{\circ} \mathrm{C}$

b) After 40 minutes $-23.5^{\circ} \mathrm{C}$

c) After thour $-24.2^{\circ} \mathrm{C}$

b) After 2 hours $-25^{\circ} \mathrm{C}$

c) After 3 hours $-26^{\circ} \mathrm{C}$

d) After 4 hours - $26^{\circ} \mathrm{C}$

Experiment switched off.

\section{Current Efficiency $87.5 \%$}

Observations Flakes of ductile whitish bright Nickel as thin sheets were deposited.

Remarks. The Nickel flakes deposited is in the form of thin sheets growing outwards from the sides. The stirrer speed was reduced to avoid the breaking of the nickel flakes from the cathode surface. It is unlike the previous experiments in which case the nickel flakes grew outward in the middle towards the anodes increasing the risk of short circuiting. 
NICKEL ELECTROPLATING

Two Anodes and one Cathode System

Current Density applied $-2.15 \mathrm{~A} / \mathrm{dm}^{2} \equiv 20 \mathrm{~A} / \mathrm{ft}^{2}$

Voltage applied - $1.5-2.0 \mathrm{~V}$

Anode to cathode distance - 3.5 inches

Total Time allowed for Electroplating - 4 hours

Nickel ion concentration as the function of time

Time interval for metal ion concentration determination - 1 hour

At the start of experiment $-9.80 \mathrm{oz} /$ gallon

a) After 1hour - $9.80 \mathrm{oz} /$ gallon

b) After 2 hours - 9.80 oz/gallon

c) After 3 hours - $9.70 \mathrm{oz} / \mathrm{gall}$ on

d) After 4 hours - $9.80 \mathrm{oz}$ /gallon

Temperature Recording The thermometer was dipped in corner at a depth of $\sim 2.5$ inches.

Time interval for monitoring the temperature changes - 1 hour

At the start of experiment $-24^{\circ} \mathrm{C}$

a) After Ihour $-26^{\circ} \mathrm{C}$

b) After 2 hours $-26.2^{\circ} \mathrm{C}$

c) After 3 hours $-26.5^{\circ} \mathrm{C}$

d) After 4 hours $-26.7^{\circ} \mathrm{C}$

Experiment switched off. $\because$

Current Efficiency $\quad 82.6 \%$

Observations Flakes of ductile whitish bright Nickel as thin sheets were deposited.

Remarks. As the anode-cathode distarice is increased he nickel flakes grew outward from the sides. These flakes were as large as 2 inches extending towards the sides into the solution. 


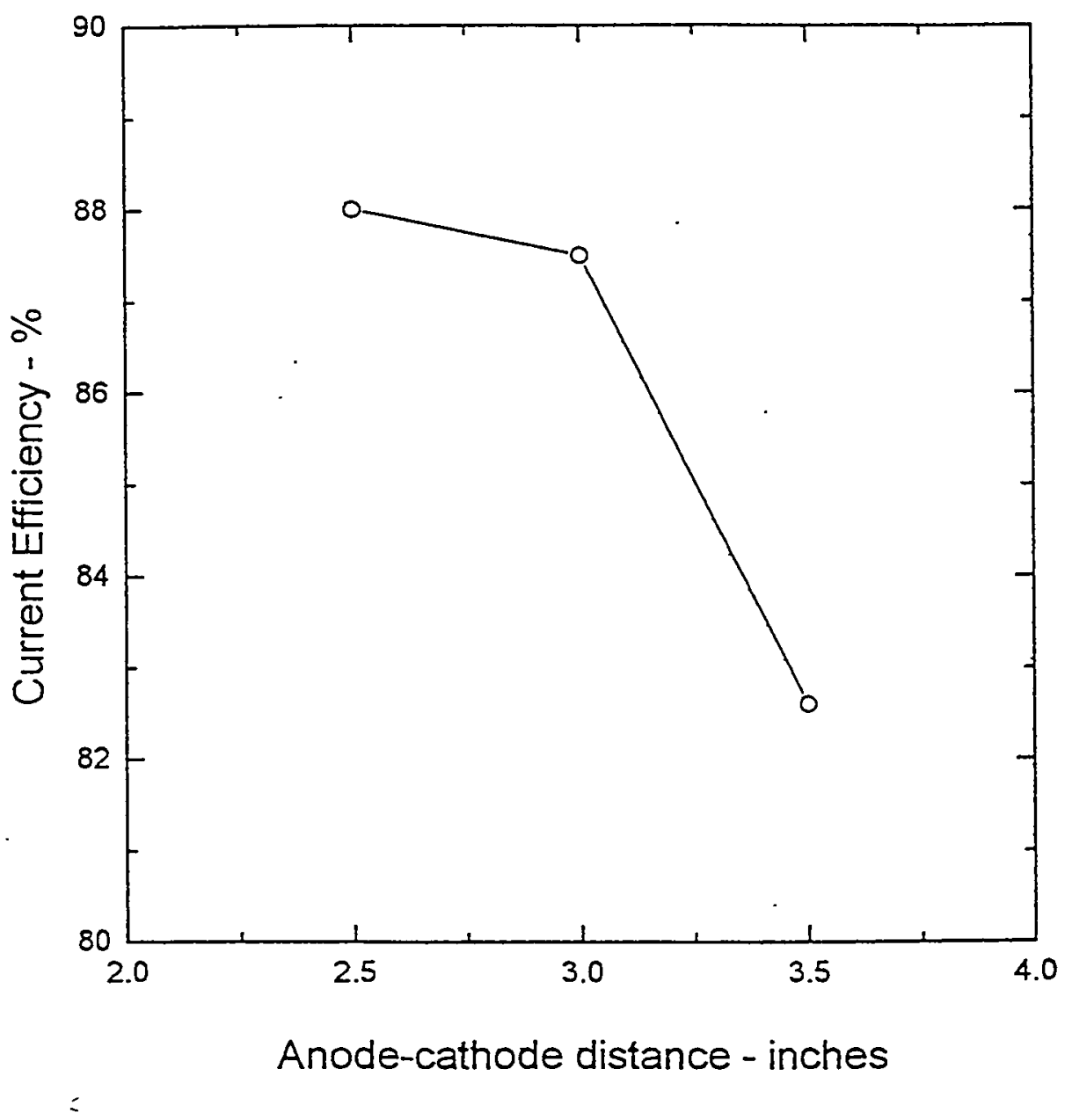

Figure showing the effect of the anode to cathode distance on the current efficiency at an applied current density of $20 \mathrm{~A} / \mathrm{ft}^{2}$ 


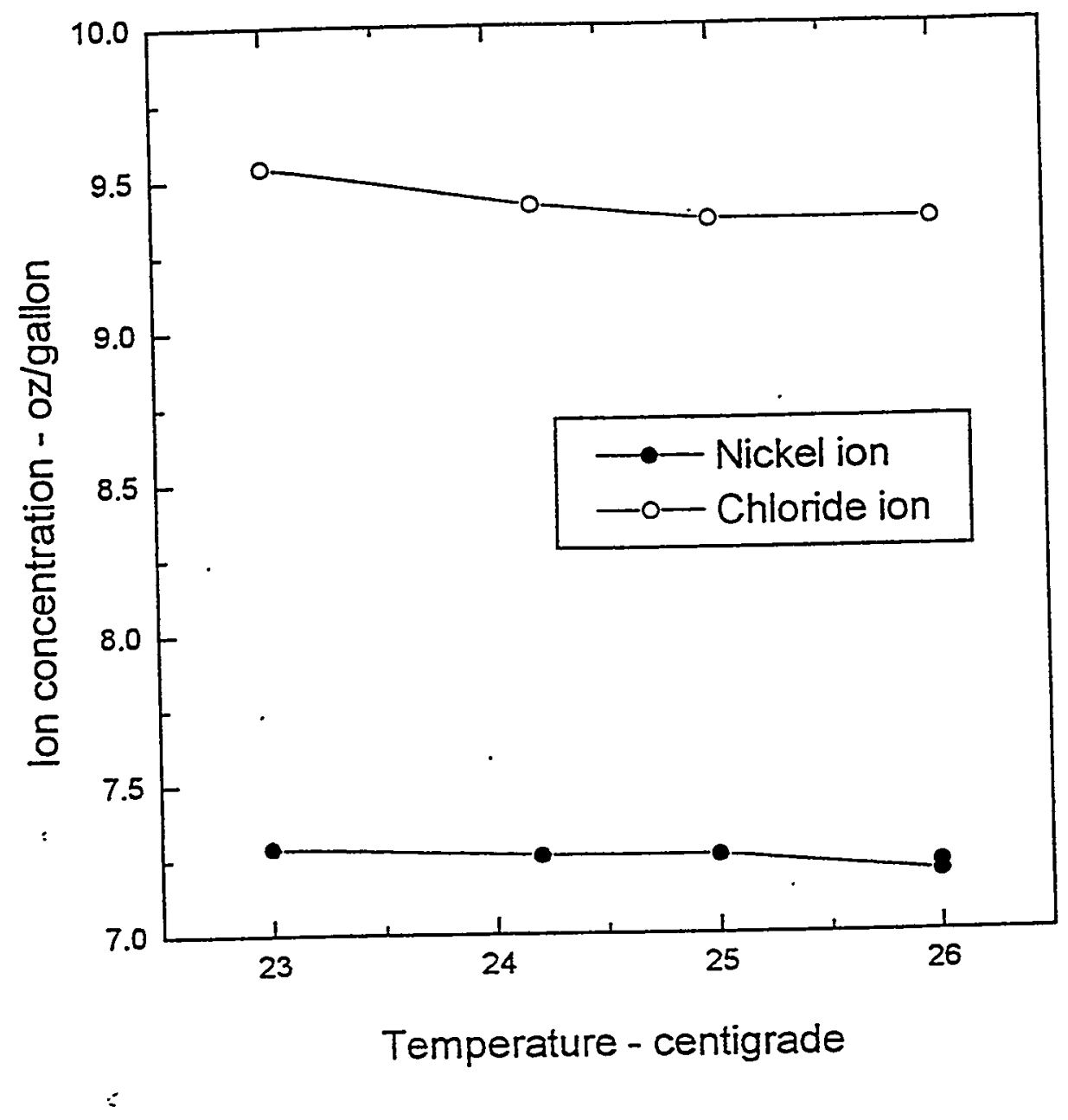

Change in the nickel ion and the chloride ion concentration with temperature.

Current density - $20 \mathrm{Amps} / \mathrm{ft}^{2}$

Anode-cathode distance -3 inches 


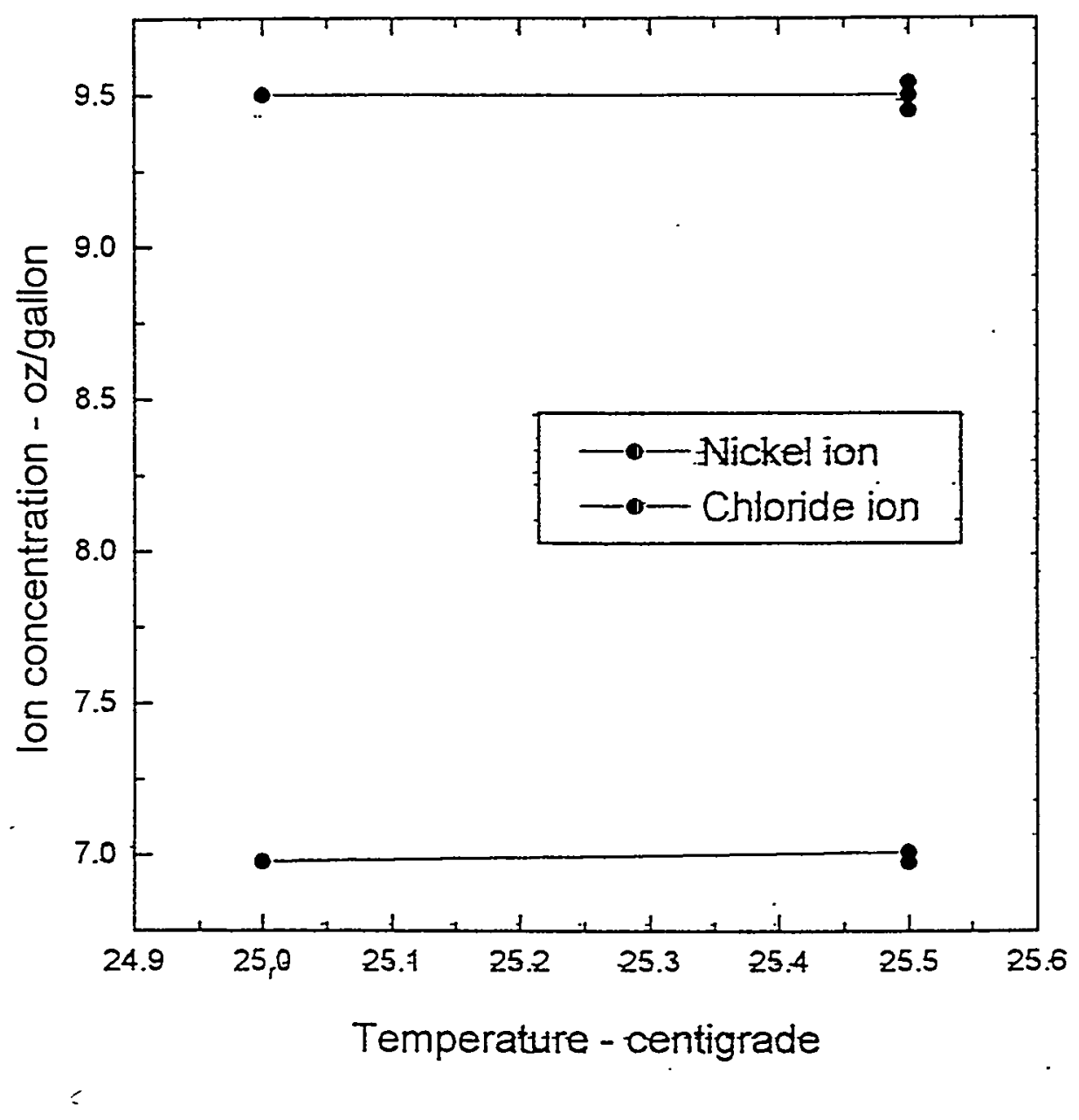

Change in the nickel ton and the chloride ion concentration with temperature.

Current density - 11.5 Amps/ft ${ }^{2}$

Anode-cathode distance -2.5 inches 


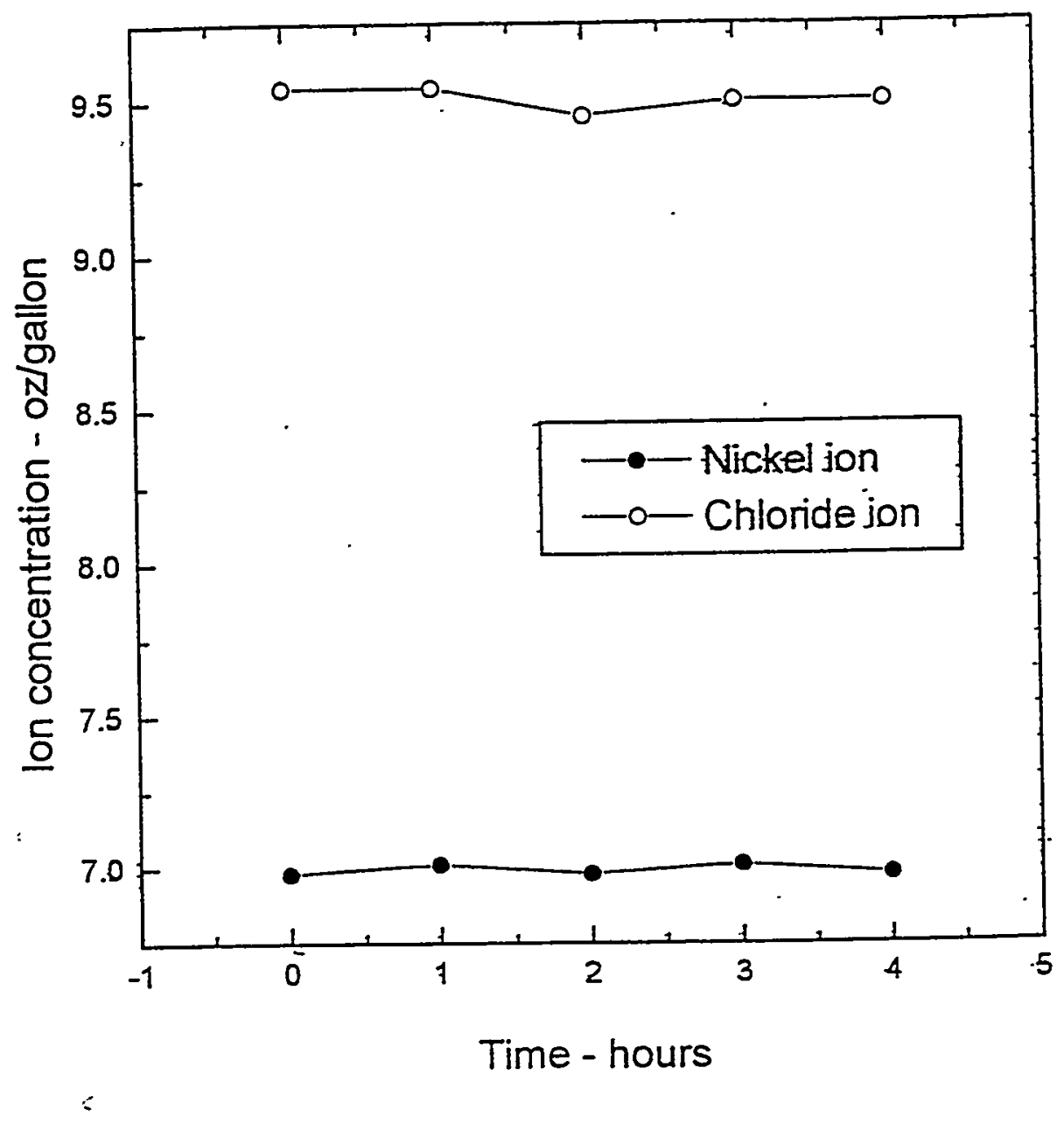

Change in the nickel ion and the chloride ion concentration with time.

Current density - 11.5 Amps/ $/ \mathrm{ft}^{2}$

Anode-cathode distance -2.5 inches 


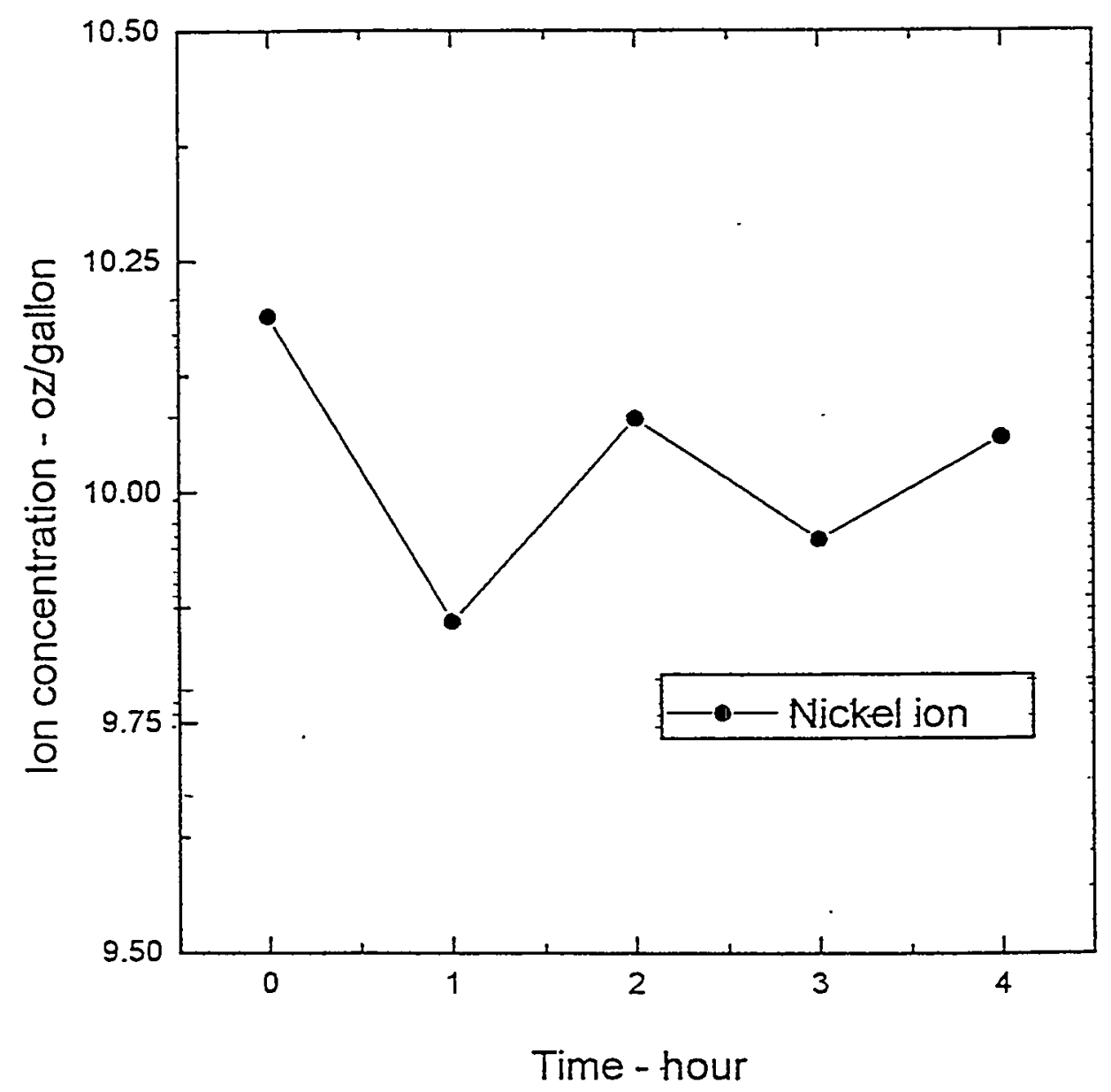

Change in the nickel ion concentration with time. Current density - 20 Amps $/ \mathrm{ft}^{2}$ Anode-cathode distance -2.5 inches 


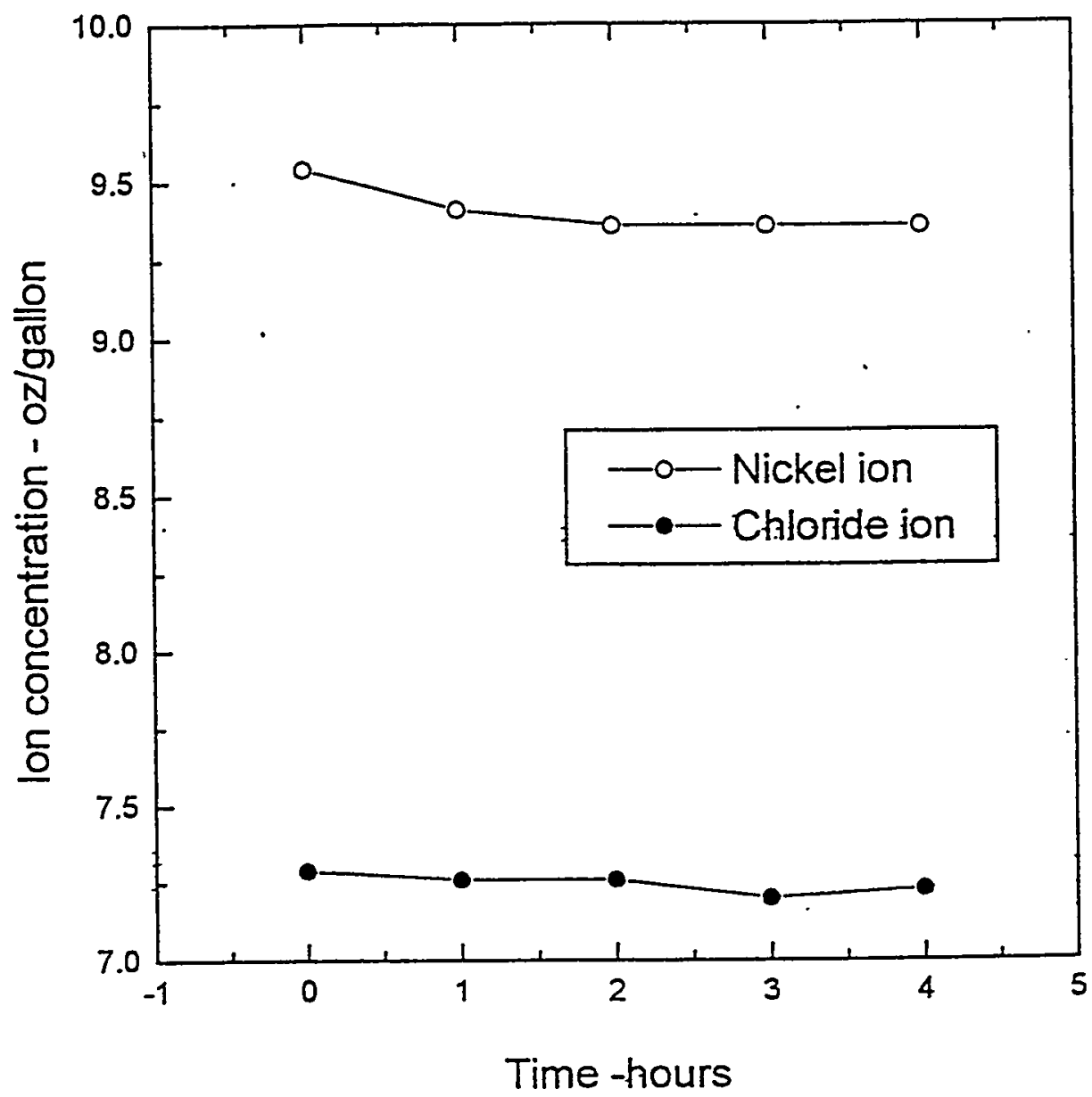

Change in the nickel ion and the chtoride ion concentration with time.

Current density - 20 Amps $/ \mathrm{ft}^{2}$

Anode-cathode distance - 3 inches 
MANUFACTURING SCIENCES CORPORATION

U.S. DEPARTMENT OF ENERGY

METC/FETC

\section{TASKS 311, 312, 313 COST SUMMARY}

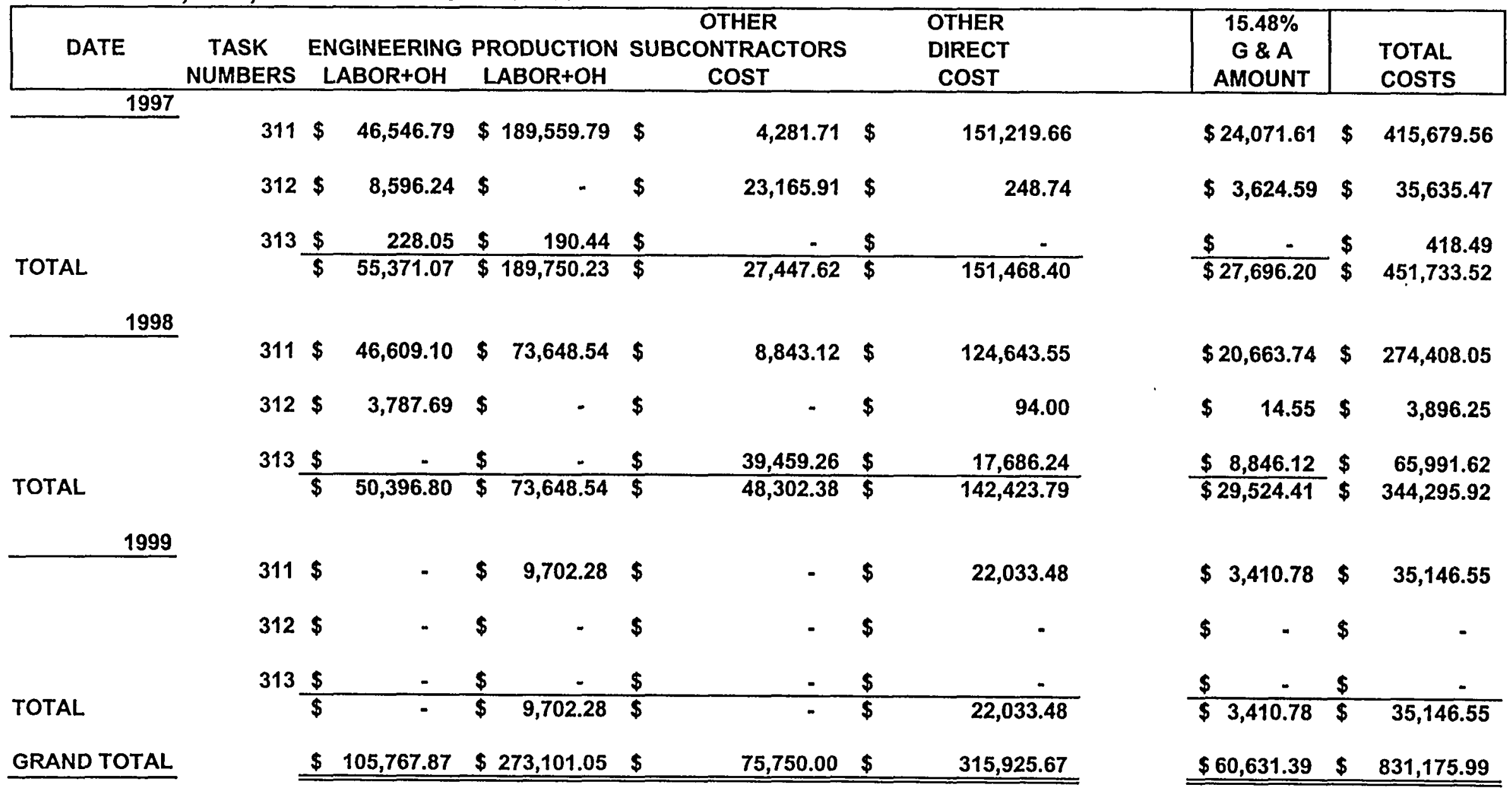




\section{OTHER DIRECT COSTS SUMMARY - TASKS 311,312,313 (ELECTROREFINING)}

Numbers are approximate

\begin{tabular}{|c|c|c|}
\hline Description & Includes & Price \\
\hline Electrical supplies & $\begin{array}{l}\text { Controllers, analyzers, meters, panel meters, } \\
\text { instrumentation, power supplies, heaters }\end{array}$ & $\$ 27,858$ \\
\hline Mold (anode melting) & & $\$ 24,850$ \\
\hline Main cell tank & Polyconcrete $\sim 15^{\prime}$ long & $\$ 5,300$ \\
\hline Tanks, frames, piping & $\begin{array}{l}\text { Sump, cementation, MRU, pipe, fittings, flex } \\
\text { duct, spheres, gaskets, clamps, membrane } \\
\text { frame }\end{array}$ & $\$ 33,967$ \\
\hline External Support services & $\begin{array}{l}\text { Design, safety analysis, programming, } \\
\text { calculations, consultation, reporting }\end{array}$ & $\$ 63,234$ \\
\hline Waste Tank & Tank for holding waste solutions & $\$ 1,365$ \\
\hline Pumps & & $\$ 2,842$ \\
\hline External Installation & Install ducts, fans, scrubber, etc. & $\$ 12,350$ \\
\hline Shipping & & $\$ 1,802$ \\
\hline Metal fab & $\begin{array}{l}\text { Purchase or copper, steel, fabrication, stands, } \\
\text { racks, buss, starter sheets, cementation starter, } \\
\text { etc. }\end{array}$ & $\$ 36,784$ \\
\hline Membrane frames & Cathode boxes & $\$ 17,585$ \\
\hline Chemicals & & $\$ 19,181$ \\
\hline Anode bags & & $\$ 354$ \\
\hline Cationic membrane & & $\$ 21,106$ \\
\hline Miscellanous & & $\$ 47,348$ \\
\hline Total & & $\$ 315,926$ \\
\hline
\end{tabular}


Appendix 3.2 
Final Report

Project No. 40578CSP

\author{
on \\ Remote Laser Cutting Demonstration \\ to
}

Rockwell Intemational
Canoga Park, CA

February 24, 1997

D

Lome Weeter

EDISON WELDING INSTITUTE

1250 Arthur E. Adams Drive

Columbus, $\mathrm{OH} 43221$ 


\section{Contents}

1.0 Introduction $\ldots \ldots \ldots \ldots \ldots \ldots \ldots \ldots \ldots \ldots \ldots \ldots \ldots \ldots \ldots \ldots \ldots$

2.0 Objectives $\ldots \ldots \ldots \ldots \ldots \ldots \ldots \ldots \ldots \ldots \ldots \ldots \ldots \ldots \ldots \ldots \ldots \ldots \ldots$

3.0 Testing $\ldots \ldots \ldots \ldots \ldots \ldots \ldots \ldots \ldots \ldots \ldots \ldots \ldots \ldots \ldots \ldots \ldots \ldots \ldots$

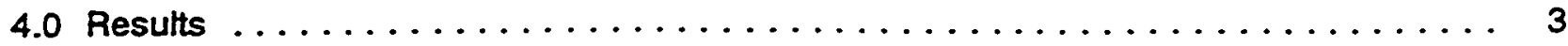

$4.1 \quad$ F4 Optical End Effector Trials $\ldots \ldots \ldots \ldots \ldots \ldots \ldots \ldots \ldots \ldots \ldots \ldots$

4.2 F8 Optical End Effector Trials ..................... 3

5.0 Discussion $\ldots \ldots \ldots \ldots \ldots \ldots \ldots \ldots \ldots \ldots \ldots \ldots \ldots \ldots \ldots \ldots \ldots \ldots \ldots$

6.0 Conclusions and Recommendations $\ldots \ldots \ldots \ldots \ldots \ldots \ldots$

7.0 Possible Follow-On Projects $\ldots \ldots \ldots \ldots \ldots \ldots \ldots \ldots \ldots \ldots \ldots \ldots$

\section{Appendix A}

Appendix B

\section{Tables}

Table 1. Chemical Composition of Steel Pipe $\ldots \ldots \ldots \ldots \ldots \ldots \ldots$

Table 2. Range of Parameters Used in Study $\ldots \ldots \ldots \ldots \ldots \ldots$

Table 3. Cutting Results for F4 End Effector $\ldots \ldots \ldots \ldots \ldots \ldots \ldots$

Table 4. Cutting Results for F8 End Effector . . . . . . . . . . . . . 9

Figures

Figure 1. Picture of the Experimental Set-up and Cutting end Effector $\ldots \ldots \ldots 10$

Figure 2. Picture of the Robotic Set-Up, Without the Rotary Positioner in Place . . . 11

Figure 3. Photomicrograph of Cut Surface Made with F4 End Effector ....... 11

Figure 4. Photomicrograph of Cut Sufface Made with F8 End Effector $\ldots \ldots \ldots \ldots$ 


\section{Remote Laser Cutting Demonstration}

\subsection{Introduction}

Rockwell is evaluating laser technology to size reduce radioactively contaminated power generation plants. The laser cutting process offers:

- Remote processing capability

- Low emission production

- Low consumable costs.

Because of these benefits, laser cutting is considered one of the prime processes for the sizereduction projects.

\subsection{Objectives}

The objective of this work was to use two different cutting end effectors to cut 0.375-in.-thick steel pipe. ETEC had prepared a matrix to establish a set of parameters for subsequent laser cutting demonstration tests. EWI used this matrix of parameters to vary power, travel speed, focal position, cutting gas, and cutting pressure to achieve "acceptable" cuts.

\subsection{Testing}

The chemical composition of the 0.375-in.-thick steel pipe that was used for the cutting trials is listed :-: Table 1. The pipe diameter was 12.75 in.. Rc:' :.ell as. .ed that this standard pipe would adequately simulate the piping that must be size reduced in the various applications.

All of the laser cutting trials were performed with a Lumonics/Hobart HLP3000 continuous wave Nd:YAG laser. The laser was operated at a maximum output of 2000 watts to simulate the achievable power of the MW2000 laser that Rockwell is leasing for additional trials. The power level was varied from 1000 to 2000 watts to determine the affect of output power on cutting speed and cut quality.

A 15-m-long fiberoptic cable was used to deliver the laser beam to the workpiece. The fiberoptic cable has a $0.6-\mathrm{mm}$-diameter fused silica core. Typical power losses for a 15-m-long fiberoptic cable are approximately $8 \%(3.5 \%$ at each end of the fiber and $1 \%$ in the fiber 
itself). Combined with the $2 \%$ loss in the beam injection optics inside of the laser and the $2 \%$ loss in the beam focusing optics at the end of the fiber, the total power loss is approximately $12 \%$.

Two optic: 1 end effectors with different $F$ numbers (the $F$ number is the focal length divided by the beam diameter at the focusing optics) were used to perform the cutting. An F4 end effector that can produce a 1.2-mm spot size and an F8 end effector that can produce a 2.4$\mathrm{mm}$ spot size were selected due to the thickness of the pipe and the long depth-of-field of these end effectors. Both end effectors use four optics to recollimate and focus the beam after the laser beam exits the fiberoptic cable. Both end effectors used 50-mm-diameter optics.

A standard co-axial cutting cone and nozzle were used to direct the cutting gas. A copper cutting nozzle with two different diameters (2.5 mm for the $F 4$ and $4.4 \mathrm{~mm}$ for the $F 8$ ) was used.

Both oxygen and air were used as the cutting gas. The yas pressures were varied from 1060 psi for oxygen and 100-120 psi for air.

The range of parameters and values used for the cutting trials is listed in Table 2.

The experimental set-up and cutting end effector are shown in Figure 1.

A Motoman K60S articulated arm robot was used to locate the optical end effector above an Aronson rotary-tilt positioner. The speed of the rotary positioner was varied to provide the different cutting speeds. The rotary positioner had approx:mately $3 \mathrm{~mm}$ of run-out. This runout affected the focal position of the beam on the cuts for the longer cuts or the 360-degree cuts, but did not dramatically affect the cut quality or the shorter cuts. The focal position was measured at various points to record the actual dimension. The robotic set-up, without the rotary positioner in place, is shown in Figure 2. 


\subsection{Results}

\subsection{F4 Optical End Effector Trials}

The results of the better cuts for the F4 end effector trials are summarized in Table 3 . Various tests were performed outside of the tabulated values to ensure that the best values were achieved. The total list of trials is included in Appendix A.

Results using the F4 (1.2-mm spot size) cutting end effector showed that the 0.375-in.-thick steel could be cut with minimal dross on the backside at laser powers between 1000 and 2000 watts (leaving the laser) and speeds of 26 to $32 \mathrm{ipm}$ with a oxygen assist gas at 18 psi. The focal position could be varied $\pm 3 \mathrm{~mm}$. $(0.120 \mathrm{in}$.) with little affect on the cut quality or speed. Figure 3 shows the cut surface for the 2000 watt, $32 \mathrm{ipm}$ with oxygen trial.

The main controlling parameters were gas type and gas pressure. Oxygen at too low or too high of gas pressure caused excessive dross on the backside. With the oxygen cutting gas set at $18 \mathrm{psi}$, the laser power could be varied from 1000 to 2000 watts with only a 6-ipm reduction in cutting speed (from $32 \mathrm{ipm}$ at 2000 watts to $26 \mathrm{ipm}$ at 1000 watts). The focal position also seemed to have minimal affect on the cut quality.

1... Parameters that cut through the material but left lots of dross could also be produced with air assist gas at 120 psi of gas pressure, but the cutting speed had to be reduced to approximately $10 \mathrm{ipm}$. The surface roughness of the air gas assist cuts also seemed rougher than the oxygen cuts.

The karf width varied from 0.038 to 0.070 in. depending on the narameters. At slow speeds and high powers, the kerf width was wide. At faster speeds or lower powers, the kerf is narrower. The width of the cut is important in producing emissions or fumes and providing the path for the dross to bridge the gap. A wider kerf may be desirable to ensure that the two pieces fall apart after cutting.

\subsection{F8 Optical End Effector Trials}

- The results of the F8 end effector trials are summarized in Table 4. Only the better cuts are tabulated in Table 1. The total list of trials are included in Appendix B. 
The F8 end effector (2.4-mm spot size) trials were similar to the F4 trials except that a much higher oxygen flow level was required and the cutting speed was slightly slower. To produce acceptable cuts, the oxygen pressure had to be increased to 60 psi. The cutting speed decreased from 26 ipm at 1000 watts with an F4 to $20 \mathrm{ipm}$ at 1000 watts with an F8 and from $32 \mathrm{ipm}$ at 2000 watts with an F4 to $26 \mathrm{ipm}$ at 2000 watts with an F8. Figure 4 shows the cut surface for the 2000 watt, $26 \mathrm{ipm}$ with oxygen trial.

Again, acceptable cuts could be made from 1000 to 2000 watts. Similar to the F4 results, the gas type and gas pressure were the controlling parameters. Oxygen at too low or too high gas pressure caused excessive dross on the backside.

Air gas assist did not produce acceptable cuts. 2700 watts of laser power was used to determine if a higher laser power would help the cutting process. Even with the higher laser power, the cut was very heavy with dross.

The kerf width varied from 0.083 to 0.133 in. for the $F 8$ end effector. The wider kerf was expected since the focused spot size is $1.2 \mathrm{~mm}(0.048 \mathrm{in}$.) wider than the F4. Although the F8 would produce more emissions than the F4, the F8s wider kerf width may be advantageous to ensure the pieces fall apart.

\subsection{Discussion}

The results indicate that the exothermic reaction of the oxygen cutting gas and the iron in the steel create the majority of the energy needed to melt the steel. The laser provides the initial heat source needed to reach this exothermic reaction level and some additional cutting power. However, doubling the laser power does not double the cutting cpeed since the oxygen is doing most of the cutting. The correct amount of oxygen per volume of steel is needed to produce acceptable cuts.

Too little oxygen for a set travel speed does not input enough oxygen to successfully cut through the steel. Increasing the laser power at low oxygen flows does help, but cannot overcome the loss of the oxygen.

Too much oxygen for the volume of metal in the kerf causes excessive melting of the steel. The oxygen's gas pressure can not force this excessive molten steel through the kerf and dross/bur is left on the backside of the cut. Increasing the cutting speed does not necessarily help since then not enough oxygen and laser power is delivered to melt the steel. 
Since air is approximately $82 \%$ nitrogen, it does not produce the same exothermic reaction as oxygen. Thus, the cutting speed and cut quality are both reduced.

The F8 (2.4-mm spot size) optical end effector requires 3.3 times more oxygen pressure (60 psi compared to $18 \mathrm{psi}$ ) to achieve acceptable cuts. The F8 needed a nozzle opening of 4.4 $\mathrm{mm}$ compared to $2.5 \mathrm{~mm}$ to allow the laser beam to pass through the nozzle opening without clipping the nozzle. This larger nozzle diameter opening calculates to a 3-time increase in area of the nozzle opening. Because of this 3-time increase in area, the oxygen pressure had to be increased approximately 3 times to achieve the same volume of gas reaching the cutting surfaces.

The amount of additional oxygen used per cut is also compounded by the slower cutting speeds of the F8 end effector. The power density (laser power divided by the focused spot area) is 4 times less than the F4 end effector. As explained above, the oxygen cutting gas supplies the majority of the energy for cutting; thus, the lower power density does not have a major affect but it does decrease the cutting speed from 18 to $26 \%$.

Because of the larger kerf width, the F8 end effector also generates more emissions than the F4 end effector. If we assume all of the material in the kerf produces emissions either as gas or as resolidified debris on the floor, the F8 end effector produce approximately 1.8-2.0 times as much emissions as the F4. These extra emissions will increase the costs of the fume filters and other associated emission devices that must be properly disposed.

The main reason for using the F8 end effector was to achieve a longer depth of field. A longer depth of field should permit more tolerance for focal position and possibly produce better cuts in thick materials. However, the results of this test did not demonstrate the benefits of a longer depth of field for this application. For these trials, it was assumed that the focal position would be fixed to the end of the nozzle. Thus, if the focus moved away from the part, the nozzle would also move the same distance away from the part. This was done to simulate the production application of laser cutting. Therefore, this study actually evaluated the compounded influence of focus and nozzle stand-off (the distance from the cutting nozzle to the workpiece) distance. Since this study has clearly demonstrated the major influence of the oxygen cutting gas on the cutting speed and quality, it is believed that the nozzle stand-off distance overshadowed the depth-of-field affect. This study did show that the nozzle stand-off and focus could change by as much as $\pm 3 \mathrm{~mm}$ without detrimentally affecting the cutting speed or cut quality. For the production cutting cell, surface followers are available that can easily maintain the nozzle stand-off and focus to within $\pm 0.2 \mathrm{~mm}$. 
Since only one material thickness was cut, it is impossible to quantify the affect of the F8's longer depth of field on cutting thicker material. Additional trials are required to assess this -...- effect.

The F8. end effector did produce a wider kerf width than the F4 end effector. This wider kerf width helps keep the motten dross from bridging the gap and "rewelding" the cut closed. In production, this wider kerf width may be beneficial for remote cutting applications where it is difficult to maintain consistent conditions or the material thickness is changing.

\subsection{Conclusions and Recommendations}

The results from this study generate the following conclusions and recommendations:

1. The type of cutting gas and the cutting gas pressure are the major controlling factor for cutting thick steel. Oxygen generated the best cuts. The oxygen pressure depended greatly on the diameter of the cutting nozzle opening.

2. Consistent, acceptable cuts can be produced in 0.375-in.-thick steel material throughout a wide range of laser parameters. The laser power could change $50 \%$ with only a $20 \%$ change in speed required to maintain acceptable cuts.

3. The nozzle stand-off can vary $\pm 3 \mathrm{~mm}$ without greatly affecting the cutting speed or cut quality. In production, a device that maintains a set stand-off should be incorporated into the cutting system.

4. The F4 end effector produced faster cuts anr narrower kerf widths with 3 times less oxygen consumption than the $F 8$ end effector.

5. Although not quantified, the F4 end effector should produce fewer emissions than the F8 end effector.

6. The wide kerf width of the F8 end effector may be beneficial for certain production applications where it is difficult to control the laser parameters. 


\subsection{Possible Follow-On Projects}

The results of this study have shown several key factors for size reducing radioactively contaminated fabrications. Several important areas still exist to properly understand the laser cutting procenss for these applications.

1. Quantify the amount of emissions produced with bath the F4 and F8 end effectors at the different laser parameters.

2. Evaluate cutting thicker (0.5-in.-thick) steel.

3. Optimize the cutting parameters for various thicknesses of steel.

4. Assist with the design of a production cutting system.

5. Assist in training operators and transferring the knowledge gained from this study to production.

EWI offers the capability, equipment and experience to assist Rockwell with additional portions of this project. We can provide assistance at EWI, at Rockwell or at Manufacturing Sciences Corporation. Please let us know how we can help you.

For more information, contact: Lome Weeter at 614-688-5239. 
Table 1. Chemical Composition of Steel Pipe

\begin{tabular}{|c|c|}
\hline Element & Composition, weight \% \\
\hline $\mathrm{C}$ & 0.072 \\
\hline $\mathrm{Mn}$ & 0.098 \\
\hline $\mathrm{P}$ & 0.009 \\
\hline $\mathrm{S}$ & 0.007 \\
\hline $\mathrm{Si}$ & 0.190 \\
\hline $\mathrm{Cu}$ & 0.013 \\
\hline $\mathrm{Sn}$ & 0.015 \\
\hline $\mathrm{Ni}$ & 0.004 \\
\hline $\mathrm{Cr}$ & 0.018 \\
\hline $\mathrm{Mo}$ & 0.012 \\
\hline $\mathrm{Al}$ & 0.028 \\
\hline $\mathrm{V}$ & 0.000 \\
\hline $\mathrm{Nb}$ & 0.035 \\
\hline $\mathrm{Zr}$ & 0.001 \\
\hline $\mathrm{Ti}$ & 0.001 \\
\hline $\mathrm{Ca}$ & 0.001 \\
\hline $\mathrm{Co}$ & 0.001 \\
\hline $\mathrm{Fe}$ & $B a 1 a n c e$ \\
\hline
\end{tabular}

Table 2. Range of Parameters Used in Study

\begin{tabular}{|c|c|c|c|}
\hline Variables & High Value & Low Value & Comments \\
\hline Power (watts) & 2000 & 1000 & Measured at laser \\
\hline Cutting speed (m/min) & 32 & 10 & \\
\hline Gas pressure (psi) & $60 / 120$ & $10 / 80$ & Oxygen/air \\
\hline Gas type & oxygen & air & \\
\hline Focus $( \pm \mathrm{mm})$ & +4 & -2 & \\
\hline Nozle distance $(\mathrm{mm})$ & +4 & 0.2 & $3 \mathrm{~mm}$ is nominal \\
\hline \multicolumn{4}{|c|}{ Constants } \\
\hline Nozzle opening & $2.5 / 4.4$ & $2.5 / 4.4$ & F4/ 88 optics \\
\hline Fiber length (meters) & 15 & 15 & \\
\hline Motion system & robot & robot & \\
\hline Material & 3/8-in. steel & 3/8-in. steel & \\
\hline
\end{tabular}


Table 3. Cutting Results for F4 End Effector

\begin{tabular}{|c|c|c|c|c|c|c|c|c|}
\hline $\begin{array}{l}\text { Trial } \\
\text { No. }\end{array}$ & $\begin{array}{l}\text { Power } \\
\text { (watts) }\end{array}$ & $\begin{array}{l}\text { Speed } \\
\text { (jpm) }\end{array}$ & $\begin{array}{l}\text { Focus } \\
(\mathrm{mm})\end{array}$ & $\begin{array}{l}\text { Nozzle } \\
\text { Diameter } \\
\text { (mm) }\end{array}$ & $\begin{array}{l}\text { Gas } \\
\text { Type }\end{array}$ & $\begin{array}{c}\text { Gas } \\
\text { Pressure } \\
\text { (psi) }\end{array}$ & $\begin{array}{l}\text { Stand- } \\
\text { off } \\
(\mathrm{mm})\end{array}$ & Comments \\
\hline 2 & $20 n n$ & 10 & 0 & 2.5 & Air & 100 & 3 & $\begin{array}{l}\text { Dross, aimost } \\
\text { through }\end{array}$ \\
\hline 4 & 2000 & 10 & -2 & 2.5 & Air & 100 & 2 & $\begin{array}{l}\text { Still dross, but } \\
\text { best cut so far }\end{array}$ \\
\hline 10 & 2000 & $\overline{10}$ & 0 & 2.5 & Air & 120 & $\overline{1.5}$ & $\begin{array}{l}\text { Still drass, but } \\
\text { slightly better }\end{array}$ \\
\hline 14 & 2000 & 32 & -2 & 2.5 & $\Omega_{2}$ & 18 & 1.5 & No cut \\
\hline 17 & 2000 & 32. & 0 & 2.5 & $\mathrm{O}_{2}$ & 18 & 3.0 & $\begin{array}{l}\text { Cut all the way } \\
\text { around. looks } \\
\text { good. }\end{array}$ \\
\hline 19 & 1800 & .26 & 0 & 2.5 & $\mathrm{O}_{2}$ & 18 & 3.0 & Faity clean cut \\
\hline 27 & 1200 & 26 & 0 & 25 & $\mathrm{O}_{2}$ & 20 & 3.0 & $\begin{array}{l}\text { Nice cut. faity } \\
\text { clean }\end{array}$ \\
\hline 30 & 1000 & 26 & $\overline{0}$ & 2.5 & $\overline{\mathrm{O}_{2}}$ & 20 & 3.0 & $\begin{array}{l}\text { Nice cut. fairty } \\
\text { clean }\end{array}$ \\
\hline
\end{tabular}

Table 4. Cutting Results for F8 End Effector

\begin{tabular}{|c|c|c|c|c|c|c|c|c|}
\hline $\begin{array}{l}\text { Trial } \\
\text { No. }\end{array}$ & $\begin{array}{l}\text { Power } \\
\text { (watts) }\end{array}$ & $\begin{array}{l}\text { Speed } \\
\text { (ipm) }\end{array}$ & $\begin{array}{l}\text { Focus } \\
(\mathrm{mm})\end{array}$ & $\begin{array}{l}\text { Nozzle } \\
\text { Diameter } \\
\text { (mm) }\end{array}$ & $\begin{array}{l}\text { Gas } \\
\text { Type }\end{array}$ & $\begin{array}{c}\text { Gas } \\
\text { Pressure } \\
\text { (psi) }\end{array}$ & $\begin{array}{l}\text { Stand- } \\
\text { off } \\
(\mathrm{mm})\end{array}$ & Comments \\
\hline $3 a$ & 2000 & 20 & 0 & 4.4 & $\mathrm{O}_{2}$ & 35 & 3.0 & $\begin{array}{l}\text { Lots of dross, but } \\
\text { would separate }\end{array}$ \\
\hline $5 a$ & 2000 & 26 & $\overline{0}$ & 4.4 & $\overline{\mathrm{O}_{2}}$ & EJ & 20 & $\begin{array}{l}\text { Kerf is } 0.133 \text { in. } \\
\text { good cut. }\end{array}$ \\
\hline $6 a$ & 1500 & 32 & $\overline{0}$ & 4.4 & $\overline{\mathrm{O}_{2}}$ & $\sim \dot{v}$ & 2.0 & $\begin{array}{l}\text { More dross, but } \\
\text { would separate. }\end{array}$ \\
\hline$\overline{9 a}$ & 1000 & 20 & 0 & 4.4 & $\overline{\mathrm{O}_{2}}$ & 60 & 2.0 & $\begin{array}{l}\text { Full separation. } \\
\text { some dross. Kerf } \\
=0.094 \text { in. }\end{array}$ \\
\hline 108 & 2000 & 10 & 0 & 4.4 & air & 120 & 2.0 & No cut \\
\hline $11 \mathrm{a}$ & 2700 & 10 & 0 & 4.4 & air & 120 & 2.0 & $\begin{array}{l}\text { Looks like it } \\
\text { would separate, } \\
\text { but lots of dross. } \\
\text { Kerf }=0.098 \text { in. }\end{array}$ \\
\hline
\end{tabular}




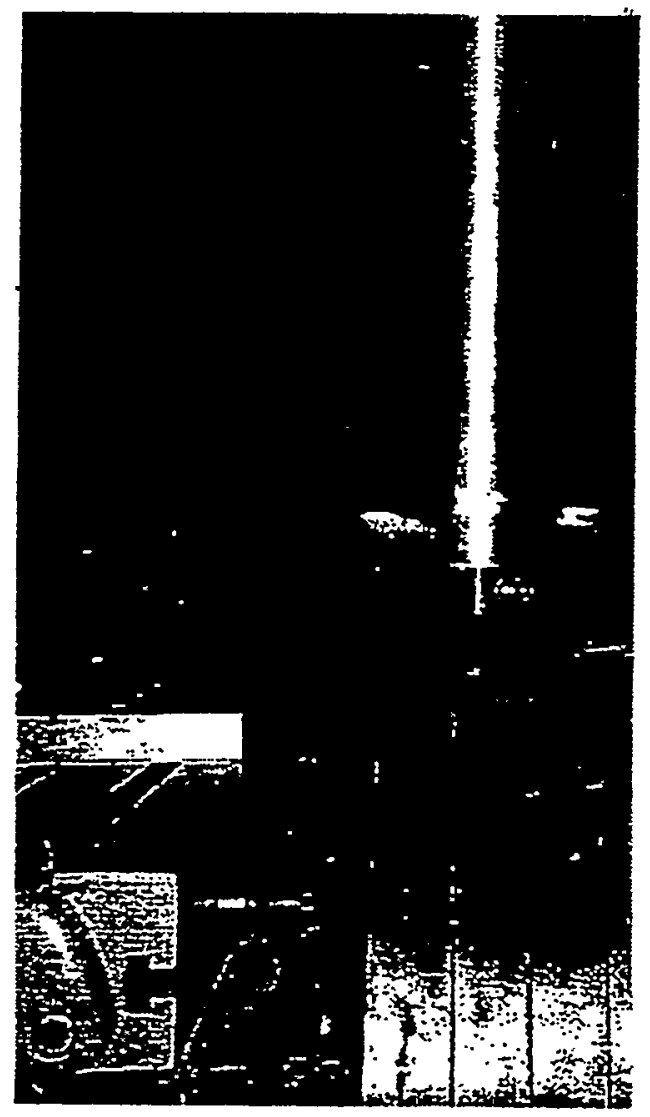

Figure 1. Picture of the Experimental Set-up and Cutting end Effector 


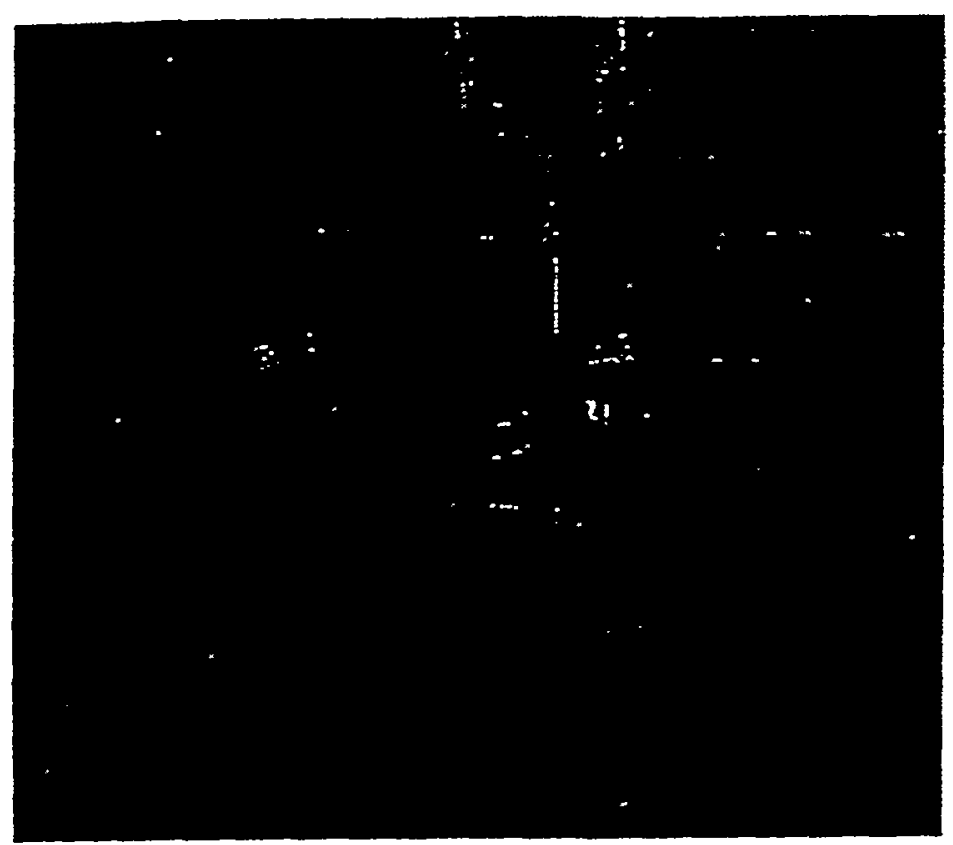

Figure 2. Picture of the Robotic Set-Up, Whout the Rotary Positioner in Place

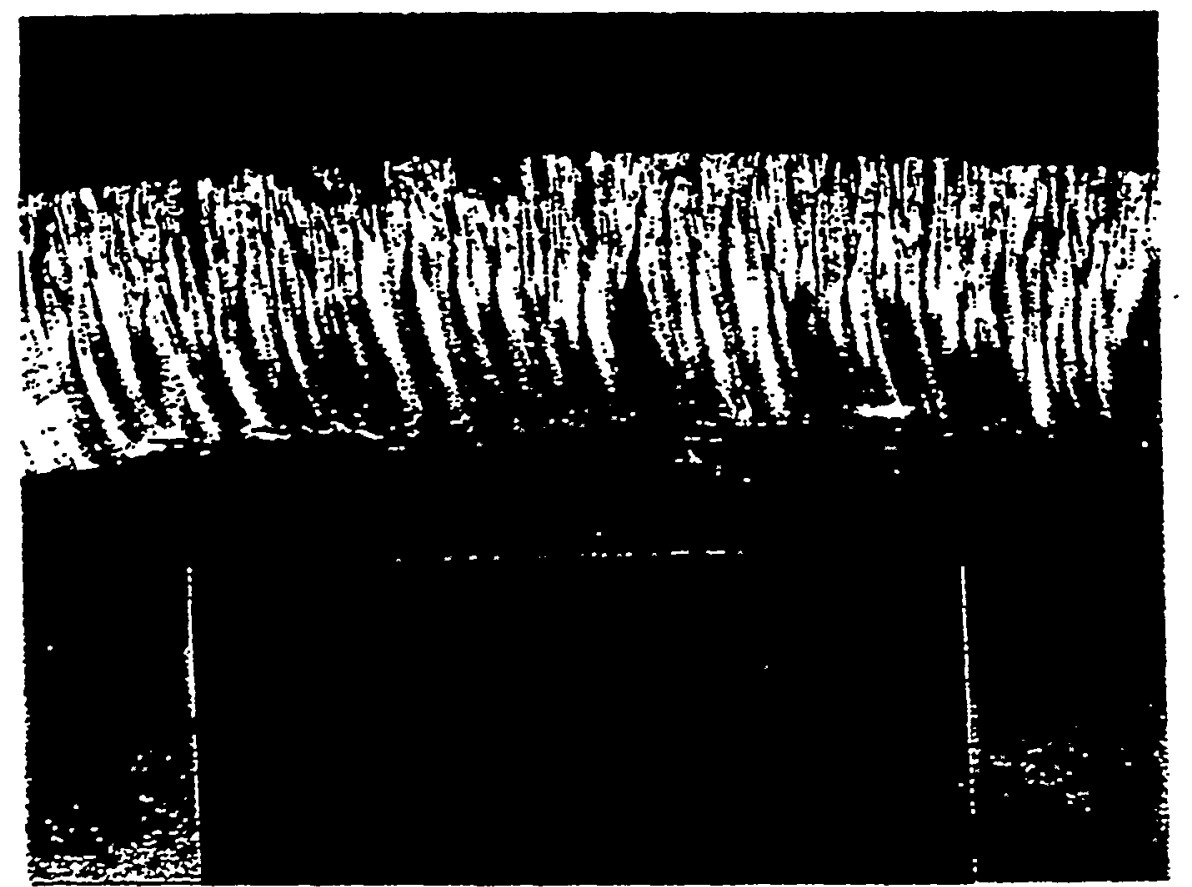

Figure 3. Photomicrograph of Cut Surface Made with F4 End Effector (2000 watts, 32 ipm and oxygen assist gas) 


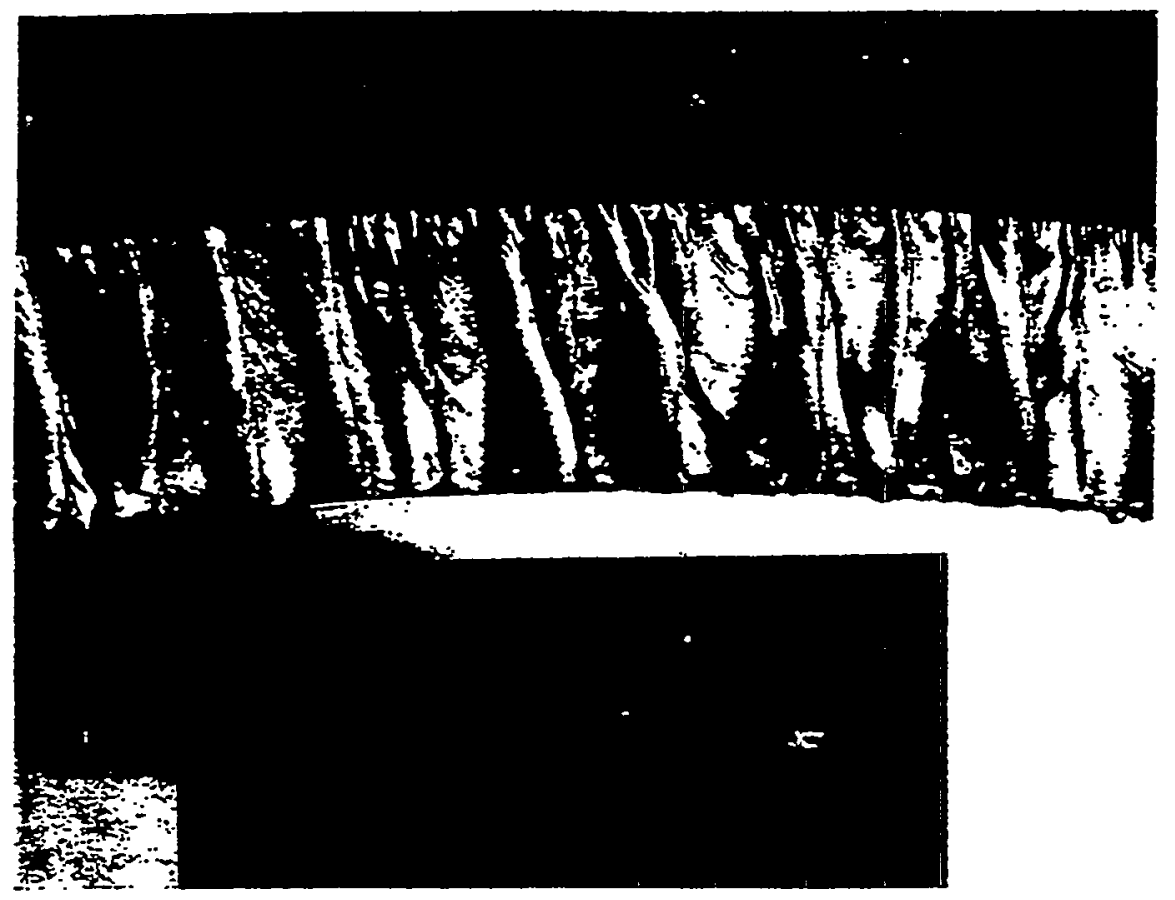

Figure 4. Photomicrograph of Cut Surface Made with F8 End Effector (2000 watts, 26 ipm rnd oxygen assist gas) 


\section{Appendix A}

)

।

1

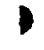




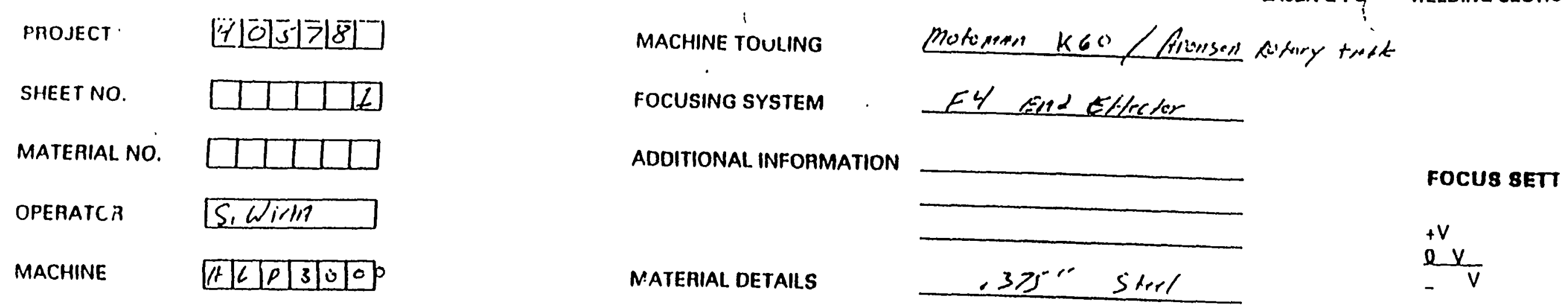

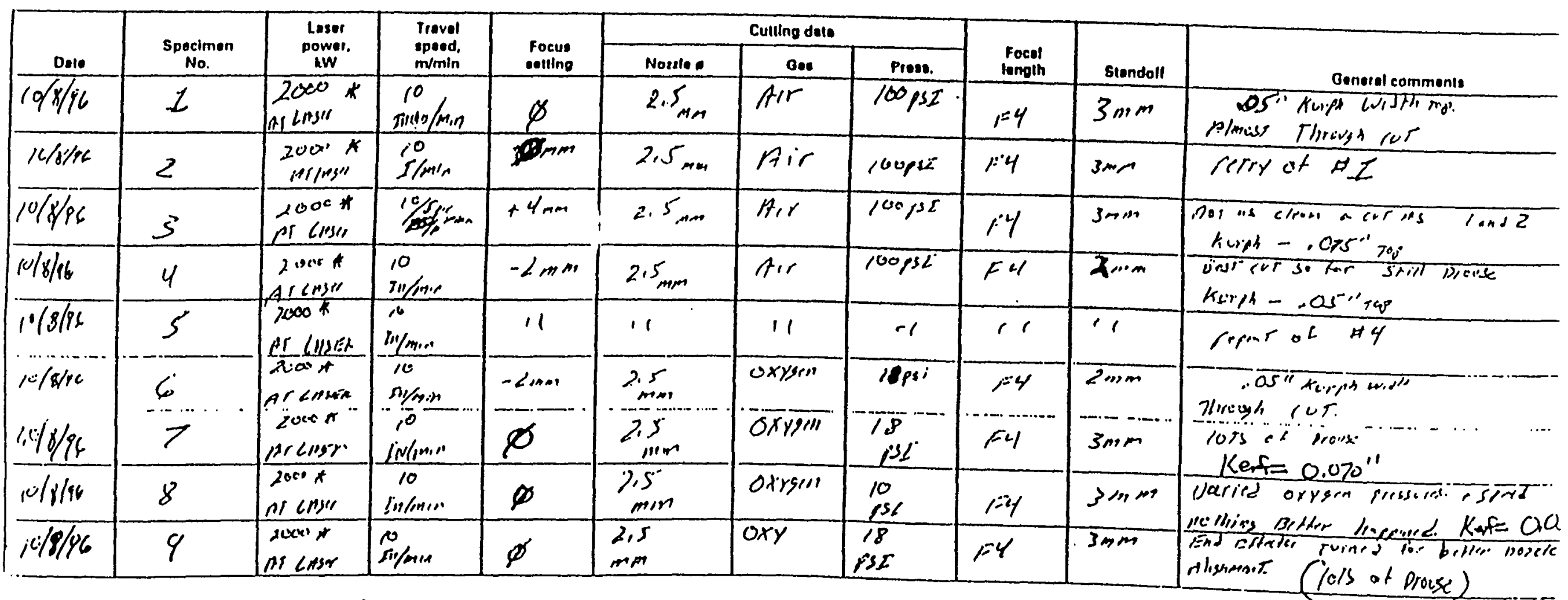

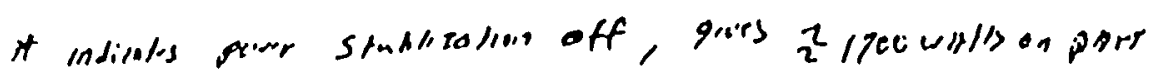

icin 
DATA SHEET

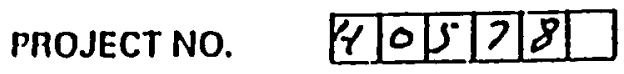

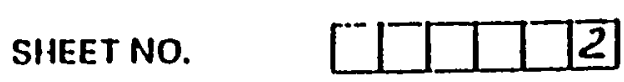

PROCESS: LASER CUTTING

CONTINUATION SHEET

LASER \& FORGE WELDING SECT

Dotalle as shoot No. $\square \square \square \square \square$

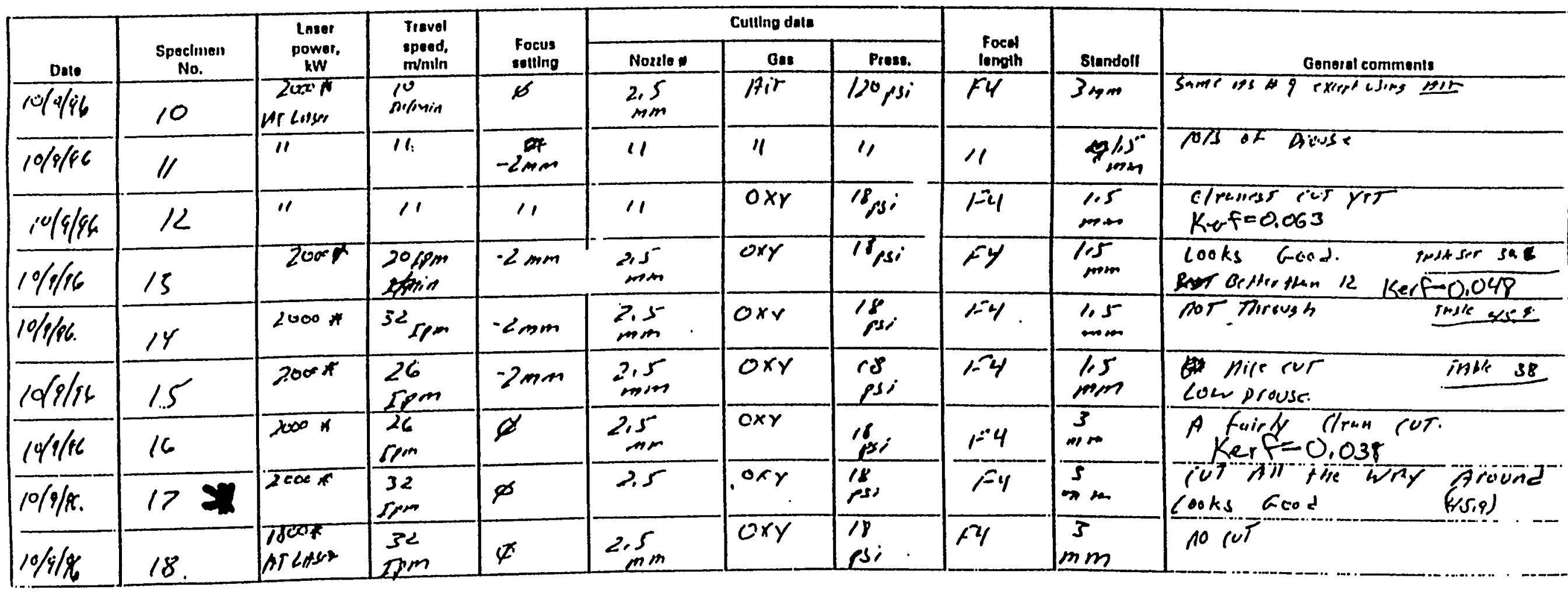

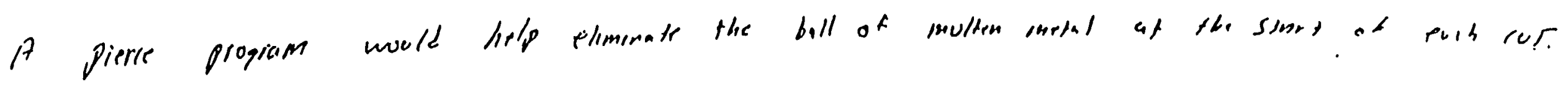


DATA SHEET

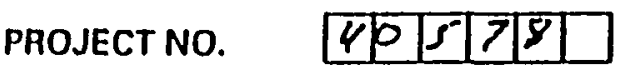

SHEET NO.

\section{PROCESS: LASER CUTTING}

CONTINUATION SHEET

Dot alle as sheot No. $\square \square \square \square \square$

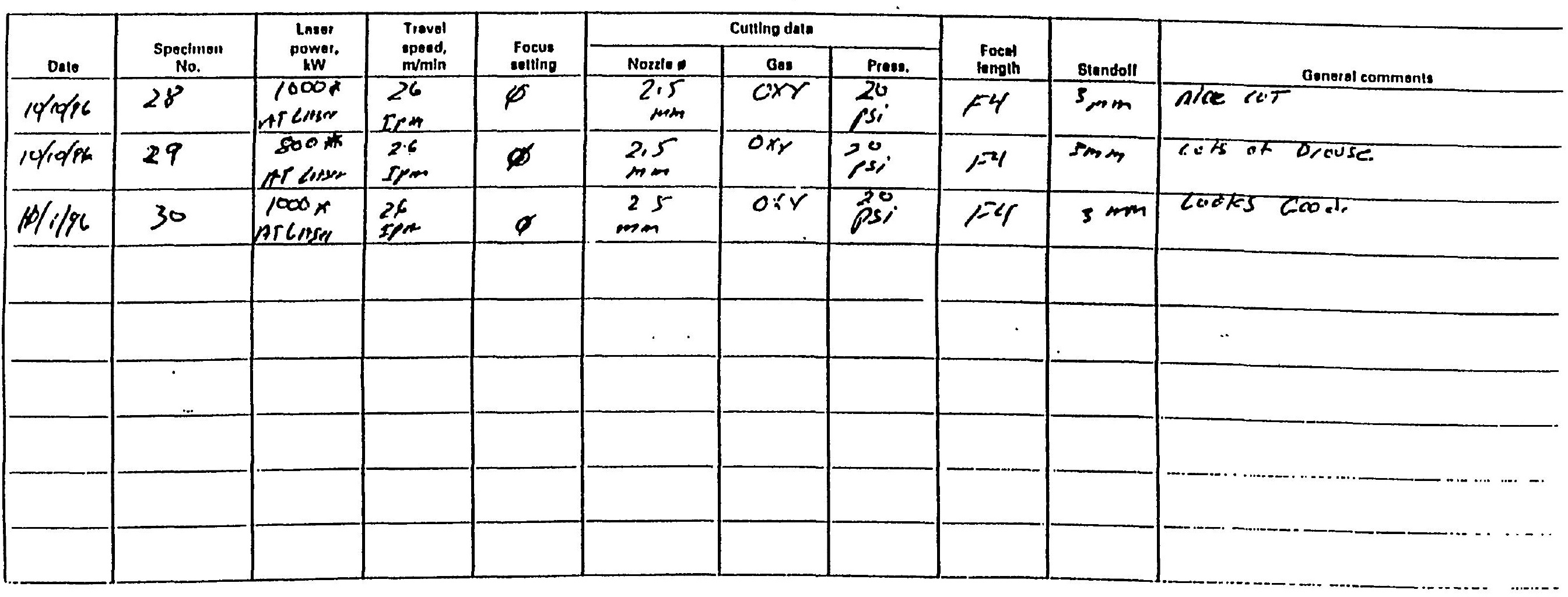


Appendix B 
DATA SHEET

PROCESS: $r-$ LASER CUTTING

LASER \& FOP Y MELDING SECTOI

PROJECT

MACHINE TOOLING
FOCUSING SYSTEM

SHEET NO. $\square \square \square \square$

MATERIAL No. $\square \square \square \square$

ADDITIONAL INFORMATION to segerede perterial

FOCUS SET

OPERATOR SCOrIA

MATERIAL DETAILS

$.585^{\prime \prime}$ shed

$e_{-v}^{+v}$

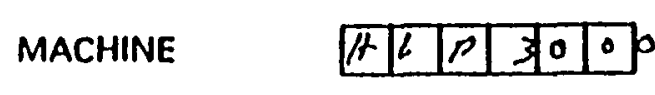

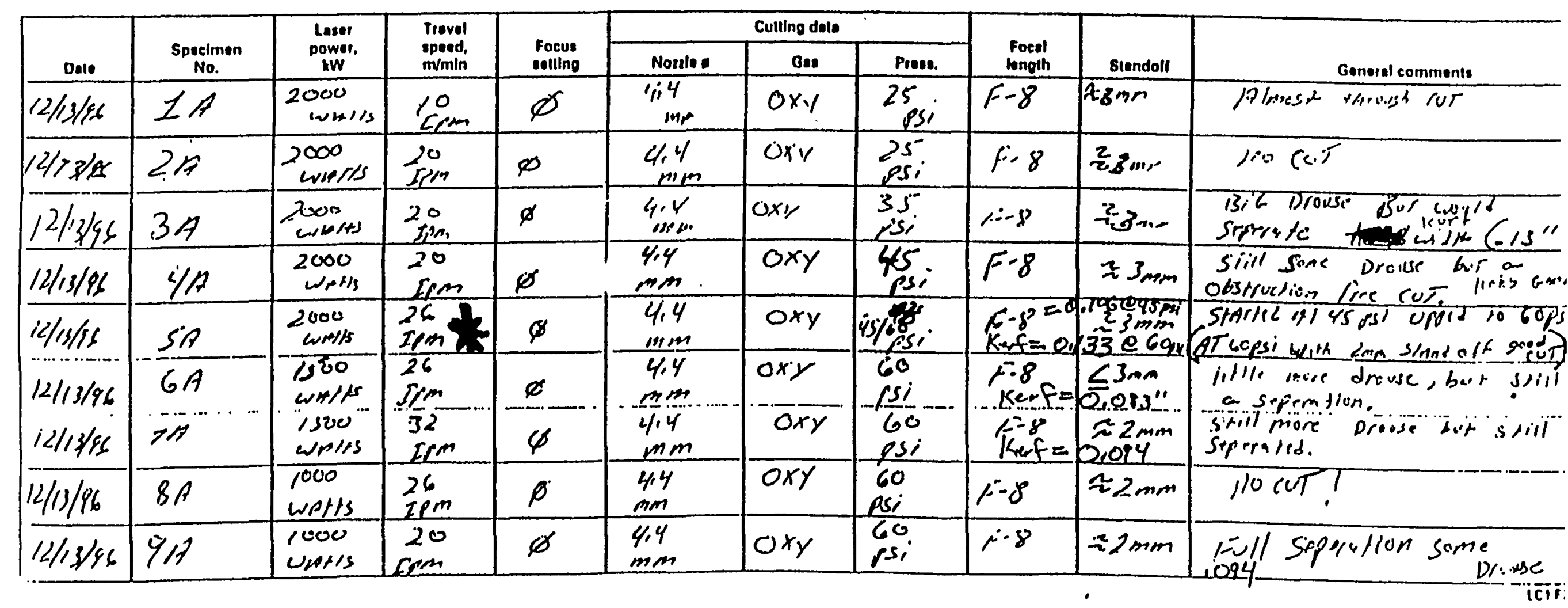




\section{DATA SHEET}

PROJECTNO. 40.578

SHEET NO.
PROCESS: CO, LABEA CUTTINO

CONTINUATION SHEET

Dotalle as shoot No. $\square \square \square \square \square$

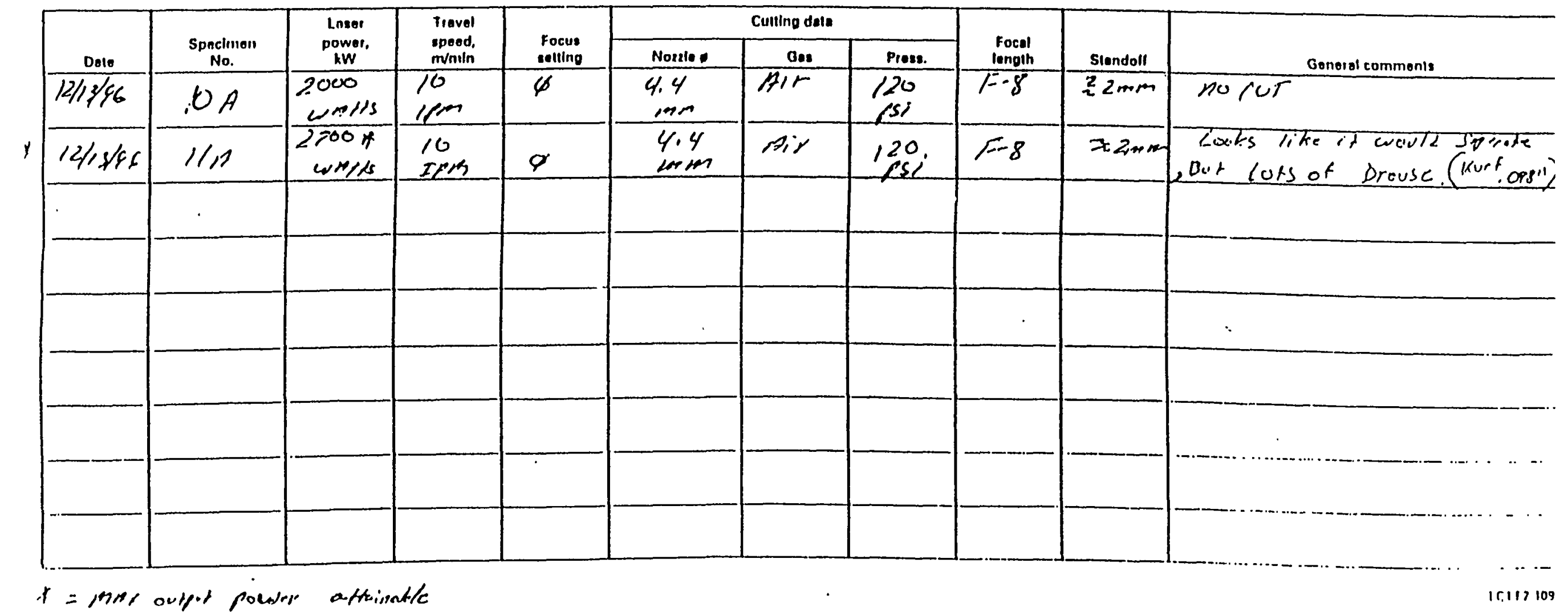




\section{REMOTE LASER SLZE-REDUCTION OF RADIOACTIVE COMPONENTS}

\author{
S. N. Shah, R. B. Hardy, and D. W. Kneff \\ Energy Technology Engineering Center \\ The Boeing Company, Rocketdyne Propulsion \& Power \\ P.O. Box 7930 \\ Canoga Park, CA 91309 \\ (818) $586-5007$
}

\author{
V. MacNair and S. Sarten \\ Manufacturing Sciences Corporation \\ 804 Kerr Hollow Road \\ Oak Ridge, TN 37830 \\ (423) $481-0455$
}

\section{ABSTRACT}

A technology development program was undertaken to evaluate the effectiveness of remote laser cutting in decontamination and decommissioning (D\&D) activities. The program employed an off-the-shelf laser with fiberoptic beam delivery to size-reduce various components. It included four distinct steps: (1) an initial series of laboratory tests to establish the cutting capabilities of a commercially available Nd:YAG laser with a fiberoptic beam delivery system, and to develop laser system parameters for subsequent deployment demonstration programs; (2) a deployment demonstration at the Energy Technology Engineering Center (ETEC), where a large inventory of radiologically contaminated reactor fuel storage tubes was size-reduced for disposal using remote laser cutting; (3) a follow-on deployment demonstration at the Manufacturing Sciences Corporation (MSC), where the remote laser cutting operation was further automated and used to size-reduce thicker materials; and (4) a subsequent series of laboratory bench-scale tests to enhance the laser cutting data base in areas identified by the deployment demonstrations. The results of the program demonstrate that an off-the-shelf laser system with fiberoptic beam delivery can be used effectively in D\&D applications.

\section{INTRODUCTION}

The DOE complex and the commercial nuclear industry encompass a large number of nuclear reactor and processing facilities that require near-term dismantlement. :The dismantlement tasks are major challenges for which technology innovations in size reduction, decontamination, and characterization are required to decrease operating costs and personnel exposures over conventional techniques. The use of lasers has been investigated recently for nuclear facility decontamination and decommissioning (D\&D) tasks. A preliminary Oak Ridge National Laboratory study showed that approximately $\$ 1$ billion can be saved by using lasers for the size reduction of diffusion plant structural components at the K-25 Plant in Oak Ridge, Tennessee. The Energy Technology Engineering Center (ETEC) investigated the application of laser technology to dismantlement tasks and waste management using fiberoptic beam delivery to remote cutting sites, and found it to offer substantial benefits as a new D\&D tool. ${ }^{2}$ The ETEC investigation identified two laser systems as promising candidates for semote laser curting in D\&D applications: Nd:YAG (neodymium-doped ytrium aluminum garnet) for current, off-the-shelf use, and the chemical oxygen iodine laser (COIL) for later-term use at much higher laser output powers. Both lasers have wavelengths that transmit through optical fibers with minimum power loss for remote beam delivery. Based on the study results, several bench-scale tests and two deployment tests were performed to investigate and demonstrate the effectiveness of available Nd:YAG lasers for $D \& D$ size-reduction activities.

The size-reduction test activities included four steps that lead toward the large-scale implementation of lasers in D\&D applications: (1) an imitial series of laboratory tests to establish Nd:YAG cutting capabilities and to develop laser system parameters for the subsequent deployment demonstration programs; (2) a deployment demonstration at ETEC to size-reduce a large inventory of radiologically contaminated fuel storage tubes for disposal using remote laser cutting; (3) a follow-on deployment demonstration at the Manufacturing Sciences Corporation (MSC) to further automate the remote laser cutting operation and size-reduce thicker materials; and (4) a subsequent series of laboratory bench-scale tests to enhance the laser cutting data base in areas identified by the deployment demonstrations. The results of the four sets of tests and demonstrations are summarized in this paper.

\section{INITLAL LASER CUTTING TESTS}

The initial series of laboratory tests was performed by the Edison Welding Instinte under contract to ETEC. ${ }^{3}$ A continuous-wave (non-pulsed) $3-k W$ Nd:YAG with a $15-\mathrm{m}$ long fiberoptic beam delivery system was used to cut $1-\mathrm{cm}$ thick steel pipe over a laser power range of 1000 to 2700 Watts. Variables examined included beam power, laser endeffector focal length, assist gas type and pressure, and 
cutting speed. The assist gas is a gas flow across the work area which blows debris created by the cutting process away from the cutting zone and supplies energy required to perform the cutting. An important consideration was the effect of these variables on kerf (cut) width, for which a smaller kerf minimizes secondary waste while a wider kerf helps keep molten dross from bridging the cut and rewelding it. A total of forty-one test cuts were made, with an estimated total power loss associated with the beam delivery system of about $12 \%$. The assist gas type and pressure were found to be the primary parameters controlling the quality of the cuts. The results were used to select a laser focusing head, identify oxygen as the optimum assist gas, and establish initial cutting parameters to be used in the subsequent deployment demonstrations.

\section{ETEC LASER DEPLOYMENT DEMONSTRATION}

The ETEC laser deployment program used an off-the-shelf 2-kW Nd:YAG laser system to section approximately 300 radiologically contaminated nuclear fuel storage tubes for inspection and disposal. ${ }^{4}$ Figure 1 provides a schematic diagram of the general configuration used for the deployment tests. The laser resonator, power supply, water chiller, gas assist supply, and operational controls were located in a nonhazardous environment for protection and maintenance accessibility. The laser focusing head and a tube-holding fixture were located within a radiologically controlled containment tent, which was fitted with a HEPAfiltered ventilation system. The laser beam was delivered to the focusing head through a $15-\mathrm{m}$-long fiberoptic cable. Each 3-m-long, 12.7-cm-diameter storage tube was positioned horizontally on the fixture, where two longitudinal cuts were made by moving the laser head lengthwise along the tube and one circumferential cut was made by rotating the tube. Each tube was thus sectioned into four approximately equal half-cylinder sections. A continuous-wave laser power level of $0.8 \mathrm{~kW}$ was used for these thin-wall (1.6-mm-thick) tubes, with an oxygen assist gas and a linear cutting speed of about $400 \mathrm{~cm} / \mathrm{min}$. Each tube was size-reduced in about $2 \frac{1}{2}$ minutes, including the time to load each tube and unload the tube sections manually. (Only the laser cutting was automated for this demonstration.) Figure 2 is a photograph of the laser cutting activity.

A number of additional test cuts were performed using a plasma-arc torch to provide comparative data using currentpractice technologies. The plasma-arc tests used an identical geometry and cutting procedure. Comparisons showed that the laser and plasma-arc had comparable cutting speeds, but the plasma-arc generated a much larger quantity of secondary waste because of its much larger kerf. That difference, plus the higher plasma-arc maintenance requirements, result in higher cutting costs for the plasmaarc system. Cost comparisons for the ETEC demonstration,

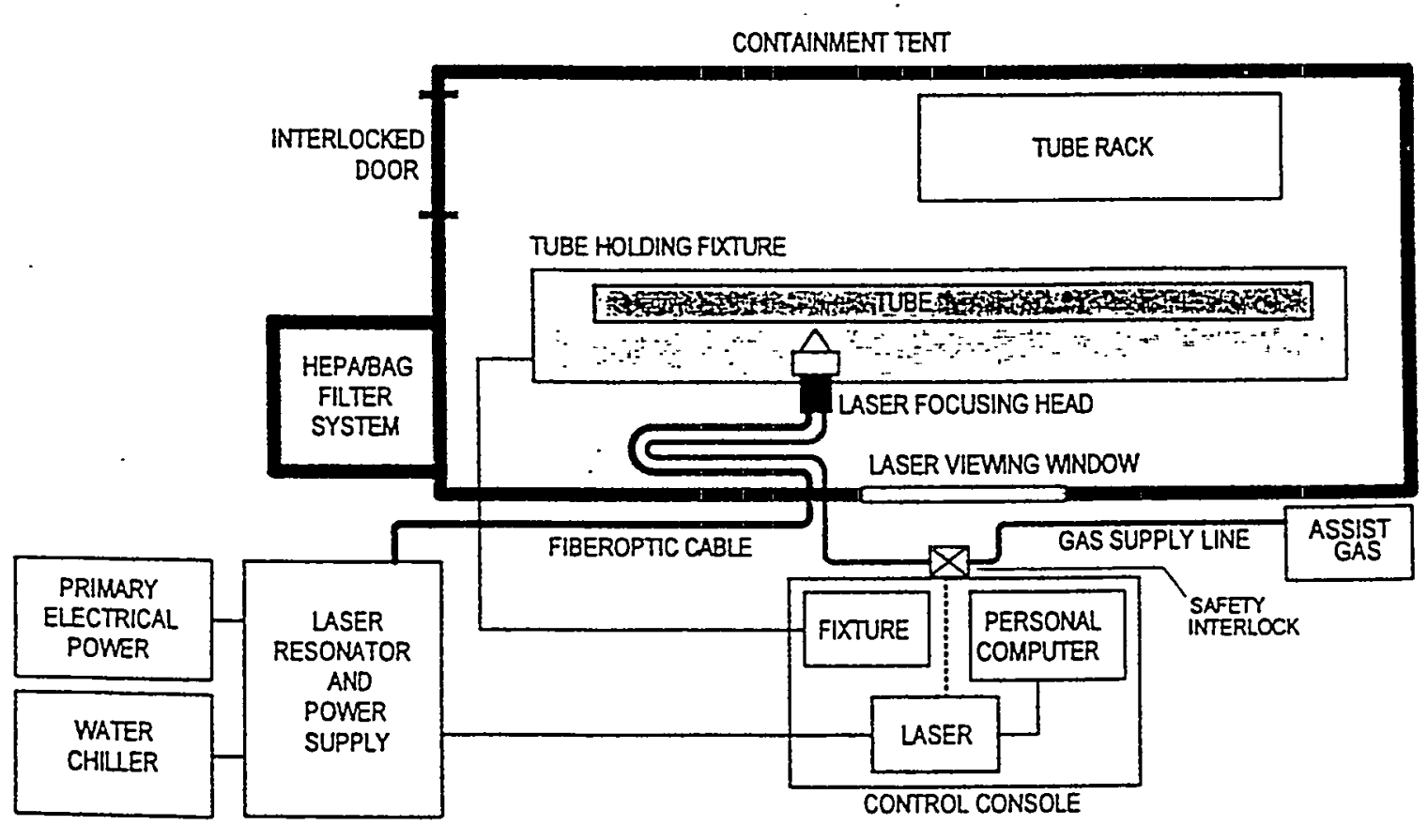

Figure 1. Schematic Diagram of the Laser Cutting Configuration for the ETEC Tests. 


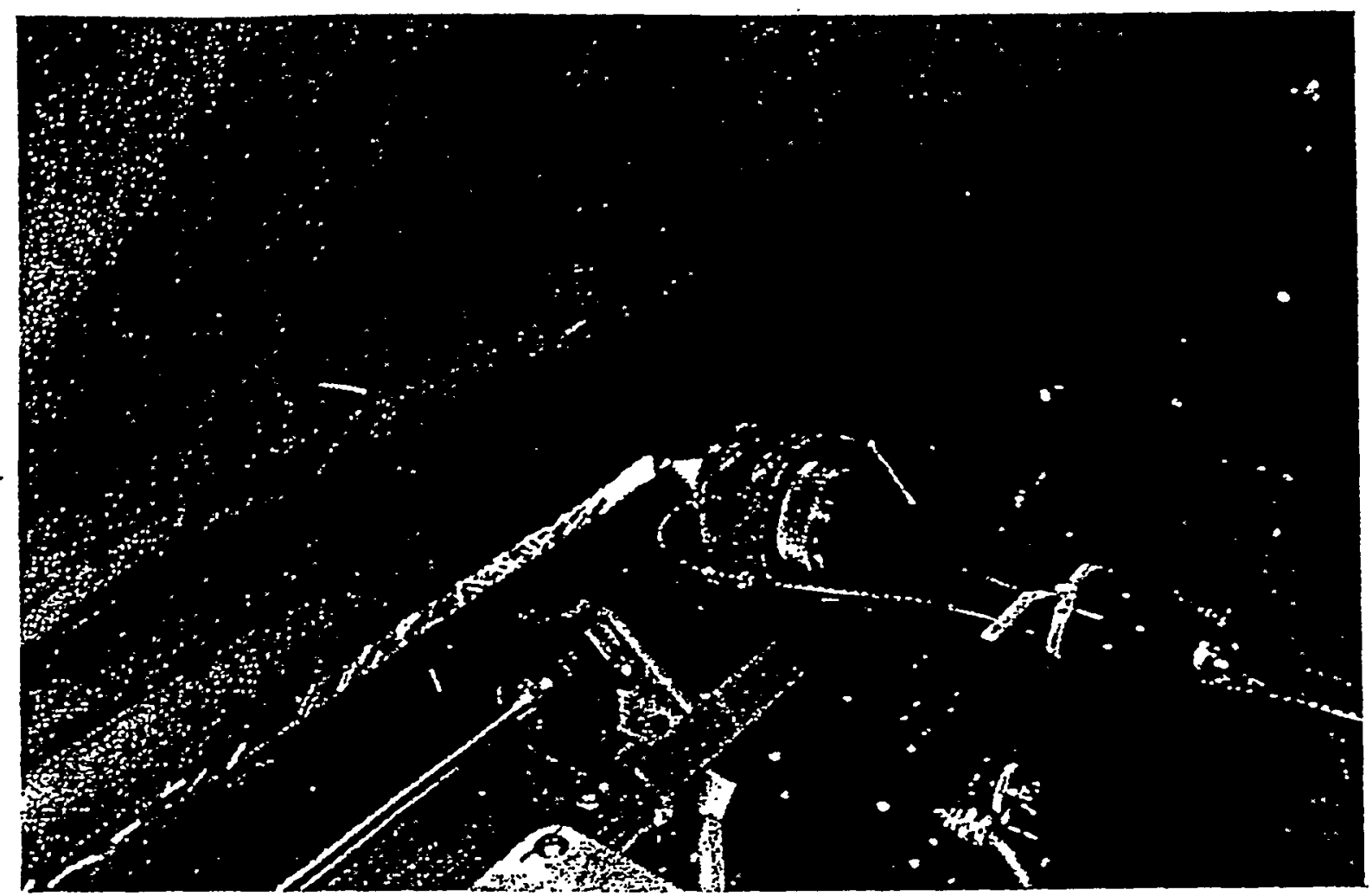

Figure 2. ETEC Laser Size Reduction of Radiologically Contaminated Storage Tubes Using Fiberoptic Beam Delivery to a Remote Cutting Head.

omitting set-up and hardware costs, are summarized in Table I. Significant cost savings were realized because of the reduced secondary waste and maintenance requirements. Maintenance requirements were still significant, however, because substantial airborne debris was generated that required frequent filter change-outs. Additional cost estimates were made for the size-reduction of significantly larger quantities of contaminated tubes. Those estimates included the capital equipment costs of the cutting hardware (significantly bigher for the laser system), and assumed replacement of the filter system with self-cleaning filters, but otherwise adopted a manual procedure that does not take advantage of the added flexibility of a robotically controlled laser system. The results indicated that plasma-arc cutting is less expensive for smaller quantities of rubing (because of capital equipment costs), while laser cutting is less expensive for large quantities. The break-even in those comparisons was at about 230,000 tubes.

Table I

Summary Cost Comparison Between Remote Laser and Plasma-Arc

Size-Reduction of the ETEC Storage Tubes

\begin{tabular}{|l|cc|}
\hline \multirow{2}{*}{ Cost Element } & \multicolumn{2}{|c|}{ Labor \& Materials Cost (\$) } \\
\cline { 2 - 3 } & Laser & Plasma-Arc \\
\hline Tube Size-Reduction & 5,600 & 5,600 \\
Cutting Head Maintenance & 5 & 423 \\
Filter Maintenance & 5,315 & 11,354 \\
Transportation \& Disposal & 8,000 & 10,990 \\
\hline Totals: & $J 8,920$ & 28,367 \\
\hline
\end{tabular}


- The conclusion from the ETEC demonstration was that significant reductions in secondary waste generation, personnel exposure, and cost can be realized by the implementation of laser cutting technologies. The reduction in personnel exposure, not demonstrated in this task because of the manual tube handling, arises from the reduced routine maintenance requirements for the laser system and the placement of the key laser system components in a nonhazardous environment.

\section{MSC DEPLOYMENT DEMONSTRATION}

The successful ETEC results provided the basis for technology transfer to commercial projects, and the Manufacturing Sciences Corporation performed a series of follow-on deployment tests that utilized the same laser system and capitalized on lessons learned from the ETEC demonstration. The MSC deployment further automated the laser cutting system and applied it to the size-reduction of a much larger component requiring the cutting of thicker materials. This component was a 1.8 -m-diameter, $2.1-\mathrm{m}$ long cylindrical converter shell with $1.3-\mathrm{cm}$-thick carbon steel walls from the Oak Ridge K-25 site.

The MSC set-up is shown in Figure 3. Here the laser system was augmented with a Lumonics auto-focus cutting bead that was mounted on the working arm of a Cincinnati Milacron robot, and the converter shell was placed on a track-mounted table with an automatic turning roll and part indexer. The function of the auto-focus cutting head was to maintain a constant stand-off distance between the cutting head and the cutting surface as the cuts were made. Axial cuts were made along the converter shell by using the robotic arm to move the cutting head axially along the converter shell, and circumferential cuts were made by rotating the converter shell on the remotely controlled table. Laser cutting head motions were directed by a programmable logic controller, which provided the capability to use the robotic arm to move the cutting head over the full converter shell surface. The adopted procedure limited the cutting head motion to linear travel with the laser head pointing downward, to restrict the laser orientation for increased safety and to allow the sectioned pieces to drop directly into a waste box. This waste box was attached to a track-mounted support structure that could be retracted from the work area remotely for material disposal. Similarly, the track-mounted table supporting the converter shell could be independently moved into and out of the work area under remote control. The work area was a pre-fabricated containment building with laser-protective film covering the observation ports. It utilized the high-efficiency facility ventilation system for airborne contaminant control.

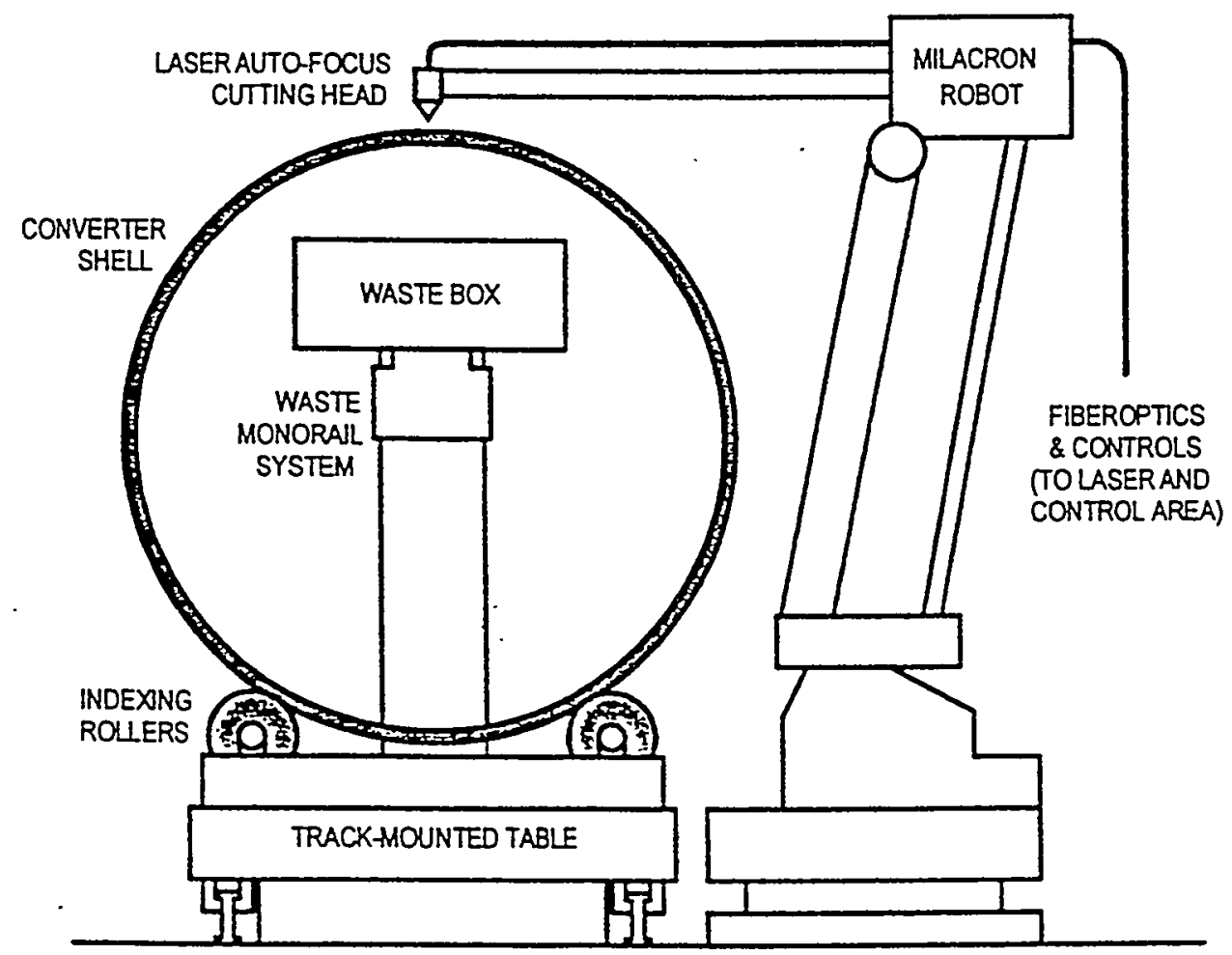

Figure 3. Schematic Diagram of the Laser Cutting Configuration for the MSC Tests. 
- This system was used to remove $30-\mathrm{cm}$ by $30-\mathrm{cm}$ sections of the converter shell by remote laser cutting. Cutting parameters included a laser power level of $1.8 \mathrm{~kW}$, an oxygen assist gas, and a cutting speed of $76 \mathrm{~cm} / \mathrm{min}$. The auto-focus enhancement of the laser cutting head was found to provide improved cutting performance by controlling the cutting head stand-off distance. There were two notable differences in cutting performance between the MSC and ETEC deployment demonstrations. First, the airborne contaminant generation at MSC was much less and more easily manageable than at ETEC. This appears to be a function of the thickness of the material cut, with less airborme contaminant generation for thicker parts, and was also observed in the subsequent bench-scale tests. Second, the maintenance requirements for the focusing head were greater at MSC, with frequent cleaning necessary to remove deposited airbome debris. Focusing head cleaning was not required for any of the other cutting tests, and the difference was attributed to the location of the cutting head directly above the cutting site in conjunction with the greater amount of cutting performed. This problem was minimized by installing a protective glass plate in front of the focusing lens and directing a dry-nitrogen purge gas through the autofocus head to blow airbome debris away from the lens assembly. Those changes reduced maintenance requirements significantly.

Additional laser cutting tests were performed at MSC to investigate the ability of the remote laser system to cut other materials. Results are summarized in Table II. Most of the laser cutting was performed using a continuous-wave (CW) laser beam. Aluminum was an exception, for which the laser beam was delivered in a square-wave pulsed mode. Aluminum cutting requires higher laser power than steel, and more instantaneous power can be delivered to the cutting site using a pulsed beam. Drawbacks are that the cutting may be uneven and the cutting speed is slower.

\section{SUPPLEMENTAL BENCH-SCALE IESTS}

The two deployment demonstrations identified a number of areas where additional laser cutting information would be beneficial for future applications. A supplemental series of laboratory bench-scale tests was subsequently performed at the Edison Weiding Institute under contract to ETEC to investigate the following: (1) the quantity of airbome particulate that is generated during laser cutting; (2) maximum cutting speeds for cutting $1.3-\mathrm{cm}$-thick and 1.5 $\mathrm{cm}$-thick steel pipe; and (3) the maximum thickness of stee! plate that can be cut with a $3-\mathrm{kW}$ off-the-shelf Nd:YAG laser using fiberoptic beam delivery.

The airborme particulate studies used $0.2-\mathrm{cm}$-thick and $1-\mathrm{cm}$ thick flat plates, to simulate the material thicknesses in the ETEC and MSC tests, respectively, and a laser power level of $2 \mathrm{~kW}$. Cutting was performed within a small enclosure using an exhaust system that drew the airbome particulate generated by the laser cuts through a HEPA filter system. The filters were weighed before and after each test to determine the weight of the collected debris. In addition, the material ejected from the bottom of the cuts and the dross removed from the bottom surface were collected and weighed, and kerf width measurements were made for the plate cuts. The data were used to determine the distribution of the secondary waste generated by the cutting process. Results are summarized in Table III.

The Table III results show that the airborne particulate was only a small fraction of the total debris generated by the laser cuts, and that the thin $(0.2-\mathrm{cm}$-thick) material produced about thirteen times the airborne particulate as the thick (1$\mathrm{cm}$ ) material for an equivalent volume of cutting debris. This is consistent with the observations from the ETEC and MSC demonstrations. Reasons for the difference were not investigated, but may be associated with higher heat conduction in the thicker material, resulting in more melting and less vaporization.

Sixty test cuts were made to investigate maximum. laser cutting speeds for steel pipe with $1.3-\mathrm{cm}$-thick and $1.5-\mathrm{cm}$ thick walls. For those tests, a pipe section was rotated beneath a fixed laser beam at various speeds, and the laser power level was stepped from $2 \mathrm{~kW}$ to $3 \mathrm{~kW}$ in $250-\mathrm{W}$ increments. Some variations were also made in the focusing

Table II

Summary of the MSC Remote Laser Test Cuts Using Various Materials

\begin{tabular}{|c|cccc|}
\hline Material & Thickness & Assist Gas & Laser Power & Cutting Speed \\
\hline Carbon Steel & $1.3 \mathrm{~cm}$ & 10 psi oxygen & $1800 \mathrm{~W}, \mathrm{CW}$ & $76 \mathrm{~cm} / \mathrm{min}$. \\
Carbon Steel & $2.5 \mathrm{~cm}$ & 10 psi oxygen & $1900 \mathrm{~W}, \mathrm{CW}$ & $7.6 \mathrm{~cm} / \mathrm{min}$. \\
Stainless Steel & $1.3 \mathrm{~cm}$ & 10 psi oxygen & $1800 \mathrm{~W}, \mathrm{CW}$ & $76 \mathrm{~cm} / \mathrm{min}$. \\
Aluminum & $0.3 \mathrm{~cm}$ & 10 psi oxygen & $1500 \mathrm{~W}, \mathrm{pulsed}$ & $7.6 \mathrm{~cm} / \mathrm{min}$. \\
\hline
\end{tabular}


Table III

Results of the Cutting Tests to Quantify Airbome Particulate Generation

\begin{tabular}{|c|ccc|cc|}
\hline \multirow{2}{*}{$\begin{array}{c}\text { Material } \\
\text { Thickness }\end{array}$} & \multirow{2}{*}{$\begin{array}{c}\text { Laser } \\
\text { Power }\end{array}$} & $\begin{array}{c}\text { Cutting } \\
\text { Speed }\end{array}$ & $\begin{array}{c}\text { Assist } \\
\text { Gas }\end{array}$ & \multicolumn{2}{|c|}{ Airborne Particulate } \\
\cline { 5 - 6 } & & & Normalized Weight & Debris Fraction \\
\hline $0.2 \mathrm{~cm}$ & $2 \mathrm{~kW}$ & $152 \mathrm{~cm} / \mathrm{min}$. & $20 \mathrm{psi} \mathrm{O}_{2}$ & $0.45 \mathrm{~g} / \mathrm{cm}^{3}$ of cut & $4.7 \%$ \\
$1 \mathrm{~cm}$ & $2 \mathrm{~kW}$ & $51 \mathrm{~cm} / \mathrm{min}$. & $30 \mathrm{psi} \mathrm{O}$ & $0.034 \mathrm{~g} / \mathrm{cm}^{3}$ of cut & $0.4 \%$ \\
\hline
\end{tabular}

head stand-off distance and in the oxygen assist gas pressure. Good cuts through the pipe wall were defined as those for which there was no weld-back on the interior surface of the pipe. Results of successful cuts are summarized in Table IV.

An additional fourteen test cuts were made to determine the maximum steel thickness that could be cut with a $3-\mathrm{kW}$, fiberoptic-delivered Nd:YAG beam. Those tests were performed using $1.9-\mathrm{cm}$-thick and 2.5 -cm-thick steel plates, where the plates were moved remotely beneath a fixed laser beam. The tests showed that $1.9-\mathrm{cm}$-thick plate could be cut successfully at $51 \mathrm{~cm} / \mathrm{min}$. and 2.5 -cm-thick plate could be cut successfully at $41 \mathrm{~cm} / \mathrm{min}$. The cut zones were crosssectioned to examine the shapes of the cuts, and it was determined that thicker sections would be difficult to cut based on the amount of dross produced and the taper in the cuts for the $2.5-\mathrm{cm}$-thick plate. The depth profiles for the cuts showed a relatively narrow front surface width, a widening of the kerf below the surface (probably from divergence of the laser beam), and a very narrow kerf with significant slag at the back surface (Figure 4).

Table $\mathrm{N}$

Summary of Bench-Scale Laser Cutting Speed Tests

\begin{tabular}{|c|cc|}
\hline $\begin{array}{c}\text { Pipe Wall } \\
\text { Thickness }\end{array}$ & $\begin{array}{c}\text { Laser } \\
\text { Power }\end{array}$ & $\begin{array}{c}\text { Successful } \\
\text { Cutting Speed }\end{array}$ \\
\hline $1.3 \mathrm{~cm}$ & $2000 \mathrm{~W}$ & $43 \mathrm{~cm} / \mathrm{min}$. \\
& $2250 \mathrm{~W}$ & $43 \mathrm{~cm} / \mathrm{min}$. \\
& $2500 \mathrm{~W}$ & $56 \mathrm{~cm} / \mathrm{min}$. \\
& $3000 \mathrm{~W}$ & $89 \mathrm{~cm} / \mathrm{min}$. \\
& & \\
$1.5 \mathrm{~cm}$ & $2000 \mathrm{~W}$ & $48 \mathrm{~cm} / \mathrm{min}$. \\
& $2250 \mathrm{~W}$ & $58 \mathrm{~cm} / \mathrm{min}$. \\
& $2500 \mathrm{~W}$ & $58 \mathrm{~cm} / \mathrm{min}$. \\
& $2750 \mathrm{~W}$ & $58 \mathrm{~cm} / \mathrm{min}$. \\
& $3000 \mathrm{~W}$ & $76 \mathrm{~cm} / \mathrm{min}$. \\
\hline
\end{tabular}

\section{CONCLUSIONS}

The series of tests described here demonstrated the laser cutting of both thin and thick components, various degrees of remote operation and automation, and the ability to cut 2.5-cm-thick steel at high linear cutting rates with a commercially available Nd:YAG laser. The ETEC demonstration showed the potential for cost savings using remote laser cutting, the MSC demonstration extended the application to thick materials using automated robotics, and the bench-scale tests provided further data on cutting capabilities using off-the-shelf laser systems. Although relatively high laser hardware costs make other technologies more cost effective for small-scale applications, reductions in personnel exposures by using remote laser cutting, with its minimal maintenance requirements, may override cost considerations in hazardous-environment applications. The overall conclusion from this successful series of laboratory and field-deployment tests is that current, off-the-shelf laser technology with remote fiberoptic beam delivery can be used effectively for component size-reduction in D\&D applications.

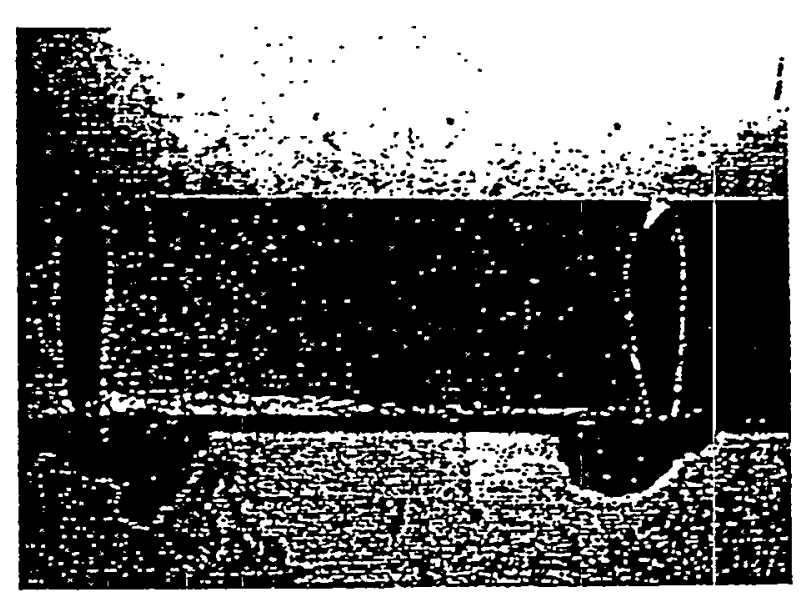

Figure 4. Photograph of Laser Cuts Made in 2.5-cm-Thick Steel with a 3-kW Nd:YAG Laser Beam, Incident from the Top. 


\section{ACKNOWLEDGMENTS}

The ETEC activities were sponsored by the U.S. Department of Energy's Office of Environmental Management. The MSC activities were sponsored by the Department of Energy under the PRDA contract "Advanced Technologies for Decontamination and Conversion of Scrap Metals." The authors wish to thank T. Kugler and C. Ankerson of Lumonics, Ltd. for the loan of the Nd:YAG laser system for the demonstration activities. They also acknowledge the programmatic and funding support from J. M. Hyde (DOE-HQ), K. Abbott (DOE-OAK), J. Malholtra (FETC-Morgantown), and $M$. E. Lee (ETEC), and the technical support of $M$. A. Spenard, P. H. Waite, R. A. Marshall, R. I. Brownell, D. W. Hickman, R. G. Palmer, Jr., and K. Darcy (ETEC).

\section{REFERENCES}

1. Technology Logic Diagram, Oak Ridge National Laboratory Report ORNL/M-2751 (1993).
2. G. Subbaraman, L. B. Spiegel, J. Vetrovec, and R. N. Hindy, "Fiber Delivered Lasers for Dismantlement Applications," in Decommissioning, Decontamination and Reutilization Worldwide Experience - D\&D. What Does It Mean, M. G. White, Ed., American Nuclear Society, Washington, DC, 10-14 November 1996, pp. 126-131.

3. L. Weeter, "Remote Laser Cutting Demonstration," Edison Welding Institute Final Report, Project 40578CSP, February 1997 (unpublished).

4. S. N. Shah, R. B. Hardy, and D. W. Kneff, "Remote Laser Processing of Radioactive Components at the Energy Technology Engineering Center (ETEC)," Proceedings from WM'98 Conference, Tucson, AZ, 1-4 March 1998 (to be published).

5. L. Weeter, "Thick Section Laser Cutting by Nd:YAG Lasers," Edison Welding Institute Final Report, Project 41931CSP, February 1998 (unpublished). 
Appendix 3.3 


\section{MSC Recycled Contaminated Metals Concept Paper for Mr. Vince Adams, DOE Oak Ridge Operations}

\section{January 23, 1998}

Currently their exists limited production capability within the US to produce products made from Recycled Contaminated Metals (RCM) in a cost competitive manner. Even more important, there is no obvious market for RCM that currently is competitive with existing candidate products. To be successful a product will have to be developed that will utilize the largest amount of metal possible using the most cost effective production method. In this way, reduction of DOE's liabilities will be maximized and RCM products will become competitive. Therefore, a product that substitutes for rather than mimics existing products would be the logical choice.

Fundamentally a product for recycled metals should include some or all of the following traits;

contain a large volume of RCM

not designed for efficient use of material

minimize processing steps

and compete as a substitute for, not as a replica of non-contaminated products.

It should be noted that product candidates requiring sophisticated machining and testing, with low material utilization, have much less chance of ever being successfully deployed.

Ideas for Recycled Contaminated Metals:

1. Pursue building an industrial base to manufacture biological shield plugs for spent nuclear fuel canisters. This would utilize large volumes of depleted uranium and the stainless steel cladding could be RCM as well. This has received significant attention from the DOE and it may be time now to implement the concept within the industry.

2. Look at additional options for the repository at Yucca Mountain (longer term). Potential candidates are rail ties and rails for the tunnel road system. Other options include the use of RCM in rock bolts and other structural members 
used to stabilize the tunnels during mining and operation. This would take some development work to determine if the RCM could result in a product that could meet QA certification requirements imposed on Yucca Mountain by the NRC. Other considerations include using RCM as reinforcement rods for concrete in the repository and even using RCM as part of the aggregate in the concrete itself.

Both of the above options would require buy in by OCRWM in HQ and at the Yucca Mountain project.

3. A undetermined amount of material (carbon steel) could be taken from the K25 site and cast into shield blocks for use in the Spallation Neutron Source. The cost would include the melting and casting into molds and a minimal amount of machining. To minimize cost you would want to cast at a continuous rate over a long period. Starting and stopping a casting operation adds considerable cost.

4. Lead can be recycled into liners at a reasonable cost and represents a significant liability reduction for the current owner. These products already appear to be competitive in today's market. Oak Ridge may want to be the center for the recovery and reuse of lead for DOE (i.e. require all of DOE to purchase or recycle their lead through a central location such as ORO).

5. Consider alternate designs for residue containers (i.e. maximum material, minimum processing).

6. Counter weights for cranes, fork lifts, and oil rigs. This would process a lot of metal however, it would be challenging to sell the concept to industry.

7. Use RCM as aggregate in concrete.

8. Use RCM for artificial reefs and break waters. This option would require the confidence of the public.

9. Develop specialty alloys that would not be in direct competition with a mass production vendor.

Currently with no clear market for RCM, the challenge is to find a low tech option that utilizes large quantities of metal. We would like to support the DOE in finding a successful end use of RCM. OCRWM has the potential to consume large quantities of metal within the repository given the right applications. Our success will only come from thinking out side the norm and doing this before design/selection is finalized. 
Appendix 3.4 


\begin{tabular}{|c|c|c|c|}
\hline \multicolumn{4}{|c|}{$\begin{array}{c}\text { Measurements reported by Thermo NUtech } \\
\text { for Batch 2 }\end{array}$} \\
\hline \hline \multirow{2}{*}{$\begin{array}{c}\text { Sample } \\
\text { Location }\end{array}$} & $\begin{array}{c}\text { Results } \\
(\mathrm{pCi} / \mathrm{L})^{*}\end{array}$ & $\begin{array}{c}\text { Error } \\
(\mathrm{pCi} / \mathrm{L})\end{array}$ & $\begin{array}{c}\text { Minimum } \\
\text { detectable activity } \\
(\mathrm{pCi} / \mathrm{L})\end{array}$ \\
\hline \multirow{6}{*}{6} & 560.66 & 31.26 & 29.57 \\
& $(28.03 \mathrm{pCi} / \mathrm{g})$ & $(1.56 \mathrm{pCi} / \mathrm{g})$ & $(1.48 \mathrm{pCi} / \mathrm{g})$ \\
& {$[1.037 \mathrm{~Bq} / \mathrm{g}]$} & {$[0.058 \mathrm{~Bq} / \mathrm{g}]$} & {$[0.055 \mathrm{~Bq} / \mathrm{g}]$} \\
\hline & 465.09 & 30.26 & 30.99 \\
6 & $(23.25 \mathrm{pCi} / \mathrm{g})$ & $(1.51 \mathrm{pCi} / \mathrm{g})$ & $(1.55 \mathrm{pCi} / \mathrm{g})$ \\
& {$[0.860 \mathrm{~Bq} / \mathrm{g}]$} & {$[0.056 \mathrm{~Bq} / \mathrm{g}]$} & {$[0.057 \mathrm{~Bq} / \mathrm{g}]$} \\
\hline & 430.03 & 19.63 & 16.54 \\
6 & $(21.50 \mathrm{pCi} / \mathrm{g})$ & $(0.98 \mathrm{pCi} / \mathrm{g})$ & $(0.83 \mathrm{pCi} / \mathrm{g})$ \\
& {$[0.796 \mathrm{Bg} / \mathrm{g}]$} & {$[0.036 \mathrm{~Bq} / \mathrm{g}]$} & {$[0.031 \mathrm{~Bq} / \mathrm{g}]$} \\
\hline & 120.70 & 12.94 & 16.15 \\
6 & $(6.04 \mathrm{pCi} / \mathrm{g})$ & $(0.65 \mathrm{pCi} / \mathrm{g})$ & $(0.81 \mathrm{pCi} / \mathrm{g})$ \\
& {$[0.223 \mathrm{~Bq} / \mathrm{g}]$} & {$[0.024 \mathrm{~Bq} / \mathrm{g}]$} & {$[0.030 \mathrm{~Bq} / \mathrm{g}]$} \\
\hline
\end{tabular}

*The reported activity levels are for $20.0 \mathrm{~g}$ of sample in a 1.00-L solution.

\begin{tabular}{|c|c|}
\hline \multicolumn{2}{|c|}{$\begin{array}{l}\text { Results from application of statistical tests to the } \\
\text { measurements reported by Thermo NUtech for Batch } 2\end{array}$} \\
\hline Mean & $\begin{array}{l}19.705 \mathrm{pCi} / \mathrm{g} \\
(0.730 \mathrm{Bg} / \mathrm{g})\end{array}$ \\
\hline Standard deviation & $\begin{array}{c}9.519 \mathrm{pCi} / \mathrm{g} \\
(0.355 \mathrm{~Bq} / \mathrm{g})\end{array}$ \\
\hline Standard error of the mean & $\begin{array}{r}4.759 \mathrm{pCi} / \mathrm{g} \\
(0.177 \mathrm{~Bq} / \mathrm{g}) \\
\end{array}$ \\
\hline $\begin{array}{l}\text { Probability that data is } \\
\text { normally distributed }\end{array}$ & 0.148 \\
\hline
\end{tabular}

With a probability of 0.148 , the data fails the Kolmogorov-Smirnov test for normality. The small probability suggests that there may be a systematic, rather than random, error in the measurements. Visual inspection of the Batch 2 data in Figure 1 reveals three measurement around $27 \mathrm{pCi}(1 \mathrm{~Bq} / \mathrm{g})$ [the mean of the three measurements is $24.3 \mathrm{pCi} / \mathrm{g}(0.898 \mathrm{~Bq} / \mathrm{g})]$ and one much smaller value. The most likely systematic error that would produce the observed measurements would be the loss of ${ }^{99} \mathrm{Tc}$ during sample preparation. The validity of the measurements is also called into question by the change in minimum detectable activity: for two measurements the mean is $1.5 \mathrm{pCi} / \mathrm{g}(0.056$ $\mathrm{Bq} / \mathrm{g})$ and for the other two the mean is $0.82 \mathrm{pCi} / \mathrm{g}(0.030 \mathrm{~Bq} / \mathrm{g})$. This suggests a substantial change in experimental conditions. 


\begin{tabular}{|c|c|c|}
\hline \multicolumn{2}{|c|}{$\begin{array}{c}\text { Set 1 measurements of beta particle emissions from } \\
\text { cathode \#3 with an alpha/beta scintillation probe }\end{array}$} \\
\hline \hline $\begin{array}{c}\text { Sample } \\
\text { location }\end{array}$ & $\begin{array}{c}\text { Beta particles } \\
\text { count rate }^{a} \\
\text { (counts/min) }\end{array}$ & $\begin{array}{c}\text { Alpha particles } \\
\text { count rate } \\
\text { (counts/min) }\end{array}$ \\
\hline 6 & 387 & 2 \\
\hline 6 & 420 & 1 \\
\hline 6 & 423 & 1 \\
\hline 6 & 443 & 1 \\
\hline 6 & 420 & 1 \\
\hline $1 \mathrm{~A}^{b}$ & 427 & 2 \\
\hline $1 \mathrm{~A}$ & 447 & 1 \\
\hline $1 \mathrm{~A}$ & 451 & 0 \\
\hline $1 \mathrm{~A}$ & 443 & 3 \\
\hline $1 \mathrm{~A}$ & 457 & 1 \\
\hline $1 \mathrm{~B}^{\mathrm{c}}$ & 418 & 6 \\
\hline 1B & 427 & 5 \\
\hline $1 \mathrm{~B}$ & 463 & 2 \\
\hline 1B & 486 & 3 \\
\hline $1 \mathrm{~B}$ & 462 & 2 \\
\hline Background & 408 & 3 \\
\hline Background & 417 & 2 \\
\hline Background & 472 & 3 \\
\hline Background & 484 & 2 \\
\hline Background & 385 & 1 \\
\hline Background & 397 & 1 \\
\hline
\end{tabular}

${ }^{a}$ Each count of the cathode or background was for one minute.

${ }^{b}$ Location $1 \mathrm{~A}$ is on the same side of the cathode as location 6.

${ }^{c}$ Location $1 \mathrm{~B}$ is on the opposite side of the cathode from locations

$1 \mathrm{~A}$ and 6.

\begin{tabular}{|c|c|c|c|}
\hline \multicolumn{3}{|c|}{$\begin{array}{c}\text { Statistical analysis of Set } 1 \text { measurements of cathode \#3 } \\
\text { with an alpha/beta scintillation probe }\end{array}$} \\
\hline \hline $\begin{array}{c}\text { Sample } \\
\text { location }\end{array}$ & $\begin{array}{c}\text { Mean } \\
\text { (counts/min) }\end{array}$ & $\begin{array}{c}\text { Standard } \\
\text { deviation } \\
\text { (counts/min) }\end{array}$ & $\begin{array}{c}\text { Standard } \\
\text { error } \\
\text { of the mean } \\
\text { (counts/min) }\end{array}$ \\
\hline 6 & 418.6 & 20.11 & 8.99 \\
\hline $1 \mathrm{~A}^{a}$ & 445.0 & 11.31 & 5.06 \\
\hline $1 B^{b}$ & 451.2 & 28.08 & 12.56 \\
\hline Background & 427.2 & 40.99 & 16.73 \\
\hline
\end{tabular}

${ }^{a}$ Location $1 \mathrm{~A}$ is on the same side of the cathode as location 6 , the front. 
${ }^{b}$ Location $1 \mathrm{~B}$ is on the opposite side of the cathode from locations $1 \mathrm{~A}$ and 6 , the back.

The mean of the measurements taken at location 6 is smaller than the mean of the background measurements. Meyer, Meir and Zünd, and NCRP Report No. 58 state that such data should be used if possible rather than discarded. An applicable test to determine the potential usefulness of the data is an analysis of variance. If the measurements pass this test, they can be combined to produce an average count rate.

\begin{tabular}{|c|c|c|c|c|c|}
\hline \multicolumn{7}{|c|}{ One-way analysis of variance of measurements } \\
from locations 6, 1A, and 1B \\
\hline \hline $\begin{array}{c}\text { Source of } \\
\text { variation }\end{array}$ & $\begin{array}{c}\text { Degrees of } \\
\text { freedom }\end{array}$ & $\begin{array}{c}\text { Sum of } \\
\text { squares }\end{array}$ & $\begin{array}{c}\text { Mean } \\
\text { squares }\end{array}$ & F statistic & Probability \\
\hline $\begin{array}{c}\text { Between } \\
\text { groups }\end{array}$ & 2 & 2996.9 & 1498.5 & 3.4 & 0.067 \\
\hline Residual & 12 & 5284.0 & 440.8 & & \\
\hline Total & 14 & 8280.9 & & & \\
\hline
\end{tabular}

Because the probability that the measurements are drawn from the same populations is greater than 0.05 , the measurements pass the test. The measurements all arose from a single population. Therefore, they may be combined to obtain a single measure of the mean. 


\begin{tabular}{|c|c|c|}
\hline \multicolumn{3}{|c|}{$\begin{array}{c}\text { Statistical analysis for combined } \\
\text { measurements from locations } \\
\text { 6, 1A, and 1B }\end{array}$} \\
\hline \hline $\begin{array}{c}\text { Mean } \\
\text { (counts/min) }\end{array}$ & $\begin{array}{c}\text { Standard } \\
\text { deviation } \\
\text { (counts/min) }\end{array}$ & $\begin{array}{c}\text { Standard } \\
\text { error } \\
\text { of the mean } \\
\text { (counts/min) }\end{array}$ \\
\hline 438.3 & 24.32 & 6.28 \\
\hline
\end{tabular}

The average surface activity of cathode \#3 may be calculated from the Set 1 measurements by subtracting the mean combined count rate from the mean background count rate and converting to Becquerels.

$$
\begin{aligned}
& \mathrm{A}=\left((438.3 \pm 24.3)-(427.2 \pm 41.0) \frac{\text { counts }}{\text { minute }}\right)\left(\frac{\text { disintegrations }}{0.094 \text { counts }}\right)\left(\frac{\mathrm{min}}{60 \mathrm{sec}}\right)\left(\frac{\mathrm{Bq}}{\frac{\text { disintegrations }}{\mathrm{sec}}}\right) \\
& \mathrm{A}=1.97 \pm 0.30 \mathrm{~Bq} \cong 2.0 \pm 0.3 \mathrm{~Bq}
\end{aligned}
$$

The average bulk activity of cathode \#3 is found by dividing the measured surface activity by the mass of the emitting layer, $2.23 \mathrm{~g}$.

$$
A_{\text {bulk, cathode } \# 3}=\frac{(1.97 \pm 0.30 \mathrm{~Bq})}{2.23 \mathrm{~g}}=0.883 \pm 0.13 \frac{\mathrm{Bq}}{\mathrm{g}} \cong 0.88 \pm 0.13 \frac{\mathrm{Bq}}{\mathrm{g}}
$$




\begin{tabular}{|c|c|c|c|c|c|c|c|c|}
\hline \multicolumn{9}{|c|}{$\begin{array}{l}\text { Set } 2 \text { measurements of beta particle emissions from cathode \#3 } \\
\text { with an alpha/beta scintillation probe }\end{array}$} \\
\hline \multicolumn{9}{|c|}{ Location on the cathode } \\
\hline $5 \mathrm{~A}^{a}$ & $1 \mathrm{~A}$ & $2 \mathrm{~A}$ & $3 \mathrm{~A}$ & $4 \mathrm{~A}$ & $1 \mathrm{~B}^{6}$ & $2 \mathrm{~B}$ & 3B & $4 \mathrm{~B}$ \\
\hline \multicolumn{9}{|c|}{$\begin{array}{l}\text { Beta particles count rate } \\
\text { (counts } / \mathrm{min} \text { ) }\end{array}$} \\
\hline 156 & 179 & 179 & 203 & 168 & 189 & 168 & 158 & 169 \\
\hline 197 & 189 & 213 & 190 & 191 & 191 & 165 & 169 & 199 \\
\hline 166 & 176 & 209 & 186 & 174 & 192 & 182 & 181 & 146 \\
\hline 173 & 214 & 186 & 195 & 167 & 182 & 185 & 161 & 172 \\
\hline 186 & 195 & 158 & 198 & 204 & 185 & 183 & 140 & 170 \\
\hline
\end{tabular}

${ }^{a}$ Locations designated $\mathrm{A}$ are on the front of cathode \#3.

${ }^{b}$ Locations designated $B$ are on the back of cathode \#3.

${ }^{c}$ All counts were one minute long.

\begin{tabular}{|c|c|c|c|c|}
\hline \multicolumn{5}{|c|}{ Set 2 background measurements with an alpha/beta scintillation probe } \\
\hline \multicolumn{5}{|c|}{$\begin{array}{c}\text { Beta particle count rate } \\
\text { (counts/min) }\end{array}$} \\
\hline 183 & 209 & 169 & 168 & 153 \\
\hline 157 & 170 & 147 & 168 & 176 \\
\hline
\end{tabular}

${ }^{a}$ All counts were one minute long.

\begin{tabular}{|c|r|r|r|}
\hline \multicolumn{4}{|c|}{$\begin{array}{c}\text { Statistical analysis of Set } 2 \text { measurements of cathode \#3 } \\
\text { with an alpha/beta scintillation probe }\end{array}$} \\
\hline \hline $\begin{array}{c}\text { Sample } \\
\text { location }\end{array}$ & $\begin{array}{c}\text { Mean } \\
\text { (counts/min) }\end{array}$ & $\begin{array}{c}\text { Standard } \\
\text { deviation } \\
\text { (counts/min) }\end{array}$ & $\begin{array}{c}\text { Standard } \\
\text { error } \\
\text { of the mean } \\
\text { (counts/min) }\end{array}$ \\
\hline 5A & 175.6 & 16.20 & 7.24 \\
\hline 1A & 190.6 & 15.14 & 6.77 \\
\hline 2A & 189.0 & 22.62 & 10.11 \\
\hline 3A & 194.4 & 6.66 & 2.98 \\
\hline 4A & 180.8 & 16.15 & 7.22 \\
\hline 1B & 187.8 & 4.21 & 1.88 \\
\hline 2B & 176.6 & 9.34 & 4.18 \\
\hline 3B & 161.8 & 15.09 & 6.75 \\
\hline 4B & 171.2 & 18.81 & 8.41 \\
\hline Background & 170.0 & 17.39 & 5.50 \\
\hline
\end{tabular}

The mean of the measurements taken at location $3 \mathrm{~B}$ is smaller than the mean of the background measurements and the mean of measurements taken at locations $2 \mathrm{~B}, 4 \mathrm{~B}$, and $5 \mathrm{~A}$ are only slightly greater than the background measurement average. As stated by Meyer, Meir and Zünd, and NCRP Report No. 58, such data should be used if possible 
rather than discarded. An analysis of variance was used to determine if the measurements from the nine locations are sufficiently similar to be averaged together.

\begin{tabular}{|l|c|c|c|c|c|}
\hline \multicolumn{7}{|c|}{$\begin{array}{c}\text { One-way analysis of variance of measurements from } \\
\text { locations 1A, 2A, 3A, 4A, 5A, 1B, 2B, 3B, and 4B }\end{array}$} \\
\hline \hline $\begin{array}{l}\text { Source of } \\
\text { variation }\end{array}$ & $\begin{array}{c}\text { Degrees of } \\
\text { freedom }\end{array}$ & $\begin{array}{c}\text { Sum of } \\
\text { squares }\end{array}$ & $\begin{array}{c}\text { Mean } \\
\text { squares }\end{array}$ & F statistic & Probability \\
\hline $\begin{array}{l}\text { Between } \\
\text { groups }\end{array}$ & 8 & 4475.2 & 559.4 & 2.524 & 0.027 \\
\hline Residual & 36 & 7978.0 & 221.611 & & \\
\hline Total & 44 & 12453.2 & & & \\
\hline
\end{tabular}

The probability of similarity among the measurements is 0.027 . This is a statistically significant difference, the differences in the mean values among the measurements are greater than would be expected by chance. Therefore, the measurements from the nine locations can not be averaged together to obtain an average surface activity.

The measurements were tested to determine if exclusion of a single group of measurements (Group 3B, the measurements from location 3B, with a mean surface activity of 161.8 counts $/ \mathrm{min}$ ) would allow the measurements to be averaged. A one-way analysis of variance test was conducted on the eight groups of measurements remaining after Group 3B was excluded.

\begin{tabular}{|l|c|c|c|c|c|}
\hline \multicolumn{7}{|c|}{$\begin{array}{c}\text { One-way analysis of variance of measurements from } \\
\text { locations 1A, 2A, 3A, 4A, 5A, 1B, 2B, and 4B }\end{array}$} \\
\hline \hline $\begin{array}{l}\text { Source of } \\
\text { variation }\end{array}$ & $\begin{array}{c}\text { Degrees of } \\
\text { freedom }\end{array}$ & $\begin{array}{c}\text { Sum of } \\
\text { squares }\end{array}$ & $\begin{array}{c}\text { Mean } \\
\text { squares }\end{array}$ & F statistic & Probability \\
\hline $\begin{array}{l}\text { Between } \\
\text { groups }\end{array}$ & 7 & 2430.3 & 347.186 & 1.572 & 0.18 \\
\hline Residual & 32 & 7067.2 & 220.85 & & \\
\hline Total & 39 & 9497.5 & & & \\
\hline
\end{tabular}

Without the Group 3B data, the probability that the data are sufficiently similar to be combined is 0.180 . This probability is much greater than the cutoff value of 0.05 . Hence, the measurements may be combined to compute an average surface activity.

The following analysis of beta particle emissions measurements excludes data collected from location 3B (Group 3B). The Group 3B data are inconsistent with the normally distributed measurements of beta emissions from other locations on cathode \#3. The inconsistency may arise from two possible causes: (1) the number of beta particles emitted from location $3 \mathrm{~B}$ is different from the emissions elsewhere on cathode $\# 3$ or (2) a machine or operator error occurred. The first possible cause is inconsistent with the assumption that the ${ }^{99} \mathrm{Tc}$ is uniformly distributed throughout the cathode. Without confirmatory measurements, such as liquid scintillation counting, from location $3 \mathrm{~B}$, potential cause (1) will be discarded. It is assumed that a machine or operator error 
occurred and that no significant information will be lost by excluding the data collected from location $3 \mathrm{~B}$ from further analysis.

\begin{tabular}{|c|c|c|}
\multicolumn{2}{|c|}{$\begin{array}{c}\text { Statistical analysis for combined } \\
\text { measurements from cathode \#3 locations } \\
\text { 1A, 2A, 3A, 4A, 5A, 1B, 2B, and 4B }\end{array}$} \\
\hline \hline $\begin{array}{c}\text { Mean } \\
\text { (counts/min) }\end{array}$ & $\begin{array}{c}\text { Standard } \\
\text { deviation } \\
\text { (counts/min) }\end{array}$ & $\begin{array}{c}\text { Standard } \\
\text { error } \\
\text { of the mean } \\
\text { (counts/min) }\end{array}$ \\
\hline 183.25 & 15.61 & 2.47 \\
\hline
\end{tabular}

The average surface activity of cathode \#3 may be calculated from the Set 2 measurements by subtracting the mean combined count rate from the mean background count rate and converting to Becquerels.

$$
\begin{aligned}
& A=\left((183.25 \pm 15.61)-(170.0 \pm 17.4) \frac{\text { counts }}{\text { minute }}\right)\left(\frac{\text { disintegrations }}{0.094 \text { counts }}\right)\left(\frac{\mathrm{min}}{60 \mathrm{sec}}\right)\left(\frac{\mathrm{Bq}}{\frac{\text { disintegrations }}{\mathrm{sec}}}\right) \\
& \mathrm{A}=2.35 \pm 0.44 \mathrm{~Bq} \cong 2.4 \pm 0.4 \mathrm{~Bq}
\end{aligned}
$$

The average bulk activity of cathode \#3 resulting from Set 2 measurements is computed by dividing the average surface activity by the mass of the emitting layer, $2.23 \mathrm{~g}$.

$$
A_{\text {bulk, cahode \#3 }}=\frac{(2.35 \pm 0.44 \mathrm{~Bq})}{2.23 \mathrm{~g}}=1.054 \pm 0.197 \frac{\mathrm{Bq}}{\mathrm{g}} \cong 1.05 \pm 0.20 \frac{\mathrm{Bq}}{\mathrm{g}}
$$




\begin{tabular}{|c|c|c|}
\hline \multicolumn{3}{|c|}{$\begin{array}{c}\text { Set } 3 \text { measurements of particle emissions from cathode } \\
\# 3 \text { with an alpha/beta scintillation probe }\end{array}$} \\
\hline $\begin{array}{l}\text { Sample } \\
\text { location }\end{array}$ & $\begin{array}{l}\text { Beta particles } \\
\text { count rate } \\
\text { (counts } / \mathrm{min} \text { ) }\end{array}$ & $\begin{array}{l}\text { Alpha particles } \\
\text { count rate } \\
\text { (counts } / \text { min) }\end{array}$ \\
\hline $2 \mathrm{~A}^{6}$ & 236 & 2 \\
\hline $2 \mathrm{~A}$ & 263 & 0 \\
\hline $2 \mathrm{~A}$ & 264 & 1 \\
\hline $2 \mathrm{~A}$ & 230 & 0 \\
\hline $2 \mathrm{~A}$ & 235 & 2 \\
\hline $2 \mathrm{~A}$ & 268 & 0 \\
\hline $2 \mathrm{~A}$ & 235 & 1 \\
\hline $2 \mathrm{~A}$ & 248 & 0 \\
\hline $2 \mathrm{~A}$ & 237 & 1 \\
\hline $2 \mathrm{~A}$ & 270 & 0 \\
\hline $2 \mathrm{~B}^{\mathrm{c}}$ & 250 & 2 \\
\hline $2 \mathrm{~B}$ & 222 & 1 \\
\hline $2 \mathrm{~B}$ & 229 & 1 \\
\hline $2 B$ & 238 & 0 \\
\hline $2 \mathrm{~B}$ & 225 & 0 \\
\hline $2 \mathrm{~B}$ & 251 & 3 \\
\hline $2 \mathrm{~B}$ & 234 & 3 \\
\hline $2 \mathrm{~B}$ & 217 & 2 \\
\hline $2 \mathrm{~B}$ & 245 & 1 \\
\hline $2 \mathrm{~B}$ & 221 & 1 \\
\hline Background & 281 & 3 \\
\hline Background & 289 & 0 \\
\hline Background & 298 & 3 \\
\hline Background & 299 & 2 \\
\hline Background & 286 & 2 \\
\hline Background & 244 & 2 \\
\hline
\end{tabular}

${ }^{a}$ All counts were one minute long.

${ }^{b}$ Location $2 \mathrm{~A}$ is on the front of cathode \#3.

${ }^{c}$ Location $2 \mathrm{~B}$ is on the back of cathode \#3. 


\begin{tabular}{|c|c|c|c|}
\hline \multicolumn{3}{|c|}{$\begin{array}{c}\text { Statistical analysis of Set } 3 \text { measurements of } \\
\text { beta particle emissions from cathode } \# \mathbf{3} \\
\text { with an alpha/beta scintillation probe }\end{array}$} \\
\hline \hline $\begin{array}{c}\text { Sample } \\
\text { location }\end{array}$ & $\begin{array}{c}\text { Mean } \\
\text { (counts/min) }\end{array}$ & $\begin{array}{c}\text { Standard } \\
\text { deviation } \\
\text { (counts/min) }\end{array}$ & $\begin{array}{c}\text { Standard } \\
\text { error } \\
\text { of the mean } \\
\text { (counts/min) }\end{array}$ \\
\hline $2 \mathrm{~A}^{a}$ & 248.6 & 15.95 & 5.04 \\
\hline $2 \mathrm{~B}^{b}$ & 233.2 & 12.40 & 3.92 \\
\hline Background & 282.8 & 20.25 & 8.27 \\
\hline
\end{tabular}

${ }^{a}$ Location $2 \mathrm{~A}$ is on the front of cathode \#3.

${ }^{b}$ Location $2 \mathrm{~B}$ is on the back of cathode \#3.

The means of the Set 3 measurements of beta particle emissions from cathode \#3 are both more than two standard deviations below the mean background. Although the data appear to be internally consistent, they are unusable. The alpha/beta scintillation probe and scaler appear to have been malfunctioning.

Cathode \#3 was moved to a new location, the receiving area of the manufacturing facility, prior to collecting the Set 4 measurements. The move was an attempt to find a low-background location. According to Tsoulfanidis and NCRP Report No. 58, an increase in the integration time will increase the total number of counts received and lower the minimum detectable activity. Hence, in an attempt to lower the minimum detectable activity, the counting or integration time for the Set 4 measurements was set to two minutes. This is a factor of two greater than the integration time used while measuring Sets 1-3. 


\begin{tabular}{|c|c|c|}
\hline \multicolumn{3}{|c|}{$\begin{array}{l}\text { Set } 4 \text { measurements of particle emissions from cathode } \\
\# 3 \text { with an alpha/beta scintillation probe }\end{array}$} \\
\hline $\begin{array}{l}\text { Sample } \\
\text { location }\end{array}$ & $\begin{array}{l}\text { Beta particles } \\
\text { Total counts }{ }^{a}\end{array}$ & $\begin{array}{l}\text { Alpha particles } \\
\text { Total counts }\end{array}$ \\
\hline $2 \mathrm{~B}^{b}$ & 509 & 1 \\
\hline $2 \mathrm{~B}$ & 498 & 6 \\
\hline $2 \mathrm{~B}$ & 538 & 2 \\
\hline $2 B$ & 539 & 1 \\
\hline $2 \mathrm{~B}$ & 504 & 5 \\
\hline $2 \mathrm{~B}$ & 533 & 2 \\
\hline $2 B$ & 513 & 1 \\
\hline $2 \mathrm{~B}$ & 530 & 1 \\
\hline $2 B$ & 524 & 2 \\
\hline $2 \mathrm{~B}$ & 527 & 4 \\
\hline $2 \mathrm{~B}$ & 547 & 0 \\
\hline $2 \mathrm{~B}$ & 534 & 2 \\
\hline $2 B$ & 534 & 1 \\
\hline $2 \mathrm{~B}$ & 541 & 1 \\
\hline $2 \mathrm{~B}$ & 534 & 0 \\
\hline $2 B$ & 544 & 1 \\
\hline $2 \mathrm{~B}$ & 485 & 2 \\
\hline $2 \mathrm{~B}$ & 567 & 4 \\
\hline $2 \mathrm{~B}$ & 560 & 2 \\
\hline $2 \mathrm{~B}$ & 515 & 2 \\
\hline Background & 632 & 1 \\
\hline Background & 601 & 2 \\
\hline Background & 636 & 1 \\
\hline Background & 627 & 3 \\
\hline Background & 601 & 1 \\
\hline Background & 627 & 2 \\
\hline Background & 616 & 1 \\
\hline Background & 668 & 0 \\
\hline Background & 623 & 3 \\
\hline Background & 552 & 2 \\
\hline
\end{tabular}

${ }^{a}$ Each count was for two minutes.

${ }^{b}$ Location 2B is on the back of cathode \#3. 


\begin{tabular}{|c|c|c|c|}
\hline \multicolumn{4}{|c|}{$\begin{array}{c}\text { Statistical analysis of Set } 4 \text { measurements of } \\
\text { beta particle emissions from cathode \#3 } \\
\text { with an alpha/beta scintillation probe }\end{array}$} \\
\hline \hline $\begin{array}{c}\text { Sample } \\
\text { location }\end{array}$ & $\begin{array}{c}\text { Mean } \\
\text { (counts/2 min) }\end{array}$ & $\begin{array}{c}\text { Standard } \\
\text { deviation } \\
\text { (counts/2 min) }\end{array}$ & $\begin{array}{c}\text { Standard error } \\
\text { of the mean } \\
\text { (counts/2 min) }\end{array}$ \\
\hline $2 \mathrm{~B}^{a}$ & 521.5 & 14.55 & 4.60 \\
\hline $2 \mathrm{~B}$ & 536.1 & 23.10 & 7.30 \\
\hline Background & 618.3 & 30.08 & 9.51 \\
\hline
\end{tabular}

${ }^{a}$ Location $2 \mathrm{~B}$ is on the back of cathode \#3.

As with the Set 3 measurements, the average Set 4 beta particle emissions from cathode \#3 were more than two standard deviations from the mean of the background measurements. Clearly, these data are unusable. The alpha/beta scintillation probe and scaler appear to have been malfunctioning.

Following the unsuccessful attempts to acquire useful information from sets 3 and 4 , it was decided to increase the counting interval from 1-2 $\mathrm{min}$ to $30 \mathrm{~min}$. This required modifications to the scalar for the alpha/beta scintillation counting system. After the modifications, the system efficiency was $18.7 \%$ for alpha particles and $11.0 \%$ for beta particles. 


\begin{tabular}{|c|c|c|c|}
\hline \multicolumn{4}{|c|}{$\begin{array}{l}\text { Set } 5 \text { measurements of particle emissions from cathode \#3 } \\
\text { with an alpha/beta scintillation probe }\end{array}$} \\
\hline $\begin{array}{c}\text { Sample } \\
\text { Location }^{a}\end{array}$ & $\begin{array}{c}\text { Counting start } \\
\text { time }\end{array}$ & $\begin{array}{l}\text { Beta particles } \\
\text { Total counts }\end{array}$ & $\begin{array}{l}\text { Alpha particles } \\
\text { Total counts }\end{array}$ \\
\hline Background & $9: 40 \mathrm{AM}$ & 5985 & 62 \\
\hline $2 \mathrm{~B}^{c}$ & $10: 15 \mathrm{AM}$ & 6025 & 81 \\
\hline $2 \mathrm{~B}$ & $10: 45 \mathrm{AM}$ & 5948 & 63 \\
\hline $2 \mathrm{~B}$ & $11: 15 \mathrm{AM}$ & 5895 & 59 \\
\hline $2 \mathrm{~B}$ & $11: 45 \mathrm{AM}$ & 5970 & 54 \\
\hline $2 \mathrm{~B}$ & $12: 15 \mathrm{PM}$ & 5843 & 56 \\
\hline $2 \mathrm{~B}$ & $12: 45 \mathrm{PM}^{d}$ & 5707 & 57 \\
\hline Background & $2: 15 \mathrm{PM}$ & 8501 & 54 \\
\hline Background & $2: 45 \mathrm{PM}$ & 8400 & 57 \\
\hline Background ${ }^{e}$ & $3: 20 \mathrm{PM}$ & 7581 & 41 \\
\hline
\end{tabular}

${ }^{a}$ Except as noted, all measurements were made in the Manufacturing

Sciences Corporation laboratory.

${ }^{b}$ Each count was for 30 minutes.

${ }^{\circ}$ Location 2B is on the back of cathode \#3.

${ }^{d}$ The scintillation counter and scaler were not turned off between 1:10 and 2:15 PM. The instrument remained on from 9:40 AM until 3:50 PM.

${ }^{e}$ This background measurement was made in the engineering offices located in the manufacturing facility. The move from the laboratory was to determine if a lower background area was available.

\begin{tabular}{|c|c|c|c|}
\hline \multicolumn{4}{|c|}{$\begin{array}{l}\text { Statistical analysis of Set } 5 \text { measurements of } \\
\text { beta particle emissions from cathode } \# 3 \\
\text { with an alpha/beta scintillation probe }\end{array}$} \\
\hline $\begin{array}{l}\text { Sample } \\
\text { location }\end{array}$ & $\begin{array}{c}\text { Mean } \\
\text { Total counts }\end{array}$ & $\begin{array}{l}\text { Standard } \\
\text { deviation } \\
\text { Total counts }\end{array}$ & $\begin{array}{l}\text { Standard error } \\
\text { of the mean }\end{array}$ \\
\hline $2 \mathrm{~B}^{a}$ & 5898.0 & 112.54 & 45.95 \\
\hline Background & 7628.7 & 1424.35 & 822.35 \\
\hline Background $^{b}$ & 7581 & $N / A^{c}$ & N/A \\
\hline
\end{tabular}

${ }^{a}$ Location $2 \mathrm{~B}$ is on the back of cathode \#3.

${ }^{b}$ This background measurement was made in a separate building.

N/A = not applicable

Once again the average beta particle emissions are more than two standard deviations away from the mean background. The most likely explanation is that the alpha/beta scintillation probe and scaler were malfunctioning. 


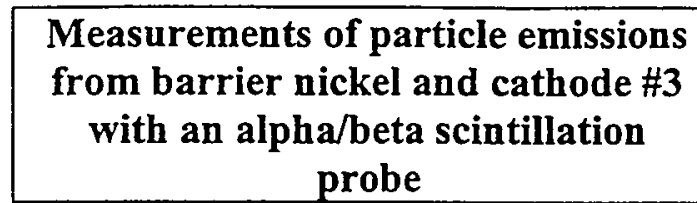

\begin{tabular}{|c|c|}
\hline $\begin{array}{l}\text { Sample } \\
\text { location }\end{array}$ & $\begin{array}{l}\text { Beta particles } \\
\text { count rate } \\
\text { (counts } / \mathrm{min} \text { ) }\end{array}$ \\
\hline Barrier nickel & 2032 \\
\hline Barrier nickel & 1990 \\
\hline Barrier nickel & 1965 \\
\hline Barrier nickel & 1979 \\
\hline Barrier nickel & 1953 \\
\hline Barrier nickel & 2016 \\
\hline Barrier nickel & 1987 \\
\hline Barrier nickel & 1950 \\
\hline Barrier nickel & 1896 \\
\hline Barrier nickel & 1935 \\
\hline $\begin{array}{c}\text { Cathode \#3 } \\
\text { (removed piece) }\end{array}$ & 294 \\
\hline $\begin{array}{c}\text { Cathode \#3 } \\
\text { (removed piece) }\end{array}$ & 301 \\
\hline $\begin{array}{c}\text { Cathode \#3 } \\
\text { (removed piece) }\end{array}$ & 333 \\
\hline $\begin{array}{c}\text { Cathode \#3 } \\
\text { (removed piece) }\end{array}$ & 331 \\
\hline $\begin{array}{c}\text { Cathode \#3 } \\
\text { (removed piece) }\end{array}$ & 317 \\
\hline $\begin{array}{c}\text { Cathode \#3 } \\
\text { (removed piece) }\end{array}$ & 323 \\
\hline $\begin{array}{c}\text { Cathode \#3 } \\
\text { (removed piece) }\end{array}$ & 330 \\
\hline $\begin{array}{c}\text { Cathode \#3 } \\
\text { (removed piece) }\end{array}$ & 317 \\
\hline $\begin{array}{c}\text { Cathode \#3 } \\
\text { (removed piece) }\end{array}$ & 328 \\
\hline $\begin{array}{c}\text { Cathode \#3 } \\
\text { (removed piece) }\end{array}$ & 355 \\
\hline Background & 315 \\
\hline Background & 283 \\
\hline Background & 316 \\
\hline Background & 316 \\
\hline Background & 327 \\
\hline Background & 304 \\
\hline Background & 290 \\
\hline
\end{tabular}




\begin{tabular}{|l|l|}
\hline Background & 278 \\
\hline Background & 253 \\
\hline Background & 305 \\
\hline
\end{tabular}

${ }^{a}$ Each count was for 30 minutes. 


\begin{tabular}{|c|c|}
\hline $\begin{array}{c}\text { Measurements of particle emissions } \\
\text { from barrier nickel and cathode \#3 } \\
\text { with a shielded Geiger-Müller tube }\end{array}$ \\
\hline \hline $\begin{array}{c}\text { Sample } \\
\text { location }\end{array}$ & $\begin{array}{c}\text { Beta particles } \\
\text { Total counts }\end{array}$ \\
\hline Barrier nickel & 34,670 \\
\hline Barrier nickel & 34,138 \\
\hline Barrier nickel & 34,511 \\
\hline Barrier nickel & 34,767 \\
\hline $\begin{array}{c}\text { Cathode \#3 } \\
\text { (removed piece) }\end{array}$ & 2128 \\
\hline $\begin{array}{c}\text { Cathode \#3 } \\
\text { (removed piece) }\end{array}$ & 2147 \\
\hline $\begin{array}{c}\text { Cathode \#3 } \\
\text { (removed piece) }\end{array}$ & 2225 \\
\hline $\begin{array}{c}\text { Cathode \#3 } \\
\text { (removed piece) }\end{array}$ & 2094 \\
\hline $\begin{array}{c}\text { Cathode \#3 } \\
\text { (location 1B) }\end{array}$ & 2213 \\
\hline $\begin{array}{c}\text { Cathode \#3 } \\
\text { (location 1B) }\end{array}$ & 2013 \\
\hline $\begin{array}{c}\text { Cathode \#3 } \\
\text { (location 1B) }\end{array}$ & 2121 \\
\hline
\end{tabular}

${ }^{a}$ Each count was for 60 minutes. 


\section{FACSIMULE COVER SHEET}

TO:

COMPANY: $\frac{\text { Valexie thad Var }}{\text { Marufacturiy Siences }}$

LOCATION:

FAXNO:

FROM:

COMPANY:

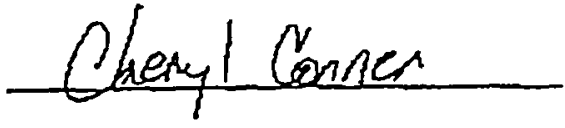

Thermo NUtech

Oak Ridge, Tennessee

PHONE NO: $423 / 481-0683$

FAX NO: $\quad 423 / 481-0121$ (Admin) 423/483-4621 (Lab)

\section{MESSAGE:}

DATE:<smiles>CC1CCCCC1</smiles>

TIME: $8: 02, n$.

\section{NUMBER OF PAGES INCLUDING}

COVER:

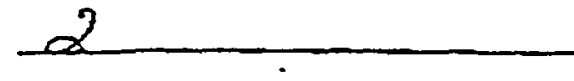

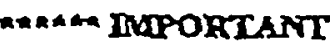

This cove stoct end the documeats.

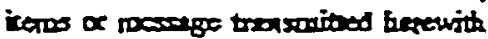
are intouded anty for the were of the individes or cartity to which is is odtreceod and sory contin infonotion that is pritilend, confdectivil and corope from de closure uoder applicablo Ww. If the reader of this mesege is not the inteaded recipient, or the cosployec or xyl ropoarible for delivaing the mesoge to tho intended sccipion, you are bertoy notifod ther any ditedocar, distribution or copying of thic communition is triedy probition. If yoo breveriod this cocomoniction in cror, plase notify us imenedidely by telophooe and Jcture one crigion message bo us at the. addres above vic to Unitod Stutes Postel Savioen

Throk you

Lab 4702022 - TC-99 Results 


\begin{tabular}{|c|c|c|c|c|c|c|c|c|c|c|c|c|}
\hline Lab ID & & Cilent ID & $\begin{array}{l}\text { Sample } \\
\text { Dato }\end{array}$ & $\begin{array}{l}\text { Recelpt } \\
\text { Dale }\end{array}$ & $\begin{array}{l}\text { Analysls } \\
\text { Dalo }\end{array}$ & Batch 10 & Analyte & Mothod & Pesult & Eiror & MDA & Units \\
\hline 87.02022 .01 & $\mathrm{~K}$ & KNOWN & $02 / 11 / 87$ & $02 / 11 / 87$ & $02 / 20 / 87$ & 9702022 & Technelium-89 & ECCHrom TCSOI Modilled & 538.51 & 11.80 & & $\mathrm{pCl} / \mathrm{g}$ \\
\hline $97-02022-01$ & S & SPIKE & $02 / 11 / 87$ & $02 / 11 / 87$ & $02 / 20 / 87$ & 8702022 & Technolium-89 & ElcHrom Tasol Modliled & 563.96 & 8.41 & 1.72 & $\mathrm{pCi} / \mathrm{g}$ \\
\hline $97-02022 \cdot 02$ & B & BLANK & $02 / 11 / 87$ & $02 / 1\} / 87$ & 0220187 & 9702022 & Technetlum-89 & ElCHrom TCS01 Modlfled & -0.55 & 0.83 & 1.65 & $p \mathrm{Ci}_{g}$ \\
\hline 97.02022 .03 & $D$ & AI & $10 / 01 / 98$ & $02 / 11 / 97$ & $02 / 20 / 87$ & 9702022 & Techngtum-89 & EJCHrom TCSOS Modified & 3.20 & 1.22 & 1,02 & $\mathrm{pCi} / \mathrm{g}$ \\
\hline 97-02022-04 & & $M 1$ & $10 / 01 / 98$ & $02 / 11 / 97$ & $02 / 20 / 97$ & 8702022 & Technstium-88 & ECHrom TCSOI Modifled & 2,14 & 1.20 & 1.05 & $\mathrm{pCi} / \mathrm{g}$ \\
\hline 87-02022-05 & & $\sharp 2$ & $10 / 01 / 88$ & $02 / 11 / 97$ & $02 / 20 / 97$ & 8702022 & Techriellum-99 & EiCHrom TCSO1 Modilled & 26.50 & 1.67 & 1.89 & $\mathrm{pCi} / \mathrm{g}$ \\
\hline 97.02022 .06 & & $\$ 3$ & $10 / 01 / 98$ & $02 / 11 / 97$ & $02 / 20 / 87$ & 8702022 & Technetlum-99 & ElCHrom TCSOr Modiffed & 4,90 & 1.10 & 1.82 & pCi/g \\
\hline $97.02022 \cdot 07$ & & $\$ 4$ & $10 / 01 / 96$ & $02 / 11 / 97$ & $02 / 20 / 87$ & $870202 ?$ & Technollum-89 & ElCHrom TCSO1 Modifled & 2.23 & 1.05 & 1.89 & pCilg \\
\hline
\end{tabular}


Valerie McNair

Manufacturing Sciences

804 Kerr Hollow Road

Oak Ridge, TN 37830
PO\#: 972443

SDG: 9705089

Matrix: Liquid
Final Report of Analysis

Date of Report: 5/28/97

Page 1 of 1

\begin{tabular}{|c|c|c|c|c|c|c|c|c|c|c|c|c|}
\hline Lab ID & & Client ID & $\begin{array}{l}\text { Sample } \\
\text { Dale }\end{array}$ & $\begin{array}{l}\text { Receipt } \\
\text { Dale }\end{array}$ & $\begin{array}{l}\text { Analysis } \\
\text { Dale }\end{array}$ & Batch ID & Analyle & Melhod & Result & Error & MDA & Units \\
\hline $97-05089-01$ & K & KNOWN & $05 / 20 / 97$ & $05 / 20 / 97$ & $05 / 23 / 97$ & 9705089 & Technetium-99 & EiCHrom TCW01 Modified & 546.26 & 12.00 & & $\mathrm{PCI} / \mathrm{L}$ \\
\hline $97-05089-01$ & $\mathrm{~S}$ & SPIKE & $05 / 20 / 97$ & $05 / 20 / 97$ & $05 / 23 / 97$ & 9705089 & Technelium-99 & EiCHrom TCW01 Modified & 575.20 & 6.62 & 1.80 & $\mathrm{PCI} / \mathrm{L}$ \\
\hline $97-05089-02$ & B & BLANK & $05 / 20 / 97$ & $05 / 20 / 97$ & $05 / 23 / 97$ & 9705089 & Technetium-99 & EiCHrom TCW01 Modified & -0.42 & 0.98 & 1.72 & $\mathrm{PCI} / \mathrm{L}$ \\
\hline $97-05089-03$ & $\mathbf{D}$ & $\# 1$ & & $05 / 20 / 97$ & $05 / 23 / 97$ & 9705089 & Technellum-99 & ElCHrom TCW01 Modilied & 560.66 & 31.26 & 29.57 & $\mathrm{PCI} / \mathrm{L}$ \\
\hline $97-05089-04$ & & $\# 1$ & & $05 / 20 / 97$ & $05 / 23 / 97$ & 9705089 & Technelium-99 & EiCHrom TCWO1 Modifled & 465.09 & 30.26 & 30.99 & $\mathrm{PCl} / \mathrm{L}$ \\
\hline 97-05089-05 & & $\# 2$ & & $05 / 20 / 97$ & $05 / 23 / 97$ & 9705089 & Technelium-99 & EiCHrom TCWoi Modified & 430.03 & 19.63 & 16.54 & $\mathrm{PCl} / \mathrm{L}$ \\
\hline 97-05089-06 & & \#3 & & $05 / 20 / 97$ & $05 / 23 / 97$ & 9705089 & Technelium-99 & EiCHrom TCW01 Modified & 120.70 & 12.94 & 16.15 & $\mathrm{PCl} / \mathrm{L}$ \\
\hline
\end{tabular}




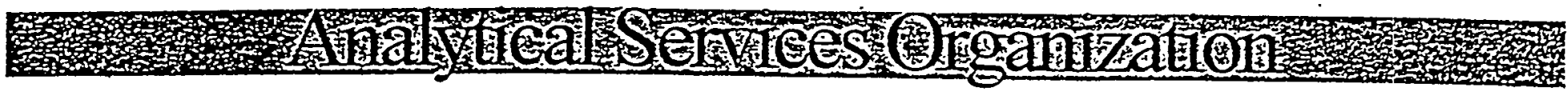

November 17, 1997

Manufacturing Science Corp.

Dear Libby Terry:

Enclosed please find a Level 4 "like" package for the analysis performed on A972120260. All the information that you need to validate the numbers is included If you have any questions, please feel free to contact me.
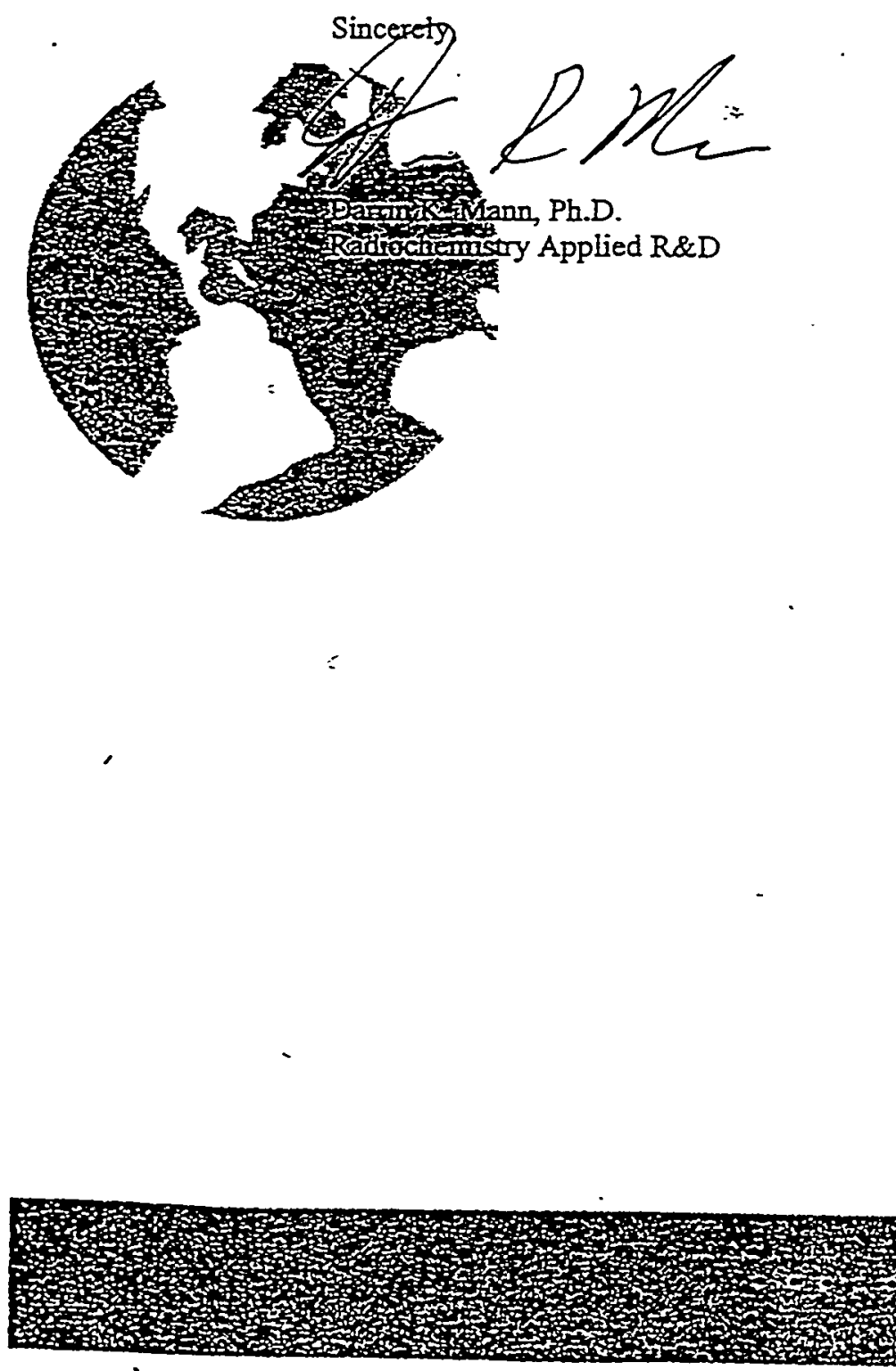


\section{CASE NARRATIVE}

Lab Project ID: KMSMSC

Sample Numbers: A972120260 (QA File \# PE-1141)

\section{Method Summary}

The methods requested were defined in the ASO Project Summary, which was given to the lab.

\begin{tabular}{|c|c|c|}
\hline Parameter & Separation Prócedure iD & Counting Procedure ID \\
\hline Technetium-99 & ACD-160074.R2 & ACD-160063.R1 \\
\hline
\end{tabular}

A duplicate and spike were analyzed with the sample.

The samples received were in the form of Nickel drill tumings. The turnings were reduced in size with metal cutters to facilitate digestion. An appropriate amount of sample was placed in a reaction vessel and digestion in a CEM STAR Open Vessel Microwave system using both Nitric and Hydrogen Peroxide to solubilize the sample. The digestion temperature was controlled to $80+1-0.1$ degrees Celsius. The digested sample was diluted to $1 \mathrm{M}$ HNO3 and placed in a Gilson ASPEC XL Automated Solid Phase Extraction (SPE) Unit An audit log of the run is attached. The sample is extracted from the column and counted by Liquid Scintillation on a Packard Tri-Carb 2550 LSC unit Data reduction is performed by a VMS spreadsheet

III. Quality Control Summary

\section{A. Holding Times}

All holding times were met, where applicable.

B. Calibration

1. Initial Calibration

Guidelines for initial instrument calibration are in each counting procedure, which are listed under the Method Summary. Initial CalibrationNerification is conducted using NIST traceable standards. The values must be within $10 \%$ of the known value to be acceptable.

2. Continuing Calibration

Quality control standards are counted on each instrument or detector daily and must fall within established limits before samples are counted. Daily instrument checks are aiso discussed in the counting procedures listed in the Method Summary.

\section{Tuning Not Applicable}

C. Quality Control Samples

1. Blanks All blanks were acceptable.

2. Laboratory Control Samples 
All laboratory control samples recovered within specified parameters.

3. Duplicates

The duplicate was within acceptable limits, being $-8.17 \%$

4. Matrix Spikes

The spike was within acceptable limits, with a recovery of $97.96 \%$

5. Post-Digestion Spikes (Surrogates/Tracers)

Not applicable.

6. Matrix interferences

None experienced.

\section{Standards}

All standards are traceable to a certified agency, and certificates of analysis are on file in the laboratory. Altemate sources are used if protocol dictates. 


\section{ASO Sample Worksheet}

\section{Laboratory Site: K-25 Radiochemistry}

Deadline: $\quad$ 8/24/97 11:59:59 PM

+ Due In Nucleąr Measurements: Immediately

!

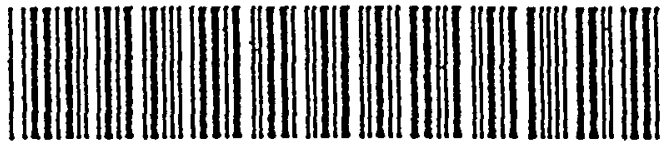

Project: MSC

Subproject: ERD94YA212

CUSTOMER: FM FAULCON

Charge Number: SN949400

Project Manage FM FAULCON (007949)

Logged In By: A MCGEE

Batched By: A. LIKENS (034896)

Date Sampled: 10/31/96

Sampled From: MAN. SCIENCES CORP.

Date Received: 7/28/97 11:45:47 AM

Sample 10 A972120260

Matrix SOLID

Material Descr.: NICKEL SHAVINGS

Comments: RETURN UN-USED SAMPLE TO MSC.

Special Handling:

1 Sample Aclivity Screen Results:

Test Title

Tc-99 Act. using LSC by 160063
Lab Test $1 D$

TC99-WP
Test Components

TC-99
Units

$\mathrm{pCi} / \mathrm{g}$ 


\section{RADIOCHEMISTRY LABB}

\section{SAḾPLE BATCH LOG}

Projecl Number: KMSMSC

Botch Type/Customer: Faulcoin (MSC)

J Homogenizalion Required

] Homogenization Required

i) Sample Prep. Method:

$\because: \frac{}{\text { Analysis }}$

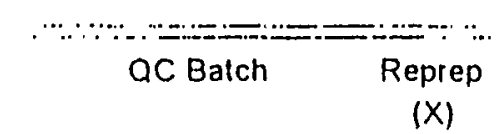

\section{Report Deadline: 8/24/97 11:59:59 PM .}

Projecl Manager: FM FAULCON (007949)
VI: Requires Data Pkg. SDG Case \#: MSC Sample Matrix: $\underline{\text { SOLID }}$

I TC99.WP

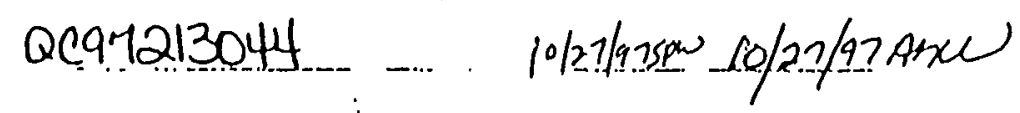

$\square$ High-Sreed Mixing

$\checkmark$ MAC-OPEN

[ other:

\begin{tabular}{|c|c|c|c|}
\hline \multicolumn{2}{|c|}{ Shaking } & [] other: & \\
\hline I.. MAD-ASH & ITAF-ASH & OOther: & {[} \\
\hline
\end{tabular}

$\because$

pecified Location of Sampies: $\underline{215-3}$

QA Baich contains 1 samples.

\begin{tabular}{|l|l|l|l|}
\hline A972120260 & & & \\
\hline & & & \\
\hline & & & \\
\hline & $\cdot$ & & \\
\hline & - & & \\
\hline
\end{tabular}

dditional Comments: MSc Nl aample

pecial Handling: NICKEL SHAYINGS 


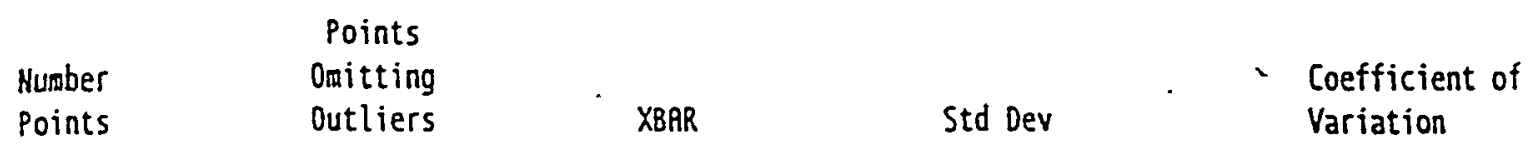

Current

$2 \theta$

19

972.228

138.285

$14.22 \%$

Units: dpm/ml

$$
\text { Lower }=783.7 \theta
$$

Upper $=1873.7 \theta$

Std $=928.7 \theta$

Pt Date Badge QA File Humber

71 24-0CT-1997 34120 PE-1141

$7 \theta 23-0 \mathrm{CT}-199733626 \mathrm{HP}-5292 / 5222$

69 23-0CT-1997 $33626 \mathrm{HP}-5222$

$68 \quad 22-0 C T-1997 \quad 336264$

67 22-0CT-1997 $3412 \theta \mathrm{HP}-5224$

66 19-0CT-1997 $3412 \theta$ ENV-2006

- 65 14-0CT-1997 33626 HP-5217

64 14-0CT-1997 $3412 \theta \mathrm{HP}-5210$

63 9-0CT-1997 $34896 \mathrm{HP}-5208$

62 B-0CT-1997 $3412 \theta$ ENV-2005

61 8-0CT-1997 $3412 \theta \mathrm{HP}-52 \theta 7$

$6 \theta \quad 8-0 C T-19973412 \theta \mathrm{HP}-5283$

59 7-0CT-1997 $33626 \mathrm{HP}-5213$

58 6-0CT-1997 34128 ENV-2082

$57 \quad 5-0 \mathrm{CT}-1997 \quad 33626 \mathrm{HP}-5213$

56 .5-0CT-1997 $33626 \mathrm{HP}-5213$

55 5-0CT-1997 $34128 \mathrm{HP}-5195$

54 3:0CT-1997 $3412 \theta \mathrm{KP}-5196$

53 1-OCT-1997 33626 ENV-2803

52 12-SEP-1997 33626 HP-5174

0

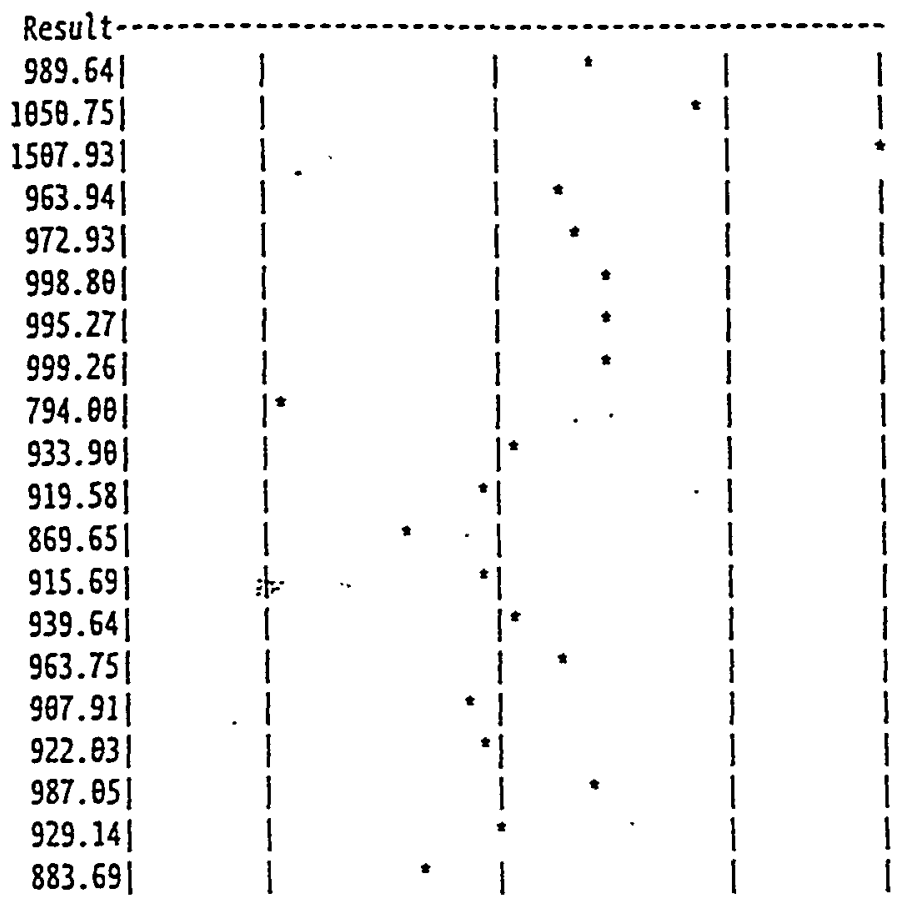


DRTE COUNTED:24-OCT-1997

OATE CALCULRTED:27-OCF-1997

QR FILE-PE-1141

ANRLYST:DKH/KRL
QR DRTA SHEET

SAMPLE COUNTING TIME IN UNITS OF MINUTES:

PACKARD 2559TR LIO. SCINTILLATION COUNTER HS 1, 2, OR-3:

DESIRED ACTIVITY UNITS $(1=p[i, 2=u C i, \quad 3=d p m)$ :

DESIRED HEIGHT FRACTION UNITS ( $1=g, 2=f i l t e r)$ :

INTERNAL CONTROL CHART PROGRAM NUMBER:

ENTER: $\theta$ FOR $16 \theta 6 \theta \theta$

1 FOR $162 \theta 1 \theta$

2 FOR $162 \theta 11$

INTERNAL CONTROL CHART BATCH NUKBER:

3 FOR $1606 \theta 1$ (LL mode)
246.0

2

1

1

$\theta$

$989.64 \mathrm{DPK} / \mathrm{ML}$

$1073.7 \theta$

$783.7 \theta$

$2.51 \mathrm{e}+81 \quad(p[i / g)$

$2.51 e+\theta 1 \quad(p(i / g)$

$-8.17 \%$

$97.96 \%$

$1023.56 \mathrm{DPH} / \mathrm{ML}$

KNOHN RCTIVITY OF CONTROL, DECAY CORRECTED:

STANDRRD: R1-128-H REFERENCE DATE: O1-JAH-1987

Analis report: 
DATE COUNTED:24-OCT-1997

DRTE CRLCULATED:27-OCT-1997

OR FILE-PE-1141

ANALYST:DKM/KAL

Tc-99 (Teva5pec)

SAMPLE HO EFFIC. TSIE GROSS DILUTION HEIGHT HET NET COUNTING

NUHBER OO FRCT. VALUE ACTIVITY FACTOR FRACTION ACTIVITY RCTIVITY CERTAINTY

$=\frac{\text { HS CPH/DPH }}{=}=\frac{\text { (CPH) }}{=0.922}=$

CONTROL

$0.921245 .89 \quad 479.06$

(al)

(g)

$(p[i / L) \quad(p(i / g) \quad(+/-)$

OUPLICATE

SPIKE

$0.926262 .69 \quad 26.92$

$0.925260 .51 \quad 490.21$

26.71

$\theta .500$

$\theta . \theta 0 \theta$

0.929267 .45

0.929267 .45

D971020801HS

0.921253 .15

26.71

26.06

$0.925260 .53 \quad 26.1 \theta$

$25.7 \theta$

$\theta . \theta \theta \theta$

$\theta . \theta 77$

$4.47 e+65$

NA $2.83 \mathrm{e}+\theta 3$

$\theta . \theta \theta \theta$

$\theta .077$

NA $2.73 e+\theta 1^{\prime} 5.73 e+\theta \theta$

$\theta . \theta \theta \theta$

$\theta: \theta 77$

NA $\quad 2.95 \mathrm{e}+\theta 3 \quad 1.85 \mathrm{e}+61$

$\theta . \theta \theta \theta$

$\theta . \theta 77$

NA $2.51 \mathrm{e}+\theta 1<5.71 \mathrm{e}+\theta \theta$

NA $\quad 2.51 \mathrm{e}+\theta 1 \quad 5.71 \mathrm{e}+8 \theta$

0971020928

D97101082C

0.925260 .62

$\theta . \theta \theta \theta$

$\theta .076$

NA $2.39 \mathrm{e}+01 \cdot 5.81 \mathrm{e}+\theta \theta$

Nh $2.29 \mathrm{e}+\theta 1 \div 5.8 \theta \mathrm{e}+\theta \theta$

$\theta .08 \theta$

0.076

$\theta .88 \theta$

0.976

NA $2 . \theta 3 \mathrm{e}+\theta 1^{\prime} 5.78 \mathrm{e}+\theta \theta$

$1.01 \% 0.21 d p=/ 9$

$0.93 \% 0.21 \mathrm{~d} / \mathrm{p3} / \mathrm{g}$

$0.95 \% 0.21 \mathrm{dp} / \mathrm{g}$

$0.88+1-0.22 \mathrm{dps} / \mathrm{g}$

$0.85 \% 0.22 \%$
$0.75 \% 0.21$.

lOHl\#66keSs9B

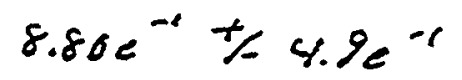




\section{RADIOCHEMICAL ANALYSIS}

\section{LABORATORY PREPARATION SHEET FOR LIQUID SCINTILLATION COUNTING}

Prep. (Grale): 123 Com Trme: 240 min.

QA FII :

Project/Analysis: DEV , TC

CLRoom Rocd: $10,24,97$ by DKM

Cour Date: 10,24197 by DKM

Inoris.t/Prococolf: 21,103999/5
Packego Deadline: ASHP I

Prep.Data/Aarlyut: 10124197 by DKM

Comrol Number. 160600

Pipexte ID: Daity Chock by:

MGicrowavo Fleanmo: $\quad N A$

Procoduro Number. ACD-1600746

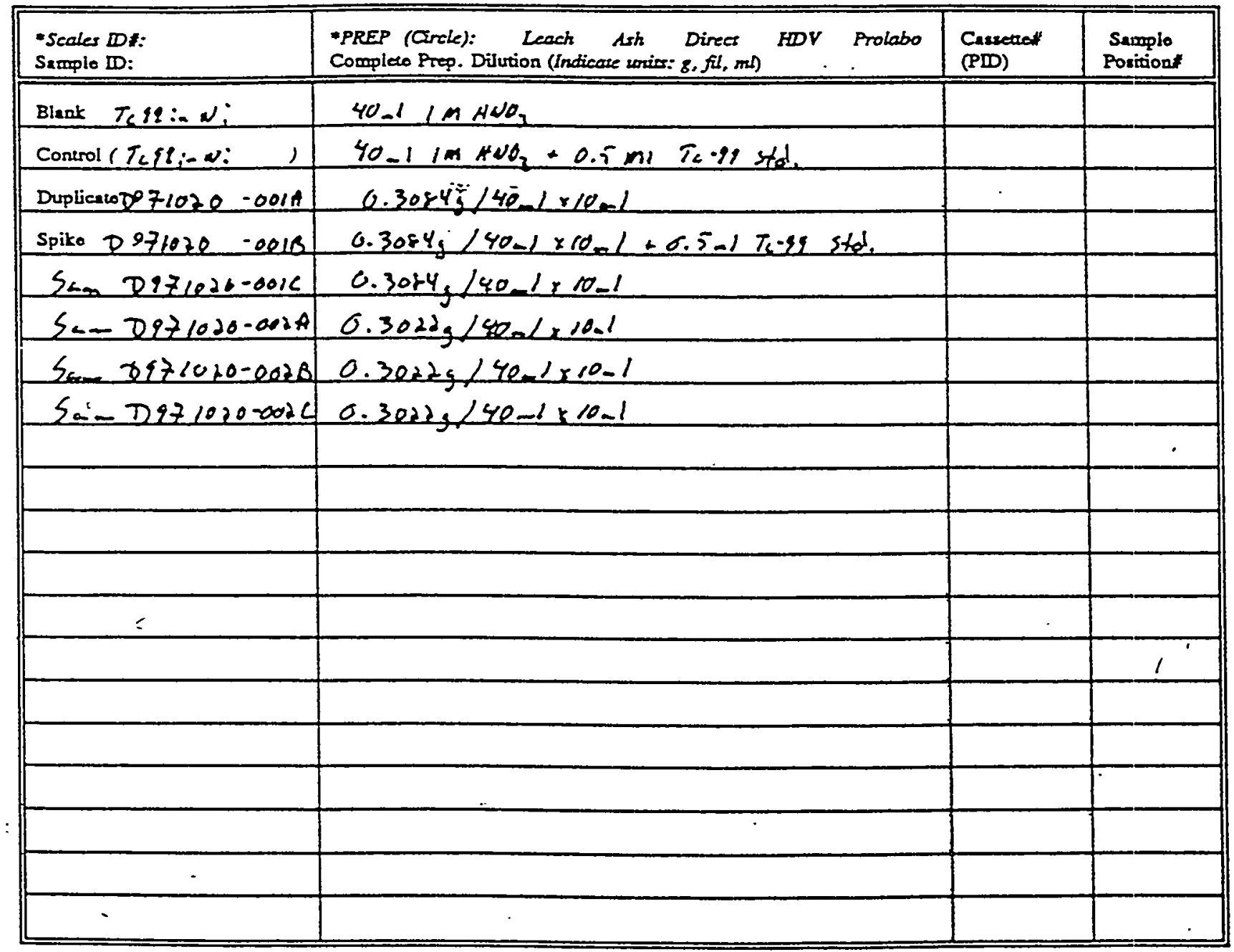

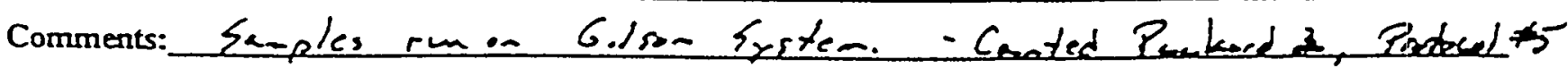


24 oct $97 \quad 21: 18$ Protocol \#: 5

Tise: 240.00

Data Kode: DPY

Eackground Eubtract: Kanual

Regien 3:

IL UL

$0.0-293$

$6.0-293$

$293-2000$

Region C:

Huclide: TC_TEYA_LE Juench Set: TC_TEVAA

Tc-99/Teva UG

User : K25 Radiochemistry

Quench Indicator: tSSIE/AEC

Ext Sto Tercinatcr: Count

Packard Liquid Scintillation 2550TR-12 . Sk.103999

Luninescence Correction on

Heterogeneity Monitor On

Color Euench Correction on

\begin{tabular}{|c|c|c|c|c|c|c|c|c|c|c|c|}
\hline $\begin{array}{l}5 \\
5\end{array}$ & $\begin{array}{l}75 \\
75\end{array}$ & $\begin{array}{l}1 \\
2\end{array}$ & 240.00 & & 520.12 & .466 .00 & 69.516 & 245.89 & 0.921055 & & $\frac{1}{3}$ \\
\hline $\begin{array}{l}5 \\
5\end{array}$ & $\begin{array}{l}75 \\
75\end{array}$ & $\frac{2}{3}$ & $\begin{array}{l}240.00 \\
240.00\end{array}$ & $\begin{array}{r}479.06 \\
26.92\end{array}$ & 29.06 & 25.24 & 58.609 & 262.69 & 0.926501 & & 20 \\
\hline 5 & 75 & $\begin{array}{l}3 \\
4\end{array}$ & $\begin{array}{l}240.00 \\
240.00\end{array}$ & 490.21 & 530.03 & 478.64 & 77.953 & 260.51 & 0.924872 & & 2 \\
\hline 5 & 75 & 5 & 240.00 . & 26.71 & 28.74 & 24.99 & 68.436 & 267.45 & 0.927270 & & 17 \\
\hline 5 & 75 & $b$ & 240.00 & 26.06 & 28.29 & 24.64 & 67.968 & 253.15 & 0.921369 & & 17 \\
\hline 5 & 75 & 7 & 240.00 & 26.10 & 28.22 & 24.63 & 67.558 & 260.53 & $0.9248 \Omega 2$ & & 16 \\
\hline 3 & 75 & 8 & 240.00 & 25.70 & 27.73 & 24.58 & 67.725 & 260.62 & 0.927944 & & is \\
\hline
\end{tabular}

SYSTEM NOFMALIIZED

I C14 IFA DATA FFICLESSED

C14 CHI SGUARE IFA DATA FFOCESSED

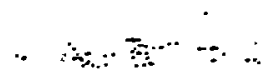

$D^{\mu / 2}$

0.00

0.00

\author{
SYSTEM NORMALIZED
}

1

HE. IFA DATA FF:OCESSED

HI CHI SQUAFE IFA DATA FRDCESSED

EKE IFA DATA FF:CCESSED 
Analysis Tc-99

Date Printed 10/27/97 3:21 PM

QAFile \# PE-1141

\section{MDA GENERAL CALCULATION}

Equation Used: $\quad[(4.65 \times$ Sqri(BIK. Cts. $))+2.71 / T i m e \times$ Eff. $\times$ Vol $\times$ Convertion $]$

Count Time

Blank Counts

5596.8
240 Minutes

\begin{tabular}{ccccccc} 
Sample 1.D. & Type & Det. Eff. & Weight (g) & $\begin{array}{c}\text { MDA } \\
\text { (dpm/g) }\end{array}$ & $\begin{array}{c}\text { MDA } \\
\text { (pCi/g) }\end{array}$ & $\begin{array}{c}\text { MDA } \\
\text { (Bq/g) }\end{array}$ \\
\hline D971020001AMD & A & 0.926 & $7.71 E-02$ & $2.05 E+01$ & $9.22 E+00$ & $3.41 E-01$ \\
D971020001BMS & A & 0.925 & $7.71 E-02$ & $2.05 E+01$ & $9.23 E+00$ & $3.41 E-01$ \\
D971020001C & A & 0.929 & $7.71 E-02$ & $2.04 E+01$ & $9.19 E+00$ & $3.40 E-01 ;$ \\
D971020002A & A & 0.921 & $7.56 E-02$ & $2.10 E+01$ & $9.46 E+00$ & $3.50 E-01$ \\
D971020002B & A & 0.925 & $7.56 E-02$ & $2.09 E+01$ & $9.42 E+00$ & $3.4 B E-01$ \\
D971020002C & A & 0.925 & $7.56 E-02$ & $2.09 E+01$ & $9.42 E+00$ & $3.4 B E-01$
\end{tabular}

$\because$ 



\section{Point and Column Means}

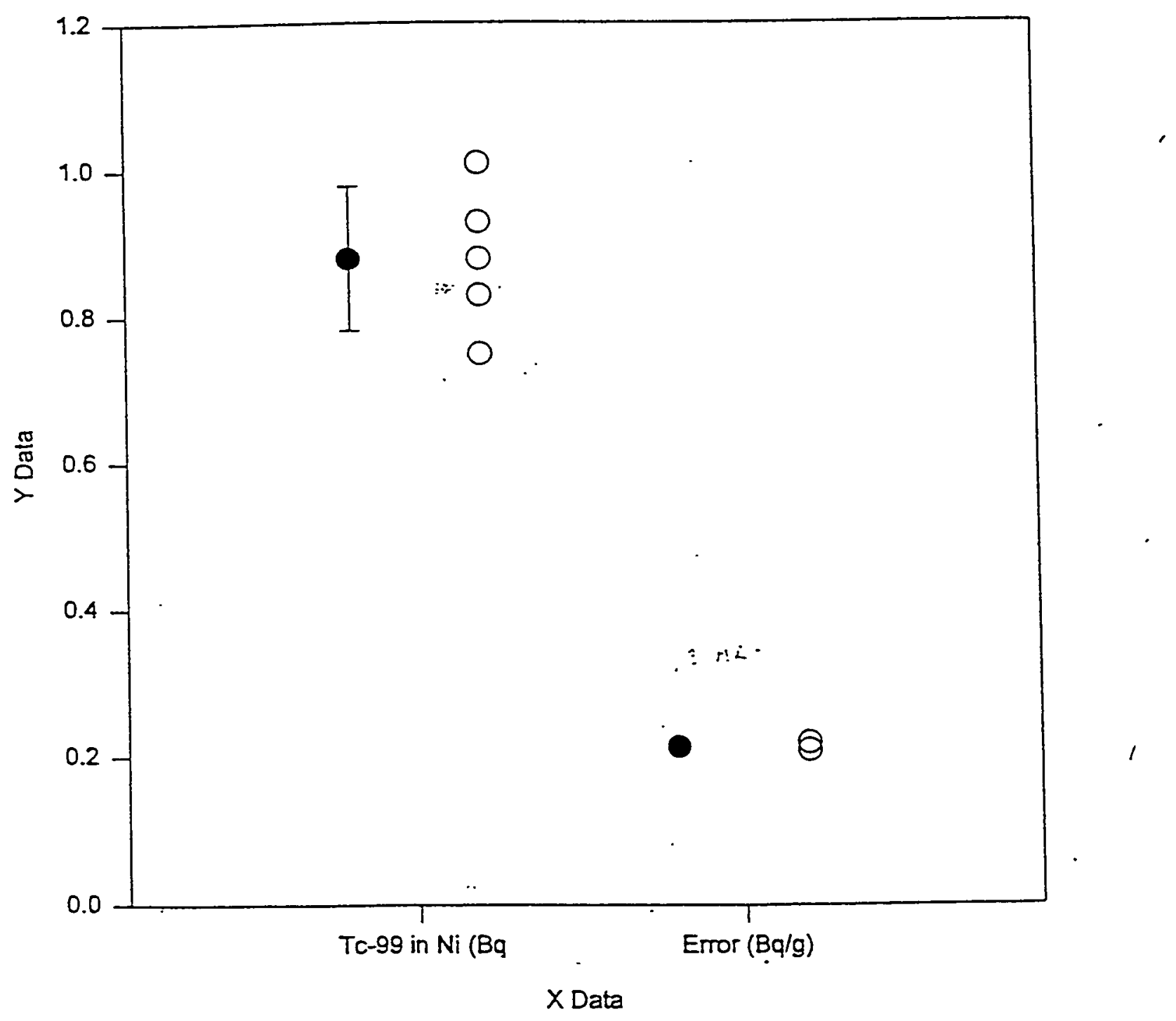


$1997-10-22$

14:41:12 **** Open file Logl.Log****

Gilson Sampler Controller Software 721 V2.00

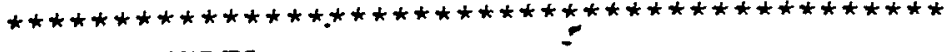

NAME : FILEI

RINSE ASPEC NEEDLE

14:41:39. Iinsing aspec needle... CONDITION

$14: 42: 13$ Dispensing 5.000m in DEC

14:44:03 Dispensing 5.000m in DEC

14:45:27 Dispensing 5:000m in DEC

$14: 47: 17$ Dispensing 5.000ml in DEC

$14: 48: 41$ Dispensing 5.000ml in DEC

14:50:31 Dispensing 5.000m in DEC

14:51:56 Dispensing 5.000ml in DEC

14:53:46 Dispensing 5.000m in DEC CONDITION

14:55:11 Aspirating 9.500m from SOLVENT_A

14:56:26 Dispensing 9.500m in DEC

14:58:57 Aspirating 9.500m] from SOLVENT_A

15:00:11 Dispensing 9.500m in DEC

15:02:44 Aspirating 9.500ml from SOLVENT_A

15:03:58 Dispensing 9.500m in DEC.

15:06:31 Aspirating 9.500ml from SOLVENT_A

15:07:55 Dispensing 9.500ml in DEC

15:10:27 Aspirating 9.500m from SOLVENT_A

$15: 11: 42$ Dispensing $9.500 \mathrm{ml}$ in DEC

$15: 14: 14$ : Aspirating 9.500ml from SOLVENT_A

15:15:29 Dispensing $9.500 \mathrm{ml}$ in DEC

15:18:01 Aspirating 9.500ml Erom SOLVENT_A

15:19:17 Dispensing 9.500m in DEC

15:21:49 Aspirating 9.500m from SOLVENT_A

15:23:03 Dispensing 9.500m in DEC

WAIT

15:25:37 Waiting for : $2.00 \mathrm{~min}$

15:27:40 Current vial: $1 / 8$

RINSE ASPEC NEEDLE

15:27:42 rinsing aspec needle...

IOAD

15:28:14 Aspirating 9.970m from SAMPIE_A

15:29:2.8 Dispensing 9.970m in DEC

WAIT

15:32:13 Waiting for $: 0.30 \mathrm{~min}$

LOAD

15:32:35 Aspirating 9.970ml from SAMPLE_A

$15: 33: 49$ Dispensing 9.970ml in DEC

WAIT

$15: 36: 35$ Waiting for : $0.30 \mathrm{~min}$

LOAD

15:36:56 Aspirating 9.970m from SAMPLE_A

15:38:10 Dispensing 9.970m in DEC

WAIT

$15: 40: 55$ Waiting for : $0.30 \mathrm{~min}$ 
LOAD

15:41:16 Aspirating 9.970ml from SAMPLE_A

15:42:30 Dispensing 9.970ml in DEC

RINSE ASPEC NEEDLE

15:45:14 rinsing aspec needle...

DISPENSE

$15: 45: 46$

Aspirating B000uí from SOLVENT A

15:46:52 Dispensing 8000ul into SAMPLE_ $\bar{A}$

MIX

15:47:32 Mixing SAMPIE_A with 7000ul of liquid LOAD

15:48:33 Aspirating 8.100ml from SAMPLE_A

15:49:37 Dispensing 8.100ml in DEC

RINSE ASPEC NEEDIE

15:51:53 rinsing aspec needle... DISPENSE

15:52:25 Aspirating 8000ul from SOIVENT_A

15:53:29. Dispensing 8000ul into SAMPLE $\bar{A}$

MIX

15:54:07 Mixing SAMPLE A with 7000ul of liquid IOAD

15:55:08 AsFizating 8.100ml from SAMPLE_A

15:56:13 Dispensing $8.100 \mathrm{ml}$ in DEC

15:58:30 Current vial: $2 / 8$

RINSE ASPEC NEEDIE

15:58:33 rinsing aspec needle...

IOAD

15:59:05 Aspirating 9.970ml from SAMPLE_A

16:00:19 Dispensing 9.970ml in DEC : WAIT

16:03:04 Waiting for : $0.30 \mathrm{~min}$ IOAंD

16:03:25 Aspirating 9.970mi from SAMPIE_A

16:04:39 Jisenersing 9.970ml in DEC WAIT

16:07:23 Waiting for : $0.30 \mathrm{~min}$ IOAD

16:07:44 Asṕirating 9.970ml from SAMPLE_A

16:08:58 Dispensing 9.970ml in DEC WAIT

$16: 11: 44$ Waiting for : $0.30 \mathrm{~min}$ IOAD

16:12:06 Aspirating 9.970m from SAMPLE A

16:13:20 Dispensing 9.970ml in DEC.

RINSE ASPEC NEEDLE

16:16:05 rinsing aspec needle... $D=\because \because E$ ?

16:16:36 Aspirating 8000uI from SOLVENT A

16:17:41 Dispensing 8000ul into SAMPIE $\bar{A}$ MIX

16:18:19 Mixing SAMPIE A with 7000ul of Iiquid LOAD

16:19:20 Aspirating 8.100ml from SAMPLE_A

16:20:23 Dispensing 8.100ml in DEC RINSE ASPEC NEEDIE

16:22:41 rinsing aspec needle... 



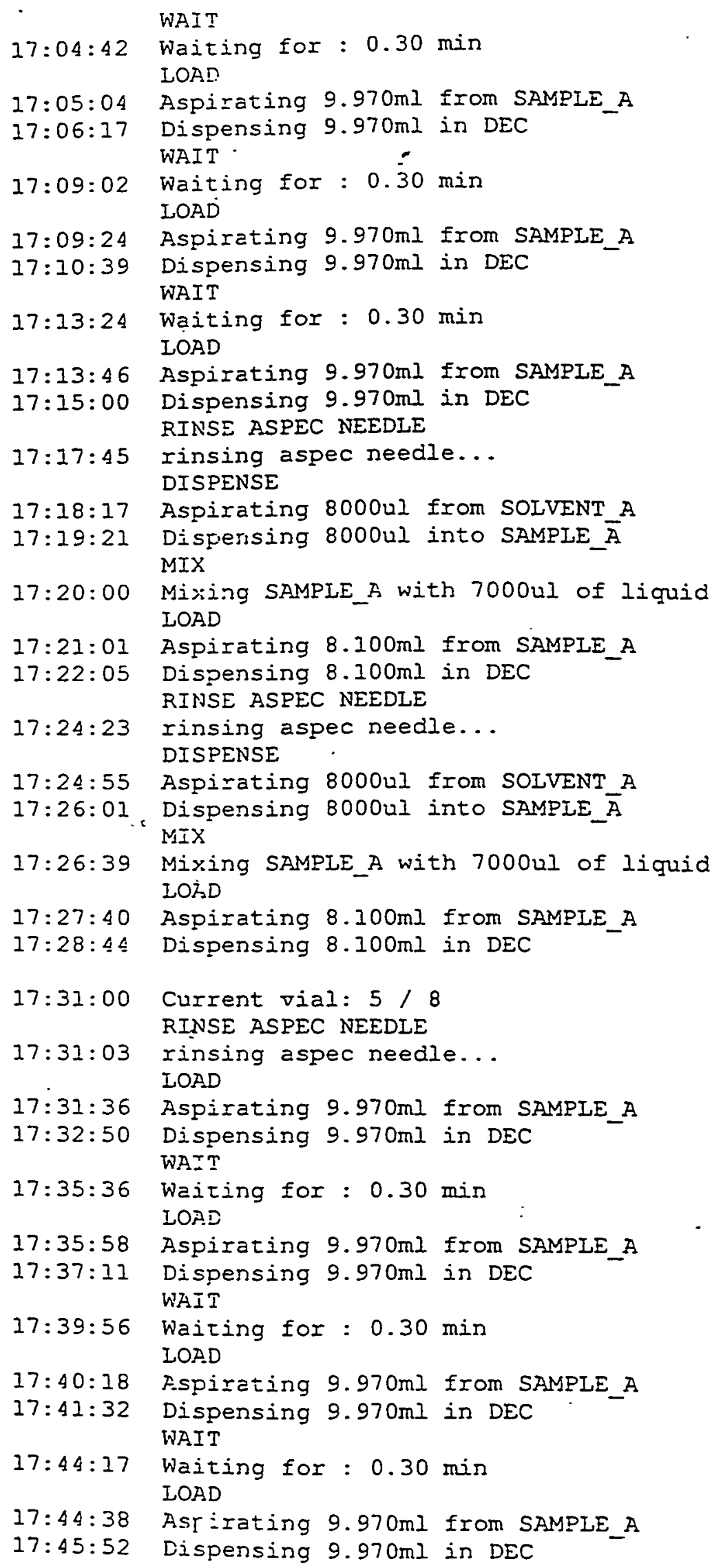




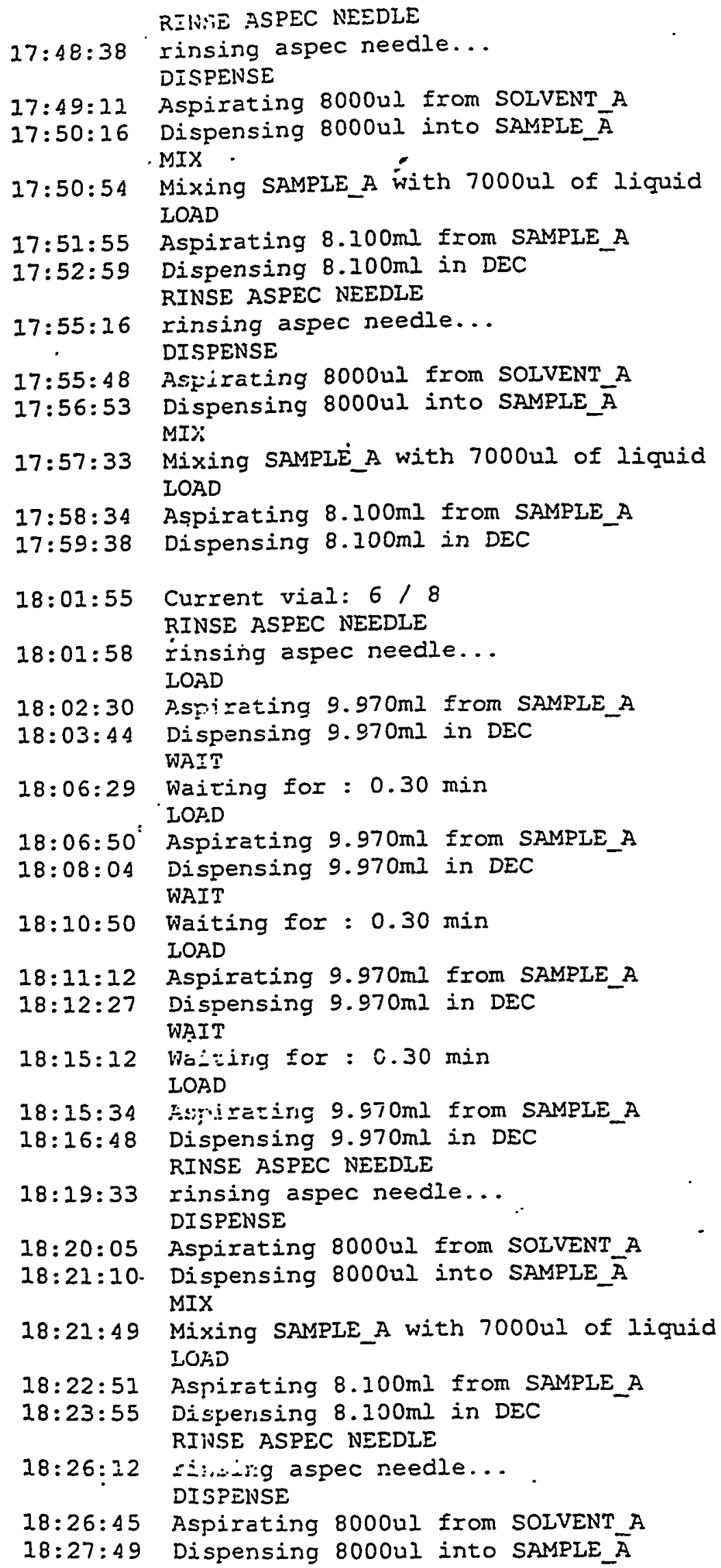


MIX

18:28:28 Mixing SAMPLE_A with 7000ul of liquid LOAD

18:29:29 Aspirating 8.100ml from SAMPIE_A

$18: 30: 33$ Dispensing $8.100 \mathrm{ml}$ in DEC

18:32:49 Current vial: ? 8

RINSE ASPEC NEEDLE

18:32:53 rinsing aspec needle...

LOAD

18:33:26 Aspirating 9.970ml from SAMPLE_A

18:34:40 Dispensing 9.970m in DEC

WAIT

$18: 37: 26$ Waiting for $: 0.30 \mathrm{~min}$

LOAD

$18: 37: 48$ Aspirating 9.970m from SAMPLE_A

18:39:02 Dispensing 9.970ml in DEC WAIT

$18: 41: 47$ Waiting for $: 0.30 \mathrm{~min}$ LOI:D

18:42:08 Aspirating 9.970m from SAMPLE_A

18:43:22 Difperising 9.570ml in DEC

WAIT

$18: 46: 08$ Waiting for $: 0.30 \mathrm{~min}$ IOAD

$18: 46: 30$

$18: 47: 44$

Aspirating $9.970 \mathrm{ml}$ from SAMPLE_A

Dispensing $9.970 \mathrm{ml}$ in DEC

RINSE ASPEC NEEDLE

18:50:30 rinsing aspec needle... DISPENSE

$18: 51: 02$

$18: 52: 07$

Aspireting 80c0ul from SOLVENT $A$

Dispersing $80 C \cdot 0 u 1$ into SAMPLE_ $\bar{A}$

$M I \%$

18:52:45 Mixing SAMPIE_t with 7000ul of liquid I0rij

18:53:45 Aspirating 8.100m from SAMPLE_A

18:54:49 Dispensing 8.100ml in DEC

RIYSE ASPEC NEEDLE

18:57:05 rinsing aspec reedle... DISPENSE

18:57:37 Aspirating 8000ul from SOLVENT_A

$18: 58: 43$ Dispensing 8000ul into SAMPLE $\bar{A}$ MIY.

18:59:22 Mixing SAMPLE_ $A$ with 7000ul of liquid ini:n

19:00:23 Aspirating 8.IJ0ml from SAMPIE_A

19:01:27 Jisperssing 8.1COml in DEC

19:03:43 Current vial: 8/8

RJ INSE ASPEC NEEDLE

19:03:46 ri:is:.r.g espec needle...

LOind

19:04:18 Aspirating 9.970ml from SAMPLE_A

19:05:32 Dispensing 9.970m in DEC WAIT

19:08:16 Weitir:g for : $0.30 \mathrm{~min}$

LOAD 


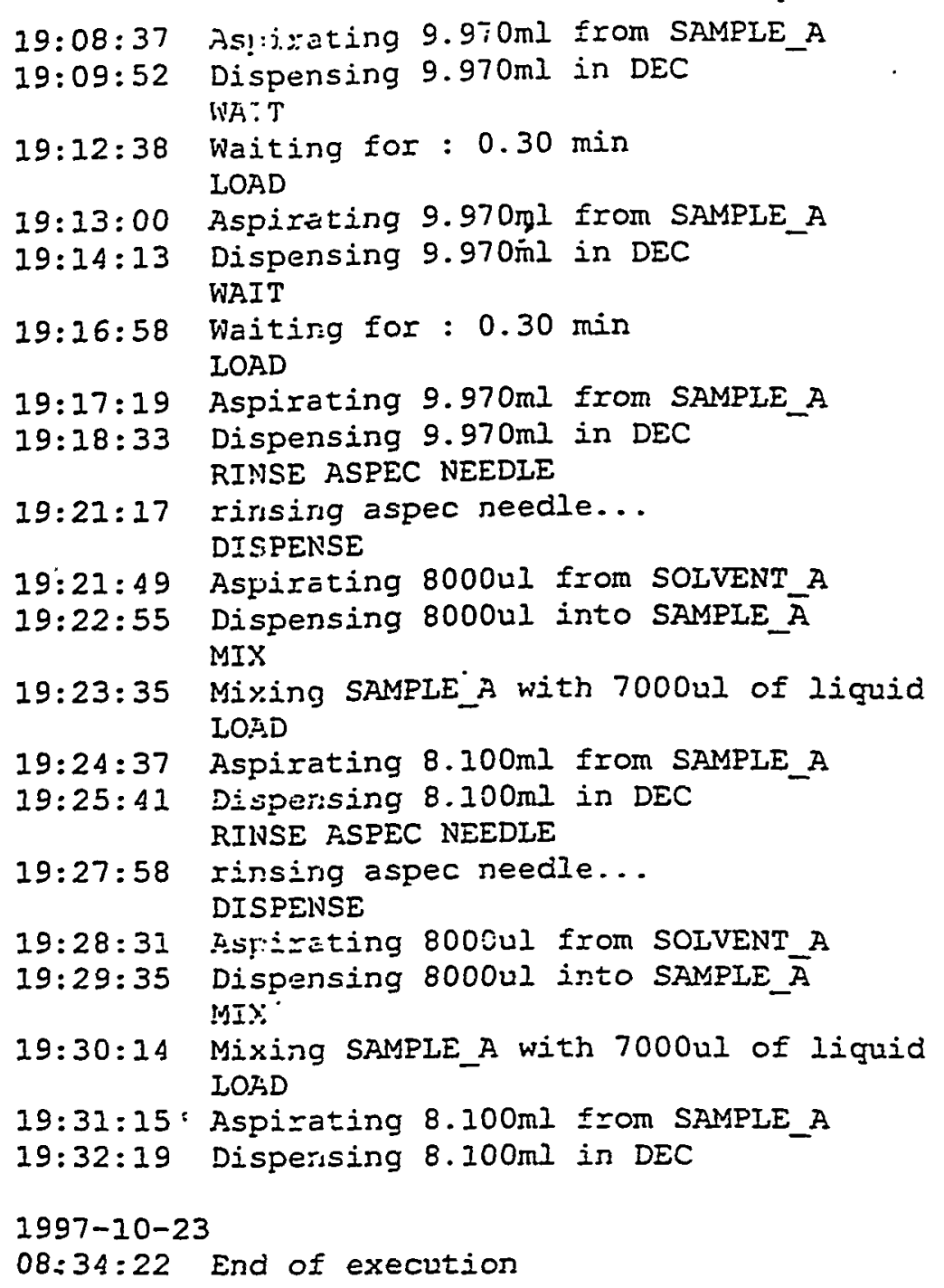


3H BACKGROUHS:

Value Date

16.15

16.37

16.40

16.20

16.35

16. 22

16.12

16.23

15.22

16.70

15.98

15.65

16.77

16.33

16.88

17.10

15.97

16.85

16.27

16.85

16.17

16.45

16.22

17.25

15.62

16.87

16.42

16.32

17.65

16.45

15.65

16.62

16.63

16.45

16.67

16.52

15.42

17.58

16.08

17.17

16.65

16. 12

16. 92

19.00

14.27

15.37

14.75

14.38

14.53

15.22

14.75

13.72

13.22

15.48

14.95
01 Aug 97 10:06

02 Aug 97 20:45

03 Aug 97 00:11

04 Aug 97

05 Aug 97

05 Aug 97

D6 Aug 97

D6 AUE 97

07 Aug 97

08 Aug 97

11 Aug 97

12 Aug 97

13 Aug 97

13 Aug 97

14 Aug 97

18 Aug 97

19 Aug 97

20 Aug 97

21 Aug 97

21 Aug 97

22 Aug 97

22 Aug 97

25 Aug 97

26 Aug 97

26 Aug 97

27 Aug 97

28, Aug 97

28 Aug 97

29 Aug 97

29 Aug 97

30 Aug 97

02 Sep 97

D3 Sep 97

04 Sep 97

05 Sép 97

05 Sep 97

07 Sep 97

08 Sep 97

09 Sep 97

10 Sep 97

10 Sep 97

11 Sep 97

12 Sep 97

30 Sep 97

30 Sep 97

30 Sep 97

01 Oct 87

02 Oct 97

03 Oct 97

05 Oet 97

OS Oct 97

07 Oct 97

07 Oct 97

07 Oct 97

08 Oct 97
$08: 50$.

$09: 55^{\circ}$

$18: 32$

$00: 32$

11:05

$09: 57$

$10: 13$

10: 12

10: 28

$10: 18$

$17: 22$

$09: 59$

10: 12

$10: 10$

10:15

$10: 14$

$18: 45$

$10: 10$

$16: 20$

$10: 25$

$09: 45$

$14: 46$

10:10

$10: 16$

18: 45

$10: 12$

11: 58

$17: 41$

10:21

10:07

$13: 31$

$08: 48$

$18: 15$

10: 52

$10: 26$

$10: 20$

$10: 34$

$17: 07$

$10: 29$

$10: 36$

$12: 32$

$14: 02$

$15: 47$

10:57

11:59

$09: 05$

$12: 09$

$12: 30$

$08: 59$

12: 40

21:29

$08: 01$

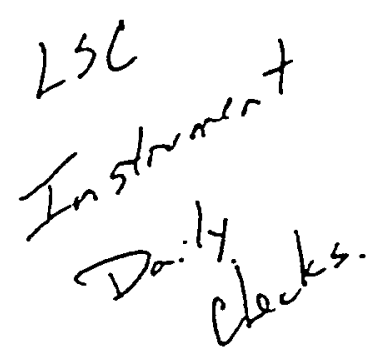




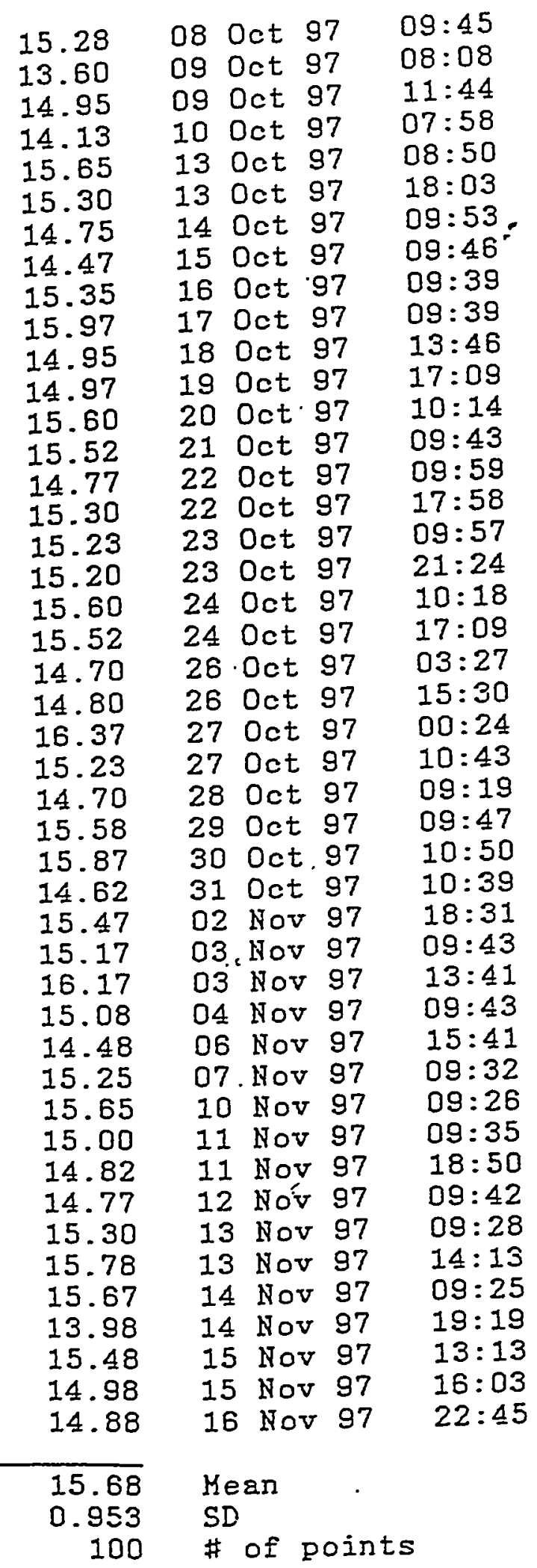




\begin{tabular}{|c|c|c|c|c|}
\hline 66.72 & 05 & Aug & 97 & $08: 44$ \\
\hline 66.51 & 05 & Aug & 97 & $17: 21$ \\
\hline 66.64 & 05 & Aug & 97 & $23: 21$ \\
\hline 66.66 & 06 & Aug & 97 & $09: 54$ \\
\hline 66.55 & 07 & Aug & 97 & $08: 46$ \\
\hline 67.02 & 08 & Aug & 97 & $08: 02$ \\
\hline 66.38 & 11 & Aug & 97 & $09: 01$ \\
\hline 66.55 & 12 & Aug & 97 & $09: 17$ \\
\hline 66.75 & 13 & Aug & 97 & $09: 07$ \\
\hline 66.72 & 13 & Aug & 97 & $16: 11$ \\
\hline 66.95 & 14 & Aug & 97 & $08: 48$ \\
\hline 66.46 & 18 & Aug & 97 & $09: 01$ \\
\hline 66.71 & 19 & Aug & 97 & $08: 59$ \\
\hline 66.63 & 20 & Aug & 97 & $09: 04$ \\
\hline 66.50 & 21 & Aug & 97 & $09: 03$ \\
\hline 66.84 & 21 & Aug & 97 & $17: 34$ \\
\hline 66.49 & 22 & Aug & 97 & $08: 59$ \\
\hline 66.84 & 22 & Aug & 97 & $15: 09$ \\
\hline 66.52 & 25 & Aug & 97 & $09: 14$ \\
\hline 66.38 & 26 & Aug & 97 & $08: 34$ \\
\hline 66.49 & 26 & Aug & 97 & $13: 35$ \\
\hline 66.81 & 27 & Aug & 97 & $08: 58$ \\
\hline 66.59 & 28 & Aug & 97 & $09: 05$ \\
\hline 66.82 & 28 & Aug & 97 & $17: 34$ \\
\hline 66.57 & 29 & Aug & 97 & $09: 01$ \\
\hline 66.41 & 29 & Aug & 97 & $10: 47$ \\
\hline 66.61 & 30 & Aug & 97 & $16: 30$ \\
\hline 66.19 & 02 & Sep & 97 & $09: 10$ \\
\hline 66.61 & 03 & Sep & 87 & $08: 56$ \\
\hline 66.61 & 04 & Sep & 97 & $12: 20$ \\
\hline 66.26 & $05^{\circ}$ & Sep & 97 & $07: 37$ \\
\hline 66.44 & 05 & $S \in P$ & 87 & $17: 05$ \\
\hline 66.55 & 07 & Sep & 97 & $09: 41$ \\
\hline 66.51 & 08 & Sep & 97 & $09: 15$ \\
\hline 66.71 & 09 & Sep & 97 & $09: 09$ \\
\hline 66.72 & 10 & Sep & 97 & $09: 23$ \\
\hline 66.48 & 10 & Sep & 97 & $15: 56$ \\
\hline 66.61 & 11 & Sep & 97 & $09: 18$ \\
\hline 66.46 & 12 & Sep & 97 & $09: 25$ \\
\hline 67.09 & 30 & Sep & 87 & $11: 21$ \\
\hline 67.24 & 30 & Sep & 97 & $12: 51$ \\
\hline 66.78 & 30 & Sep & 97 & $14: 36$ \\
\hline 67.00 & 01 & Oct & 87 & $08: \triangle 6$ \\
\hline .52 & 02 & Oct & 97 & $10: 48$ \\
\hline 66.90 & 03 & Oct & 97 & $07: 54$ \\
\hline 66.75 & 05 & Oct & 97 & $10: 58$ \\
\hline 67.00 & 06 & Oct & 97 & $11: 19$ \\
\hline 66.76 & 07 & Oct & 97 & $07: 48$ \\
\hline 67.02 & 07 & Oct & 97 & $11: 29$ \\
\hline 66.09 & 07 & Oct & 97 & $20: 18$ \\
\hline .94 & 08 & Oct & 97 & $06: 50$ \\
\hline & 08 & Oct & 97 & $08: 34$ \\
\hline & 09 & Oct & 97 & $06: 57$ \\
\hline & 09 & Oct & 97 & $10: 33$ \\
\hline & 10 & Oct & 97 & $06: 47$ \\
\hline & 13 & Oct & 97 & $07: 38$ \\
\hline & 13 & Oct & 97 & 16: \\
\hline & 14 & Oct & 97 & 08 \\
\hline
\end{tabular}


$66.00 \quad 15$ Oct $97 \quad 08: 35$

$65.92 \quad 16$ Det $97 \quad 08: 28$

$66.00 \quad 17$ Oct $97 \quad 08: 28$

$66.08 \quad 18$ Oet $97 \quad 12: 35$

$65.99 \quad 19$ Oct $97 \quad 15: 58$

65.9120 Oct $97 \quad 08: 03$

$\begin{array}{llll}65.73 & 22 \text { Oct } 97 & 08: 48 \\ 66.04 & 22 \text { Oct } 97 & 16: 47\end{array}$

$65.68 \quad 23$ Oct $97 \quad 08: 46$

65.6723 oct $97 \quad 20: 13$

$65.82 \quad 24$ oct $97 \quad 09: 07$

$65.92 \quad 24$ Oct $97 \quad 15: 58$

$65.86 \quad 26$ Oct $97 \quad 02: 16$

$65.86 \quad 26$ oct $97 \quad 14: 19$

$65.93 \quad 26$ oct $97 \quad 23: 13$

$65.72 \quad 27$ oct $97 \quad 09: 32$

$65.92 \quad 28$ Det $97 \quad 08: 08$

65.6929 oct $97 \quad 08: 36$

65.9730 Oet $97 \quad 019: 39$

$65.79 \quad 31$ Oct $97 \quad 09: 28$

$66.26 \quad 02$ Nov $97 \quad 17: 19$

$65.73 \quad 03$ Nov $97 \quad 08: 32$

$66.06 \quad 03$ HOV $97 \quad 12: 30$

66.02 04 Hov 97 08:32

65.86 O6 Nov 97 09:05

65.92 O6 NOV 97 14:30

65.90 07 Nov'97 08:21

$65.87 \quad 10$ Hov $97 \quad 08: 15$

66.0511 Nov 97 08:24

$65.74 \quad 11$ Nov $97 \quad 17: 39$

$65.69 \quad 12$ Nov $97 \quad 08: 31$

$65.97 \quad 13$ Hov $97 \quad 08: 17$

$65.63 \quad 13$ Hov $97 \quad 13: 02$

$65.78 \quad 14$ Nov $97 \quad 08: 14$

$65.84 \quad 14$ Nov $97 \quad 18: 08$

$65.62,15$ Nov $97 \quad 12: 02$

$65.58 \quad 15$ Nov $97 \quad 14: 52$

$65.82 \quad 16$ Nov $97 \quad 21: 34$

66.27 Hean

0.434 SD

100 \# of points

3H EIGURE OF MERIT $\left(E^{\wedge} 2 / B\right)$ :

Value Date Time

272.52 01 Aug 97 10:06

263.48 02 Aug $97 \quad 20: 45$

266.11 03 Aug 97 00:11

273.27 . 04 Aug 97 09:50

271.98 05 Aug 97 09:55

275.63 05 Aug $97 \quad 18: 32$

272.81 O6 Aug 97. 00:32

274.65 OS AUE $97^{\circ} 11: 05$

$\begin{array}{lll}286.20 & 07 \text { Aug } 97 & 09: 57\end{array}$ 


\begin{tabular}{|c|c|c|c|c|}
\hline 265.71 & 08 & Aug & 97 & $10: 13$ \\
\hline 275.39 & 11 & Aug & 97 & $10: 12$ \\
\hline 282.65 & 12 & Aug & 97 & $10: 28$ \\
\hline 263.96 & 13 & Aug & 87 & $10: 18$ \\
\hline 272.92 & 13 & Aug & 97 & $17: 22$ \\
\hline 63.53 & 14 & Aug & 97 & $09: 59$ \\
\hline 56.37 & 18 & Aug & 97 & $10: 12$ \\
\hline 79.81 & 18 & Aug & 97 & $10: 10$ \\
\hline 60.03 & 20 & Aug & 97 & $10: 15$ \\
\hline 69.26 & 21 & Aug & 97 & $10: 14$ \\
\hline 66.36 & 21 & Aug & 97 & $18: 45$ \\
\hline 71.84 & 22 & Aug & 87 & $10: 10$ \\
\hline 71.43 & 22 & Aug & 97 & $16: 20$ \\
\hline 70.20 & 25 & Aug & 97 & $10: 25$ \\
\hline 4.78 & 26 & Aug & 97 & $09: 45$ \\
\hline .86 & 26 & Aug & 97 & $14: 46$ \\
\hline 3.26 & 27 & Aug & 97 & $10: 10$ \\
\hline 9. 84 & 28 & Aug & 97 & $10: 16$ \\
\hline 72.55 & 28 & Aug & 97 & $18: 45$ \\
\hline 3.74 & 29 & Aug & 97 & $10: 12$ \\
\hline 66.83 & 29 & Aug & 97 & $11: 58$ \\
\hline 36.70 & 30 & Aug & 97 & $17: 4$ \\
\hline .12 & 02 & Sep & 97 & $10: 2$ \\
\hline.$\$ 1$ & 03 & Sep & 97 & $10: 0$ \\
\hline 9.45 & 04 & Sep & 97 & $13: 31$ \\
\hline 32.26 & 05 & Sep & 97 & $08: 48$ \\
\hline 57.97 & 05 & Sep & 97 & $18: 1$ \\
\hline 5.02 & 07 & SeI & 97 & $10: 52$ \\
\hline 1.64 & 08 & Sep & 97 & $10: 2$ \\
\hline .59 & 09 & Sep & 97 & $10: 2$ \\
\hline 7.96 & 10 & Sep & 97 & $10: 3$ \\
\hline .79 & 10 & Sep & 97 & $17: 0$ \\
\hline .51 & 11 & Sep & 97 & $10: 29$ \\
\hline 1.46 & 12 & Sep & 97 & $10: 36$ \\
\hline .03 & 30 & Sep & 97 & $12: 3$ \\
\hline .01 & 30 & Sep & 97 & $14: 02$ \\
\hline .33 & 30 & Sep & 97 & $15: 4$ \\
\hline .75 & 01 & Oct & 97 & $10: 57$ \\
\hline .01 & 02 & Dct & 97 & $11: 5$ \\
\hline .13 & 03 & Oct & 97 & 09 \\
\hline .23 & 05 & Oct & 97 & 12 \\
\hline .24 & 06 & Oct & 97 & 12 \\
\hline .75 & 07 & Oct & 97 & 08 \\
\hline .03 & 07 & Oct & 97 & 12: \\
\hline .88 & 07 & Oct & 97 & 21 \\
\hline .43 & 08 & Oct & 97 & 08 \\
\hline .44 & 08 & Oct & 97 & \\
\hline & 09 & Oct & 97 & 08: \\
\hline & ๑९ & Oct & 97 & 11 \\
\hline & 10 & Oct & 97 & 07 \\
\hline & 13 & Oct & 97 & 08 \\
\hline & 13 & Oct & 97 & 18: \\
\hline & 14 & Oct & 97 & $09: 5$ \\
\hline & 15 & Oct & 97 & 09 \\
\hline & 16 & Oct & 97 & 09 \\
\hline & 17 & Oct & 97 & 09 \\
\hline & & Oct & 97 & \\
\hline & 15 & Oct & 97 & 17 \\
\hline
\end{tabular}




\begin{tabular}{|c|c|c|c|c|}
\hline 26.22 & 19 & Aug & 97 & 09:09 \\
\hline 29.01 & 20 & Aug & 97 & $09: 14$ \\
\hline 21.29 & 21 & Aug & 97 & $09: 14$ \\
\hline 19.10 & 21 & Aug & 97 & $17: 44$ \\
\hline 25.45 & 22 & Aug & 97 & 09:09 \\
\hline 22.59 & 22 & Aug & 97 & $15: 20$ \\
\hline 18.84 & 25 & Aug & 97 & $09: 24$ \\
\hline 22.23 & 26 & Aug & 97 & $08: 45$ \\
\hline 17.07 & 26 & Aug & 97 & $13: 46$ \\
\hline 16.65 & 27 & Aug & 97 & $09: 10$ \\
\hline 9.84 & 28 & Aug & 97 & $09: 16$ \\
\hline 20.98 & 28 & Aug & 97 & $17: 44$ \\
\hline 23.49 & 29 & Aug & 97 & $09: 12$ \\
\hline 9.40 & 29 & Aug & 97 & $10: 57$ \\
\hline 19.53 & 30 & Aug & 97 & $16: 40$ \\
\hline 24.43 & 02 & Sep & 97 & $09: 21$ \\
\hline 17.02 & 03 & Sep & 97 & $09: 07$ \\
\hline 21.48 & 04 & Sep & 97 & $12: 31$ \\
\hline 14.87 & 05 & Sep & 97 & $07: 48$ \\
\hline 22.09 & 05 & Sep & 97 & $17: 15$ \\
\hline 12.05 & 07 & Sep & 97 & $09: 51$ \\
\hline 15.91 & 08 & Sep & 97 & $09: 26$ \\
\hline 22.54 & 09 & Sep & 97 & $09: 18$ \\
\hline 22.35 & 10 & Sep & 87 & $09: 33$ \\
\hline 17.14 & 10 & Sep & 97 & $16: 06$ \\
\hline 15.63 & 11 & Sep & 97 & DQ: 28 \\
\hline 12.66 & 12 & Sep & 97 & $09: 35$ \\
\hline 25.78 & 30 & Sep & 97 & $11: 32$ \\
\hline 23.51 & 30 & Sep & 97 & $13: 02$ \\
\hline 22.84 & 30 & Sep & 97 & $14: 47$ \\
\hline 15.35 & 01 & Oct & 97 & $09: 57$ \\
\hline $3 i .43$ & 02 & Oct & 97 & $10: 59$ \\
\hline 19.03 & 03 & Dct & 97 & $08: 04$ \\
\hline 16.94 & 05 & Oct & 87 & $11: 09$ \\
\hline 14.92 & 06 & Oct & 97 & $11: 29$ \\
\hline 22.56 & 07 & Oct & 97 & $07: 59$ \\
\hline 18.18 & 07 & Oct & 97 & $11: 40$ \\
\hline 16.25 & 07 & Oct & 97 & $20: 28$ \\
\hline 15.41 & 08 & Oet & 97 & $07: 00$ \\
\hline 10.04 & 08 & Oct & 97 & $08: 45$ \\
\hline 23.07 & 09 & Oct & 97 & $07: 08$ \\
\hline 30.52 & 09 & Oct & 97 & $10: 44$ \\
\hline 19.42 & 10 & Oct & 97 & $06: 58$ \\
\hline 20.42 & 13 & Det & 97 & $07: 49$ \\
\hline 11.91 & 13 & Oct & 97 & $17: 03$ \\
\hline 14.99 & 14 & Oct & 87 & $08: 52$ \\
\hline 18.82 & 15 & Oct & 87 & $08: 45$ \\
\hline 31.64 & 16 & Oct & 97 & $08: 39$ \\
\hline 14.21 & 17 & Oct & 97 & $08: 39$ \\
\hline 12.89 & 18 & Oct & 87 & $12: \leqslant 6$ \\
\hline 14.61 & 19 & Oct & 97 & $16: 08$ \\
\hline 27.56 & 20 & Oct & 97 & $09: 14$ \\
\hline 20.14 & 21 & Oct & 97 & $08: 4$ \\
\hline 26.31 & 22 & Oct & 97 & 08: \\
\hline 25.65 & 22 & Oct & 97 & $16: 58$ \\
\hline 25.41 & 23 & Oct & 97 & 08 \\
\hline 18.81 & 23 & Oct & 97 & 20 \\
\hline 17.87 & 24 & Oct & 97 & $09: 1$ \\
\hline
\end{tabular}


17 Hov 97 08:53 IRA TABLES

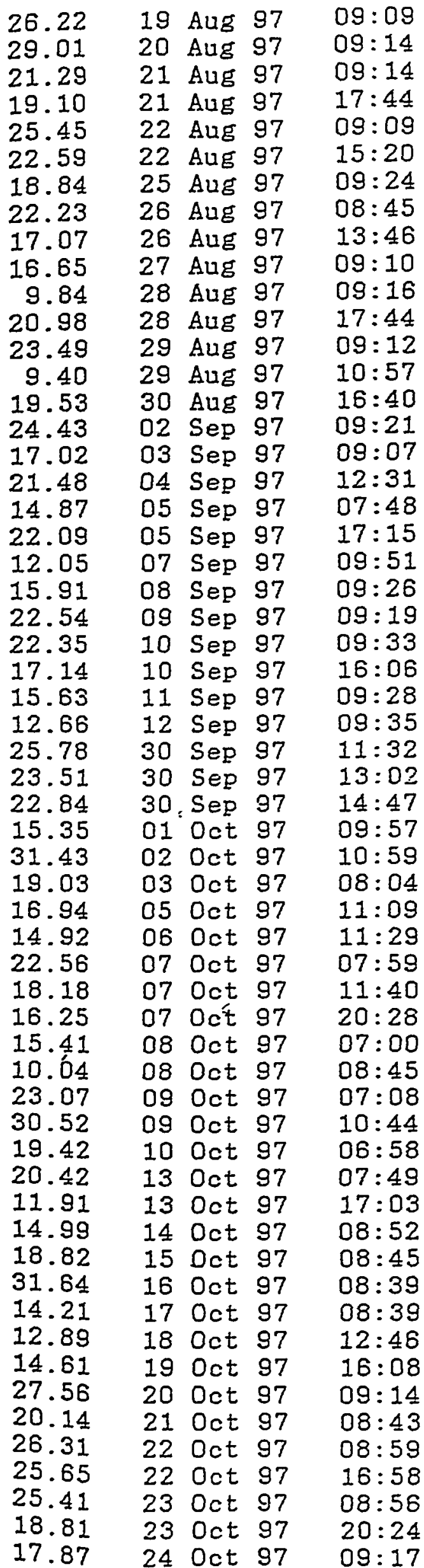


17 Nov $97 \quad 08: 53$

$21.59 \quad 24$ Oct $97 \quad 16: 09$

$25.74 \quad 26$ Oct $97 \quad 02: 27$

$21.57 \quad 26$ Oct $97 \quad 14: 30$

15.0726 oct $97 \quad 23: 23$

$9.70 \quad 27$ Oct $97 \quad 09: 43$

10.7528 Oct $97 \quad 08: 19$

10.6529 Oct $97 \quad 08: 46$

13.26 30 Oct $97 \quad 09: 49$

$32.43 \quad 31$ Oet $97 \quad 09: 38$

$20.38 \quad 02$ Nov $97 \quad 17: 30$

$16.60 \quad 03$ Nov $97 \quad 08: 43$

17.50 03 Nov $97 \quad 12: 40$

15.6704 Nov $97 \quad 08: 43$

17.98 06 Nov 97 09:16

5.99 O6 Nov 97 14:40

29.4107 Nov $97 \quad 08: 32$

$23.16 \quad 10 \mathrm{Nov} 97 \quad 08: 26$

21.6211 Nov $97 \quad 08: 34$

$20.26 \quad 11$ Nov $97 \quad 17: 49$

13.5912 Nov 97 08:42

$30.71 \quad 13$ Nov $97 \quad 08: 28$

13.09 13 Nov $97 \quad 13: 13$

$17.07 \quad 14 \mathrm{Nov} 97 \quad 08: 24$

11. 1414 Nov $97 \quad 18: 18$

$11.62 \quad 15$ Nov $97 \quad 12: 12$

20.91 15 Nov $97 \quad 15: 02$

9.35 Is Nov $97 \quad 21: 45$

13.67 Kean

5.921 SD

100 of points

14C BACKGROUND:

Value Date

22.25 01 Aug 97 10:06

$22.62 \quad 02$ Aug $97 \quad 20: \$ 5$

23.15 03 Aug 97 00:11

$23.20 \quad 04$ Aug $97 \quad 09: 50$

$23.27 \quad 05$ Aug $97 \quad 09: 55$

$22.92 \quad 05$ Aug $97 \quad 18: 32$

22.50 O6 Aug 97 00:32

22.80 O6 Aug 97 11:05

$21.47 \quad 07$ Aug $97 \quad 09: 57$

23.78 08 Aug 97 10:13

$22.47 \quad 11$ Aug $97 \quad 10: 12$

$22.67 \quad 12$ Aug $97 \quad 10: 28$

$23.50 \quad 13$ Aug 97 10:18

$22.95 \quad 13$ Aug $97 \quad 17: 22$

23.10 14 Aug 97 09:59

23.80 18 Aug $97 \quad 10: 12$

$22.28 \quad 19$ Aug $97 \quad 10: 10$

$23.43 \quad 20$ Aug $97 \quad 10: 15$

$22.75 \quad 21$ Aug $97 \quad 10: 14$

23.37 21 AUg $97 \quad 18: 45$

$22.83 \quad 22$ Aug 97 10:10 


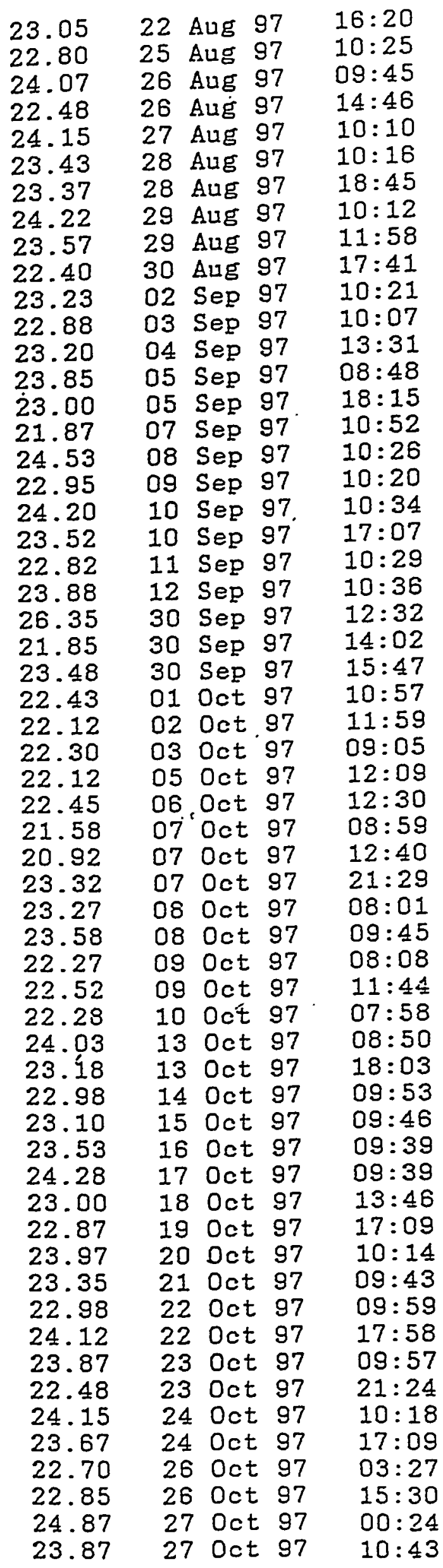




$\begin{array}{llll}17 \text { Hey } 97 & \text { 08:56 } & \text { IPA T } \\ 23.63 & 28 \text { Oct } 97 & 09: 19 \\ 23.40 & 29 \text { Oct } 97 & 09: 47 \\ 23.50 & 30 \text { Oct } 97 & 10: 50 \\ 22.62 & 31 \text { Oct } 97 & 10: 39 \\ 23.33 & \text { 02 Nov } 97 & 18: 31 \\ 23.52 & 03 \text { Nov } 97 & 09: 43 \\ 24.80 & \text { 03 Nov } 97 & 13: 41 \\ 22.78 & \text { 04 Nov } 97 & 09: 43 \\ 22.83 & 06 \text { Nov } 97 & 15: 41 \\ 22.98 & 07 \text { Nov } 97 & 09: 32 \\ 23.52 & 10 \text { Nov } 97 & 09: 26 \\ 23.10 & 11 \text { Nov } 97 & 09: 35 \\ 23.35 & 11 \text { Nov } 97 & 18: 50 \\ 22.95 & 12 \text { Nov } 97 & 09: 42 \\ 24.20 & 13 \text { Nov } 97 & 09: 28 \\ 24.48 & 13 \text { Nov } 97 & 14: 13 \\ 24.53 & 14 \text { Nov } 97 & 09: 25 \\ 21.75 & 14 \text { Nov } 97 & 19: 19 \\ 23.65 & 15 \text { Nov } 97 & 13: 13 \\ 22.82 & 15 \text { Nov } 97 & 16: 03 \\ 23.72 & 16 \text { Nov } 97 & 22: 45 \\ & & & \\ 23.19 & \text { Mean } & \\ 0.808 & \text { SD } & \\ 100 & \text { \# of points } & \end{array}$

\section{C EFEICIENCY:}

$\begin{array}{llll}\text { Value } & \text { Date } & \text { Time } \\ 96.46 & \text { 02 Aug } 97 & & 19: 22 \\ 96.39 & \text { 02 Aug } 97 & 22: 48 \\ 96.33 & \text { D4 Aug } 97 & 08: 27 \\ 96.76 & \text { 05 Aug } 97 & 08: 33 \\ 96.61 & \text { 05 Aug } 97 & 17: 09 \\ 96.62 & \text { 05 Aug } 97 & 23: 09 \\ 96.14 & 06 & \text { Aug } 97 & 09: 43 \\ 96.27 & 07 \text { Aug } 97 & 08: 34 \\ 96.56 & \text { 08 Aug } 97 & 08: 50 \\ 96.32 & 11 \text { Aug } 97 & 08: 49 \\ 96.26 & 12 \text { Aug } 97 & 09: 05 \\ 96.08 & 13 \text { Aug } 97 & 08: 55 \\ 96.48 & 13 \text { Aug } 97 & 15: 59 \\ 96.09 & 14 \text { Aug } 97 & 08: 36 \\ 96.34 & 18 \text { Aug } 97 & 08: 50 \\ 96.15 & 19 \text { Aug } 97 & 08: 47 \\ 96.39 & 20 \text { Aug } 97 & 08: 52 \\ 95.94 & 21 \text { Aug } 97 & 08: 52 \\ 96.69 & 21 \text { Aug } 97 & 17: 22 \\ 96.67 & 22 \text { Aug } 97 & 08: 47 \\ 96.48 & 22 \text { Aug } 97 & 14: 57 \\ 96.56 & 25 \text { Aug } 97 & 09: 02 \\ 96.60 & 26 \text { Aug } 97 & 08: 22 \\ 96.65 & 26 \text { Aug } 97 & 13: 23 \\ 96.81 & 27 \text { Aug } 97 & 08: 47 \\ 96.38 & 28 \text { Aug } 97 & 08: 53 \\ 96.40 & 28 \text { Aug } 97 & 17: 22\end{array}$




$\begin{array}{llll}96.51 & 29 \text { Aug } 97 & 08: 49 \\ 96.73 & 29 \text { Aug } 97 & 10: 35 \\ 96.61 & 30 \text { Aug } 97 & 16: 18 \\ 96.24 & 02 \text { Sep } 97 & 08: 59 \\ 96.08 & 03 \text { Sep } 97 & 08: 45 \\ 96.22 & 04 \text { Sep } 97 & 12: 08 \\ 96.66 & 05 \text { Sep } 97 & 07: 25 \\ 96.76 & \text { 05 Sep } 97 & 16: 53 \\ 96.19 & 07 \text { Sep } 97 & 09: 29 \\ 96.30 & 08 \text { Sep } 97 & 09: 04 \\ 96.23 & 09 \text { Sep } 97 & 08: 57 \\ 96.34 & 10 \text { Sep } 97 & 09: 11 \\ 96.90 & 10 \text { Sep } 97 & 15: 44 \\ 95.94 & 11 \text { Sep } 97 & 09: 06 \\ 96.14 & 12 \text { Sep } 97 & 09: 13 \\ 96.49 & 30 \text { Sep } 97 & 11: 10 \\ 96.27 & 30 \text { Sep } 97 & 12: 39 \\ 96.53 & 30 \text { Sep } 97 & 14: 24 \\ 96.13 & 01 \text { Oct } 97 & 09: 34 \\ 96.80 & 02 \text { Oct } 97 & 10: 37 \\ 96.79 & 03 \text { Oct } 97 & 07: 42 \\ 96.29 & 05 \text { Oct } 97 & 10: 46 \\ 96.81 & 06 \text { Oct } 97 & 11: 07 \\ 96.90 & 07 \text { Oct } 97 & 07: 36 \\ 97.10 & 07 \text { Oct } 97 & 11: 17 \\ 96.53 & 07 \text { Oct } 97 & 20: 06 \\ 97.36 & 08 \text { Oct } 97 & 06: 38 \\ 97.06 & 08 \text { Oct } 97 & 08: 22 \\ 96.68 & 09 \text { Oct } 97 & 06: 45 \\ 96.75 & 09 \text { Oct } 97 & 10: 21 \\ 96.87 & 10 \text { Oct } 97 & 06: 35 \\ 97.00 & 13 \text { Oct } 97 & 07: 27 \\ 96.93 & 13 \text { Oct } 97 & 16: 41 \\ 96.95 & 14 \text { Oct } 97 & 08: 30 \\ 96.96 & 15 \text { Oct } 97 & 08: 23 \\ 96.52 & 16 \text { Oct } 97 & 08: 16 \\ 96.38 & 17 \text { Oct } 97 & 08: 17 \\ 96.67 & 18 \text { Oct } 97 & 12: 23 \\ 96.77 & 19 \text { Oct } 97 & 15: 46 \\ 96.73 & 20 \text { Oct } 97 & 08: 51 \\ 97.02 & 21 \text { Oct } 97 & 08: 20 \\ 96.80 & 22 \text { Oct } 97 & 08: 36 \\ 96.95 & 22 \text { Oct } 97 & 16: 36 \\ 96.40 & 23 \text { Oct } 97 & 08: 34 \\ 96.63 & 23 \text { Oct } 97 & 20: 02 \\ 96.45 & 24 \text { Oct } 97 & 08: 55 \\ 96.41 & 24 \text { 0ct } 97 & 15: 47 \\ 97.07 & 26 \text { Oct } 97 & 02: 05 \\ 96.78 & 26 \text { Oct } 97 & 14: 08 \\ 96.14 & 26 \text { Oct } 97 & 23: 01 \\ 96.65 & 27 \text { Oct } 97 & 09: 21 \\ 96.52 & 28 \text { Oct } 97 & 07: 56 \\ 96.85 & 29 \text { Oct } 97 & 08: 24 \\ 95.90 & 30 \text { Oct } 97 & 09: 27 \\ 96.85 & 31 \text { Oct } 97 & 09: 16 \\ 96.27 & 02 \text { Nov } 97 & 17: 08 \\ 96.91 & 03 \text { Nov } 97 & 08: 20 \\ 97.04 & 03 \text { Hov } 97 & 12: 13 \\ 9 & & & \end{array}$




$\begin{array}{llll}97.48 & 04 \text { Nov } 97 & 08: 20 \\ 96.72 & 06 \text { Nov } 97 & 08: 54 \\ 96.93 & 06 \text { Nov } 97 & 14: 18 \\ 96.95 & 07 \text { Nov } 97 & 08: 09 \\ 96.18 & 10 \text { Nov } 97 & 08: 04 \\ 96.83 & 11 \text { Nov } 97 & 08: 12 \\ 96.87 & 11 \text { Nov } 97 & 17: 27 \\ 97.08 & 12 \text { Nov } 97 & 08: 20 \\ 96.48 & 13 \text { Nov } 97 & 08: 05 \\ 96.65 & 13 \text { Nov } 97 & 12: 50 \\ 96.93 & 14 \text { Nov } 97 & 08: 02 \\ 97.00 & 14 \text { Nov } 97 & 17: 56 \\ 96.68 & 15 \text { Nov } 97 & 11: 50 \\ 96.92 & 15 \text { Nov } 97 & 14: 40 \\ 96.43 & 16 \text { Nov } 97 & 21: 23 \\ & & \\ 96.59 & \text { Mean } & \\ 0.324 & \text { SD } & \end{array}$

14C EIGURE OF MERIT $\left(E^{\wedge} 2 / B\right):$

\begin{tabular}{|c|c|c|c|c|}
\hline Yalue & Dat & & & Time \\
\hline 550.52 & 01 & Aug $S$ & 87 & $10: 06$ \\
\hline 544.48 & 02 & Aug & 97 & $20: 45$ \\
\hline 522.82 & 03 & Aug $S$ & 87 & $00: 11$ \\
\hline 516.81 & 04 & Aug & 97 & $08: 50$ \\
\hline 528.68 & 05 & Aug & 87 & $09: 55$ \\
\hline 539.71 & 05 & Aug & 97 & $18: 32$ \\
\hline 553.04 & 06 & Aug & 97 & $00: 32$ \\
\hline 524.63 & 06 & Aug & 97 & $11: 05$ \\
\hline 578.00 & 07 & Aug & 97 & $09: 57$ \\
\hline 518.01 & 08 & Aug & 97 & $10: 13$ \\
\hline 547.07 & 11 & Aug & 97 & $10: 12$ \\
\hline 537.74 & 12 & Aug & 97 & $10: 28$ \\
\hline 512.51 & 13 & Aug & $\$ 7$ & $10: 18$ \\
\hline 539.02 & 13 & Aug & 97 & $17: 22$ \\
\hline 531.96 & 14 & Aug & 87 & $09: 59$ \\
\hline 517.24 & 18 & Aug & 97 & $10: 12$ \\
\hline 548.58 & 19 & Aug & 97 & $10: 10$ \\
\hline 534.90 & 20 & Aug & 97 & $10: 15$ \\
\hline 543.17 & 21 & Aug & 97 & $10: 14$ \\
\hline 532.07 & 21 & Aug & 97 & $18: 45$ \\
\hline 531.30 & 22 & Aug & 37 & $10: 10$ \\
\hline 533.98 & 22 & Aug & 97 & $16: 20$ \\
\hline 527.30 & 25 & Aug & 97 & $10: 25$ \\
\hline 520.55 & 26 & Aug & 97 & $09: 45$ \\
\hline 532.76 & 26 & Aug & 87 & $14: 46$ \\
\hline 496.87 & 27 & Aug & 97 & $10: 10$ \\
\hline 526.44 & 28 & Aug & 97 & $10: 16$ \\
\hline 521.41 & 28 & Aug & 97 & $18: 45$ \\
\hline 515.72 & 29 & Aug & 87 & $10: 12$ \\
\hline 516.72 & 29 & Aug & 97 & $11: 58$ \\
\hline & 30 & Aug & 97 & $17: 41$ \\
\hline 531.84 & 02 & Sep & 97 & $10: 21$ \\
\hline 538.28 & 03 & & 97 & 10 \\
\hline
\end{tabular}


528.73

528.11

53.5 .13

567.17

505.08

528.30

515.95

522.59

543.99

510.37

475.15

524.08

477.42

504.89

512.77

518.16

520.07

512.41

520.97

555.46

494.93

500.81

487.67

502.34

512.34

515.44

462.62

496.70

486.98

490.93

494.96

472.87

507.41

512.68

479.03

494.85

492.50

463.53

479.39

503.93

472.55

485.02

499.01

501.91

460.84

488.31

482.08

486.44

486.21

502.91

477.56

497.95

461.14

517.65

496.84

509.42

477.07

501.41
04 Sep $97 \quad 13: 31$

05 Sep 97 08:48

05 Sep 97 18:15

07 Sep $97 \quad 10: 52$

08 Sep 97 10:26

09 Sep 97 10:20

10 Sep 97 10:34

10 Sep $97 \quad 17: 07$

11 Sep $97 \quad 10: 29$

12 Sep 97 10:36

30 Sep 97 12:32

30 Sep 97 14:02

30 Sep $97 \quad 15: 47$

01 Oct $97 \quad 10: 57$

02 oct 97 11:59

03 Oct 97 09:05

05 Oct $97 \quad 12: 09$

06 Oct $97 \quad 12: 30$

07 Oet $97 \quad 08: 59$

07 Det $97 \quad 12: 40$

07 Oct 97 21:29

08 Oct $97 \quad 08: 01$

08 Oct 97 09:45

09 Det $97 \quad 08: 08$

09 Det $97 \quad 11: 44$

10 Det $97 \quad 07: 58$

13 Oet 97 08:50

13 Oet 97 18:03

14 Oet 97 09:53

15 Oct $97 \quad 09: 46$

$16^{\circ}$ Oct $97 \quad 09: 39$

17 Oct 97 09:39

18 Oct $97 \quad 13: 46$

19 Det 97 17:09

20 Oet 97 10:14

21 Det 97 09:43

22 Oct 97 09:59

22 Oct 97 17:58

23 Oct 97 09:57

23 Oct $97 \quad 21: 24$

24 Oct 97 10:18

24 Oct $97 \quad 17: 09$

26 Oct 97 03:27

26 Oct $97 \quad 15: 30$

27 Oct 97 00:24

27 Oct $97 \quad 10: 43$

28 Oct $97 \quad 09: 19$

29 Oct $97 \quad 09: 47$

30 Oct $97 \quad 10: 50$

31 Oct $97 \quad 10: 39$

02 Nov 97 18:31

03 Nov $97 \quad 09: 43$

03 Nov 97 13:41

04 Nov $97 \quad 09: 43$

06 Nov $97 \quad 15: 41$

07 Nov $97 \quad 09: 32$

10 Nov 97 09:26

11 Nov 87 09:35 


$\begin{array}{llll}486.96 & 11 \text { Nov } 97 & 18: 50 \\ 507.87 & 12 \text { Nov } 97 & 09: 42 \\ 475.57 & 13 \text { Nov } 97 & 09: 28 \\ 465.71 & 13 \text { Nov } 97 & 14: 13 \\ 474.13 & 14 \text { Nov } 97 & 09: 25 \\ 534.67 & 14 \text { Nov } 97 & 19: 19 \\ 486.17 & 15 \text { Nov } 97 & 13: 13 \\ 519.26 & 15 \text { Nov } 97 & 16: 03 \\ 478.27 & 16 \text { Nov } 97 & 22: 45\end{array}$

510.35 Mean

25.294 SD

100 \# of points

\section{C CHI-SQUARE:}
Value
19.29
23.03
21.16
12.48
34.61
33.21
21.74
26.50
27.82
24.02
17.65
19.59
16.62
16.05
21.04
15.96
27.06
16.96
20.95
18.44
22.59
14.91
15.72
15.28
14.22
18.52
11.62
22.41
23.18
16.96
12.54
18.13
15.90
25.46
19.40
23.59
18.97
13.14
23.10
Time
$22: 58$
$08: 38$
$08: 43$
$17: 20$
$23: 19$
$09: 53$
$08: 45$
09:01
09:00
$09: 16$
09:06
16:09
08: 47
09:00
$08: 58$
$09: 03$
09:02
$17: 33$
$08: 58$
$15: 08$
$09: 13$
$08: 33$
$13: 34$
$08: 58$
$09: 04$
$17: 32$
09:00
$10: 46$
$16: 28$
$09: 09$
$08: 55$
$12: 19$
$07: 36$
$17: 03$
$09: 39$
09: 14
09:08
$09: 22$ 


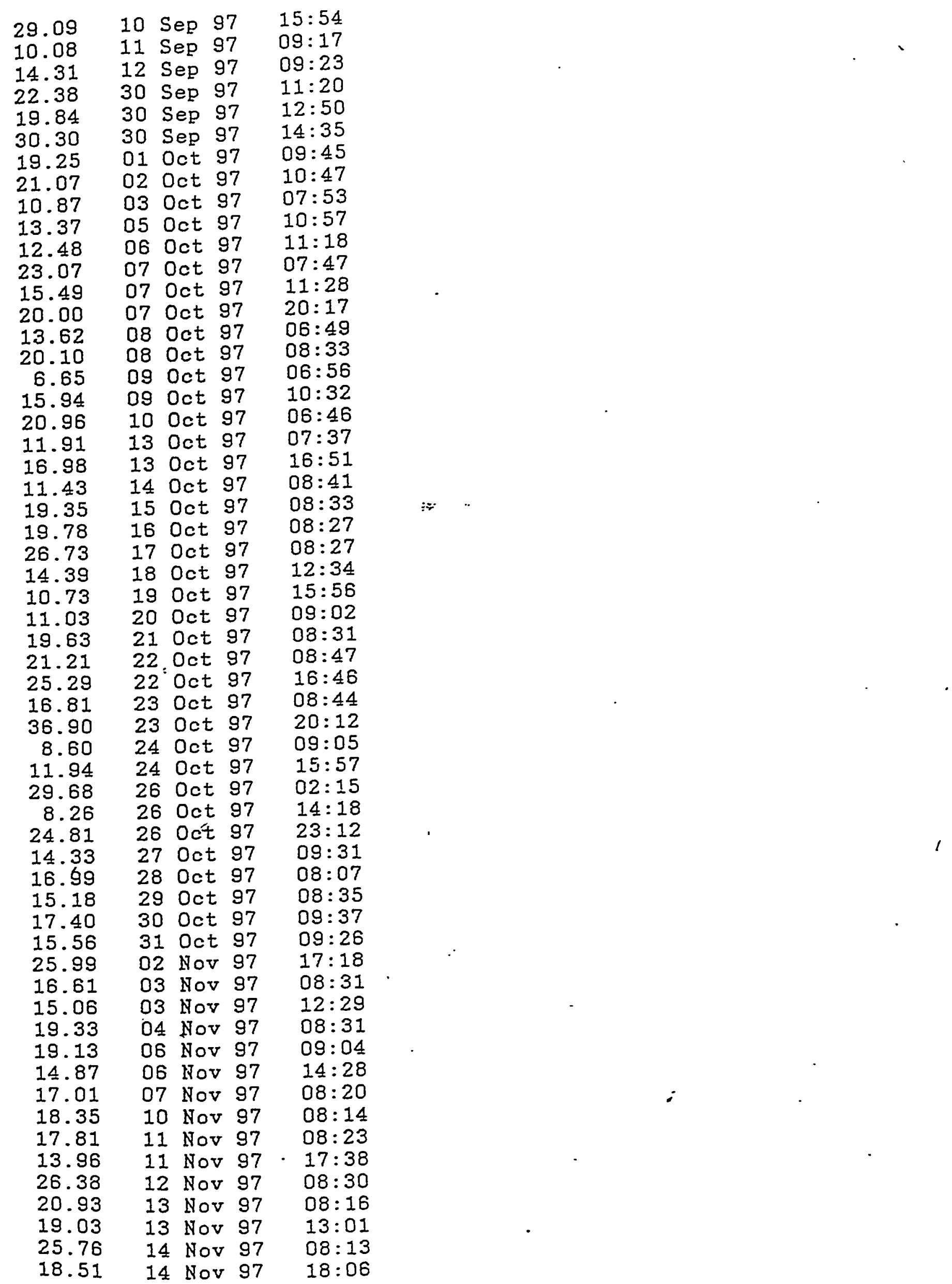


17 Noy 97 09:04_IPA TABLES

Page $\# 16$

$\begin{array}{rlll}\because & 15.12 & 15 \text { Nov } 97 & 12: 00 \\ 23.73 & 15 \text { Nov } 97 & 14: 50 \\ 14.39 & 16 \text { Nov } 97 & 21: 33 \\ & & & \\ 18.86 & & \text { Mean } \\ 5.751 & \text { SD } & \\ 100 & \# \text { of points }\end{array}$

$\begin{array}{llllllllll}5 & 21 & 5 & 60.00 & 22.38 & 24.30 & 20.50 & 39.010 & 242.00 & 0.921168\end{array}$ 
17 Nov $97 \quad 09: 35$

IPA CHARTS

Page \#1

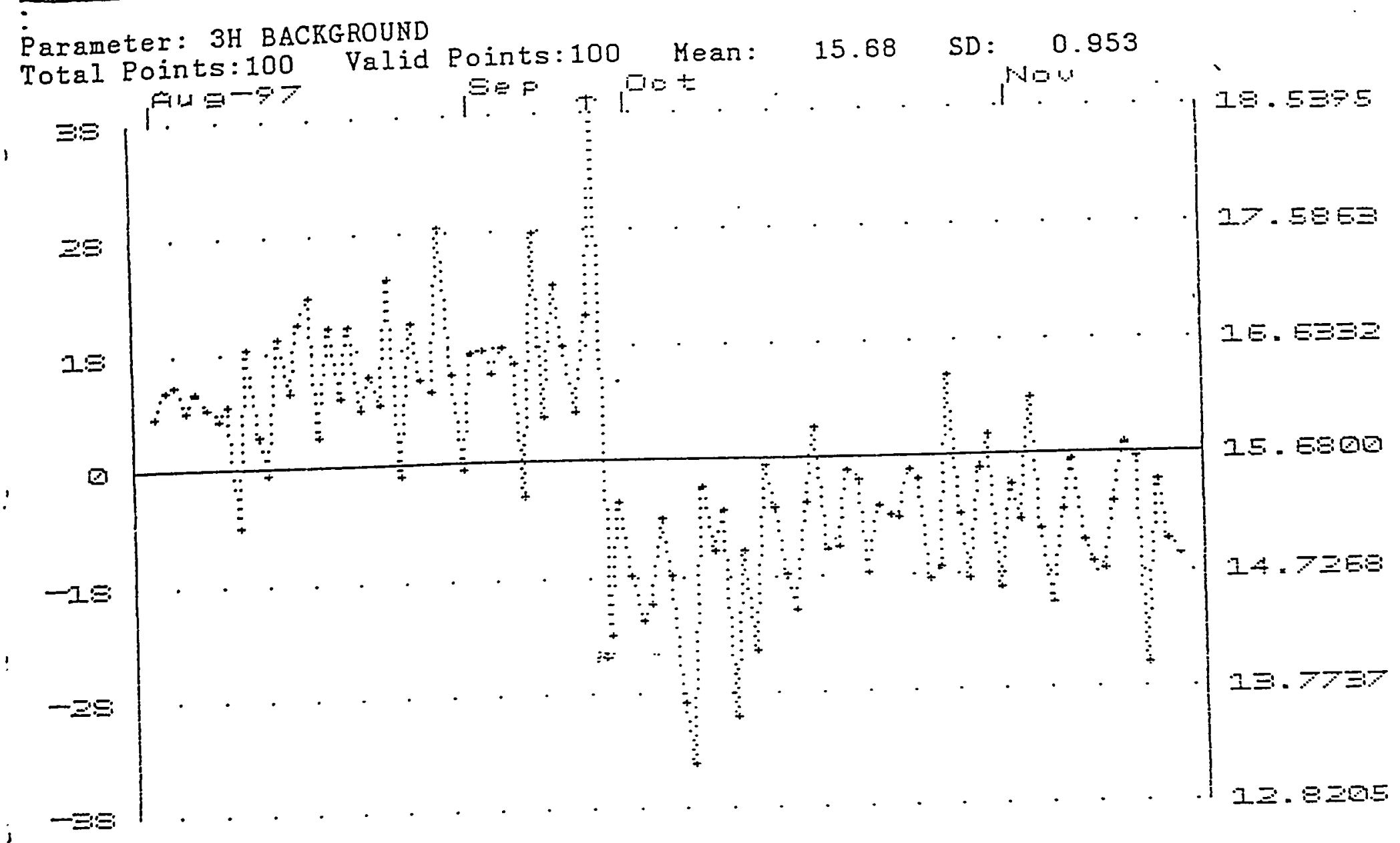


Parameter: 3 H FIGURE OF MERIT (E^2/B)

Total Roints: 100

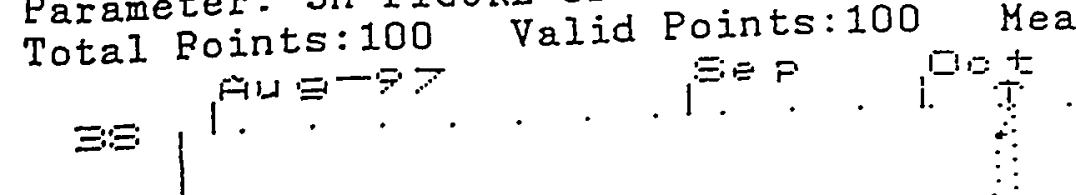

Mean: 278.21 SD: 15.557

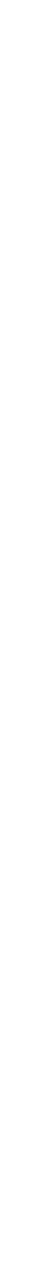


Parameter: 14C BACKGROUND

Total Points: 100 Valid Points: 100

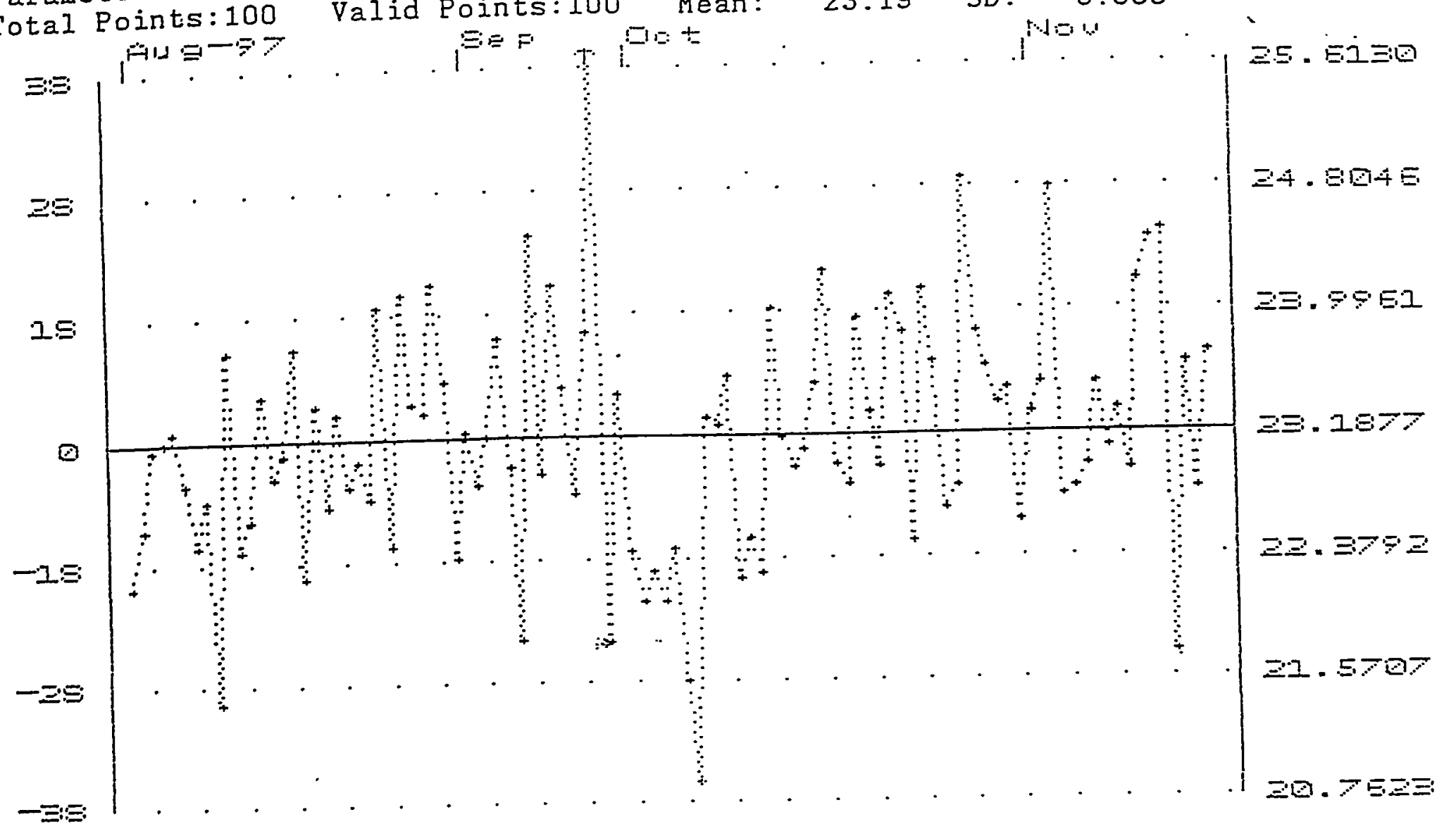


Parameter: 14C EFFICIENCY

Total Points:100 Valid Points:100 Mean: 96.59 SD: 0.322

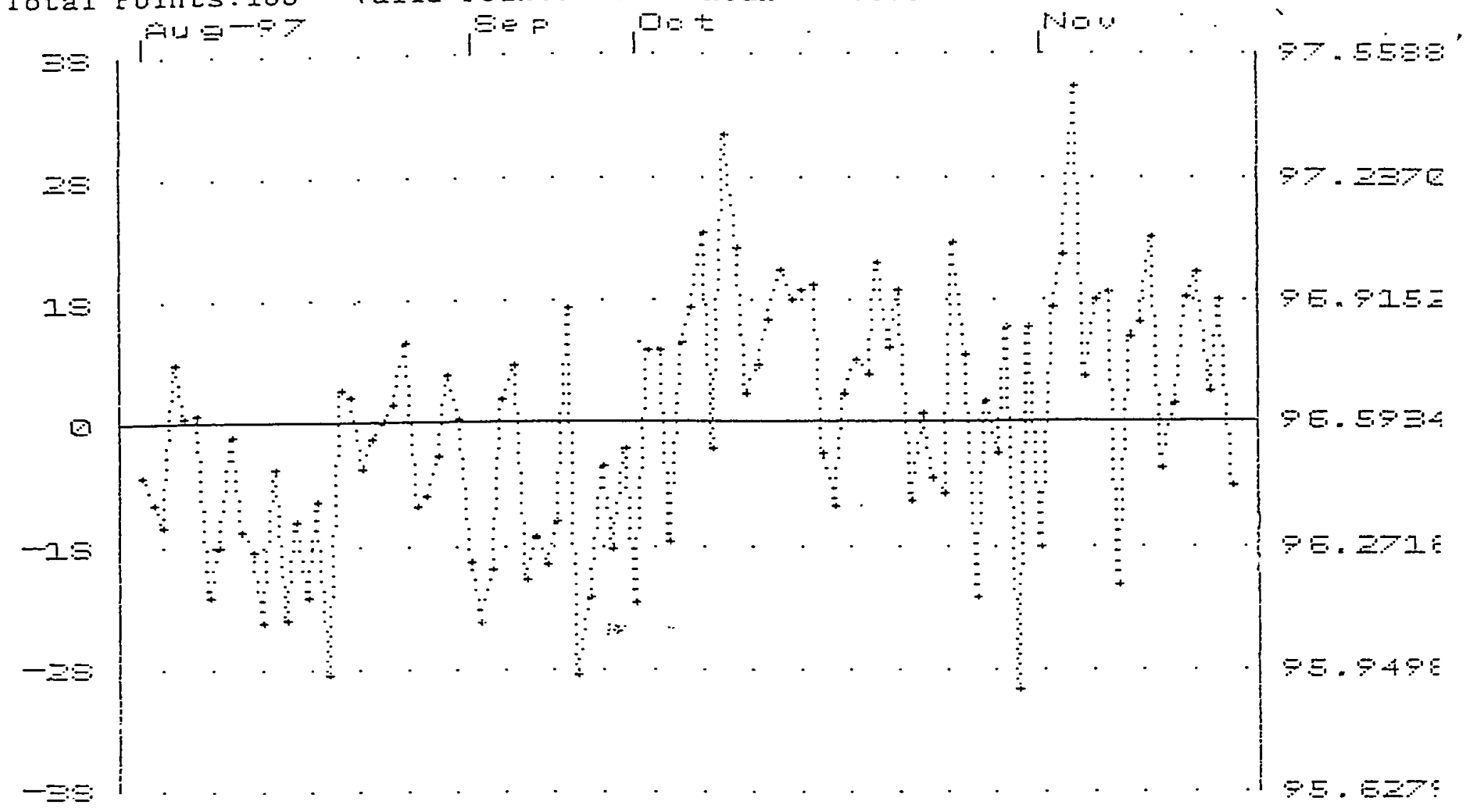


17 Nov 97 09:41

IPA CHARTS

Pase $\# 1$

Parameter: 14C FIGURE OF MERIT ( $\left.\mathrm{F}^{\wedge} 2 / \mathrm{B}\right)$

Total Points: 100 Valid Points:100 Mean: 510.35 SD: 25.298

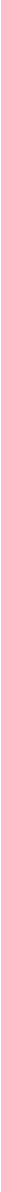


Parameter: 14C CHI-SQUARE

Total Points:100 Valid Points:100 Mean: 18.86 SD: 5.751

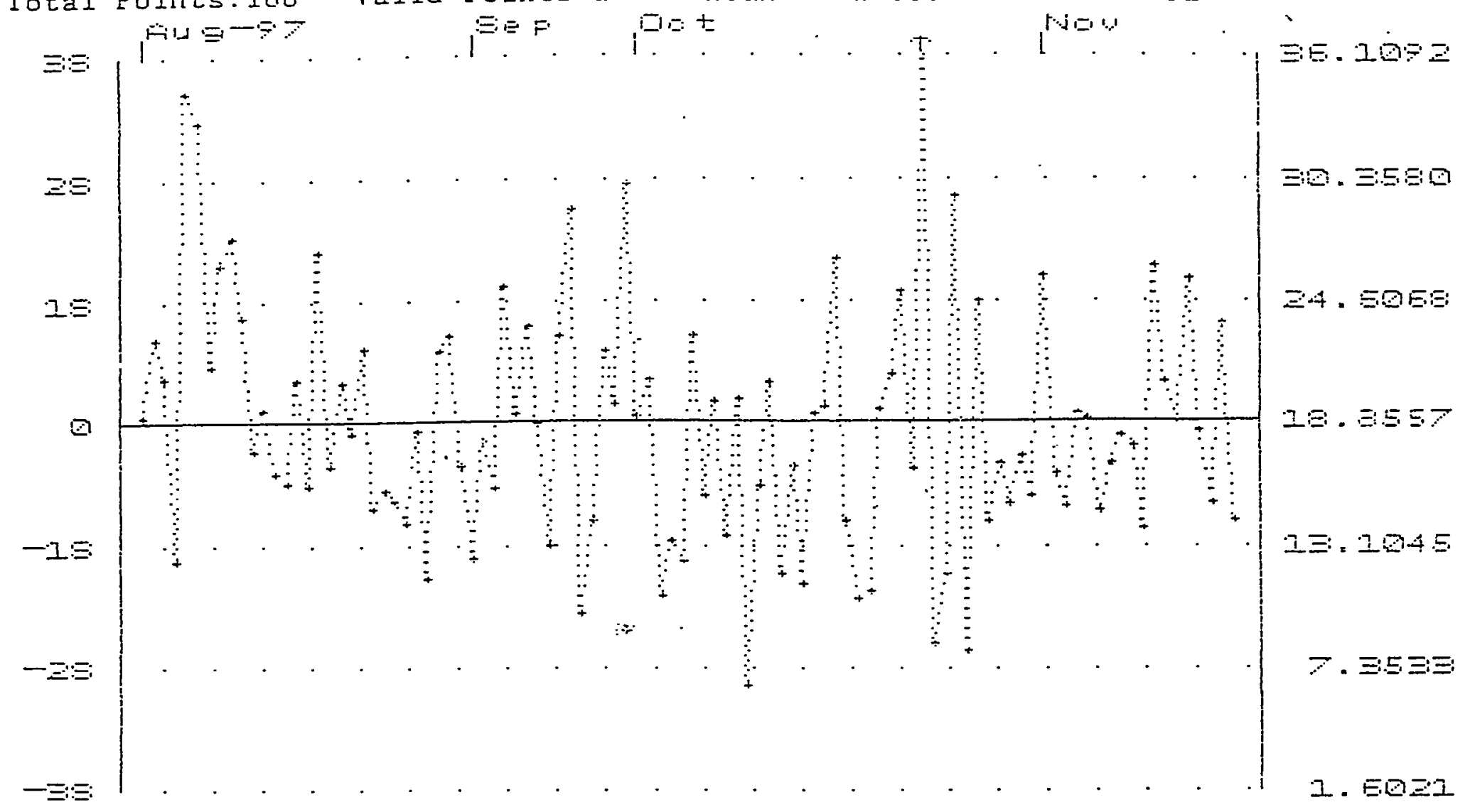

ㄱ. $E D \equiv 2$ 


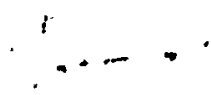

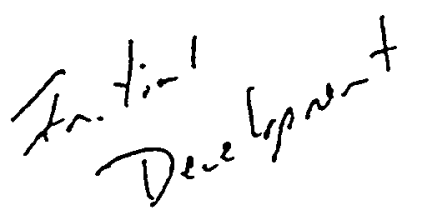

$$
\begin{aligned}
& 5 / 2+19+ \\
& \text { DFA } \\
& \text { DATE COUNIED:22-ADG-1997 } \\
& \text { DATE CALCULATED:02-SEP-1997 } \\
& \text { QA FIIE-PE- } 1141 \\
& \text { ANAIYYST : DKM/SPW } \\
& \text { GI:SON } \\
& \text { Tc-99 (Tevaspec) }
\end{aligned}
$$

\begin{tabular}{|c|c|c|c|c|c|c|c|c|c|}
\hline SAMPIE & MD & EFFIC. & ESIE & GROSS & DIIUTION & WEIGHT & NET & NET & COUNTING \\
\hline JMBER & $\begin{array}{l}\text { OI } \\
\text { MS }\end{array}$ & $\begin{array}{l}\text { EACT. } \\
\text { CPM/DPM }\end{array}$ & VALUEE & $\begin{array}{l}\text { ACIIVITY } \\
\text { (CPM) }\end{array}$ & $\begin{array}{l}\text { FACTOR } \\
\text { (ml) }\end{array}$ & $\begin{array}{l}\text { FRACTION } \\
(g)\end{array}$ & $\begin{array}{c}\text { ACTIVIIY } \\
(p C i / I)\end{array}$ & $\begin{array}{l}\text { ACTIVITY } \\
(\mathrm{pCi} / \mathrm{g})\end{array}$ & $\begin{array}{c}\text { CERTAINIY } \\
(+/-)\end{array}$ \\
\hline$==x==x=x=$ & $==$ & $======$ & $====$ & $== \pm=====$ & $=======8$ & $===== \pm===$ & 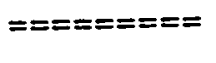 & 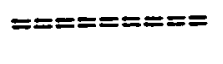 & $== \pm====$ \\
\hline CONIROI & & $\begin{array}{l}0.930 \\
0.936\end{array}$ & $\begin{array}{l}284.73 \\
282.78\end{array}$ & $\begin{array}{r}19.30 \\
502.78\end{array}$ & 0.500 & 0.000 & $4.61 e+05$ & NA & $5.70 e+03$ \\
\hline DUPLICATE & & $\begin{array}{r}0.936 \\
\text { NA }\end{array}$ & 202.10 & NA & 0.000 & 0.000 & NA & NAA & \\
\hline SPIXE & & 0.935 & 278.84 & 496.97 & 0.000 & 0.070 & $N A$ & $3.26 e+03$ & $4.05 e+01$ \\
\hline NA & $\mathrm{MD}$ & NAA & NNA & SDA & 0.000 & 0.000 & NA & $\cdot \quad \quad \mathrm{NDA}$ & \\
\hline $175+2$ & MS & 0.934 & 276.44 & 24.25 & 0.000 & 0.070 & NA & $9.08 e+00$ & $1.22 e+0$ \\
\hline
\end{tabular}

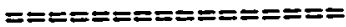

$$
\begin{aligned}
& 98.7470 \\
& \text { Spilce }
\end{aligned}
$$


60.0

PACKARD 2550TR IIQ. SCINTIIIATION COUNIER \#6 1, 2, OR 3 :

DESIRED ACTIUITY UNITS ( $I=p C i, \quad 2=u C i, \quad 3=d p m):$

DESIRED WEIGHT FRACTION UNITS ( $1=9,2$ =filter):

INTERNAI CONIROI CHART PROGRAM NUMBER:

ENIER: 0 FOR 160600

3 FOR 160601 (II mode)

1 FOR 162010

2 FOR 162011

INTERNAI CONTROL CIART BATCH NUMBER:

MEASURED CONTROI VAIUE, CORRECTED FOR DECAY:

UPPER CONTROI IIMIT IN UNITS OF DPM/ME:

LOWER CONTROL LIMIT IN ONITS OF DPM/ML:

- ACTIVITY OF THE SAMPIE THAT WAS DUPIICATED:

*ACTIVITY OF THE SAMPIE THAT WAS SPIKED:

INA

WAS DUPIICATED, PERCENT DIFFERENCE:

$970815-002$

WAS SPIKED, PERCENT RECOVERY:

KNOWN ACTIUITY OF CONIROL, DECAY CORRECTED:

STANDARD: \# RI- $128-W$

REFERENCE DATE:

$01-$ JAN - 1987

E
4

\author{
$1032.59 \mathrm{DPM} / \mathrm{MI}$ \\ 1073.70 \\ 783.70 \\ NA (pCi/g) \\ $9.08 e+00 \quad(\mathrm{pCi} / \mathrm{g})$ \\ NA \\ ERR / \\ $98.74 \div$ \\ $1023.56 \mathrm{DPM} / \mathrm{MII}$.
}

Analis report:

\begin{tabular}{|c|c|c|c|c|}
\hline & ACTUAI & AMOUNI & SPIKE & PERCENT \\
\hline DNITS & RESULT & SPIKED & RESULT & RECOVERY \\
\hline$= \pm=x=2==$ & $==x=\varepsilon=2=$ & $\Rightarrow=\Sigma x=x=\simeq$ & $E=E x=E=x$ & $==x== \pm==$ \\
\hline$D P M$ & 1.41 & 511.78 & 506.72 & 98.74 \\
\hline
\end{tabular}


DATE COUNTED:29-ADG-1997

DATE CAICULATED : 02 - SEP - 1997

QA FIIE-PE-II4I

ANAIYST : DKM/SPW
GIISON

Tc-99 (Tevaspec)

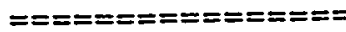

SAMPIE

NOMBER

Iニะニニะே=

BIANKK

CONTROL

NRTDUPICATE SPIKE

NN NA ND

970815-002MS

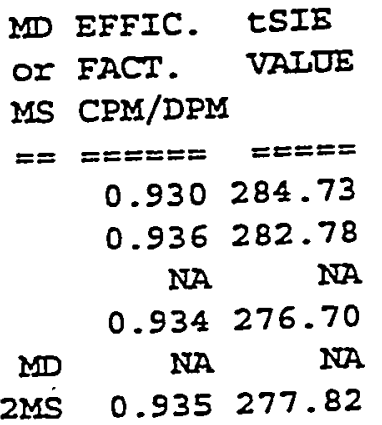

MD EFFIC. TSIE

OI FACT.

MS CPM/DPM

$=======$

$=====$

0.930284 .73

0.936282 .78

NA NA

0.934276 .70

NA NA

0.935277 .82

\begin{tabular}{|c|c|c|}
\hline GROSS & DIIUTION & WEIGHT \\
\hline $\begin{array}{l}\text { ACTIVITY } \\
\text { (CPM) }\end{array}$ & $\begin{array}{l}\text { FACTOR } \\
\text { (mI) }\end{array}$ & $\begin{array}{l}\text { FRACTION } \\
\text { (g) }\end{array}$ \\
\hline$===== \pm==$ & $=====x==$ & $==== \pm=\leq==$ \\
\hline 19.30 & & \\
\hline 502.78 & 0.500 & 0.000 \\
\hline NAP & 0.000 & 0.000 \\
\hline 493.58 & 0.000 & 0.070 \\
\hline$N A$ & 0.000 & 0.000 \\
\hline 23.52 & 0.000 & 0.070 \\
\hline
\end{tabular}

\section{NET}

ACIIVITY (pCi/I)

$========$

4. 61e+05

NA

NA

NA.

NA

\begin{tabular}{|c|c|}
\hline NET & COUNIING \\
\hline $\begin{array}{l}\text { ACIIVITY } \\
\text { (pCi/g) }\end{array}$ & $\begin{array}{c}\text { CERTATNTY } \\
(+/-)\end{array}$ \\
\hline$E==E=$ = $=$ & $==2 \stackrel{\prime}{=}==\varepsilon=$ \\
\hline NA & $5.70 e+03$ \\
\hline NAR & INA \\
\hline $3.24 e+03$ & $4.04 e+01$ \\
\hline & $\mathbf{N A}$ \\
\hline $3.81 e+00$ & $1.21 e+01$ \\
\hline
\end{tabular}

98.3090

Spile
vecovery 
SAMPIE COONTING TIME IN UNITS OF MINUIES:

PACKARD 2550TR IIQ. SCINTILIATION COUNTER \#5 I, 2, OR 3:

DESIRED ACTIVITY DNITS ( $I=p C i, 2=u C i, \quad 3=d p m$ ):

DESIRED WEIGHT FRACTION UNITS ( $1=9,2=f i l t e I):$

INTERNAI CONTROI CHART PROGRAM NUMBER:

$$
\begin{array}{ll}
\text { ENTER: } & 0 \text { FOR } 160600 \\
& 1 \text { FOR } 162010 \\
& 2 \text { FOR } 162011
\end{array}
$$

60.0

\section{2}

1

1

0

4

INTERNAI CONTROI CHART BATCH NUMBER:

4
$1032.59 \mathrm{DPM} / \mathrm{MI}$
1073.70
783.70
$\mathrm{NA} \quad(\mathrm{pCi} / \mathrm{g})$
$3.81 e+00 \quad(\mathrm{pCi} / \mathrm{g})$
$\mathrm{NDA}$
$98.30 \% \quad \mathrm{ERR}$
$1023.56 \mathrm{DPM} / \mathrm{ML}$

MEASURED CONTROI VALUE, CORRECTED FOR DECAY: UPPER CONTROL IIMIT IN UNITS OF DPM/MI: LOWER CONTROI IIMIT IN UNITS OF DPM/MI:

*ACTIVITY OF THE SAMPIE THAT WAS DUPIICATED:

*ACTIVITY OF THE SAMPLE THAT WAS SPIKED:

NA WAS DUPIICATED, PERCENT DIFFERENCE:

$970815-002$ WAS SPIKED, PERCENT RECOVERY:

KNOWN ACTIVITY OF CONTROI, DECAY CORRECTED: STANDARD:\# RI- I28-W REFERENCE DATE: $\quad 01-J A N-I 987$

\begin{tabular}{|c|c|c|c|c|}
\hline & ACTUAI & AMOUNTI & SPIKE & PERCENT \\
\hline ONITS & RESULT & SPIKED & RESULT & RECOVERY \\
\hline$=======$ & $==== \pm=x=$ & 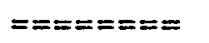 & $====x===$ & $=======5$ \\
\hline$D P M$ & 0.59 & 511.78 & 503.68 & 98.30 \\
\hline
\end{tabular}

$E$

Analis report: 
DATE COUNIED:29-ADG-1997

DATE CAICULATED:02-SEP-1997

QA EIIE-PE-1141

ANAIYST :DKM/SPW

MANUALI

Tc-99 (Tevaspec)

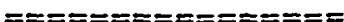

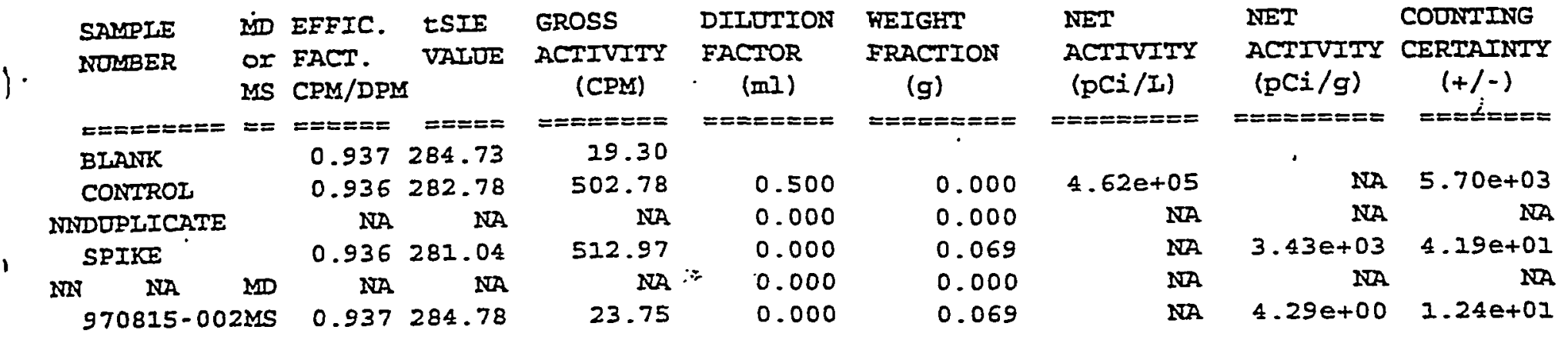

$$
\begin{gathered}
102.16 \text { joike } \\
\text { recouerg }
\end{gathered}
$$


SAMPIE COUNTING TIME IN ONITS OF MINUIES:

60.0

PACKARD 2550TR IIQ. SCINTIITATION COONTER \#5 1, 2, OR 3:

DESIRED ACTIVITY UNITS ( $I=p C i, 2=u C i, 3=d p m$ ):

DESIRED WEIGHT FRACTION UNITS $(1=9,2$ =filteI):

INTERNAL CONTROL CHART PROGRAM NUMBER:

$\begin{array}{ll}\text { ENTER: } & 0 \text { FOR } 160600 \\ & 1 \text { FOR } 162010 \\ & 2 \text { FOR } 162011\end{array}$

3 FOR 160601 (II mode)

2 FOR 162011

INTERNAI CONTROI CHART BATCH NUMBER:

$\because-$

MEASURED CONTROI VAIUE, CORRECTED FOR DECAY:

UPPER CONTROI IIMIT IN UNITS OF DPM/MI:

LOWER CONTROI, IIMIT IN UNITS OF DPM/MI:

-ACIIVITY OF THE SAMPIE THAT WAS DUPIICATED:

- ACTIUITY OF THE SAMPIE THAT WAS SPIKED:

NA WAS DUPIICATED, PERCENT DIFFERENCE:

970815-002 WAS SPIKED, PERCENT RECOVERY:

KNOWN ACTIVITY OF CONTROI, DECAY CORRECIED:

STANDARD: \# RI-128-W REFERENCE DATE: OI-JAN-I987

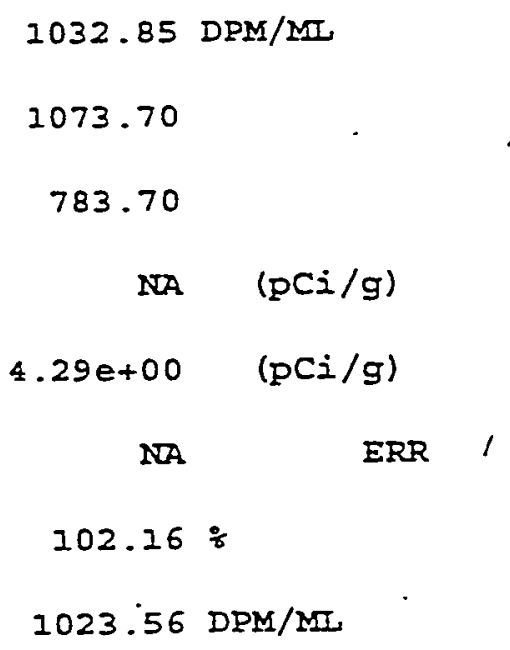

4

1

1

0

.


DATE COUNTED:29-ADG-1997

DATE CALCULATED:02:SEP-1997

QA FIIE-PE-1141

ANAIYST:DKM/SPF

MANUALI

Tc-99 (Tevaspec)

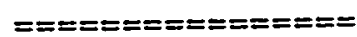

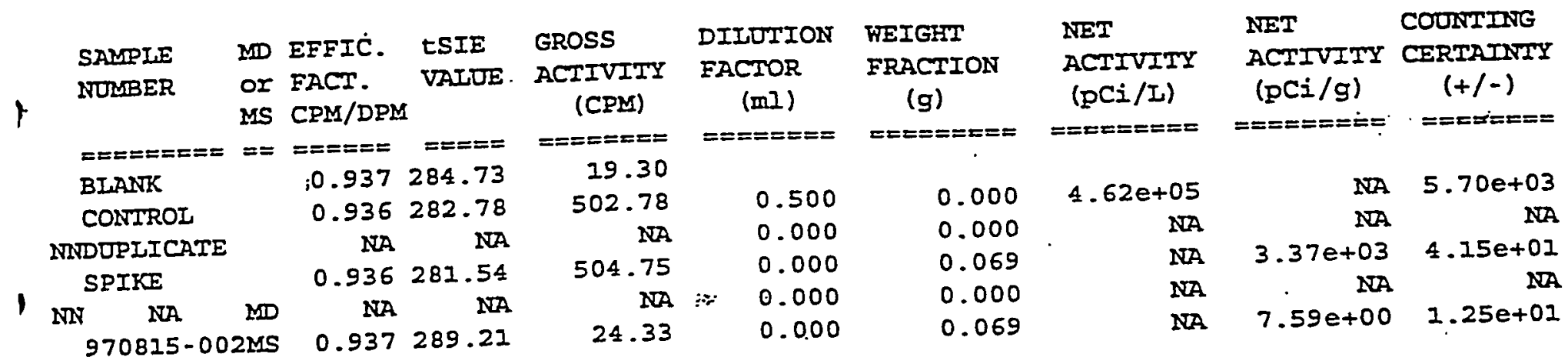

$$
\begin{gathered}
100.3320 \text { spike } \\
\text { recovery. }
\end{gathered}
$$


Manual

QA DATA SHEET

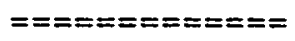

SAMPIE COUNTING TIME IN UNITS OF MINUIES:

PACKARD 2550TR LIQ. SCINTIITATION COUNTER \#5 1, 2, OR 3 :

DESIRED ACIIVITY UNITS $(1=\mathrm{pCi}, \quad 2=\mathrm{uCi}, 3=\mathrm{dpm})$ :

DESIRED WEIGHT FRACIION UNITS $(I=g, 2= \pm$ ilteI) :

INTERNAI CONIROI CILART PROGRAM NUMIBER:

$$
\begin{array}{ll}
\text { ENTER: } & 0 \text { FOR } 160600 \\
& 1 \text { FOR } 162010 \\
& 2 \text { FOR } 162011
\end{array}
$$

INTERNAI CONTROL CHART BATCH NUMBER:
60.0

\section{2}

1

I

0

4
MEASURED CONTROL VALUE, CORRECTED FOR DECAY:

UPPER CONTROL IIMIT IN UNITS OF DPM/MI:

LOWER CONTROI IIMIT IN UNITS OF DPM/MU:

*ACTIVITY OF THE SAMPLE THAT WAS DUPIICATED:

-ACTIVITY OF THE SAMPIE THAT WAS SPIKED:

NA WAS DUPIICATED, PERCENT DIFFERENCE:

970815-002 WAS SPIKED, PERCENT RECOVERY:

KNOWN ACTIVITY OF CONTROI, DECAY CORRECTED:

STANDARD: \# RI- $228-W$

REFERENCE DATE: $\quad 01-J A N-1987$

\author{
$1032.85 \mathrm{DPM} / \mathrm{ML}$ \\ 1073.70 \\ 783.70 \\ NA $(p C i / g)$ \\ $7.59 e+00 \quad(\mathrm{pCi} / \mathrm{g})$ \\ NA \\ ERR / \\ $100.33 \%$ \\ $1023.56 \mathrm{DPM} / \mathrm{MH}$
}

\begin{tabular}{|c|c|c|c|c|}
\hline & ACTUAL & AMOONI & SPIKE & PERCENI \\
\hline ONITS & RESULT & SPIKED & RESULT & RECOVERY \\
\hline$==== \pm==$ & $==== \pm==$ & $=== \pm== \pm=$ & 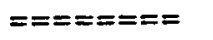 & $==\approx== \pm=0$ \\
\hline DPM & 1.16 & 511.78 & 514.63 & 100.33 \\
\hline
\end{tabular}

$E$

AnaIIs report: 
Descriptive Statistics:

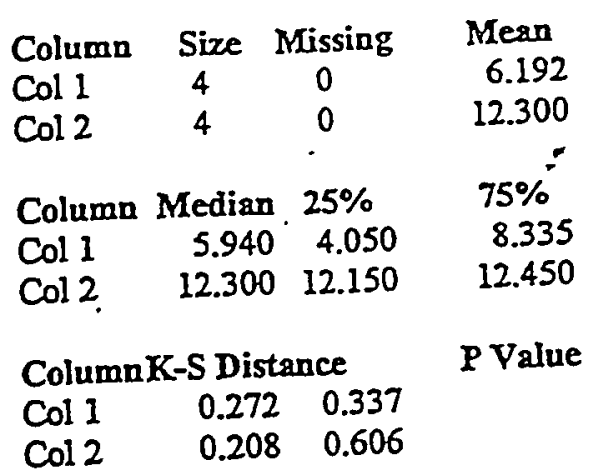

$\begin{array}{lll}\text { Col } 1 & 0.272 & 0.337 \\ \text { Col } & 0.208 & 0.606\end{array}$
Friday, September 12, 1997, 09:36:52

2.555

0.183

Sum

24.770

49.200

$\begin{array}{cccc}\text { Std. Error } & \text { Range } & \text { Mar } & \text { Min } \\ 1.278 & 5.270 & 9.080 & 3.810 \\ 0.0913 & 0.400 & 12.500 & 12.100\end{array}$

Sum of Squares ConfidenceSkewness Kurtosis

$\begin{array}{llll}172.975 & 4.066 & 0.256 & -4.221\end{array}$

$605.260 \quad 0.291 \quad 2.916 \mathrm{E}-014-3.300$ 
Descriptive Statistics:

Friday, September 12, 1997, 09:40:12

$\begin{array}{lccc}\text { Column } & \text { Size } & \text { Missing } & \text { Mean } \\ \text { Col 1 } & 2 & 0 & 31.200 \\ \text { Col 2 } & 2 & 0 & 8.940 \\ & & & = \\ \text { Column } & \text { Median } & 25 \% & 75 \% \\ \text { Col 1 } & 31.200 & 28.100 & 34.300 \\ \text { Col 2 } & 8.940 & 8.900 & 8.980 \\ & & \\ \text { ColumnK-S Distance } & \text { P Value } \\ \text { Col 1 } & 0.260 & 0.481 & \\ \text { Col 2 } & 0.260 & 0.481 & \end{array}$

Std Dev

4.384

0.0566

Std. Error Range Max Min

$\begin{array}{llll}3.100 & 6.200 & 34.300 & 28.100\end{array}$

$\begin{array}{llll}0.0400 & 0.0800 & 8.980 & 8.900\end{array}$

Sum

62.400

17.880

Sum of Squares ConfidenceSkewness Kurtosis $1966.100 \quad 39.389$ undefinedundefined $159.850 \quad 0.508$ undefinedundefined

ColumnK-S Distance

$\begin{array}{lll}\text { Col } 2 & 0.260 & 0.481\end{array}$ 
Descriptive Statistics:

$\begin{array}{lcccc}\text { Column } & \text { Size } & \text { Missing } & \text { Mean } & \text { Std Dev } \\ \text { Col 1 } & 2 & 0 & 31.200 & 4.384 \\ \text { Col 2 } & 2 & 0 & 8.940 & 0.0566 \\ & & - & \ddots & \\ \text { Column } & \text { Median } & 25 \% & 75 \% & \text { Sum } \\ \text { Col 1 } & 31.200 & 28.100 & 34.300 & 62.400 \\ \text { Col 2 } & 8.940 & 8.900 & 8.980 & 17.880\end{array}$

Friday, September 12, 1997, 09:40:12

\begin{tabular}{lll}
\multicolumn{3}{c}{ ColumnK-S Distance } \\
Col 1 & 0.260 & 0.481 \\
Col 2 & 0.260 & 0.481
\end{tabular}

P Value 


$$
\text { Maral: }
$$

$$
\text { For Chris }
$$

ThES,

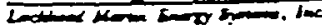

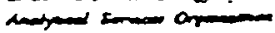

Nudear Meorurements

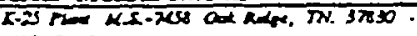

(5) $54 \pi$

\section{RADIOCHEMICAL ANALYSIS}

\section{LABORATORY PREPARATION SHEET FOR LIQUID SCINTILLATION COUNTING}

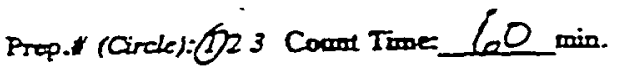

QA Fin : PE-\|Y\|

Projectanabris: DEV ITE

CRRoom Re'd: $8,29,97$ by Kte

Com Date 81,29,97 by EN

iner.fis f/Prowoll: $21,03999,3$
Packege Dondlixe:

Prop.Dare/Analya: 8128197 by Jer

Control Number: 160600

Pipere ID: Deily Cbock by:

Mererowave Fileanme:

\begin{tabular}{|c|c|c|c|}
\hline $\begin{array}{l}\text {-Scales DX: } \\
\text { Semple D: }\end{array}$ & 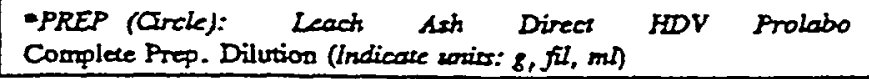 & $\begin{array}{l}\text { Cossetert } \\
\text { (PID) }\end{array}$ & $\begin{array}{l}\text { Semple } \\
\text { Porition }\end{array}$ \\
\hline Blenk $920515-002 B$ & In HNO & 25 & 2 \\
\hline Comtrol storis-002l & 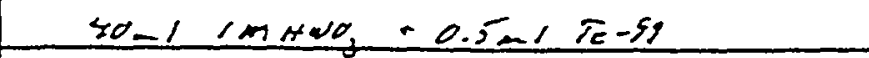 & 1 & 3 \\
\hline Duplicate $9764,5-02 A$ & $0.2749 \times 100 / / 40,1 \times 10-1 / 40 d$ & & 4 \\
\hline Spike $970+15-0020$ & $+0.5-1 T_{e}-89$ & & 5 \\
\hline$s_{x=a b}$ storis-eose & & & 6 \\
\hline Stanke s70,15=002D & $+0.501 \pi 0.99$ & & 7 \\
\hline INST STO & \pm 15 & $\checkmark$ & 1 \\
\hline & & & \\
\hline & & & . \\
\hline & & & \\
\hline & & & \\
\hline & & & \\
\hline & & & \\
\hline & & & 1 \\
\hline & & & \\
\hline & & & \\
\hline & & & \\
\hline & . & & \\
\hline & & & \\
\hline & & & \\
\hline
\end{tabular}

Procodure Number.

Comments:

SUPERVISOR APPROVAL: 


$$
\text { G.Ison Run. }
$$

Linestaca

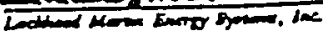

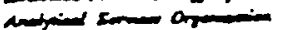

Nudear Mearwements

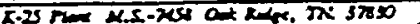
(oIS) 574Ten

\section{RADIOCHEMICAL ANALYSIS}

LABORATORY PREPARATION SHEET FOR LIQUTD SCINTILLATION COUNTING

Prop." raiclet If 3 cosut Twe to win.

QA Fil:

Project/Anetyris:

C.Room Roc'd:

Coment Date:

Latr.H/S.H/Prolocoly:
Pactege Dandite:

Prop.Datel Anelya:

Comol Number: 16

Pipene ID: Daily Cbock by:

Mierowave Fileanere:

Procodure Number:

\begin{tabular}{|c|c|c|c|}
\hline $\begin{array}{l}\text {-Scales Dt: } \\
\text { Sanople D: }\end{array}$ & $\begin{array}{l}\text {-PREP (Grete): Leach Ach Direct FDV Prolabo } \\
\text { Complete Prep. Dilution (Inticare umura: 8, fil, mh) }\end{array}$ & $\begin{array}{l}\text { Carsedent } \\
\text { (PDD) }\end{array}$ & $\begin{array}{l}\text { Semple; } \\
\text { Pontiont }\end{array}$ \\
\hline Blank $970815-B 1 K$ & $40 \mathrm{al} / \mathrm{m} \mathrm{NNO}_{3}$ & & \\
\hline Control ( $970215-\operatorname{Con})$ & Stel lm $\mathrm{Ant}_{3}+0.5=1 \tau_{2}-99$ & & \\
\hline Puptiente & & & \\
\hline \multicolumn{4}{|l|}{ Spika_e - } \\
\hline $270515=001 A$ & $0.2801, y 60+14001 \times 10-1 / 40-1$ & & \\
\hline $570515-0018$ & $20.5-1 T_{e}-9$ & & \\
\hline \multicolumn{4}{|l|}{$970815-0010$} \\
\hline $970815-0.110$ & $+0.5-1 T_{c}-9$ & & \\
\hline & & & \\
\hline & & & \\
\hline & & & \\
\hline 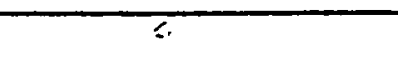 & & & \\
\hline & & & \\
\hline & & & \\
\hline & & & $\cdot$ \\
\hline & - & & \\
\hline & $\cdot$ & & \\
\hline 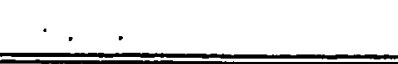 & 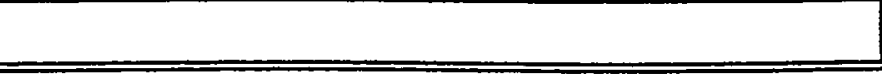 & & \\
\hline
\end{tabular}

Comments:

SUPERVISOR APPROVAL: 
Time: 60.00

Data Mode: DPM

Background Subtract: Manual

$\begin{array}{lrrrrr} & \text { LL } & \text { UL } & \text { LCR } & 25 \% & \text { BKG } \\ \text { Region A: } & 0.0-.293 & =0 & 0.0 & 0.00 \\ \text { Region B: } & 6.0-293 & 0 & 0.0 & 0.00 \\ \text { Region C: } & 293-2000 & 0 & 0.0 & 0.00\end{array}$

Quench Indicator: tSIE/AEC

Ext Std Terminator: Count

Packard Liquid Scintillation 2550TR-\#2 SN 103999

Luminescence Correction On

Heterogeneity Monitor On

l Color Quench Correction On
Tc-99/Teva UG

User : K25 Radiochemistr

\author{
Nuclide: TC_TEVA_UG Quench Set: TC_TEVA
}

$\begin{array}{rrrrr}P \text { PID } & \text { S\# } & \text { TIME } & \text { CPMA } \\ 3 & 25 & 1 & 60.00 & 2431.38 \\ 3 & 25 & 2 & 60.00 & 19.30 \\ 3 & 25 & 3 & 60.00 & 502.78 \\ 3 & 25 & 4 & 60.00 & 24.33 \\ 3 & 25 & 5 & 60.00 & 504.75 \\ 3 & 25 & 6 & 60.00 & 23.75 \\ 3 & 25 & 7 & 60.00 & 512.97 \\ 3 & 25 & 8 & 60.00 & 18.65 \\ 3 & 25 & 9 & 60.00 & 494.68 \\ 3 & 25 & 10 & 60.00 & 24.25 \\ 3 & 25 & 11 & 60.00 & 496.97 \\ 3 & 25 & 12 & 60.00 & 23.52 \\ 3 & 2 & 13 & 60.00 & 493.58\end{array}$

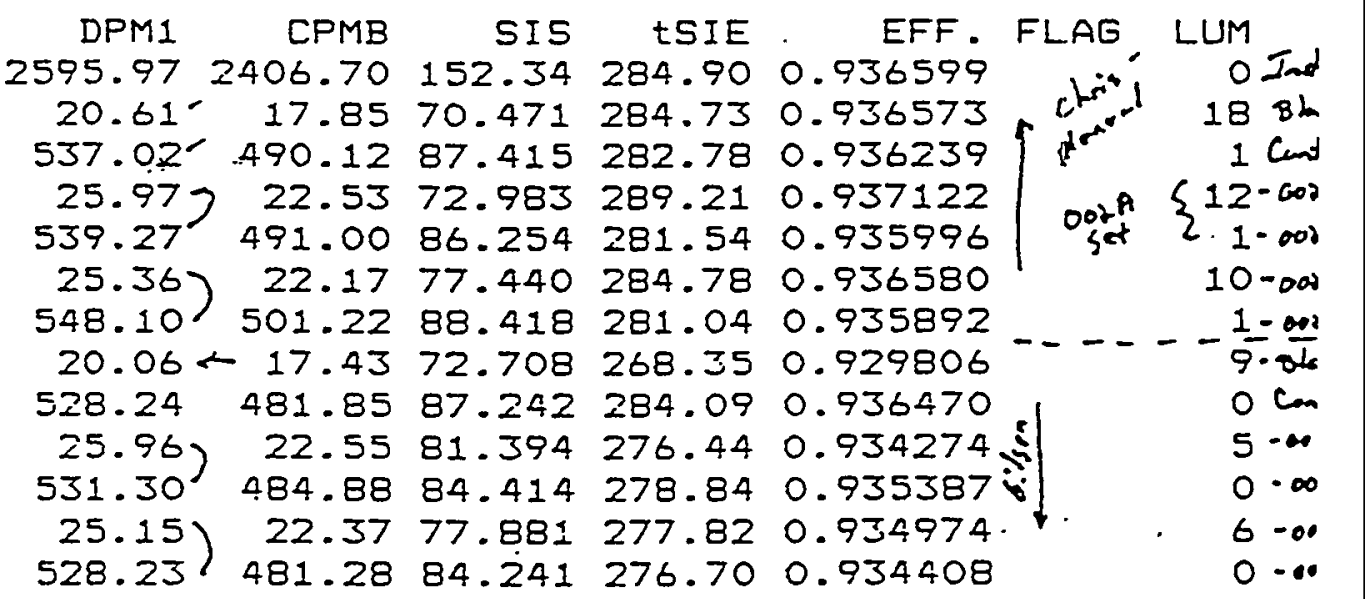


- Il uelopmestal paoe \#1

Time: 20.00

Data Mode: DPM

Background Subtract: None
Nuclide: TOTACT UG Quench Set: TOTAL UG

$\begin{array}{lrrrrr} & \text { LL } & \text { UL } & \text { LCR } & 25 \% & \text { BKG } \\ \text { Region A: } & 0.0-2000 & 0 & 0.0 & 0.00 \\ \text { Region B: } & 6.0-293 & 0 & 0.0 & 0.00 . \\ \text { Region C: } & 293-2000 & 0 & 0.0 & 0.00\end{array}$

Quench Indicator: tSIE/AEC

Ext Sto Terminator: Count

Packard Liquid Scintillation Counter 2550 \#2

Luminescence Correction On

Heterogeneity Monitor On

Color Quenct Correction On

\begin{tabular}{|c|c|c|c|c|c|c|c|c|c|c|}
\hline P\# & PID & S\# & TIME & CPMA & CPMB & $\begin{array}{l}\text { CPMC } \\
7.15\end{array}$ & $\begin{array}{r}\text { DPM1 } \\
28.08\end{array}$ & $\begin{array}{r}\text { tSIE } \\
225.77\end{array}$ & $\begin{array}{l}\text { EFF FLAG } \\
.946\end{array}$ & $\underset{59}{\operatorname{LUM}} B$ \\
\hline $\begin{array}{l}10 \\
10\end{array}$ & 28 & 1 & 20.00 & 26.55 & 16.60 & $\begin{array}{l}7.15 \\
5.80\end{array}$ & 26.08 & 232.77 & .945 & $20 \mathrm{~N}$ : metal \\
\hline $\begin{array}{l}10 \\
10\end{array}$ & 28 & $\frac{2}{3}$ & 20.00 & $\begin{array}{l}24.65 \\
29.35\end{array}$ & $\begin{array}{l}16.60 \\
16.85\end{array}$ & 6.55 & 31.88 & 145.71 & .921 & $544 \mathrm{mD}: 1$ \\
\hline $\begin{array}{l}10 \\
10\end{array}$ & $\begin{array}{l}28 \\
28\end{array}$ & $\begin{array}{l}3 \\
4\end{array}$ & $\begin{array}{l}20.00 \\
20.00\end{array}$ & $\begin{array}{l}29.35 \\
25.20\end{array}$ & 15.35 & 7.55 & 26.74 & 212.35 & .942 & 30 /MD: / (1) \\
\hline 10 & $\begin{array}{l}20 \\
28\end{array}$ & 5 & 20.00 & 25.35 & 17.35 & 7.00 & 26.88 & 214.62 & .943 & $28 \mathrm{im} 0: 1^{(2)}$ \\
\hline 10 & 28 & 6 & 20.00 & 26.20 & 16.75 & 6.90 & 27.78 & 214.96 & .943 & 26 im $0: 1(3)$ \\
\hline
\end{tabular}


$2 r^{d}$
Gur
Gor DATE COONTED:02-SEP-1997

DATE CALCULATED: 04-SEP-1997

$Q A$ FILE-PE-I141

ANAIYST:DKM/SPW

Tc-99 (Tevaspec)

$==\approx=$ = $=$ = $=$ = $=$ = =

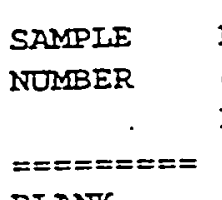

$$
\text { ins }
$$

MD EFFIC. ESIE

OI FACT.

MS CPM/DPM

BLANK

CONTROI

NNDUPLICATE

SPIKE

NN9 70815-002MD

970815-002MS
$0.924 \quad 271.07$

0.931290 .30

NA NA

0.929284 .06

NA NA

0.929283 .09

GROSS
ACIIVIIY
(CPM)
$========$
22.50
495.02
NA
501.83
NA
26.80

DIIUTION

FACTOR

(mI)

$== \pm=== \pm=$

0.500

0.000

0.000

NA

0.000

WEIGHT
FRACTION
(g)
$========$
0.000
NA
0.070
NA
0.070

NET

ACTIVITY

$(\mathrm{pCi} / \mathrm{L})$

$==== \pm== \pm=$

$4.57 e+05$

NA

NA

NA.

NA
NET

IT CERTAINTY

(pCi/g) (+/-)

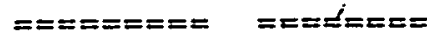

$\begin{array}{rr}N A \cdot & 4.02 e+03 \\ N A A & N A \\ 3.32 e+03 & 2.89 e+01 \\ N A A & N L A \\ 2.81 e+01 & 8.90 e+00\end{array}$


SAMPIE COUNTING TIME IN ONITS OF MINUTES:

PACKARD 2550TR IIQ. SCINTIITATION COONIER \#̈ 1, 2, OR 3 :

DESIRED ACIIVITY UIITS ( $1=p C i, 2=u C i, \quad 3=0 \mathrm{pm}$ ):

DESIRED WEIGHT FRACIION DNITS ( $1=9,2=$ EiIter):

INTERNAL CONIROL CHART PROGRAM NOMBER:

ENIER:
- FOR 160600
1 FOR 162010
2 FOR 162011

INIERNAI CONTROL CHART BATCH NUMBER:

MEASURED CONTROL VAIUE, CORRECTED FOR DECAY:

UPPER CONTROI IIMIT IN UNITS OF DPM/ML:

LOWER CONIROI ITMIT IN ONITS OF DPM/ML:

*ACTIVITY OF THE SAMPLE THAT WAS DUPIICATED:

*ACTIVITY OF THE SAMPIE THAT WAS SPIKED:

970815-002 WAS DUPLICATED, PERCEITT DIFFERENCE:

970815-002 WAS SPIKED; PERCENT RECOVERY:

KONOWN ACTIVITY OF CONTROI, DECAY CORRECTIED:

STANDARD: \# RI-128-W

$$
\text { REFERENCE DATE: O1-JAN-I987 }
$$

120.0

3

2

1

0

4

$\mathbf{E}$

Aratis Ieport:

\begin{tabular}{|c|c|c|c|c|}
\hline & ACIUAI & AMOUNT & SPIKE & PERCENI \\
\hline UNITS & RESULT & SPIKED & RESULI & RECOVERY \\
\hline$=E \pm x=x$ & 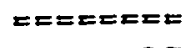 & $==E=x=x=$ & EEEEx=EL & $=\varepsilon=E=E E x$ \\
\hline$D P$ & 4.37 & 511.78 & 515.57 & 99.89 \\
\hline
\end{tabular}

20/20 Iicense \#4828, Program validarion \#:SOP160063.R4-T2IG, 09/28/94 DFH 
DATE COUNTED:02-SEP- 1997

DATE CALCULATED: 04-SEP-1997

QA FIIE-PE-II4I

ANDAIYST : DFOM/SPF

Tc-99 (Tevaspec)

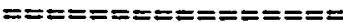

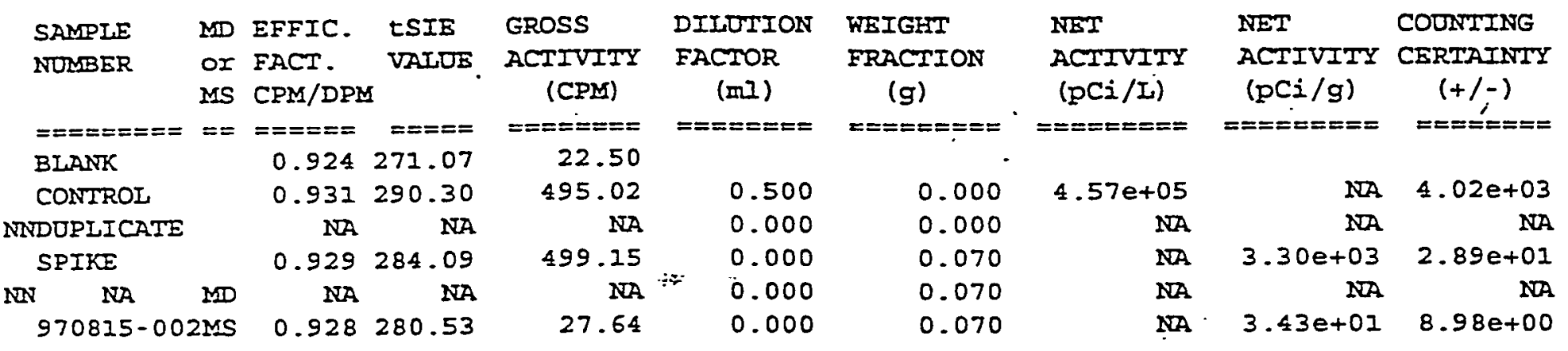


DATE COUNTED:02-SEP- 1997

DATE CAICULATED:04-SEP- 1997

QA FIIE-PE-1141

ANATYST : TKM/SPW

QA DATA SHEET

$====+=======$

SAMPIE COONIING TIME IN. UNITS OF MINUTES:

220.0

RACKARD 2550TR IIQ. SCINTIITATION COUNIER \#S 1, 2, OR 3 :

3

DESIRED ACTIVITY UNITS ( $1=p C i, 2=u C i, 3=q \mathrm{pm})$ :

1

DESIRED WEIGHT FRACIION DNITS ( $I=9,2=f i$ teI) :

1

INTERNAI CONTROL CHART PROGRAM NUMBER:

ENTER: 0 FOR 160500

3 FOR 160601 (II mode)

1 FOR 162010

2 FOR 162011

$\because \%$

INTERIAI CONIROI CHART BATCH NUMBER:

MEASURED CONIROL VAIUE, CORRECTED FOR DECAY:

UPPER CONTROI IIMIT IN UNITS OF DPM/ML:

LOWER CONIROI IIMIT IN UNITS OF DPM/MI:

*ACTIVITY OF THE SAMPIE THATt has DUPLICATED:

-ACTIVITY OF THE SAMPIE THAT WAS SPIKED:

NA WAS DUPIICATED, PERCENT DIFFERENCE:

970815-002 WAS SEIKED, PERCENT RECOVERY:

KNOWN ACTIVITY OF CONIROI, DECAY CORRECIED:

STANDARD: \# RI-128-W

REFERENCE DATE: $\quad 01-J A N-1987$
$1015.12 \mathrm{DPM} / \mathrm{MI}$

1073.70

783.70

INA (pCi/g)

$3.43 e+0 i \quad(p C i / g)$

IA.

ERR I

$$
99.13 \%
$$

$1023.56 \mathrm{DPM} / \mathrm{ML}$

$E$

AnaIIS report:

\begin{tabular}{|c|c|c|c|c|}
\hline & ACIUAI & AMOUNT & SPIKE & PERCENI \\
\hline ONITS & RESULT & SPIKED & RESULI & RECOVERY \\
\hline$=\Sigma=== \pm==$ & $==== \pm==$ & $==\geq===$ = & $====== \pm=$ & $=======0$ \\
\hline$D P M$ & 5.33 & 511.78 & 512.69 & 99.13 \\
\hline
\end{tabular}

20/20 Iicense \#\&828, Program validation \#:SOPI60063.R4-T2IG, 09/28/94.DFH 
DATE COUNTED : $02-$ SEP -1997

DATE CALCULATED:04-SEP-1997

QA FIIE-PE- 2141

ANUAYST : DKM/SPW
Tc-99 (Tevaspec)

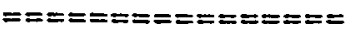

\begin{tabular}{|c|c|c|c|c|c|c|c|c|c|}
\hline AMPIEE & MD & EFFIC. & tSIE & GROSS & DILUTION & WEIGHI & NET & NET & COUNIING \\
\hline NUMBER & $\begin{array}{l}\text { or } \\
\text { MS }\end{array}$ & $\begin{array}{l}\text { FACT. } \\
\text { CPM/DPM }\end{array}$ & VAIUE & $\begin{array}{l}\text { ACTIVITY } \\
\text { (CPM) }\end{array}$ & $\begin{array}{c}\text { FACIOR } \\
\text { (mI) }\end{array}$ & $\begin{array}{l}\text { FRACIION } \\
\text { (g) }\end{array}$ & $\begin{array}{l}\text { ACTIVITY } \\
(\mathrm{DC} i / L)\end{array}$ & $\begin{array}{l}\text { ACTIVITY } \\
(\mathrm{pCi} / \mathrm{g})\end{array}$ & $\begin{array}{c}\text { CERTAINIT } \\
(+/-)\end{array}$ \\
\hline$z=x=x=2=5$ & $==$ & Ex=E=E & $E= \pm=s=$ & $=x====\Sigma=$ & $=====x==$ & 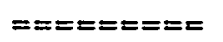 & $===\varepsilon=x=2 \pi$ & 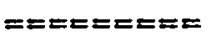 & $==\varepsilon=\hat{S}==0$ \\
\hline BILANK & & 0.924 & 271.07 & 22.50 & & & & & \\
\hline CONIROI & & 0.931 & 290.30 & 495.02 & 0.500 & 0.000 & $4.57 e+05$ & NA & $4.02 e+03$ \\
\hline DOPIICATE & & 0.929 & 283.09 & 26.80 & 0.000 & 0.070 & NIA & $2.81 e+01$ & $8.90 e+00$ \\
\hline SPIKE & & 0.929 & 284.09 & 499.15 & 0.000 & 0.070 & $N A$ & $3.30 e+03$ & $2.89 e+01$ \\
\hline $970815-00$ & $2 \mathrm{MD}$ & 0.928 & 280.53 & 27.64 & $0: 000$ & 0.070 & NAP & $3.43 e+01$ & $8.98 e+00$ \\
\hline $970815-00:$ & $2 \mathrm{MS}$ & 0.928 & 280.53 & 27.64 & 0.000 & 0.070 & NDA & $3.43 e+01$ & $8.98 e+00$ \\
\hline
\end{tabular}


SANIIE COONTING TIME IN UNITS OF MINUTES:

120.0

DESIRED ACTIVITY UNITS ( $1=p C i, 2=u C i, 3=\delta \mathrm{m}$ ):

DESIRED WEIGHT FRACTION UNITS ( $1=g, 2=f$ ilter) :

INTERNAT CONTROI CHART PROGRAM NOMBER: ENTER: 0 FOR 160600

3 FOR 160601 (II mode)

\section{0}

1 FOR 162010

2 FOR 162011

4

INTERRAI CONTROI CFART BATCH NUMBER:

$1015.12 \mathrm{DPM} / \mathrm{MI}$

MEASURED CONTROL VAIUE, CORRECTED FOR DECAY:

1073.70

UPPER CONTROL IIMIT IN UNITS OF DPM/MU:

783.70

IOWER CONTROI IIMIT IN ONITS OF DPM/MI:

$3.43 e+01 \quad(p \mathrm{Ci} / \mathrm{g})$

*ACTIVITY OF THE SAMPLE THAT WAS DUPIICATED:

$3.43 e+01 \quad(p C i / g)$

*ACIIVITY OF THE SAMPLE THAT WAS SPIKED:

970815-002 WAS DUPLICATED, PERCENT DIFFERENCE:

19.868

$99.13 \div$

970815-002 WAS SPIKED, PERCENI RECOVERY:

$1023.56 \mathrm{DPM} / \mathrm{MI}$

KNOWN ACTIUITY OF CONTROL, DECAY CORRECTED:

STANDARD:\# RI-128-W REFERENCE DATE:

$01-$ JAN-1987

Analis report:

\begin{tabular}{|c|c|c|c|c|}
\hline & & DUNT & SPIKE & PERCENTI \\
\hline UNITS & RESULT & SPIKED & RESULI & RECOVERY \\
\hline$=x=\varepsilon=E=$ & $=2 x=x=x=$ & $== \pm=2=x=5$ & $==\varepsilon=x==x$ & $=E x=E x=5$ \\
\hline & 5.33 & 511.78 & 512.69 & 99.13 \\
\hline
\end{tabular}




\section{Gilsow}

02 Sep $97 \quad 18: 19$ Protocol \#: 4

TiEe: 220.00

Data Kode: DPK

Background Subtract: Kanual
Fage \#1

User : k-25 Radiochemistry
Nuclide: TC_IEVA_LE Quench Set: TE_iEVA

$\begin{array}{rrrrrr} & \text { II } & \text { UL } & \text { ICR } & 251 & \text { BLE } \\ \text { Region A: } & 0.0-293 & 0 & 0.0 & 0.00 \\ \text { Region B: } & 6.0-293 & 0 & 0.0 & 0.00 \\ \text { Region C: } & 293-2000 & 0 & 0.0 & 0.00\end{array}$

Buench Indicato:: tSIE/AEE

Ext Sid Terzinator: Count

Packard Liquid Scintillation 2550iTR 40225\%

Luninescence Correction On

Heterogeneity Honitor On

Color Quench Correction on

Coincióence Tise(ns): 18

Delay Eefore Burst(ns): Foral

\begin{tabular}{|c|c|c|c|c|c|c|c|c|c|c|}
\hline$=$ & S\# & FID & TIME & CPMAA & DPMI & CFME & CFMIC & tEIE & FLAG & LUIM \\
\hline 4 & 1 & 27 & 120.00 & 22.50 & 24.55 & 21.00 & 9.74 & 271.07 & $0.923 \% 0$ & 12 \\
\hline 4 & 2 & 27 & 120.00 & 495.02 & $53 i .72$ & 483.89 & 10.11 & 290.50 & $0.9310 \mathrm{C}$ & 1 \\
\hline 4 & $\Xi$ & 27 & 120.00 & 27.64 & 29.79 & 25.52 & 9.53 & 280.5 .5 & $0.9278 A$ & $\theta$ \\
\hline 4 & 4 & 27 & 120.00 & 499.15 & 597.19 & $4 E 2.51$ & 10.22 & 284.09 & 0.92028 opite & i \\
\hline 4 & 5 & 27 & 120.00 & 26.80 & 28.85 & 25.10 & 10.08 & 283.09 & $0.9228 \mathrm{C}$ & \\
\hline 4 & ó & 27 & 120.00 & 501.85 & 540.09 & 490.38 & 9.55 & 284.06 & 0.9292 & g \\
\hline
\end{tabular}




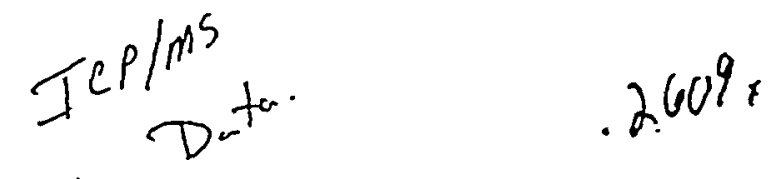

20.d TH1OL

\section{Qnalepis of To in Ni Metal} Specific activity

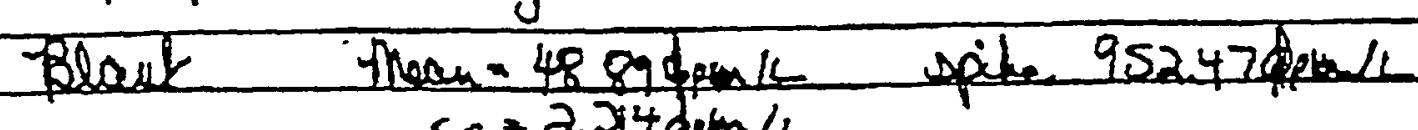

$y_{i} d d=\frac{952.47-48.89}{942.63}, 00=95.86$

:Resects $48.99 / 0.9586=51.00 \mathrm{dmm} / \mathrm{h}$

MPA $-4.65(2.21) / 0.9586=10.72 \mathrm{dPm} / 2$

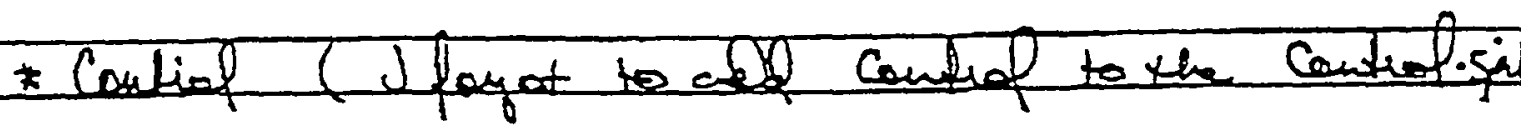

Gied - $911.07 / 62.63 * 100=96.72 z_{0}$

Reselt $=181.6 / 09672=187.939 \%$

Tuse value $=187.15$ dente

$z_{0}$ bise $=187.93-182.15 / 187.15 \times 100+047$

$M P A=4.65(221) / 0.9672=10.63 \mathrm{~kg} / \mathrm{L}$

dample $\frac{y \text { ild }-109135-250.65}{942.63}, 00 \frac{891906}{2}$

\begin{tabular}{ll}
$56.33 \% 1.00$ 08i/ge \\
\hline
\end{tabular}

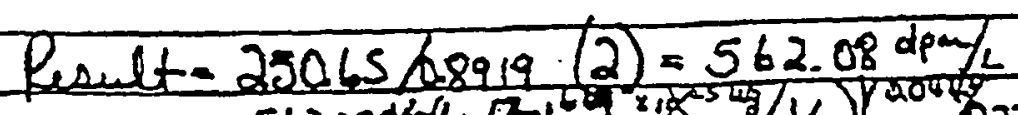

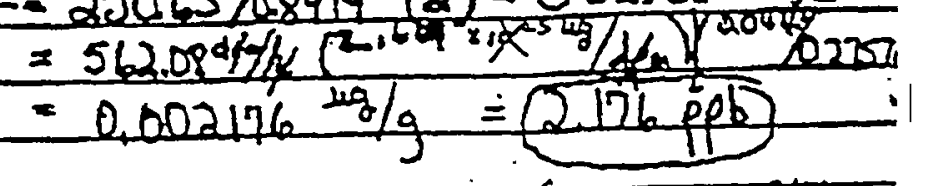

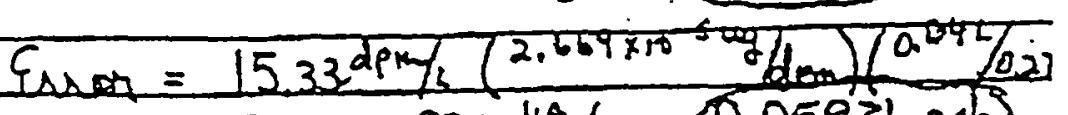

$=0.00005936 \mathrm{~kg} / \mathrm{g}=0.05931 . \mathrm{ppo}$

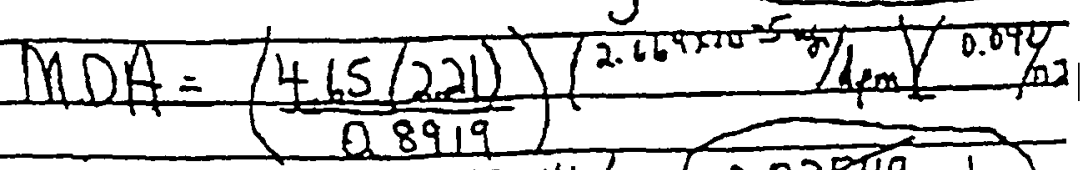

$=000003549 \mathrm{w} / \mathrm{g}=\frac{0.03549 \mathrm{peb}}{0.06}$ 
To: $\quad$ Valerie MacNair

Cc: $\quad$ Steve Sarten

Subject: $\quad$ Ni Results from Ni cathodes stripped from Ti Base

Ni cathode was sectioned off in 9 equal portions. Sections were counted using a Ludlum 2224 with a alpha/beta scintillation detector. The counted section was marked and a $100 \mathrm{~cm} 2$ area cut from the quadrant and cut into small pieces. Twenty $\mathrm{ml}$ of HNO3 was added to the samples and heated until dissolved. Water was adcled and the solution evaporated down to $15 \mathrm{ml}$ at 60 degrees $C$ to reduce the nitric acid concentration. The sample was quantitatively rinsed into a $100 \mathrm{ml}$ volumetric flash and diluted to $100 \mathrm{ml}$ with distilled water. One ml of the solution was removed and added to $12 \mathrm{ml}$ of a liquid scintillation cocktail and counted for 100 minutes in the Packard 2700 TR counter.

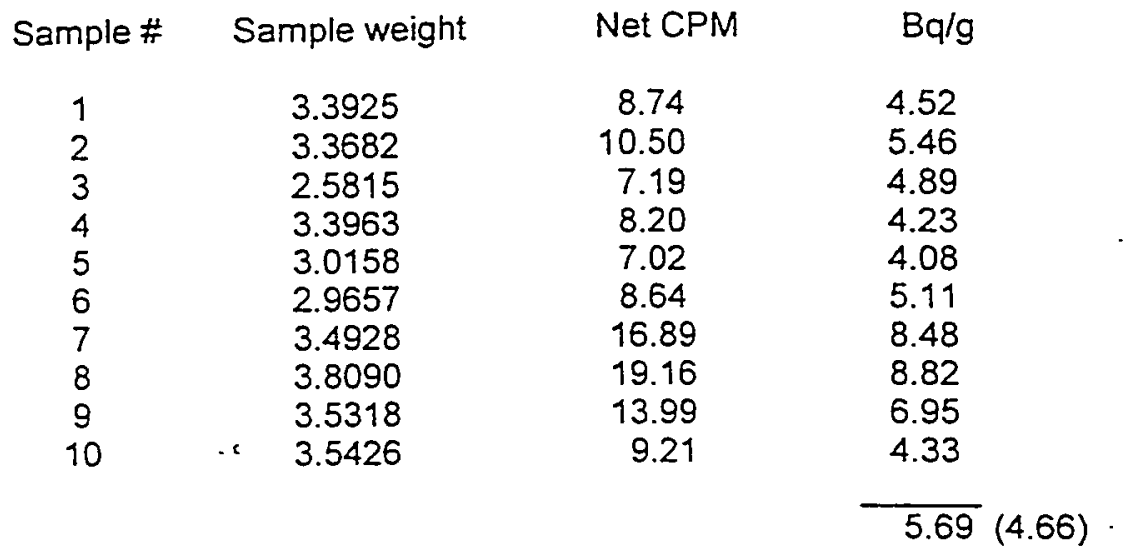

Sample B (from the backside of Base) Sampled and counted as in A. 002752B

July 29,1998

\section{Sample \#}

1
2
3
4
5
6
7
8
9
10

10

$$
\text { Sample Weight }
$$

3.7675

2.9325

3.6843

3.0726

3.3547

3.3039

3.7473

3.1548

2.6881

4.1284
Net CPM

8.01

8.60

9.31

8.62

9.14

8.02

8.75

7.34

8.10

11.69
$\mathrm{Bq} / \mathrm{g}$

3.73

5.15

4.43

4.68

4.54

4.05

3.89

4.97

5.29

4.97

4.46

$\begin{array}{llll}\text { Cementation 1 } & 3.1269 & 1,852 & 2,306 \\ \begin{array}{r}\text { Cementation 2 (a) } \\ 1.00 \mathrm{ml} \text { sample }\end{array} & 2.8363 & 1,219 & 1,674 \\ \begin{array}{r}\text { Cementation 2 (b) } \\ 0.50 \mathrm{ml} \text { sample }\end{array} & 617.7 & 1,696 \\ \begin{array}{c}\text { Cementation 2 (c) } \\ 2.00 \mathrm{ml}\end{array} & 2,461 & 1690\end{array}$


Tc-99 Results from Ni Cathode: Lab. $\#$ 002752A July 23, 1998 Model 2224 alpha/beta scintillator $100 \mathrm{~cm} 2$ Area SN 125601 Cal. Date : 12-11-97

Alpha eff. : $18.5 \% \quad$ Beta eff. : $11.4 \%$

\section{Area \#}

$\begin{array}{lllllllllll}1 & 259 & 251 & 246 & 274 & 238 & 217 & 232 & 233 & 247 & 246\end{array}$

244.3

$\begin{array}{llllllllll}2 & 245 & 225 & 252 & 247 & 231 & 247 & 229 & 240242 & 217\end{array}$

$\begin{array}{lllllllllll}3 & 243 & 261 & 250 & 253 & 225 & 256 & 238 & 241 & 276 & 240\end{array}$

$\begin{array}{lllllllllll}4 & 257 & 240 & 220 & 234 & 260 & 233 & 232 & 240 & 242 & 220\end{array}$

$\begin{array}{lllllllllll}5 & 210 & 233 & 236 & 245 & 265 & 268 & 243 & 254 & 226 & 242\end{array}$

$\begin{array}{lllllllllll}6 & 234 & 249 & 227 & 260 & 244 & 255 & 264 & 239 & 247 & 232\end{array}$

$\begin{array}{lllllllllll}7 & 216 & 250 & 251 & 246 & 269 & 252 & 237 & 246 & 238 & 250\end{array}$

$\begin{array}{lllllllllll}8 & 227 & 241 & 270 & 236 & 247 & 247 & 244 & 259 & 244 & 254\end{array}$

$\begin{array}{lllllllllll}9 & 244 & 229 & 236 & 263 & 256 & 242 & 262 & 229 & 233 & 251\end{array}$

AVERAGE

243.6

$<$

$\begin{array}{lllllllllll}\text { Bkg. } & 231 & 251 & 240 & 223 & 219 & 245 & 212 & 256 & 236 & 235 \\ & 230 & 262 & 254 & 240 & 231 & 254 & 234 & 246 & 227 & 231\end{array}$

Net CPM

DPM

50.0

$\mathrm{Bq}$

0.83

$\mathrm{Bq} /$ gram

0.37 
Tc-99 Results from Ni Cathode: Lab. \#002752

Model 2224 alpha/beta scintillator $100 \mathrm{~cm} 2$ Area

SN $146728 \quad$ Cal. Date : 4-24-98

Alpha eff. : $20.6 \% \quad$ Beta eff. : $13.0 \%$

Area \#

$\begin{array}{lllllllllll}1 & 397 & 444 & 412 & 414 & 425 & 402 & 419 & 383 & 427 & 418\end{array}$

413.2

$\begin{array}{lllllllllll}2 & 436 & 426 & 396 & 419 & 408 & 410 & 392 & 390 & 425 & 444\end{array}$

413.7

$\begin{array}{lllllllllll}3 & 420 & 392 & 368 & 442 & 457 & 401 & 419 & 422 & 397 & 379\end{array}$

408.9

$\begin{array}{lllllllllll}4 & 402 & 417 & 396 & 366 & 413 & 385 & 434 & 401 & 420 & 420\end{array}$

404.5

$\begin{array}{lllllllllll}5 & 404 & 404 & 423 & 416 & 414 & 437 & 366 & 402 & 400 & 419\end{array}$

407.4

$\begin{array}{lllllllllll}6 & 375 & 435 & 396 & 442 & 395 & 427 & 409 & 418 & 394 & 399\end{array}$

408.1

$\begin{array}{lllllllllll}7 & 386 & 374 & 421 & 404 & 393 & 432 & 429 & 381 & 403 & 411\end{array}$

402.7

$\begin{array}{lllllllllll}8 & 394 & 408 & 404 & 435 & 443 & 400 & 390 & 363 & 387 & 426\end{array}$

404.2

$\begin{array}{lllllllllll}9 & 392 & 418 & 406 & 411 & 390 & 426 & 441 & .401 & 393 & 399\end{array}$

$407.0^{\circ}$

AVERAGE

407.7

$\begin{array}{lllllllllll}\text { Bkg. } & 335 & 317 & 342 & 360 & 338 & 334 & 347 & 312 & 305 & 276\end{array}$

326.6

Net CPM

81.1

DPM

624.2

$\mathrm{Bq}$

10.40

$\mathrm{Bq} /$ gram

4.66 
Tc-99 Results from Ni Cathode: · Lab. \# 002858A

Thicker Material

Model 2224 alpha/beta scintillator $100 \mathrm{~cm} 2$ Area

SN 125578 Cal. Date : 5-26-98

Alpha eff. : $20.1 \% \quad$ Beta eff. : $9.1 \%$

Area \#

$\begin{array}{llllllllllll}1 & 707 & 715 & 760 & 689 & 698 & 745 & 687 & 699 & 702 & 633 & 702.8\end{array}$

$\begin{array}{llllllllllll}2 & 755 & 768 & 724 & 690 & 723 & 746 & 714 & 756 & 741 & 707 & 737.4\end{array}$

$\begin{array}{llllllllllll}3 & 688 & 641 & 661 & 670 & 646 & 636 & 655 & 649 & 679 & 672 & 659.7\end{array}$

$\begin{array}{llllllllllll}4 & 771 & 743 & 753 & 718 & 760 & 739 & 710 & 726 & 755 & 751 & 742.6\end{array}$

$\begin{array}{llllllllllll}5 & 746 & 713 & 765 & 775 & 769 & 724 & 746 & 744 & 718 & 760 & 746.0\end{array}$

$\begin{array}{llllllllllll}6 & 695 & 698 & 670 & 644 & 689 & 709 & 707 & 702 & 687 & 689 & 689.0\end{array}$

$\begin{array}{llllllllllll}7 & 772 & 799 & 771 & 768 & 820 & 738 & 765 & 806 & 800 & 779 & 781.8\end{array}$

$\begin{array}{llllllllllll}8 & 762 & 769 & 720 & 770 & 751 & 771 & 777 & .751 & 768 & 737 & 757.6 .\end{array}$

$\begin{array}{llllllllllll}9 & 7478 & 787 & 768 & 738 & 763 & 764 & 776 & 784 & 765 & 782 & 767.4\end{array}$

AVERAGE $\quad 732.0$

$\begin{array}{llllllllllll}\text { Bkg. } 290 & 271 & 289 & 268 & 242 & 279 & 240 & 274 & 273 & 259 & 270.0\end{array}$ $\begin{array}{llllllllll}242 & 271 & 282 & 260 & 281 & 258 & 285 & 278 & 276 & 275\end{array}$

Net CPM

.462 .0

DPM

$5,076.9$

$\mathrm{Bq}$

84.6

$\mathrm{Bq} / \mathrm{gram}$

37.9

$2.981 \mathrm{~g}$ from cathode dissolved in $20 \mathrm{ml}$ HNO3: Diluted to $100 \mathrm{ml}, 1 \mathrm{ml}$ counted in LSC.

Sample 1: 30 net $\mathrm{cpm}$ Sample 27.8 net $\mathrm{cpm} \quad$ Background $=21.5 \mathrm{cpm}$

Ave: 28.9 net cpm or $30 \mathrm{dpm} / \mathrm{ml}=1,020 \mathrm{dpm} / \mathrm{g}$ or $17.0 \mathrm{~Bq} / \mathrm{g}$.

Anolyte $=60.4$ net $\mathrm{cpm}=64 \mathrm{dpm}=1.06 \mathrm{~Bq} / \mathrm{ml}$ Catholyte $=14.7 \mathrm{cpm}=15 \mathrm{dpm}=0.25 \mathrm{~Bq} / \mathrm{ml}$ 


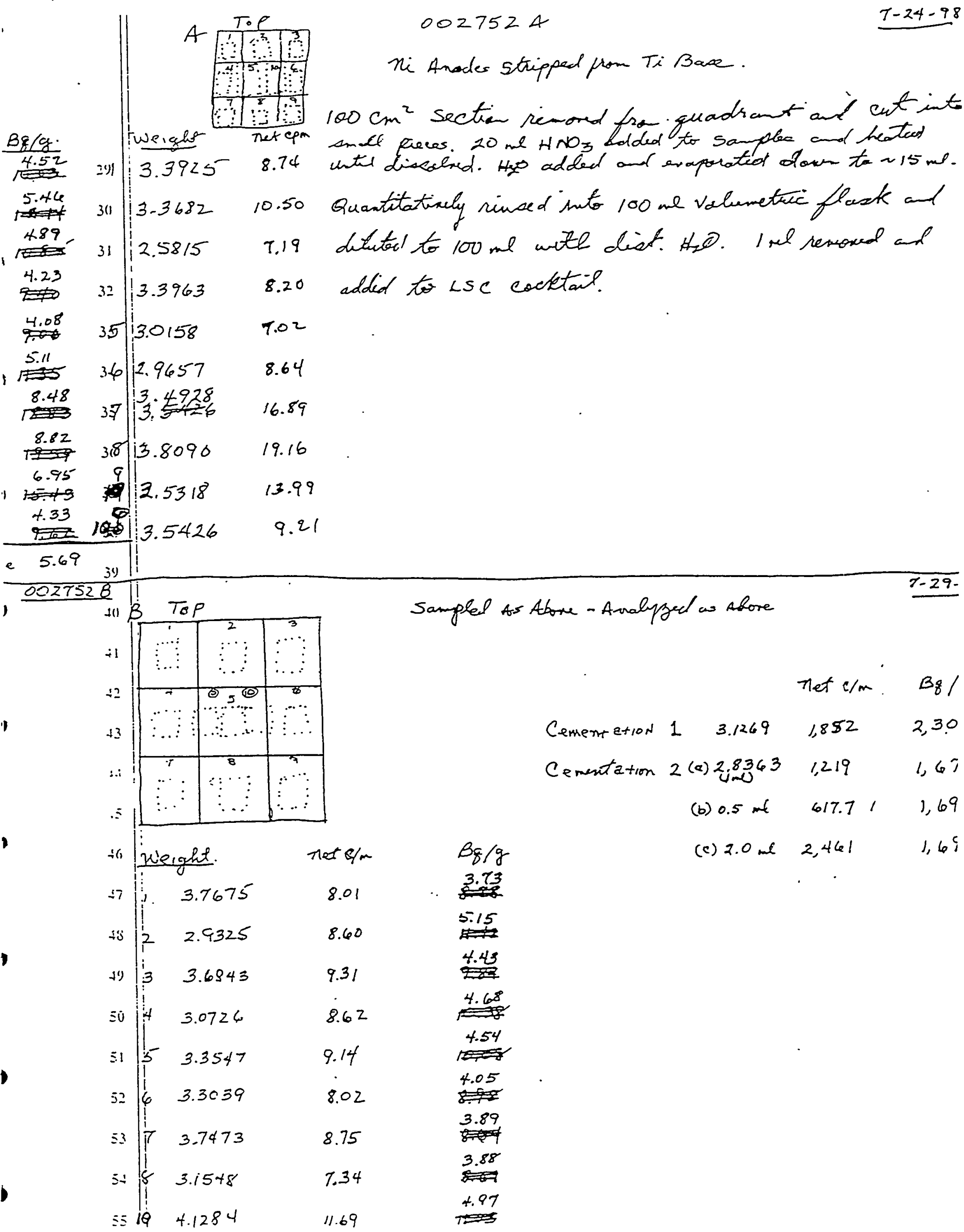


$\frac{24 \quad \mathrm{Jul}}{\text { Protocol } \#: 2} 22: 28$

Tine: 100.00

Data Hode: CPM

Nuclide: MaNUAL

ALPHA/BETA - 1.08

TC-99

\# 002752A

Background Subtract: None

$\begin{array}{rrrrrr} & \text { LL } & \text { UL } & \text { LCR } & 25 \% & \text { BKG } \\ \text { Region A: } & 0.0-200 & 0 & 0.0 & 0.00 \\ \text { Region B: } & 4.0-200 & 0 & 0.0 & 0.00 \\ \text { Region C: } & 0.0- & 0.0 & 0 & 0.0 & 0.00\end{array}$

Quench Indicator: tSIE/AEC

Ext std Terminator: Count

Tc-99 in Ni solution

$\begin{array}{rrr}\text { S\# } & \text { TIME } & \text { CPMA } \\ 1 & 100.00 & 30.12 \\ 2 & 100.00 & 31.88 \\ 3 & 100.00 & 28.57 \\ 4 & 100.00 & 29.58 \\ 5 & 100.00 & 28.40 \\ 6 & 100.00 & 30.02 \\ 7 & 100.00 & 38.27 \\ 8 & 100.00 & 40.54 \\ 9 & 100.00 & 35.37 \\ 10 & 100.00 & 30.59 \\ 11 & 100.00 & 891.06 \\ 12 & 100.00 & 21.38\end{array}$

DPM1

SIS FLAG

\begin{tabular}{lc}
59.725 & 8.74 \\
59.729 & 10.5 \\
60.555 & 7.19 \\
56.369 & 8.20 \\
58.850 & 7.02 \\
59.629 & 8.64 \\
59.241 & 16.89 \\
56.433 & 19.16 \\
60.557 & 13.99 \\
57.715 & 9.21 \\
\hline 50.716 & Anolyte \\
66.843 & Bkgnd
\end{tabular}

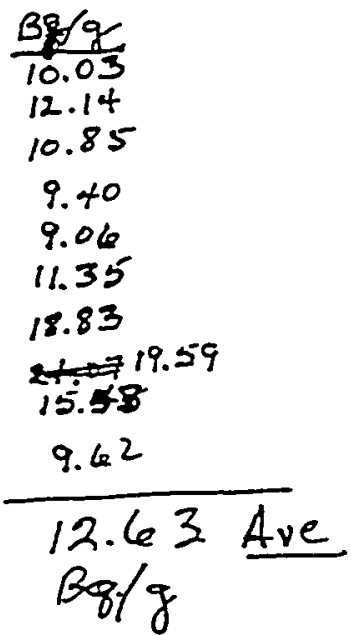

SYSTEM NORMALIZED

$$
\begin{aligned}
& \text { C14 IPA DATAEPROCESSED - 27-JUL-1998 06:27 } \\
& \text { C14 Eff }(0-156 \mathrm{keV})=95.99 \% \\
& \text { H3 IPA DATA PROCESSED - 27-JUI-1998 06:28 } \\
& \text { H3 Eff }(0-18.6 \mathrm{keV})=67.60 \% \\
& \text { BKG IPA DATA PROCESSED - 27-JU1-1998 07:29 } \\
& \text { B kg }(0-18.6 \mathrm{keV})=15.43 \mathrm{cPm} \\
& \text { Bkg }(0-156 \mathrm{keV})=23.50 \mathrm{cPm} \\
& C_{14} E^{-2 / B}(1-156 \mathrm{keV})=523.08 \\
& \mathrm{H} 3 \mathrm{E}^{\wedge} 2 / \mathrm{B}(1-18.6 \mathrm{keV})=302.99
\end{aligned}
$$




$\begin{array}{lcccc}29 \text { Jul } 199821: 55 & \text { ALPHA/BETA } & -1.08 & \text { Page } \\ \text { PTotocol \#: } 2 & \text { TC-99 } & 002752 B & \text { User : Tc-96 }\end{array}$

Time: 60.00

Data Hode: $\mathrm{CPH}$

Background Subtract: None
Nuclide: MANUAL

LL UL LCR 25\% BKG

Region A: $\quad 0.0-200 \quad 0 \quad 0.0 \quad 0.00$

Region 8: $4.0-200 \quad 0 \quad 0.0 \quad 0.00$

Region C: $\begin{array}{lllll} & 0.0-0.0 & 0 & 0.0 & 0.00\end{array}$

Quench Indicator: tSIE/AEC

Ext Std Terminator: Count

Tc-99 in Ni solution

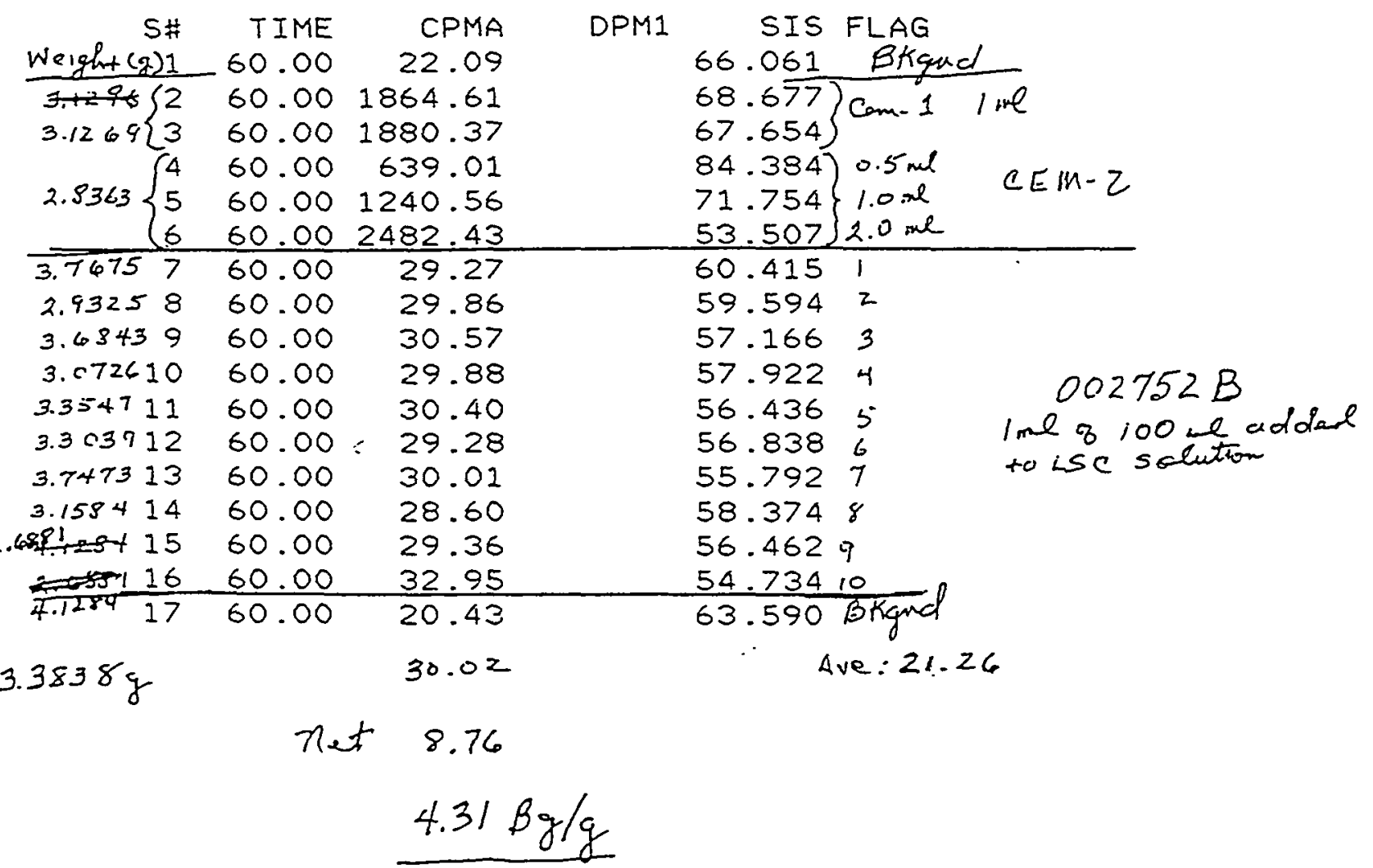




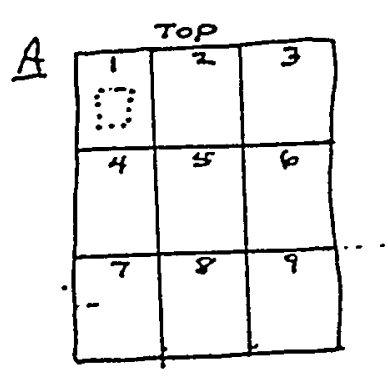

$002752 A$

Model zzZZ Q $\beta^{-S O n t i l l a t o r}$

SN 12560I

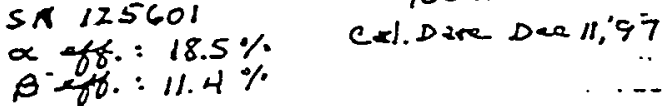

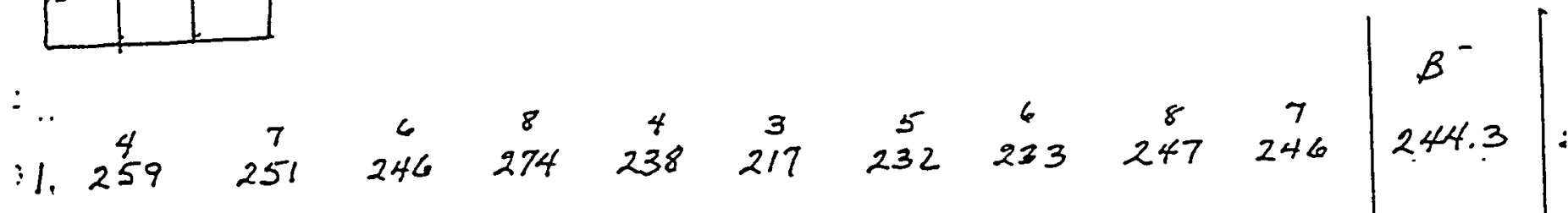

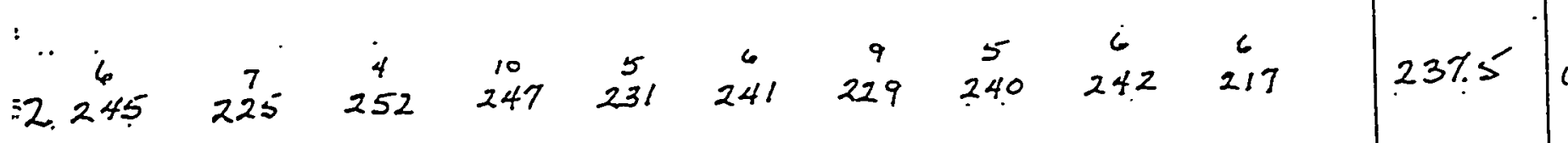

$$
\begin{aligned}
& \begin{array}{cccccccccc}
3 & 5 & 4 & 5 & 2 & 5 & 6 & 6 & 7 & 6 \\
-3.243 & 261 & 250 & 253 & 225 & 256 & 238 & 241 & 276 & 240
\end{array}
\end{aligned}
$$

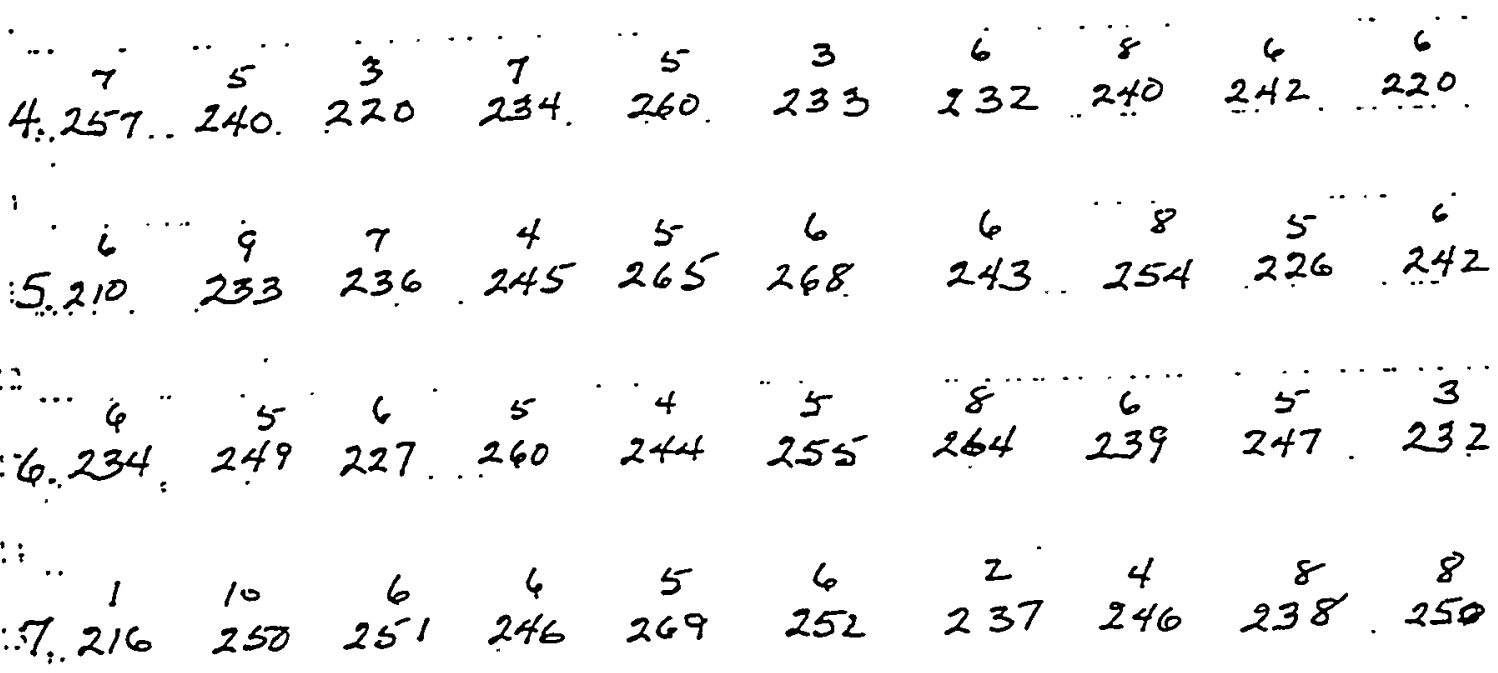

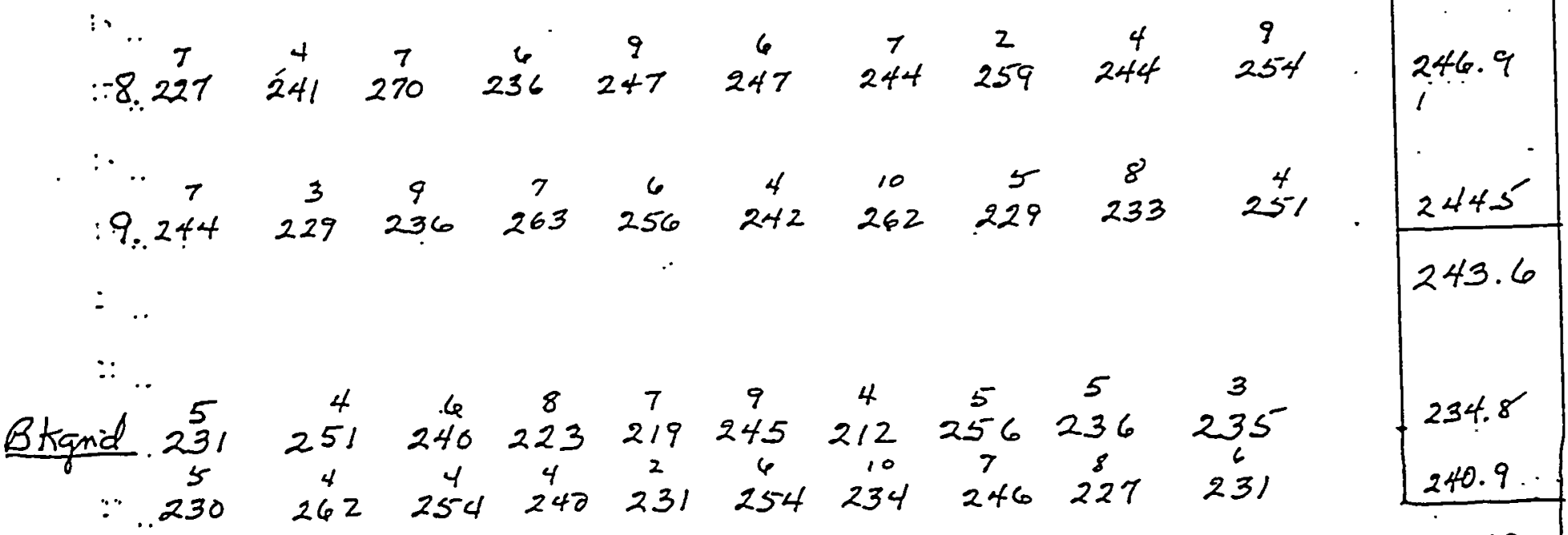

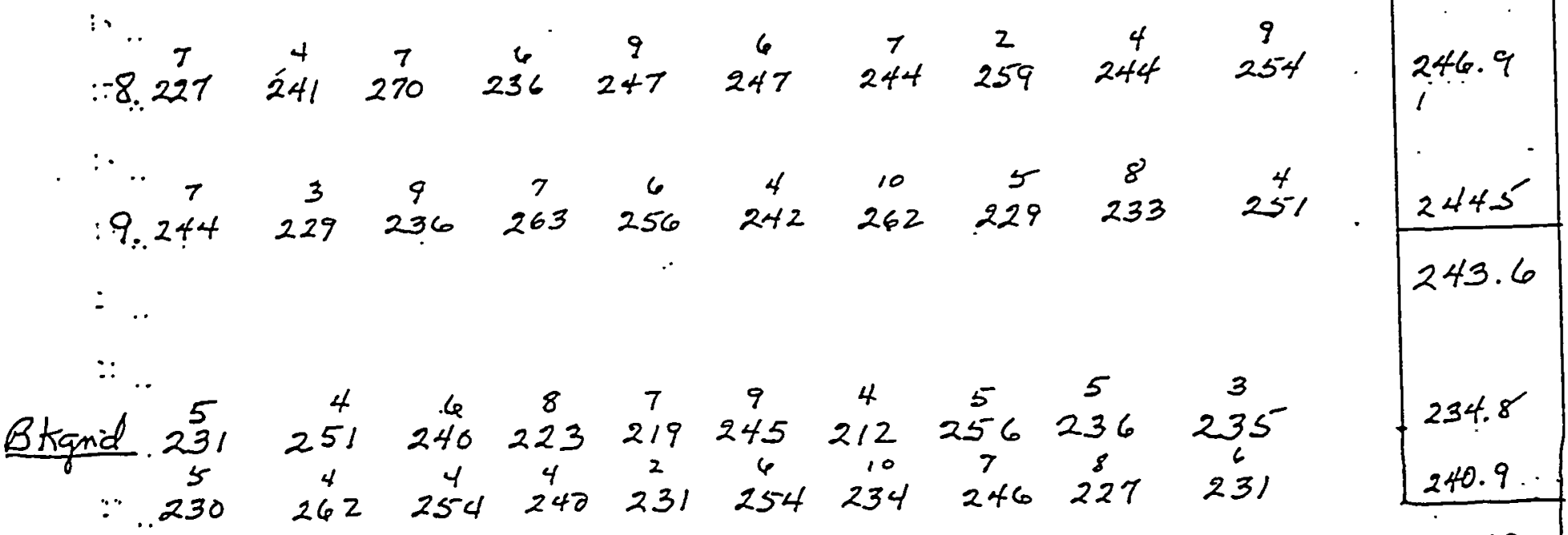

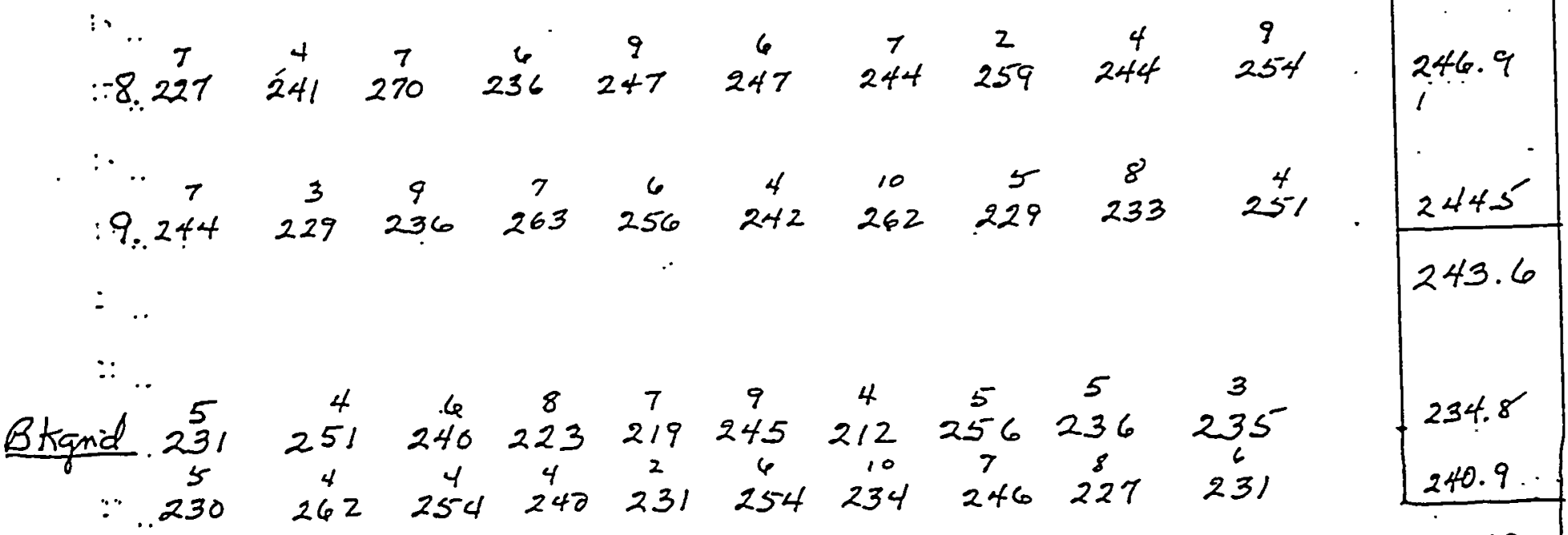

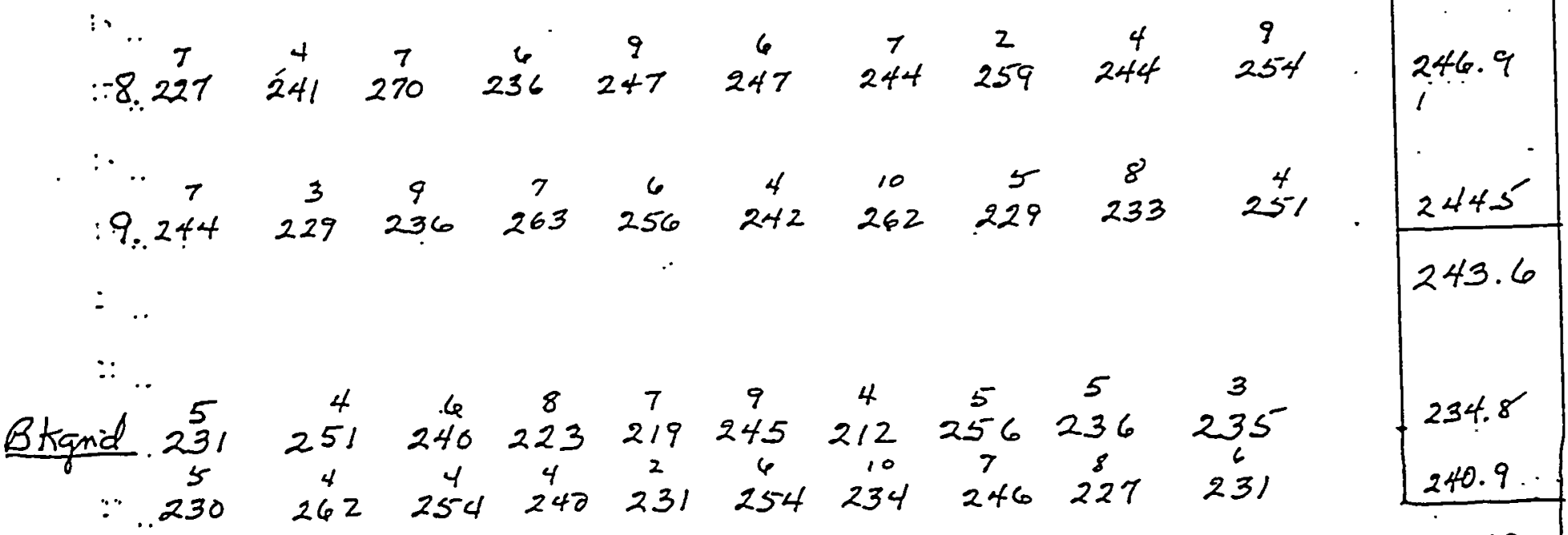

$$
\begin{aligned}
& 248.3 \\
& 237.9
\end{aligned}
$$

net $C / M$ : 5.7

$d p_{M}: 49.7$

R. . 184 


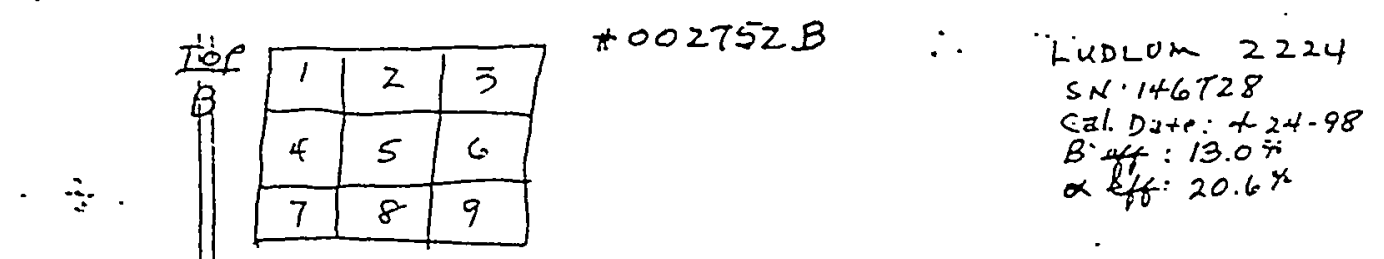

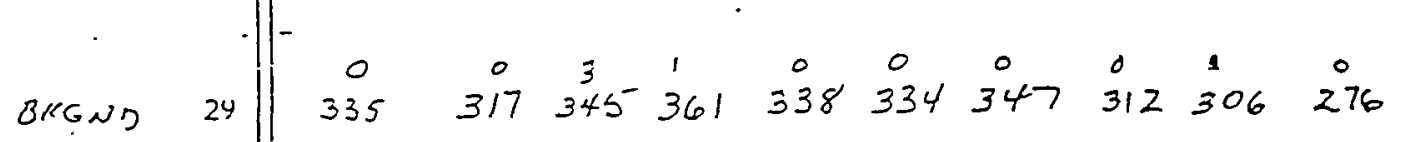

0.5

327.1

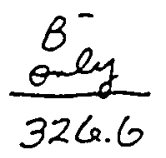

30

$\begin{array}{cccccccccc}1 & 1 & 0 & 0 & 2 & 1 & 1 & 1 & 1 & 1 \\ 397 & 444 & 412 & 414 & 425 & 402 & 419 & 383 & 427 & 418\end{array}$

0.9

$31 \mid \begin{array}{cccccccccc}397 & 444 & 412 & 414 & 425 & 402 & 419 & 383 & 427 & 418 \\ 0 & 1 & 1 & 4 & 1 & 1 & 0 & 0 & 1\end{array}$

41나:-1

86.6

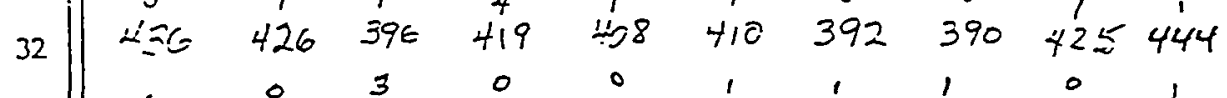

0.9

414.6

$8 \% .1$

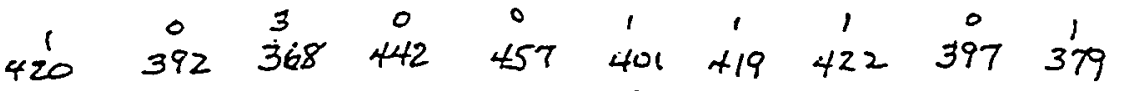

409.7

$\begin{array}{llllllllll}2 & 2 & 0 & 3 & 0 & 0 & 0 & 1 & 1 & 0\end{array}$

82.3

405.4

77.9

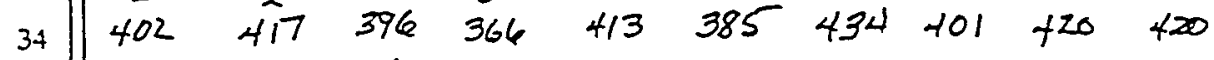

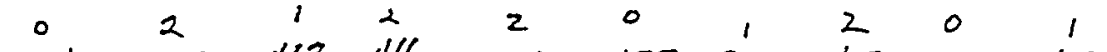

35404 40if $413 \quad 416 \quad 414 \quad 437 \quad 366 \quad 402 \quad 400 \quad 419$

36

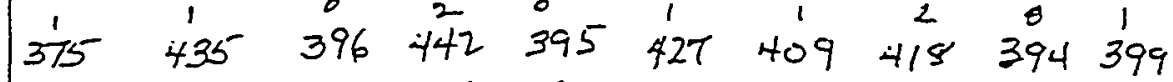

1.1

408.5

0.9

409.0

0.7

$\begin{array}{cccccccccc}2 & 0 & 1 & 0 & 1 & 0 & 0 & 0 & 1 & 2 \\ 386 & 374 & 421 & 404 & 393 & 432 & 429 & 381 & 403 & 411\end{array}$

37

$\begin{array}{lllllllllll}0 & 1 & 1 & 1 & 2 & 0 & 1 & 0 & 1\end{array}$

$38 \quad 394 \quad 408404435443 \quad 100 \quad 590 \quad 363 \quad 387 \quad 126$

39

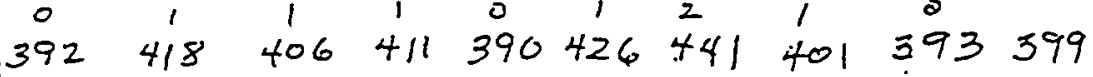

403.4

0.8

405.0

0.7

407.7

80.8

81.5

76.1

77,6

50.4

$\begin{array}{llllllllll}10 & 6 & 3 & 3 & 2 & 7 & 4 & 9 & 6 & 5\end{array}$

$41 \mid \begin{array}{llllllllll}269^{\circ} & 313 & 300 & 269 & 304 & 312 & 287 & 297 & 295 & 267\end{array}$

5.5

$29 / .3$

64.5

$42 \mid \begin{array}{cccccccccc}7 & 3 & 5 & 3 & 3 & 5 & 6 & 4 & 7 & 5 \\ 295 & 300 & 269 & 302 & 274 & 264 & 312 & 287 & 289 & 280 \\ 4 & 6 & 7 & 7 & 6 & 3 & 4 & 3 & 3 & 4\end{array}$

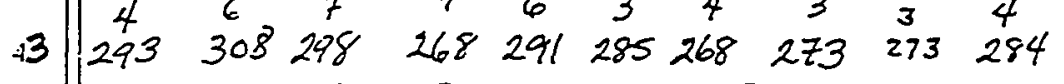

$+4 \mid \begin{array}{cccccccccc}9 & 3 & 2 & 5 & 4 & 3 & 55 & 3 & 10 & 6 \\ 298 & 308 & 283 & 307 & 270 & 309 & 298 & 308 & 3 i 0 & 273\end{array}$

$15 \mid \begin{array}{cccccccccc}0 & 6 & 5 & 5 & 9 & 3 & 5 & 4 & 8 & 2 \\ 284 & 289 & 325 & 297 & 339 & 274 & 269 & 295 & 291 & 347\end{array}$

$16 \mid \begin{array}{cccccccccc}4 & 5 & 3 & 5 & 4 & 2 & 0 & 4 & 4 & 3 \\ 274 & 329 & 294 & 320 & 288 & 285 & 306 & 290 & 299 & 308 \\ 4 & 6 & 4 & 4 & 7 & 5 & 49\end{array}$

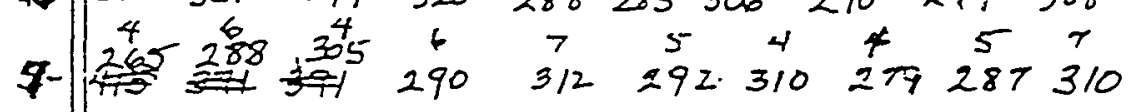

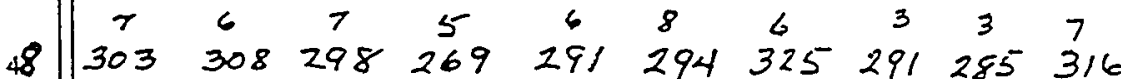

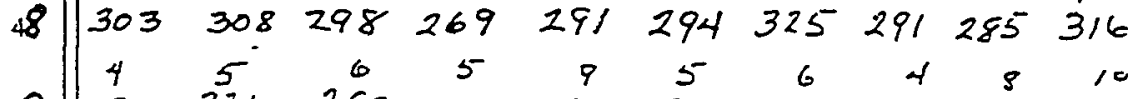

$49 \mid \begin{array}{cccccccccc}4 & 5 & 6 & 5 & 9 & 5 & 6 & 4 & 9 & 10 \\ 292 & 321 & 288 & 293 & 310 & 268 & 302 & 287 & 310 & 340\end{array}$

5.3

287.1

4.7

284.

5.0

296.4

$+.7$

301.0

3.4

299.3

5.2

293.8

5.8

298.0

6.2

289.1

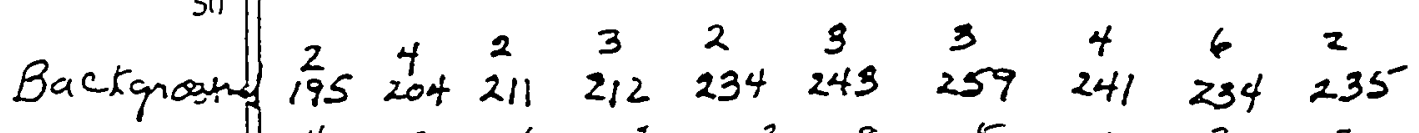

$52 \mid \begin{array}{cccccccccc}4 & 8 & 6 & 3 & 3 & 8 & 5 & 7 & 3 & 3 \\ 248 & 289 & 242 & 269 & 253 & 238 & 268 & 268 & 286 & 258\end{array}$

3.1

$226.8(4 m)$

5.0

261.9

(Pm) 


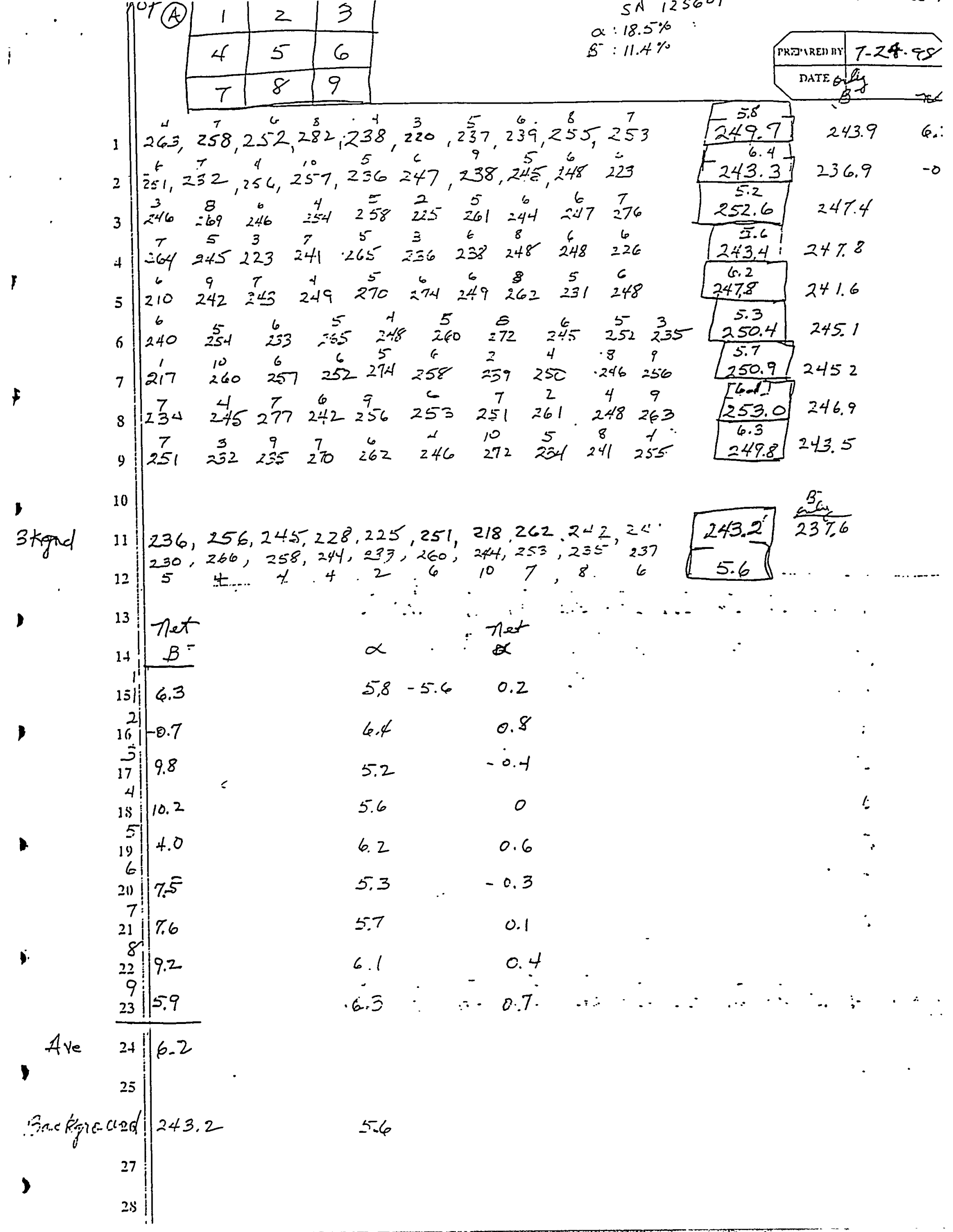




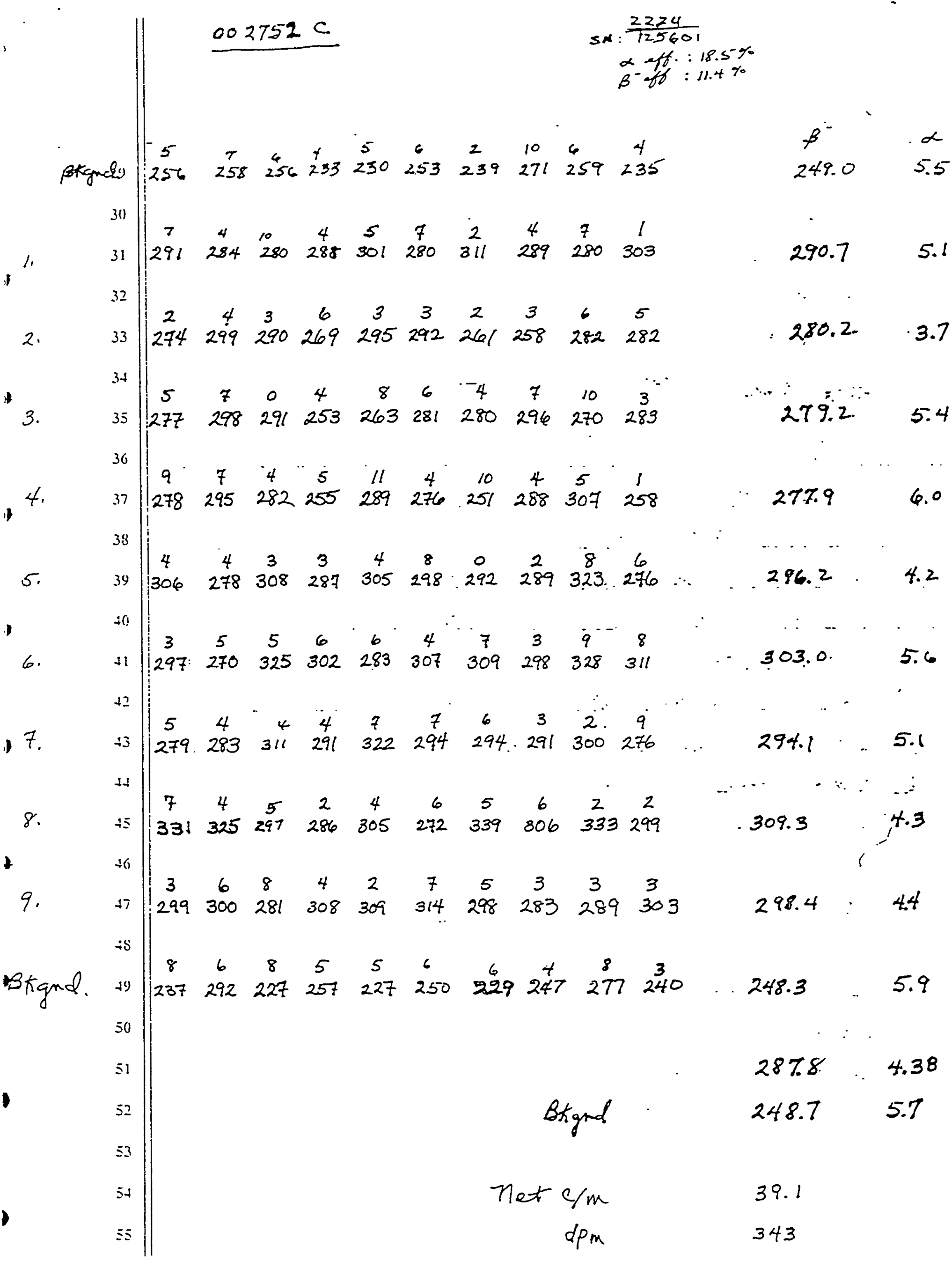


1.

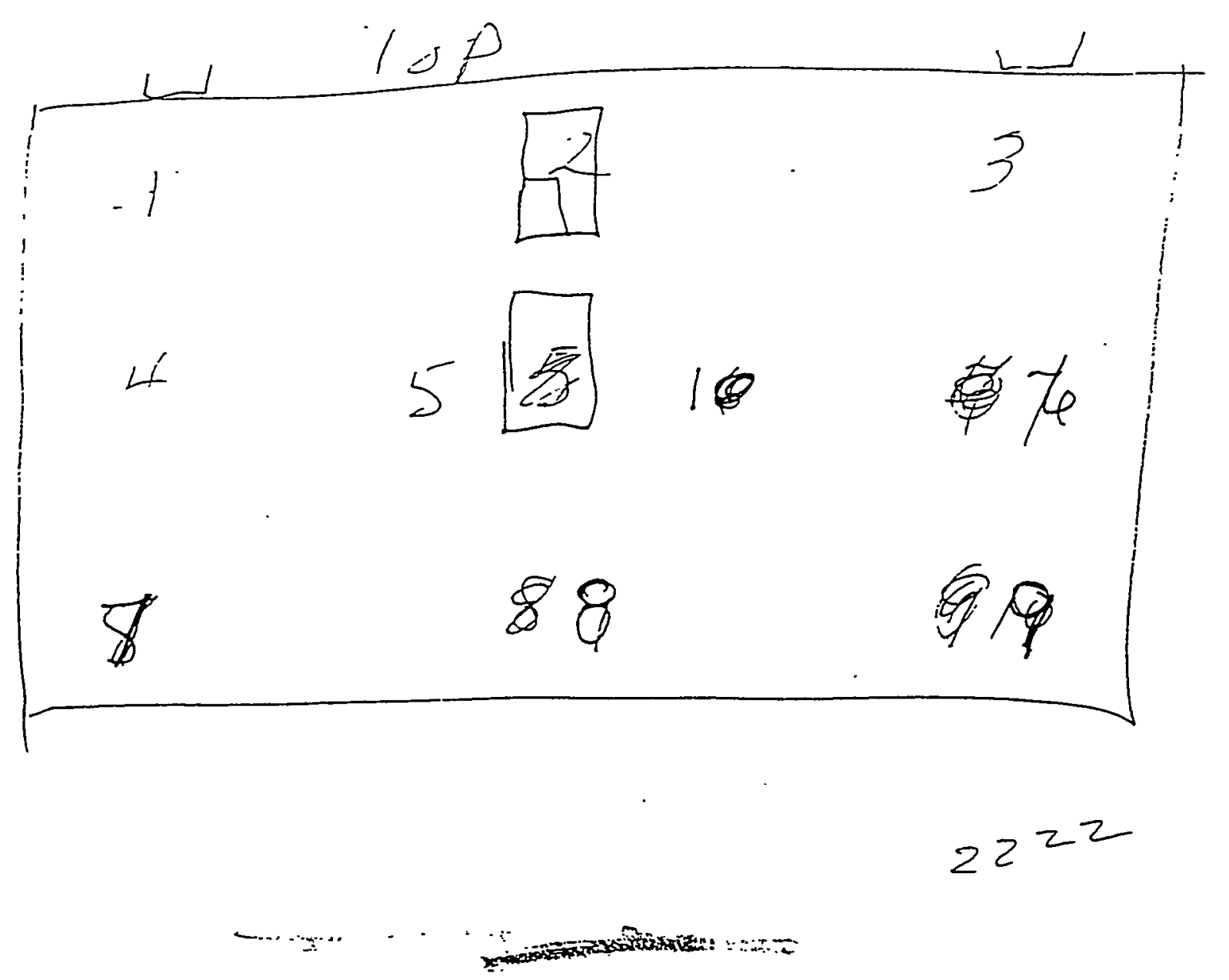



Thickek

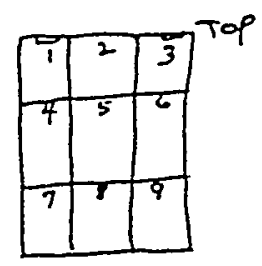

$\begin{array}{cccccccccc}1 & -2 & 4 & 4 & 1 & 2 & 3 & 1 & 1 & 2 \\ 797 & 715 & 760 & 682 & 698 & 745 & 687 & 699 & 702 & c_{33}\end{array}$

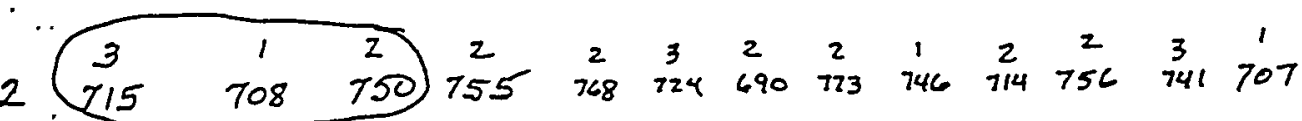

i

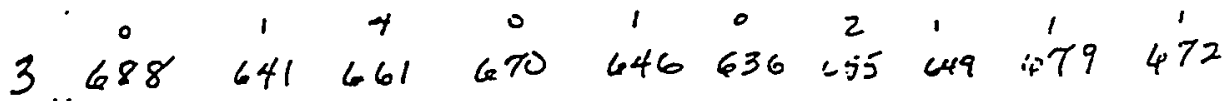

$\begin{array}{ccccccccccc}. \prime & 0 & 1 & 4 & 3 & 2 & 1 & 1 & 0 & 2 & 2 \\ 771 & 743 & 753 & 718 & 760 & 739 & 710 & 726 & 755 & 751\end{array}$

$\begin{array}{lcccccccccc}6 & 2 & 1 & 1 & 2 & 4 & 0 & 1 & 2 & 1 & 1 \\ 698 & 670 & 644 & 689 & 709 & 707 & 702 & 687 & 689\end{array}$

$\therefore$

$\begin{array}{cccccccccc}7.0 & 1 & 3 & 2 & 1 & 2 & 0 & 1 & 1 & 2 \\ 772 & 799 & 771 & 768 & 322 & 738 & 765 & 800 & 800 & 719\end{array}$

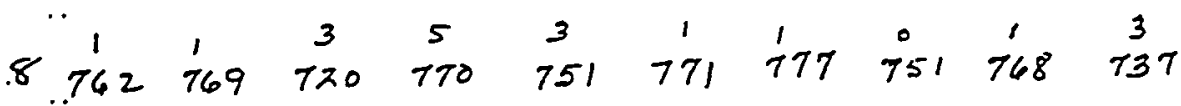

$\begin{array}{ccccccccccc}9^{\prime} & 2 & 3 & 2 & 1 & 1 & 2 & 5 & 4 & 1 & 1 \\ & 747 & 787 & 768 & 738 & 763 & 764 & 776 & 784 & 765 & 782\end{array}$

$\therefore$

SN 125578

$\alpha$ off: 20.199 .
Mi Anode

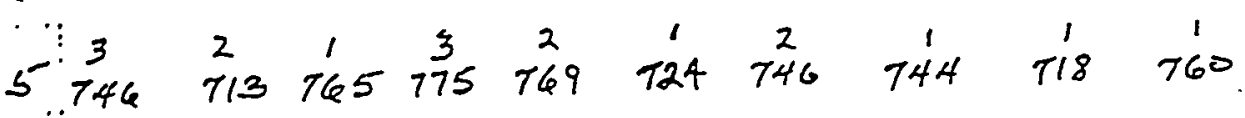

2224 Cul.pote:5.26.78 \#002858A

$8-6-48$

$-\beta$

702.8

$2.1 \quad 702.8$
\pm 34

737.4

$\pm 28$

659.7

$\pm 17$

742.6

$\pm 19$

746.0

$\pm 22$

689.0

$\pm 19$

$78 \% .8$

$\pm 22$

757.6

$\pm 18$

767.4

$1 \pm 16$

Ave $732 \pm 40$

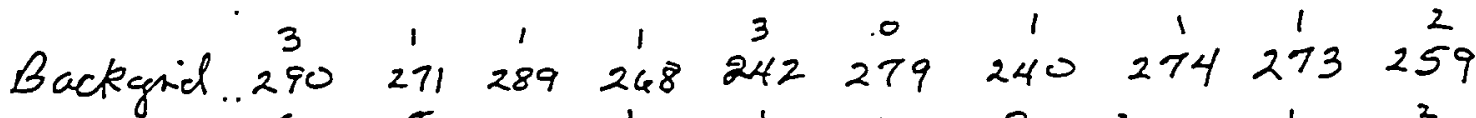

$\therefore \begin{array}{cccccccccc}4 & 1 & 0 & 1 & 1 & 1 & 0 & 2 & 11 & 27 \\ 271 & 282 & 260 & 281 & 258 & 285 & 278 & 276 & 275\end{array}$

$270\left\{\begin{array}{l}268.5 \\ 271.8\end{array}\right.$

$\because 2.981 \mathrm{~g}$ dissolved in $20 \mathrm{~g} \mathrm{HNO}_{3}$. D.luted to 100 we I wh Counted far h hour

$\therefore$.. Sarple $1 \quad 51.5 \mathrm{cpm}$

$\because$ Sample $2 \quad 49.3 \mathrm{cpm}$

$\left.\begin{array}{l}30 \text { net epr } \\ 27.8\end{array}\right\} 28.9 \quad 30$ dpros $\quad 1,020$

$\therefore$ Anolpte

$81.9 \mathrm{cpm}$

60.4

$\because$ Cathalyte

$36.2 \mathrm{cpm}$

14.7 
Tine: 60.00

Data Hode: CPM

Nuclide: MaNUAL

Background Subtract: None

$\begin{array}{lrrrrr} & \text { UL } & \text { UL } & \text { LCR } & 25 \% & \text { BKE } \\ \text { Region A: } & 0.0-200 & 0 & 0.0 & 0.00 \\ \text { Region B: } & 4.0-200 & 0 & 0.0 & 0.00 \\ \text { Region C: } & 0.0-0.0 & 0 & 0.0 & 0.00\end{array}$

Quench Indicator: tSIE/AEC

Ext Std Terninator: Count Tc-99 in Ni solution

\begin{tabular}{|c|c|c|c|c|c|}
\hline $\begin{array}{l}\text { S\# } \\
1\end{array}$ & $\begin{array}{r}\text { TIME } \\
60.00\end{array}$ & $\begin{array}{r}\text { CPMA } \\
51.50\end{array}$ & DPM1 & $\begin{array}{r}\text { SIS } \\
64.137\end{array}$ & FLAG \\
\hline 2 & 60.00 & 49.30 & & 63.128 & 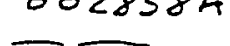 \\
\hline
\end{tabular}




$560.00 \quad 21.46 \quad 65.374$ BKgnd

1

$\therefore$ 
17 Sép $1998 \quad 18: 43$ Protocol \#: 10

Tine: 60.00 Data Hode: CPH Background Subtract: None
ALPHA/BETA - 1.08 Page \#: $T C-99 / U-238: a / b 3.0 \mathrm{~g}$ diecelued $;$ USeT : MSC I $2 \mathrm{ml}$ of $100 \mathrm{ml}$ dilution cedded to

Nuclide: MANUAL cocktail.

$\begin{array}{lrrrrr} & \text { LL } & \text { UL } & \text { LCR } & 25 \% & 8 K G \\ \text { Region A: } & 0.0- & 250 & 0 & 0.0 & 0.00 \\ \text { Region B: } & 100-500 & 0 & 0.0 & 0.00 \\ \text { Region C: } & 0.0- & 0.0 & 0 & 0.0 & 0.00\end{array}$

Quench Indicator: tSIE/AEC

Ext Std Terminator: Count

Alpha/Beta analysis of $\mathrm{IC}-99: \mathrm{U}-238$

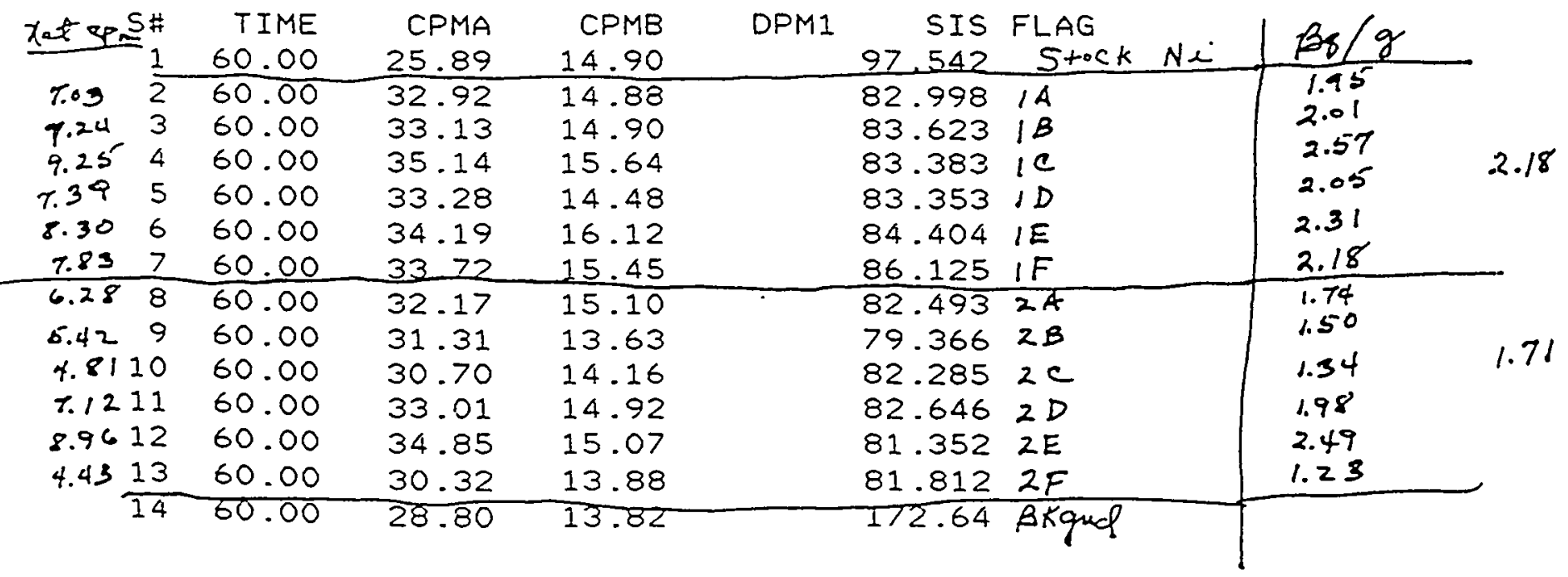




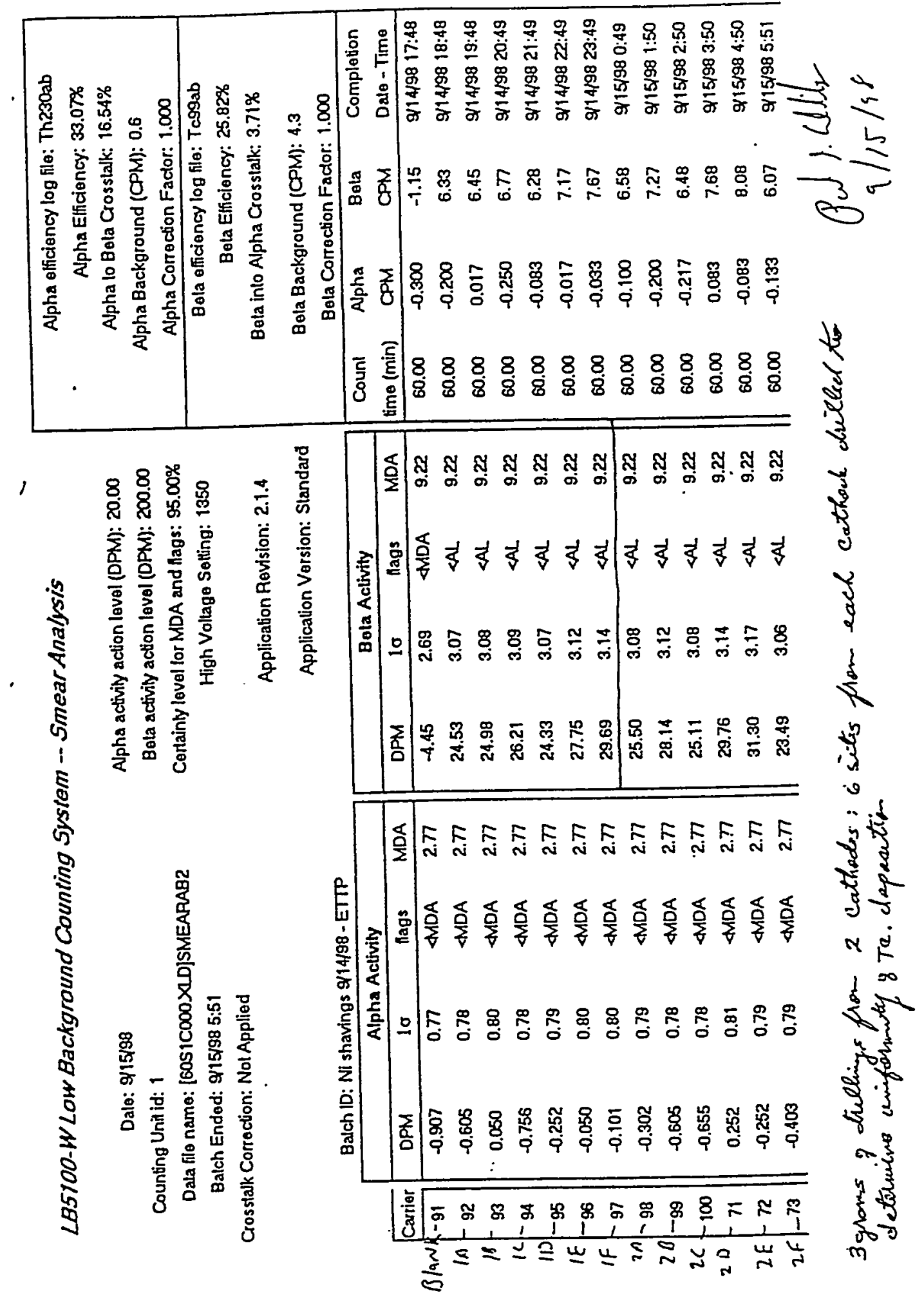


21 Oct $1998 \quad 18: 21$ Protocol \#: 6

ALPHA/BETA - 1.08 $T C-99 / N i$

Tine: 60.00

Data Mode: DPM

Nuclide: TC-99/NI

Quench Set: $T C-99$ OC

1 Background Subtract: None

$\begin{array}{lrrrrr} & \text { LL } & \text { UL } & \text { LCR } & 25 \% & \text { BKG } \\ \text { Region A: } & 0.0-293 & 0 & 0.0 & 0.00 \\ \text { Region B: } & 2.0-293 & 0 & 0.0 & 0.00 \\ \text { Region C: } & 0.0- & 0.0 & 0 & 0.0 & 0.00\end{array}$

Quench Indicator: tSIE/AEC

Ext Std Terminator: Count

$\mathrm{Ni}$ in Nitric Acid:Nominal 19/25mL

Coincidence Time(ns): 18

Delay Before Burst(ns): Normal

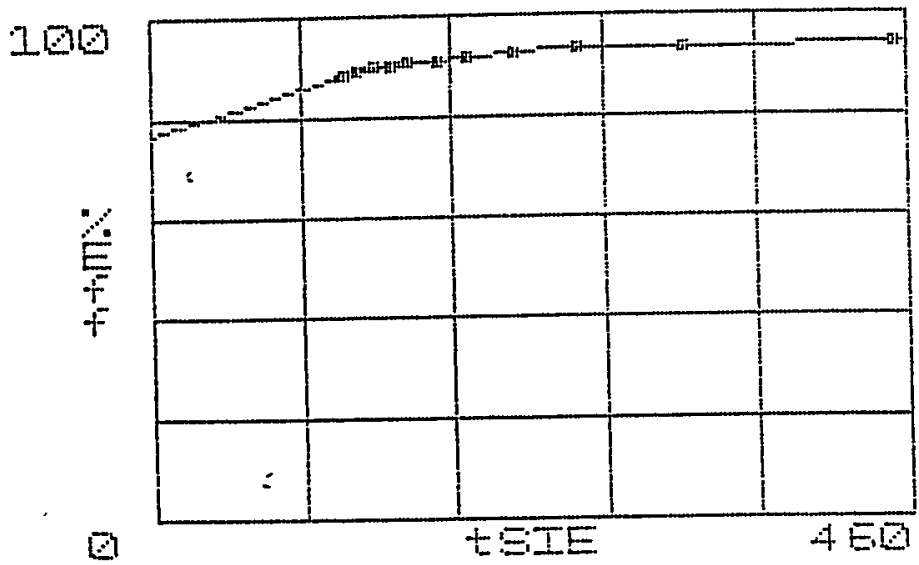

E

$E=I E$

$$
\begin{array}{ll}
\text { tSIE } & \% E f f \\
452.85 & 94.17 \\
326.05 & 93.21 \\
262.00 & 93.69 \\
222.04 & 92.34 \\
193.79 & 91.83 \\
175.40 & 90.98 \\
157.38 & 91.14 \\
145.19 & 90.27 \\
135.44 & 89.72 \\
125.28 & 89.08 \\
116.84 & 88.24
\end{array}
$$

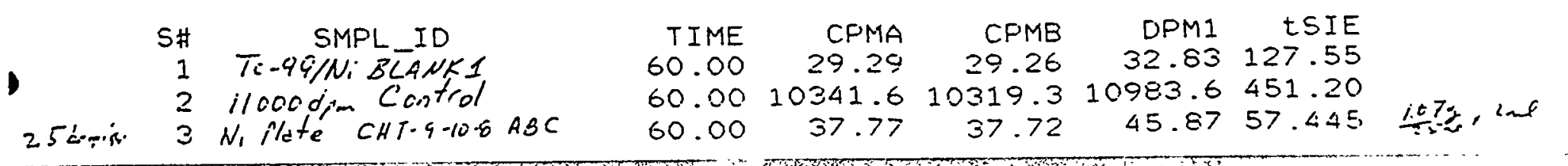




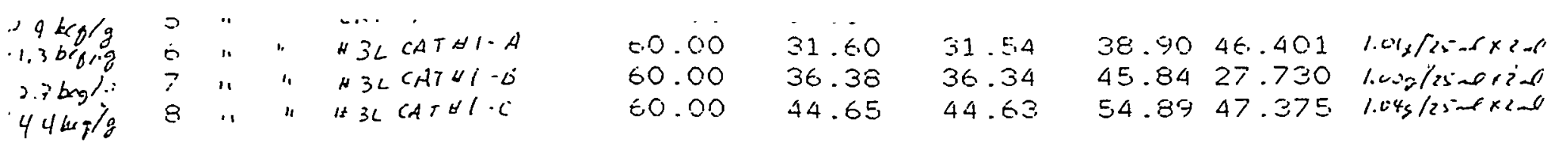

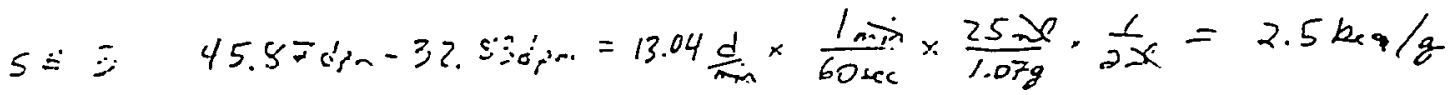

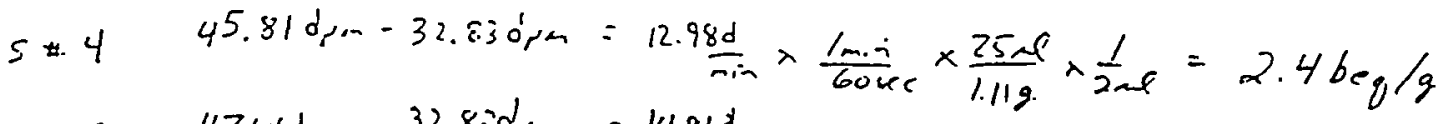

$$
\begin{aligned}
& 2.6 \mathrm{Bg} / \mathrm{g} \\
& 5 * 5 \quad 47.64 \mathrm{dgm} \cdot 32.83 \mathrm{o} / \mathrm{m}=14.81 \mathrm{~d}
\end{aligned}
$$

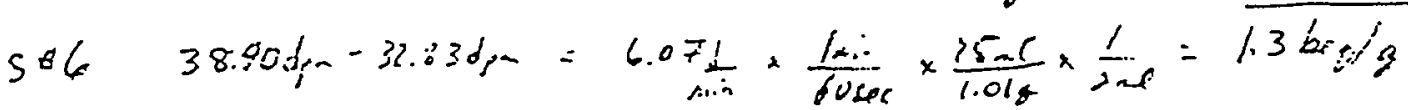

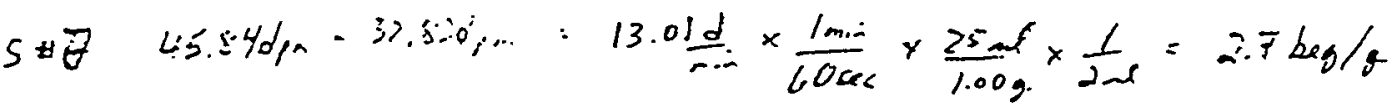

$$
\begin{aligned}
& 2.8 \mathrm{Bg} / \mathrm{g}
\end{aligned}
$$

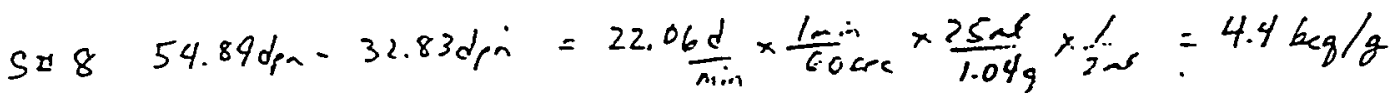

AVE

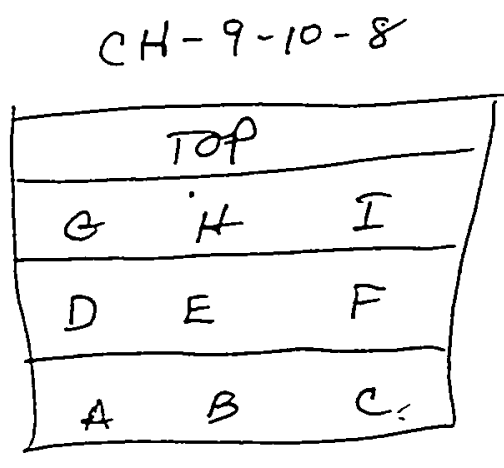

\begin{tabular}{|c|}
\hline 3L.CATH\#1 \\
\hline$A$ \\
\hline$B$ \\
\hline$C$ \\
\hline
\end{tabular}


1.B5100-W Low Background Counting System -- Smear Analysis

Dale: $10 / 15 / 98$

Counting Unil id: 1

Dala file name: (10S1J002.XI.D)SMEARAB2

Balch Endad: 10/15/98 16:47

Crossialk Correclion: Nol Applied

$1 T-7-10 \cdot \% \quad G, H, I$

. A, B. C

उLCAT*I D.E.

$"$

,

B

Balch ID: Ni CATHODE SHAVINGS 10-5 \& 10-15
Alpha aclivily action level (DPM): 20.00

Bela aclvity aclion level (DPM): 200.00

Cerlainty level for MDA and lags: $95.00 \%$

High Vollage Setling: 1350

Applicalion Revision: 2.1.4

Applicalion Version: Slandard

\begin{tabular}{|c|c|c|c|c|c|c|c|c|}
\hline \multirow[b]{2}{*}{ Carrier } & \multicolumn{4}{|c|}{ Apha Aclivity } & \multicolumn{4}{|c|}{ Bota Arolivity } \\
\hline & DPM & 10 & nags & MDA & DPM & $1 \pi$ & llags & MDA \\
\hline 1 & 0.907 & 1.17 & $\angle M D A$ & 4.27 & 24.01 & 4.74 & $<A l$. & 12.88 \\
\hline 2 & 0.605 & 1.13 & ADA & 4.27 & 27.88 & 4.91 & $\angle A L$ & 12.88 \\
\hline 3 & 0.000 & 1.05 & $\angle M D A$ & 4.27 & 25.17 & 4.79 & $\angle A L$ & 12.88 \\
\hline 4 & 0.605 & 1.13 & $\angle M D A$ & 4.27 & 32.14 & 5.08 & $e \Lambda L$ & 12.88 \\
\hline 5 & -0.302 & 1.00 & $\angle M O A$ & 427 & 17.43 & 4.45 & CAL & 12.88 \\
\hline 6 & -0.302 & 1.00 & AMA & 4.27 & 27.50 & 4.89 & $=\mathrm{Al}$. & 12.88 \\
\hline
\end{tabular}

$C H T-9-10-8$

$$
\begin{aligned}
\frac{77.06}{a^{\prime} d_{1}} & =23.78 \pi, \mathrm{r} / \mathrm{g} \\
& =0.40 \mathrm{fig} / \mathrm{g}
\end{aligned}
$$

$$
\text { 3LEAT+ } 1 \quad \begin{aligned}
\frac{1707}{3.70 g} & =20.83 \mathrm{~d} / \mathrm{pm} / \mathrm{g} \\
& =0.35 \mathrm{Bg} / \mathrm{g}
\end{aligned}
$$

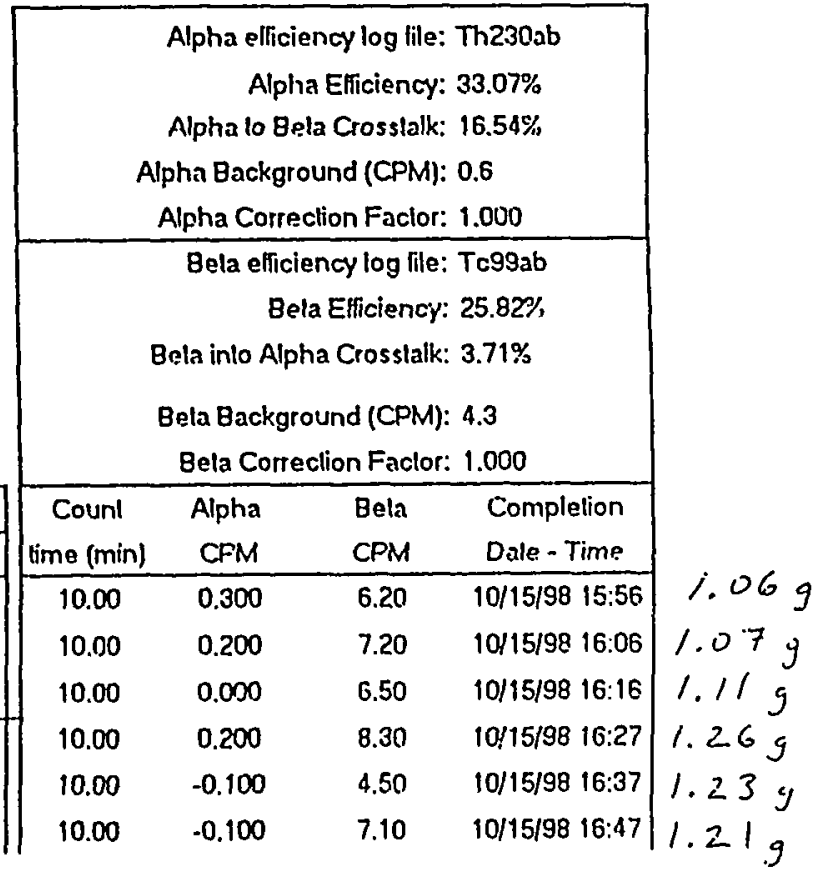

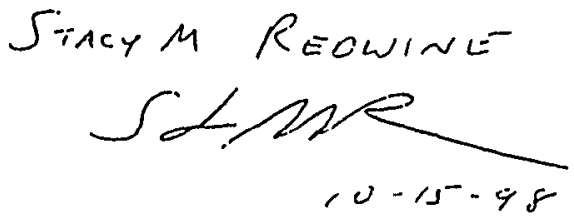




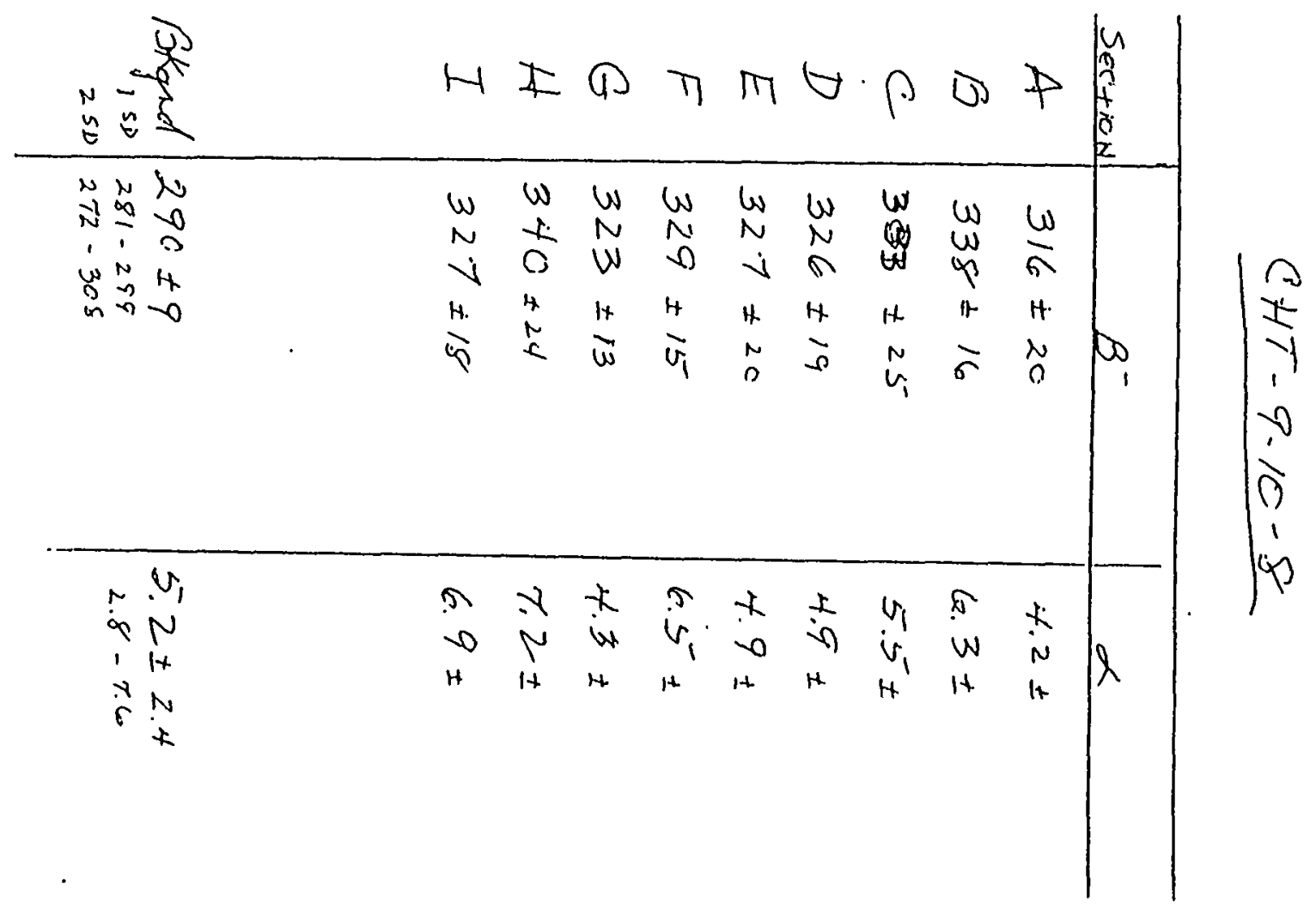




$\begin{array}{ll}\text { From: } & \text { Lab } \\ \text { Sent: } & \text { 11. mai 1999 08:25 } \\ \text { To: } & \text { Steve Sarten } \\ \text { Cc: } & \text { Dianna Walker } \\ \text { Subject: } & \text { FW: Tc-99 And Nickel Anolyte/Catholyte/Starter Plate Results }\end{array}$

I left off the Nickel results from the 1st e-mail. Here they are!

Sample 10

Anolyte 5/7/99 3:00 PM

Catholyte 5/7/99 3:00 PM

Anolyte 5/8/99 6:30 AM

Catholye 5/8/99 6:30 AM

Arolyte 5/10/99 6:30 AM

Catholyte 5/10/99 6:30 AM

Starter Plate-right side

Starter Plate-leít side
TC-99

$2.68 \mathrm{~Bq} / \mathrm{mL}$

$<0.06 \mathrm{~Bq} / \mathrm{mL}$

$2.70 \mathrm{~Bq} / \mathrm{mL}$

$<0.06 \mathrm{~Bq} / \mathrm{mL}$

$2.54 \mathrm{~Bq} / \mathrm{mL}$

$<0.06 \mathrm{~Bq} / \mathrm{mL}$

$1.83 \mathrm{~Bq} / \mathrm{g}$

$1.59 \mathrm{~Bq} / \mathrm{g}$
Nickel (ppm)

104,300

64,800

90,400

67,800

96,300

50,400 


\section{Steve Sarten}

$\begin{array}{ll}\text { From: } & \text { Lab } \\ \text { Sent: } & \text { 7. mai 1999 08:39 } \\ \text { To: } & \text { Steve Sarten } \\ \text { Cc: } & \text { Dianna Walker } \\ \text { Subject: } & \text { Tc-@9 Results on Anolyte/Catholytes May 5-6 }\end{array}$

Samole :0

Anolyte 5/5/99 3:30 PM

Catholyte 5/5/99 3:30 AM

Anolyte 5/6/99 6:15 AM

Catnolyte 5/6/99 6:15 AM

Anolyte 5/6/99 2:30 PM

Catholyte 5/6/99 2:30 PM
$\underline{T c-g g(B c / m L})$

\subsection{7}

$<0.06$

2.27

$<0.06$

2.44

$<0.06$ 


\section{Steve Sarten}

From: Lab

Sent: $\quad 6$ mai 1999 08:34

To: Steve Sarten

Cc: Dianna Walker

Subject: $\quad$ Tc-99 Results on Anolyte/Catholyte 5/4-5/99

Below are the final results (long count) of samples analyzed yesterday with a shorter screening colin: ...: $:$ :

Sample 10

Anolyte 5/4/99 3:30 PM

Anolyte 5/5/99 6:30 AM

Catholyte 5/5/99 6:30 AM

\section{$\underline{T C-99(B c / m L})$}

\subsection{2}

2.08

0.11 
From: Lab

Sent: $\quad$ 5. mai $199914: 52$

To: $\quad$ Steve Sarten

Cc: Dianna Walker

Subject: $\quad$ Tc-99 Screen Results on 5/4-5/5 Anolytes

These results are from a $15 \mathrm{~min}$ count instead of the usua! hour count time. This will give you an idea ci: is approximate Tc-99 activity.

Samcle ID

Anolyte 5/4/99 3:30 PM

Anclyte 5/5/99 6:30 AM

Catholyte 5/5/99 6:30 AM

Call if you have any questions.

Harold $\times 248$

\section{$\underline{T c-99(B a / m L)}$}

1.95

1.99

0.13 
Steve Sarten

From: Lab

Sent: $\quad$ 5. mai 1999 10:07

To: Steve Sarten

Cc: Dianna Walker

Subject: $\quad$ Tc-99 Resutls for Anolytes 4/30 thru 5/4

Sample ID

Anolyte 4/30/99 3:30 PM

Anolyte 5/3/99 6:15 AM

Anolyte 5/3/99 3:30 PM

Anolyte 5/4/99 6:15 AM
Tc-99 (bc/mL)

2.16

2.14

2.10

1.95 
Steve Sarten

From: $\quad$ Lab

Sent: $\quad 3$ mai $199912: 35$

To: Steve Sarten

Cc: Dianna Walker

Subject: $\quad$ Anolyte Tc-99 Results

Sample ID Tc-99(bo/mL)

Anolyte 4/29/99 3:30 PM $\quad 2.53$

Anolyte 4/30/99 6:15 AM $\quad 2.51$ 


\section{Steve Sarten}

From: $\quad$ Lab

Sent: $\quad$ 27. april $199911: 19$

To: Steve Sarten

Cc: Dianna Walker

Subject: $\quad$ Nickel plating solution Analytical Lab Results

Sample Description $\quad T c-99(\mathrm{Bg} / \mathrm{mL})$

Charcoal H2O 4/24/99 $\quad 0.17$

Anolyte 4/23/99 3:30 PM $\quad 5.61$

Catholyte 4/23/99 3:30 PM $\quad<0.06$

Anolyte 4/24/99 6:30 AM $\quad 5.53$

Anclyte 4/24/99 11:30 AM $\quad 4.15$

Catholyte \#1 $4 / 24 / 99 \quad 0.06$

Anolyte 4/26/99 6:30 AM $\quad 2.09$

Catholyte 4/26/99 6:30 AM $\quad<0.06$

CAT茾价 plate $2.73 \mathrm{~Bq} / \mathrm{g}$

CATH1R piate $\quad 3.29 \mathrm{~Bq} / \mathrm{g}$

Let us know if you have questions.

Harcld 


\section{Steve Sarten}

From: $\quad$ Lab

Sent: $\quad 23$. april $199913: 53$

To: Steve Sarten

Cc: Dianna Walker

Subjec: $\quad$ Tc-99 Results on Anolyte Samples

Results from recent Anolyte samples:

\section{Sample Description}

Anolyte 4/21/99 3:30 PM

Anolyte 4/22/99 6:30 AM

\section{$T c-99(\mathrm{bc} / \mathrm{mL})$}

5.56

5.52

Results below are short counts results to give you an icea of your approximate Tc-99 activity:

$\begin{array}{ll}\text { Anoiyte 4.22/99 3:30 PM } & 5.65 \\ \text { Anolyte 4/23/99 7:00 AM } & 2.65 \\ \text { Catholyte 41 4/23/99 7:30 AM } & \text { <MDA }\end{array}$

Will count this later batch to give you a more derinitive activity on Monday.

Harold 


\section{Steve Sarten}

$\begin{array}{ll}\text { From: } & \text { Lab } \\ \text { Sent: } & \text { 22. april 1999 09:06 } \\ \text { To: } & \text { Steve Sarten } \\ \text { Cc: } & \text { Dianna Walker } \\ \text { Subject: } & \text { Anolyte Analytical Results }\end{array}$

Steve,

Below are the results of several anolyte batches:

\begin{tabular}{lcl} 
Sample Description & Tc-99 (bq/mL) & Ni (opm) \\
\cline { 2 - 2 } Anclyte-Before 4/17/99 7:00AM & 14.41 & 72,900 \\
Anolyte-After 4/17/99 11:30AM & 15.15 & 73,400 \\
Ariolyte-Before 4/19/99 6:30AM & 15.22 & 74,700 \\
Anclyte 4/19/99 3:30PM & 14.78 & N/A \\
Anolyte 4/20/99 7:00AM & 15.50 & N/A \\
Anolyte 4/20/99 3:30PM & 15.83 & N/A \\
Anciyte 4/21/99 6:30AM & 15.29 & N/A \\
Anolyte 4/21/99 10:00AM & 15.35 & N/A
\end{tabular}

If you have any questions, Let Elbert or me know.

Hiarold 


\section{Steve Sarten}

From: Lab

Sent: $\quad$ 6. april 1999 13:09

To: Steve Sarten

Cc: Dianna Walker

Subjec: $\quad$ Tc-99 Results for Anolyte/Catholyte 4/6/99 Samples

Dianne,

Please forward a Hard copy of these results to Sam Fritts.

Sample \#

Anolyte-Before 4/6/99

Anolyte-After

Catholyte\#1

Catholyte和
TC-99

$15.2 \mathrm{bq} / \mathrm{mL}$

$15.4 \mathrm{bq} / \mathrm{mL}$

$1.7 \mathrm{bo} / \mathrm{mL}$

$0.8 \mathrm{~b} q / \mathrm{mL}$

Thanks,

Harold Waddle 
From: Lab

Sent: $\quad$ 5. april $199914: 33$

To: Steve Sarten

Subject: $\quad$ Anolyte/Catholyte Results from 4-5-99

Steve,

Reported below are the TC-99 Results from sample brought in 4/5/99 AM:

Sample

TC-99

Anolyte

$15.5 \mathrm{bq} / \mathrm{mL}$

Catholyte \#1

$1.2 \mathrm{bq} / \mathrm{mL}$

Catholyte $\# 2$

$0.7 \mathrm{bq} / \mathrm{mL}$

Anolyte-Before

$15.2 \mathrm{bq} / \mathrm{mL}$

Anolyte-After

$15.3 \mathrm{bq} / \mathrm{mL}$

Let me know if you have any questions about the results.

Harold 


\section{Steve Sarten}

From: $\quad$ Lab

Sent: $\quad$ 2. april $199908: 16$

To: Steve Sarten

Subject: $\quad$ Nickel Starter Plate Tc-99 Results for RFA $\$ 004630$

Steve,

Below are the results you so anxiously await. The $Q C$ ran did very well. The blanks that were used were batched along with these samples. We normally use an older blank and it was in close proximity to these iwo rie!v blanks. The spike on \#1 Right sample had a $95.8 \%$ Tc-99 recovery.

Sample Description

茾1 Right

\#1 Left

\#2 Right

莎2 Leít

\section{Tc-99 Results}

$29.8 \mathrm{bq} / \mathrm{g}$

$22.1 \mathrm{bq} / \mathrm{g}$

$7.8 \mathrm{bq} / \mathrm{g}$

$8.1 \mathrm{bq} / \mathrm{g}$

Elbert is out today for Good Friday. If you have any questions, please call.

Harold Waddle 


\section{Steve Sarten}

From: $\quad$ Lab

Sent: $\quad$ 24. mars $199910: 51$

To: Steve Sarten

Cc: $\quad$ Tom Muth; Valerie MacNair

Subject: $\quad$ Tc-99 in Anolyte and Anodes

Concentrations of Tc-99 in Anolyte from 3-22-99 and Anodes $\# 1, \# 3, \&$ \#5 from 3-20-99 are as follows:

Anolyte $\quad 3-22-99$ A.M. $\quad 15.5 \mathrm{~Bq} / \mathrm{ml}$

Anode \# 1 3-20-99 A.M. $\quad 578.3 \mathrm{~Bq} / \mathrm{g}$

Anode \# $3 \quad 3-20-99$ A.M. $\quad 654.1 \mathrm{Bg} / \mathrm{g}$

Anode \# 5 3-20-99 A.M. $\quad 544.9 \mathrm{~Bq} / \mathrm{g}$

The table of elemental concentrations in the above samples is in your mailbox.

Call me if you have any questions.

SIbert Cariton

Analytical Services 


\section{Steve Sarten}

From: Lab

Sent: $\quad$ 19. mars $199912: 22$

To: Steve Sarten

Cc: $\quad$ Tom Muth; Valerie MacNair

Subject: $\quad$ Anolyte/catholytes

Enclosed are the results to Tc-99 in anlyyte and catholyte for 3-17-99.

3-17-99 A.M.

$\begin{array}{lc}\text { Anolyte } & 16.34 \mathrm{~Bq} / \mathrm{ml} \\ \text { Catholyte \#1 } & 0.03 \mathrm{~Bq} / \mathrm{ml} \\ \text { Catholyte \#2 } & 0.06 \\ \text { Catholyte \# } 3 & 0.12 \\ \text { Catholyte \# 4 } & 0\end{array}$

3-i $7-99$ P.M.

Catholyte $\stackrel{\vec{\pi}}{\pi} 1$

Catholyte $\ddot{\#} 2$

Catholvte $\# 3$

Catholyte 4

$1.77 \mathrm{~Bq} / \mathrm{ml}$
$0.26 \mathrm{~Bq} / \mathrm{ml}$
$0.34 \mathrm{~Bq} / \mathrm{ml}$
$0.22 \mathrm{~Bq} / \mathrm{ml}$

EiberiCariton

Ladoratcry Services 
From: $\quad$ Lab

Sent: $\quad$ 18. mars $199917: 25$

To: Steve Sarten

Cc: $\quad$ Tom Muth; Valerie MacNair

Subject: $\quad$ Tc concentrations in solutions from 3-13 thru 3-17 AM

Steve,

Enclosed are the concentrations of Tc-99 in anclytes/catholytes and starter sheets.

3-13-99 A.M.

Anolyte

Catholyte 1

Catholyte 3

Catholyte 4

3-15-99 A.M.

Ariolyte

Catholyte \# 1

Catholyte $\# 2$

Cathclyte $\neq 3$

Catholyte $\# 4$

3-16-S9 A.M.

Anolyte

Catholyte $\ddot{\#} 1$

Catholyte $\# 2$

Catholyte \#3

Catholyte $\# 4$

SS 1

2 RSS

$\triangle R S S$

Pilot Sample

Nickel Starter
13.5 Bq/ml

0

$0.05 \mathrm{~Bq} / \mathrm{ml}$

0

$15.25 \mathrm{~Bq} / \mathrm{ml}$

0

$0.009 \mathrm{~Bq} / \mathrm{ml}$

$0.030 \mathrm{~Bq} / \mathrm{ml}$

0

3-17-99 A.M.

Anolyte

Catholyte

Catholyte \#2

Catholyte \# 3

Catholyte $\ddot{\pi} 4$
$15.93 \mathrm{~Bq} / \mathrm{ml}$

$0.33 \mathrm{~Bq} / \mathrm{ml}$

$0.10 \mathrm{~Bq} / \mathrm{ml}$

$0.12 \mathrm{~Bq} / \mathrm{ml}$

$0.01 \mathrm{Bc} / \mathrm{ml}$

$0.96 \mathrm{~Bq} / \mathrm{g}$ - Clezn N.6

$56.70 \mathrm{~Bq} / \mathrm{g}$

$40.06 \mathrm{~Bq} / \mathrm{g}$

$1.95 \mathrm{~Bq} / \mathrm{g}$

$30.07 \mathrm{~Bq} / \mathrm{g}$
$16.30 \mathrm{~Bq} / \mathrm{ml}$

0

$0.05 \mathrm{~Bq} / \mathrm{ml}$

$0.09 \mathrm{~Bq} / \mathrm{ml}$

0 
From: $\quad$ Lab

Sent: $\quad$ 15. mars $199915: 37$

To: $\quad$ Steve Sarten

Cc: $\quad$ Tom Muth; Valerie MacNair

Subjec:: $\quad$ Comparison of TC-99 in Ni using LSC and LB5100

Steve,

The Tc-99 determined by the two procedures are as follows:

Approximately $1 \mathrm{gram}$ of Ni was removed by drilling into each of four sheets, spread uniformly in a planciet and counted for 10 minutes in the LB5100 alpha/beta counter.

The samples were then transferred to individual beakers. $10 \mathrm{ml}$ of concentrated $\mathrm{HNO} 3$ was added to each and heated to dissolve the Nickel. After dissolution, distilled water was added and evaporated to reduce the NC22 concentration. The final volume was made up to $25 \mathrm{ml}$ with distilled water and mixed thoroughly. Ore .ni was removed from each flask and added to a $15 \mathrm{ml}$ aliquot of scintillation cocktail and counted for 60 minutes.

$\begin{array}{llll}\text { Cathode } & \text { LSC } & \text { LB5100 } \\ & & \\ \# 1(1.0037 \mathrm{~g} \mathrm{Ni}) & 14.21 \mathrm{~Bq} / \mathrm{g} & 1.09 \mathrm{~Bq} / \mathrm{g} \\ \# 2(1.0011 \mathrm{~g} \mathrm{Ni}) & 30.48 \mathrm{~Bq} / \mathrm{g} & 3.27 \mathrm{~Bq} / \mathrm{g} \\ \# 3(1.0127 \mathrm{~g} \mathrm{Ni}) & 22.45 \mathrm{~Bq} / \mathrm{g} & 2.04 \mathrm{~Bq} / \mathrm{g} \\ \# 4(1.0013 \mathrm{~g} \mathrm{Ni}) & 13.36 \mathrm{~Bq} / \mathrm{g} & 1.77 \mathrm{~Bq} / \mathrm{g} \\ \# 4 \text { Duplicate }\end{array}$




\section{Steve Sarten}

$\begin{array}{ll}\text { From: } & \text { Lab } \\ \text { Sent: } & \text { 15. mars 1999 15:04 } \\ \text { To: } & \text { Steve Sarten } \\ \text { Cc: } & \text { Tom Muth; Valerie MacNair } \\ \text { Subject: } & \text { Tc-99 in Catholytes/Anolytes }\end{array}$

Steve,

Enclosed are the results for anolytes/catholytes from 3-12-99 A.M.

Virgin Ni (1.0045 g/25 ml HNO3) $2 \mathrm{ml}$

Catholyte \# $02 \quad$ 3-12-99 A.M. $1 \mathrm{ml}$ Anolyte (before) 3-12-99 A.M. $1 \mathrm{ml}$ Anolyte (after) 3-12-99 A.M. $1 \mathrm{ml}$

Catholyte \# 01 3-12-99 A.M. $1 \mathrm{ml}$ Catholyte \# 1 3-12-99 A.M. $1 \mathrm{ml}$ Catholyte \# 2 3-12-99 A.M. $1 \mathrm{ml}$ Catholyte \# 4 3-12-99 A.M. $1 \mathrm{ml}$

Catholyte \# $3+100$ dpm Tc spike
$38.82 \mathrm{dpm}$

$359.3 \mathrm{dpm}$ $858.1 \mathrm{dpm}$ $846.9 \mathrm{dpm}$ $5.34 \mathrm{~Bq} / \mathrm{ml}$ 13.7 Bq/ml $13.5 \mathrm{~Bq} / \mathrm{ml}$

$401.2 \mathrm{dpm}$ $63.9 \mathrm{dpm}$ $107.1 \mathrm{cpm}$ $79.3 \mathrm{dpm}$ $6.0 \mathrm{~Bq} / \mathrm{ml}$ $0.42 \mathrm{~Bq} / \mathrm{ml}$ $1.15 \mathrm{~Bq} / \mathrm{ml}$ $0.68 \mathrm{~Bq} / \mathrm{ml}$

$178.0 \mathrm{dpm}$ 
From: Lab

Sent: $\quad 3$. mars $199910: 09$

To:

Steve Sarten

Subject: $\quad$ Anolyte/Catholyte analyses for Tc-99

Concentrations for Tc-99 in Anolyte and Catholyte, and Cathodes are shown in the following table.

$\begin{array}{ll}\text { 2-26-99 PM } & \mathrm{Bq} / \mathrm{ml} \\ & \\ \text { Anolyte } & 9.24 \\ \text { Catholyte - 1 } & 0.05 \\ \text { Catholyte - 2 } & 0.19 \\ \text { Catholyte - 3 } & 0.05 \\ \text { Catholyte - 4 } & 0.52\end{array}$

2-27-99 AM Bq/ml

$\begin{array}{ll}\text { Anolyte } & 9.27 \\ \text { Catholyte }-1 & 0.12 \\ \text { Cathoiyte }-2 & 0.18 \\ \text { Catholyte }-3 & 0.05 \\ \text { Catholyte }-4 & 0.00\end{array}$

2-27-\$9 PM $\quad B q / m i$

Anolyte $\quad 10.32$

Catholyte $-1 \quad 0.31$

Catholyte $-2 \quad 0.39$

Catholyte - $3 \quad 0.15$

Catholyte $-4 \quad 0.05$

$\begin{array}{lr}\text { 2-28-99 AM } & \mathrm{Bq} / \mathrm{ml} \\ & \\ \text { Anolyte } & 10.87 \\ \text { Catholyte - } & 0.10 \\ \text { Catholyte - 2 } & 0.18 \\ \text { Catholyte - 3 } & 0.09 \\ \text { Catholyte - 4 } & 0.00\end{array}$

2-28-S9 PM $\quad \mathrm{Bq} / \mathrm{ml}$

Anolyte $\quad 11.05$

Catholyte - $1 \quad 0.14$

Catholyte - $2 \quad 0.30$

Catholyte - $3 \quad 0.18$

Catholyte $-4 \quad 0.00$

3-1-99 AM

Bqiml

Anolyte

11.10 
Catholyte - 1

Catholyte - 2

Catholyte - 3

Catholyte - 4
0.03

0.20

0.20

0.08
3-2-99 AM

Anolyte

Catholyte - 1

Catholyte - 2

Catholyte - 3

Catholyte -4

Anolyte - Before

Anolyte - After

3-1-99

Cathode \# 1

Cathode \#2

Cathode \# 3

Cathode \# 4
$\mathrm{Bq} / \mathrm{ml}$

12.18

0.66

0.50

0.33

0.00

31.33

14.86

$\mathrm{Bq} / \mathrm{g}$

20.55

17.52

7.41

6.82

Page 2 


\section{Steve Sarten}

From: Lab

Sent: $\quad$ 1. mars $199909: 19$

To: Steve Sarten

Subject: Anolyte-Catholyte Concentrations

Steve, The concentrations of Tc-99 in Anolyte and Catholytes for 2-25-99

$\mathrm{PM}$ and 2-26-99 AM are as follows.

2-25-99 5:30 PM

Anolyte

Catholyte -1

Catholyte -2

Catholyte - 3

Catholyte -4

2-25-99 6:00 AM

Anolyte

8.27

Catholyte - 1

Catholyte - 2

Catholyte -3

Catholyte -4

Anolyte Before

Ancolyte After

Cementation \# 3 ( $1.75 \mathrm{~g})$

(1 $\mathrm{ml}$ of $28 \mathrm{ml}$ )

$(2 \mathrm{ml}$ of $28 \mathrm{ml}$ )

0.12

0.02

8.08

8.55

$\mathrm{Bq} / \mathrm{g}$

2,500

2,130
Tc-99 Bq/ml

8.43

0.14

0.21

0.08

0.06 


\section{Steve Sarten}

From: Lab

Sent: $\quad 26$. februar 1999 09:34

To: Steve Sarten

Cc: Valerie MacNair

Subject: $\quad$ Tc-99 in Anolytes-Catholytes

Steve, the concentrations in the Anolytes and Cathoiytes for 2-24-99 PM and 2-25-99 AM are given tulcw:

2-24-99 5:30 PM TC-99 (Bq/ml)

Anolyte $\quad 6.96$

Catholyte $-1 \quad \cdot 0.32$

Catholyte $-2 \quad 0.24$

Catholyte $-3 \quad 0.09$

Catholyte $-4 \quad 0.03$

2-25-99 6:00 AM TC-99 (Bq/ml)

Anolyte $\quad 7.64$

Catholyte - $1 \quad 0.42$

Catholyte - $2 \quad 0.30$

Catholyte - $3 \quad 0.08$

Catholyte $-4 \quad 0.04$ 


\section{Steve Sarten}

From: $\quad$ Lab

Sent: $\quad$ 25. februar $199914: 31$

To:

Cc:

Steve Sarten

Valerie MacNair

Subject: Anolyte-Catholytes

The following values were determined for Tc-99 in Ni materials:

\section{Sample \#}

$4 \mathrm{~L}-1$ new membrane ( $1.0343 \mathrm{~g} \mathrm{Ni})$

$4 \mathrm{~L}-1$ " "

$4 \mathrm{~L}-2 \quad " \quad(1.0465 \mathrm{~g} \mathrm{Ni})$

Anolyte 2-23-99 (6:00 am)

Catholyte - 1

Catholyte -2

Catholyte -3

Catholyte -4

$\mathrm{Bq} / \mathrm{mi}$ or gram

7.80

8.45

8.06

7.04

1.56

4.59

0.99

1.07

Anolyte and catholyte recounted using Ultima Gold a/b cocktail

\section{Anolyte}

Catholyte -1

Catholyte - 2

Catholyte - 3

Catholyte -4

Water from pump
6.92

1.50

4.65

1.04

1.11

0.05
$\mathrm{Ni}$ irom $4 \mathrm{~L}$ before Washing

Ni from 4L after Washing

Anolyte

Catholyte - 1

Catholyte - 2

Catholyte - 3

Catholyte -4

Anolyte

Catholyte - 1

Catholyte - 2

Catholyte - 3

Catholyte -4

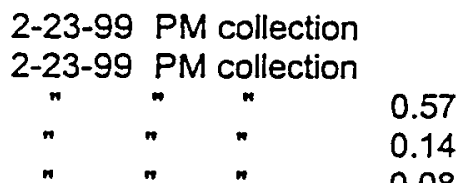

6.73

0.01

0.12

0.03

0.03 


$\begin{array}{ll}\text { From: } & \text { Lab } \\ \text { Sent: } & \text { 22. februar 1999 12:33 } \\ \text { To: } & \text { Steve Sarten } \\ \text { Cc: } & \text { Valerie MacNair } \\ \text { Subject: } & \text { Tc-99 concentrations in Anolyte and Catholyte solutions }\end{array}$

The concentrations in the Anolyte and Catholyte samples from 2-18-99 and 2-19-99 are as follows:

Anolyte 5:50 PM 2-18-99: $\quad 5.87 \mathrm{~Bq} / \mathrm{ml}$

Catholyte 1 5:50 PM 2-18-99: $0.01 \mathrm{~Bq} / \mathrm{ml}$

Catholyte 2

Catholyte $3 \quad 0.01 \mathrm{~Bq} / \mathrm{ml}$

Catholyte 4

0

\begin{tabular}{ll}
\hline Anolyte 5:30 AM 2-19-99 & $6.34 \mathrm{~Bq} / \mathrm{ml}$ \\
Catholyte 1 5:30 AM 2-19-99 & $0.28 \mathrm{~Bq} / \mathrm{ml}$ \\
Catholyte 2 & 0 \\
Catholyte 3 & 0 \\
Catholyte 4 & 0
\end{tabular}

Anolyte PM 2-19-99 $\quad 6.80 \mathrm{~Bq} / \mathrm{ml}$

Catholyte 1 PM 2-19-99 0

Catholyte 2

$\begin{array}{ll}\text { Catholyte } 3 & 0\end{array}$

$\mathrm{Ni}-1 \mathrm{~L}$

$\mathrm{Ni}-1 \mathrm{R}$

$12.5 \mathrm{~Bq} / \mathrm{g}$

$\mathrm{Ni}-2 \mathrm{~L}$

$9.7 \mathrm{~Bq} / \mathrm{g}$

$\mathrm{Ni}-2 \mathrm{R}$

$6.7 \mathrm{~Bq} / \mathrm{g}$

$9.4 \mathrm{~Bq} / \mathrm{g}$ 